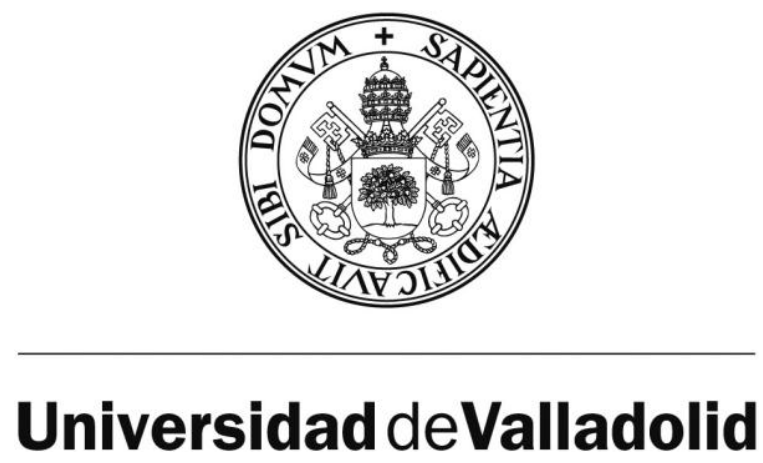

Facultad de Filosofía y Letras

Departamento de Historia del Arte

TESIS DOCTORAL:

\title{
ARQUITECTURA GÓTICA EN ZAMORA Y SU PROVINCIA
}

Presentada por José María Vicente Pradas para optar al grado de doctor por la Universidad de Valladolid

Dirigida por:

Clementina Julia Ara Gil y Luis Vasallo Toranzo 



\section{ARQUITECTURA GÓTICA EN ZAMORA Y SU PROVINCIA \\ Volumen I ESTUDIO}





\section{ÍNDICE}

PROPÓSITO, ESTADO DE LA CUESTIÓN Y PROPUESTA METODOLÓGICA

Propósito

Estado de la cuestión

Propuesta metodológica

INTRODUCCIÓN A LA ARQUITECTURA GÓTICA EN LA CIUDAD DE ZAMORA Y SU PROVINCIA 20

LOS INICIOS DEL GÓTICO

Notas históricas

La actividad artística en los inicios del gótico: la arquitectura religiosa

Las primeras manifestaciones de cambio en la arquitectura religiosa románica. La influencia cisterciense

Puertas de tránsito y ventanas con dintel

Los vanos en los exteriores. La introducción del arco apuntado

Los arcosolios

Elementos estructurales. El apuntamiento y la bóveda de crucería

Las transformaciones de las torres

La arquitectura civil en los inicios del gótico

La fortificación de Zamora. Las murallas, el castillo y el puente

La fortificación y el puente de Toro

Restos de otras fortificaciones

\section{EL GÓTICO PLENO}

Notas históricas

La actividad arquitectónica religiosa en Zamora y su provincia durante los siglos XIII y XIV

$\begin{array}{lr}\text { Obras en la catedral de Zamora } & 132 \\ & 138\end{array}$

Obras en la colegiata de Toro

Transformaciones en iglesias románicas. San Cipriano y Santa María la Nueva en Zamora y Santa María la Real de la Hiniesta

La implantación de las órdenes mendicantes en Zamora y su provincia

Los restos conservados 
$\begin{array}{ll}\text { Notas históricas } & 173\end{array}$

La arquitectura religiosa durante el gótico tardío 181

La actividad arquitectónica durante los dos primeros tercios del siglo XV

La actividad arquitectónica durante las décadas finales del siglo XV y las primeras del siglo XVI

Los promotores

Las obras

Transformaciones góticas y obras de ampliación durante las últimas décadas del siglo XV y las primeras del XVI en edificios religiosos ya existentes

Edificios levantados de nueva planta durante las últimas décadas del siglo XV y las primeras del XVI

Los elementos arquitectónicos de las obras gótico-tardías: problemas de cronología

Análisis formal de los elementos arquitectónicos

Materiales

201

Exteriores

204

Soportes 206

Ménsulas 207

Arcos 208

Bóvedas 210

Vanos 230

Puertas 231

Ventanas 233

Decoración 234

Talleres locales en el gótico tardío zamorano 238

La arquitectura civil durante el gótico tardío

Los castillos

El castillo-palacio de los Pimentel en Benavente 
El patio

El pozo

La escalera

El salón

Decoración

La casa noble urbana

Las portadas

Otros restos

Obras públicas

Arquitectura hospitalaria

LA PERVIVENCIA DEL GÓTICO EN LA EDAD MODERNA

Notas históricas

Las pervivencias del gótico en la Edad Moderna: la arquitectura religiosa 312 Los promotores

La actividad arquitectónica religiosa zamorana y sus aspectos conservadores durante los dos últimos tercios del siglo XVI

Análisis formal de los elementos arquitectónicos

Materiales

Planimetría y configuración interior

Exteriores

Soportes

Arcos

Portadas

Ventanas

Bóvedas

Nervios

Decoración

Talleres locales durante los dos últimos tercios del siglo XVI

La pervivencia del gótico en la arquitectura civil de los dos últimos tercios del siglo XVI 



\section{PROPÓSITO, ESTADO DE LA CUESTIÓN Y PROPUESTA METODOLÓGICA}

\section{Propósito}

Dadas las circunstancias especiales que concurren en la arquitectura gótica zamorana, especialmente el escaso interés de que ha sido objeto, el propósito de este trabajo es ofrecer una visión lo más ajustada posible de su desarrollo durante los siglos del gótico mediante la catalogación y el estudio sistemático de los restos que han llegado a nuestros días así como el análisis y la valoración de los elementos artísticos que se han conservado de este estilo o de los que tenemos noticias documentales aunque hayan desaparecido. Todo ello con el objeto de encuadrarlos, en la medida que sea posible, en su momento concreto y ofrecer unas características generales a esa arquitectura estableciendo las distintas fases en su evolución, además de una valoración completa de la actividad constructiva en este periodo y en este contexto. De este modo se va a establecer una línea en la evolución de las formas que se sucedieron en un periodo que abarca más de tres siglos. Es importante valorar cómo se produjo la introducción del gótico en un ambiente en el que el románico estaba tan sólidamente arraigado, cuáles fueron las formas del gótico por las que se optó en los momentos centrales del estilo, desarrollar en el contexto de la arquitectura castellana las creaciones realizadas durante el gótico tardío y, como consecuencia de todo ello, analizar la contribución de la arquitectura religiosa y civil al conjunto de nuestra provincia. Habría que añadir, que así como las formas góticas tardaron en incorporarse al lenguaje arquitectónico zamorano, sin embargo se mantuvieron durante mucho tiempo, conviviendo con la influencia renacentista en una pervivencia que alcanzó casi hasta bien entrada la segunda mitad del siglo XVI.

Por ello, deseamos que este estudio permita obtener una visión de conjunto de la actividad arquitectónica desarrollada en este espacio geográfico en los últimos siglos de la Edad Media, visión que facilite un acercamiento y comprensión aún mayor desde el punto de vista histórico, artístico y social. Y es que, la arquitectura gótica en Zamora, aunque más modesta que en otros lugares, no deja de ser un elemento de gran importancia para seguir completando el panorama artístico de este estilo en nuestro país.

Este trabajo pretende, además de otorgar la relevancia que merecen a estos aspectos artísticos del periodo gótico, que han tenido menor valoración, contribuir mediante su puesta en valor a la conservación y defensa de edificios que a causa de las posibles remodelaciones y derribos podrían desaparecer en épocas venideras. 
Es, por tanto, necesario ayudar a la defensa de un patrimonio que, en esta ciudad y provincia, es especialmente frágil por su desconocimiento.

\section{EI territorio}

Somos conscientes de que el marco geográfico elegido, que se corresponde con la provincia de Zamora, es arbitrario, por cuanto es fruto de límites establecidos en época reciente y además no coincide, con lo que es ni con lo que fue en términos generales, la diócesis de Zamora. Lo hacemos, sin embargo, porque la mayor parte de los últimos estudios sobre arquitectura se ajustan a las delimitaciones puramente provinciales. De este modo, podremos tener, en algún momento, un panorama completo de la arquitectura gótica en Castilla y León ${ }^{1}$.

La provincia de Zamora, perteneciente a la Comunidad Autónoma de Castilla y León y cuya extensión es de 10.559 kilómetros cuadrados, se encuentra situada en el extremo noroccidental de la Meseta Central. Al norte limita con las provincias de Orense y de León, al este con la de Valladolid, al sur con la de Salamanca y al oeste con Portugal.

Su territorio está dividido en las siguientes comarcas: Aliste y Alba, Los Arribes y Sayago, Sanabria y Carballeda, Benavente y los Valles, Tierra de Campos y del Pan y Tierra del Vino y Guareña. Cada una de estas comarcas posee una serie de particularidades que le vienen dadas por las características geográficas que presentan y cuyo mayor contraste se produce entre las altas montañas sanabresas y las grandes llanuras de Tierra de Campos. Los ríos más importantes que atraviesan la provincia son el Duero y el Esla.

Desde el punto de vista eclesiástico la provincia se encuentra dividida actualmente en dos diócesis. El territorio de menor tamaño (3.526 kilómetros cuadrados) y que se corresponde, en lo fundamental, con el extremo noroccidental de la provincia, pertenece a la diócesis de Astorga. Cuenta con poco más de 37.000 habitantes distribuidos en 218 núcleos de población. El resto del territorio pertenece a la diócesis de Zamora, que recientemente ha sido reordenada y

\footnotetext{
1 Aunque algunos estudios han sido elaborados bajo el marco geográfico de la diócesis, como es el caso de los realizados por Emilio Piriz Pérez y Felipe Heras García, en la actualidad se tiende a tomar como referencia el ámbito provincial. PIRIZ PÉREZ, Emilio, La arquitectura gótica en la diócesis de Ciudad Rodrigo, Centro de Estudios Salmantinos, 1974; HERAS GARCÍA, Felipe, Arquitectura religiosa del siglo XVI en la primitiva Diócesis de Valladolid, Diputación Provincial de Valladolid, Valladolid, 1975; MARTÍNEZ FRÍAS, José María, El gótico en Soria: Arquitectura y escultura monumental, Universidad de Salamanca, Salamanca, 1980; ZALAMA RODRÍGUEZ, Miguel Ángel, La arquitectura del siglo XVI en la provincia de Palencia, Diputación Provincial de Palencia, Palencia, 1980; MARTÍNEZ, Rafael, La arquitectura gótica en la ciudad de Palencia, Diputación Provincial de Palencia, 1989; MORENO ALCALDE, María, La arquitectura gótica en la tierra de Segovia, Segovia, 1990; CASTÁN LANASPA, Javier, Arquitectura gótica religiosa en Valladolid y su provincia: (siglos XIII-XVI), Valladolid, 1998.
} 
reducida a siete arciprestazgos: Aliste-Alba, que incluye 84 parroquias y 11.416 habitantes, Benavente-Tierra de Campos, que incluye 41 parroquias y 30.325 habitantes, Toro-La Guareña, que incluye 32 parroquias y 19.297 habitantes, El Pan, que incluye 40 parroquias y 12.961, Sayago, que incluye 56 parroquias y 9.339 habitantes, El Vino, que incluye 32 parroquias y 14.151 habitantes y Zamora ciudad, que incluye 18 parroquias y 65.998 habitantes. El total de parroquias y habitantes pertenecientes a la diócesis de Zamora es de 303 y 163.487 habitantes respectivamente.

\section{Estado de la cuestión}

Como ya se ha dicho en el propósito, no existe ningún estudio de conjunto de la arquitectura gótica en la provincia de Zamora. No obstante, la literatura artística nos aporta noticias más o menos precisas relativas a aspectos particulares o a obras concretas de gran utilidad para este trabajo ${ }^{2}$.

Los autores anteriores al siglo XX apenas prestan atención en sus escritos a los edificios y se limitan a descripciones genéricas de la geografía y de las ciudades más importantes de la provincia de Zamora. Las primeras referencias de este tipo las encontramos en los viajeros extranjeros que visitaron la Península Ibérica desde finales del siglo XV hasta el siglo XIX. EI testimonio más antiguo pertenece al alemán Jerónimo Münzer, que visitó la provincia de Zamora entre finales del año 1494 y principios del año 1495. Le siguieron otros viajeros como Antoine de Lalaing (1501), Alfred Jouvin (1672), William Dalrymple (1774), Joseph Townsend (17861787) o Jean-Charles Davillier (1862), que realizaron también comentarios muy generales ${ }^{3}$.

Ya en el siglo XIX y principios del siglo XX junto a las aportaciones hechas por algunos viajeros son importantes las realizadas por los eruditos locales, aunque éstos se ciñan fundamentalmente a los aspectos históricos. Destaca en primer lugar don Cesáreo Fernández Duro con su obra Memorias históricas de la ciudad de Zamora su provincia y obispado (1883). También son importantísimos, por lo que a Zamora ciudad se refiere, todos aquellos artículos y análisis realizados por don Ursicino Álvarez Martínez, director de la Revista Literaria Semanal Zamora llustrada (1881-1883); revista en la que se publicaron numerosos grabados, algunos de ellos de edificios o partes de edificios góticos que aparecen comentados con escasa atención y rigor artístico. Para el estudio de Benavente es destacable la obra de don José Ledo del Pozo Historia de la nobilísima villa de Benavente, con la antigüedad de su ducado (1853) y para el estudio de Toro la correspondiente a don Gaspar Calvo Alaguero denominada Historia de la muy leal y antigua ciudad de Toro: noticias biográficas de sus más ilustres hijos (1909).

\footnotetext{
2 Todos los estudios mencionados en este estado de la cuestión han sido frecuentemente utilizados por el autor de este trabajo de ahí que la referencia bibliográfica completa se encuentre tanto en la bibliografía general como a lo largo de este estudio.

3 A este respecto puede consultarse GARCÍA MERCADAL, José, Viajes de extranjeros por España y Portugal: desde los tiempos más remotos hasta comienzos del siglo XX, Valladolid, 1999.
} 
Las primeras referencias concretas al estilo de los edificios con un carácter ya científico las encontramos en autores que escribieron sobre la historia y el arte de las ciudades más destacadas de la provincia, otorgando mayor importancia en lo que a las manifestaciones artísticas se refiere al estilo románico pero sin olvidar la mención y, en algunos casos, la realización de un breve comentario de los edificios góticos. Este es el caso de José María Quadrado y su obra España, sus monumentos y artes, su naturaleza e Historia. Valladolid, Palencia y Zamora (1861) en la que deja constancia de muchos de los acontecimientos históricos que se sucedieron en nuestra provincia y realiza algunas apreciaciones sobre los edificios de interés que visitó. De entre ellos habla del convento de San Francisco de Zamora que ya se encontraba en ruinas, aunque conservaba muchas partes aún en pie que no han llegado a nuestros días. En este libro son de gran interés los grabados que acompañan e ilustran el texto, realizados por Francisco Javier Parcerisa, y constituyen un documento gráfico de gran valor puesto que permiten conocer algunos edificios tal y como se habían conservado a mediados del siglo XIX. Recientemente ha sido publicado un libro bajo el título Zamora Año de 1850 que recoge el cuaderno de dibujos que José María Avrial y Flores realizó a mediados del siglo XIX durante una estancia en nuestra ciudad y que se custodia en la Real Academia de Bellas Artes de San Fernando (Madrid). Está compuesto por 57 láminas con dibujos de edificios, plazas y panorámicas de Zamora. Su relevancia es tal que constituye el primer catálogo gráfico de la ciudad, y a su vez un documento imprescindible para el estudio histórico, artístico y urbanístico de Zamora. Un paso más dio don Manuel Gómez-Moreno al realizar los tomos correspondientes a la Provincia de Zamora del Catálogo Monumental de España (1927), que constituye el primer estudio pormenorizado del arte de la ciudad y su provincia. Este autor cita y comenta la práctica totalidad de las creaciones artísticas contenidas en el espacio geográfico que nos ocupa realizando análisis muy sugestivos, muchos de los cuales están actualmente en plena vigencia. Esta obra de Gómez-Moreno ha sido y sigue siendo para los investigadores referencia fundamental.

Muy posteriormente, ya en el último cuarto del siglo XX y a lo largo del siglo XXI, se han publicado una serie de obras que aportan datos muy valiosos y ayudan a enriquecer el análisis del periodo que se va a estudiar. Por lo que se refiere a obras colectivas que recogen numerosos artículos y muy diversos, resultan imprescindibles en primer lugar, los volúmenes correspondientes al Anuario del Instituto de Estudios Zamoranos «Florián de Ocampo» y los números de la revista Stvdia Zamorensia. Igualmente son indispensables los tres tomos de la Historia de Zamora (1995) y la publicación de las Jornadas sobre Zamora, su entorno y América (1992).

Por lo que se refiere a obras de carácter individual contamos en primer lugar con el libro de Guadalupe Ramos de Castro titulado La Catedral de Zamora (1982) en el que se estudia exhaustivamente el edificio catedralicio, que aunque de estilo románico en su concepción 
general, recibió, con el paso del tiempo, añadidos y ampliaciones, muchas de ellas en estilo gótico. Ramos de Castro concede una importancia especial a todas las obras patrocinadas entre finales del siglo XV y principios del siglo XVI por los obispos diocesanos. También Rivera de las Heras, en sus publicaciones realizadas sobre los templos de la ciudad, describe y aporta nuevos datos producto de sus investigaciones.

Aunque se acaba de citar con carácter general el Anuario del Instituto de Estudios Zamoranos "Florián de Ocampo» y los tomos correspondientes a la Historia de Zamora, es preciso resaltar algunos de los estudios concretos que figuran en ellos por su relevancia. Es el caso del realizado por Montero Aparicio titulado "Arte medieval en Zamora", publicado en el Anuario del año 1995, y que da una visión general de la arquitectura gótica y, del trabajo de Navarro Talegón titulado "Manifestaciones artísticas de la Edad Moderna" publicado en el tomo II de Historia de Zamora. La Edad Moderna (1995), que aporta un análisis muy interesante de toda la arquitectura del siglo XVI. Para el estudio de la arquitectura en la ciudad de Toro son imprescindibles el resto de publicaciones de Navarro Talegón que tratan este tema, principalmente su Catálogo Monumental de Toro y su Alfoz (1980) y la tesis doctoral de Vasallo Toranzo titulada Arquitectura en Toro (1500-1650) (1994).

Indudablemente los edificios más significativos de la provincia cuentan con estudios históricos y artísticos concretos exhaustivos como sucede con la catedral de Zamora, de la que junto al ya mencionado de Ramos de Castro tenemos las obras realizadas por García Martínez Historia de la Santa Iglesia Catedral de Zamora (1904) y Rivera de las Heras La catedral de Zamora (2001) entre otros. Sobre la colegiata de Toro existen varias publicaciones, unas se circunscriben a alguna de las partes más sobresalientes del edificio como es el Pórtico de la Majestad y, otras, como la obra de Navarro Talegón La colegiata de Toro (2005), abarcan todo el conjunto. El monasterio cisterciense de Santa María de Moreruela ha sido tratado habitualmente en los estudios generales de arquitectura medieval así como en todos aquellos que se han circunscrito a nuestro ámbito provincial. La obra publicada recientemente y titulada Un monasterio en la historia del Císter (2008), que ha sido coordinada por Hortensia Larrén, recoge toda la bibliografía existente y aporta análisis del edificio desde el punto de vista de todas las disciplinas. Sobre el monasterio, también cisterciense, de San Martín de Castañeda las obras más completas son las realizadas por Fernández de Prada, El Real Monasterio de San Martín de Castañeda (1998) y por Miguel Hernández, El monasterio de San Martín de Castañeda. Zamora. Análisis de su pasado para el futuro (2010). Del desaparecido monasterio cisterciense de Santa María de Valparaíso se hizo la exposición El Imperial Monasterio de Nuestra Señora de Valparaíso, 23 de diciembre de 1986-11 de enero de 1987. Con posterioridad en Instituto de Estudios Zamoranos "Florián de Ocampo» publicó sobre él un corpus documental titulado Colección Diplomática del Imperial Monasterio de Nuestra Señora de Valparaíso (1143-1499), (1998). Para el conocimiento del convento de San Francisco de la ciudad de Zamora es preciso 
consultar el libro, publicado con motivo de su rehabilitación, titulado El Convento de San Francisco. Memoria histórica, intervención arqueológica y rehabilitación arquitectónica (1998). Existen otras publicaciones de carácter más sencillo y divulgativo en las que, no obstante, se realizan importantes observaciones sobre templos parroquiales de la provincia. Es el caso de los títulos Pereruela de Sayago. La parroquia, la desamortización y los Docampo (1984), Parroquias, archivos y cofradías de Villalpando (2003), Castroverde de Campos. Notas de su historia y patrimonio (2011) y El Perdigón. El Pueblo, el Chantre y los Vizcondes (2014).

La arquitectura civil ha despertado menor interés de tal forma que no existe ninguna publicación concreta que aborde el estudio de un edificio. Vamos a tener que recurrir, por tanto, a catálogos generales como el ya citado de Gómez-Moreno o a otros más específicos como el libro titulado Casas y palacios de Castilla y León coordinado por Jesús Urrea (2002).

Por último, y por lo que respecta a la bibliografía, aunque a priori tanto el estudio de Ramos de Castro El arte románico en la provincia de Zamora (1977) como el volumen correspondiente a Zamora y su provincia de la Enciclopedia del Románico (2002) se aparten del marco estilístico estudiado al hacer referencia a la arquitectura del periodo artístico que antecede al gótico, un buen número de los edificios que contienen estas publicaciones incorporan, por lo tardío de su construcción, formas que son la base o el origen del gótico.

\section{Propuesta metodológica}

Las circunstancias especiales que concurren en la arquitectura gótica en la ciudad de Zamora y su provincia dan lugar a un cierto desfase en relación con algunos de los marcos cronológicos que actualmente se aplican para la división en etapas del arte gótico y que se pueden concretar en los periodos inicial, pleno y tardío. Las formas góticas aparecen con retraso en el contexto zamorano. Entre el gótico inicial y pleno no existe, en la mayor parte de los casos, una ruptura aparente, a lo que se añade el hecho de que algunas de las fórmulas creadas durante el periodo gótico tardío tengan una prolongación en el tiempo hasta bien avanzado el periodo renacentista.

En consecuencia parece más oportuno acudir a criterios estilísticos para la clasificación de la arquitectura gótica zamorana y tratar las diferentes fases con una cierta relatividad e independencia de los parámetros establecidos. Esta es la razón por la que se ha añadido a los tres periodos citados una última fase dedicada a la pervivencia de las formas góticas fuera de su natural tiempo de desarrollo.

La pretensión de este trabajo es, primero, ofrecer un catálogo exhaustivo de los monumentos o restos conservados pertenecientes al periodo gótico a través del estudio científico de los mismos. Dado el número de pérdidas y transformaciones que han sufrido los edificios góticos 
en la provincia de Zamora es necesaria la utilización de fuentes de tipo muy diverso que ayuden a recomponer y completar, en la medida de lo posible, el panorama arquitectónico gótico que, sin duda, fue mucho más amplio de lo que ha llegado hasta hoy. En segundo lugar se ha realizado una valoración y análisis, circunscrito a los distintos momentos en que hemos dividido el periodo arquitectónico gótico, de aquellos elementos que se han conservado.

El estudio de cualquier periodo de la Historia del Arte y de sus monumentos hace imprescindible la revisión de la documentación conservada de época para poder juzgar con la mayor veracidad posible lo que nos ha llegado, en algunos casos, muy parcialmente y, en otros, tremendamente transformado. No son muy abundantes las fuentes históricas del periodo que se va a estudiar pero sí muy útiles. También indudablemente tiene enorme interés la documentación perteneciente a siglos posteriores.

Consecuentemente ha sido fundamental en primer lugar la información que proporciona la exhaustiva revisión de la bibliografía existente, de las fuentes gráficas y de las fuentes documentales, así como la visita a cada una de las obras conservadas.

\section{Documentación escrita y bibliografía}

Fundamental para todo trabajo de investigación es la consulta de la documentación escrita, tanto de la época, como de siglos posteriores. Para la realización de este trabajo se ha revisado el contenido de aquellos archivos que contienen documentos esenciales para el estudio de este periodo. Estos han sido el Archivo Histórico Diocesano de Zamora, el Archivo Histórico Provincial de Zamora, el Archivo de la Diputación Provincial de Zamora, el Archivo de la Real Chancillería de Valladolid y el Archivo General de Simancas. Los catálogos ya realizados acerca de la documentación que contienen estos archivos han sido de gran ayuda. Como documento esencial para el estudio histórico de la provincia de Zamora durante la Edad Media es fundamental la consulta de los Tumbos blanco y negro conservados en el Archivo Catedralicio de Zamora. También han sido de gran ayuda los repertorios documentales y las hemerotecas.

Para la recopilación bibliográfica he contado principalmente con los fondos de la Biblioteca Pública del Estado de Zamora, de la Biblioteca de la Facultad de Filosofía y Letras de la Universidad de Valladolid y de la Biblioteca General Universitaria Reina Sofía de Valladolid. No obstante, también he consultado las bibliotecas públicas de Benavente, Toro, Puebla de Sanabria, Valladolid y Peñafiel.

\section{Fuentes gráficas.}

El conocimiento que aportan las noticias literarias acerca del gótico zamorano se complementan con el material gráfico conservado ya se trate de grabados, pinturas, dibujos o fotografías antiguas. Este material permite, en algunos casos, saber cómo estaban 
configuradas algunas ciudades o cómo era un edificio o un espacio concreto de un edificio que ha desaparecido.

De la ciudad de Zamora y dentro del ámbito del dibujo, la vista más antigua que conservamos es la realizada por Antón van den Wyngaerde fechada en 1570 y que nos ofrece la apariencia que tenía la ciudad en aquel momento. Este artista, más conocido en España como Antonio de las Viñas, trabajó durante la segunda mitad del siglo XVI al servicio de Felipe II. Realizó varios recorridos por España inmortalizando de manera muy precisa la panorámica de diversas ciudades. El dibujo que representa a la ciudad de Zamora está firmado y fechado en 1570 . El aspecto que la ciudad presentaba siglos más tarde, concretamente en el año 1756, quedó recogido en otro dibujo, en este caso, realizado por José Augier y que ha sido publicado en el catálogo CIVITAS. MC. La obra lleva la siguiente leyenda: VISTA DE LA CIUDAD DE ZAMORA POR LA PARTE DEL RIO. CAPITAL DE CASTILLA LA VIEJA, ES LA RESIDENCIA DE LOS EXCELENTISIMOS CAPITANES GENERALES, ILUSTRÍSIMOS SEÑORES OBISPOS, INTENDENTES Y DEMÁS OFICINAS.

De mediados del siglo XIX son los dibujos de Ivo de la Cortina y de José María Avrial tomados desde la Cruz del Rey don Sancho y que, por tanto, recogen una vista general del lateral norte de la ciudad de Zamora. El realizado por De la Cortina fue estampado en 1844 para el Semanario Pintoresco Español mientras que Avrial ejecutó en suyo durante una estancia en Zamora en el año 1850. Ambos dibujos aportan datos muy interesantes para el conocimiento urbano y arquitectónico de la ciudad en el momento en el que fueron dibujados, pues entre otros aspectos, todavía se reflejan edificios que en las décadas siguientes desaparecerían.

En el ámbito pictórico, aunque las obras sean menos precisas y, en algunos casos, estén idealizadas, nos aportan datos que son de interés. Una de estas pinturas lleva por título Traslado de la Virgen de la Concha a Zamora y su jura como Patrona de la ciudad. Se trata de un óleo sobre tela de finales del siglo XVII o principios del XVIII que se conserva en la actualidad en la iglesia de San Vicente. En ella se representa la ciudad de Zamora y sus murallas y, en primer plano, una puerta de acceso que ha sido identificada con la de Zambranos, también denominada impropiamente como puerta de doña Urraca.

Otro óleo sobre lienzo, en este caso firmado por J. Acedo y Torres en 1874 y conservado en el Museo de Zamora recoge la vista característica de la ciudad desde la margen izquierda del río Duero.

De la ciudad de Benavente la imagen más antigua que nos ha llegado se encuentra en el anverso de un sello de cera del siglo XIII conservado en el Archivo Histórico Diocesano de la Catedral de Astorga. En él se observa una ciudad rodeada por murallas y edificada en un alto y bajo ella un puente salva un río. El resto de representaciones tienen fundamentalmente como protagonista al castillo-palacio de los condes de Benavente. Este grupo de pinturas, grabados y dibujos tienen un significado trascendental, por cuanto ayudan a la reconstrucción de uno de 
los edificios más espléndidos de la provincia y del que apenas se ha conservado una mínima parte.

De la ciudad de Toro contamos igualmente con una vista realizada por Wyngaerde. También de esta ciudad y de algunas otras localidades importantes de la provincia se conservan grabados, dibujos y pinturas que son de gran utilidad.

A todo ello habría que sumar un buen número de fotografías antiguas indispensables por lo que aportan ya que algunas de ellas recogen la imagen de algunos edificios desaparecidos y otras muchas la imagen de otros antes de su restauración o rehabilitación. Esto les concede un valor esencial. Todas ellas han sido publicadas y, en su mayor parte, están recogidas en las publicaciones Zamora en imágenes. 1925-1950. Fotografías y Sociedad, Memoria Gráfica de Zamora y Ayer y Hoy de Zamora.

Por último, no hay que olvidar aquellas planimetrías y alzados de edificios conservadas principalmente en los archivos provinciales.

\section{Trabajo de Campo}

Junto a la consulta documental, bibliográfica y de las fuentes gráficas resulta imprescindible el estudio de campo para lo que ha sido necesario recorrer y visitar cada uno de los edificios que en este trabajo se señalan y de los cuales se ofrece una ficha en la que se aborda el edificio o los restos góticos que se han conservado en algún edificio desde el punto de vista histórico y artístico. Estas fichas se presentan acompañadas de una serie de fotografías tomadas durante las visitas a todos los edificios y realizadas en la práctica totalidad de los casos por el autor de este trabajo. Cuando no es así se ha especificado en el pie de foto.

Las poblaciones que he recorrido han sido muy numerosas y en su gran mayoría circunscritas a la provincia de Zamora. No obstante he visitado otras localidades pertenecientes a otras provincias donde se conservaban elementos que resultaban de interés y de ayuda para este estudio. Todo ello ha supuesto una gran cantidad de tiempo y organización pues los edificios que se han estudiado se encuentran dispersos por toda la provincia. En concreto, las localidades que se reseñan en el catálogo son 51 y el número total de edificios o partes de ellos que tienen su estudio particularizado en el mismo son más de 100. Durante el proceso de realización de esta tesis doctoral, la complejidad se ha visto también acentuada por constituir muchos de ellos pequeñas poblaciones, que pertenecen además a dos diócesis distintas y que a su vez, por lo que se refiere al ámbito eclesiástico, son atendidas por un grupo reducido de sacerdotes. Es por ello que los trámites para concertar determinadas visitas no hayan estado a veces exentos de algunas dificultades, que en todos los casos han podido ser solventadas. 


\section{Organización del trabajo}

Dos aspectos se han tenido en cuenta como elementos conductores del trabajo. Por un lado la realización de las fichas en las que se incluye la localización precisa de la obra, la sucinta historia del monumento y el análisis pormenorizado de las partes objeto de estudio. En estas fichas, bajo el epígrafe de cada uno de los edificios estudiados se ha colocado entre paréntesis la cronología alusiva solamente a las obras que en dicho edificio pertenecen por su estilo al arte gótico. También se incluye la planimetría de la mayor parte de los edificios conservados. Un importante número de planimetrías han sido realizadas para este estudio por Francisco M. Morillo, licenciado en Historia del Arte y colaborador del Laboratorio de Fotogrametría de la Escuela de Arquitectura de la Universidad de Valladolid, que figura como autor en cada una de ellas. Otras se han realizado de acuerdo con esquemas prexistentes pero han sido reelaboradas en función del estudio del edificio realizado por el autor. En ellas se ha señalado en negrita la parte conservada correspondiente al periodo gótico mientras que las que responden a otro momento constructivo se encuentran en gris claro. A su vez hemos decidido sombrear en un gris más oscuro aquellos arcos o bóvedas góticas que están situados en estructuras que no pertenecen a este estilo y decolorar aquellas bóvedas que no se han conservado pero, bien tenemos constancia de como eran o, bien hemos planteado un trazado hipotético. La ejecución técnica correspondiente a los retoques de estas planimetrías que ya habían sido publicadas, supervisada por el autor de esta tesis, la ha llevado a cabo Sergio García Sánchez, doctor en Física. Solamente se ha dejado constancia de ello en el pie de foto cuando la alteración ha sido significativa. Fundamentalmente estos cambios atañen al trazado de las nervaduras de algunas bóvedas que hasta el momento se habían publicado erróneamente. Corregimos y aportamos, por tanto, por vez primera, el trazado real de ellas, imprescindible, como no podía ser de otro modo, en un trabajo de este tipo. Cada ficha se completa con las correspondientes referencias bibliográficas.

Este primer aspecto del trabajo constituye la infraestructura de esta tesis y figura en el apartado final de la misma.

El segundo aspecto es la parte propiamente de elaboración, en la que se asientan las conclusiones. Está basada en el estudio de los elementos arquitectónicos, con especial atención a aquellos que pueden encuadrarse en unos límites cronológicos más o menos precisos, con el objeto de establecer comparaciones con la mayor parte de las obras que no están fechadas y así elaborar una secuencia tipológica de las formas a lo largo del periodo comprendido entre los siglos XIII al XVI y trazar el proceso evolutivo de las formas que se manifiestan en dichos edificios, con el objeto de que las conclusiones puedan extrapolarse, como elemento de comparación, más allá del caso zamorano, al conjunto de la arquitectura gótica española y europea. Para ello se ha prestado una atención especial a los aspectos definidores de estilo 
como son el tipo de arco, la sección de nervios y los repertorios ornamentales entre otros; algunos de los cuales son muy reveladores de cronologías concretas.

Este segundo aspecto constituye el cuerpo principal de la investigación y se ofrece dividido en capítulos que se ajustan a los periodos arquitectónicos significativos dentro de la arquitectura gótica zamorana.

Por razones tipológicas y estilísticas, en esta tesis se ha concedido, cuando se ha considerado oportuno, un tratamiento independiente a la arquitectura religiosa y a la arquitectura civil, respetando, sin embargo el momento histórico al que pertenecen sus manifestaciones.

Es importante señalar que en los estudios de fondo de esta tesis doctoral he omitido datos complementarios, no determinantes, de los edificios que se estudian, pero que, sin embargo, se encuentran recogidos en la ficha correspondiente del catálogo que aportamos, donde pueden ser consultados para una visión más completa de cada uno de los edificios citados. 


\section{INTRODUCCIÓN A LA ARQUITECTURA GÓTICA EN LA CIUDAD DE ZAMORA Y SU PROVINCIA}

Así como la arquitectura románica zamorana ha merecido el máximo interés por parte de los historiadores del arte por la calidad y el número de sus edificios, las manifestaciones artísticas del periodo gótico, tanto en el ámbito religioso como en el civil, apenas han suscitado mayor respuesta que algunas referencias parciales. No existe ningún estudio de conjunto, ni análisis pormenorizado del proceso experimentado por la arquitectura durante el espacio de tiempo propuesto. Esta carencia justifica mi interés por la investigación en las formas arquitectónicas de este periodo gótico tan desatendido en esta zona geográfica.

Durante el periodo románico tuvo lugar en la provincia de Zamora una intensa actividad constructiva que afectó tanto a pueblos y aldeas como a las localidades más destacadas, especialmente a la capital, a Benavente, Toro y Villalpando. El gran número de edificios religiosos levantados entonces dejaron resueltas las necesidades de estos núcleos de población para las generaciones venideras. La sólida arquitectura de estas construcciones y la escasez de recursos económicos con que contó esta zona geográfica durante la Baja Edad Media fueron razones poderosas para la conservación, y mantenimiento en uso de esos edificios románicos.

Como consecuencia de ello, la arquitectura gótica ha tenido menor incidencia en el paisaje urbano de la provincia, y sus manifestaciones han sido prácticamente invisibles en conjunto. Pero a pesar de que los siglos del gótico no se correspondan con una época especialmente pujante desde el punto de vista económico para Zamora, sin embargo, la actividad arquitectónica no se frenó a lo largo de este periodo. El panorama arquitectónico general en la provincia está configurado en una buena parte por intervenciones parciales que completaron o reformaron en su momento algunas edificaciones ya existentes. Asimismo, durante ese periodo se levantaron edificios de nueva planta, la mayor parte de los cuales, bien por la modestia del proyecto, bien por el deseo de renovación en épocas posteriores, no han llegado a nuestros días o sólo han dejado pequeños vestigios como testimonio de su existencia. Sólo excepcionalmente se puede hablar de grandes edificios, de los que lamentablemente también se ha conservado una mínima parte.

Ante este estado de cosas se puede comprender que el estudio de la arquitectura de este periodo esté limitado por importantísimas carencias que dificultan en gran manera el establecimiento de la secuencia evolutiva en relación con el desarrollo de la arquitectura tanto en los territorios hispánicos como en Europa. Aunque en este trabajo se ha procurado mantener 
las divisiones estilísticas aceptadas para el estudio de este estilo, en general se observa un retraso en la introducción de las formas, con los consiguientes desfases cronológicos.

La introducción del gótico en Zamora tuvo lugar a partir de algunos elementos formales aislados que se incorporaron progresivamente desde finales del siglo XII en construcciones románicas tardías, tales como el arco apuntado que comienza a aparecer muy tímidamente en los numerosos arcosolios que se abrieron en los muros de muchos templos y en los vanos del cuerpo superior de las torres de las iglesias de San Cipriano, San Vicente, Santa María de la Horta y San Leonardo ${ }^{4}$ de Zamora, de la iglesia de Santa María del Azogue de Benavente y de Santa María del Río en Castroverde de Campos. El apuntamiento del arco se manifestó igualmente en las portadas de algunos templos como puede observarse en el vano ciego situado en el muro norte de la iglesia de Santa María de la Horta de Zamora, en el arco doblado apuntado de la hoy condenada portada occidental de la iglesia de Santa Lucía de Zamora y de forma más evidente en la portada sur de la iglesia de San Isidoro y en la portada norte, hoy cegada, de la iglesia de Nuestra Señora de la Asunción de Venialbo. Este apuntamiento ira con el tiempo adquiriendo mayor agudeza como ocurre en la puerta norte de la iglesia de Santa María la Nueva de Zamora y en las portadas meridionales de las iglesias de Santa María del Río, San Nicolás y de Santa María la Mayor o de la Sagrada, todas ellas en Castroverde de Campos.

El otro elemento que, junto con el arco apuntado, tiene una importancia capital en la introducción de las formas góticas en Zamora es la bóveda de crucería que comenzó a utilizarse en fecha muy temprana. Probablemente antes de 1200 estaban construidas las bóvedas de la girola de la iglesia del monasterio de Santa María de Moreruela. Prácticamente al tiempo se levantaron las bóvedas de crucería de la nave central de la Catedral, y quizá muy poco después la que cubre el cuerpo superior de la torre de este mismo edificio así como las bóvedas de la nave de la iglesia de Santa María de la Horta.

La arquitectura civil que se ha conservado de este periodo es escasa y se limita fundamentalmente a estructuras de carácter defensivo en las que precisamente por su funcionalidad no acusaron rasgos de estilo. Únicamente el arco apuntado liso comienza a ser habitual en ellas hacia 1200, aunque su presencia cabría interpretarse no solo como una mera evolución de las formas sino también como una solución técnica de mayor consistencia que las que se venían usando hasta el momento. Los vanos en arco apuntado se encuentran en su mayoría en el castillo de Zamora y en los puentes de Zamora y de Toro y carecen de elementos decorativos.

4 En este último edificio, no se han conservado, pero los conocemos a través de fotografías antiguas. 
Durante el periodo gótico pleno, que viene a corresponderse con los siglos XIII y XIV, la actividad constructiva fue menos intensa de lo que había sido a lo largo del siglo XII y principios del siglo XIII. A ello hay que sumar la pérdida de muchas construcciones levantadas en este momento por circunstancias diversas.

Desde el punto de vista religioso, hay que destacar, en primer lugar, la importancia que desempeñaron las órdenes mendicantes, que se asentaron durante el siglo XIII en las poblaciones más importantes de la provincia y comenzaron a levantar sus casas en el nuevo estilo. Desgraciadamente la mayor parte de lo que edificaron estas comunidades de religiosos y religiosas durante el periodo gótico pleno ha desaparecido; en gran parte por los traslados a los que se vieron sometidos $y$, probablemente también, por tratarse en muchos casos de edificios de poca entidad arquitectónica o escasa solidez. A ello hay que sumar, por lo que se refiere fundamentalmente a las grandes construcciones monásticas, los procesos desamortizadores que tuvieron lugar durante el siglo XIX y que significaron el inicio de la decadencia de muchos de estos edificios, que con el paso del tiempo serían abandonados por completo. De forma particular se vieron afectados dos de los conjuntos arquitectónicos religiosos más destacados de la provincia: el monasterio dominico de San Ildefonso en Toro y el convento de San Francisco en Zamora. De estos dos edificios, no obstante, permanecen en pie algunas estructuras que, desde el punto de vista cronológico, pertenecen a los siglos XIV y $X V$. Su estudio y contextualización dentro de la arquitectura zamorana es de gran importancia. También se han conservado restos de edificios pertenecientes en origen al siglo XIV pero que fueron remodelados y ampliados posteriormente, como es el caso del monasterio de Sancti Spiritus el Real de Toro, en cuyo claustro ha permanecido un grupo de portadas y vanos del siglo XIV así como el arco de ingreso a la capilla mayor de la iglesia y su acceso original, de la misma época.

Pero, sobre todo, en este momento, proliferaron las reformas en edificios existentes, como las realizadas en la catedral de Zamora (capilla funeraria fundada en la segunda mitad del siglo XIII por parte de un miembro de la familia del obispo Suero, y que fue transformada en el siglo XVI por el doctor Grado, y capilla de San Bernardo fundada en la segunda mitad del siglo XIV por Alonso Fernández de Valencia, obispo de Zamora) y en la colegiata de Toro, donde se edificó la capilla de la Majestad, el espacio más completo que se ha conservado del gótico pleno y en cuyo interior se encuentra una de las portadas monumentales más destacadas del medievo. Pocas décadas después se dotó a la iglesia de Santa María la Real de la Hiniesta con un pórtico y portada hacia el sur, que constituye junto a la portada citada de Toro el otro gran conjunto de escultura monumental en la provincia de Zamora. A todo ello hay que sumar las transformaciones que sufrieron en sus naves algunas iglesias románicas como San Cipriano y Santa María la Nueva en Zamora, San Pedro del Olmo en Toro y la mencionada de La Hiniesta. 
Por lo que respecta al ámbito civil, las estructuras arquitectónicas que se han conservado de este periodo también son escasas y se encuentran muy mutiladas o transformadas. A las que tienen carácter defensivo, como las murallas de Zamora o pequeños lienzos de muro que todavía subsisten en otras localidades, se une su finalidad puramente funcional lo que hace que carezcan de elementos referenciales de estilo. Solamente las puertas de Santiago y de San Andrés (esta última muy reformada en el siglo XVI), pertenecientes al segundo recinto amurallado de Villalpando, levantado durante el siglo XIV, presentan sus vanos en arco apuntado. No obstante, mantienen en esencia modelos del siglo XIII.

En el ámbito de la arquitectura doméstica los testimonios son aún más escasos, pero se han conservado partes muy significativas de un único edificio que, por otro lado, tiene una gran importancia dentro del contexto de la arquitectura gótica en la provincia de Zamora. Se trata de las antiguas casas del obispo de Coria en Toro, que fueron donadas a María de Molina y que actualmente están integradas en el monasterio de Santa Sofía. De ellas se ha conservado el cuerpo bajo del torreón con una sencilla portada en arco agudo que acusa influjos cistercienses y el patio de la Cisterna, de planta rectangular y articulado mediante una serie de columnas cuyos capiteles contienen un destacadísimo repertorio ornamental, que está en consonancia con lo que se hacía en el momento en la arquitectura religiosa.

Durante los dos primeros tercios del siglo XV la actividad constructiva en territorio zamorano siguió siendo escasa. A esta época podemos adscribir dos estructuras parciales pero de enorme singularidad. La primera de ellas es el cuerpo superior de la fachada occidental de la iglesia de San Juan de Puerta Nueva en Zamora, que fue renovado en estos momentos al colocar un gran ventanal con tracerías. La segunda es la fachada del palacio de las Leyes de Toro, único elemento conservado de este significativo edificio.

Avanzado el siglo XV y sobre todo a partir del último tercio se inició en la provincia de Zamora un periodo de intensa actividad constructiva que se prolongó durante buena parte del siglo XVI. Habría que distinguir, no obstante, dos grandes fases desde el punto de vista estilístico.

La primera viene a corresponder con el denominado gótico tardío y se desarrolla durante las décadas finales del siglo XV y primeras del siglo XVI. Coincide, aproximadamente, con el reinado de los Reyes Católicos. La actividad constructiva se incrementa de forma sustancial, debido en gran medida a la prosperidad que trajo consigo la consolidación del reino. La pujanza económica dio lugar a que destacados prelados como Meléndez Valdés y fray Diego de Deza y nobles como los condes de Benavente o los condes de Alba de Aliste patrocinaran obras de envergadura. Especialmente destacables fueron las reformas llevadas a efecto en la catedral durante este periodo, como la sustitución de la cabecera románica por una tardogótica, patrocinada por el 
obispo Meléndez Valdés, así como la adición de nuevos espacios con funciones, entre otras, de antesacristía y sacristía. Nos parece ciertamente atractiva y relevante la posible intervención de Juan Gil de Hontañón en la consecución de esta parte del templo catedralicio, que hemos planteado como hipótesis. En el mismo edificio e igualmente bajo el mecenazgo de Meléndez Valdés, se levantó el coro y se labró su sillería. Ello supuso una de las transformaciones más grandes sufridas por la catedral. También este prelado patrocinó las reformas que se llevaron a cabo en la iglesia de San Pedro y San Ildefonso que consistieron en transformar las tres naves románicas originales en una sola nave de mayor altura y cubierta por bóvedas de crucería semejantes a las que se habían utilizado en el crucero de la catedral.

La actividad llevada a efecto en la catedral tuvo también otras repercusiones. Durante los inicios del siglo XVI se levantaron las cabeceras de las iglesias parroquiales de Morales del vino, de Corrales del Vino y de Casaseca de las Chanas, en las que habría que ver la influencia de la cercana catedral zamorana, adaptada, en cualquier caso, a su condición de edificios de menor importancia. Sin embargo, en el cuerpo de estas iglesias, quizá por la demora en la construcción, las formas se apartan ya del lenguaje gótico tardío e incorporan repertorios renacentistas, salvo en algún elemento muy puntual como ocurre con la portada sur de la iglesia de la Asunción de Nuestra Señora de Morales del Vino que guarda todavía una estrecha vinculación con modelos propios del gótico tardío. No obstante en el espacio que se prolonga hacia occidente en la iglesia de Casaseca de las Chanas se utilizaron bóvedas de crucería con nervios combados. Lo mismo podríamos decir de la iglesia de Nuestra Señora de la Asunción de Villamor de los Escuderos iniciada por Juan Gil de Hontañón a quien se debe la cabecera y el crucero y continuada por su hijo Rodrigo Gil que se hizo cargo de la nave de la iglesia. Sin embargo, en este caso, aunque la estructura arquitectónica del cuerpo del edificio y su portada meridional son totalmente renacentistas, los tramos de la nave se cubrieron con bóvedas de crucería con combados.

Durante este periodo son excepcionales los edificios levantados de nueva planta, que se hayan conservado. Por eso son particularmente interesantes las iglesias de San Sebastián de los Caballeros en Toro y de El Salvador en Ayoó de Vidriales, En ambos casos se trata de construcciones pertenecientes en su conjunto al gótico tardío, lo que les confiere un valor especial en el panorama de esta etapa artística en la provincia de Zamora.

Pero, sobre todo, en esta época, fueron muy numerosos los añadidos y reformas en edificios preexistentes. En esta línea hay que destacar las capillas funerarias que se edificaron, mayoritariamente de dimensiones reducidas y sin grandes alardes en el diseño y la ornamentación. Podemos citar desde la renovación que hizo el doctor Juan de Grado de la 
capilla de la familia Suero en la catedral de Zamora hasta capillas como la del Chantre en la iglesia de San Félix de El Perdigón, la capilla conocida actualmente como Jesús Nazareno en la iglesia de San Pedro Apóstol de Villalpando y la capilla de los Tapia en la iglesia de San Lorenzo el Real de Toro.

También fue destacable la construcción de pórticos, cubiertos por bóvedas de crucería, para cobijar la portada de acceso de las iglesias de Santa María la Real de La Hiniesta y de Santa María del Río de Castroverde de Campos.

Por último, hay que señalar algunas fachadas decorativas de enorme interés. La más sencilla se encuentra en el muro norte de la capilla del Deán del convento de San Francisco de Zamora. La siguiente se abre en el muro sur de la iglesia de San Vicente Mártir de Villar de Fallaves y, por último, la más espléndida en cuanto a dimensiones y riqueza ornamental es la incorporada en la fachada occidental de la iglesia de San Julián de los Caballeros y que en origen estuvo ubicada en el crucero del convento de San Ildefonso de Toro.

La arquitectura de carácter civil en los territorios zamoranos durante las últimas décadas del siglo XV y las primeras del siglo XVI se vio afectada igualmente por una actividad constructiva más intensa, favorecida por los Reyes Católicos, que mandaron edificar el Ayuntamiento viejo y financiaron otras intervenciones, tales como arreglos en calles y murallas. También la nobleza local, que poseía en este momento una mayor capacidad económica, pudo construir un número importante de castillos y palacios de los que se han conservado algunos ejemplos notorios.

Importantes reformas, más bien reconstrucciones, sufrieron algunos castillos como los de Castrotorafe, Villalpando, Benavente y Alba de Aliste, cuyos orígenes se sitúa en los siglos XII y XIII y de los que desgraciadamente han llegado a nuestros días solamente ruinas o elementos muy puntuales como la torre del Caracol, que no deja de ser una parte muy reducida de lo que fue la gran residencia de los condes de Benavente. Otros se levantaron por completo a finales del siglo XV como sucedió con los de Villalonso y Puebla de Sanabria. Ambos se han conservado en la actualidad de forma bastante completa.

Junto a todas estas obras, más o menos parciales pero con entidad en sí mismas, se ha conservado un gran número de testimonios arquitectónicos fragmentarios de edificios que pertenecieron a éste momento -ahora desaparecidos-, en unos casos descontextualizados y en otros incorporados a inmuebles hoy en día vigentes. A pesar de su escaso impacto monumental, son elementos de gran valor para completar, al menos de forma virtual, la 
perspectiva que ofrecían los núcleos de población de la provincia de Zamora durante los últimos momentos del gótico.

Como conclusión, en esta secuencia del estilo gótico en el territorio zamorano, hay que señalar que las fórmulas estructurales y decorativas góticas -cuya implantación fue lenta y tardía debido al arraigo del estilo románico-, se prolongaron durante un periodo de tiempo muy amplio dificultando la introducción del renacimiento en estado puro. Hasta casi finales del siglo XVI se siguió utilizando la bóveda de crucería que adquirió en estos momentos la mayor elaboración y ornamentación. En algunos casos también se siguió utilizando el tipo de soporte en forma de pilar fasciculado propio de la arquitectura gótica tardía. Con frecuencia se mantuvo como elemento decorativo de las portadas, el alfiz, que aunque de origen mudéjar había sido utilizado habitualmente en la arquitectura civil y religiosa del periodo gótico tardío. Ocasionalmente, motivos decorativos góticos de carácter vegetal o animal conviven con los repertorios renacentistas en uso. Por estas razones se ha querido dedicar un último apartado dentro del trabajo a las obras que sin ser ya plenamente góticas pueden considerarse como pervivencias del estilo gótico.

\section{Agradecimientos}

Esta tesis doctoral se ha llevado a cabo en el seno del Departamento de Historia del Arte de la Facultad de Filosofía y Letras de la Universidad de Valladolid, dirigido durante el periodo de realización de esta tesis, primero, por el doctor don Francisco Javier de la Plaza Santiago y, actualmente, por el doctor don Jesús María Parrado del Olmo, a quienes agradezco todas las facilidades que me han proporcionado para llevar a efecto las tareas de investigación, así como el acceso a los fondos bibliográficos y fotográficos.

Es indudable que un estudio de esta índole no hubiera podido realizarse de una manera individual, al contrario, ha sido posible gracias al apoyo de múltiples personas e instituciones.

Quiero dejar, por tanto, constancia de mi agradecimiento, en primer lugar, a la Fundación Las Edades del Hombre en las personas de su actual Secretario General, el profesor don Gonzalo Jiménez Sánchez y en la de sus anteriores responsables don José Ramos Domingo y don Juan Álvarez Quevedo, que me han facilitado en todo momento el poder compatibilizar mis responsabilidades como trabajador de la mencionada Fundación con la realización de este estudio. Muy especialmente también a todos mis compañeros de "Las Edades".

Ha de constar mi gratitud hacia el Excelentísimo Ayuntamiento de Zamora y la Fundación Rei Alfonso Enríquez que en todo momento han estado prestos en facilitar todo lo necesario para el desarrollo de este estudio. 
Agradezco también las facilidades dadas por don José Ángel Rivera de las Heras, Delegado para el Patrimonio y la Cultura de la Diócesis de Zamora, don José María Voces Jolías, anterior Delegado de Patrimonio de la Diócesis de Astorga y al actual don José Manuel Ramos Gordón. Todos ellos me facilitaron el acceso a los edificios o elementos arquitectónicos necesarios para la realización de este trabajo así como me permitieron la toma de fotografías. A su vez doy las gracias al Cabildo de la Catedral de Zamora y a su anterior Déan-Presidente don Juan González López por la inestimable y desinteresada colaboración que me han prestado, a los sacerdotes responsables de las iglesias de la ciudad de Zamora y a aquellos que lo son de los templos de todos y cada uno de los pueblos visitados pertenecientes tanto a la diócesis de Zamora como a la diócesis de Astorga. También agradezco la amabilidad y paciencia mostrada por las comunidades de religiosas de nuestra ciudad y provincia. No puedo olvidar tampoco a aquéllas personas que trabajan en los templos estudiados y que, aparte de facilitarme en la medida de sus posibilidades lo requerido por mi parte, me han apoyado dando grandes muestras de ánimo.

Igualmente reconozco a todo el personal de la Biblioteca Pública de Zamora y de la Biblioteca de la Facultad de Filosofía y Letras de la Universidad de Valladolid, la ayuda prestada proporcionándome todos los fondos bibliográficos requeridos a lo largo de estos años de investigación. Quede constancia de mi reconocimiento a sus responsables y a todos los profesionales que en ellas trabajan.

Es de justicia mencionar las amplias facilidades que nos han brindado para nuestro estudio todas las instituciones y archivos visitados entre los que destaco el Museo Provincial de Zamora, el Archivo Histórico Provincial de Zamora, el Archivo Diocesano de Zamora y la Real Academia de Bellas Artes de San Fernando, desde sus máximos responsables hasta los técnicos que en ellas trabajan.

Debo una mención especial en esta relación de agradecimientos a las personas que facilitaron este trabajo, sobre todo, a don José Luis Hernández Luis, Jefe de Departamento del Centro Documental de la Memoria Histórica; a don Francisco Somoza, arquitecto; don Agustín Lorenzo Sanz, empresario zamorano propietario de la iglesia de San Leonardo; a don José Ramón Nieto profesor de la Universidad de Salamanca y ya fallecido; a don José Andrés Casquero Fernández del Archivo Histórico Provincial de Zamora; a don José Carlos de Lera Maíllo, Técnico archivero del Archivo Histórico Diocesano de Zamora; a don Luis Brualla SantosFuncia, que fue Presidente de la Audiencia Provincial de Zamora y a don José Andrés García Redondo, Arquitecto Jefe del Área Técnica de la Subdirección General de Obras y Patrimonio del Ministerio de Justicia.

No quisiera concluir estos agradecimientos por la gran ayuda recibida sin dejar constancia igualmente de mi gratitud hacia el profesor don José Navarro Talegón cuyas aportaciones al 
conocimiento del arte zamorano son indispensables a la hora de abordar el arte de la ciudad de Zamora y su provincia.

Tampoco han sido ajenos a este trabajo mi familia, especialmente mis padres y mi hermana y mis amigos, cuyo apoyo ha estado presente en todo momento. Un agradecimiento especial merecen Sergio García Sánchez y Francisco M. Morillo, que además de amigos me han ayudado en todo momento de manera desinteresada en la elaboración, como señalaba anteriormente, de las citadas planimetrías así como en cuestiones técnicas que tienen que ver con el diseño y la maquetación de este trabajo. A este respecto de la maquetación también agradezco la ayuda de Olalla González Cuadrado.

Sea mi último reconocimiento para el Departamento de Historia del Arte de la Facultad de Filosofía y Letras de la Universidad de Valladolid y sus directores, a los que ya he mencionado anteriormente. Y, sobre todo, mi agradecimiento a los doctores Clementina Julia Ara Gil y Luis Vasallo Toranzo, profesores de Historia del Arte de la Universidad de Valladolid, directores de esta tesis y cuya ayuda, empeño y dedicación han sido imprescindibles para la realización de la misma. 
LOS INICIOS DEL GÓTICO 



\section{LOS INICIOS DEL GÓTICO}

\section{Notas históricas}

Para comprender las circunstancias históricas que concurrieron en la ciudad de Zamora a finales del siglo XII y principios del siglo $\mathrm{XIII}$ es necesario remontarse a los siglos $\mathrm{X}$ y $\mathrm{XI}$, periodo en el que comenzó la formación y consolidación del núcleo urbano de la ciudad. La restauración Ilevada a efecto por Alfonso III en el año 893, durante los primeros momentos de la Reconquista, se consolidó gracias a la repoblación de la ciudad promovida por este mismo monarca que facilitó la llegada de gentes provenientes del norte así como de mozárabes procedentes del sur. En muy poco tiempo, Zamora, gracias en gran medida a su situación estratégica, se convirtió en una de las ciudades más destacadas del incipiente reino de León. Sin embargo, esta primera etapa de esplendor de la ciudad, se vio interrumpida por la destrucción provocada por Almanzor en el año 9865. Para superar esta situación fueron necesarios nuevos procesos repobladores en el transcurso del siglo XI, auspiciados por Fernando I y Alfonso VI. Durante el reinado del primero llegaron a la ciudad, una vez más, gentes procedentes del norte, mientras que, bajo el poder de Alfonso $\mathrm{VI}$, se asentaron, por vez primera, los francos, cuyas actividades comenzaron a ser determinantes para el buen desarrollo de la urbe. El mismo Alfonso VI consiguió la anexión de los diferentes reinos: Castilla, León, Galicia y algunos señoríos en uno solo, hasta que, tras la muerte de su nieto el emperador Alfonso VII, los reinos de León y Castilla volvieron a dividirse formando Zamora parte del primero.

A Alfonso VII le sucedió al frente del reino de León su hijo Fernando II y a éste el monarca nacido en Zamora Alfonso IX. Durante el reinado de Alfonso IX (1188-1230) la ciudad de Zamora y su diócesis se vieron generosamente favorecidas.

5 Señala Domingo Montero que esta destrucción de la ciudad de Zamora no debió ser total, quedando en pie parte de las murallas y restos de algunos templos que sirvieron como modelo o, al menos, ejercieron una influencia decisiva que hicieron de nuestro románico un estilo muy particular. MONTERO APARICIO, Domingo, "Arte medieval en Zamora" en AA.VV., Historia de Zamora. De los orígenes al final del medievo, tomo I, Zamora, 1995, pp.755-821. 
Por lo que se refiere a la arquitectura religiosa es probable que en la ciudad de Zamora como sucedió en la provincia (iglesia de San Pedro de la Nave) se edificaran templos durante el periodo visigodo ${ }^{6}$. Los cronistas e historiadores venían admitiendo el establecimiento de los visigodos en la ciudad, hecho que pudo constatarse en el año 1989 durante los trabajos de excavación arqueológica llevados a cabo en la iglesia de San Ildefonso7. Dichas excavaciones dieron como resultado la aparición de diversos materiales entre los que destaca un ajuar funerario fechable en el siglo $\mathrm{Vl}^{8}$. Sin embargo, y a pesar de que las intervenciones arqueológicas desarrolladas en este lugar certifican el poblamiento de la ciudad por parte de los visigodos no se ha podido constatar la existencia de una iglesia advocada en Santa Leocadia, que según los cronistas debió levantarse en este mismo lugar en época visigoda ${ }^{9}$. Las posteriores referencias que tenemos hablan de iglesias, edificios civiles y construcciones defensivas erigidas ya en el siglo $\mathrm{X}^{10}$.

Desde el punto de vista de la organización eclesiástica, Zamora no alcanzó el obispado y la diócesis hasta el año 901, apenas ocho años después de la restauración de la ciudad llevada a efecto por Alfonso III ${ }^{11}$.

6 Acerca de la implantación visigoda en Zamora y su provincia, vid. CABALLERO ZOREDA, Luis, "Zamora en el tránsito de la Edad Antigua a la Edad Media. Siglos V-X" en AA.VV., Historia de Zamora. De los origenes al final del medievo, tomo I, Zamora, 1995, pp. 339-430.

7 SANCHEZ-MONGE LLUSA, Macarena, y VIÑE ESCARTÍN, Ana Isabel, "Excavaciones arqueológicas en la iglesia de San Ildefonso (Zamora)", Anuario del Instituto de Estudios Zamoranos «Florián de Ocampo», Zamora, 1989, pp. 133-144.

8 LARRÉN IZQUIERDO, Hortensia, “Ajuar funerario" en Catálogo de la Exposición CIVITAS. MC. Aniversario de la Ciudad de Zamora, Junta de Castilla y León, Caja España, Zamora, 1993, pp. 86-87.

9 FERNÁNDEZ DURO, C., op. cit., tomo I, 1883 (2003), pp. 216-217.

10 GUTIÉRREZ GONZÁLEZ, José Avelino, “Orígenes y evolución urbana de Zamora" en Catálogo de la Exposición CIVITAS. MC. Aniversario de la Ciudad de Zamora, Junta de Castilla y León, Caja España, Zamora, 1993, p. 24.

11 Los estudios realizados por el profesor Sánchez Herrero acerca de la diócesis de Zamora son fundamentales a la hora de abordar cuestiones relativas a este tema. SÁNCHEZ HERRERO, José, "La iglesia y la religiosidad en la diócesis de Zamora a finales del siglo XV" en Jornadas sobre Zamora, su entorno y América, Instituto de Estudios Zamoranos "Florián de Ocampo", Diputación de Zamora, 1992. SÁNCHEZ HERRERO, José, "Historia de la iglesia de Zamora. Siglos V al XV" en AA.VV., Historia de Zamora, De los orígenes al final del medievo, tomo I, Zamora, 1995. SÁNCHEZ HERRERO, José, "La Diócesis de Zamora en su Historia" en Catálogo de la Exposición Remembranza. Las Edades del Hombre, Zamora, 2001, pp. 33-52. Igualmente es imprescindible la publicación realizada con motivo del IX centenario de la fundación de la diócesis en la que también participó el profesor Sánchez Herrero. 


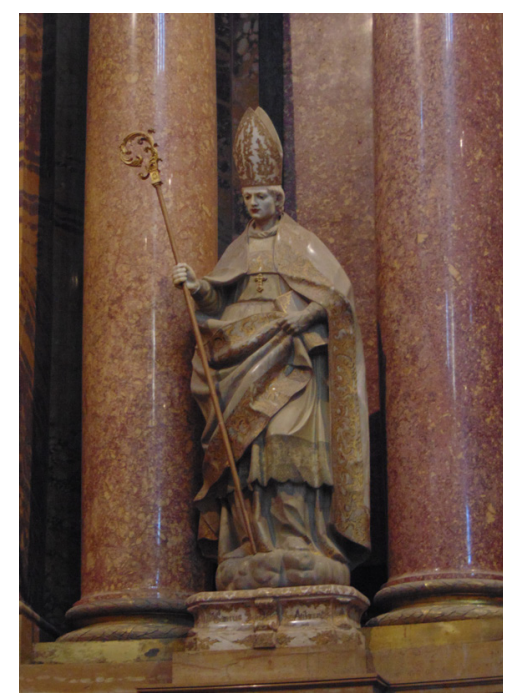

Fig. 1. San Atilano, primer obispo de la diócesis. Catedral de Zamora

No fue fácil el nacimiento del obispado de Zamora ${ }^{12}$. Su territorio había pertenecido a las diócesis cercanas y, como consecuencia de ello, éstas no estaban dispuestas a perder parte de su jurisdicción. Tras muchos litigios surgió la diócesis que quedó prácticamente configurada en el siglo XII. San Atilano ${ }^{13}$, como se señalará a continuación, encabeza el episcopologio al ser considerado su primer obispo (Fig. 1) ${ }^{14}$. Le siguieron a lo largo de la Edad Media una serie de prelados cuya marcada personalidad y forma de actuación fueron decisivas para la Iglesia de Zamora.

Este periodo inicial de la diócesis correspondiente al siglo $\mathrm{X}$ no transcurrió sin importantes sobresaltos, de entre los cuales destacó la citada devastación de la ciudad por las tropas de Almanzor en el 981, y que trajo como consecuencia la desaparición de la diócesis y de la figura del obispo, hasta su restablecimiento a principios del siglo XII ${ }^{15}$. Entre los edificios que sucumbieron a la devastación se encontraba la primitiva catedral que había sido edificada durante el siglo $X$ como consecuencia del nacimiento de la diócesis.

Los obispos que gobernaron la diócesis desde su fundación hasta fines del siglo X fueron los siguientes: San Atilano (901917), primer obispo de Zamora y actual patrono de su diócesis, Dulcidio, cuyo obispado debió ocupar el segundo cuarto del siglo X, Domingo (probablemente desde el año 954 hasta el 967), Juan

AA.VV., Ciclo de Conferencias. Enero 2002. XI Centenario de la Fundación Diócesis de Zamora. 5 octubre 2001-26 mayo 2002, Zamora, 2002

12 DE LERA MAÍLLO, José Carlos, "Los procesos de erección y restauración de la Diócesis de Zamora (siglos X-XII)" en AA.VV., Ciclo de Conferencias. Enero 2002. XI Centenario de la Fundación Diócesis de Zamora. 5 octubre 2001-26 mayo 2002, Zamora, 2002, pp. 7-19.

13 Fernández Duro en su obra Memorias Históricas de la ciudad de Zamora glosa la figura de San Atilano. FERNÁNDEZ DURO, C., op. cit., tomo I, 1883 (2003), pp. 211-216.

14 Ramos de Castro ofrece un Episcopologio de la diócesis de Zamora en su obra La catedral de Zamora. RAMOS DE CASTRO, Guadalupe, La Catedral de Zamora, Zamora, 1982, pp. 549-565. Otro episcopologio con una breve biografía de los obispos se puede consultar en GARCÍA MARTÍNEZ, Jesús, Historia de la Santa Iglesia Catedral de Zamora, Zamora, 1904, pp. 147-174.

15 En el periodo que transcurrió desde la destrucción de la ciudad por Almanzor hasta principios del siglo XVI el territorio que ocupó la diócesis de Zamora volvió a dividirse entre las de Braga, Salamanca y Astorga, a cuyos territorios había pertenecido anteriormente. FERRERO FERRERO, Florián, "Delimitación de la Diócesis de Zamora" en Catálogo de la Exposición Remembranza. Las Edades del Hombre, Zamora, 2001, p.150, ficha 4; DE LERA MAÍLLO, José Carlos, "Los procesos de fundación y restauración de la Diócesis de Zamora. Siglo X-XII" en Ciclo de Conferencias con motivo del IX Centenario de la Fundación de la Diócesis de Zamora (901-2001), Zamora, 2002, p. 15. 
(también con probabilidad desde el 968 hasta el 983) y Salomón (983-986). A partir de este momento y debido a la destrucción de la ciudad por parte de Almanzor se interrumpe la vida diocesana, de tal forma, que Zamora no volverá a contar con obispo hasta principios del siglo XII.

Restaurada la diócesis en la persona de Jerónimo de Perigord (1102-1120), ésta se fue fortaleciendo progresivamente gracias a los ingresos que recibía de sus posesiones. Dichos ingresos provenientes de sus vasallos fueron incrementados merced a la política de repoblación llevada a cabo por los propios obispos. De este siglo XII data el primer documento que se conserva de relación directa entre Zamora y Roma ${ }^{16}$.

A Jerónimo de Perigord le siguieron en el cargo a lo largo del siglo XII y principios del XIII los siguientes prelados: Bernardo de Perigord (1121-1149), Esteban (1149-1174) bajo cuyo obispado se puso la primera piedra y se consagró el templo catedralicio, Guillermo (1174-1193) y Martín Arias (1193-1212) ${ }^{17}$.

La diócesis de Zamora se mantuvo con la misma extensión desde el siglo XIII hasta finales del siglo $X X^{18}$. Era una diócesis pequeña ya que gran parte del territorio que la integra en la actualidad se repartía entre las diócesis de León, Oviedo, Astorga y Santiago de Compostela. Aun así no dejó de ser una sede apetecible, que además servía a sus obispos para promocionarse de cara a una diócesis más rica en rentas y con mayor peso político y social.

Desde el punto de vista de la sociedad se ha señalado cómo desde finales del siglo IX en los territorios situados al norte del Duero de la provincia zamorana se habían establecido campesinos libres que explotaban la tierra y vivían, por tanto, de la agricultura y de la ganadería ${ }^{19}$. Entre ellos formaron pequeños núcleos de 16 DE LERA MAILLO, José Carlos, "Confirmación pontificia de la sede de Zamora por Eugenio III” en Catálogo de la Exposición Remembranza. Las Edades del Hombre, Zamora, 2001, pp. 156-157, ficha 9.

17 RAMOS DE CASTRO, G., op. cit., 1982, p. 554; GARCÍA MARTÍNEZ, J., op. cit., 1904, pp. 151-152.

18 A finales del siglo XIX se incorporaron a la diócesis las tierras de Alba y Aliste y a mediados del siglo XX lo hicieron las tierras de Benavente y Villalpando. SÁNCHEZ HERRERO, José, "La diócesis de Zamora en su historia" en Catálogo de la Exposición Remembranza. Las Edades del Hombre, Zamora, 2001, p. 33.

19 Un estudio pormenorizado de la sociedad zamorana durante los siglos X al XIII puede consultarse en MORETA VELAYOS, Salustiano, "La sociedad zamorana en los 
población de forma tal que además de sus pequeñas posesiones particulares explotaban en común los montes, pastos y aguas que se situaban en torno a la aldea. Pero muy pronto la sociedad fue transformándose pues se realizaron numerosas fundaciones monásticas que recibieron importantes donaciones por parte de los reyes de tal forma que los campesinos se vieron privados de muchas de sus posesiones. A ello se suma el incremento de propiedades que comenzó a atesorar la aristocracia que se encargaba en buena medida de la defensa y colonización del territorio. Todo ello provocó muy pronto un cambio sustancial en la sociedad del momento que consistió en la relación de dependencia a partir de este momento del campesinado respecto de los señores, civiles o eclesiásticos. Baste señalar como ejemplo el dominio ejercido por el monasterio cisterciense de Santa María de Moreruela ${ }^{20}$.

Era pues la sociedad zamorana semejante a la existente en el resto de los territorios conquistados a los musulmanes, esto es una sociedad fragmentada entre aquellos que tenían el poder económico, político y social como los nobles y eclesiásticos y, por otro lado, el campesinado que en entre otras obligaciones tenía la de pagar una renta anual a sus señores.

En una sociedad estructurada de esta forma no fueron ajenos los conflictos entre los señores y los concejos y sus vasallos de lo que se conserva abundante documentación. Como compendio de ello podemos citar el famoso Motín de la Trucha, acontecimiento que tuvo lugar en el año 1158, envuelto en gran medida en la leyenda pues no se han conservado relatos contemporáneos al hecho aunque sí existen algunos datos que le otorgan cierta verosimilitud ${ }^{21}$. En cualquier caso es un suceso que refleja de

siglos X-XIII" en Historia de Zamora. De los orígenes al final del medievo, tomo I, Diputación de Zamora-Instituto de Estudios Zamoranos «Florián de Ocampo»-Caja España, Zamora, 1995, pp. 545-585.

20 BUENO DOMÍNGUEZ, María Luisa, El monasterio de Santa María de Moreruela (1143-1300), Zamora, 1975; ALFONSO ANTÓN, Isabel, La colonización cisterciense en la meseta del Duero. El dominio de Moreruela (siglos XII-XIV), Zamora, 1986; ALFONSO ANTÓN, Isabel, "Moreruela en época cisterciense" en A.A.V.V., Moreruela. Un monasterio en la historia del Císter, Hortensia Larrén Izquierdo (Coord.), Junta de Castilla y León, Salamanca, 2008, pp. 119-141

21 Un análisis de este acontecimiento se encuentra en LUIS CORRAL, Fernando, "Leyenda y realidad histórica: el contexto político del "motín de la trucha" de Zamora en el siglo XII", Studia Zamorensia, Zamora, 2002, VI, pp. 29-48 y FERNÁNDEZXESTA Y VÁZQUEZ, Ernesto, “«El motín de la trucha» y sus consecuencias sobre don Ponce Giraldo de Cabrera, "Príncipe de Zamora»", en I Congreso de Historia 
manera certera la conflictividad existente en este momento. En resumidas cuentas todo aconteció como señalábamos a mediados del siglo XII, cuando un pechero, hijo de un zapatero, adquirió en el mercado de la ciudad una hermosa trucha. A pesar de haberlo hecho a partir de las diez de la mañana, que era el momento en el que ya tenían permitido adquirir productos, pues con anterioridad a esa hora solo podían hacerlo los nobles y sus criados, el despensero del noble don Gome Álvarez de Vizcaya se la arrebató para llevársela a su señor. Todo ello creó un enorme malestar entre los pecheros que se encontraban a esa hora en el mercado y que una vez más veían atropellados sus derechos. Los nobles por su lado acordaron reunirse en la iglesia de San Román con el objeto de establecer un castigo pues se sentían ofendidos por el revuelo ocasionado. Enterados los pecheros rodearon la iglesia y le prendieron fuego de tal modo que fenecieron la mayor parte de nobles de la ciudad incluido el hijo de don Ponce de Cabrera, Príncipe de Zamora.

Es interesante señalar que aunque la mayor parte de la sociedad era cristiana también existieron determinadas minorías como los judíos y los mudéjares, de los que se sabe muy poco durante este primer momento.

Algunas de las localidades más destacadas del momento y que hoy pertenecen a la provincia de Zamora fueron junto a la propia ciudad de Zamora, Toro, Benavente, Villalpando, Villafáfila, Fermoselle, y Castroverde de Campos.

La actividad artística en los inicios del gótico: la arquitectura religiosa

Ya se ha comentado cómo la diócesis quedó interrumpida desde la devastación de Almanzor hasta el siglo XII, momento en que tuvo lugar su restauración. Esta restauración unida a la mayor estabilidad de la que empezó a gozar la ciudad propició 


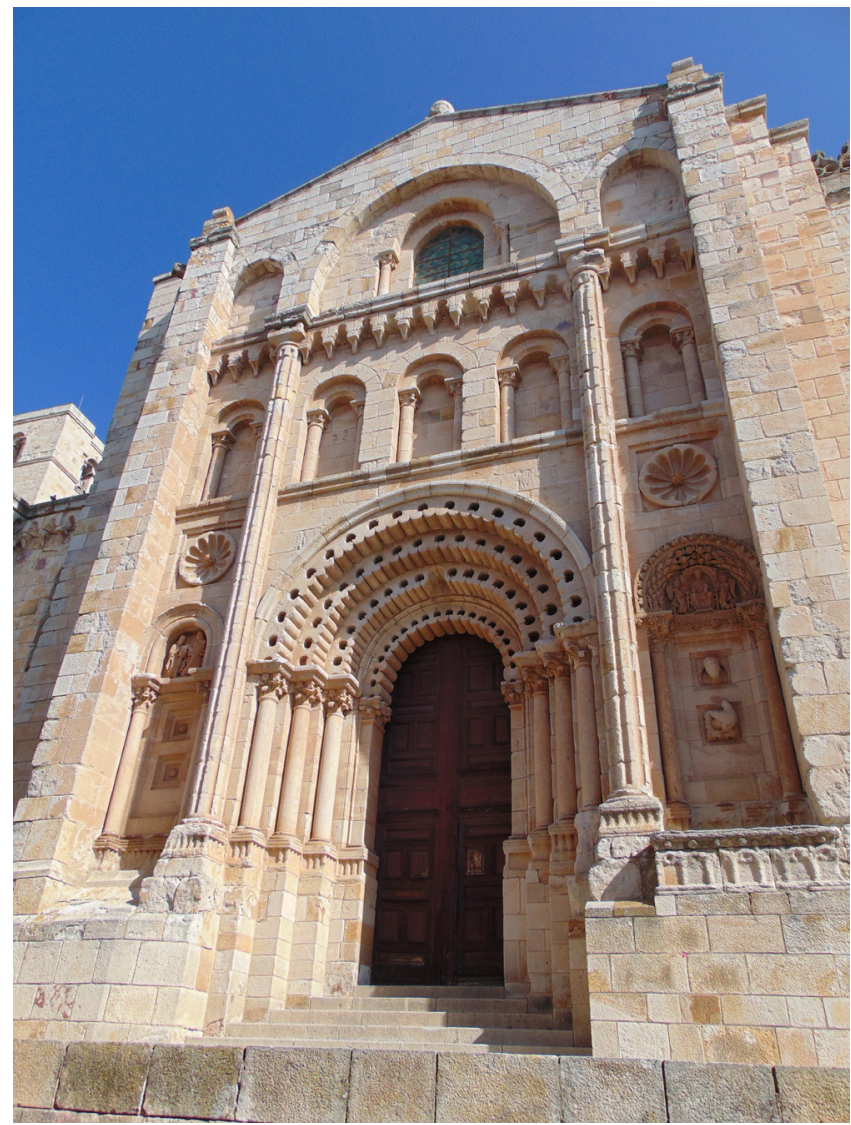

muy pronto la construcción de una nueva catedral, que es la que ha llegado a nuestros días. Ésta se levantó en el mismo lugar que había ocupado la primitiva y en su parte norte se edificó un claustro cuyas obras se prolongaron durante las primeras décadas del siglo XIII, lo que supuso la incorporación de algunas formas góticas en un espacio esencialmente románico. Desgraciadamente de aquel claustro medieval con que contó la catedral y que sufrió un terrible incendio en el siglo XVI no se ha conservado nada.

Este nuevo edificio catedralicio, románico en su esencia pero con elementos muy significativos que preludian el gótico, tuvo una influencia decisiva en las iglesias de la ciudad que se comenzaron a construir apenas unos años después y que no se concluyeron hasta las primeras décadas del siglo XIII. Iglesias que sirvieron de base para la articulación de la actual estructura urbana de Zamora y cuya construcción asentó una fuerte tradición románica con resultados de alta calidad. El peso que llegó a adquirir este sistema formal no favorecía su sustitución por las novedades constructivas que se habían producido en Francia con el nacimiento del estilo gótico, de ahí que la 
arquitectura zamorana se mantuviera durante mucho tiempo poco permeable a los cambios.

De todos modos, antes de comenzar con el desarrollo de la arquitectura durante este periodo, sería conveniente reparar en la fachada sur de la catedral de Zamora, la única fachada románica del edificio que ha llegado a nuestros días. Esta fachada conocida como Puerta del Obispo es una obra paradigmática del estilo románico (Fig. 2). Sin embargo tiene el gran interés desde el punto de vista iconográfico de haber introducido el tema de la Virgen entronizada con el Niño sobre sus rodillas en el tímpano del vano ciego situado en la puerta principal según se mira a la derecha del espectador (Fig. 3). Todo el grupo está enmarcado por una arquivolta vegetal compuesta de tallos de cardo que todavía no han abierto la flor. A su vez el arcosolio está perfilado por una chambrana cuya moldura en forma de escocia está decorada con palmetas. Este tema aparece en torno a 1150 en la catedral de Chartres en un emplazamiento similar. La imagen de Chartres ha sido valorada como el inicio de una sensibilidad ya gótica y la primera imagen de la Virgen, que entronizada y de forma independiente, aparece en un portal, ya que hasta este momento la Virgen con el Niño aparecía en los portales asociada al grupo de la Epifanía. Es por ello que aunque los rasgos estilísticos son todavía románicos, la iconografía es interesantísima puesto que está evidenciando un cambio de orientación teológica relacionado con la naturaleza humana de Cristo. El grupo escultórico de la catedral de Zamora habría que fecharlo en el entorno de 1178.

A pesar de las reticencias mencionadas anteriormente, tampoco una ciudad como Zamora, situada en la antigua Vía de la Plata y con intensas relaciones de tipo comercial, podía permanecer totalmente ajena a las novedades, que desde la segunda mitad del siglo XII afectaban a la arquitectura francesa. En menor medida, pero también ciertamente significativa, fue la actividad constructiva desarrollada en otros núcleos urbanos de la provincia, especialmente en Toro y Benavente.

Inicialmente fueron los modelos cistercienses, los que aportaron las primeras sugerencias para el cambio, ya que incorporaban a sus edificios formas que utilizaba el estilo gótico 


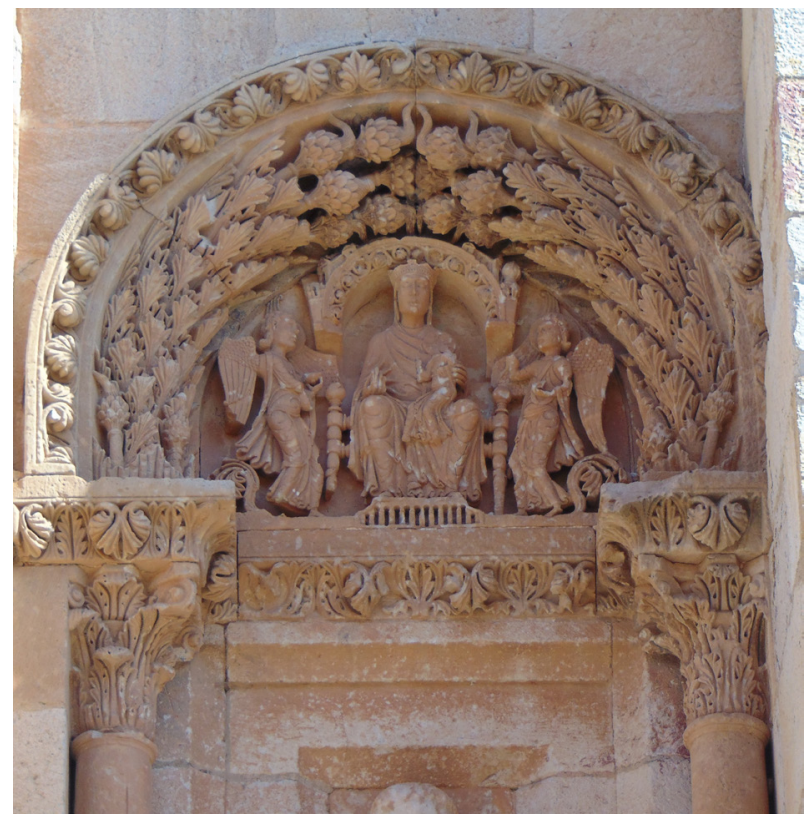

en un contexto diferente. La reforma monacal emprendida por San Bernardo en el siglo XII creó una forma de pensamiento que influyó en los postulados artísticos europeos. Los principios de austeridad decorativa fueron determinantes en los monasterios de su Orden. Pero su capacidad de influencia afectó también a una parte importante de la arquitectura de su época. Basta un acercamiento a los templos zamoranos, un breve vistazo a sus elementos decorativos, a sus capiteles, tímpanos, etc., para advertir la gran austeridad por la que se vieron afectados. Priman fundamentalmente los elementos geométricos y vegetales, mientras que escasean las representaciones figuradas. La sencillez, la pureza de líneas y la ausencia de elementos decorativos caracterizan la mayor parte de las estructuras arquitectónicas vistas pertenecientes a este periodo, como son las puertas de tránsito, portadas y vanos, arcosolios y bóvedas de los templos zamoranos.

Por todo ello parece evidente que, el Císter en general y los monasterios zamoranos adscritos a esta orden, en particular, encaminaron y sirvieron de pauta a la arquitectura zamorana de los siglos XII y XIII. A ellos principalmente se debe la incorporación de las formas góticas que llegaban a ser más fácilmente asimilables manteniendo la estructura románica y todo ello con una escasa introducción de elementos ornamentales. A falta de un estudio riguroso sobre la enorme influencia que debió ejercer el Císter sobre la arquitectura zamorana y sobre los aspectos decorativos 
de nuestras iglesias haremos a continuación un pequeño análisis o valoración.

Las primeras manifestaciones de cambio en la arquitectura religiosa románica. La influencia cisterciense

El paso hacia el nuevo estilo, se produce muy lentamente y en aspectos puntuales que, en principio, aparecen integrados en los edificios románicos. A pesar de lo modesto de estas manifestaciones, es necesario tratarlas de forma independiente en el deseo de establecer una secuencia de los primeros momentos del estilo gótico. Los primeros síntomas de cambio se manifiestan en la introducción de arcos apuntados en portadas, ventanas y arcosolios, así como en la aparición de las primeras bóvedas de crucería.

Resulta difícil establecer una separación en estos momentos iniciales, entre aquello que procede directamente del gótico francés o de la asimilación que de ello hizo el Císter, aunque en lo relativo a Zamora parece más probable que esa influencia viniera por la vía de la Orden monástica. El establecimiento en la provincia de una de las fundaciones cistercienses más antiguas y vitales como lo fue Santa María de Moreruela debió influir de manera decisiva tanto en las formas como en el carácter desornamentado que presenta la arquitectura de finales del siglo XII y la de principios del siglo XIII. También muy destacado fue el monasterio de San Martín de Castañeda del que se ha conservado su iglesia del periodo medieval. Otras fundaciones monásticas de la provincia como Santa María de Valparaíso, en las inmediaciones de la localidad de Peleas de Arriba, y San Bernardo en Benavente (San Salvador de las Dueñas), este último de monjas, desaparecieron completamente pero en buena lógica acusarían en su arquitectura primitiva los cambios que comenzaban a darse en la arquitectura de este tipo.

Nuestro objeto no va a ser tanto estudiar estas construcciones de finales del siglo XII y principios del siglo XIII, que responden en lo fundamental al estilo románico y románico tardío y a las cuales se han dedicado ya muchos trabajos de investigación, sino valorar y analizar la incorporación de aquellos elementos nuevos 
vinculados al gótico que se van abriendo camino lentamente en estas estructuras románicas.

Por tanto, a continuación se relacionan una serie de elementos, tipos y formas arquitectónicas en los que si bien no es posible aplicar con justeza el término gótico, son los primeros síntomas que anticipan el cambio de estilo.

\section{Puertas de tránsito y ventanas con dintel}

Entre los elementos que caracterizan esta arquitectura de tránsito del románico al gótico destaca la presencia de un grupo de puertas y ventanas de características comunes. Son vanos de pequeño tamaño con un carácter esencialmente funcional, cuya finalidad es la comunicación con estancias tales como el baptisterio o, más comúnmente, con la escalera de caracol que da acceso a la torre. También existen ventanas con este mismo tipo de estructura aunque son muy pocos los ejemplos con los que contamos.

El problema que plantean estos vanos es el de su neutralidad estilística con elementos mínimos referenciales para establecer su datación. El marco general cronológico lo dan, al margen de las fechas en las que se encuadra la construcción de los edificios a los que pertenecen, los escasos elementos decorativos que presentan. A pesar de su semejanza, existen diferencias desde el punto de vista compositivo y decorativo, de forma que pueden establecerse una serie de grupos.

\section{Puertas con dintel sobre mochetas}

El origen o base de este modelo de puertas es un sistema arquitectónico adintelado con zapatas, generado desde la antigüedad, para acortar el espacio entre los apoyos de los dinteles. Se trata de puertas adinteladas, con las jambas desprovistas de ornamentación y los sillares superiores con una forma oblicua que configuran ménsulas, o más propiamente, mochetas, con sencillos elementos decorativos unas veces $y$, otras, con ausencia total de éstos. En algunos casos el dintel está aligerado del peso del muro mediante un triángulo de descarga. 
Este sistema de dintel sobre mochetas, se utilizaba ya en la arquitectura románica para fortalecer el apoyo de los tímpanos, debido a que venía a resolver un problema técnico constructivo de manera fácil. También se utilizó este tipo de configuración, simplificado, en vanos más sencillos durante el periodo románico. Con esta simplificación, sobre todo en lo que se refiere a la reducción de las proporciones, el problema técnico-constructivo desaparece para dar paso a una configuración que debe su ser a un modismo estilístico. Así podemos verlo claramente en el interior de la iglesia de la Magdalena22. La mitad inferior de su ábside presenta, sobre un plinto de considerable altura, tres nichos adintelados y con mochetas, separados entre sí por semicolumnas adosadas al muro y, divididos cada uno de ellos en dos partes idénticas de formas cóncavas (Fig. 4). Don Manuel Gómez-Moreno a la hora de mencionarlas dice “...hay extrañas hornacinas de doble seno curvilíneo..." ${ }^{23}$. Rivera de las Heras habla de "...exedras adinteladas en el primer cuerpo..." ${ }^{24}$. En este caso de la Magdalena, no son puertas; se trata simplemente de un horadamiento en la cara interna del ábside, muy probablemente con intención decorativa, para aligerar y dotar de cierta belleza y elegancia el muro. Esto es, con una voluntad puramente estética.

Esta forma, que en el interior del ábside de la Magdalena es únicamente decorativa, ha sido utilizada la mayor parte de las veces con fines utilitarios en pequeñas puertas de tránsito. Estas puertas se encuentran prácticamente todas en el interior de los templos como acceso a lugares secundarios y el número conservado es bastante notable. Entre ellas hay variantes e incluso se pueden reconocer afinidades. En la ciudad de Zamora conservamos varias en las iglesias de la Magdalena, San Vicente, Santa María de la Horta, San Juan y San Andrés, así como también en la Catedral, concretamente en el acceso a la torre desde la cubierta de la nave del evangelio. En Toro es de este tipo la puerta que comunica el interior de la Colegiata con el cuerpo

22 La edificación de este templo románico tuvo lugar durante los años finales del siglo XII y las primeras décadas del siglo XIII. RAMOS DE CASTRO, Guadalupe, El arte románico en la provincia de Zamora, Diputación Provincial de Zamora, Zamora, 1977, pp. 122-137.

23 GÓMEZ-MORENO, M., op. cit., I, 1927 (1980), p. 167.

24 RIVERA DE LAS HERAS, José Ángel, Zamora: Iglesias de Santa Isidoro, La Magdalena, y San Pedro y San Ildefonso, Col. Arte Románico en Zamora, n 2, Ediciones Nobel, Oviedo, 2006, p. 39. 
bajo de la torre. En Benavente tenemos ejemplos en la iglesia de Santa María la Mayor y en la de San Juan del Mercado, aunque la única correspondiente a esta última iglesia y que da acceso a la escalera que conduce a la torre, posee las mochetas labradas en el propio dintel. En el monasterio de San Martín de Castañeda y en la iglesia de Santa María la Real de la Hiniesta igualmente la puerta que se ha conservado en cada uno de estos edificios de este tipo comunica con el husillo que conduce a la torre.

En relación a su cronología, en la provincia de Zamora este tipo de puerta, tanto por su forma como por los elementos decorativos que llevan incorporados, cuando existen, corresponde tanto al periodo románico como al momento de transición entre este estilo y el gótico. La mayoría de ellas, por tanto, las encontraremos en edificios románicos tardíos levantados a finales del siglo XII y principios del siglo XIII. Se trata de puertas funcionales, modestas, pero que aportan una cierta voluntad estilística. Esta sencillez estructural así como la austeridad decorativa (solamente en algunos ejemplos se han representado sencillos ornamentos, generalmente vegetales) podrían hablar de un elemento desarrollado dentro de la arquitectura cisterciense e, inmediatamente, trasladado a las edificaciones contemporáneas (segunda mitad del siglo XII). $\mathrm{Si}$ en principio las encontramos integradas en arquitecturas plenamente románicas, con posterioridad (finales del siglo XII y principios del XIII) veremos que se siguió utilizando el mismo modelo.

Esta propuesta cronológica está justificada por comparación con puertas de este tipo conservadas en monasterios cistercienses de la provincia de Zamora. Las más antiguas se encuentran en los monasterios de San Martín de Castañeda y Santa María de Moreruela, ambos en plena construcción durante la segunda mitad del siglo XII. La puerta de este tipo conservada en el monasterio de Castañeda está situada en el ángulo noreste, justo al lado del acceso hacia la iglesia desde el claustro y, justo también, en el lugar que solía ocupar en los monasterios medievales el armariolum ${ }^{25}$. En el monasterio de Moreruela se

25 Se trataba de una hornacina abierta por lo general en el muro este del claustro y cerrada con puertas de madera. Dicha hornacina estaba provista de una serie de baldas en las que se colocaban los libros de lectura que utilizaban los monjes. 
encuentra en el hastial exterior del crucero sur, bajo una portada con arquivoltas de medio punto, que descansan en una imposta sustentada por columnas y, cuyos capiteles, en algunos casos, han desaparecido. Esta puerta de Moreruela tiene unas dimensiones mayores que las puertas vistas en las iglesias de la ciudad, debido al lugar que ocupa en el exterior del templo de la que fue una de las más importantes abadías de la Península Ibérica. Aún así la desornamentación es absoluta, quedando de manifiesto, una vez más, la gran importancia que tuvo la arquitectura cisterciense, y en concreto la desarrollada en el monasterio de Santa María de Moreruela, en las edificaciones contemporáneas de la provincia y la ciudad de Zamora. Y, especialmente, en este caso, para la creación de este modelo de puerta de configuración sobria y utilitaria. También en el monasterio cisterciense navarro de Iranzu, cuya parte más primitiva corresponde a finales del siglo XII y principios del siglo XIII, se utilizó el mismo modelo de puerta en el acceso al cuarto del cillerero desde el claustro, aunque sobre ella se sitúa un tímpano, que en Zamora solamente lo encontramos en el acceso plenamente románico a la antigua sacristía de la iglesia benaventana de Santa María la Mayor.

Para concluir, como ya quedó reflejado en la introducción de este apartado, este tipo de estructura de puerta adintelada con mochetas constituyó un sistema general que se ha utilizado en toda la arquitectura de manera continuada. Así fue muy común el uso de puertas con mochetas en las iglesias románicas. Con posterioridad siguió utilizándose este mismo sistema en la arquitectura gótica, de tal forma, que muchas de las puertas monumentales de las grandes catedrales e iglesias se resolvieron mediante dintel sobre mochetas.

Este tipo de puerta en los templos zamoranos se presenta con ligeras variaciones que se manifiestan principalmente en la decoración de sus mochetas, y en la presencia de un triángulo de descarga sobre el dintel.

\section{Puertas con dintel sobre mochetas sin decoración}

En la iglesia de la Magdalena se conservan dos puertas con dintel sobre mochetas sin decoración. Una se encuentra 


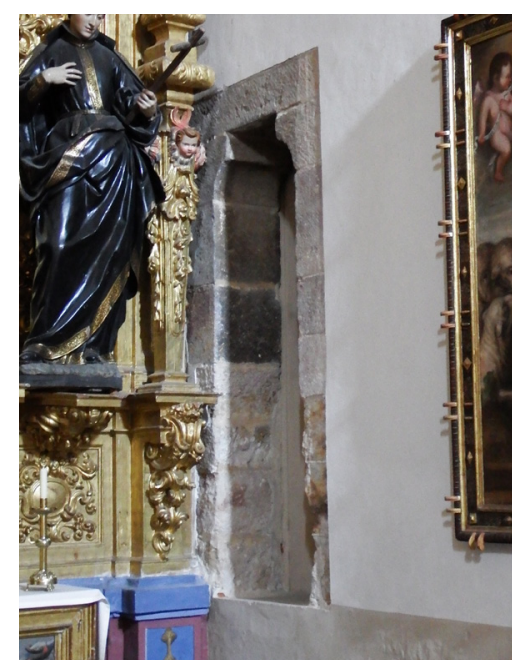

Fig. 5. Portada de acceso a la antigua torre románica Iglesia de San Andrés. Zamora

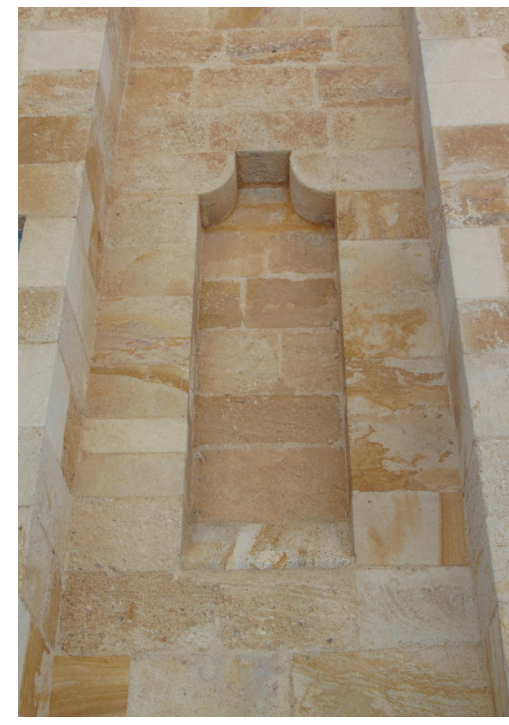

Fig. 6. Vano con mochetas cegado del muro occidental. Iglesia de Santiago del Burgo. Zamora abierta en el muro norte del tramo recto presbiterial justo en el lugar en el que el amplio banco que recorre todo el ábside se ve interrumpido reduciéndose a un pequeño escalón. Comunicaba, al igual que la puerta que se conserva frente a ella, con un pequeño habitáculo cubierto con bóveda de medio cañón y que, posteriormente, fue ampliado y convertido en sacristía. Curiosamente las mochetas de esta puerta, que presentan una pequeña acanaladura en la arista superior, sobresalen de la línea de las jambas en lo que constituye el único caso de entre todas las que hemos visto en la provincia. La otra se abre en el muro norte del primer tramo de la nave hacia los pies y su función es la comunicación con el husillo que conduce a la torre. Esta puerta está dotada de una mayor anchura que la citada anteriormente.

Otras puertas que no presentan ningún tipo de decoración son la que da acceso al husillo que conduce a la torre en la iglesia de San Martín de Castañeda y la situada en la iglesia de San Andrés, concretamente en la capilla de San Francisco Javier. Esta última constituye uno de los escasos restos conservados de la antigua iglesia románica, que fue derruida en su gran mayoría en el siglo XVI para levantar el templo que se conserva en la actualidad. La puerta, al igual que la citada de Castañeda, da acceso a un husillo que conduce a la torre de la iglesia (Fig. 5). Se trata, una vez más, de una puerta muy sencilla cuyos sillares de la parte superior, seccionados en oblicuo, son los que toman la forma de mochetas.

De idénticas características a las puertas descritas de las iglesias de la Magdalena, de San Martín de Castañeda y de San Andrés es el vano cegado situado a los pies de la iglesia de Santiago del Burgo (Fig. 6). Este vano podría corresponder a una antigua puerta de acceso a la torre, ya que este tipo de estructura precisamente se observa con esta finalidad de manera bastante recurrente en las iglesias zamoranas. Parece lógico suponer que en las construcciones que existieron adosadas a occidente de este templo hubiera existido una escalera de madera (no se conserva ningún resto pétreo que indique una supuesta escalera de piedra) que se elevara hasta dicho vano, convirtiéndolo en puerta de acceso a la torre de la iglesia. En el informe sobre declaración de Monumento Nacional de la Iglesia de Santiago 
del Burgo de Zamora, publicado en 1908 se puede leer: "El templo que nos ocupa [Santiago del Burgo] está actualmente rodeado, por el imafronte y por la fachada lateral del Evangelio, por construcciones particulares; los ábsides dan a la plaza de Santiago, y la fachada, por el lado de la Epístola, a la calle de Santa Clara, precedida de una crujía que tiene un portalón y dos dependencias, único ingreso que actualmente se utiliza, puesto que la puerta del hastial está tabicada y tiene por el exterior casas adosadas, y la puerta de la nave, situada frente a la descrita por la fachada Norte, está en gran parte tabicada y da a un pequeño patio o corral enclavado en las casas medianeras" ${ }^{26}$.

\section{Puertas con dintel sobre mochetas decoradas}

Es el grupo más numeroso y está compuesto por dos puertas existentes en la iglesia de San Vicente, dos en la de Santa María de la Horta, dos de las cuatro conservadas con mochetas en la iglesia de la Magdalena y la puerta de acceso a la torre de la catedral, todas ellas en la ciudad de Zamora. En la provincia contamos con la puerta de entrada al cuerpo bajo de la torre de la colegiata de Toro y con una puerta que da acceso a la ermita de la Soledad de Fermoselle. Esta última puerta plantea algunos interrogantes ya que la ermita en su conjunto fue reconstruida en época moderna. No obstante, parece que la puerta referida pudiera pertenecer a la edificación original de principios del siglo XIII.

La decoración en todos los casos se centra únicamente en las mochetas. El resto de la estructura arquitectónica está compuesta por sillería perfectamente escuadrada desprovista absolutamente de cualquier ornamento. En prácticamente todos los casos los motivos son geométricos o simbólicos. Tan sólo la puerta conservada en Fermoselle ostenta representaciones figurativas.

Las dos puertas pertenecientes a la iglesia de San Vicente presentan en sus mochetas una decoración en forma de voluta (Figs. 7 y 8). Una de ellas da acceso al baptisterio y tiende en su

26 ARBÓS, F., "Informe sobre declaración de monumento nacional de la Iglesia de Santiago del Burgo, de Zamora”, Boletín de la Real Academia de Bellas Artes de San Fernando, Segunda época, tomo IV, Madrid, 1914, pp. 169-171. 

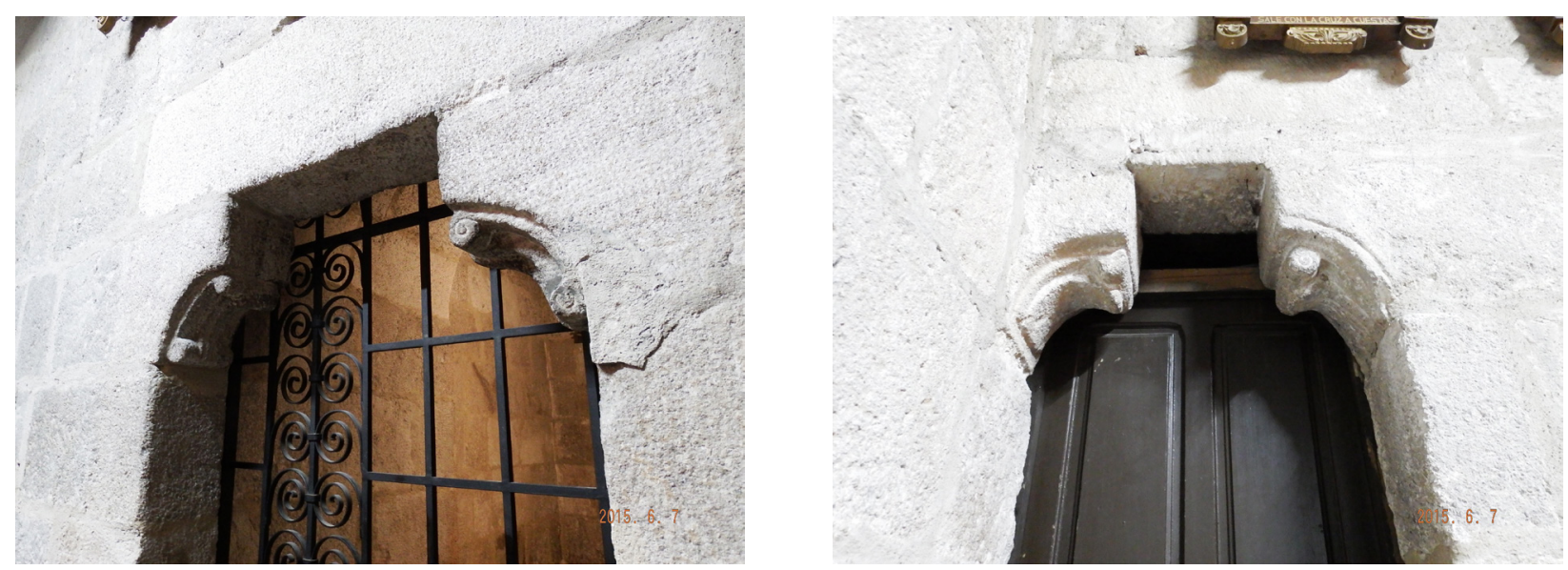

Figs. 7 y 8 . Puertas con mochetas. Iglesia de San Vicente. Zamora

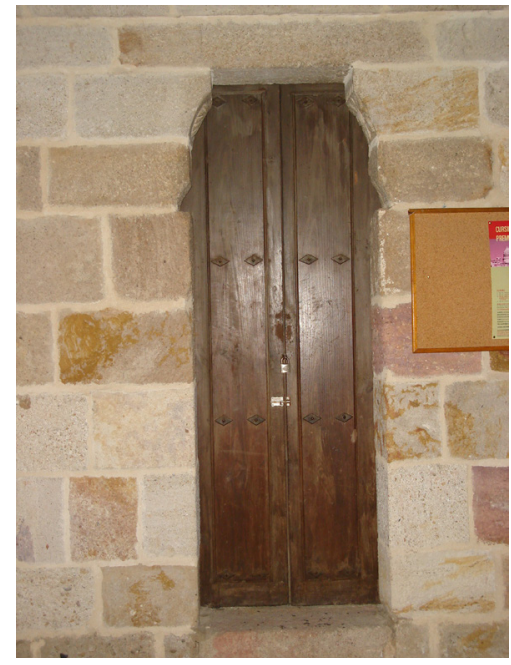

Fig. 9. Puerta de acceso a la torre. Iglesia de Santa María de la Horta. Zamora ornamentación hacia un mayor refinamiento ya que muestra en sus volutas una serie de molduras. La otra da acceso a la torre y tiene unas volutas de menor desarrollo, cuya parte central está decorada por una hoja estilizada con incisiones. En este tipo de decoración podría entreverse ciertos rasgos de clasicismo, de ese clasicismo que según algunos autores se dio hacia 1200.

La primera de las dos puertas que con estas características pertenecen a la iglesia de Santa María de la Horta se encuentra situada en el espacio que hay bajo la torre y que sirve de pórtico de entrada a la iglesia (Fig. 9). Esta puerta da acceso a la escalera de caracol que conduce a la torre de la iglesia y tiene unas mochetas de desarrollo reducido. Las dos mochetas presentan decoración en su cara interna; la izquierda, bajo una franja de dientes de sierra, tiene en relieve una concha o venera; la de la derecha, bajo una franja idéntica a la anterior de dientes de sierra, tiene una roseta, de ejecución sencilla, formada por ocho pétalos apuntados, algunos con nervio central. La segunda puerta correspondiente a la iglesia de Santa María de la Horta se sitúa propiamente en el interior del templo, concretamente en el muro norte del primer tramo por la parte de los pies (Fig. 10). Actualmente da paso a un pequeño habitáculo cerrado de escasos metros cuadrados que, en su momento, pudo estar abierto y comunicar con el convento anexo que se levantaba al norte de la iglesia27. Decora sus mochetas (de sección troncopiramidal ${ }^{28}$ )

27 Se trataba de un convento perteneciente a la Orden de San Juan de Jerusalén de cuya construcción primitiva nada ha llegado a nuestros días. La iglesia de Santa María de la Horta perteneció a este convento al menos desde el siglo XIII.

28 Esta forma es muy común en los canecillos de las iglesias zamoranas edificadas en la última fase del románico. Pueden observarse en la catedral, en la iglesia de San Ildefonso, en la iglesia de San Juan de Puerta Nueva, etc. En el propio templo de Santa María de la Horta estos diseños troncopiramidales se ven en los canecillos que recorren 
con hojas estilizadas de raíz cisterciense. Rivera de las Heras, a la hora de describir los canecillos de la iglesia de Santa Lucía, que tienen una forma y decoración muy semejante a las mochetas de esta puerta de la Horta, dice: "la mayoría son troncopiramidales, unos lisos y otros con hojas lanceoladas en las aristas, ya sean incisas o labradas en fino relieve, y algunos con hoja central" ${ }^{29}$. Esta puerta posee una particularidad y es que es la única que hemos visto en la ciudad, cuyas jambas se proyectan hacia fuera, a manera de basa, dando lugar a un estrechamiento en la parte inferior, que forma una parte simétrica con la zona superior.

En la iglesia de la Magdalena también se han conservado dos puertas con las mochetas decoradas. Una de ellas se abre en el tramo presbiterial sur, sobre el amplio banco que recorre la práctica totalidad del ábside, y conduce a un pequeño habitáculo cubierto con bóveda de medio cañón. Presenta, además de una pequeña acanaladura en las aristas de sus mochetas, restos de un elemento decorativo circular muy deteriorado. La otra puerta se abre en el ángulo noroeste del primer tramo del templo y da acceso a la estancia situada bajo la torre. La decoración de sus mochetas, una de ellas muy deteriorada, es muy propia del ámbito de la arquitectura cisterciense y consiste en una bola "con capucha" (Fig. 11).

En la catedral de Zamora existe una puerta con las mochetas decoradas que tiene como función la comunicación con la torre. En la cara interna de su mocheta izquierda tiene representada una roseta de pétalos pequeños en forma de sol, y en la derecha una voluta sencilla que recuerda a las vistas en la puerta de acceso a la torre de la iglesia de San Vicente.

En la provincia de Zamora son escasísimas las puertas que se han conservado con las mochetas decoradas. Una de ellas se corresponde con la puerta que da acceso al cuerpo bajo de la torre en la Colegiata de Toro aunque ésta presenta alguna particularidad respecto a todas las anteriores (Fig. 12). En primer lugar esta puerta se encuentra cobijada por un arco ligeramente

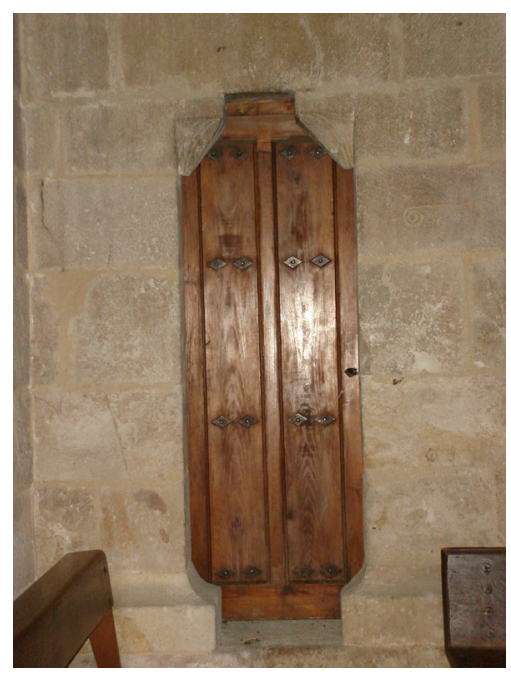

Fig. 10. Puerta abierta en el muro norte de la iglesia de Santa María de la Horta. Zamora

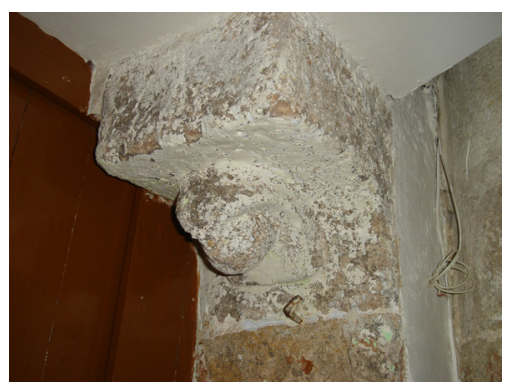

la parte superior del exterior de la nave principal, así como en los existentes bajo la moldura que separa los dos cuerpos superiores de la torre.

29 RIVERA DE LAS HERAS, José Ángel, Zamora: Iglesias de Santa Lucía, San Leonardo, San Esteban, San Andrés y Carmen del Camino, Col. Arte Románico en Zamora, nº 9, Ediciones Nobel, Oviedo, 2006, p. 18. 


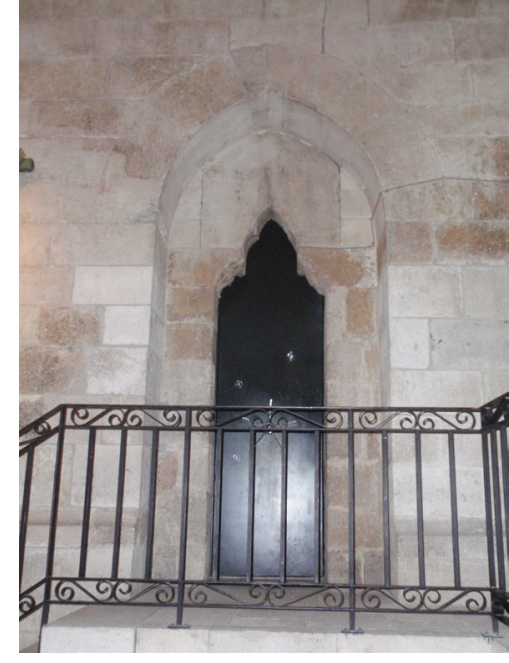

Fig. 12. Puerta de acceso al cuerpo bajo de la torre. Colegiata de Toro

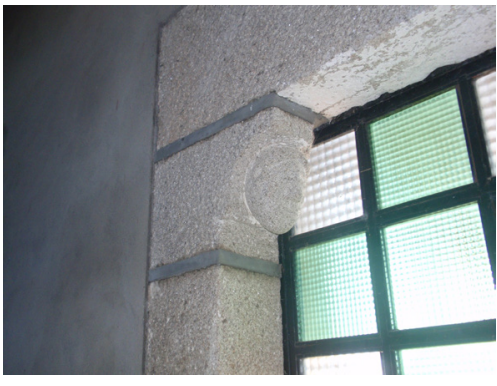

Fig. 13. Detalle de la portada de la ermita de la Soledad. Fermoselle

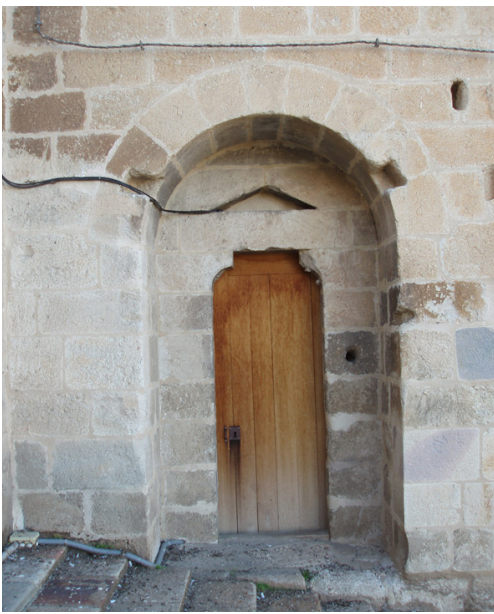

Fig. 14. Puerta de acceso a la torre. Catedral de Zamora apuntado que actúa de dobladura. En segundo lugar, el dintel, que habitualmente tiene forma rectangular lisa, en este caso, está formado por una gran piedra cuadrangular en la que se ha tallado un arco apuntado que sirve de remate. Esta gran piedra apoya sobre las mochetas que presentan su cara interna decorada a modo de capitel corintio estilizado con hojas de acanto y caulículos en la parte superior.

La segunda y última puerta vista en la provincia con mochetas decoradas se haya en la ermita de la Soledad de la localidad de Fermoselle (Fig. 13). Aunque se han planteado serias dudas sobre la originalidad de esta puerta, todo parece indicar que se trata de uno de los escasos testimonios que se conservan de la edificación primitiva de la ermita que se remonta a principios del siglo XIII. La importancia de esta puerta radica en ser la única que presenta motivos figurativos en sus mochetas. Así en la cara interna de estas pueden verse cabecitas humanas labradas de manera muy tosca.

\section{Puertas con dintel sobre mochetas y triángulo de descarga}

Se conservan dos puertas con dintel sobre mochetas y triángulo de descarga. La función de este último elemento es aligerar el peso sobre el dintel y distribuirlo hacia los laterales con el objeto de que la estructura tenga mejor repartidos los empujes y soporte mejor la carga. Este sistema constructivo se remonta a la antigüedad. Fue común en la arquitectura micénica, cuya obra más representativa, la Puerta de los Leones, presenta esta disposición.

En Zamora, el triángulo de descarga se encuentra en la puerta, ya citada, de la iglesia de San Vicente que da acceso al baptisterio y sobre la puerta de acceso a la torre de la catedral que está situada sobre la nave del Evangelio (Fig. 14). Ambas obras, iglesia de San Vicente y catedral, están relacionadas, no sólo por ser contemporáneas en la construcción, sino porque es probable que algún mismo maestro cantero interviniera en ambas.

No se ha localizado ninguna puerta interior con dintel sobre mochetas y triangulo de descarga en el resto de la provincia. 
Puertas adinteladas con triángulo de descarga

Dentro de este conjunto de pequeñas puertas de tránsito adinteladas se han conservado dos que presentan triángulo de descarga. En este caso ambas carecen de mochetas. La primera de ellas está situada en la estancia de la parte baja de la torre de la catedral. Conduce directamente a la escalera de caracol por la que se accede al resto de las dependencias de la torre. La segunda se encuentra situada en el muro occidental del baptisterio de la iglesia de Santa María la Nueva y conduce también a la escalera que lleva a la torre (Fig. 15).

No se ha localizado ninguna puerta interior adintelada con triangulo de descarga en el resto de la provincia.

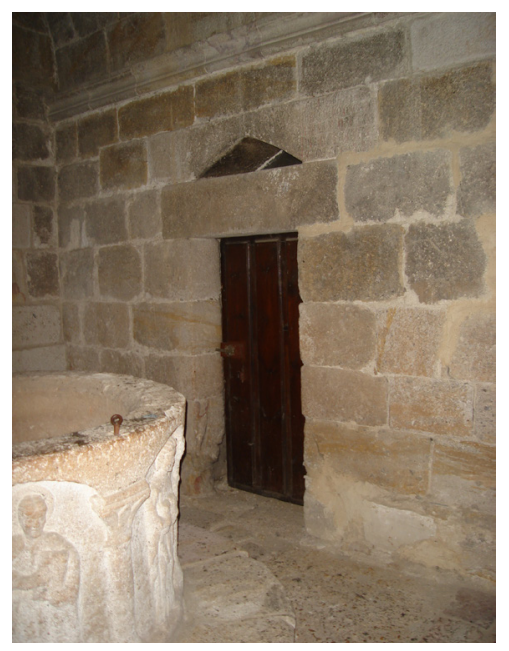

Fig. 15. Puerta de acceso a la torre de la iglesia de Santa María la Nueva. Zamora

\section{Ventanas con mochetas}

Existe un pequeño número de estructuras con una composición en su parte superior semejante a las puertas anteriormente comentadas. Responden, al igual que aquellas, a una tradición plenamente románica aunque su ejecución date de los años finales del siglo XII e incluso de los primeros años del siglo XIII. Todas ellas se han localizado en la ciudad de Zamora.

La primera de estas estructuras se encuentra, a una cierta altura, en la parte occidental de la iglesia de Santiago del Burgo integrada en su torre. No se va a incidir en el análisis de este antiguo vano, que en la actualidad permanece tapiado, puesto que se ha comentado anteriormente al plantear la hipótesis de que pudiera tratarse de una antigua puerta de acceso a la torre.

La siguiente estructura se abre en el exterior de la iglesia de Santa María de la Horta, concretamente en uno de sus contrafuertes del muro norte (Fig. 16). Semeja una hornacina y tiene unas dimensiones más reducidas en relación a las puertas vistas en este capítulo, lo que hace que las propias mochetas, cuya cara interna crea una forma ligeramente curvilínea, sean las que sirvan de dintel.

Por último se han localizado tres vanos con características semejantes: uno, en el muro sur de la iglesia del Espíritu Santo; otro, en la parte superior del hastial occidental de la iglesia de

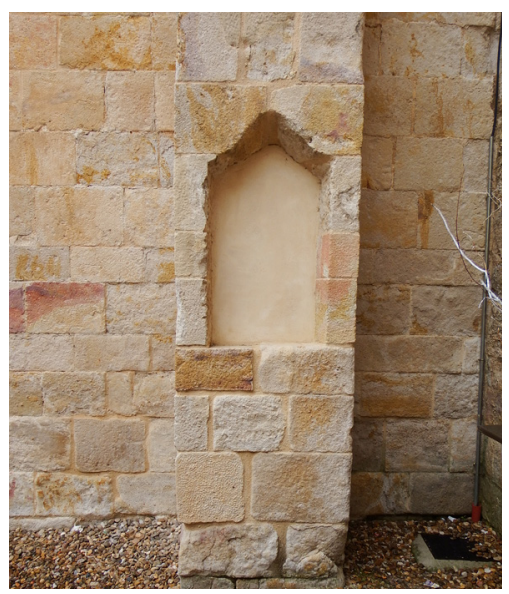




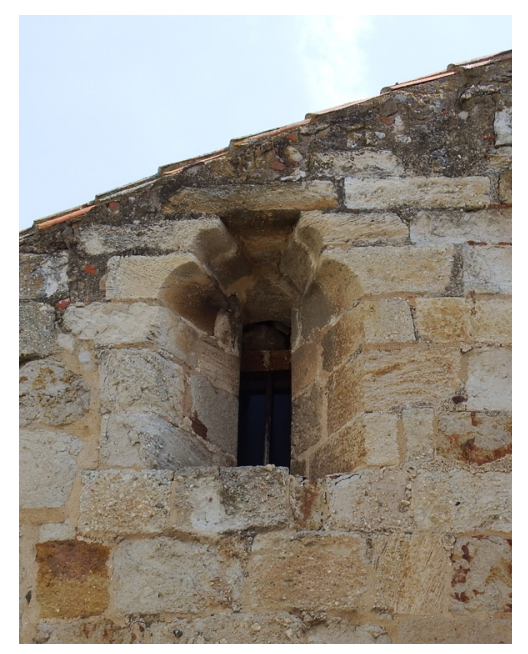

Fig. 17. Vano abierto en el hastial. Iglesia de Santa Lucía. Zamora
Santa Lucía; y, el último, en el exterior de la capilla central de la iglesia de San Esteban. El primero de ellos es muy similar a la hornacina mencionada de la iglesia de Santa María de la Horta. Las mochetas unidas conforman el dintel de la puerta y tienen sus caras internas con formas curvilíneas aunque más marcadas que las vistas en la hornacina de la Horta. El correspondiente a la ventana de la iglesia de Santa Lucía se muestra muy abocinado (Fig. 17). Presenta una estructura adintelada con superposición de mochetas que le confieren un perfil lobulado. El último de ellos, situado en el segundo cuerpo del testero del exterior de la capilla mayor de la iglesia de San Esteban, es plenamente románico. Está formado por una serie de arquivoltas aboceladas que descansan en capiteles con decoración vegetal. Tiene un acusado abocinamiento que hace que el propio vano sea considerablemente estrecho. Su apertura tiene un diseño semejante al de las anteriores puertas y ventanas aunque este vano no está adintelado, sino que remata en un lóbulo.

\section{Los vanos en los exteriores. La introducción del arco apuntado}

En la provincia de Zamora se conserva una gran riqueza de portadas románicas y, a su vez, un número nada desdeñable, también de portadas que, aunque formalmente dependen en gran medida de una concepción románica, poseen un desarrollo más avanzado motivado por los influjos cistercienses. En estas portadas y durante un corto periodo de tiempo se produce el tránsito del arco de medio punto al arco apuntado.

Algunas de estas puertas de acceso a las iglesias y edificios religiosos de la ciudad de Zamora y su provincia que se han conservado, pertenecientes a este periodo inicial gótico, se abren en el hastial occidental y, por tanto, en el eje de simetría que rige la composición de la planta del edificio. Otras se localizan en los muros longitudinales del templo y vienen a corresponderse con las orientaciones norte y sur, es decir, se abren perpendiculares al eje de simetría.

Por lo general, estas portadas carecen de una cronología exacta, que en el caso de haberla tenido facilitaría, sin duda y de manera certera, un análisis preciso de las formas y diseños 
utilizados durante este periodo. Esta carencia es debida, por un lado, a la inexistencia en la mayoría de los casos de datos cronológicos de la parte del edificio donde se encuentran. Por otro lado, la marcada tendencia conservadora que se dio en estas tierras dificulta aún más, si cabe, dilucidar el momento concreto de su construcción. Como ejemplo sirva la persistencia de puertas de doble rosca de medio punto de tradición románica, hasta mediados del siglo XVI. Pero, en cualquier caso, existen otros ejemplos que se acomodan al gusto de la época. Es por tanto, que la relación con la etapa constructiva del edificio en que se encuentran, la comparación con otras puertas de territorios cercanos de las que constan datos concretos del momento de su edificación y el estudio exhaustivo de las formas decorativas que las componen es lo que va a permitirnos establecer una secuencia en base a la evolución que presentan en sus formas. Todo ello como veremos indica que las portadas más antiguas en las que se empieza a introducir el arco apuntado podrían situarse en el entorno del año 1200.

El material utilizado en la mayoría de las portadas de acceso a los templos es la piedra trabajada en buena sillería, incluso en aquellos edificios construidos en piedra de inferior calidad. No obstante, existen algunos ejemplos, fundamentalmente en la ciudad de Toro, donde el material empleado en toda la construcción, incluida la portada, es el ladrillo.

Dentro de este grupo de portadas pertenecientes a los años finales del siglo XII y, sobre todo, a las primeras décadas del siglo XIII encontramos algunas diferencias que nos permiten clasificarlas en dos tipos, con algunas variantes dentro de cada uno de ellos, y así estudiarlas ordenadamente.

El tipo más antiguo o de formas más arcaizantes corresponde a un modelo de puerta muy sencilla que está compuesta de arco liso ligeramente apuntado y carente de molduración. En muchas ocasiones lleva la imposta realzada con una pequeña moldura. Aunque el arco apuntado no es un elemento gótico ya que se utilizó durante el periodo románico, sin embargo, en Castilla y concretamente en la provincia de Zamora, el apuntamiento sí es indicativo del cambio de las formas hacia la arquitectura gótica ya que sustituye al arco románico mucho tiempo después. De 


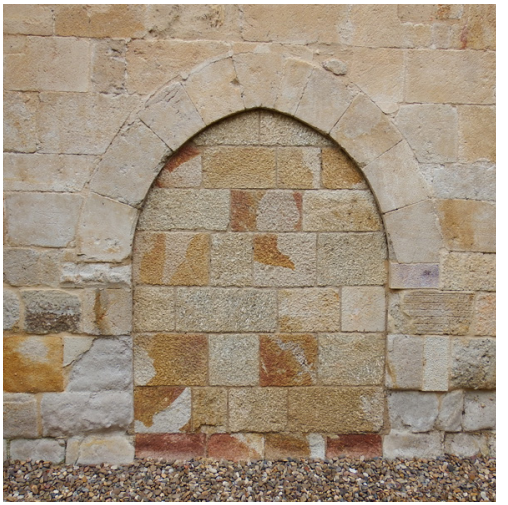

Fig. 18. Puerta cegada del muro norte. Iglesia de Santa María de la Horta. Zamora

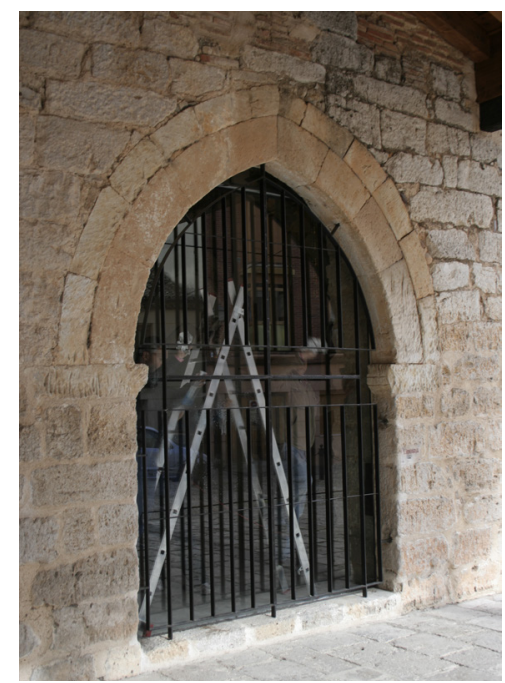

Fig. 19. Puerta de la capilla adosada al sur de la iglesia de Santa María de Roncesvalles y Santa todos modos, esta presencia del arco apuntado en la zona que estamos estudiando no llegaría de forma directa sino a través de los modelos cistercienses.

A juzgar por los ejemplos conservados, las puertas de este tipo que se relacionan con una fecha más antigua se encuentran en edificios de arquitectura militar, por las exigencias de la solidez constructiva. Se utilizan tanto en los accesos principales, como en los interiores con función de tránsito. Sirvan de ejemplo las puertas del castillo de la ciudad de Zamora, entre ellas la que constituye su entrada principal, la denominada de Santa Colomba y algunas otras interiores que aparecieron durante la reciente intervención desarrollada en este edificio para transformarlo en un centro museístico sobre la figura del escultor Baltasar Lobo. Todo este conjunto de puertas pueden fecharse en torno al año 1200.

En el ámbito de la arquitectura religiosa este tipo de puerta compuesta de un sencillo arco apuntado totalmente desornamentado aparece coetáneamente a las citadas de la arquitectura civil, en la transición del siglo XII al XIII. Es el caso de la portada cegada en el muro norte de la iglesia zamorana de Santa María de la Horta y es probable que también de la portada, perteneciente a la fachada occidental, de la antigua iglesia de Santa María de Roncesvalles y Santa Catalina de Toro, cuyo arco apuntado, en este caso, se encuentra trasdosado con chambrana (Figs. 18 y 19) ${ }^{30}$. En la arquitectura cisterciense fue muy común este tipo de portada en arco sencillo y así en la provincia de Valladolid, concretamente en el muro sur de la iglesia del monasterio cisterciense de Santa María de Valbuena, existen dos puertas de semejante composición a estas aludidas aunque en este caso del monasterio vallisoletano ambas se manifiestan sin solución de continuidad entre el arco y las jambas al no estar explícita la línea de imposta. Ambas, hoy tapiadas, permitían el acceso de los conversos desde el claustro al templo. Es por tanto, que en estos edificios de estilo románico la presencia temprana de estas puertas con arco apuntado sea índice del cambio de gusto o técnica constructiva, quizá por influencia cisterciense.

30 No sabemos con exactitud a qué momento cronológico responde la portada de este último edificio. El modelo, que venía utilizándose desde finales del siglo XII, perduró largo tiempo sin apenas cambios. Véase la ficha de este estudio correspondiente a la iglesia de Santa María de Roncesvalles y Santa Catalina. 
Este primer tipo de portada al que hemos aludido se mantuvo por un deseo de sobriedad, por la propia funcionalidad y por la optimización de recursos, en edificios construidos incluso durante el siglo XIV, especialmente en monasterios y conventos, la mayor parte de las veces con una función secundaria de tránsito entre dependencias, como es el caso del grupo de las conservadas en el monasterio de Sancti Spiritus de Toro. En estas puertas tardías se reconocen elementos nuevos como el achaflanamiento del vértice del arco y de las jambas, o la aparición, en alguna de ellas, de finas columnillas con capitelitos. Aunque la chambrana o guardapolvo es un motivo ya existente en la arquitectura del siglo XIII, como se ha visto en la portada occidental de la antigua iglesia de Santa María de Roncesvalles y Santa Catalina de Toro, en el siglo XIV se vuelve más común y así son varias las puertas del monasterio de Sancti Spiritus datadas en esta centuria que presentan ese elemento.

El segundo grupo que hemos establecido es más numeroso que el anterior y comprende un tipo de puerta de tradición románica resuelta en arco doblado y apuntado, en muchas ocasiones con columnas en las jambas, capiteles decorados y, ocasionalmente, con ornamentación geométrica en la rosca. El origen de este tipo viene a coincidir cronológicamente con el primer grupo, ya que los primeros ejemplos datan de hacia 1200 , y perdura y se mantiene hasta bien entrado el siglo $\mathrm{XIII}^{31}$. Por su naturaleza algo más decorativa este tipo de puerta es más permeable a los cambios estilísticos, que introducen en ellas elementos claramente diferenciadores de los antecedentes románicos de los que proceden. Estos cambios afectan, sobre todo, al adelgazamiento de las molduras que forman las arquivoltas y a la decoración de los capiteles que incorporan progresivamente motivos vegetales naturalistas. Dentro de este grupo hay una gran variedad, aunque la mayoría de las portadas mantienen unas características comunes como es el abocinamiento.

Las más sencillas carecen de decoración y están configuradas por doble arco apuntado de sección cuadrada o rectangular, en algún caso con la arista achaflanada. Es el caso de la puerta

31 En lo que se refiere a la pervivencia de los modelos románicos en la provincia de Zamora hay que señalar que existe un gran número de portadas de doble arquivolta en arco de medio punto cuya cronología se sitúa a mediados del siglo XIII. 


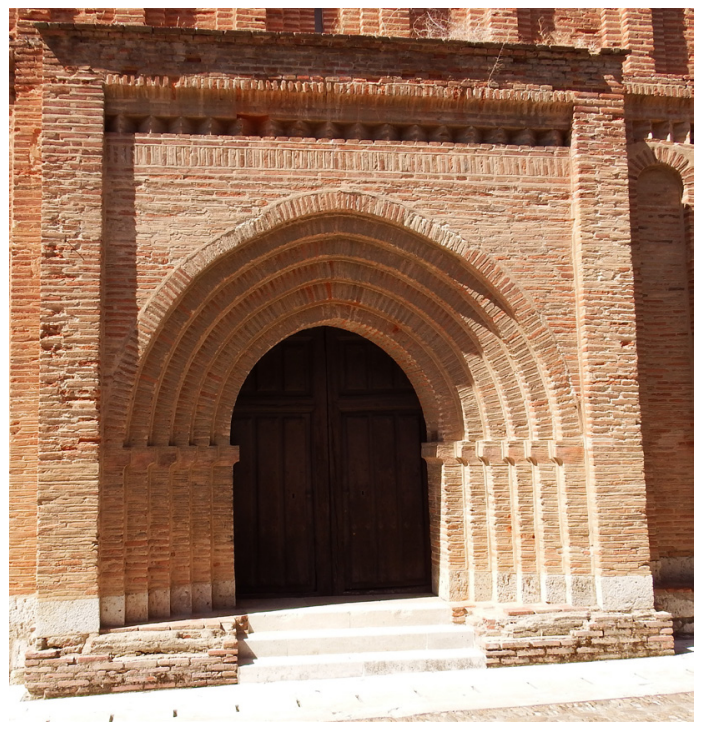

occidental de la iglesia de Santa Lucía en Zamora, que habría que fechar en torno a 1200, y de algunas puertas de templos de la provincia que responderían ya a una fecha avanzada del siglo XIII. La portada mencionada correspondiente al templo de Santa Lucía se abre mediante arco doblado y apuntado sin solución de continuidad con las jambas al no estar explícita la línea de imposta (Fig. 20). La arista del arco y de la jamba ha sido suavizada por medio de un chaflán. Desconocemos si tenía el mismo acabado la arista del arco interno puesto que hoy día no es visible al estar la puerta cegada. Una puerta de semejantes características y con las aristas achaflanadas es la que da acceso a la capilla de forasteros del monasterio cisterciense de San Andrés de Arroyo.

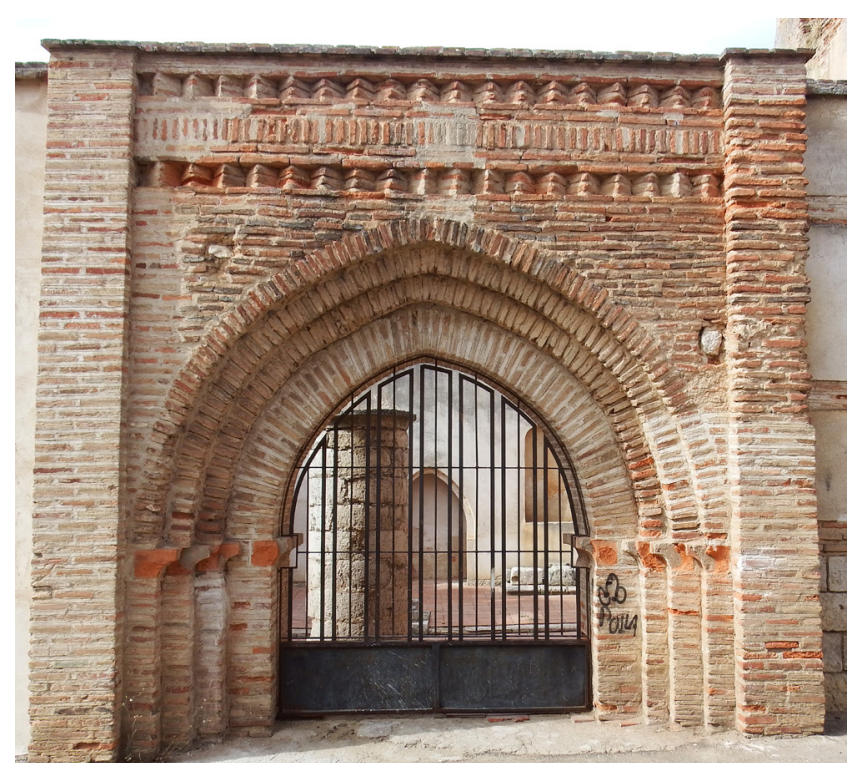




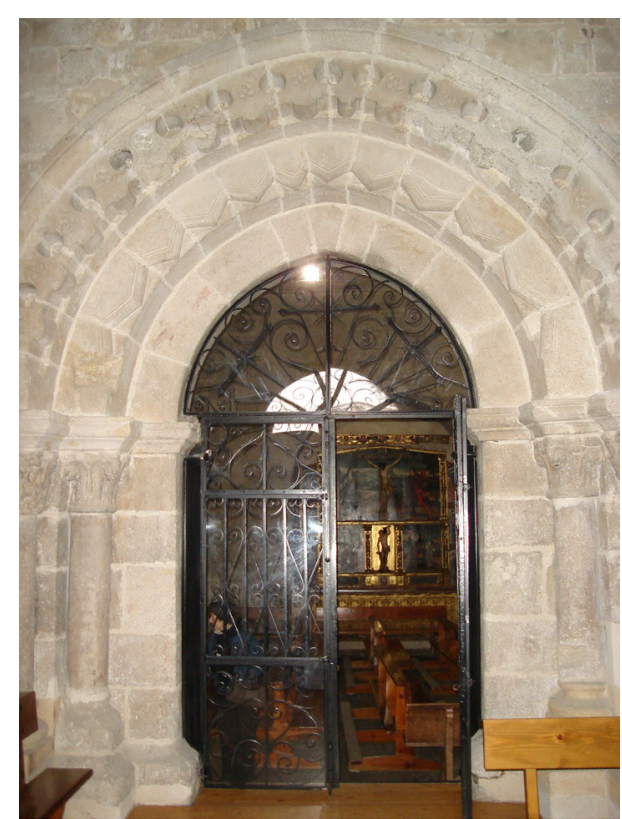

Igualmente encontramos puertas de este tipo en la provincia de Zamora asociadas a templos tardorrománicos que seguían construyéndose en pleno siglo XIII, momento al que hay que adscribir todas estas portadas. Es el caso de la portada sur de la iglesia de Nuestra Señora de la Asunción de Lanseros, de la portada norte de la iglesia de San Miguel Arcángel de Manzanal de los Infantes, de la portada de la iglesia de Nuestra Señora del Carrasco de Pinilla de Fermoselle, y de la portada de la iglesia de Santa María Magdalena de Utrera de la Encomienda, en todos los casos resueltas en arco doblado y apuntado sobre jambas escalonadas con impostas de listel y chaflán. La última de estas puertas citadas presenta la particularidad de llevar la arista del arco moldurada por una media caña. Este mismo esquema, pero compuesta de arco y doble arquivolta, tiene la portada septentrional de la iglesia de San Miguel Arcángel de Moreruela de Tábara.

Existen varios ejemplos de portadas con idéntica configuración y en la misma línea de ausencia decorativa que estas que hemos mencionado en la arquitectura tardorrománica de ladrillo realizada en Toro. Ejemplo de ello es la portada occidental de la iglesia de San Lorenzo el Real levantada a finales del siglo XII, que consta de arco doblado o la portada norte de la ermita de Nuestra Señora de la Vega y la portada sur de la iglesia de San Pedro del Olmo, ambas edificadas a principios del siglo XIII y enriquecidas con un mayor número de arquivoltas (Figs. 21 y 22).

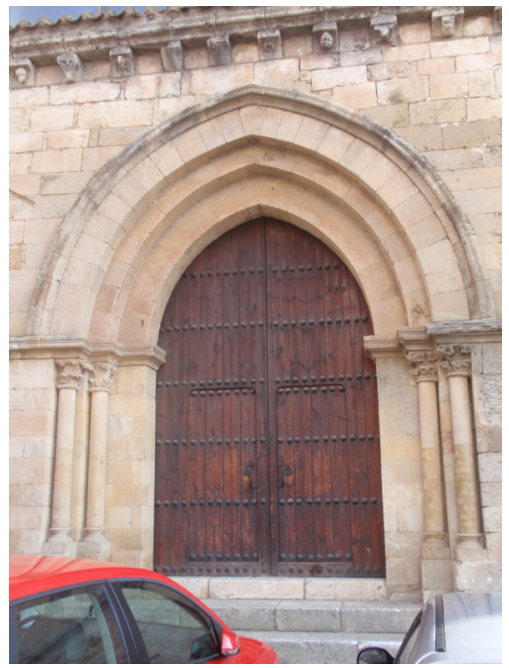

Fig. 24. Portada norte de la capilla de la Majestad 


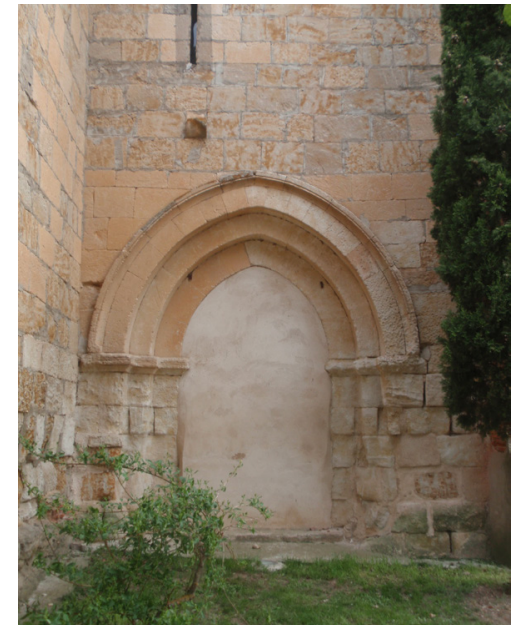

Fig. 25. Portada norte. Iglesia de Nuestra Señora de la Asunción. Venialbo
Otras presentan una composición mucho más elaborada con un mayor número de arquivoltas y una ornamentación claramente influenciada por la estética cisterciense con algunos elementos todavía propios del románico. Dependientes de esta sobriedad decorativa y con elementos tales como dientes de sierra, capiteles vegetales con el tercio inferior más estrecho y motivos geométricos son algunas de las portadas de la iglesia de Santa María de la Horta de Zamora (Fig. 23). En la misma línea compositiva vinculadas a patrones Císter, pero en este caso sin ninguna ornamentación en las arquivoltas, de sección cuadrada, son la portada norte de la capilla de la Majestad de la Colegiata de Toro y la portada también situada al norte de la iglesia de Nuestra Señora de la Asunción de Venialbo (Figs. 24 y 25). La portada sur de la iglesia de San Isidoro de Zamora, levantada hacia 1200, presenta arco ligeramente apuntado y arquivoltas enriquecidas por una sucesión de molduras (Fig. 26).

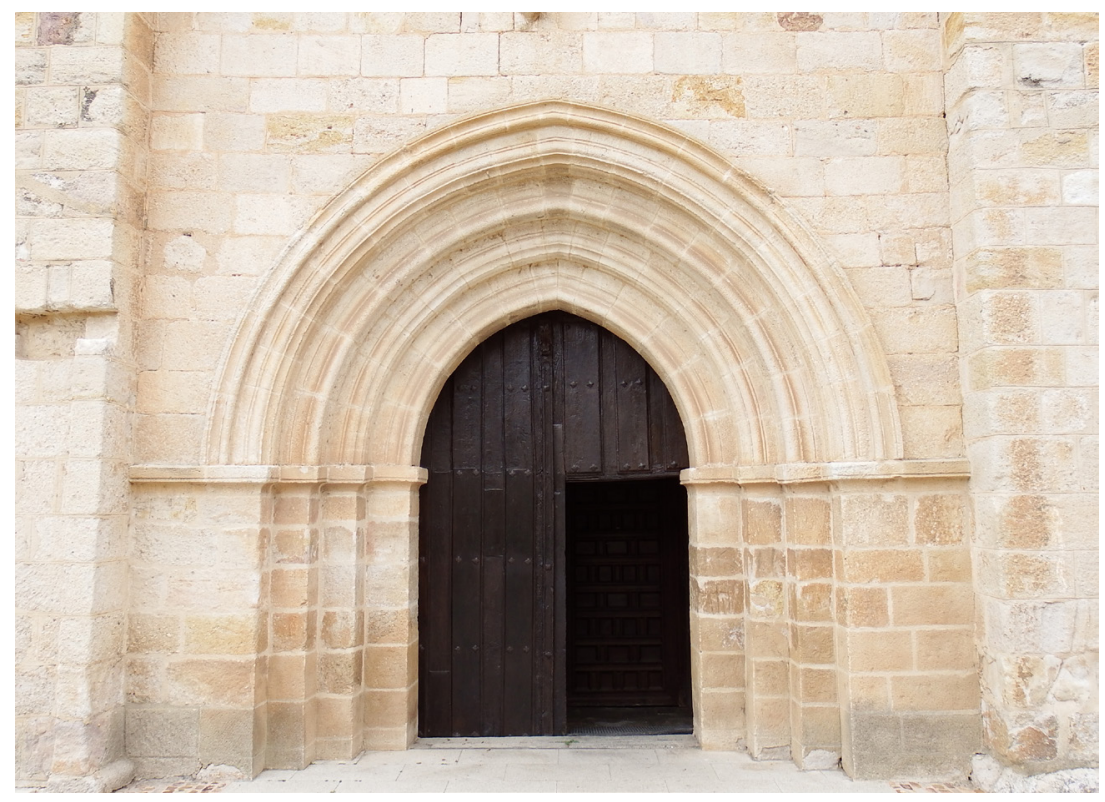

Con el paso de los años los vanos de estas portadas van adquiriendo un grado de apuntamiento mayor como puede verse en la portada norte de la iglesia de Santa María la Nueva de Zamora, de aproximadamente mediados del siglo XIII (Fig. 27). La arquivolta interior presenta únicamente moldurada la arista mientras que el resto de arquivoltas se componen de una sucesión de molduras. Siguen el mismo esquema, manteniendo en conjunto igualmente una clara vinculación con la arquitectura cisterciense, las portadas meridionales de las iglesias de San 


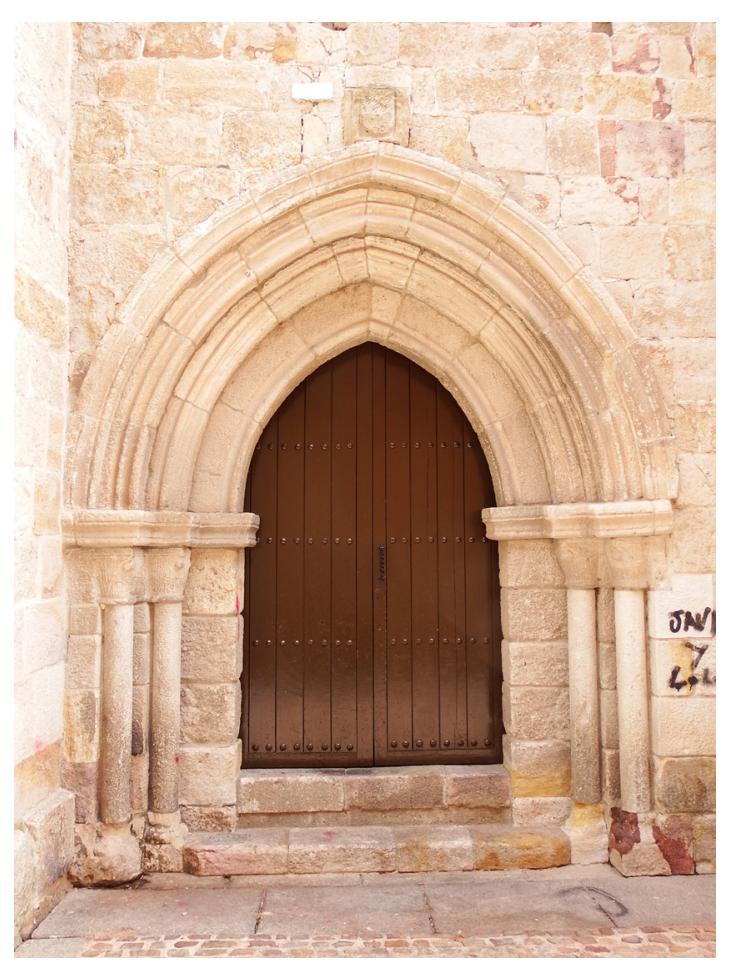

Nicolás, Santa María del Río y Santa María la Mayor o de la Sagrada de Castroverde de Campos (Figs. 28 y 29). Lo mismo sucede en la portada de la iglesia de la Asunción de la Virgen de Quintanilla del Monte, aunque en este caso la arquivolta interior es completamente lisa (Fig. 30). Cracterísticas idénticas posee la portada del torreón perteneciente al actual monasterio de Santa Sofía en Toro y que en su día constituía el acceso a un palacio que había pertenecido primero al obispo de Coria y después a la reina María de Molina. Esto constata, una vez más, la utilización de modelos y formas idénticos indistintamente tanto en la arquitectura religiosa como en la civil.

Este tipo mantuvo como el anterior una continuidad en los siglos posteriores como queda reflejado en la portada sur de la capilla de la Majestad de la colegiata de Toro, que tiene una configuración muy semejante a las mencionadas con anterioridad aunque presenta un tipo de molduraciones que delatan un periodo de construcción mucho más tardío.

Las jambas en este tipo de puertas presentan algunas variedades. Las más sencillas son completamente lisas como sucede en la portada ya mencionada de San Isidoro de Zamora o en la septentrional de la iglesia de Nuestra Señora de la Asunción en Venialbo. En la mayoría es muy común que la arquivolta 

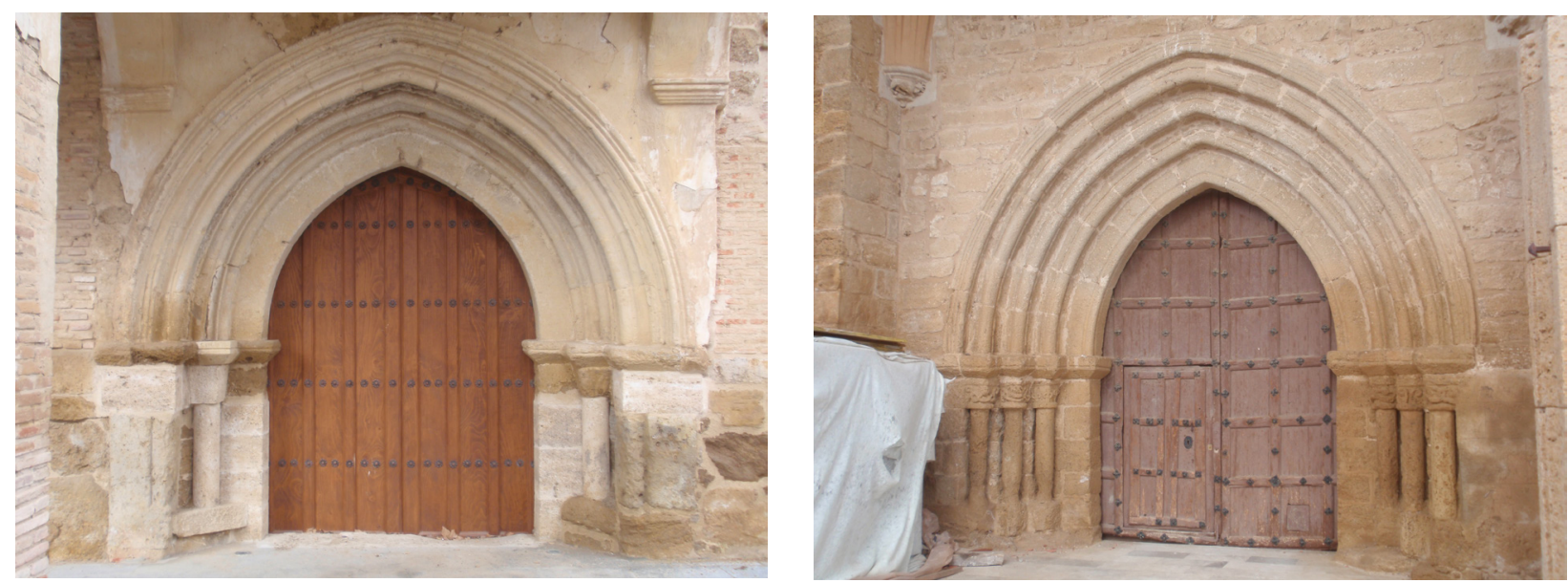

Figs. 28 y 29. Portadas meridionales de las iglesias de San Nicolás y Santa María del Río. Castroverde

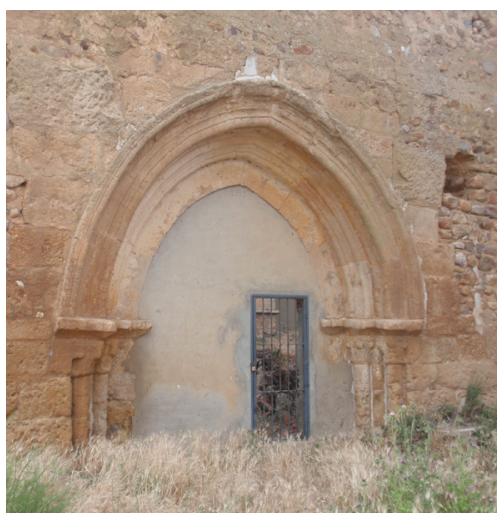

Fig. 30. Portada sur. Iglesia de la Asunción de la Virgen. Quintanilla del Monte interior apoye en jambas lisas y las restantes lo hagan en columnas con capiteles decorados con sencillos motivos, generalmente vegetales: portada norte de la iglesia de Santa María la Nueva de Zamora, portadas occidental y sur de la iglesia de la Asunción de Fermoselle (Figs. 31 y 32), portada norte de la capilla de la Majestad en la colegiata de Toro, portadas meridionales de las iglesias de San Nicolás, Santa María del Río y de Santa María la Mayor o de la Sagrada de Castroverde de Campos, y portada sur de la iglesia de la Asunción de la Virgen de Quintanilla del Monte. Por último, en la iglesia parroquial de Santa María del Azogue en Puebla de Sanabria tenemos el único ejemplo de la provincia de puerta con estatuas-columna (Fig. 33). Aunque estas esculturas pertenecen plenamente a la estética románica, su utilización en las jambas de una portada responde a modelos del gótico inicial francés con origen en Saint Denis y Chartres.

Por tanto, sin que haya una estricta correlación entre cronología y formas, se puede establecer, en la mayoría de los casos, una secuencia cronológica en base a elementos tales como la configuración del arco, primero mediante dobladuras de sección cuadrada lisa y, posteriormente, con la rosca moldurada mediante salientes en forma de gruesos baquetones que con el tiempo se van adelgazando.

Por último, hay que señalar que algunas de estas portadas zamoranas presentan en su reverso una estructura común vista en numerosas ocasiones en la arquitectura románica de la ciudad y también con posterioridad. Se trata de un pequeño resalto que remata con arco en mitra bajo el que se mantienen los goznes donde iban encajadas las hojas de la puerta. Esta estructura se 

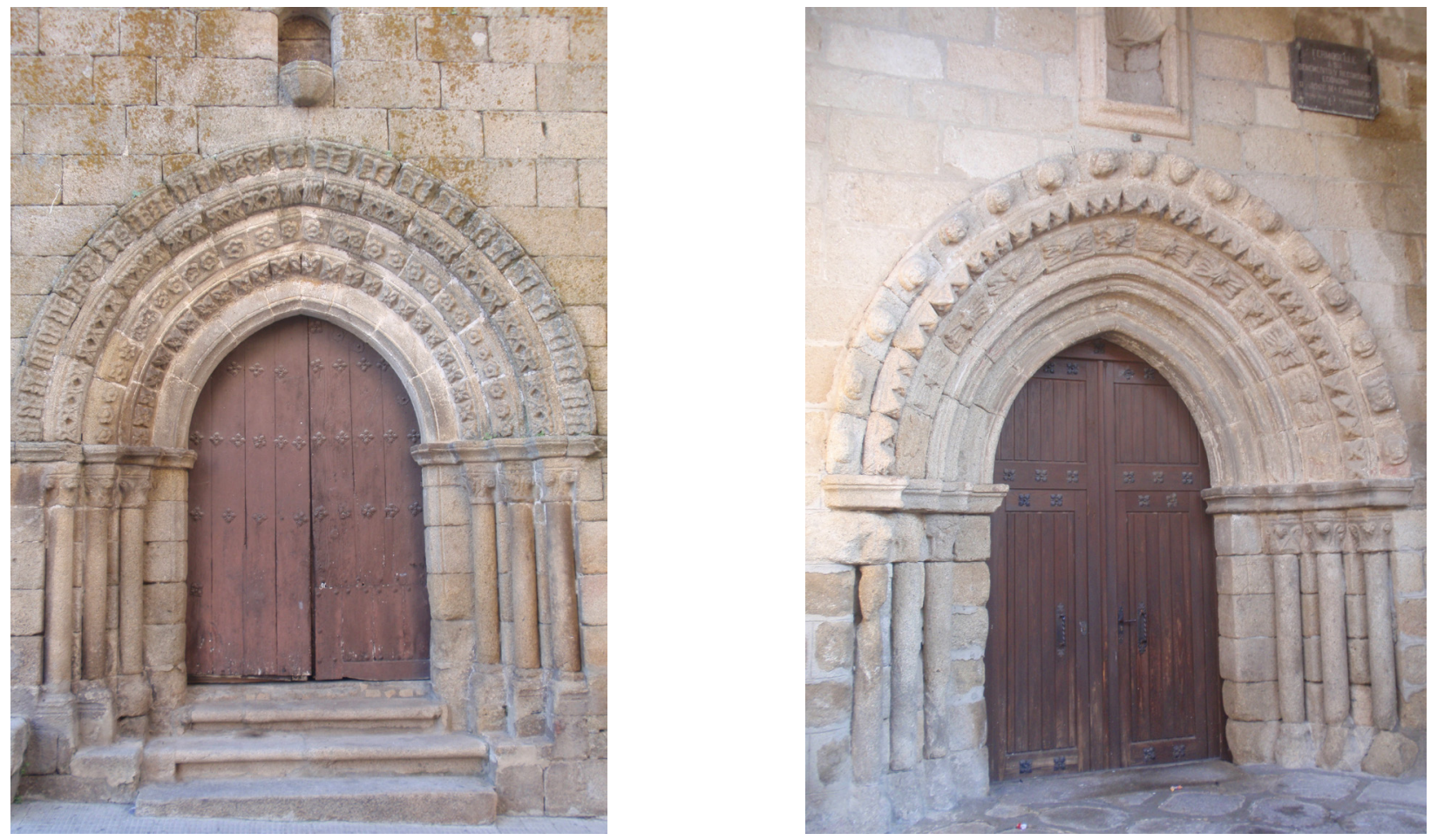

encuentra en la puerta de la actual capilla Bautismal de la iglesia de Santa María de la Horta, en todas las portadas de la iglesia Figs. 31 y 32. Portadas occidental y sur de la iglesia de la Asunción de Nuestra Señora. Fermoselle de Santiago del Burgo, en la portada sur de la iglesia de San Cipriano así como en las portadas del norte de las iglesias del Santo Sepulcro y del Espíritu Santo. Es, por tanto, una estructura de carácter funcional que se utiliza indistintamente del periodo constructivo.

También puede observarse la introducción del arco apuntado en las ventanas de algunos de estos edificios religiosos que

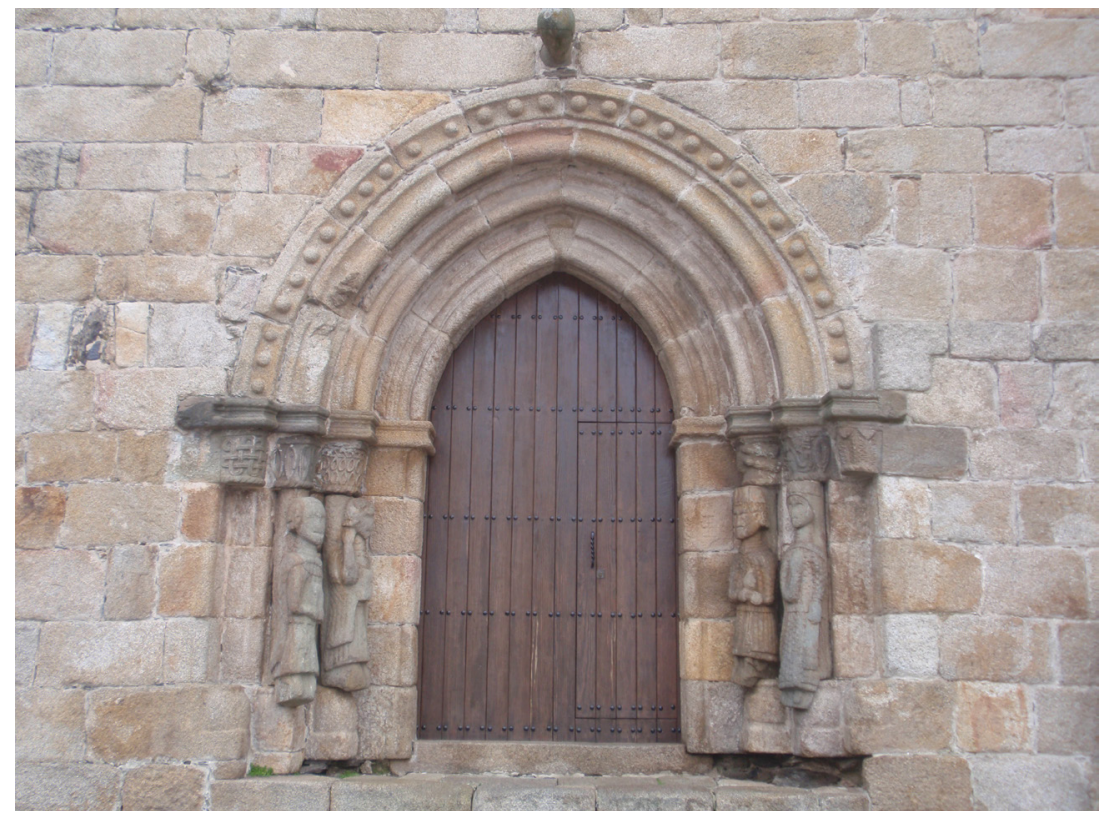




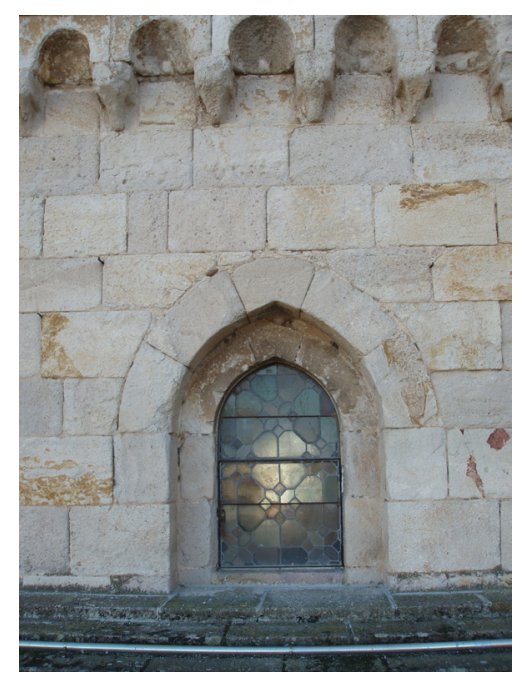

Fig. 34. Vano abierto en el muro norte de la nave central. Catedral de Zamora comenzaron a edificarse en la segunda mitad del siglo XII y que se mantuvieron en construcción durante las primeras décadas del siglo XIII. Si bien es cierto que la mayoría de las ventanas de estos templos son plenamente románicas, de pequeñas dimensiones y están por tanto integradas desde el punto de vista estético en el conjunto del edificio. Solamente en la parte alta de grandes templos como son la catedral de Zamora y la iglesia de Santa María del Azogue de Benavente es perceptible en algunas de ellas un apuntamiento ligero.

Dentro de la sencillezque muestran estas ventanas observamos ciertas variantes. En el exterior de los muros de la nave central de la catedral de Zamora se utilizaron vanos doblados y apuntados con los arcos y las jambas de sección cuadrada y sin solución de continuidad entre ambos (Fig. 34). En el muro sur del crucero de la misma catedral se abre un vano semejante a los anteriores mencionados aunque, en este caso, la dobladura exterior del arco apoya en columnas con capiteles. Otros vanos presentan un solo arco sin solución de continuidad hacia las jambas y con todo el recorrido de la arista marcado por un gran chaflán como sucede en la parte que da al exterior de los vanos del crucero de la iglesia de Santa María del Azogue (Fig. 35). Sin embargo, al interior éstos mismos vanos sustituyen el chaflán por una moldura en forma de bocel que recorre toda la arista del arco y las jambas también sin solución de continuidad entre ellos.

Cronológicamente las ventanas correspondientes a la catedral responderían a las últimas décadas del siglo XII mientras que las referidas de la iglesia de Santa María del Azogue habría que encuadrarlas ya en las primeras décadas del siglo XIII.

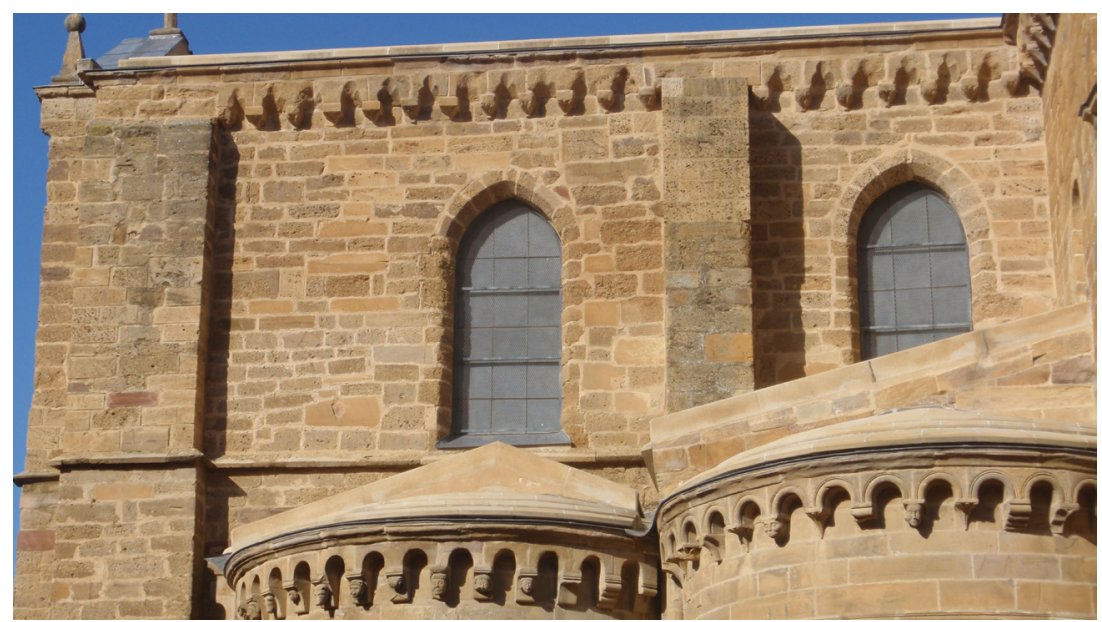




\section{Los arcosolios}

Otro de los elementos arquitectónicos donde se observa la incorporación de los primeros signos del estilo gótico es en los numerosos arcosolios sepulcrales que se encuentran situados en los muros, tanto en su interior como en su exterior, de un buen número de iglesias zamoranas. En ellos se manifiesta especialmente la introducción del arco apuntado.

El arcosolio no es una forma original creada en el gótico, sino que es un sistema de enterramiento cristiano que se remonta a época muy antigua. Concretamente tendría sus orígenes en los cubículos de las catacumbas de Roma. Llegado el siglo XII, este tipo de estructuras horadadas en el muro con la función de acoger enterramientos se volvieron a utilizar, pero esta vez se dispusieron primeramente en el exterior de las iglesias para inmediatamente después ser incorporados al interior. En la provincia de Zamora fueron muy comunes a finales del siglo XII y principios del siglo XIII y su uso se prolongó hasta el siglo XV manteniendo características muy semejantes y por lo general dotados de un diseño muy básico. Sólo se han observado ligeras diferencias en la introducción de elementos decorativos, como son los capiteles con decoración vegetal y las arquivoltas con molduraciones más o menos elaboradas.

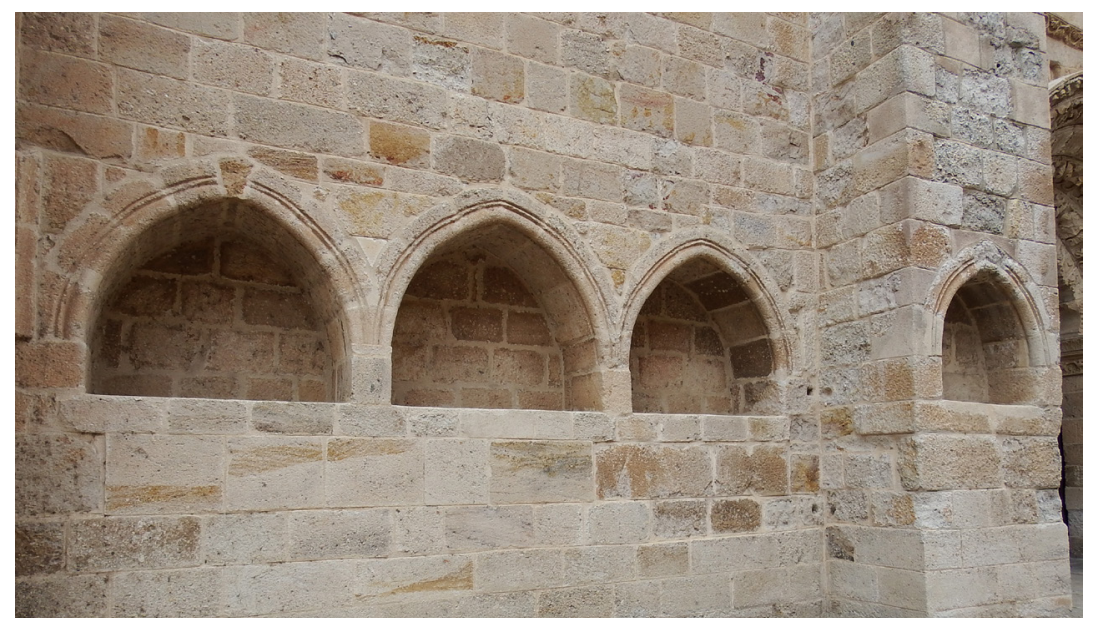

En las iglesias zamoranas la mayor parte de ellos, sobre todo los de época más antigua, carecen de decoración y, salvo en casos en los que existe una inscripción, es difícil precisar su cronología. A ello se suma la gran tendencia conservadora existente en la arquitectura zamorana de estos momentos. Por tanto, a la hora 
de datarlos, va a ser fundamental ponerlos en relación con el edificio en el que aparecen, así como elaborar una evolución estilística en base a sus elementos decorativos.

Los arcosolios más antiguos, situados tanto en el exterior como en el interior de las iglesias, responden a los primeros momentos de edificación de las mismas, lo que lleva a catalogarlos como obras plenamente románicas ejecutadas en las últimas décadas del siglo XII o primeros años del siglo XIII ${ }^{32}$.

A principios del siglo XIII, comienza a reconocerse en una serie de arcosolios un cierto avance estilístico, pero dentro del mismo lenguaje románico anterior ${ }^{33}$. No obstante, prácticamente al mismo tiempo comenzaron a aumentar el número de aquellos en los que ya se aprecia un ligero apuntamiento en la arcada, aunque aún presenten una molduración bastante tosca. Prueba de esto es el amplio grupo de la fachada principal de la iglesia de la Magdalena de Zamora (Fig. 36). De este tipo son también los situados en el muro sur de la iglesia de Santa María de la Horta (Zamora), cuyo aporte novedoso es el de situar en los dos más occidentales una cabeza labrada en sus claves. Pero, sin duda, los arcosolios de más bella factura ejecutados en estas primeras décadas del siglo XIII son los ubicados en el interior de la iglesia de Santiago del Burgo de Zamora. Se trata de dos grupos de arcosolios gemelos (un grupo, de menores dimensiones, situado en el muro norte, y otro, de las mismas características aunque de mayor envergadura, situados en el muro sur), en cuyos extremos y parte central hay dobles columnas con capiteles de decoración

32 En esta delimitación cronológica se encuadran los situados en los muros exteriores norte y sur de la iglesia de San Ildefonso (Zamora). Se trata de dos grupos de arcosolios dobles de medio punto sin ningún tipo de molduras. Responde a esta misma concepción el situado también en el muro sur (zona inferior de la torre) de la iglesia de Santiago del Burgo (Zamora).

33 Todos ellos presentan arco de medio punto con una moldura de bocel que arranca, en la mayoría de los casos, por encima de los salmeres. Pueden citarse como ejemplos el arcosolio de medio punto moldurado conservado en el interior de la iglesia de San Ildefonso (Zamora), concretamente en el primer tramo del muro norte inmediato a la cabecera; el situado en el mismo lugar en la iglesia de Santa María la Nueva (Zamora) y los dos situados en el exterior del lienzo sur de esta misma iglesia; los que se abren en el lienzo sur del cuerpo bajo de la torre de Santa María la Nueva (Zamora) y en el exterior de tramo presbiterial que da al norte $y$, finalmente, también, el situado en el interior de la iglesia de San Cipriano (Zamora) en el muro sur inmediato a la cabecera. Éste arcosolio de la iglesia de San Cipriano presenta un molduraje más rico compuesto (desde el exterior al interior) de un pequeño bocel entre dos escocias o simples incisiones en pico y a continuación un gran bocel. Muy similar a éste último es el arcosolio doble de medio punto y con sus arquivoltas molduradas, que se conserva en la iglesia del Carmen del Camino (Zamora) aunque en la actualidad se encuentra desfigurado al haber sido reconvertido en ventanal. 


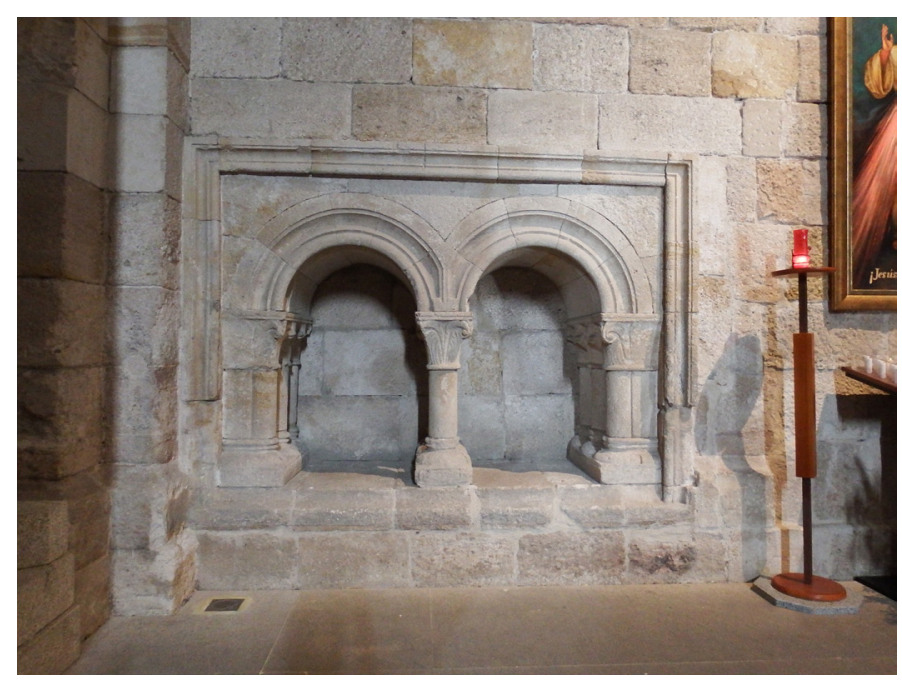

vegetal (Fig. 37). Los arcos están ligeramente apuntados y la molduración manifiesta mayor laboriosidad que la vista en los citados de la Magdalena y de la Horta. Estos arcosolios, siendo románicos en su concepción, denotan un cierto avance estilístico respecto a los primeros aludidos y pueden servir, por tanto, como nexo de unión entre ellos y los que se realizaron en las décadas sucesivas. Como particularidad hay que señalar el alfiz que los enmarca.

Seguidamente dedicaremos una atención especial a aquellos arcosolios cuyos elementos constitutivos son ya góticos, aunque se encuentren en edificios que responden plenamente a la arquitectura románica.

Ala hora deabordar su análisis, las características que presentan estos arcosolios que se han conservado permiten establecer dos grupos. El primero de ellos estaría compuesto por aquellos que presentan una total desornamentación en su configuración y diseño; el segundo, más numeroso, lo constituirían los arcosolios que tienen su embocadura adornada con molduras y presentan en su ejecución, por tanto, una técnica más elaborada y ofrecen, ya, rasgos estilísticos plenamente góticos.

En algunas ocasiones, los arcos que conforman este tipo de arquitectura funeraria tienen la línea de imposta a la altura del sepulcro; en otras, esta línea está por encima, de tal modo que da lugar a la aparición de pequeñas jambas, sencillas, unas veces, molduradas, otras. 
Por lo que respecta a su evolución formal ya se ha señalado que no fue demasiado significativa y que mantuvieron un diseño muy semejante durante un largo periodo. No obstante, con el paso del tiempo, se pueden constatar algunos cambios como son su mayor desarrollo en altura al dotarlos de jambas así como una ornamentación más profusa. De este modo de finales del siglo XIII e incluso de principios del XIV son los lucillos de la capilla que se abrió, en esta misma época, en el lienzo norte de la iglesia de San Cipriano. Presentan un desarrollo mayor que los pertenecientes a las primeras décadas del siglo XIII, elevándose a poca altura del suelo de la iglesia. Sobre una especie de basa se levantan columnas coronadas por capiteles geométricos sin decoración en los que apoyan dos arquivoltas molduradas con un grado de apuntamiento bastante acusado. Este tipo de arcosolio en arco apuntado se siguió utilizando sin apenas cambios en sepulcros del siglo XV como queda constatado en los dos que se han vaciado recientemente en el muro sur de la catedral de Zamora, que son los más completos que se han conservado de todos los mencionados, pues mantienen elementos escultóricos y policromía. El esquema en arco apuntado con sencillas molduraciones se repite en las últimas décadas del siglo $\mathrm{XV}$ en los arcosolios que se abren en la capilla de los Ocampo del antiguo templo conventual de San Francisco. En este caso, sin embargo se levantan sobre un podio y poseen un gran desarrollo en vertical.

\section{Arcosolios en arco apuntado sin molduración}

El primer grupo es el formado por aquellos arcosolios que se abren en arco apuntado simple sin ningún tipo de molduración. En general se encuentran asociados a edificios de finales del siglo XII o principios del siglo XIII.

En la iglesia de San Isidoro, pertenecen a este tipo, tres arcosolios situados en sus muros exteriores. Uno de ellos se abre en el muro norte $y$, otros dos, de menores dimensiones $y$ cegados en la actualidad, en el muro sur (Fig. 38). Carecen de inscripciones y sólo el ligero apuntamiento del arco es indicativo de su posible filiación cronológica en torno a 1200. El mismo tipo de arcosolio, con un grado mayor de apuntamiento, se encuentra 


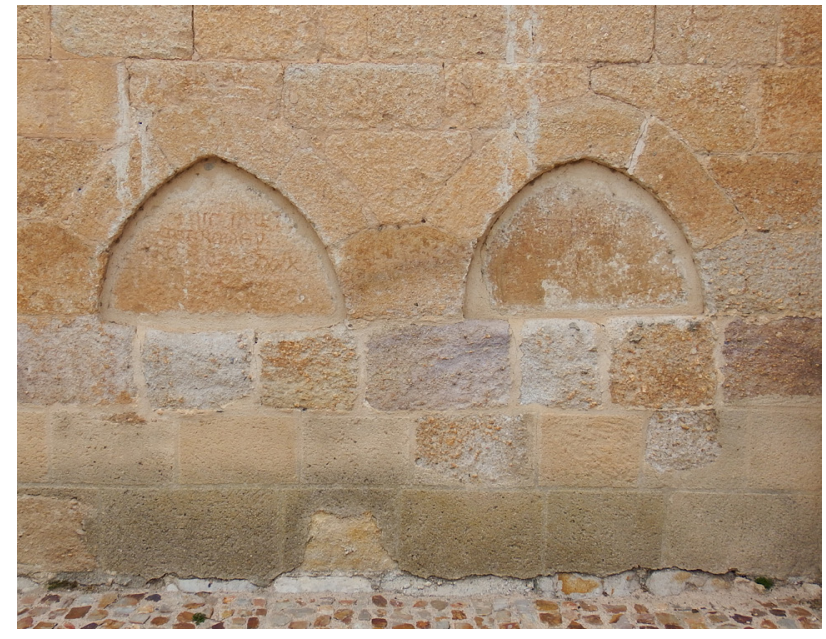

en el muro sur de la iglesia de Santa María de la Vega ${ }^{34}$. Esta iglesia, curiosamente descubierta hace escasos años, conserva una inscripción de suma importancia, que permite reafirmarnos en la cronología establecida para este grupo de arcosolios que no presentan molduración en la rosca del arco. Se trata de una inscripción funeraria sobre las dovelas de la portada principal, fechada en los primeros años del siglo XIII ${ }^{35}$. Esta portada se sitúa en el lienzo sur de la antigua iglesia, justo en el mismo muro en el que se abre el arcosolio citado, de ahí la vinculación que posibilita el datarlo de una manera más exacta. Otro arcosolio en arco apuntado carente de molduración en todo su desarrollo se encuentra en el interior de la iglesia de la Magdalena, en el segundo tramo de su muro norte. También en la iglesia de San Leonardo hay varios arcosolios semejantes situados en la parte inferior del muro norte de su capilla colateral. En la provincia arcosolios de este tipo los encontramos en el interior de las iglesias benaventanas de Santa María del Azogue y de San Juan del Mercado así como también en el interior, concretamente

34 La mayor parte de lo conservado del antiguo templo de Santa María de la Vega pertenece a principios del siglo XIII. Se trataba en origen de una iglesia románica, secularizada en el siglo XVI, que fue hallada hace escasos años al derribarse una casa, que al ser construida, había integrado en su estructura la fábrica de la iglesia. De este modo, no se tenían noticias de lo sucedido con este templo hasta que se procedió al derribo de la casa y como consecuencia salieron a la luz los restos de la antigua iglesia.

35 HIC : REQVIESCIT : FAMVL (us) : D (e) I PETR (us) : ASCENSSII : CL (er) IC (us) : ISTE ECCL (es) IE : Q (u) I : OBIIT : IX : K (a) L (en) D (a) S : + APRIL (is) : ERA : M (illesima) : CCC : V : Lo que se puede traducir por "Aquí descansa el siervo de Dios Pedro, clérigo de ascenso de esta iglesia, que murió el 9 de las Kalendas de abril de la era milésima tricentésima quinta, una fecha que corresponde al 24 de marzo del año 1267”. SALVADOR VELASCO, Mónica y VIÑÉ ESCARTÍN, Ana I., "Iglesia de Santa María de la Vega" en RODRÍGUEZ MONTAÑÉS, J. M., (coord.) Enciclopedia del Románico en Castilla y León. Zamora, Centro de Estudios del Románico, Aguilar de Campoo, 2002, pp. 531-533.
Fig. 38. Arcosilios cegados en el exterior de la iglesia de San Isidoro. Zamora 


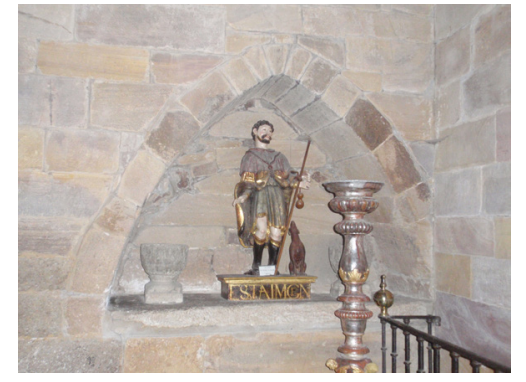

Fig. 39. Arcosolio. Iglesia de Santa María del Azogue. Benavente

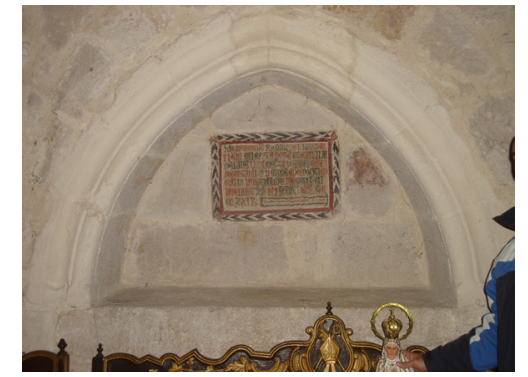

Fig. 40. Arcosolio. Iglesia de San Ildefonso. Zamora dispuestos en el muro sur, de la iglesia de Santa María la Real de La Hiniesta (Fig. 39).

Todos estos arcosolios, pertenecientes a las iglesias de San Isidoro, Santa María de la Vega, la Magdalena y San Leonardo en Zamora, Santa María del Azogue y San Juan del Mercado en Benavente y Santa María la Real de la Hiniesta presentan una gran sencillez fruto de la funcionalidad de estas estructuras y de la falta de recursos económicos del momento en esta zona geográfica. Su sencillez y ausencia decorativa también podría verse como el reflejo de la influencia que los postulados del Císter tuvieron en la arquitectura zamorana.

\section{Arcosolios en arco apuntado con molduración}

El segundo grupo y más numeroso de este tipo de enterramientos, se encuadra cronológicamente en la segunda mitad del siglo XIII. El borde del arcosolio, que en los sepulcros del tipo anteriormente citado estaba compuesto por bloques de sillería perfectamente escuadrados, ahora se presenta moldurado.

Hay un grupo en el que estas molduras son muy sencillas y por lo tanto tienen un carácter decorativo mínimo. Es, por tanto, el desarrollo del apuntamiento del arco, el que lleva a catalogar esta serie de arcosolios como elementos plenamente góticos desarrollados en una fase avanzada del siglo XIII. La inscripción funeraria que presenta uno de estos sepulcros, situado en el interior del muro norte de la iglesia de San Ildefonso de Zamora (Fig. 40), es de gran importancia a la hora de encuadrar cronológicamente este grupo. Dice la inscripción «AQUI IAZE DOMINGO VISANES: ARCIPRESTE DE ZAMORA ERA DE M: CCC E XII ANOS» (año de 1274) ${ }^{36}$. De idéntica ejecución a éste mencionado, son los que se encuentran en los muros norte y sur de la misma iglesia, los situados en la iglesia de San Juan de Puerta Nueva, concretamente en el exterior de su fachada occidental, en su fachada norte y en el interior del propio templo, el arcosolio que se abre a la derecha de la portada sur de la iglesia de Santa María de la Horta así como los conservados

36 CALDERO FERNÁNDEZ, Jesús, La iglesia arciprestal de San Pedro y San Ildefonso de Zamora, Zamora, 1978, pp. 36-37. 
en el interior de la iglesia de San Vicente, concretamente en su muro norte, muy interesantes debido a los restos de policromía que aún conservan (Figs. 41 y 42). Las iglesias de San Cipriano y Santa María la Nueva ${ }^{37}$ igualmente conservan arcosolios de estas características. En la provincia de Zamora existen dos arcosolios de este tipo en el exterior del muro norte de la iglesia de San Esteban en Fuentelcarnero (Fig. 43). Por último, también guardan una semejanza compositiva con las características propias de esta segunda mitad del siglo XIII los dos arcosolios de la capilla de San Juan Evngelista en la catedral zamorana (Fig. 44). Esta capilla, construida en la segunda mitad del siglo XIII, refuerza el periodo cronológico del que se está hablando para fechar estos elementos arquitectónicos.

Todos los arcosolios señalados muestran un arco plenamente gótico con una molduración idéntica en la mayoría de los casos compuesta de una escocia seguida de un bocel. En los vistos en el interior de la iglesia de San Cipriano abiertos en el muro norte, en el primer tramo inmediato a la cabecera, el molduraje se enriquece con pequeños boceles.

\section{Elementos estructurales. El apuntamiento y la bóveda de crucería}

Uno de los elementos característicos de la tradición románica era el arco doblado que en algunos casos puede ser apuntado y que se utiliza en multitud de templos con variadas funciones y en las bóvedas como fajón, como arco toral o en los arcos de acceso al presbiterio. La arquitectura española lo tomó en gran medida de Francia, debido al gran desarrollo que tuvo en Provenza, Borgoña y Aquitania, como consecuencia de la expansión de la arquitectura cisterciense en aquellos territorios. En Zamora el arco doblado apuntado debió aparecer muy pronto, de ahí que señale Gómez- Moreno cuando analiza la articulación interna de la catedral de Zamora "El hecho de ser apuntados los arcos acusa novedad para la España cristiana, que tal vez no puedan disputarle Ávila ni Moreruela, y, desde luego, no tenemos edificio

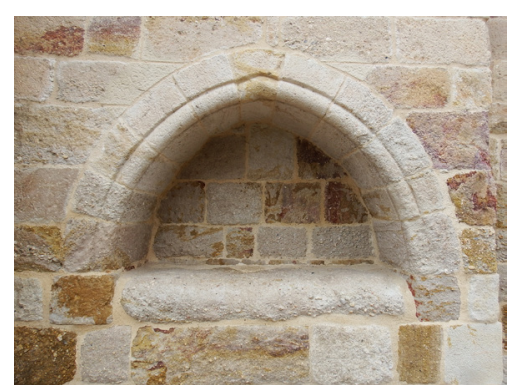

Fig. 41. Arcosolio en el exterior de la iglesia de Santa María de la Horta. Zamora

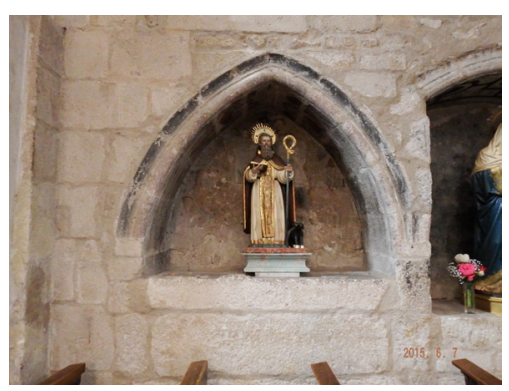

Fig. 42. Arcosolio en el interior de la iglesia de San Vicente. Zamora

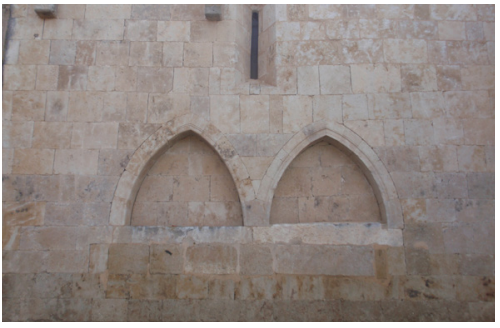

Fig. 43. Arcosolios en el exterior de la iglesia de San Esteban. Fuentelcarnero

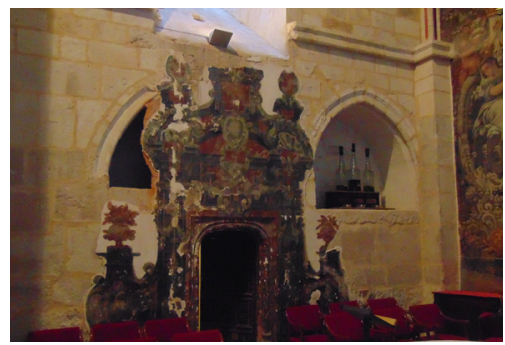

Fig. 44. Arcosolios abiertos en el muro sur de la actual capilla de San Juan Evangelista. Catedral de Zamora 
de su siglo donde ellos campeen con tanta resolución como en este" ${ }^{\prime \prime 3}$.

Ejemplos de este gusto románico son los innumerables arcos doblados y apuntados, que teniendo como primer ejemplo la catedral (arcos torales, perpiaños y formeros), pronto se utilizaron en el resto de la arquitectura zamorana. Por ejemplo, los arcos torales de las iglesias de la Magdalena, Santa María de la Horta, San Esteban y San Isidoro así como los fajones de las naves laterales de Santiago del Burgo, todos ellos templos de la ciudad de Zamora. En la provincia también son habituales, fundamentalmente en la ciudad de Benavente (iglesia de Santa María del Azogue e iglesia de San Juan del Mercado), y en la de Toro (Colegiata, iglesia de San Salvador de los Caballeros, ermita de Nuestra Señora de la Vega, iglesia del Santo Sepulcro, etc). También se conservan en templos de poblaciones menores como sucede en la iglesia de San Esteban de Fuentelcarnero. El arco doblado y apuntado y la bóveda de cañón apuntada se siguieron utilizando en edificios cuya construcción data del primer tercio del siglo XIII así como en las reformas que durante buena parte de este siglo, e incluso con posterioridad, se llevaron a cabo en algunos templos de la provincia de Zamora. Ejemplo de ello tenemos en las cabeceras de tradición románica de la ermita de San Adrián de Granucillo y de la parroquial de Villaobispo, ambas de planta rectangular y cubiertas por bóveda de cañón apuntado.

El paso de estas estructuras de origen románico a formas propiamente góticas se produce en el momento en el que no sólo el arco se hace más apuntado sino que adquiere ligereza en función de la molduración propiamente gótica.

$\mathrm{Si}$ se tiene en cuenta que la mayor parte de las iglesias zamoranas se comenzaron a construir en la segunda mitad del siglo XII se entiende que las bóvedas de las naves se elevaran a finales de ese mismo siglo y, con más probabilidad, durante las primeras décadas del siglo siguiente. No obstante, las transformaciones sufridas en nuestras iglesias románicas durante los siglos sucesivos dieron como consecuencia la sustitución de los sistemas primitivos de cubierta, con lo cual se hace muy difícil en este momento determinar cuántos edificios tuvieron

38 GÓMEZ-MORENO, M., op. cit., I, 1927 (1980), p. 103. 
como cerramiento la bóveda de crucería sin formeros, salvo en los casos conservados ${ }^{39}$. Aunque estas bóvedas de crucería acreditan el conocimiento por parte de los canteros del sistema nervado, sin embargo, demuestran igualmente que no existe un conocimiento pleno de lo que es la esencia del sistema de crucería, ya que los plementos apoyan directamente sobre los muros sin la presencia del arco formero, que es el que realmente permite descargar de peso a las paredes y acceder a un sistema más luminoso del edificio.

El sistema mayoritario utilizado durante la segunda mitad del siglo XII para cubrir determinados espacios, como son los tramos presbiteriales y el crucero de algunos edificios, fue la bóveda de cañón apuntado, que también debió emplearse para la nave central de algunos edificios destacados como fue el caso del templo monástico de Moreruela ${ }^{40}$. La misma solución fue planteada para la nave central de la catedral de Zamora, aunque llegado el momento de su edificación se optó por la utilización de otro tipo de cubierta más moderna como era la bóveda de crucería. Ambos sistemas de cerramiento, la bóveda de cañón apuntado y la bóveda de crucería, se dieron prácticamente de forma simultánea como queda constatado en el cuerpo de la iglesia monacal de Moreruela, que, al mismo tiempo que utiliza, como se ha señalado, en su nave central la bóveda de cañón apuntado, en las laterales, que lógicamente se edificaron antes, se emplearon bóvedas de crucería.

La bóveda de crucería es uno de los elementos que definen la arquitectura gótica y su aparición en la provincia de Zamora en fecha tan temprana le otorga un valor ciertamente destacable. Estas bóvedas conservadas, en número escaso, se encuentran entre las más antiguas de la Península Ibérica.

Abordar el estudio de estos elementos resulta en todo modo problemático por cuanto no conservamos documentación que

39 Los edificios que han mantenido su distribución interna y abovedamientos primitivos de forma más completa son la catedral y las iglesias de Santiago del Burgo y de Santa María de la Horta en Zamora.

40 En la actualidad no se conservan las cubiertas de las naves del antiguo templo de Santa María de Moreruela. Todo parece indicar, aunque carezcamos de testimonios visuales y documentales (solamente para la nave central ya que en los muros perimetrales sí se han conservado nervaduras que certifican la utilización de bóvedas de crucería para las naves laterales), que también fue ese el sistema utilizado para cubrir la nave central de la iglesia abacial de Santa María de Moreruela. 
permita datar de manera precisa estas estructuras y, por tanto, establecer posibles relaciones entre ellas o una secuencia cronológica que permitiera clarificar qué edificio, al menos de los conservados, tuvo el honor de contar con las primeras bóvedas con nervios góticos. Sí podríamos suponer que estos avances arquitectónicos, incorporados muy probablemente a fines del siglo XII, lo hicieron, por vez primera, bien en la iglesia perteneciente al conjunto monástico de Santa María de Moreruela, bien en el templo catedralicio. Esto es, en los dos edificios religiosos, comenzados a edificar en el siglo XII, más sobresalientes de la provincia de Zamora.

La historiografía no es clara respecto a las cronologías. Tradicionalmente se ha venido admitiendo que fueron las bóvedas utilizadas en Moreruela las que sirvieron de modelo a las levantadas en la catedral. Es más, para algunos autores como Gómez-Moreno “Moreruela ocupa un lugar tan preeminente en el desarrollo arquitectónico del siglo XII, que bien puede juzgarse irresoluble el problema de lo ogival en León y Castilla sin su conocimiento, rivalizando bajo este concepto con las catedrales de la Calzada y de Ávila que, a su vez y en cierto grado, parecen hijas de nuestro monasterio" ${ }^{41}$. El citado autor a partir de lectura errónea de un documento daba por finalizadas las obras de la iglesia de Moreruela en fecha muy temprana. Bango Torviso, por su parte, retrasa respecto a lo dicho por Gómez-Moreno la primera fase constructiva del edificio y considera la girola, cubierta por bóvedas de crucería, obra en gran parte de las últimas décadas y concluida ya en pleno siglo XIII ${ }^{42}$. En función de esta cronología Bango Torviso apunta cómo la influencia se debió producir a la inversa de lo propuesto por Gómez-Moreno, esto es, las bóvedas de crucería de la catedral de Zamora fueron las que sirvieron de modelo para los nervios utilizados en Moreruela. En esta última línea se manifiesta también Rivera de las Heras ${ }^{43}$.

41 GÓMEZ-MORENO, M., op. cit., I, 1927 (1980), p. 194.

42 BANGO TORVISO, Isidro Gonzalo, "Arte medieval en Zamora. Monasterio de Santa María de Moreruela”, Stvdia Zamorensia (Anejos 1), Universidad de Salamanca, Zamora, 1989, pp. 83-84 y nota 99. 
Aunque como se ha señalado carecemos de cronologías exactas para estas bóvedas mencionadas que permitan inclinarnos por una u otra teoría lo cierto es que contamos con algunos datos que pueden permitirnos realizar alguna valoración.

Los orígenes del monasterio de Santa María de Moreruela son confusos. Desconocemos la fecha exacta de fundación y también el año concreto en que fue incorporado a la Orden del Císter aunque todo indica que esto último sucedió a mediados del siglo XII. Para los comienzos de la construcción algunos estudiosos habían propuesto una cronología ca. 1158 y $1162^{44}$. La aparición en 1994 en el exterior del edificio de la fecha de 1162, concretamente en la parte inferior de uno de los absidiolos, vendría a confirmar, como se había planteado con anterioridad, que fue en torno a ese año cuando comenzaron las obras del edificio. Es muy probable que, en función del carácter relativamente unitario que presenta la cabecera a pesar de los matices que algunos autores han puesto de relieve, los trabajos de construcción fueran rápidos, como por otra parte fue práctica común en estos edificios monásticos. Quiere decir esto que las bóvedas de crucería conservadas en Moreruela y que se localizan en la girola, la parte más antigua que se edificó, deben ser, por lo tanto, muy tempranas (Fig. 45). Se trata de bóvedas de crucería muy sencillas, con perfiles muy gruesos y carentes de formeros. En el cruzamiento de los nervios se ha subrayado la clave, que se encuentra ornamentada de manera sencilla. Las nervaduras están compuestas de un grueso bocel central, flanqueado por escotas que a su vez tienen en sus extremos un bocel, en este caso de menores dimensiones. Estos nervios arrancan de los ángulos que forman los fajones y los muros que componen cada tramo de girola como se hacía en los orígenes del gótico francés en edificios tan significativos como Saint Denis, donde no se colocaba ex profeso ningún elemento para recibirlos. A continuación se erigió el presbiterio con una plementería ligeramente cóncava y reforzado en su interior con nervaduras compuestas de tres gruesos boceles. Para Bango Torviso esta

44 HERNANDO GARRIDO, José Luis, "Granja de Moreruela. Monasterio de Santa María de Moreruela” en RODRÍGUEZ MONTAÑÉS, J. M., (coord.) Enciclopedia del Románico en Castilla y León. Zamora, Centro de Estudios del Románico, Aguilar de Campoo, 2002, p. 319. 
solución entronca más con las bóvedas de horno con nervios del tardorrománico que con soluciones propiamente góticas.

Probablemente ya en el siglo XIII se edificó el resto del templo donde se volvió a emplear la bóveda de crucería tanto para cubrir el tramo central del crucero (bóveda octopartita) como para cubrir sus naves laterales (bóveda simple). En estos casos, los restos que todavía permanecen y que se limitan al arranque de las nervaduras permiten constatar que se componían de tres boceles, al igual que las vistas en la cubierta del presbiterio. Aproximadamente en este mismo momento se edificó la sala capitular que estaba compuesta de tres naves divididas cada una de ellas en tres tramos cubiertos con bóvedas de crucería simple sin formeros. Las nervaduras de estas bóvedas, de las que solamente se han conservado tres, están compuestas de bocel central seguido de escotas con boceles nuevamente en sus extremos.

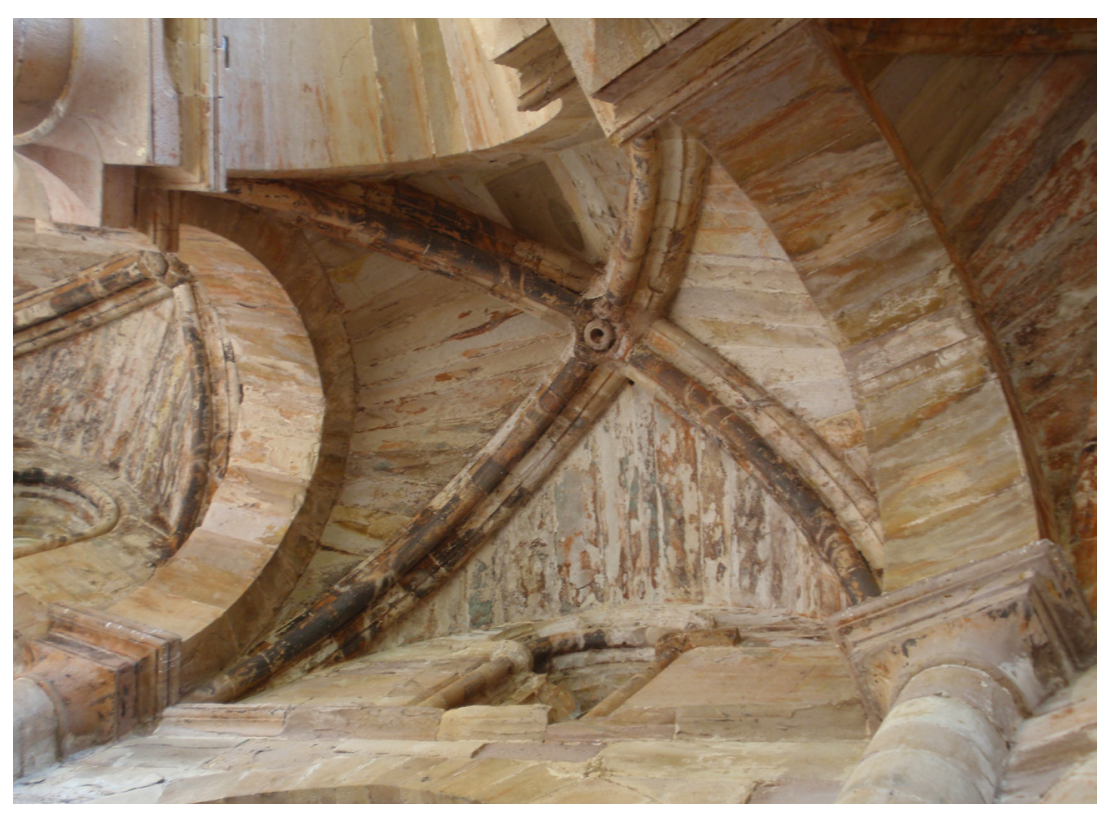

La secuencia constructiva de la catedral de Zamora también plantea muchos interrogantes. La edificación tuvo sus inicios en el año $1151^{45}$. Las reducidas dimensiones, la planimetría que muestra así como sus alzados, hablan de un edificio plenamente románico que se debió levantar en lo fundamental en un corto periodo de tiempo. Sabemos que fue consagrada en el año

45 Una lápida del siglo XVII situada en el brazo norte del transepto y que copia dos inscripciones del siglo XII aporta datos de importancia capital, entre ellos, el periodo de ejecución de las obras del templo señalando que tuvo lugar entre los años 1151 y 1174. 


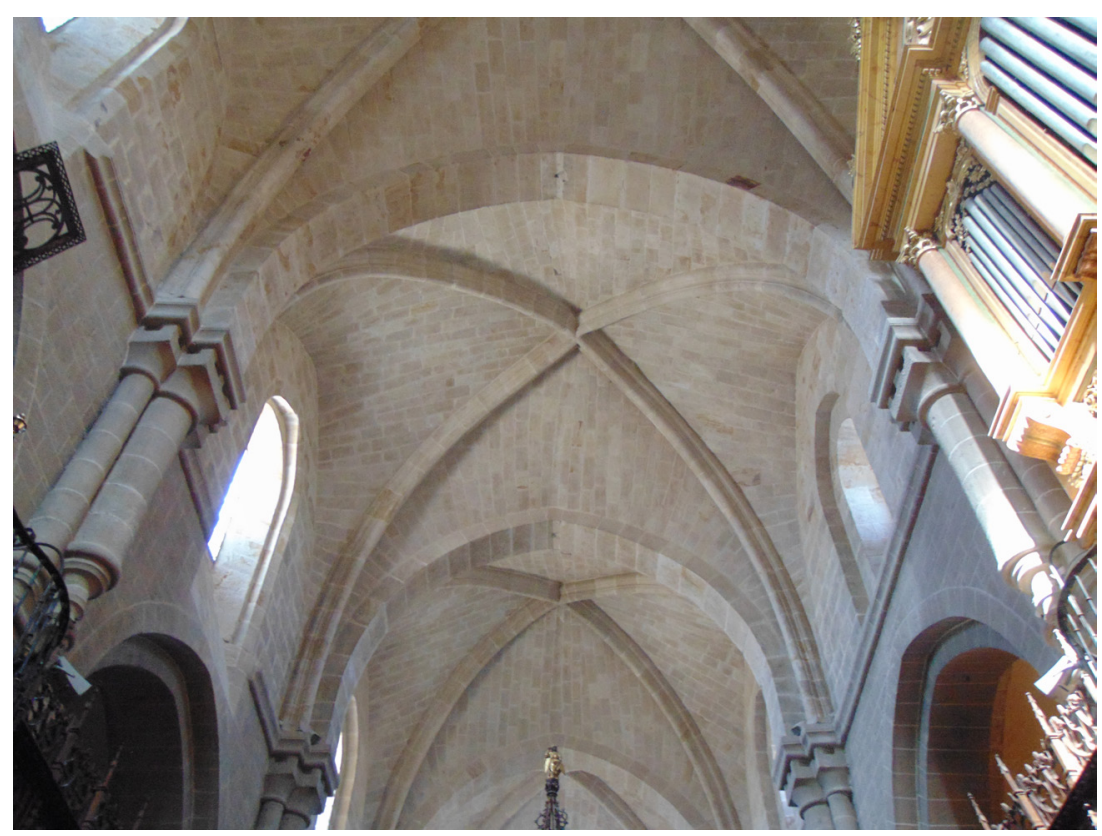

Fig. 46. Bóvedas de la nave central. Catedral de

1174 y, aunque algunos autores tomaron este año para dar por concluido todo el edificio, lo cierto es que, probablemente en ese momento, tan sólo se habría finalizado la cabecera y se estaría levantando el crucero a la vez que se trabajaba en las partes inferiores del resto del templo. Ello permitiría ya el uso del edificio. Significa todo ello que cuando se procedió a cubrir la nave central en ningún modo debió ser antes de $1200^{46}$. De esta manera se explica el cambio de cubierta que se produjo. $Y$ es que el planteamiento inicial parece que fue, como apuntó Gómez- Moreno, la utilización para la nave central de la bóveda de cañón apuntado: "Todo merece elogios en el elegimiento de estas bóvedas, aunque no previstas, de seguro, al organizar sus apoyos: bastó con hacer simples los arcos perpiaños, y, en vez de su dobladura, erigir a uno y otro lado, en diagonal, los arcos cruceros u ojivas, y sobre ellos bóvedas de aristas, muy capialzadas y de hiladas rampantes algo curvas, permitiendo abrir ventanas con absoluto desahogo en sus costados" ${ }^{47}$. No obstante, el paso del tiempo y las novedades que fueron surgiendo aconsejaron la modificación del proyecto. Para ello, se aprovecharon los soportes donde iban a descansar los doblamientos de los arcos fajones para que apoyaran los nervios

46 Lambert, que afirma la imposibilidad de fijar actualmente una fecha concreta para las bóvedas de la nave central de la catedral de Zamora, sí considera, sin embargo, que son relativamente recientes y no de la época del resto de la edificación como había señalado Gómez-Moreno. LAMBERT, Elie, El arte gótico en España en los siglos XII y XIII, Madrid, 1990, pp. 67 y 70.

47 GÓMEZ-MORENO, M., op. cit., I 1927 (1980), p. 104. 
cruceros. Fue así como los cuatro tramos de la nave central de la catedral de Zamora quedaron cubiertos por bóvedas de crucería (Fig. 46). Estas bóvedas están significativamente capialzadas, de tal forma, que sus claves se encuentran a mayor altura que las claves de los perpiaños que separan los tramos de la nave ${ }^{48}$. Las pequeñas columnas que flanquean la gran columna central de la que parte el arco fajón y que, ya Gómez-Moreno señaló que habrían servido de soporte para la dobladura del arco, son el punto de arranque de los cruceros de las bóvedas de la nave. Cada tramo abovedado está formado por dos nervios cruceros que se integran sin que la presencia de la clave esté subrayada por una forma definida. Estos nervios están formados por un bocel central, conectado mediante acanaladuras con dos boceles laterales, de menor desarrollo. La plementería está compuesta por sillares de diferente tamaño colocados en hiladas perpendiculares de norte a sur y de este a oeste, que muestran, junto a los arcos cruceros, un acabado de impecable factura. El tipo de nervio visto en las bóvedas de la nave central de la catedral de Zamora es muy común en gran parte de la estructura abovedada de la catedral de Burgos, aunque en este último caso se trate ya de un sistema gótico plenamente elaborado y que responde a una influencia directa de la arquitectura francesa ${ }^{49}$. De hecho, las bóvedas de la catedral de Burgos, como es común a la arquitectura del gótico clásico, están reforzadas por formeros, lo que permite abrir, a diferencia de lo que sucede en Zamora, grandes vanos.

De no mucho tiempo después a las bóvedas de la nave central de la catedral de Zamora es la bóveda que cubre el último piso de su torre, compuesto por los tres cuerpos de vanos que la rematan (Fig. 47). Los nervios de la bóveda que cubre este espacio cuadrangular de gran altura apoyan en unas pequeñas ménsulas gallonadas dispuestas al nivel del cuerpo superior de vanos. El perfil de los nervios cruceros que configuran esta bóveda se componen de un bocel con acanaladuras en sus extremos. La intersección de los nervios está ornada por una pequeña clave

48 Tratamiento muy distinto presenta el abovedamiento de la nave central de la catedral de Burgos cuyas dovelas de las bóvedas mayores se encuentran a la misma altura que los vértices de los arcos perpiaños. KARGE, H., La Catedral de Burgos y la Arquitectura del siglo XIII en Francia y España, Junta de Castilla y León, 1995, p. 91.

49 Ídem, p. 107. 
con anillo de bocel. En la plementería, compuesta por sillares de tamaño muy desigual entre sí, se observa un acabado menos delicado que el visto en las bóvedas de la nave central.

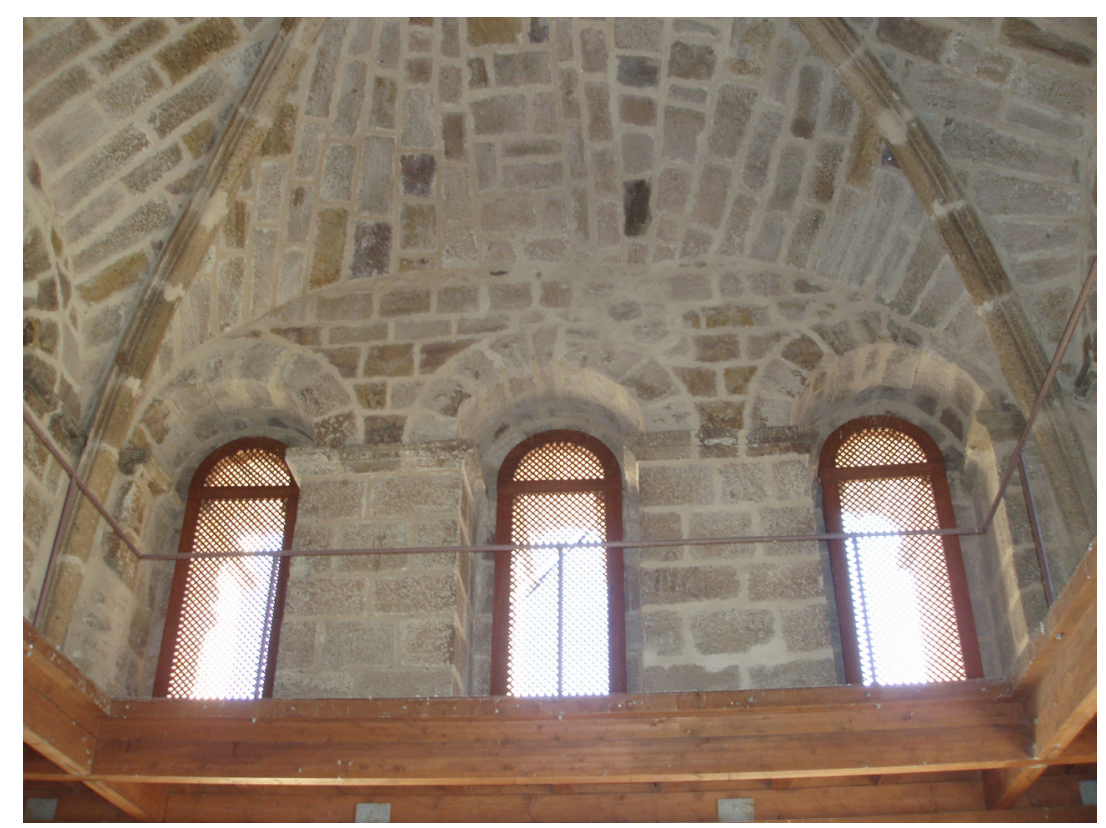

De semejantes características a la bóveda citada de la torre de la catedral es la bóveda que cubre la capilla de Santiago del mismo edificio, uno de los pocos testimonios pertenecientes al claustro primitivo y contemporáneo al mismo que no sucumbieron al incendio acaecido a finales del siglo XVI. En este caso, sin embargo, las nervaduras descansan en dos de los rincones en columnas completas sobre alto pedestal, mientras que en los dos restantes lo hacen sobre columnas cuyo fuste truncado está sostenido a cierta altura por ménsulas según una costumbre que se generalizó en la arquitectura cisterciense.

Como hemos apuntado ya, las bóvedas de la catedral de Zamora habría que situarlas en torno al año 1200. Son bóvedas que aun no han incorporado los formeros, que son los que realmente van a permitir aligerar el muro y transformar totalmente la estructura de los edificios, por lo que hay que entender que en esta fecha todavía no se han asimilado en Zamora los procedimientos constructivos del estilo gótico.

La arquitectura de cariz románico desarrollada en la catedral de Zamora tuvo su influencia inmediata en los restantes templos de la capital. Sin embargo, a la hora de considerar la introducción de nuevos elementos arquitectónicos habría que 
pensar en influencias foráneas. Así lo resalta Gómez-Moreno al analizar la cubierta de la nave de la iglesia de Santa María de la Horta, viendo en ella una posible inspiración en el gótico abulense ${ }^{50}$. Esta misma tesis la ha defendido posteriormente Rivera de las Heras ${ }^{51}$. La nave única de esta iglesia presenta tres tramos cubiertos por bóveda de crucería. Los tres tramos están separados por arcos fajones de medio punto a diferencia de los vistos en la catedral que presentan perfil agudo. Esto tiene como consecuencia un capialzamiento acusado de estas bóvedas que prácticamente aparecen convertidas en una sucesión de cúpulas.

Finalmente podemos señalar que hasta el siglo XII bien avanzado se había utilizado para cubrir las naves laterales de los templos, por norma, la bóveda de arista, al tiempo que, para la nave central, se había empleado generalmente la bóveda de cañón apuntado. Es a partir de 1200 cuando se introducen en la provincia de Zamora por vez primera estas elementales bóvedas de crucería, que no responden a un verdadero espíritu gótico, sino que más bien, siguen un modelo coetáneo que es el que introduce la arquitectura cisterciense. De hecho, estas primeras bóvedas de crucería se encuentran asociadas tanto en Zamora como en otras partes de España a edificios románicos tardíos. Así ocurrió en la catedral de Zamora, cuya nave central, con toda probabilidad, se proyectó con un tipo distinto de cubrición al que se utilizó finalmente. Esto se explica en base a que cuando se aborda la construcción de las bóvedas de la catedral se estaba en una fecha avanzada correspondiente ya a la última fase del románico, momento éste en que la arquitectura cisterciense tuvo un valor decisivo. A estos cambios de gusto que se producen con el paso del tiempo habría probablemente que añadir la presencia de un nuevo taller que incorpora novedades de la época.

En la colegiata de Toro se mantuvo, sin embargo, la bóveda de cañón apuntado para la nave central y fue en las naves laterales donde se introdujo la bóveda de crucería. El modelo más sencillo, y quizá más antiguo, es el de crucería simple, formado por dos arcos casi de medio punto que se cruzan en el centro. Para

50 GÓMEZ-MORENO, M., op. cit., I, 1927 (1980), p. 162.

51 RIVERA DE LAS HERAS, José Ángel, Zamora: Iglesias de Santa María de la Horta y Santo Tomé, Col. Arte Románico en Zamora, nº 7, Ediciones Nobel, Oviedo, 2006, p. 12. 
Gómez-Moreno estas bóvedas siguen el modelo parisién ${ }^{52}$. Se trata de un tipo de cubierta generalizado a principios del siglo XIII y que en la colegiata toresana fue utilizado para cerrar el primer tramo de las naves de la Epístola y del Evangelio. Corresponden a la segunda fase constructiva del templo y están formadas por dos nervios cruceros compuestos por bocel central flanqueado de escotaduras. Carecen de formero en la pared perimetral de tal forma que el peso de la bóveda recae sobre el muro. La plementería, un tanto descuidada, se encuentra dispuesta perpendicular a la clave según un sistema constructivo ya gótico. La crucería del primer tramo de la Epístola está formada por dos arcos que se cruzan sin clave destacada, mientras que en el cruzamiento de los arcos de la bóveda correspondiente al primer tramo del Evangelio hay una clave en forma de disco circular con una cruz que se forma con el bocel central de las nervaduras. Estas bóvedas levantadas durante el primer tercio del siglo XIII tienen su modelo más inmediato en las que se levantaron para cubrir la nave central de la catedral de Zamora.

El resto de bóvedas de las naves laterales presentan una concepción totalmente diferente $\mathrm{y}$ una complejidad mayor. Se levantaron en lo que se ha propuesto como tercera fase constructiva del templo y habría que datarlas en el segundo cuarto del siglo XIII. Más que de bóvedas de crucería propiamente dichas sería conveniente hablar de pequeñas cúpulas reforzadas por nervios. Elie Lambert señala, que el origen de este tipo de bóveda cupuliforme, que cronológicamente en Toro pertenecen al segundo cuarto del siglo XIII, se encuentra en el suroeste francés donde comenzaron a ser utilizadas en la segunda mitad del siglo XII ${ }^{53}$. En España se manifestó, años antes de que lo hiciera en Toro, en el monasterio de Santa María la Real de las Huelgas en Burgos, en la catedral vieja de Salamanca y en la catedral de Ciudad Rodrigo ${ }^{54}$. Posteriormente, es probable que a través de estas catedrales llegara a Toro la influencia aquitana, aunque desconocemos de donde la tomó, de manera concreta, el taller

52 GÓMEZ-MORENO, M., op. cit., I, 1927 (1980), p. 208.

53 LAMBERT, E., op. cit., 1977, p. 32.

54 Elie Lambert localiza este tipo de cúpulas nervadas, tanto las que están formadas por nervios cruceros como enriquecidas por nervios de ligadura en el suroeste francés. Edificios con este sistema de cubrición son la Torre de Aubin de Angers y la iglesia de Saint Martin de esta misma localidad. Ídem. 
que se ocupó de su construcción en Toro. Todas ellas presentan una plementería más cuidada formada por anillos concéntricos entorno a la clave. Las nervaduras de estas cúpulas las forman los nervios cruceros más otros dos de ligaduras que conectan la clave de los arcos. El diseño de todos los nervios es el mismo que el presentado por las bóvedas de crucería anteriores formado por bocel central entre escotaduras. También estas bóvedas carecen de formeros en los muros periféricos salvo la situada en el tercer tramo de la Epístola. Las claves presentan, unas, motivos vegetales concéntricos, otras, algunas figuras labradas.

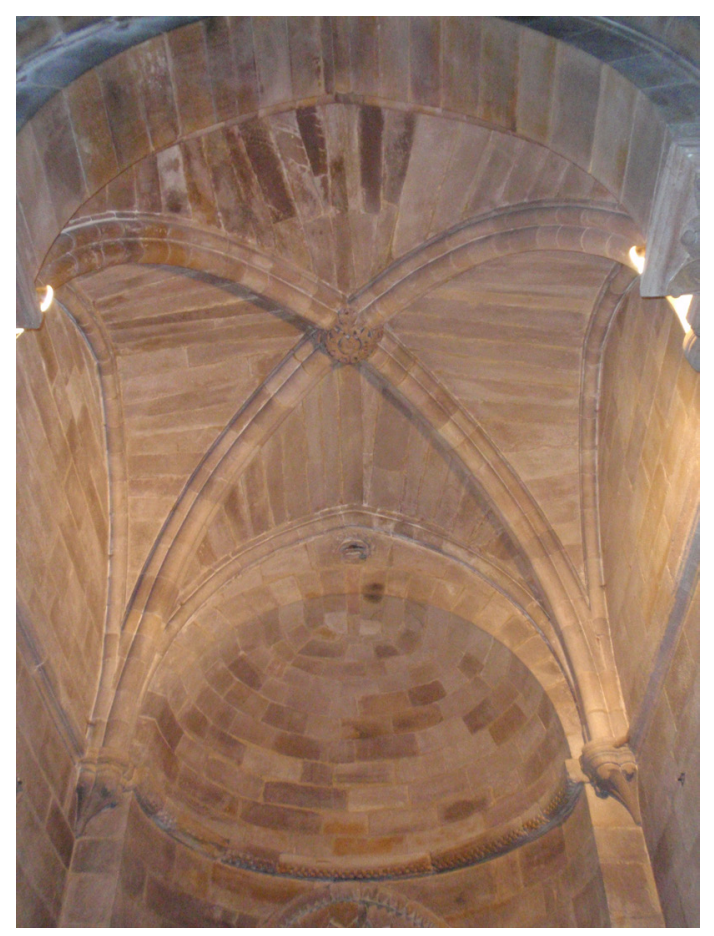

Recapitulando hay que señalar que en la ciudad de Zamora sólo se conservan bóvedas de crucería sin formeros pertenecientes a este periodo inicial del gótico en la nave central de la catedral, en la capilla de Santiago, perteneciente al claustro antiguo de la catedral, en el espacio del último cuerpo de la torre, también en el edificio catedralicio, y en la nave de la iglesia de Santa María de la Horta. En la provincia encontramos bóvedas de crucería carentes de nervios formeros en el monasterio de Santa María de Moreruela, en el monasterio de San Martín de Castañeda y en la colegiata de Toro. Es muy difícil dar una cronología precisa para este tipo de bóvedas. Atendiendo a los escasos datos documentales que se han conservado y al estudio estilístico que presentan estas estructuras, podría afirmarse que las bóvedas de 
la girola del monasterio de Santa María de Moreruela responden cronológicamente al último cuarto del siglo XII mientras que las pertenecientes a la nave central de la catedral de Zamora habría que situarlas en el entorno de 1200. Las bóvedas de la colegiata de Toro como acaba de especificarse responden ya a las primeras décadas del siglo XIII.

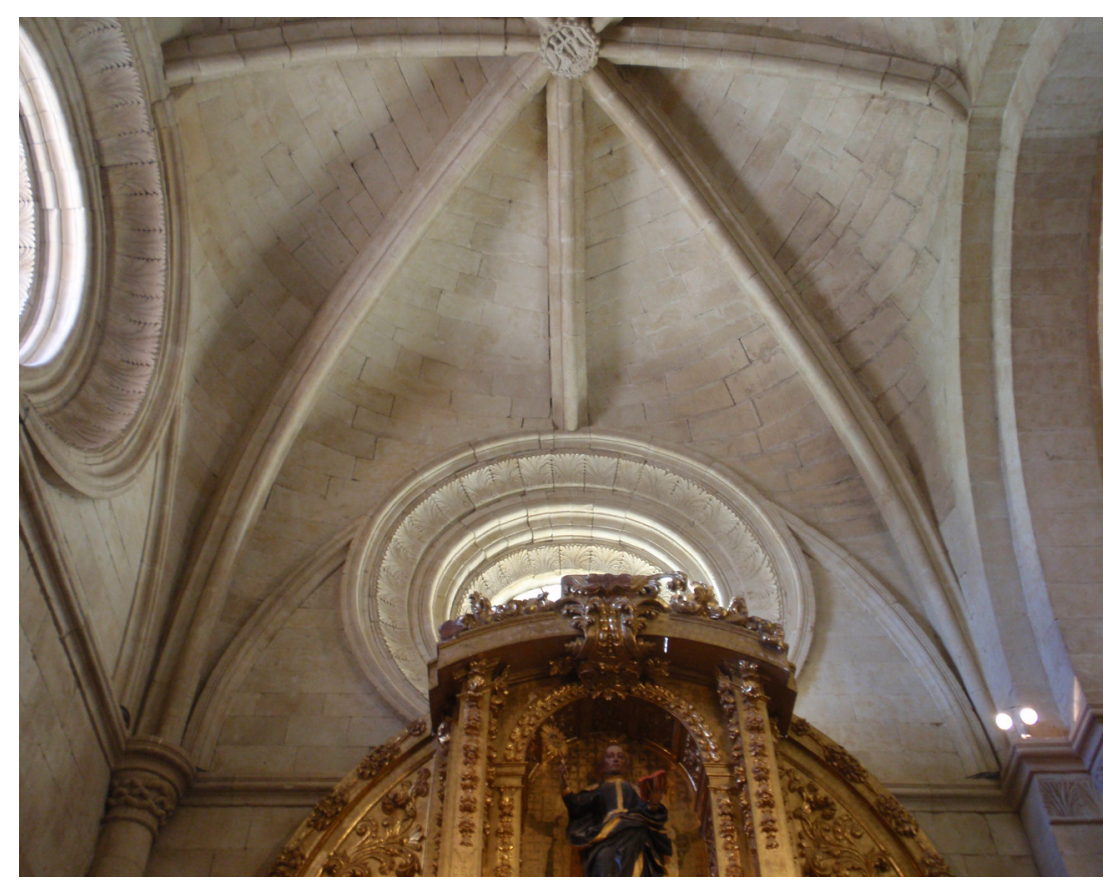

Fig. 49. Bóveda del tramo de los pies de la nave correspondiente al lateral de la Epístola. Colegiata de Toro

Ligeramente posteriores y con la presencia ya del uso de formeros tenemos que señalar aquí las bóvedas que cubren las capillas laterales de las iglesias benaventanas de San Juan del Mercado y Santa María del Azogue (Figs. 48). En ambos casos se emplearon nervaduras compuestas por tres boceles, el central un poco más grueso, siguiendo el modelo que se había utilizado en Moreruela para cubrir tanto la bóveda del tramo central del crucero como las correspondientes a las naves laterales del templo. Los formeros en este caso de Benavente, sin embargo, $y$ al contrario de lo que sucede en las edificaciones tempranas donde aparecen -Moreruela, colegiata de Toro- que suelen presentar perfil cuadrangular, están configurados mediante un grueso bocel. No obstante, hay también una excepción, concretamente en la bóveda que cubre el primer tramo hacia los pies del lateral de la Epístola de la colegiata de Toro, en la que algunos de los nervios formeros están compuestos por un bocel central con molduraciones en los laterales (Fig. 49). 


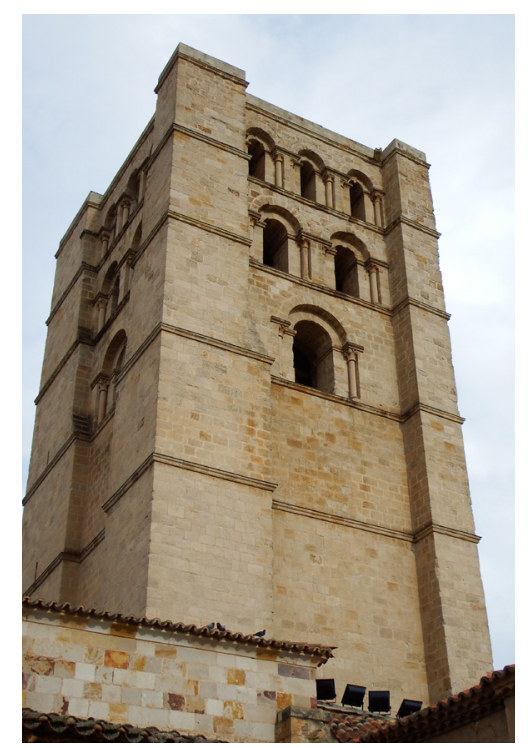

Fig. 50. Torre de la catedral de Zamora

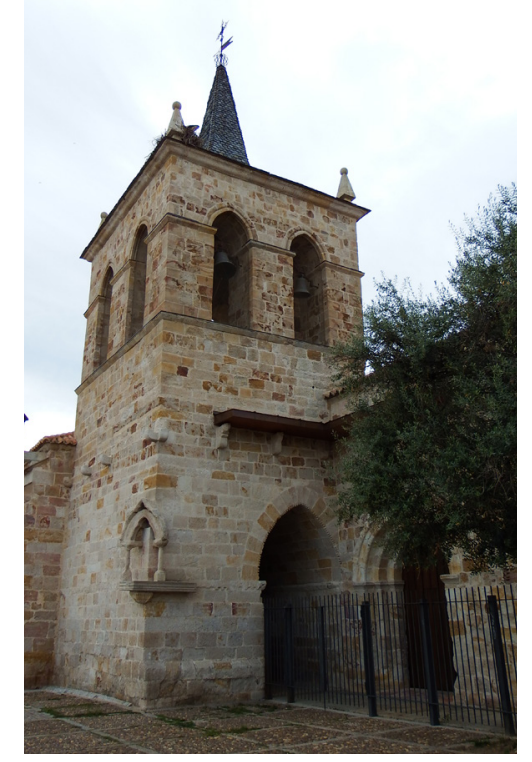

Fig. 51. Torre de la iglesia de San Cipriano. Zamora

\section{Las transformaciones de las torres}

Otra de las partes arquitectónicas en las que se manifiesta la paulatina introducción de elementos referenciales góticos en la arquitectura de la ciudad de Zamora y su provincia es en las torres de las iglesias de estilo románico y tardorrománico. En la ciudad de Zamora es el lugar donde se concentran el mayor número de ellas, de tal forma que del periodo aludido se han conservado once torres de las cuales son plenamente románicas las pertenecientes a las iglesias de la Magdalena, San Ildefonso, Santiago del Burgo, San Andrés y el Santo Sepulcro. Se trata de torres prismáticas, macizas en prácticamente todo su desarrollo y coronadas por un cuerpo de vanos - todos ellos en arco de medio punto- donde se colocan las campanas. Su solidez y la escasez de aperturas les confieren un aspecto defensivo que, en muchos casos, realmente tuvieron al comportarse como un elemento defensivo más del recinto amurallado de la ciudad. Esto fue debido fundamentalmente a la importante situación estratégica de la ciudad que hizo que sus torres se plantearan no sólo como un mero soporte para el cuerpo de campanas o un elemento simbólico del poder ejercido por la Iglesia, sino también como un apoyo relevante dentro de los elementos defensivos con que contaba la ciudad. Con este carácter de fortaleza se edificaron junto a la muralla las torres de la catedral y de las iglesias de San Juan de Puerta Nueva, San Andrés y San Cipriano. Con el avance de la reconquista el carácter defensivo que tuvieron algunas de ellas perdió su razón de ser de forma que las torres que se levantaron a continuación se aligeraron con la sucesiva apertura de vanos en la parte superior. Es en estos cuerpos superiores donde se advierte la sustitución de los huecos en arco de medio punto por un apuntamiento manifestado todavía de manera muy tímida como sucede en las ya mencionadas de la catedral y de la iglesia de San Cipriano y en las de Santa María la Nueva, San Vicente, Santa María de la Horta y San Leonardo en las que se observa una clara tendencia a la incorporación de elementos nuevos (Figs. 50, 51, 52 y 53). Lo mismo sucede en algunas de las torres conservadas en la provincia, que deudoras fundamentalmente de la estética románica, poseen ciertos elementos que parecen responder a un avance en las formas arquitectónicas. Esto es visible en la parte más antigua de la torre de la Colegiata de Toro y de la torre de la 
iglesia parroquial de Corrales del Vino que en ambas lógicamente se corresponde con el cuerpo inferior compuesto de un espacio rectangular para el que se utilizó la bóveda de cañón apuntada. Por último, dentro del marco provincial, y también deudoras de la estética románica, son la torre de la iglesia de Santa María del Río de Castroverde de Campos y la torre de la iglesia de la Asunción de Nuestra Señora de Mombuey, aunque en ambos casos se perciba más claramente, y quizás por el momento de su construcción ya en las primeras décadas del siglo XIII, una tendencia a utilizar formas que, aunque todavía románicas, se encuentran en conexión con los nuevos sistemas constructivos (Fig. 54). En Mombuey, concretamente, el remate de la torre a modo de chapitel está cubierto en el interior por una bóveda de nervios radiales, de sección cuadrangular, que se cruzan en el centro.

En otro orden de cosas es preciso hacer referencia a la torre de la iglesia de Santa María la Mayor o del Azogue en Benavente, que aunque había sido comenzada a principios del siglo XIII, la mayor parte de ella fue edificada a finales de ese mismo siglo, siendo, por tanto, la única de la provincia levantada durante el periodo correspondiente al gótico pleno (Fig. 55). En ella, los vanos se abren en arco apuntado pero la carencia de molduras decorativas de éstos, así como la propia estructura maciza de la torre y el remate de canecillos que sostiene la cornisa delatan su concepción todavía románica. Esta es la razón de que, a pesar de lo tardío de la fecha de su construcción, pueda ser incluida en este apartado inicial como ejemplo del gran conservadurismo de las formas en la provincia, puesto que en ella los síntomas del cambio de estilo no aparecen hasta fecha muy tardía.

Todas estas torres se levantaron adosadas a sus correspondientes edificios e, incluso, más comúnmente, formando parte unitaria con ellos y siempre con planta cuadrangular o rectangular. Su situación es variada aunque la mayor parte de ellas se elevan a los pies del templo; en unos casos, en el ángulo noroccidental (Catedral e iglesias de San Vicente y de San Leonardo en Zamora y Colegiata de Toro e iglesia de Santa María Magdalena en Corrales del Vino), en otros, en el ángulo suroccidental (iglesia de Santa María la Nueva (Zamora)) y, por

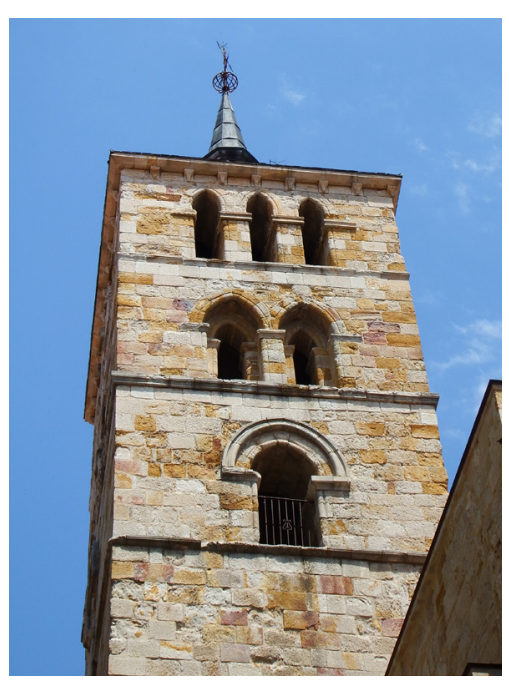
Fig. 52. Torre de la iglesia de San Vicente. Zamora

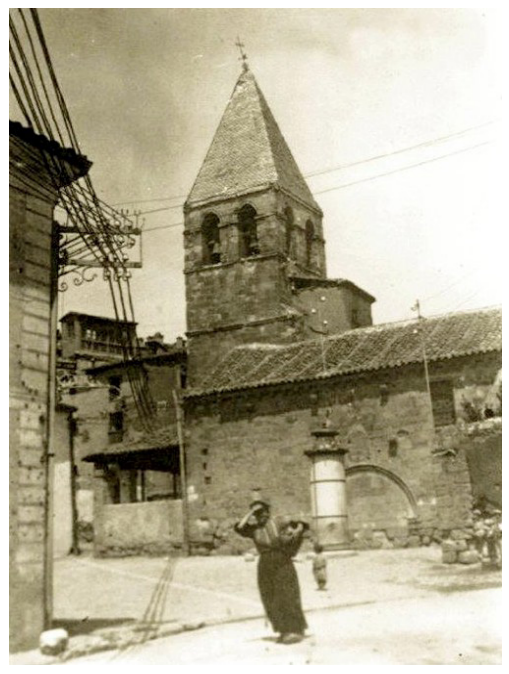

Fig. 53. Foto antigua donde se observa completa la torre de San Leonardo. Zamora 


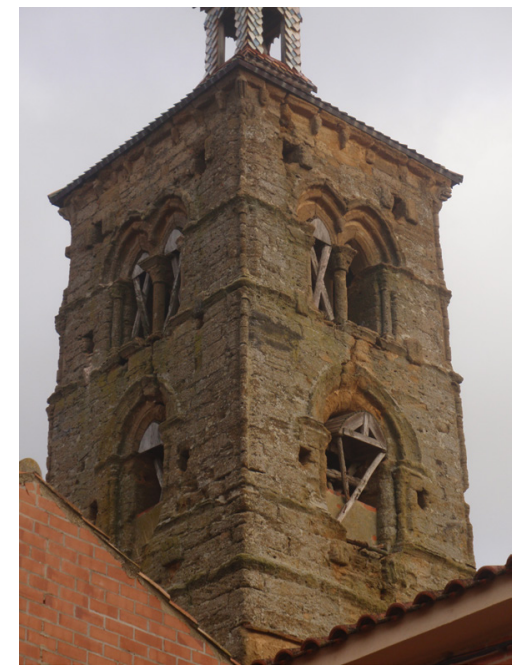

Fig. 54. Torre de la iglesia de Santa María del Río. Castroverde de Campos.

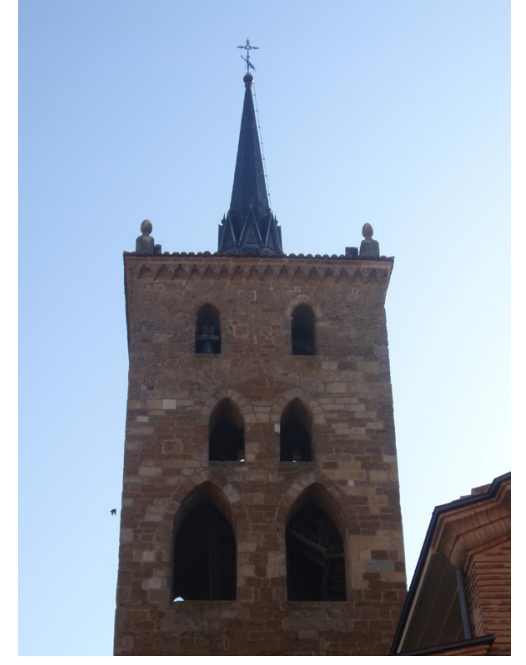

Fig. 55. Torre de la iglesia de Santa María del Azogue. Benavente último, también en el tramo medio del hastial (iglesia de Santa María del Río en Castroverde de Campos e iglesia de Nuestra Señora de la Asunción en Mombuey). Adosada al sur del tramo central de la nave se sitúa la torre de San Cipriano, a los pies del templo, sobre el pórtico de acceso, la torre de Santa María de la Horta y sobre el extremo del brazo norte del transepto está la torre de la iglesia de Santa María la Mayor de Benavente.

El problema del estudio de estas torres es complicado ya que han sufrido diversas intervenciones que han alterado de manera importante su composición original de tal forma que, aunque su estado de conservación sea bueno, éstas se encuentran en algunos casos mochadas y reformadas en época reciente lo que hace sumamente difícil una labor de recomposición.

El grupo de torres que se ha conservado en Zamora y provincia de los siglos XII-XIII no es homogéneo en el sentido estilístico, ni siquiera compositivo. Se ha señalado ya cómo algunas de ellas son plenamente románicas. Sin embargo, nos acabamos de referir a otras que, aunque muestran una clara dependencia con la arquitectura románica, aportan novedades en su estructura. Lo avanzado de la construcción de estas últimas - su conclusión tuvo lugar ya durante el siglo XIII-, es lo que hace que, a este modo arquitectónico románico que imperó en la ciudad largo tiempo, se le vayan introduciendo, aunque sea de manera débil, elementos nuevos como arcos apuntados y bóvedas de crucería en los cuerpos superiores. Es por ello que, aunque estas torres se pueden catalogar en su conjunto como obras románicas, muestran elementos más avanzados que habría que relacionar con el nuevo estilo.

El estudio de ellas tiene el propósito de delimitar el grupo que se encuadra dentro de nuestro interés histórico-artístico y que sobre todo es de suma importancia para el conocimiento de la arquitectura zamorana del siglo XIII. No obstante, nuestro objeto no es tanto estudiar la morfología de la torre, que responde todavía a unos patrones elaborados en la época románica sino aislar en ellas aquellos elementos que pertenecen ya al nuevo estilo y que contribuyen, aunque sea en una medida muy escasa, a la introducción de las formas góticas. En estas torres, que toman como modelo la catedral de Zamora, se puede observar cómo 
progresivamente se van sustituyendo los arcos prácticamente de medio punto que presenta aquella por arcos ya con un cierto apuntamiento que avanzan el cambio que va a producirse en la arquitectura.

Evolución formal en las torres de las iglesias zamoranas

Es sabido que las obras de construcción en las iglesias y catedrales medievales generalmente comienza desde el ábside (zona este) hacia los pies, con el objeto de que el templo pueda servir al culto lo antes posible, aunque tuvieran que pasar muchos años para la finalización completa del edificio. Por tanto, la zona occidental, donde se alzan la mayor parte de las torres en los periodos románico y gótico, era la última en edificarse. Precisamente esta razón aplicada a edificios que comenzaron a construirse cuando el siglo XII estaba ya muy avanzado y el arte románico, por tanto, en su última fase, propició que fuera precisamente en las torres donde se localizaran algunos elementos que anuncian el cambio del estilo, como es el apuntamiento de los arcos o las bóvedas de crucería. Estos elementos estructurales están generalmente situados en la parte superior de las torres, edificada en muchos casos ya en pleno siglo XIII.

Para el estudio de las transformaciones estilísticas que se aprecian en las torres zamoranas se puede tomar como punto de partida y de referencia la torre de la catedral. Esta monumental obra por su importancia recibió un gran número de influencias estilísticas y debido a la fecha tardía de su construcción fue afectada tanto por el espíritu desornamentado de la arquitectura cisterciense, como por el de los primeros momentos del gótico francés. Al ser la catedral de Zamora el gran edificio de la arquitectura religiosa de la ciudad, también fue un modelo a seguir para la arquitectura coetánea. De este modo, puede observarse cómo su torre ejerció una influencia directa dentro del programa constructivo tanto de la ciudad como de la provincia. En la torre en la que dejó una mayor huella fue en la correspondiente a la iglesia de San Vicente, coronada también por tres cuerpos de vanos, aunque en este caso de diseño apuntado que dotan a esta torre de una mayor esbeltez que la que posee su predecesora. 
Podemos concluir afirmando que la edificación de estas torres prácticamente durante los mismos años no permite establecer una secuencia clara en cuanto a la evolución de sus formas. Sí es cierto, sin embargo, que en algunas de ellas hay signos más evidentes de la utilización de estructuras más avanzadas que las dotan de una mayor galanura propiciada fundamentalmente por su menor tamaño en planta y por una acusada desmaterialización de sus muros a través de un importante número de vanos en arco apuntado. A ello se suma la utilización de la bóveda de crucería como sucede en la torre de la catedral de Zamora. Sin embargo en la torre de la iglesia parroquial de Mombuey, a pesar de que su construcción es más tardía, se ha utilizado una bóveda de nervios, cuya estructura está todavía muy ligada al románico tardío. 


\section{La arquitectura civil en los inicios del gótico}

Durante el siglo XII y las primeras décadas del siglo XIII algunos núcleos urbanos de la provincia de Zamora adquirieron gran importancia en función del momento histórico que se vivía y a la situación estratégica que estos tenían, de tal forma, que alcanzaron gran vitalidad y fue necesaria la edificación de numerosos edificios que atendieran las necesidades de la población. Como ya se ha visto se construyeron un gran número de iglesias, pero también fue muy significativa la edificación de todo un sistema defensivo que en tiempos tan convulsos era necesario para asegurar tanto las poblaciones como las fronteras que se iban estableciendo ${ }^{55}$. Así sucedió fundamentalmente en Zamora y Toro donde se han conservado parte de aquellas defensas y de otras construcciones del ámbito civil levantadas en este periodo.

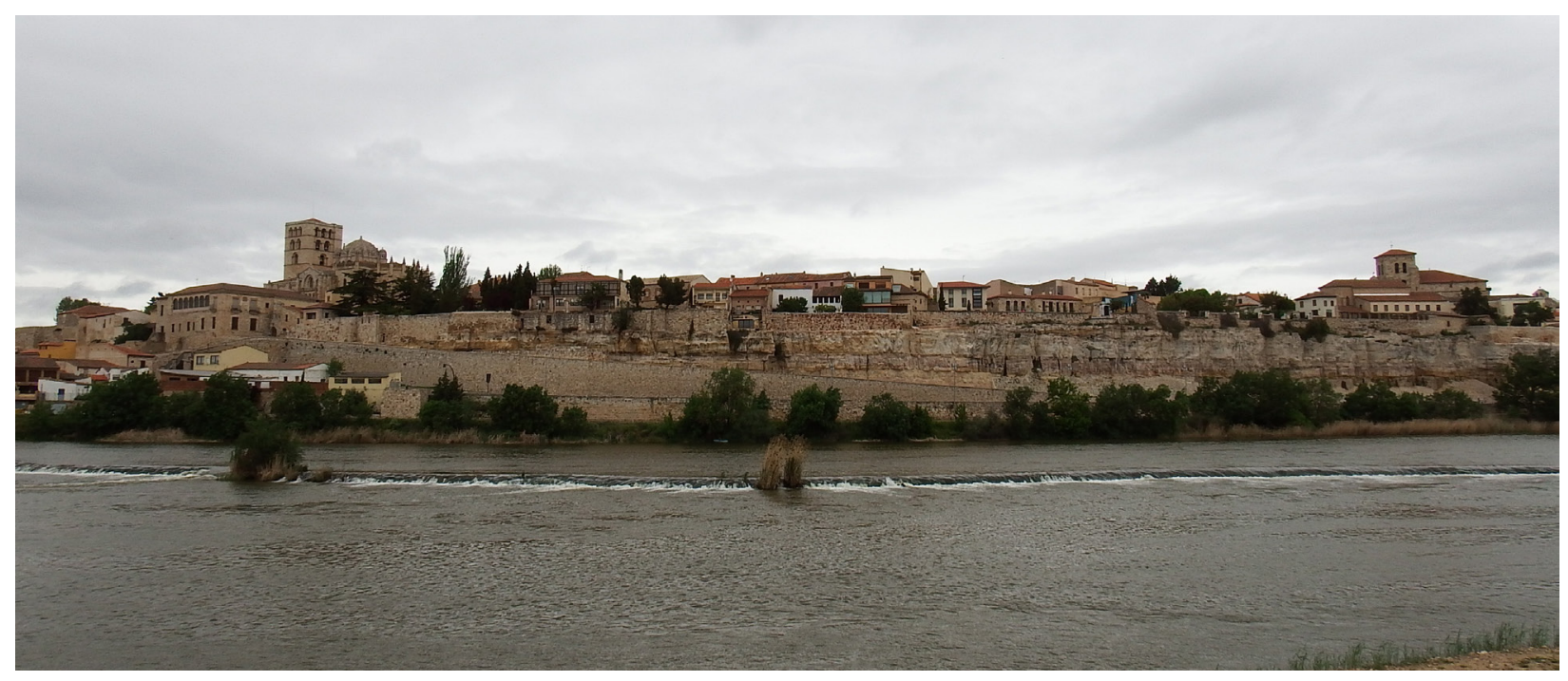

Por lo que respecta a la ciudad de Zamora, desde época romana había adquirido una relevancia notable por su situación geográfica, no en vano estaba ubicada en plena Vía de la Plata, una de las más importantes arterias de comunicación peninsulares que unía Asturica Augusta (Astorga) con Emerita Augusta (Mérida). Posteriormente, durante los tiempos de la Reconquista, Zamora se convirtió en un enclave de máxima importancia estratégica en la defensa del territorio conquistado 
hasta la línea del Duero, junto a otras ciudades como Toro y Simancas. Todo ello, junto a la cercanía con Portugal, hizo que los monarcas mostraran una decidida atención a la hora de convertir la ciudad en una plaza fuerte (Fig. 56).

No se conoce con certeza el momento en que se establecieron las bases de la fortificación de Zamora. Según algunos estudiosos, tuvo lugar a partir de la repoblación del siglo IX, aunque después de los ataques de Almanzor y con la concesión del fuero por Fernando I se planteó de nuevo el levantamiento de las defensas. Para ello, en torno al núcleo primigenio de la urbe y en las inmediaciones de la primitiva catedral del siglo X, se construyó el castillo y se levantó la primera cerca de murallas con que contó la ciudad. Paralelamente y desaparecido el puente romano, se edificaron nuevos puentes para salvar el río y conectar la ciudad con los barrios y tierras que se extendían hacia el sur. No obstante, lo conservado en la actualidad remite a época posterior.

Hasta el siglo XIX los elementos que componían la fortificación de Zamora se encontraban en muy buen estado de conservación como lo constatan, por ejemplo, las vistas realizadas por Avrial en 1850 y recientemente publicadas bajo los siguientes epígrafes: Vista general de Zamora, tomada desde la cruz del Rey D. Sancho; El Castillo, la Catedral y el palacio episcopal. Vista tomada desde el cascajar de Valorio; El puente de Zamora, sobre el Duero, Una vista de la parte oriental de Zamora; Vista tomada desde la cuesta de Pizarro; El Seminario y la parroquia de S. Andrés, vista tomada desde una huerta fuera de la puerta nueva y Otra vista tomada por fuera de la puerta nueva ${ }^{56}$. En ellas se observan los recintos amurallados completos, el castillo y el puente con todos los elementos que lo caracterizaron hasta principios del siglo XX (Figs. 57 y 58 ).

Desafortunadamente las edificaciones pertenecientes a la fortificación de Zamora, es decir las murallas, el castillo y el puente, han llegado a nuestros días tremendamente transformadas por intervenciones que tuvieron lugar a lo largo de los siglos, en algunos casos muy desafortunadas, a lo que habría

56 Zamora Año de 1850. Cuaderno de vistas de Zamora tomadas del natural y ejecutadas por Don José María Avrial y Flores (Coord. Pérez Martín, Sergio y Martín Bailón, Marco Antonio), Zamora, 2013, láms. 1, 50, 51, 52, 53, 54 y 55, pp. 175-180, 268-285. 


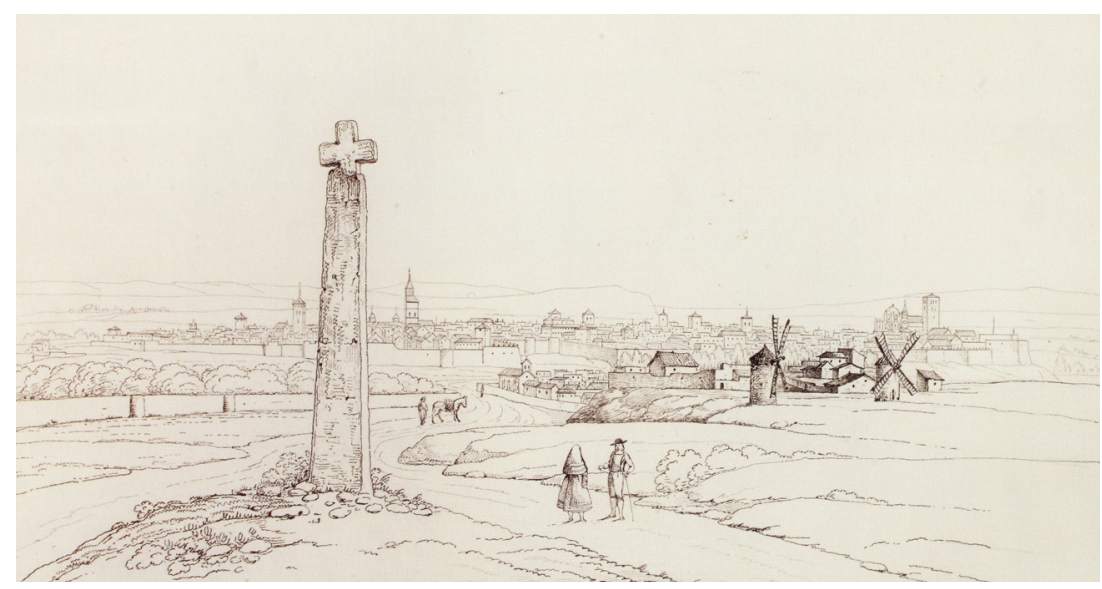

que sumar los derribos producidos durante el siglo pasado. No pretendemos en este estudio realizar un análisis pormenorizado de las edificaciones mencionadas, a las cuales ya se han dedicado cumplidos trabajos por parte de los eruditos zamoranos y demás historiadores a los cuales remitiremos a continuación, sino que se va a incidir fundamentalmente en la arquitectura levantada durante este periodo inicial del gótico dedicando una atención mayor a la aparición del arco apuntado en estos edificios.

Para el análisis de la fortificación de Zamora va a ser de indispensable ayuda el exhaustivo estudio realizado por Gutiérrez González en 1990, que revisó toda la documentación existente sobre este tema: noticias recogidas por los cronistas medievales, estudios realizados por eruditos e historiadores de los siglos XIX y XX así como la cartografía histórica generada a lo largo de los siglos y que recoge, en parte, al final de su estudio ${ }^{57}$.

La historia de Toro durante los siglos de la reconquista corrió paralela a la de la ciudad de Zamora, de tal modo que jugó un papel de enorme importancia en la defensa de la línea del Duero,

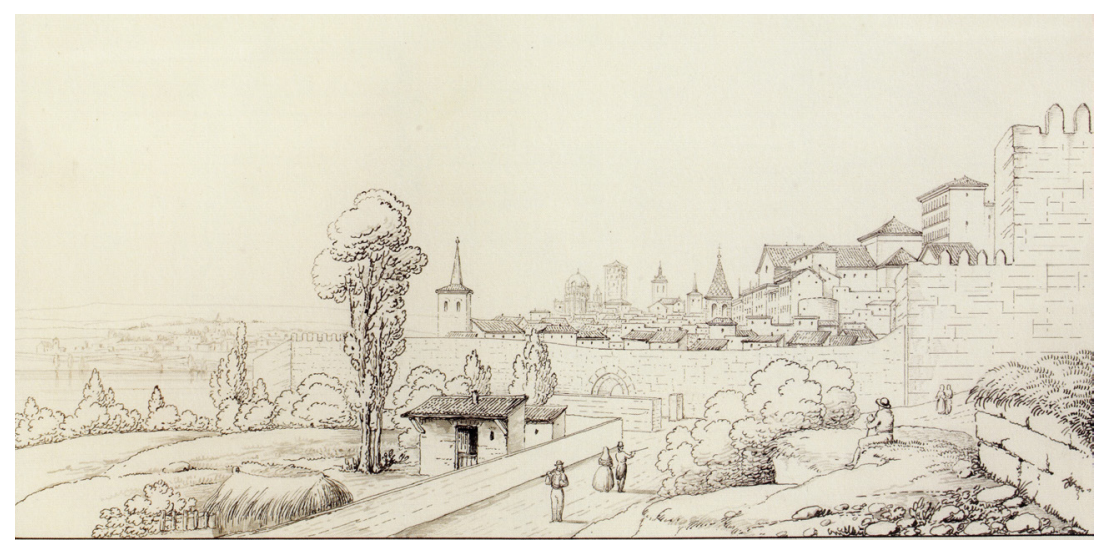

57 GUTIÉRREZ GONZÁLEZ, José Avelino, "Las fortificaciones de la ciudad de Zamora. Estudio arqueológico e histórico", Cuadernos de investigación Florián de Ocampo, nº 6, Diputación de Zamora, 1990.
Fig. 57. "Vista general de Zamora, tomada desde la cruz del Rey D. Sancho". Avrial 1850. Publicada en Pérez Martín y Martín Bailón, 2013, lám. 1
Fig. 58. "Otra vista tomada por fuera de la puerta Martín Bailón, 2013, lám. 55 


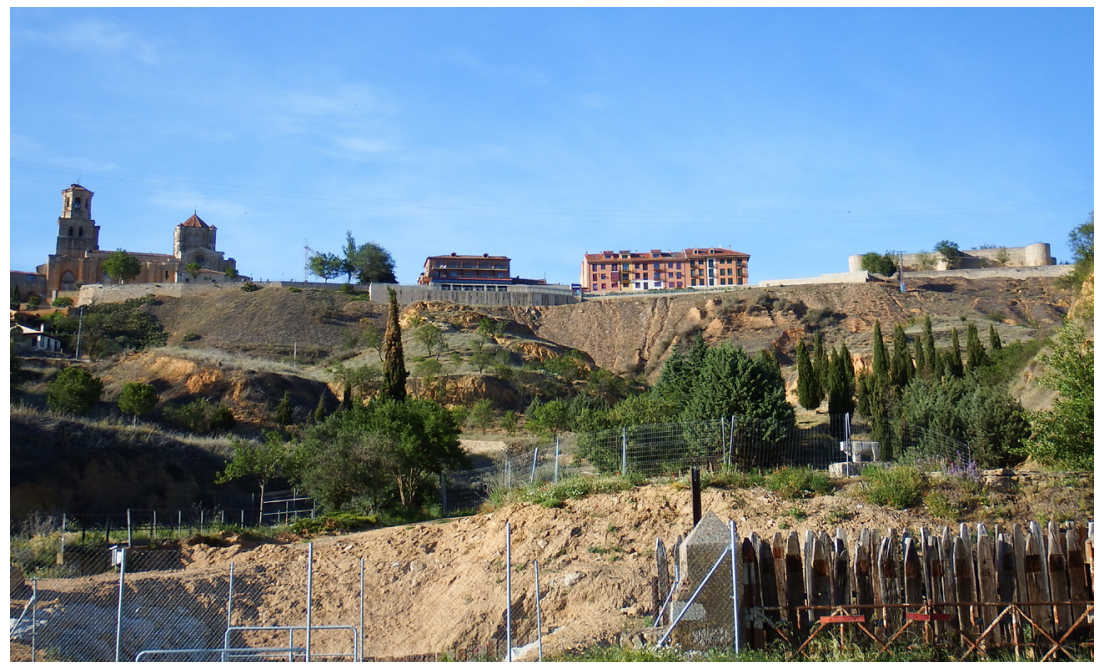

organizada por Alfonso III, repoblador de ambas ciudades ${ }^{58}$. Esta situación y función determinaron el aspecto de plaza fuerte en que se convirtió la ciudad, que muy pronto contó con alcázar y dos recintos amurallados (Fig. 59). También a finales del siglo XII y principios del siglo XIII se levantó el puente. Todas estas edificaciones pertenecen al periodo románico aunque sufrieron ampliaciones, transformaciones y reparaciones en los siglos posteriores. De ahí que el estado parcial en el que han llegado estas estructuras haga complejo un análisis en profundidad del conjunto. Solamente el puente constituye la única construcción civil de este periodo verdaderamente interesante para este estudio por haber conservado gran parte de su estructura en pie además de por lo que ésta supone de receptora de una nueva arquitectura que comienza a utilizar el arco apuntado.

Además de los puentes de Zamora y de Toro, en la provincia se conservan otros levantados durante el periodo que transcurre desde finales del románico hasta el renacimiento. En este estudio solamente se han tratado los puentes de Zamora y de Toro, por tener una gran entidad como elementos arquitectónicos en sí mismos así como por ser parte fundamental del paisaje urbano de estas ciudades. No obstante, durante el periodo señalado se debió construir el puente antiguo de Ricobayo sobre el río Esla, en la actualidad bajo las aguas del embalse del mismo nombre. De igual modo, puentes de origen romano como los de La Albañeza, sobre la Ribera de Fadoncino y el puente de Tamame, sobre el

58 El Silense señala como fecha de la repoblación de la ciudad de Toro el año de 899 mientras que Sampiro apunta la de 910 
arroyo de la Salceda ${ }^{59}$, recibieron distintas reparaciones durante este periodo.

Otras importantes ciudades de la provincia como Benavente, Castroverde de Campos, Villalpando o Fermoselle contaron igualmente con construcciones civiles, fundamentalmente de carácter defensivo y levantadas al tiempo que las citadas de Zamora y de Toro, pero de las que apenas han llegado testimonios (Fig. 60).

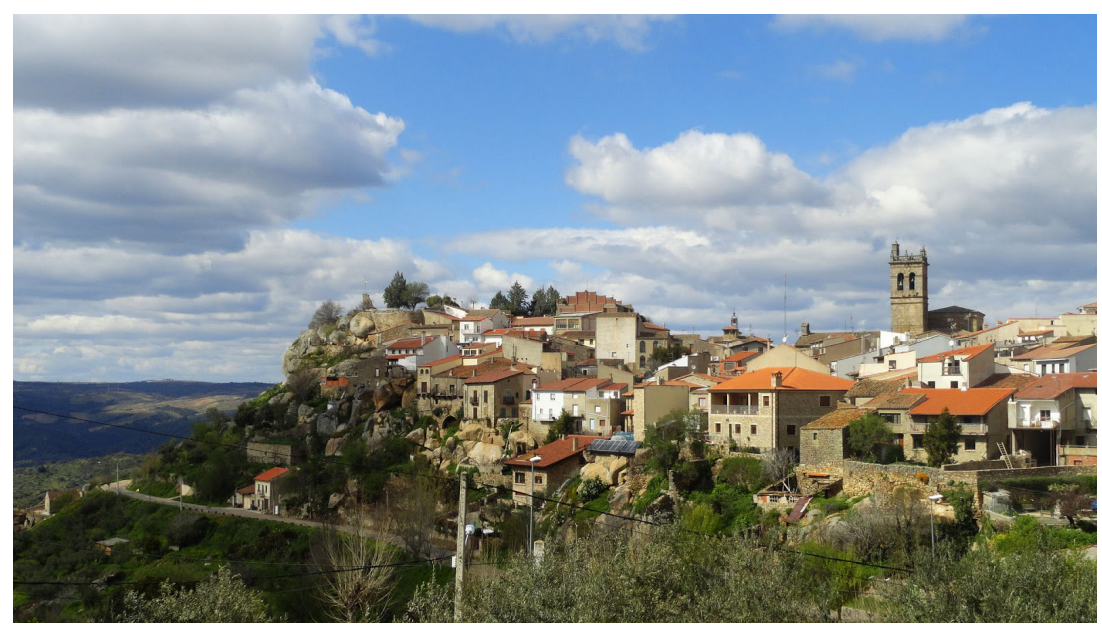

Todas estas construcciones de carácter defensivo edificadas en la provincia de Zamora durante los periodos románico y gótico confirieron a algunas ciudades como es el caso de Zamora y Toro el aspecto monumental y medieval que aún hoy las define. Un aspecto medieval, con escasez de elementos formales, difícil de encuadrar estilísticamente por encontrarse como dijo GómezMoreno "envuelto lo más de ello en esa indecisión de formas que suele resistir a toda cronología en nuestros edificios civiles de la Edad Media"60.

Al igual que ocurre en la arquitectura religiosa, la arquitectura civil de finales del siglo XII y principios del siglo XIII responde a modelos elaborados en época románica. Únicamente cabe señalar en ella la presencia de arcos apuntados en los vanos y en la generatriz de algunas bóvedas, que podríamos considerar como un signo de evolución de las formas, aspecto éste que puede ser discutible porque en este tipo de arco prevalece el

59 CHÍAS NAVARRO, P. y ABAD BALBOA, T., Los caminos y la construcción del territorio en Zamora. Catálogo de Puentes, Salamanca, 2004, pp. 76-77, 102-103 y 160-163.

60 GÓMEZ-MORENO, M., op. cit., I, 1927 (1980), p. 85. 


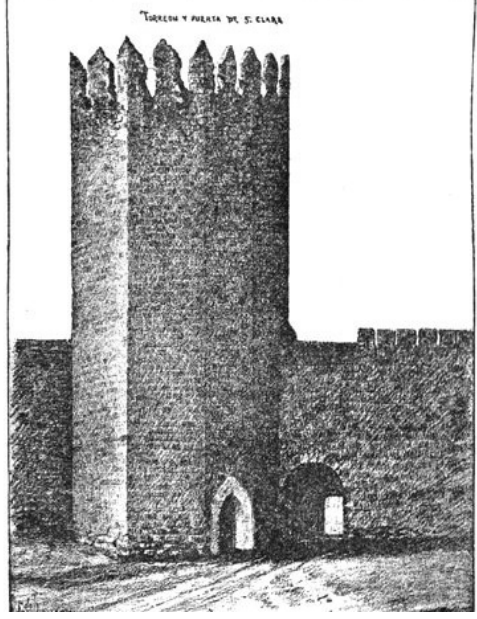

Fig. 61. Puerta desaparecida de Santa Clara.

carácter funcional sobre el estético de forma aún más acusada que en la arquitectura religiosa.

Los arcos apuntados que se pueden reconocer en la arquitectura civil de este momento son escasos y conviven con los de medio punto. Se hallan limitados a las fortificaciones de Zamora y de Toro. En las murallas de Zamora no encontramos arcos de trazado apuntado en la actualidad, aunque sí hubo en su día algún arco y bóveda con este diseño. Se tiene constancia gracias a dos dibujos publicados, uno, por la Real Academia de la Historia en su Revista (noviembre 1883, tomo III, lám. 3) y, el otro, en la portada de la revista Zamora Ilustrada (5 de junio de 1883). Ambos dibujos recogen la puerta de Santa Clara (Fig. 61), denominada primitivamente de San Miguel y que fue derruida en el año 1883 por acuerdo del Ayuntamiento con objeto de hacer más ancha la vía donde se encontraba ${ }^{61}$. Esta puerta de Santa Clara, cuya primera referencia documental es de 1164 y así llamada en época moderna por encontrarse en sus inmediaciones un convento de Franciscanas Descalzas, estaba flanqueada por un torreón poligonal con un sencillo acceso en arco apuntado de sillería en uno de sus costados ${ }^{62}$. FernándezGuerra en octubre de 1883 en un informe realizado sobre esta puerta señalaba: «Atraviesa al torreón, de lado a lado, una galería con bóveda de arco ligeramente apuntado, como el de las dos puertas en que termina (ejemplar que se repite en otra torre antigua de las de Zamora), y remata, o más bien remataba hasta ahora, en lo alto con almenas puntiagudas, sin labor o adorno de ninguna especie» ${ }^{63}$. Sin embargo, el arco apuntado sí

61 Esta puerta ha sido tratada en las siguientes publicaciones. ÁLVAREZ MARTÍNEZ, Ursicino, "Nuestro Grabado" en Zamora Ilustrada, Diputación de Zamora, tomo IV, $\mathrm{n}^{\mathrm{o}} 47,1883$, p. 375; FERNANDEZ-GUERRA, Aureliano, "Puerta y cubo de Santa Clara de Zamora (Informes)", Boletín de la Real Academia de la Historia, tomo III, noviembre de 1883, pp. 324-332; GÓMEZ-MORENO, M., op. cit., I, 1927 (1980), p. 87; GAYA NUÑO, Juan Antonio, La arquitectura española en sus monumentos desaparecidos, Madrid, 1961, p. 177; REPRESA RODRÍGUEZ, Amando, "Génesis y evolución urbana de la ciudad de Zamora medieval”, Hispania, t. XXXII, n 122, 1972, pp. 525-545; RAMOS DE CASTRO, Guadalupe, Las Murallas de Zamora, Colección Arte e Historia 1, Servicio de Publicaciones de la Delegación Provincial del Ministerio de Cultura, Zamora, 1978a, pp. 31-34; GUTIÉRREZ GONZÁLEZ, José Avelino, "Las fortificaciones de la ciudad de Zamora. Estudio arqueológico e histórico", Cuadernos de investigación Florián de Ocampo, nº 6, Diputación de Zamora, 1990, p. 28.

62 REPRESA RODRÍGUEZ, A., op. cit., 1972, pp. 544 y 545 y nota 36.

63 Cuando escribió este informe Fernández-Guerra la puerta ya había sido derruida. No obstante, para este escrito se sirvió de toda la documentación que había generado el proceso durante el cual la Comisión de monumentos históricos y artísticos de la provincia había puesto en conocimiento de las Academias de la Historia y de San 
fue abundantemente empleado en el castillo, en vanos de todo tipo y en las generatrices de las bóvedas. Asimismo se utilizaron en varios de los vanos correspondientes a los puentes de las ciudades de Zamora y Toro.

En la mayoría de los casos son arcos tímidamente apuntados, de composición muy sencilla y con todo su desarrollo desornamentado. En alguna ocasión el apuntamiento puede ser algo mayor pero de ningún modo excesivamente acusado $y$, tan sólo algunos arcos, como los pertenecientes a la puerta de acceso al castillo de Zamora y a la puerta de Santa Colomba de este mismo edificio, que en su día constituyó también un acceso principal, tienen como único elemento decorativo una moldura sencilla de relieve pronunciado que marca la línea de imposta.

Ciertamente es más complejo establecer el grado en el que la influencia gótica afecta a la introducción del arco apuntado en la arquitectura civil a causa del carácter funcional de dicho arco que puede simplemente ser consecuencia de la búsqueda de estructuras que comporten una mayor solidez. Sin embargo, es significativo que justo aparezcan estos arcos apuntados en el momento en que comienzan a generalizarse también en la arquitectura religiosa con la que coincide en las formas aunque de manera más simplificada.

\section{La fortificación de Zamora. Las murallas, el castillo y el puente}

Las murallas

Es probable que la ciudad de Zamora contara con un recinto amurallado desde época romana aunque no se haya podido constatar la existencia de elementos pertenecientes a aquel momento. La parte más antigua que se conserva, como se verá a continuación, en ningún modo es anterior al siglo XI (Fig. 62).

Fernando la intención del Ayuntamiento de derribar el torreón. A pesar del interés de la Academia de la Historia, que inmediatamente procedió a la tramitación del expediente correspondiente y solicitó se le remitiese material gráfico de esta puerta de la muralla, el Ayuntamiento, sin atender a las solicitudes de suspensión del derribo, demolió el conjunto con barrenos de pólvora. FERNANDEZ-GUERRA, Aureliano, "Puerta y cubo de Santa Clara de Zamora (Informes)", Boletín de la Real Academia de la Historia, tomo III, noviembre de 1883, pp. 328-330. 


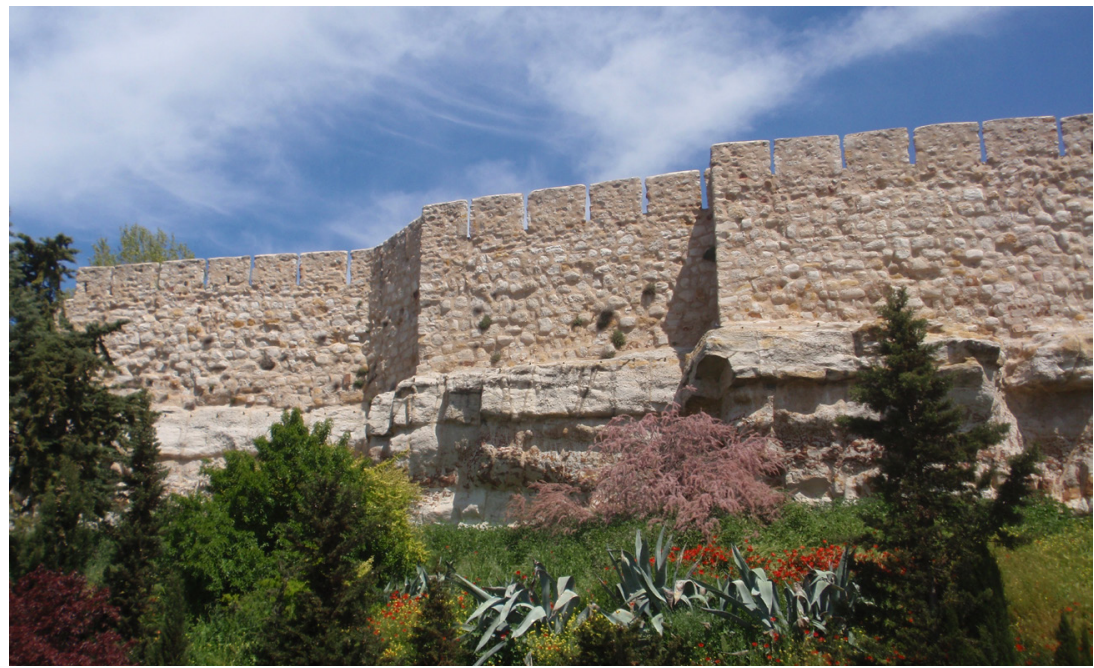

A pesar de la importancia histórica y literaria que han tenido desde siempre las murallas de Zamora y que hicieron que la mayor parte de los estudiosos zamoranos se fijaran en ellas, la verdad es que a día de hoy todavía su datación y número de recintos plantean algunos problemas ${ }^{64}$.

El asentamiento primitivo en Zamora surgió a occidente sobre una zona rocosa que dominaba el Duero. Como núcleo urbano destacado en tiempos de la reconquista la ciudad tendió a la expansión hacia la llanura que se abría al naciente, de ahí que este importante desarrollo hiciera necesario muy pronto la construcción de diferentes recintos amurallados que englobasen algunos de los burgos surgidos a extramuros. Variadas y en ocasiones contradictorias han sido las opiniones de los estudiosos que han dedicado mayor atención a las murallas de Zamora. Fernández Duro habla de un único recinto que atribuye a tiempos de Fernando I el Grande y al que corresponderían los restos que

64 Sobre las murallas de Zamora se puede consultar FONTANILLA, Pedro, "Informe relativo a oficio de la Comisión de Zamora haciendo constar se trata de proseguir la obra de demolición de un lienzo de la antigua muralla", Boletín de la Real Academia de Bellas Artes de San Fernando, XXIV, Madrid, 1930, pp. 96-98; MENÉNDEZ PIDAL, Luis, "Los restos de murallas en Zamora", Boletín de la Real Academia de Bellas Artes de San Fernando, ${ }^{\circ}$ 19, Madrid, 1964, pp. 44-46; Los castillos y las murallas de Zamora: breve recorridos por las provincias, $\mathrm{n}^{\circ} 10$, Diputación de Zamora, febrero de 1984, pp. 27-30; BUENO DOMÍNGUEZ, María Luisa, "La fortaleza de Zamora y su muralla en los acontecimientos históricos: (1072-1371)" en Estudios de Historia Medieval: homenaje a Luis Suárez Fernández, Universidad de Valladolid, 1991, pp. 67-74; LOBATO VIDAL, J. C., op. cit., 1997, pp. 135-139; MUÑOZ GARCÍA, Miguel Ángel, "Intervención arqueológica durante la restauración de los lienzos de muralla en la Ronda de la Feria (Zamora)", Anuario del Instituto de Estudios Zamoranos «Florián de Ocampo», Zamora, 2003, pp. 61-82; LARRÉN IZQUIERDO, Hortensia y PICHEL RAMOS, Luis, Bienes culturales de la provincia de Zamora, Zamora, 2010, pp. 156158. 
se han conservado ${ }^{65}$. Ursicino Álvarez, que habla de dos recintos, data el primero de ellos durante el reinado de Fernando I y en palabras suyas "...se cerraba por la torre de San Juan y muro de la calle de la Alcazaba, de la cuesta de Santa Lucía á buscar por San Bartolomé y Pizarro las alturas de Santa Marta dominando el Duero á una elevación extraordinaria" ${ }^{66}$. El segundo recinto según Ursicino Álvarez iba "desde la puerta de la Feria hasta la puerta Nueva por las de Santa Ana, San Torcuato, Santa Clara y San Pablo, coronadas entonces con un gracioso almenaje como lo estaban los pretiles del puente de los que solo se han respetado los del esbelto y elevado torreón principal, que era el de Santa Clara y un trozo en la puerta de las Ollas" ${ }^{67}$. Este segundo y último recinto al que alude Álvarez, señalando que comenzó a edificarlo el Emperador Alfonso VII, corresponde al segundo recinto de la ciudad. Gómez-Moreno ya habla de tres recintos amurallados; el primero, construido en la segunda mitad del siglo XII, el segundo, perteneciente al siglo XIII y, un tercero, que integró en la ciudad la conocida como Puebla del Valle y que no data ${ }^{68}$. Garnacho fecha el primero en el siglo XI, el segundo a principios del XIII y el tercero ya en el siglo XIV ${ }^{69}$. Ramos de Castro coincide con Garnacho al datar el primero en el siglo XI y adelanta la cronología del segundo y el tercero, fechándolos en el siglo XII uno y después de 1250 el otro ${ }^{70}$. También observamos alguna variación en las fechas que propone José Avelino Gutiérrez González ${ }^{71}$ para quien el primer recinto se construiría entre los siglos XI y XII, el segundo

65 Asimismo afirma que la ciudad había llegado a contar con siete recintos cuya edificación había ordenado Alfonso el Magno. Vid. FERNÁNDEZ DURO, C., op. cit, tomo I, 1883 (2003), p. 244.

66 ÁLVAREZ MARTÍNEZ, Ursicino, "Nuestro Grabado" en Zamora Ilustrada, Diputación de Zamora, tomo IV, n 47, 1883, p. 375.

67 Ídem.

68 GÓMEZ-MORENO, M., op. cit., I, 1927 (1980), pp. 84-87.

69 GARNACHO, Tomás María, Breves noticias sobre algunas antigüedades de Zamora y Provincia, Zamora, 1979, pp. 123-130.

70 RAMOS DE CASTRO, G., op. cit., 1978a, pp. 21-23.

71 Aunque este autor divide en tres, como viene siendo tradicional, los recintos amurallados de la ciudad de Zamora, sí es cierto que apunta la posibilidad de que hubiera existido una primera cerca en torno al castillo, la catedral e iglesia de San Isidoro que englobaría un espacio algo inferior a la mitad del conocido actualmente como primer recinto. Este primitivo recinto embrionario se habría levantado a finales del siglo IX justo después de la restauración de la ciudad llevada a cabo por Alfonso III. GUTIÉRREZ GONZÁLEZ, José Avelino, "Orígenes y evolución urbana de Zamora" en Catálogo de la exposición CIVITAS. MC. Aniversario de la Ciudad de Zamora, Junta de Castilla y León y Caja España, Zamora, 1993, p. 24. 
en el siglo XIII, en torno a 1230 y, el tercero y último, en el siglo XIV, hacia $1325^{72}$. Gutiérrez González aporta al estudio histórico un análisis desde el punto de vista técnico en Las fortificaciones de la ciudad de Zamora. Estudio arqueológico e histórico ${ }^{73}$. Por último, Lobato Vidal74 señala la existencia de una primera cerca altomedieval levantada en tiempos de Alfonso III, repoblador de la ciudad, y de la que no se habría conservado nada por edificarse sobre ella cercas posteriores. Al igual que la mayoría de autores considera que con posterioridad se dotó a la ciudad de tres recintos de murallas. La construcción del primero de ellos la sitúa fundamentalmente durante la segunda mitad del siglo XI, el segundo lo fecha entre la segunda mitad del XII y finales del siglo XIII y, el tercero, durante la primera mitad del XIV.

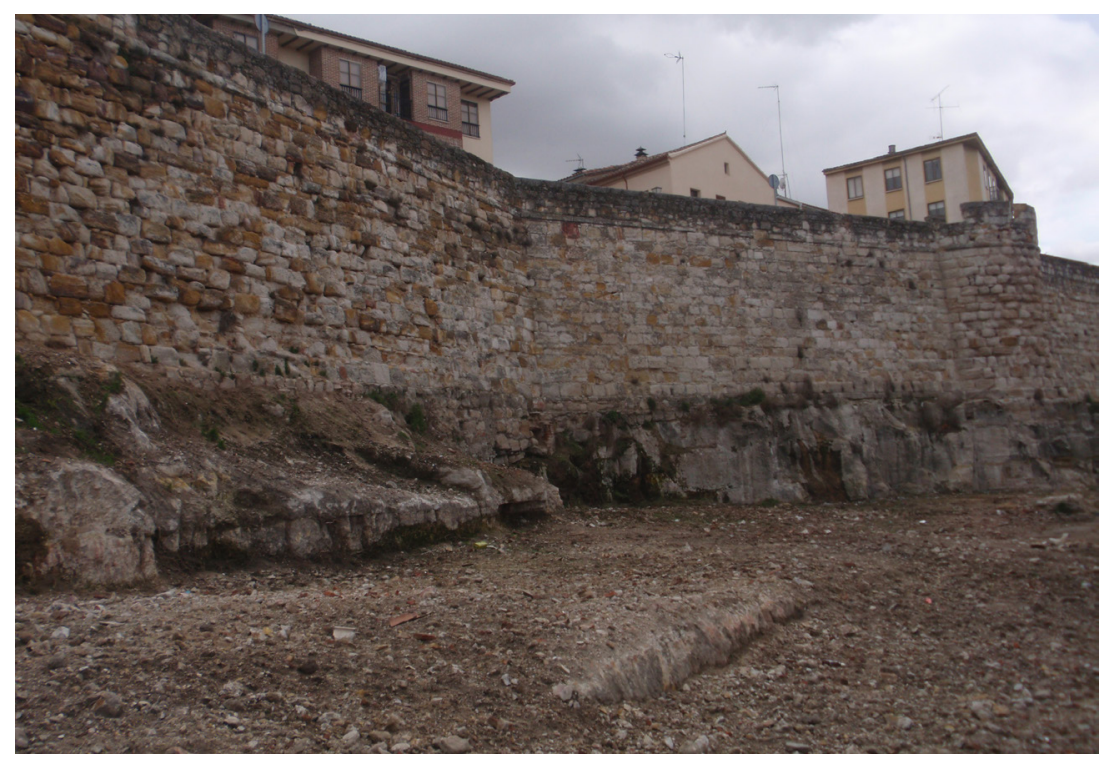

Puesto que, como se señalará a continuación, las murallas de Zamora no presentan datos de especificidad estilística me mantengo en la opinión de Gutiérrez González en relación a la cronología que aporta para los diversos recintos.

La funcionalidad eminentemente defensiva de esta estructura amurallada tuvo como consecuencia que, desde el punto de vista artístico, no exista ningún detalle específico que pudiera ser útil a la hora de adscribirla a un estilo y corroborar, por tanto, una cronología aproximada (Fig. 63). Tan sólo las referencias

72 GUTIÉRREZ GONZÁLEZ, J. A., op. cit., 1993, pp. 20-33.

73 GUTIÉRREZ GONZÁLEZ, J. A., op. cit., 1990, pp. 17-37.

74 LOBATO VIDAL, J. C., op. cit., 1997, pp. 133-142 y 144-145.. 
documentales sirven para saber cuándo se edificaron o, al menos, en qué momento estaban levantadas. La atención aquí prestada atiende a su importancia como edificación construida y reformada en gran parte durante el periodo gótico. Edificación sin la cual serían incomprensibles los aconteceres históricos de la ciudad de Zamora durante la Baja Edad Media así como la organización y desarrollo de esta urbe. Aún, en la actualidad, siguen siendo un destacado elemento arquitectónico que confiere a la ciudad un carácter inexpugnable y medieval.

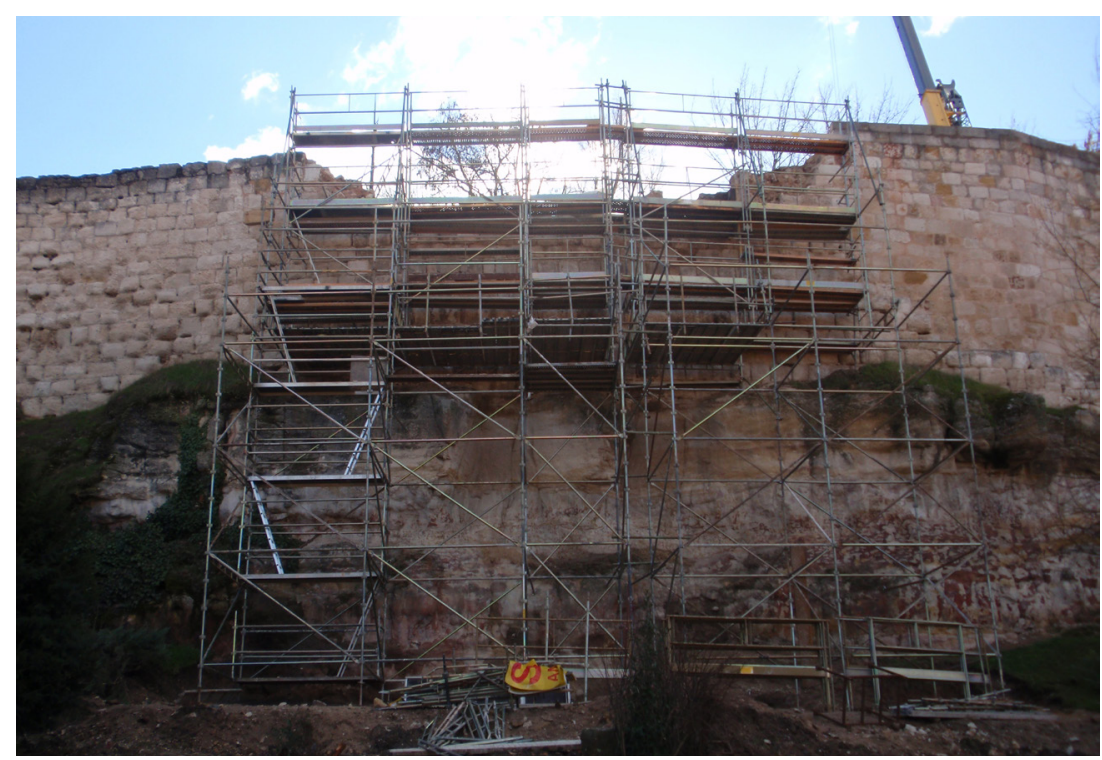

Hasta el siglo XIX los recintos amurallados que formaban la fortificación de Zamora se conservaban prácticamente en su integridad. Fue durante parte del siglo XIX y el siglo XX cuando se produjeron numerosos derribos con el objeto de facilitar la expansión de la ciudad hacia la zona este, de ahí que fuera fundamentalmente el conocido más comúnmente como segundo recinto, que iba desde la plaza Mayor hasta la actual avenida de Alfonso IX, el que se viera más afectado. Pese a todos aquellos derribos la ciudad sigue contando con amplios lienzos de muralla en pie, sobre todo pertenecientes al primer recinto amurallado que, partiendo del extremo occidental de la ciudad rodeando el Castillo y la Catedral, llegaba hasta la iglesia de San Juan de Puerta Nueva, sita en la Plaza Mayor.

Su estado actual de conservación es deficiente, aunque después del desprendimiento de quince metros de muralla en el mes de septiembre de 2008, el Ayuntamiento está preparando
Fig. 64. Reparaciones en la muralla de Zamora después de un desprendimiento 
un proyecto urgente de rehabilitación del entorno más afectado que es el situado en la zona del castillo (Fig. 64).

\section{El castillo}

Está situado en el extremo occidental de la ciudad sobre un promontorio que constituye el lugar de mejor visibilidad y defensa75 (Figs. 65 y 66). Se encuentra muy modificado debido al uso militar prolongado que ha tenido durante siglos y que hizo que fuera necesaria su adaptación a las nuevas formas defensivas de cada momento. De este modo son numerosas las obras que, con esa finalidad, se llevaron a cabo en él desde el siglo XIV hasta el siglo XIX. Recientemente el castillo ha sido objeto de un importante proceso de rehabilitación cuya dirección ha corrido a cargo del arquitecto Francisco Somoza ${ }^{76}$. Durante esta intervención se realizaron importantes hallazgos de los que se dará cuenta más adelante.

La interpretación de este castillo presenta todavía muchos problemas. Los estudios más elaborados se han circunscrito a un análisis puramente arqueológico e histórico obviando en su mayoría cualquier referencia al aspecto artístico ${ }^{77}$. En algunas publicaciones se hace remontar su origen al siglo $\mathrm{Xl}^{78}$, pero no

75 Sobre el castillo de Zamora puede consultarse AA. VV., Fotografías antiguas de Zamora, Centro de Iniciativas y Turismo. Zamora, Valladolid, 1979, $\mathrm{n}^{\circ} 32,33$ y 205; PINILlA GONZÁLEZ, Jaime, Castillos de Zamora y Salamanca, Ediciones Lancia, Madrid, 1989, pp. 30-31; LOBATO VIDAL, J.C., Castillos y murallas de la provincia de Zamora, Zamora, 1997, pp. 134-135 y 143; COBOS GUERRA, Fernando y CASTRO FERNÁNDEZ, José Javier de, Castilla y León. Castillos y Fortalezas, Edilesa, León, 1998, p. 61; MARTÍN JIMÉNEZ, Carlos Manuel, Los castillos y fortalezas de Castilla y León (Rutas para descubrir), Ámbito, Valladolid, 2003, pp. 315-316; AA. VV., Zamora en imágenes. 1925-1950. Fotografía y Sociedad, Zamora, 2005, p. 44; LARRÉN IZQUIERDO, H. y PICHEL RAMOS, L., op. cit., 2010, pp. 159-161; COOPER, Edward, La fortificación de España en los siglos XIII y XIV, vol. I, Madrid, 2015, pp. 542-546.

76 Con posterioridad a este proceso de rehabilitación se tenía previsto que el arquitecto Rafael Moneo se encargará de convertir esta vieja fortificación en un museo dedicado a la obra del artista zamorano Baltasar Lobo. Finalmente esta última fase no se llevó a cabo y se ha abierto la fortaleza a los visitantes que, no obstante, pueden contemplar algunas de las obras de este interesantísimo escultor dispuestas por el interior del edificio.

77 AA.VV., "Intervención arqueológica en el Castillo de Zamora", Anuario del Instituto de Estudios Zamoranos «Florián de Ocampo», Zamora, 1992, pp. 135-147; AA.VV., "Breves anotaciones sobre la intervención arqueológica en el castillo de Zamora (1 fase)", Anuario del Instituto de Estudios Zamoranos «Florián de Ocampo», Zamora, 2006, pp. 131-148.

78 LOBATO VIDAL, J.C., Castillos y murallas de la provincia de Zamora, Zamora, 1997, p. 135; AA.VV., "Intervención arqueológica en el Castillo de Zamora", Anuario del Instituto de Estudios Zamoranos «Florián de Ocampo», Zamora, 1992, p. 135; 


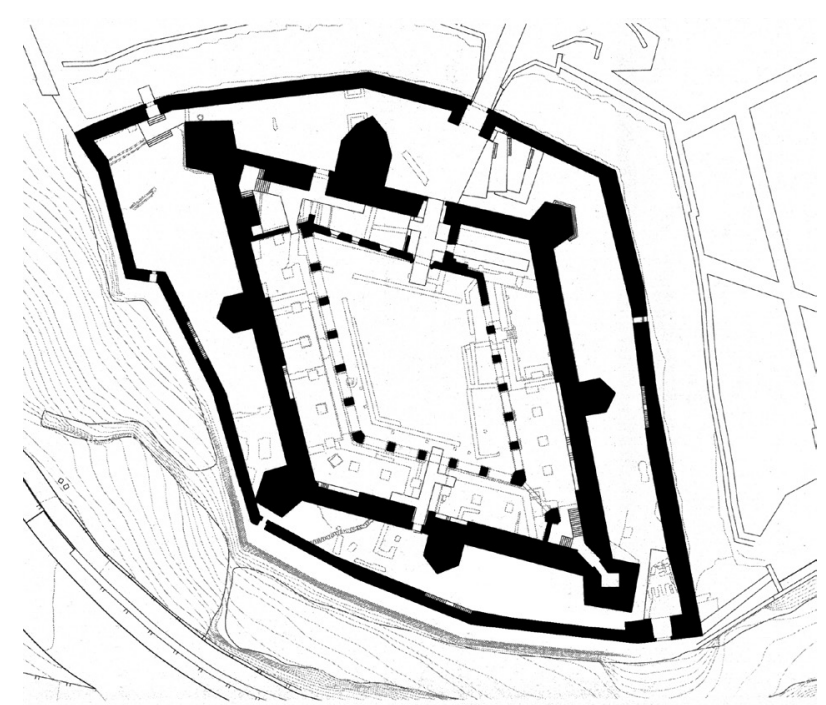

existen testimonios de ningún tipo, al menos de forma clara y evidente, que confirmen tal cronología. La mayoría de estudiosos manifiestan que el castillo que ha llegado hasta nuestros días no remonta más allá del siglo XII79. Hasta 1273 en que se le cita situado en las proximidades de la Catedral y el Mercadillo no contamos con testimonios concretos ${ }^{80}$. Fue tomado por los partidarios del rey don Juan en 1282 durante las revueltas contra Alfonso $\mathrm{X} y$, también, con posterioridad, por el infante don Felipe durante la minoría de edad de Alfonso XI. La importancia estratégica no solamente de Zamora sino también de Toro y los daños que habían sufrido sus respectivos castillos con motivo de los acontecimientos citados hizo necesario en 1326 "labrar et a enderezar los muros et a facer otras labores nuevas con que se fortalescieron mas de lo que estaban" ${ }^{81}$. Pocos años después en 1369 la villa fue cercada por Enrique II. Durante la guerra entre Juana la Beltraneja e Isabel la Católica, Zamora, una vez más, dio su apoyo al rey de Portugal. El castillo de la ciudad fue asediado durante varios meses hasta que en el año 1476 se rinde ante las tropas castellanas. Las malas condiciones en las que había quedado la fortaleza hicieron que muy pronto comenzaran las reparaciones. Así consta que, ya en 1484 y 1486, el concejo FERNÁNDEZ FERRERO, Alberto, Guía de las ciudades de Zamora y Toro, Zamora, 2003, p. 15

79 GUTIÉRREZ GONZÁLEZ, J. A., op. cit., 1990, p. 52; HERNÁNDEZ MARTÍN, J., Guía de Arquitectura de Zamora. Desde los orígenes al siglo XXI, Colegio Oficial de Arquitectos de León, 2004, p. 34.

80 MATILla TASCÓN, Antonio, Guía-inventario de los Archivos de Zamora y su provincia, Madrid, $\mathrm{N}^{\circ}$ de orden 1445, legajo 31, n 15, p. 200.

81 Citado en COBOS GUERRA, F. y CASTRO FERNÁNDEZ, J. J. de, op. cit., 1998, p. 61. 


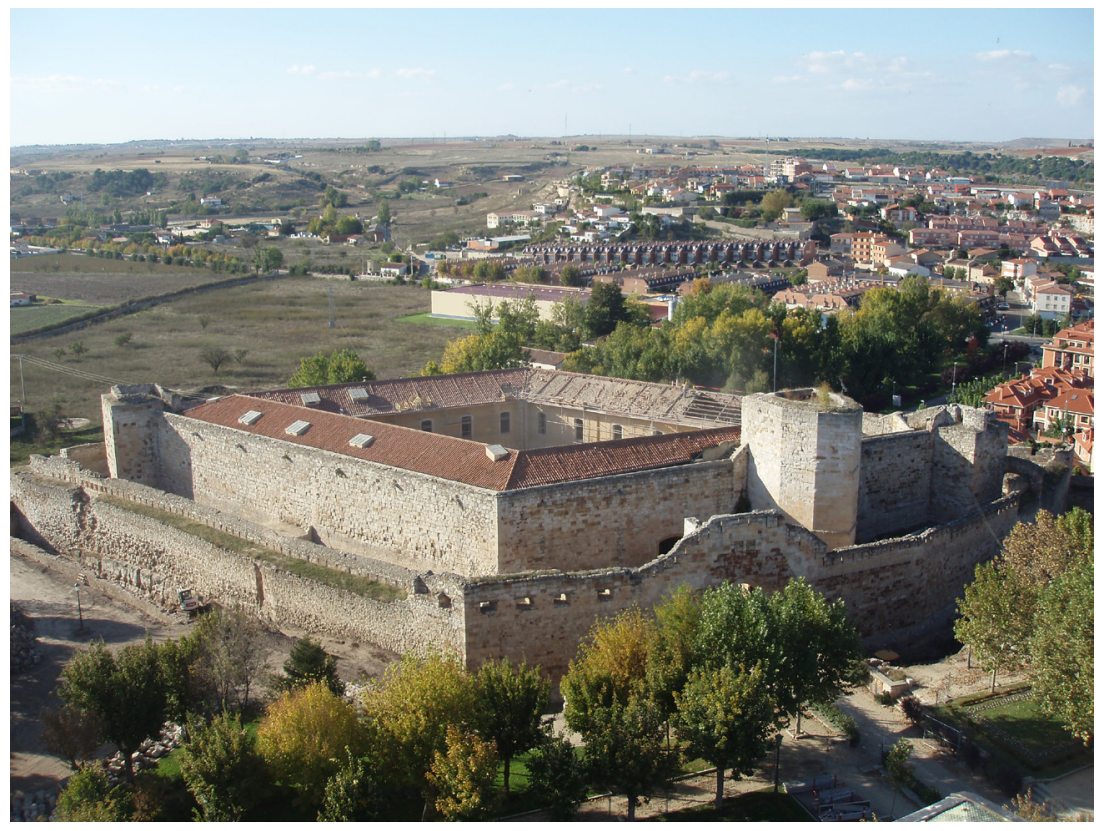

ordenó intervenir en los muros de la ciudad. De pocos años después es un texto, que recoge Gutiérrez González y que fue ya publicado por J. Paz en 1913, en el que se describe el estado en que había quedado el castillo al término de la guerra de sucesión al trono de Castilla. La importancia de esta descripción para el conocimiento de las estructuras del castillo en época gótica nos lleva a reproducirla una vez más: "La fortaleza de Zamora tenía seis torres, cinco de las cuales estaban cubiertas de madera en forma que se podían habitar, y en ellas parece estar todo demolido y sin ningún maderamiento, ni tejado, ni puertas, y mucha parte de la cantería arruinada, principalmente una torre con dos cubos que cae al Poniente y los cubos al Mediodía, que esto está todo demolido hasta su fundamento, y asimismo dos cuartos de vivienda, con sus corredores altos y bajos, que todo está demolido y arruinado hasta el cimiento, y otro lienzo de pared, que está frontero de la puerta principal, que es al nacimiento del sol, está demolido y arruinado hasta el cimiento, y otro lienzo de pared al Norte está también caído y arruinado hasta el cimiento, las cuales paredes eran todas fabricadas de sillería por dentro y fuera, y asimismo están desechas y arruinadas todas las paredes que confinan con el patio, y fuera de éstas hay otros muchos pedazos caídos, asi de paredes como de almenería y escaleras, que todo ello es de mucha consideración y requiere sea reparado, porque de no se reparar se verná todo á caer y perecer; el cual edificio, si se reparase, era de mucha importancia, por estar, 
como está, todo fundado en peña viva con su barbacana, rozando á pico de un cabo, y de otro en la dicha peña 12 pies de alto, lo cual todo, mirado y tasado, así la cantería como la carpintería, cada cosa por sí, parece costará reedificar el dicho edificio 14.000 ducados $»^{82}$.

Entre 1521 y 1522 se sucedieron nuevas intervenciones para las que se gastaron 230.000 mrs. Estas consistieron "en limpiar y ahondar la cava, aderezar un cubo grande que está cerca de la torre del homenaje que está caído y para reparar los aposentamientos y trastejar el castillo» ${ }^{83}$.

Pese a todas las reparaciones que se habían hecho tiempo atrás, un nuevo testimonio, en este caso de finales del siglo XVI, pone de manifiesto el tremendo deterioro que presentaba en aquel momento el castillo ${ }^{84}$.

Durante el siglo XVII se siguieron realizando intervenciones así como en el XVIII, siglo este último en el que Zamora se convirtió en la capitanía de la frontera con Portugal. Para ello se proyecta la realización de un almacén que poco después sería ampliado. Durante la segunda mitad del siglo XVIII los almacenes que tenía el castillo presentaban un estado deficiente por lo que se decidió la edificación de uno nuevo. También durante el siglo XVIII se edificó el patio del castillo que ha llegado a la actualidad y que se ha mantenido en la reciente intervención.

Con la ocupación de la ciudad por parte de los franceses a principios del siglo XIX el castillo vuelve a ser objeto de significativas intervenciones centradas en lo fundamental "en el acondicionamiento de las dependencias interiores del recinto del castillo y en el rehecho de los parapetos aspillerados para la fusilería, especialmente los lienzos E. y S. del segundo recinto del castillo, en los que se aprecian aspilleras fusileras adinteladas con madera o recercadas con ladrillos y revocadas con mortero de cal y polvo de ladrillo, más propio del momento que de periodos anteriores" ${ }^{\prime 85}$.

82 GUTIÉRREZ GONZÁLEZ, J. A., op. cit., 1990, pp. 56-57.

83 COBOS GUERRA, F. y CASTRO FERNÁNDEZ, J. J. de, op. cit., 1998, p. 61.

84 Ídem.

85 GUTIÉRREZ GONZÁLEZ, J. A., op. cit., 1990, p. 61. 


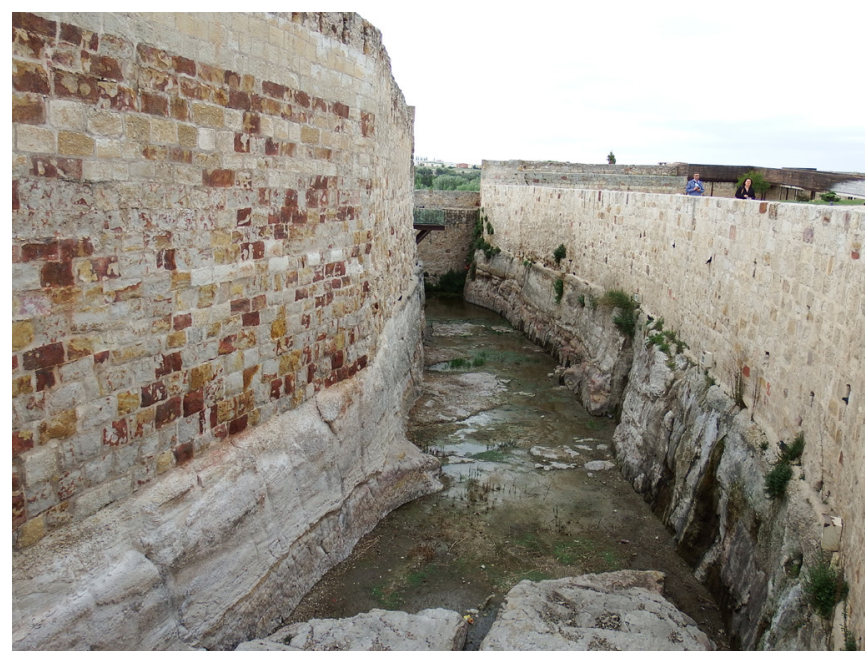

Pocos años después, en 1833-36, con motivo de las guerras carlistas se adapta el castillo y las murallas a las nuevas necesidades, así “...delante de las puertas se construyeron tambores aspillerados, en algunos cubos se abrieron nuevas cañoneras y se completó el muro que envolvía el castillo y la Catedral. A este momento puede atribuirse la construcción de la merlatura fusilera del lienzo de Trascastillo y del tramo E. del Tercer Recinto, entre Puerta Nueva y el río" ${ }^{\prime 6 .}$.

Durante las últimas décadas del siglo XX el interior del castillo fue reconstruido con el objeto de ser utilizado para usos docentes.

Por último, y como se ha señalado anteriormente, han sido de enorme importancia para completar el conocimiento del castillo las obras de recuperación y restauración que se han llevado a cabo en estos últimos años y que han estado dirigidas por el arquitecto don Francisco Somoza.

En la actualidad todo este conjunto consta del edificio del castillo propiamente dicho y de un muro exterior de menor altura. Los datos técnicos de la edificación, a la espera de que se publique el estudio que acompañará la memoria de la última restauración y que incorporará todos los elementos nuevos descubiertos, quedaron recogidos por Gutiérrez González ${ }^{87}$.

Comenzaremos el análisis de la fortaleza durante los primeros momentos del gótico atendiendo a los datos de carácter formal que pueden ser indicativos de una posible cronología.

86 Ídem, p. 62.

87 Ídem, pp. 37-41. 
La fortaleza de Zamora se encuentra situada en el extremo occidental de la ciudad medieval a escasos metros de la catedral y muy cerca también de la iglesia del Carmen de San Isidoro. El acceso se realiza a través de un puente que salva un amplio foso excavado en la roca (Fig. 67). Su recinto exterior o barrera tiene forma romboidal irregular y sigue en términos generales la disposición del castillo; en los tramos norte y oeste este recinto exterior aprovecha parte del trazado del primer recinto amurallado de la ciudad.

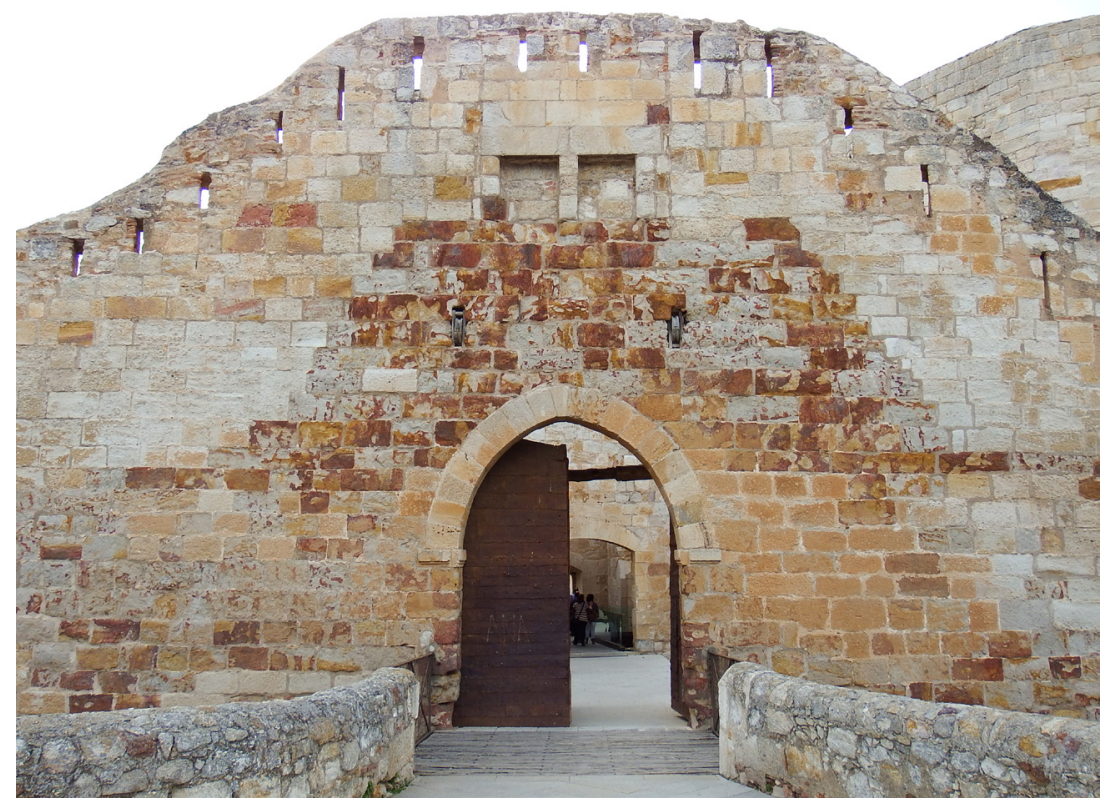

El recinto exterior, de menor altura respecto al recinto interior, contaba con dos accesos de los que hoy día solamente es practicable el situado en el tramo oriental. Este acceso constituye la entrada principal a la fortaleza y se encuentra bajo una torre cubierta por una bóveda de cañón apuntado con la línea de imposta bien definida (Figs. 68 y 69). Esta puerta se abre en arco apuntado de trazado sencillo sin molduras en sus dovelas. Da acceso a un espacio rectangular que se abre hacia el interior por medio de otro arco apuntado que corresponde al remate exterior de la bóveda de cañón apuntado que cubre este recinto. El único elemento decorativo de esta puerta es la moldura sencilla de relieve pronunciado que sigue la línea de imposta desde el exterior al interior. El macizo que se eleva sobre esta puerta hace pensar que, en origen, se trataba de una puerta-torre que reforzaba la defensa justo en este lugar. Este tipo de estructura cuya parte inferior se compone de un espacio rectangular abierto hacia uno

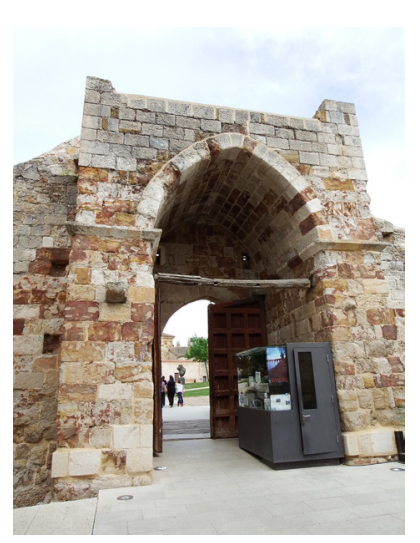
Fig. 69. Acceso al castillo de Zamora visto desde
el interior 


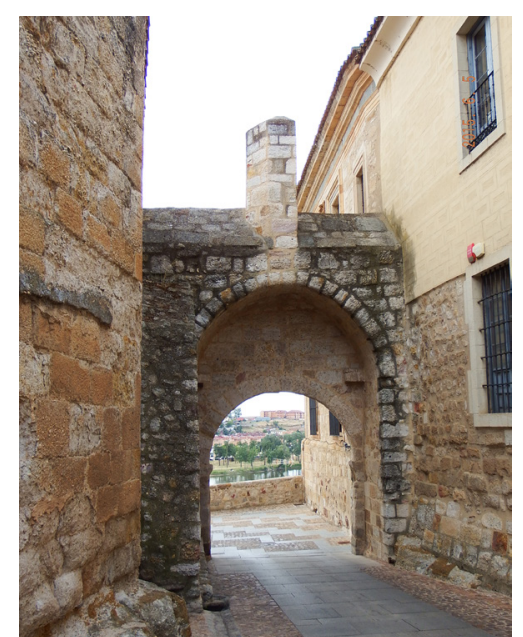

Fig. 70. Puerta del Obispo. Zamora

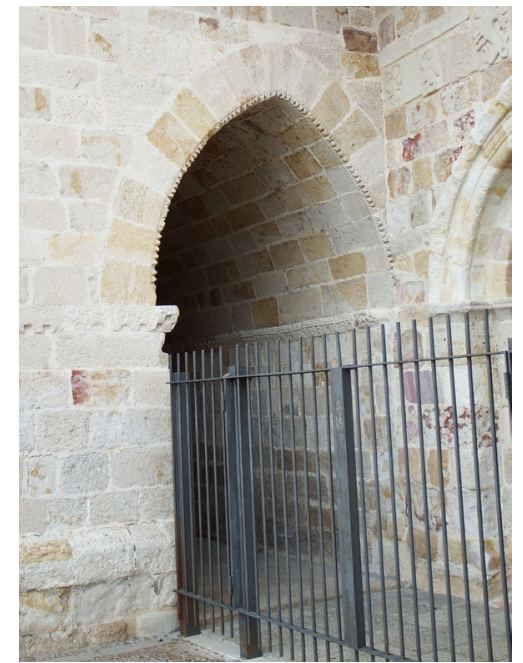

Fig. 71. Cuerpo bajo de la torre de San Cipriano.

de sus lados estrechos y cubierto por una bóveda de cañón o de cañón apuntado fue muy común en las puertas de las murallas, en los castillos y en las fortificaciones de esta época. Estructuras semejantes se encuentran en una de las puertas de la muralla de Coca (Segovia) y en la puerta del Obispo de la propia ciudad de Zamora, aunque en este último caso se trate de una estructura completamente románica que constituye uno de los accesos más antiguos que se conservan de la muralla (Fig. 70). Pero también edificios religiosos como las iglesias zamoranas de San Cipriano y San Leonardo tienen articulada de forma muy semejante la mitad inferior de su torre (Fig. 71). Curiosamente la torre de la iglesia de San Cipriano se encontraba inmediata a la muralla y, por tanto, participaría de la misma finalidad que la citada torre de la barrera del castillo. Es por ello que esta puerta de la barrera, en función de los elementos formales que la componen así como por analogía con las estructuras similares conservadas en las torres de San Cipriano y San Leonardo, parece responder a los años finales del siglo XII e, incluso, más probablemente a los primeros del siglo XIII.

Otro acceso importante al castillo, conocido como puerta de Santa Colomba, se abría al oeste y, en origen, fue una de las puertas del primer recinto amurallado de la ciudad hasta que, edificada la fortaleza, quedó integrada en ella ${ }^{88}$. Se conocía su existencia porque su exterior era visible desde la zona de Trascastillo y porque existen referencias documentales respecto a ella ${ }^{89}$. A finales de mayo de 2006 con motivo de las obras de rehabilitación que se estaban llevando a cabo en esta zona se descubrió su estructura completa, que es muy semejante a la de la puerta situada en el extremo contrario que acabamos de comentar. La puerta de Santa Colomba se abre en un arco ligeramente apuntado que comunica con un espacio de altura considerable abierto hacia la liza y cubierto por una bóveda de cañón apuntado con la línea de imposta definida (Figs. 72 y 73). Conserva los goznes en los que iban fijadas las hojas de la puerta.

88 Ramos de Castro confunde esta puerta de Santa Colomba situada en el lienzo de muralla que rodea al castillo en su parte oeste con el denominado actualmente Puerta de la Lealtad. RAMOS DE CASTRO, G., op. cit., 1978a, p. 30.

89 GUTIÉRREZ GONZÁLEZ, J. A., op. cit., 1990, p. 96, láms. 15 y 16; AA.VV., "Intervención arqueológica en el Castillo de Zamora", Anuario del Instituto de Estudios Zamoranos «Florián de Ocampo», Zamora, 1992, p. 136. 


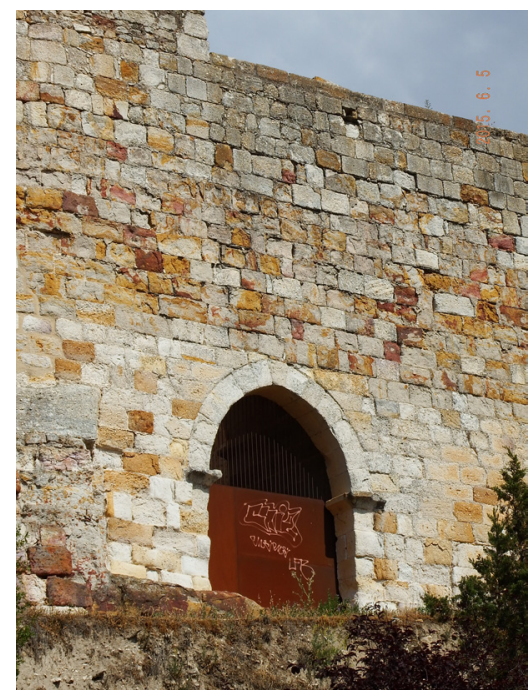

Aparentemente no parece que estuviera protegida por una torre como la anterior, y por lo que se aprecia en la actualidad, sobre ella se situaba el adarve de la muralla.

Estos dos importantes accesos al castillo, abiertos en los tramos este y oeste del recinto exterior o barrera, formarían parte, en base a los elementos formales analizados, de las estructuras más antiguas que se conservan de él.

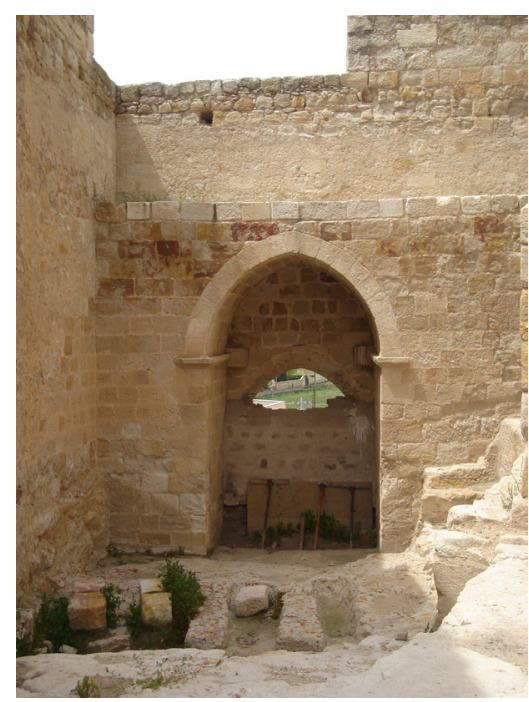

Entre este recinto exterior y el castillo propiamente dicho queda un espacio abierto, el foso, que rodea toda la fortaleza.

El castillo tiene un mayor desarrollo en altura que el recinto exterior y una planta en rombo bien definida. En las recientes intervenciones llevadas a cabo en él han aparecido también una pequeña puerta de comunicación entre estancias y un portillo; ambos, formados por un arco liso de ligerísimo apuntamiento, se encontraban tapiados (Figs. 74 y 75). Puertas de características
Fig. 72. Puerta de Santa Colomba hacia el exterior del castillo de Zamora
Fig. 73. Puerta de Santa Colomba hacia el interior del castillo de Zamora 


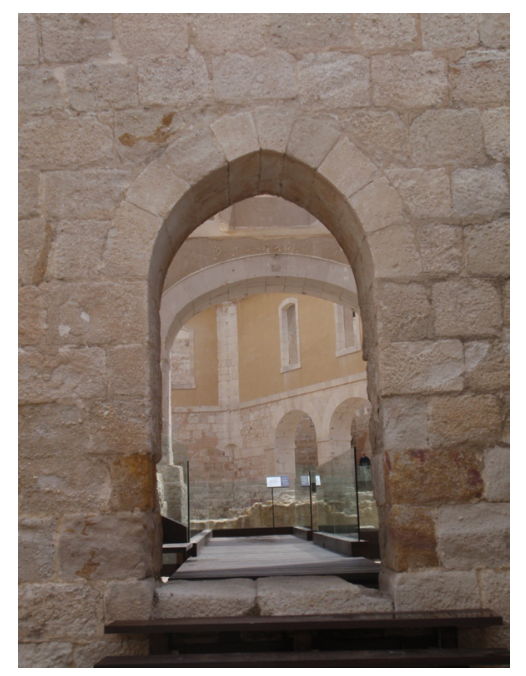

Fig. 74. Vano en arco apuntado en el interior del castillo de Zamora

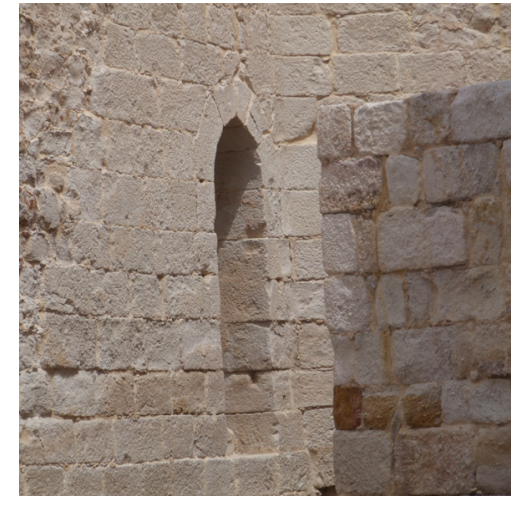

Fig. 75. Vano en arco apuntado en el interior del castillo de Zamora muy similares a estas del castillo fueron comunes en la arquitectura religiosa como puede constatarse en la abierta en el primer tramo del muro norte de la iglesia de Santa María de la Horta, aunque, no obstante, ésta presentaba en su día la línea de imposta subrayada por molduras que hoy se ha perdido (Fig. 76). También la portada de occidente en la iglesia de Santa Lucía está resuelta en sencillo arco apuntado aunque en este caso se encuentre doblado y con las aristas achaflanadas (Fig. 77). Este tipo de estructuras sencillas en las que se introduce de manera muy tímida el arco apuntado y que presentan una total desornamentación habría que situarlas cronológicamente en torno a $1200 \mathrm{y}$, por tanto, relacionarlas con la primera fase constructiva de la fortaleza.

Pero quizás el descubrimiento más significativo que ha tenido lugar dentro de todo este conjunto defensivo ha sido el hallazgo de un espacio que puede ser interpretado como capilla (Fig. 78). Solamente conserva la parte inferior de los paramentos que delimitan una estancia rectangular de pequeñas dimensiones. Con toda probabilidad estaba cubierta con una bóveda de cañón apuntado cuyos fajones reforzados apeaban en los elementos conservados: de un lado, ménsulas y, de otro, pilastras. La concepción de este espacio así como el molduraje que presentan las ménsulas, unas con modillones de rollo, otras lisas con una escocia en su parte inferior, guarda una estrecha relación con diseños propios de la arquitectura cisterciense (Fig. 79). Así se pueden observar un gran número de ménsulas con este diseño en el claustro, refectorio y sala de trabajos del monasterio cisterciense de Santa María de Valbuena (Valladolid), dependencias datadas en los años finales del siglo XII y primeras décadas del siglo XIII (Fig. 80). La datación que nosotros aportamos para la capilla del castillo es la primera mitad del siglo XIII. Incluimos aquí su mención al encontrase esta estructura plenamente incorporada en un edificio de carácter civil y al no saber con exactitud si realmente tuvo esa función.

Aunque existían referencias y constatación gráfica antigua de que en esta parte del castillo el número de torres era muy amplio, lo cierto es que hasta hace poco tiempo solamente podían observarse tres, dos en los extremos mayores de forma 
pentagonal $y$, una - la torre del homenaje, por sus mayores proporciones- cercana al acceso situado al este, de forma heptagonal. Entre las proposiciones que se han hecho para definir la estructura del castillo de Zamora hay que citar algunas planimetrías publicadas en trabajos de divulgación, para las cuales, salvo excepción, se ha tenido en cuenta únicamente en su elaboración, los restos que estaban visibles ${ }^{90}$.

Sin embargo, las noticias que aportaba el texto citado del siglo XVI, indicaban que el castillo de Zamora había tenido un mayor número de torres como quedaba reflejado en una planta del mismo conservada en el Archivo Histórico Nacional, fechada en el año 1714, y que fue publicada en 1998 en el libro Castillos y Fortalezas $^{91}$, en la que el número de torres en su perímetro es de ocho. Las últimas obras llevadas a cabo en el castillo han sacado a la luz la parte inferior de cinco torres que permanecían ocultas así como la planimetría completa del edificio. El número total de torres y la disposición de ellas concuerda con la planta mencionada de 1714 y permiten recomponer el perfil que tuvo el castillo, al menos durante la Baja Edad Media.

Es difícil precisar a qué período corresponden estas torres (Fig. 81). En el momento en que se construyó el castillo de Zamora era común que las torres de las fortalezas tuvieran sección circular del mismo modo que hoy día puede observarse en el alcázar de Toro. Sin embargo, las torres del castillo de Zamora, de sección pentagonal, podrían plantear algunos interrogantes aunque, si bien es cierto, este tipo de torres de planta pentagonal se había utilizado desde antiguo, como se constata en la fortaleza de Calatrava la Vieja (siglo XI) y en la de Alarcos (finales del siglo $X I I)$. Aunque su verdadero desarrollo tuvo lugar a finales del siglo XIII y, sobre todo, en las primeras décadas del siglo XIV. La forma en que están integradas las torres del castillo de Zamora con el propio muro, sin guardar una mínima continuidad, lleva a pensar que se edificaron con posterioridad. Las múltiples intervenciones llevadas a cabo en el castillo hacen difícil precisar cuál fue el momento exacto en el que dichas torres se levantaron o en el

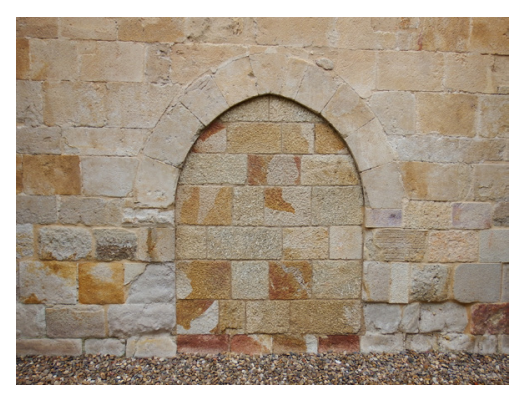

Fig. 76. Portada norte de la iglesia de Santa María de la Horta. Zamora

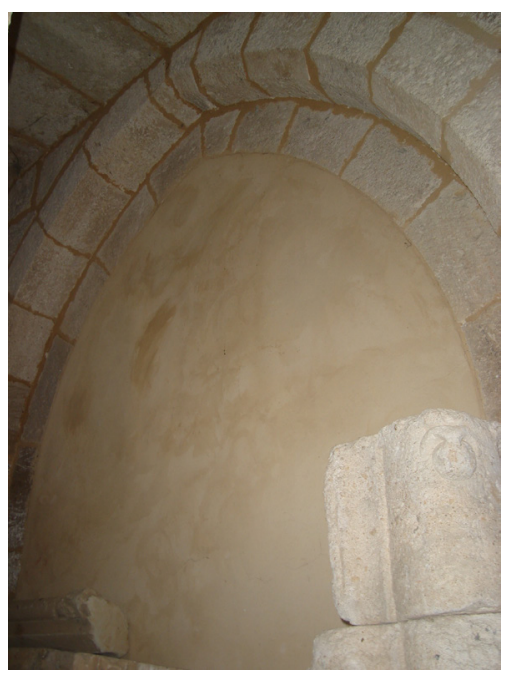

Fig. 77. Puerta occidental de la iglesia de Santa Lucía. Zamora

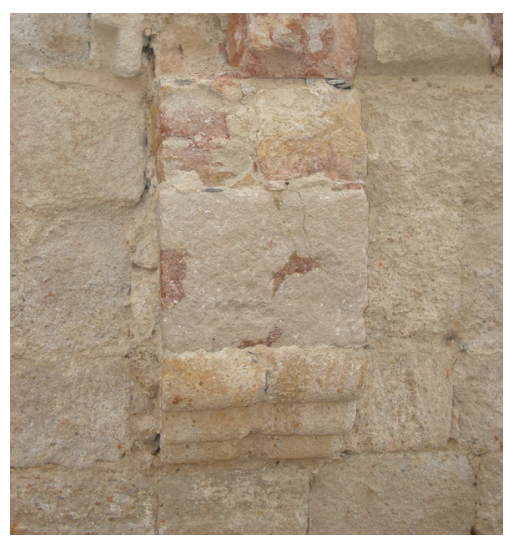

Fig. 79. Ménsula de la que se ha supuesto capilla del castillo de Zamora

90 GUTIÉRREZ GONZÁLEZ, J. A., op. cit., 1990, p. 71, figura 2; HERNÁNDEZ MARTÍN, J., op. cit., 2004, p. 34.

91 COBOS GUERRA, F. y CASTRO FERNÁNDEZ, J. J. de, op. cit., 1998, p. 61, planta. 


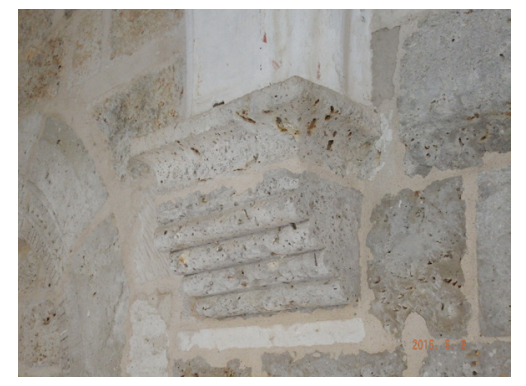

Fig. 80. Ménsula del claustro del monasterio de Santa María de Valbuena. San Bernardo
(Valladolid)

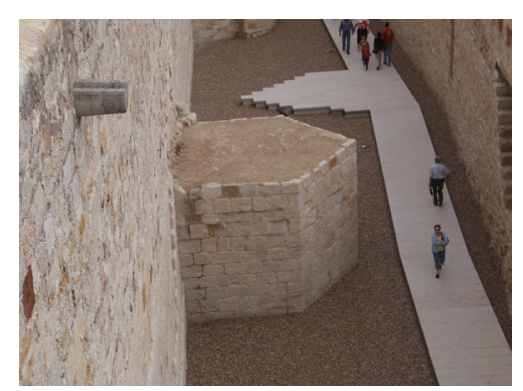

Fig. 81. Torre del castillo de Zamora

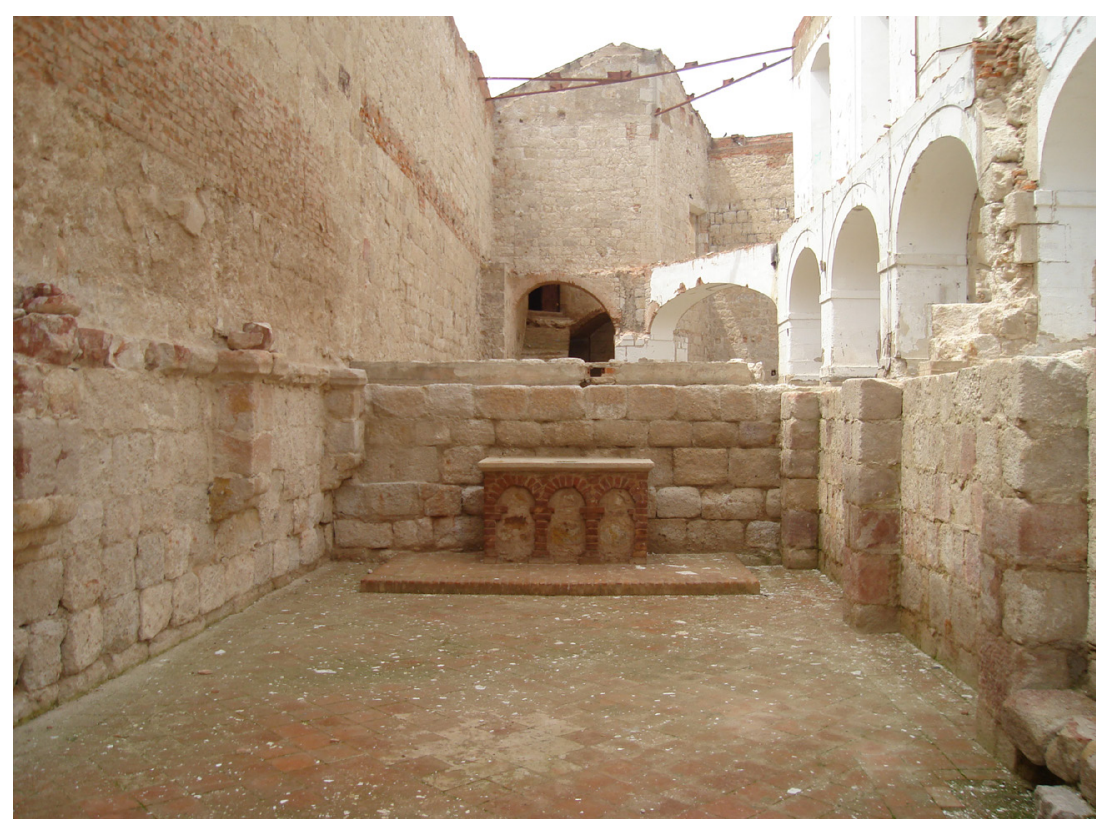

que alguna de ellas fue transformada con esta nueva forma. Aun así se conserva un testimonio ya reproducido y que corresponde al año de 1326 en el que hablando de Zamora y Toro se dice: "en cada una destas villas comenzaron luego a labrar et a enderezar los muros et a facer otras labores nuevas con que se fortalescieron mas de lo que estaban" ${ }^{\prime 2}$. Este testimonio junto al gran desarrollo que tuvo este tipo de torres de planta pentagonal durante las primeras décadas del siglo XIV podría hacernos pensar que fueron construidas justo en aquel momento.

De entre todas ellas destaca de manera acusada debido a su considerable volumen la torre del homenaje (Fig. 82), de planta heptagonal y dividida al exterior en tres cuerpos por dos molduras $^{93}$. De estas dos molduras o bandas que la adornan exteriormente una de ellas, la superior, es reciente mientras que la otra, la inferior, que va adornada con bolas, parece producto de alguna intervención llevada a cabo en tiempo de los Reyes Católicos. Es difícil concluir a que época pertenece esta primera banda ya que el tipo de ornamentación que presenta y que también se usó durante el románico tardío en la provincia de Zamora, como sucede en la portada occidental de la iglesia de Santa María del Azogue de Puebla de Sanabria, se generalizó en el periodo de los Reyes Católicos. No obstante, el volumen de estas

92 COBOS GUERRA, F. y CASTRO FERNÁNDEZ, J. J. de, op. cit., 1998, p. 61.

93 Para Cobos Guerra y Castro Fernández el diseño de esta torre del homenaje les recuerda a las del castillo de Alarcos que mandó edificar Alfonso VIII de Castilla en 1195. COBOS GUERRA, F. y CASTRO FERNÁNDEZ, J. J. de, op. cit., 1998, p. 61. 


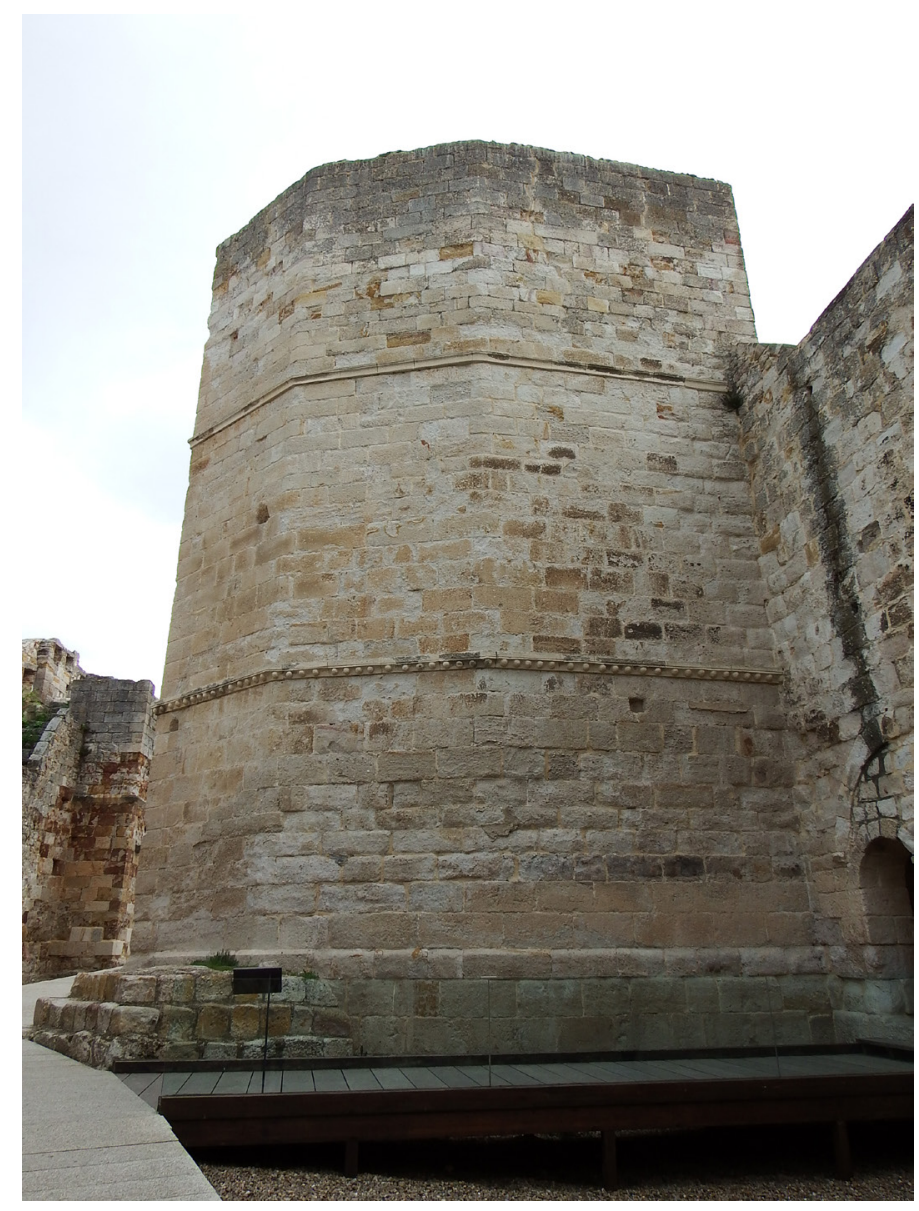

bolas, que se muestran prácticamente en todo su desarrollo, está más en consonancia con la forma de hacer durante el reinado de los Reyes Católicos. En su conjunto se trata de una torre sencilla con sus dos cuerpos bajos macizos mientras que el superior, al que se accede desde el adarve por una escalera de piedra, posee una pequeña estancia cubierta por bóveda de cañón ligeramente apuntado. Sobre él se dispone una terraza desde la que se tiene un control muy amplio de la zona.

Como conclusión podemos afirmar que las partes más antiguas que se conservan del castillo de Zamora no parecen ser anteriores a los años finales del siglo XII e, incluso, es más probable que sean ya del siglo XIII como reflejan los elementos formales que se encuentran en su estructura.

\section{El puente}

La situación de la ciudad de Zamora en una de las rutas más destacadas desde época romana hace pensar -aunque no 
existan testimonios materiales ni documentales- en la existencia de un puente de aquel periodo.

Algunos autores atribuyeron unas escasas ruinas de un puente antiguo, que todavía hoy se conservan frente a las aceñas de Olivares, a época romana y, por tanto, pertenecientes a un hipotético puente edificado en aquel tiempo ${ }^{94}$. Este puente habría sido destruido según Fernández Duro como consecuencia de un terremoto acaecido en el año 93995. Quadrado, sin embargo, señala que el 24 de enero de 1310 una crecida destruyó el puente “...al cual algunos han supuesto de romano origen..."96.

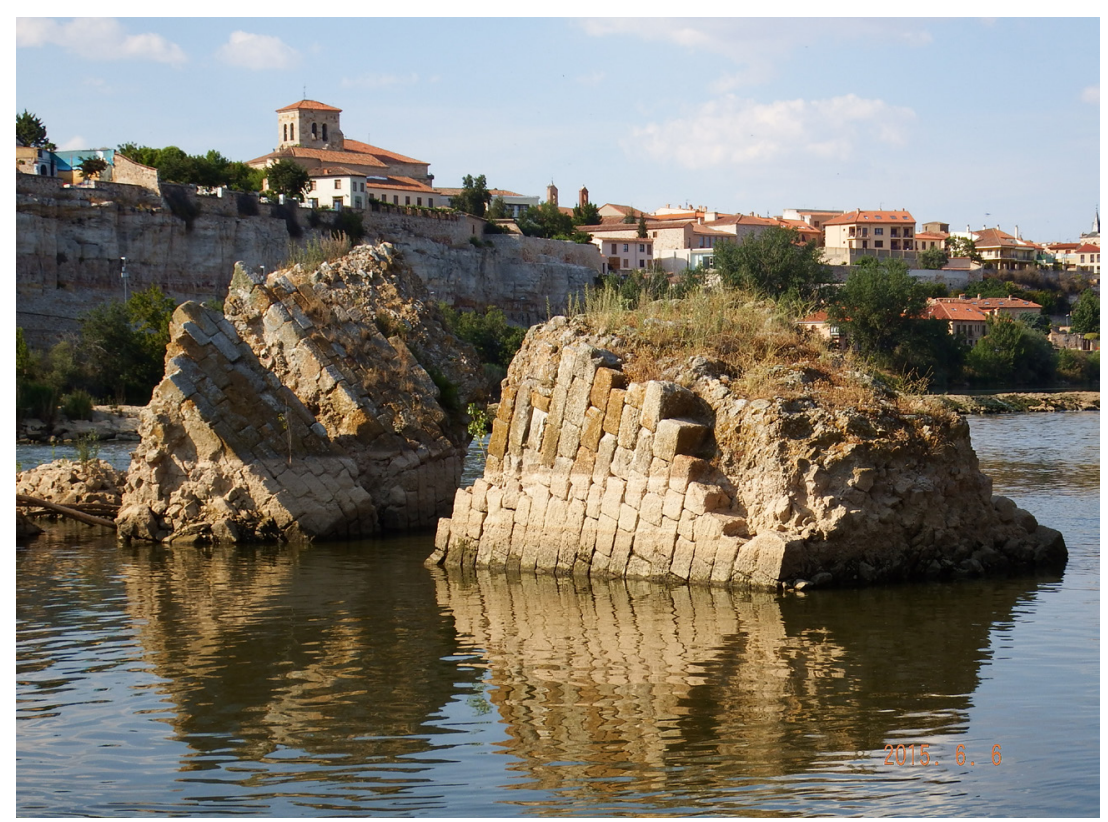

Otros autores, que tampoco dudan de la posible existencia de un puente romano, sin embargo, relacionan esas ruinas con un puente al que se cita como "viejo" y que debió responder al periodo medieval. Gómez-Moreno señala que en el siglo XII existían dos puentes en uso "...el uno, apellidado ya "Viejo" en 1157, junto a la azuda de Olivares, y el "pontem novum» que se cita en $1167 " 97$. Todo parece indicar que las actuales ruinas, las mismas que Quadrado y otros vieron en su día, son con toda probabilidad parte de ese puente "viejo" construido en época

94 Así lo manifiesta José María Quadrado. QUADRADO, J. M. y PARCERISA, F. J., op. cit., 1861 (1990), p. 50.

95 FERNÁNDEZ DURO, C., op. cit., tomo IV, 1883 (2003), p. 398.

96 QUADRADO, J. M. y PARCERISA, F. J., op. cit., 1861 (1990), p. 50.

97 GÓMEZ-MORENO, M., op. cit., I, 1927 (1980), p. 172. 


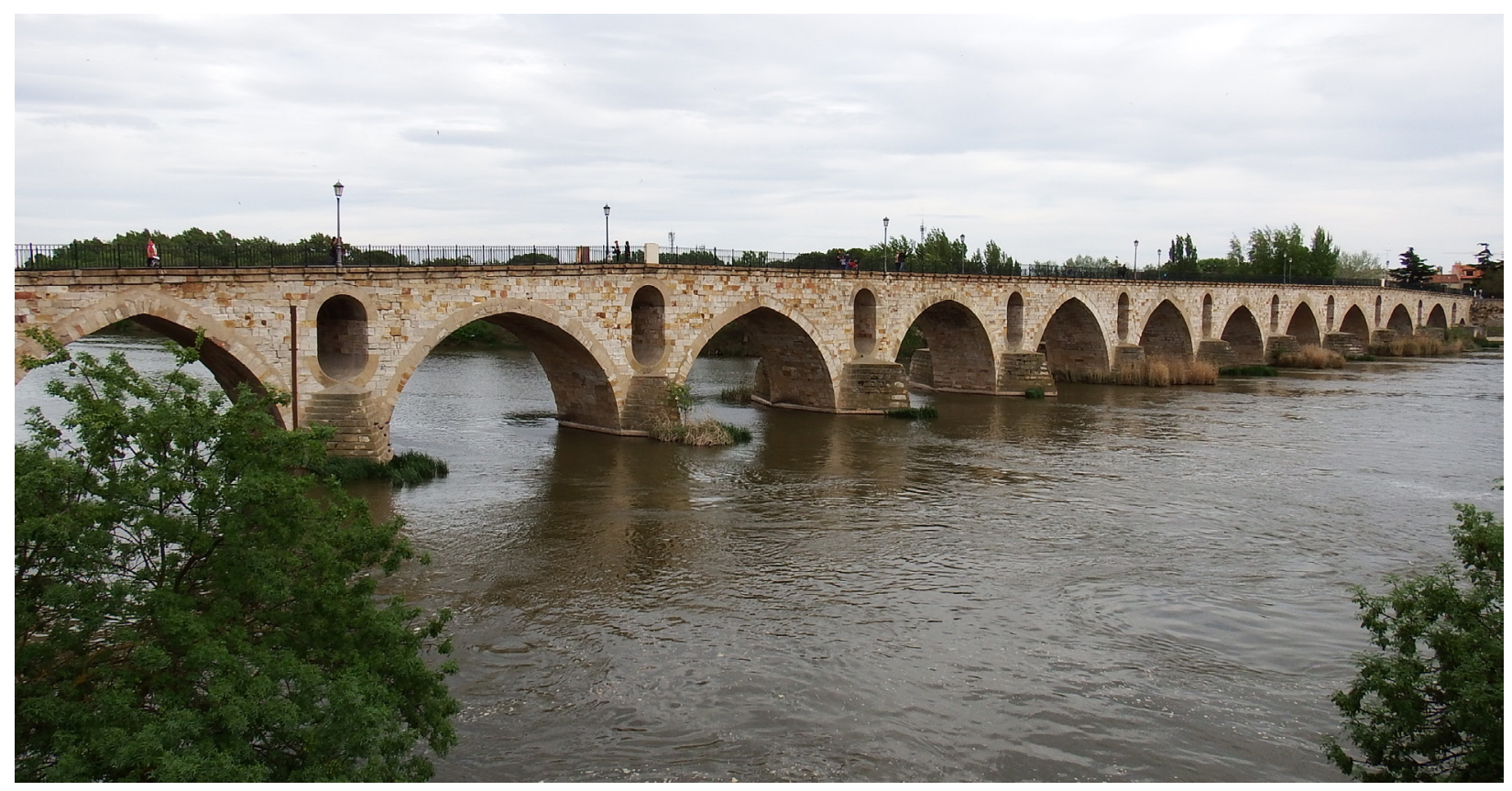

medieval que conectaba la ciudad a través de la Puerta del Obispo con las tierras que se extendían al sur del Duero (Fig. 83).

La confusión radica en la similitud existente entre el tipo de construcción romana y la empleada en los puentes que se levantaron con posterioridad, que lleva en algunos casos en los que no se conserva documentación o inscripciones, a plantear serias dificultades en la distinción de un puente romano de uno medieval.

En la actualidad, la ciudad de Zamora, al margen de las ruinas mencionadas, cuenta con un puente medieval, que se correspondería con el denominado por Gómez-Moreno como "pontem novum», y que comenzó a construirse con toda probabilidad a finales del siglo XII, y cuyas obras se debieron prolongar durante los primeros años del siglo XIII98 (Fig. 84). Fernández Duro afirma, que en base a unos documentos por él consultados, se deduce que el puente pudiera haberse edificado durante el reinado de Alfonso IX (1188-1230) ${ }^{99}$.

Este puente ha sido citado, descrito y representado en multitud de ocasiones ${ }^{100}$. De él dieron cuenta Münzer $y$, como

98 Quadrado señala que se construyó en el siglo XIV a raíz de la destrucción del puente viejo. QUADRADO, J. M. y PARCERISA, F. J., op. cit., 1861 (1990), p. 50.

99 FERNÁNDEZ DURO, Cesáreo, "El puente de Zamora", Zamora Ilustrada, tomo II, $n^{\circ}$ 39, Diputación de Zamora, 1881, pp. 3 y 4.

100 Sobre el puente medieval de Zamora puede consultarse QUADRADO, J. M ${ }^{\mathrm{a}}$ y PARCERISA, F. J., op. cit., 1861, (1990), p. 50; FERNÁNDEZ DURO, Cesáreo, "E1 puente de Zamora", Zamora Ilustrada, tomo II, n 39, Diputación de Zamora, 1881, 
se ha señalado, también Quadrado, Fernández Duro y GómezMoreno entre otros ${ }^{101}$. El estudio más profundo está incluido en la publicación titulada Los caminos y la construcción del territorio en Zamora. Catálogo de puentes ${ }^{102}$.

Presenta actualmente una apariencia muy diferente de la que tuvo en origen y de la que fue adquiriendo con los años. Según el aspecto que de él ofrece el dibujo realizado en el siglo XVI por Anton van den Wyngaerde ${ }^{103}$ estaba torreado en sus extremos y contaba en todo su desarrollo con un pretil de piedra almenado $^{104}$ (Fig. 85). Los accesos hacia el puente en ambas orillas se realizaban a través de una puerta abierta en el cuerpo bajo de las torres. En su acceso de la margen izquierda del río tenía una capilla advocada en la Virgen de la Guía. Con los siglos las torres medievales fueron sustituidas por otras edificadas en el siglo XVI y reformadas posteriormente ${ }^{105}$. A principios del XVIII

pp. 3 y 4; STREET, George Edmund, La arquitectura gótica en España, Madrid, 1926, pp. 97 y 112; GÓMEZ-MORENO, M., op. cit, I, 1927 (1980), p. 172; GAYA NUÑO, J. A., op. cit., 1961, p. 315; AA. VV., Fotografías antiguas de Zamora, Centro de Iniciativas y Turismo. Zamora, Valladolid, 1979, $\mathrm{n}^{\circ}$ 1, 2, 3, 4, 5, 8, 6 y 7; NAVARRO TALEGÓN, José, "La gobierna. Veleta" en Catálogo de la Exposición CIVITAS MC Aniversario de la Ciudad de Zamora, ficha 35, Zamora, 1993, p. 125; ENRÍQUEZ DE SALAMANCA, Cayetano, Rutas del románico en la provincia de Zamora, Ediciones Castilla, 1998, pp. 69-70; AA.VV., Memoria gráfica de Zamora, La Opinión-El Correro de Zamora, Zamora, 2000, p. 1 y 42-59; NIETO GONZÁLEZ, José Ramón, "El patrimonio arquitectónico" en AA.VV., El patrimonio histórico en el río Duero, Fundación "Rei Alfonso Henriques", Salamanca, 2001, p. 163; CHÍAS NAVARRO, P., y ABAD BALBOA, T., op. cit., 2004, pp. 82-95; AA. VV., Zamora en imágenes. 1925-1950. Fotografía y Sociedad, Zamora, 2005, pp. 6 y 18-19; GARCÍA RUBIO, José Manuel, Ayer y Hoy de Zamora, La Opinión. El Correo de Zamora, 2006, pp. 110 y 146; LARRÉN IZQUIERDO, Hortensia, "Una vista de la parte oriental de Zamora" en AA.VV., Zamora Año de 1850 (Sergio Pérez Martín y Marco Antonio Martín Bailón (Coord.)), Zamora, 2013, pp.279-284 y lám. 52; PÉREZ MARTÍN, Sergio y MARTÍN BAILÓN, Marco Antonio "El puente de Zamora, sobre el Duero" y "Vista tomada desde la cuesta de Pizarro" en AA.VV., Zamora Año de 1850 (Sergio Pérez Martín y Marco Antonio Martín Bailón (Coord.)), Zamora, 2013, pp. 268-279 y láms. 51 y 53.

101 QUADRADO, J. M. y PARCERISA, F. J., op. cit., 1861 (1990), p. 50; GÓMEZMORENO, M., op. cit., I, 1927 (1980), p. 172; GARCÍA SIMÓN, Agustín, Castilla y León según la visión de los viajeros extranjeros. Siglos XV-XIX, Junta de Castilla y León, Salamanca, 1999, p. 355.

102 En este catálogo se realiza un exhaustivo estudio del puente de piedra de Zamora desde el punto de vista histórico atendiendo a las numerosas vicisitudes por las que a lo largo de los siglos ha pasado y además se recoge una amplia bibliografía. CHÍAS NAVARRO, P. y ABAD BALBOA, T., op. cit., 2004, pp. 82-95.

103 KAGEN, RICHARD L., (Dir): Ciudades del Siglo de Oro. Las vistas españolas de Antón Van den Wyngaerde, Ediciones El Viso, 1986, pp. 370-372.

104 Las torres que dibujó Wyngaerde no son las que tuvo en origen sino unas nuevas que hubo que reedificar después de una gran avenida. FERNÁNDEZ DURO, C., op. cit., tomo II, 1883 (2003), p. 317.

105 La participación de Pedro de Ybarra en algunas de las reformas que sufrió el puente durante el siglo XVI ha sido documentada por Ana Castro en CASTRO SANTAMARÍA, Ana, "Pedro de Ybarra, a la sombra de Juan de Álava" en AA. VV., 


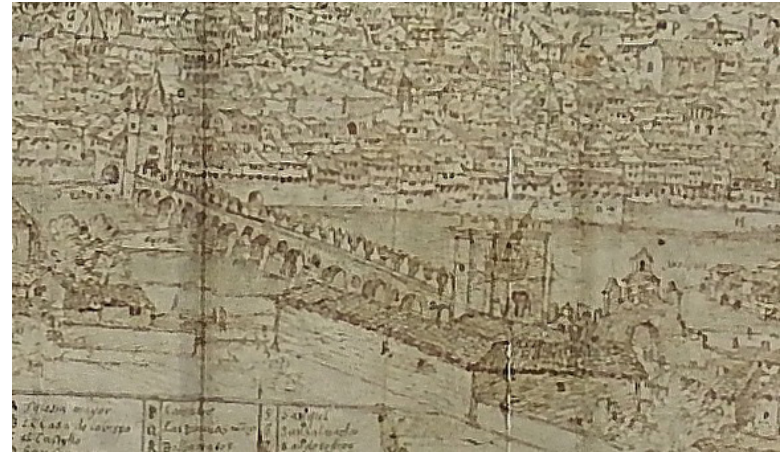

se colocó sobre una de ellas la renombrada veleta de la Gobierna que se conserva en la actualidad en el Museo Provincial de Zamora ${ }^{106}$. Las torres, que todavía llegó a ver Gómez-Moreno, fueron demolidas en $1905^{107}$.

Estos elementos desaparecidos, las torres y el pretil de piedra almenado, que le conferían un carácter monumental a la vez que defensivo, hay que tenerlos presentes ya que sin ellos la comprensión de este puente sería incompleta (Figs. 86 y 87). A falta de estos elementos que enriquecían el puente hay que añadir los enormes desperfectos causados por las múltiples crecidas del río Duero que le afectaron sobremanera, de tal modo que ha tenido que ser reparado en diversas ocasiones, siendo sumamente complejo llegar a saber con exactitud en algunas zonas, qué responde a la construcción primitiva y qué a intervenciones posteriores (Fig. 88).

Desdeel punto devista descriptivoyatendiendoaloconservado se trata de un puente de grandes dimensiones $-281 \mathrm{~m}$ - que ha sido determinante para el propio desarrollo de la ciudad desde el punto de vista político, económico y social. Hasta hace muy poco tiempo ha sido fundamental para la comunicación de ambas orillas del río Duero. En marzo de 2013 quedó definitivamente cerrado al tráfico rodado y, posteriormente, después de reparar aquello más urgente, se procedió a la redacción del proyecto de

Los últimos arquitectos del Gótico (Begoña Alonso Ruiz Coord.), Madrid, 2010, pp. 438-441.

106 Esta veleta junto con los escudos que se encuentran en los jardines del castillo de la ciudad de Zamora son los únicos restos conservados de las torres del puente derruidas en 1905, hecho que recoge don Manuel Gómez-Moreno: "Una posterior reforma del puente ha hecho desaparecer ambas torres, con todas sus piezas decorativas: nuevo atentado artístico seguido de impunidad silenciosa". GÓMEZ-MORENO, M., op. cit., I, 1927 (1980), p. 172. Sobre la veleta vid. NAVARRO TALEGÓN, José, "La gobierna. Veleta" en Catálogo de la Exposición CIVITAS MC Aniversario de la Ciudad de Zamora, ficha 35, Zamora, 1993, p. 125.
Fig. 85. Representación del puente medieval de Zamora en el dibujo realizado por Wyngaerde 


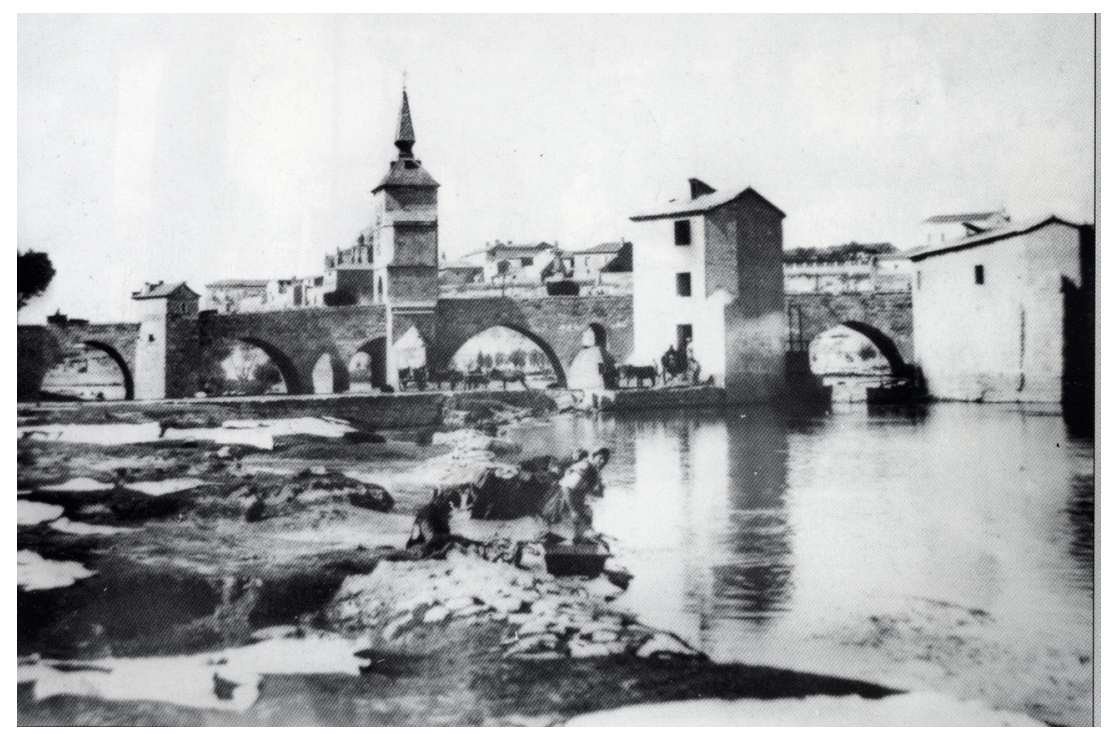

rehabilitación y a la puesta en valor con el objeto de convertirlo en un puente peatonal. Está construido en muy buena sillería y su estructura se compone de un tablero recto soportado por gruesos pilares entre los que se abren grandes arcadas, de trazado en medio punto unas y, las más, en trazado apuntado; todas con una luz no demasiado amplia. Los pilares en su mitad inferior están reforzados, tanto al este como al oeste, por tajamares de sección triangular; en su mitad superior se abren, en forma ovalada, unos arquillos de aligeramiento. Ambos elementos, los tajamares y los arquillos, son fundamentales para que el puente soporte las enormes crecidas que el Duero acostumbra a tener cada cierto tiempo.

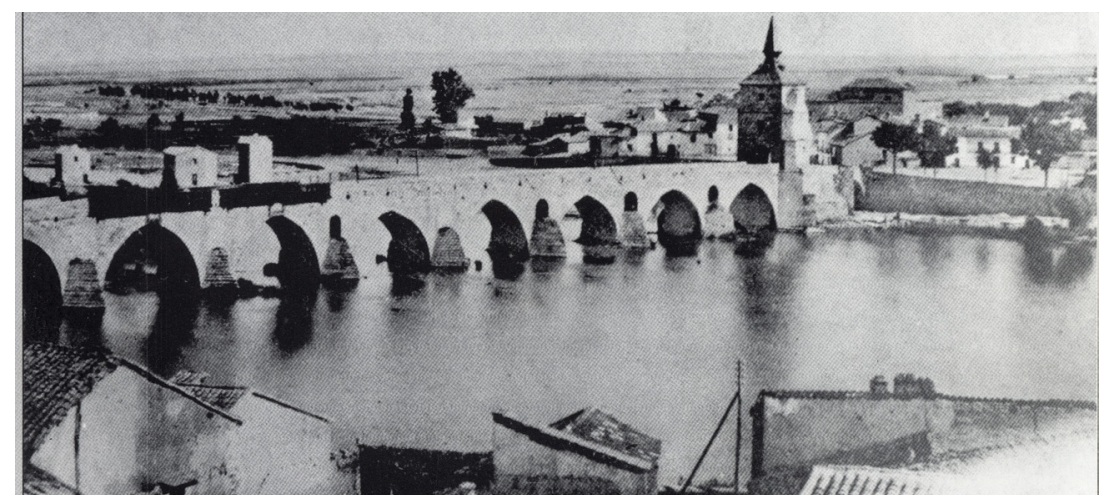

La única referencia para la cronología es la presencia de algunos arcos apuntados que sugieren una tímida inclinación hacia formas nuevas relacionadas con la introducción de los primeros cambios de la arquitectura en este momento. 


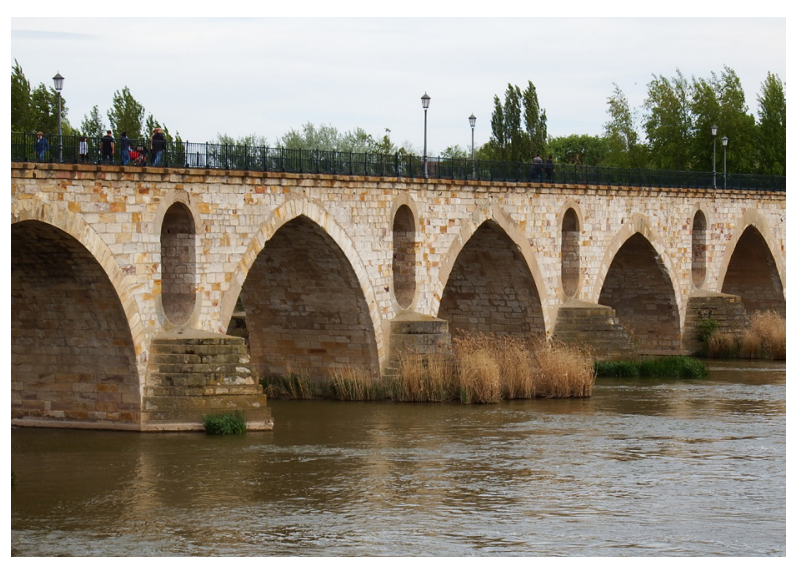

En la provincia de Zamora, concretamente en la localidad de Toro, se conserva un puente muy similar y contemporáneo a éste ${ }^{108}$.

\section{La fortificación y el puente de Toro}

La historia de Toro durante los siglos de la reconquista corrió paralela a la de la ciudad de Zamora, de tal modo que jugó un papel de enorme importancia en la defensa de la línea del Duero, organizada por Alfonso III, repoblador, como ya se ha dicho, de ambas ciudades ${ }^{109}$.

Esta situación y función determinaron el aspecto de plaza fuerte en que se convirtió la ciudad, que muy pronto contó con alcázar, dos recintos amurallados y puente. Todas estas edificaciones se levantaron durante el periodo románico aunque sufrieron ampliaciones, transformaciones y reparaciones en los siglos posteriores. También el paso del tiempo y el desarrollo de la ciudad les ha afectado gravemente, de ahí que el estado parcial en el que han llegado estas estructuras a nuestros días haga complejo un análisis en profundidad de todo este conjunto. Solamente el puente constituye la única construcción civil de este periodo verdaderamente interesante para nuestro estudio no solo por haber conservado gran parte de su estructura en pie sino además de por lo que ésta supone de receptora de una nueva arquitectura que comienza a utilizar el arco apuntado.

\footnotetext{
108 El puente medieval conservado en Toro se levantó en el mismo lugar en el que se alzaba el puente romano del cual se conservan algunos vestigios integrados en el actual. CORZO SÁNCHEZ, J. R., San Pedro de la Nave. Estudio histórico y arqueológico de la iglesia visigoda, Instituto de Estudios Zamoranos «Florián de Ocampo», Zamora, 1986, p. 30.

109 El Silense señala como fecha de la repoblación de la ciudad de Toro el año de 899 mientras que Sampiro apunta la de 910.
} 


\section{El alcázar}

El alcázar, que solamente conserva su perímetro exterior, se alza al sureste de la ciudad dominando la amplísima vega toresana ${ }^{110}$. Actualmente está desprovisto del foso y de la muralla que lo rodeaba.

Algunos estudiosos ${ }^{111}$ hacen remontar su origen al siglo $\mathrm{X}$, momento en el que Alfonso III ordenó repoblar la ciudad. Otros lo creen más bien de tiempos de Alfonso IX $^{112}$ (1188-1230) e, incluso, del momento inmediatamente posterior a la donación de Toro y su alfoz por parte de Sancho IV a su esposa María de Molina (finales del siglo XIII), que habría sido la encargada de redificarlo ${ }^{113}$.

110 Sobre el Alcázar de Toro puede consultarse GÓMEZ DE LA TORRE, A., Corografia de la provincia de Toro, Madrid, 1802 (2002), p. 34; MADOZ, Pascual, Diccionario Geográfico-Estadístico-Histórico de España y sus posesiones de Ultramar, Madrid, 1845, ((edición facsímil, Almendralejo, 1989), tomo XV, pp. 37-43; FERNÁNDEZ DURO, C., op. cit., I, 1883, pp. 220-221; GÓMEZ-MORENO, M., op. cit., I, 1927 (1980), p. 205; CASAS RUIZ DEL ÁRBOL, Francisco, Motivos de Toro, Zamora, 1970, pp. 199-202; VELASCO RODRÍGUEZ, Victoriano, Guía turística de la Provincia de Zamora, Zamora, 1961, p. 193; NAVARRO TALEGÓN, J., op. cit., 1980, pp. 91-126, pp. 43-45; SARTHOU CARRERES, Carlos, Castillos de España, Espasa-Calpe, Madrid, 1984, p. 352; QUINTANILLA RASO, María Concepción, Alcaides, tenencias y fortalezas del reino de León en la baja edad media, 1989, p. 78, PINILLA GONZÁLEZ, Jaime, Castillos de Zamora y Salamanca, Ediciones Lancia, Madrid, 1989, pp. 22-23; GUTIÉRREZ GONZÁLEZ, José Avelino, Fortificaciones y feudalismo en el origen y formación del reino leonés (siglos IX-XIII), Universidad de Valladolid, Zaragoza, 1995, pp. 389-392; ENRÍQUEZ DE SALAMANCA, C., op. cit., 1998, pp. 115-116; MARTÍN JIMÉNEZ, Carlos M., Los castillos y fortalezas de Castilla y León (Rutas para descubrir), Ámbito, Valladolid, 2003, pp. 316-317; MARTÍN JIMÉNEZ, Carlos Manuel, Los castillos y fortalezas de Castilla y León (Rutas para descubrir), Ámbito, Valladolid, 2003, pp. 316-317; LARRÉN IZQUIERDO, H. y PICHEL RAMOS, L., op. cit., 2010, p. 135.

111 En el Catálogo Monumental Navarro Talegón lo considera del siglo X, sin embargo en la Enciclopedia del Románico dice: "es posible que [al actual] le precediera un fuerte levantado a comienzos del siglo X, cuando Alfonso III mandó repoblar la ciudad". NAVARRO TALEGÓN, J., op. cit., 1980, p. 43; NAVARRO TALEGÓN, José, “Alcázar" en RODRÍGUEZ MONTAÑÉS, J. M., (coord.) Enciclopedia del Románico en Castilla y León. Zamora, Centro de Estudios del Románico, Aguilar de Campoo, 2002, p. 261; García Lobato considera que fue levantado por García I a instancias de su padre el monasrca Alfonso III durante los últimos años del siglo IX y los primeros del siglo X. LOBATO VIDAL, J.C., op. cit., 1997, p. 100.

112 Alfonso IX, rey de León, nació en la ciudad de Zamora en 1171 y reinó desde el año 1188 hasta su muerte acaecida en 1230 .

113 Aunque Cobos Guerra y Castro Fernández consideran que el origen y primera edificación de la fortaleza habría de situarlo durante el reinado de Alfonso IX afirman que fue María de Molina la que reconstruyó el edificio dándole su forma actual. COBOS GUERRA, Fernando y CASTRO FERNÁNDEZ, José Javier de, Castilla y León. Castillos y Fortalezas, León, 1998, p. 62. Serrano-Piedecasas Fernández, que también sitúa su origen en tiempos de Alfonso IX, señala que casi cuarenta años después de su inicio la fortaleza no estaba concluida. SERRANO-PIEDECASAS FERNÁNDEZ, Luis, "La arquitectura militar" en AA. VV., El patrimonio histórico en el río Duero, Fundación "Rei Alfonso Henriques”, Salamanca, 2001, p. 316. 


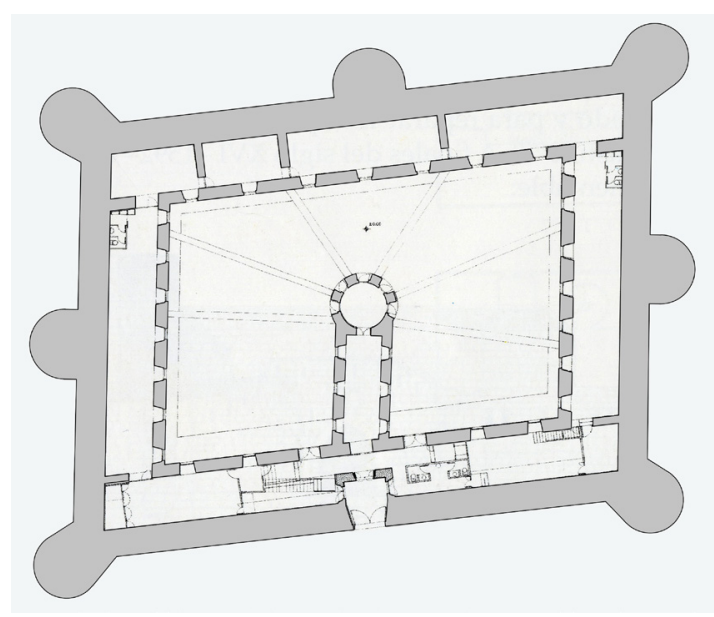

Fig. 89, Planimetría del alcázar de Toro. Cobos Guerra y Castro Fernández, 1998, p. 62. (Arch. J.C.

El edificio tiene planta rectangular con una ligera deformación que tiende a convertirla en romboidal (Fig. 89). Su perímetro está reforzado por siete cubos macizos, tres semicirculares en los entrepaños, y otros cuatro ultrasemicirculares en las esquinas (Fig. 90). La torre del homenaje, de planta cuadrada y situada en la zona media del muro norte, fue derribada en el siglo XIX para abrir el actual acceso adintelado ${ }^{114}$. Toda esta parte conservada está construida mediante dos hiladas paralelas de mampuesto de piedra caliza con el interior relleno de cal y canto rodado ${ }^{115}$.

Todo indica - su función concreta en una época determinada, las formas y el sistema constructivo- que fue bajo el reinado de Alfonso IX (1188-1230) cuando se levantó el Alcázar junto al primer recinto de murallas. De hecho su composición planimétrica guarda una gran semejanza con la del desaparecido alcazarejo de Valladolid, cuyas excavaciones arqueológicas ofrecen una cronología correspondiente a la segunda mitad del siglo XII y principios del siglo XIII116. Lobato Vidal, sin embargo, considera que de la reedificación hecha durante los siglos XII y XIII no se conserva nada y atribuye el castillo que ha llegado a nuestros días a un momento avanzado de la Edad Media ${ }^{117}$.

La función defensiva que cumplían estos elementos arquitectónicos les imprimió un aspecto sólido desprovisto de elementos específicamente relacionables con las formas características del estilo que imperaba en el momento. De este 114 NAVARRO TALEGÓN, J., op. cit., 1980, p. 43.

\section{5 Ídem.}

116 MARTÍN MONTES, Miguel, El Alcázar Real de Valladolid, Fundación Municipal de Cultura del Excmo. Ayuntamiento de Valladolid, Valladolid, 1995, p. 95.

\section{LOBATO VIDAL, J.C., op. cit., 1997, p. 100.}




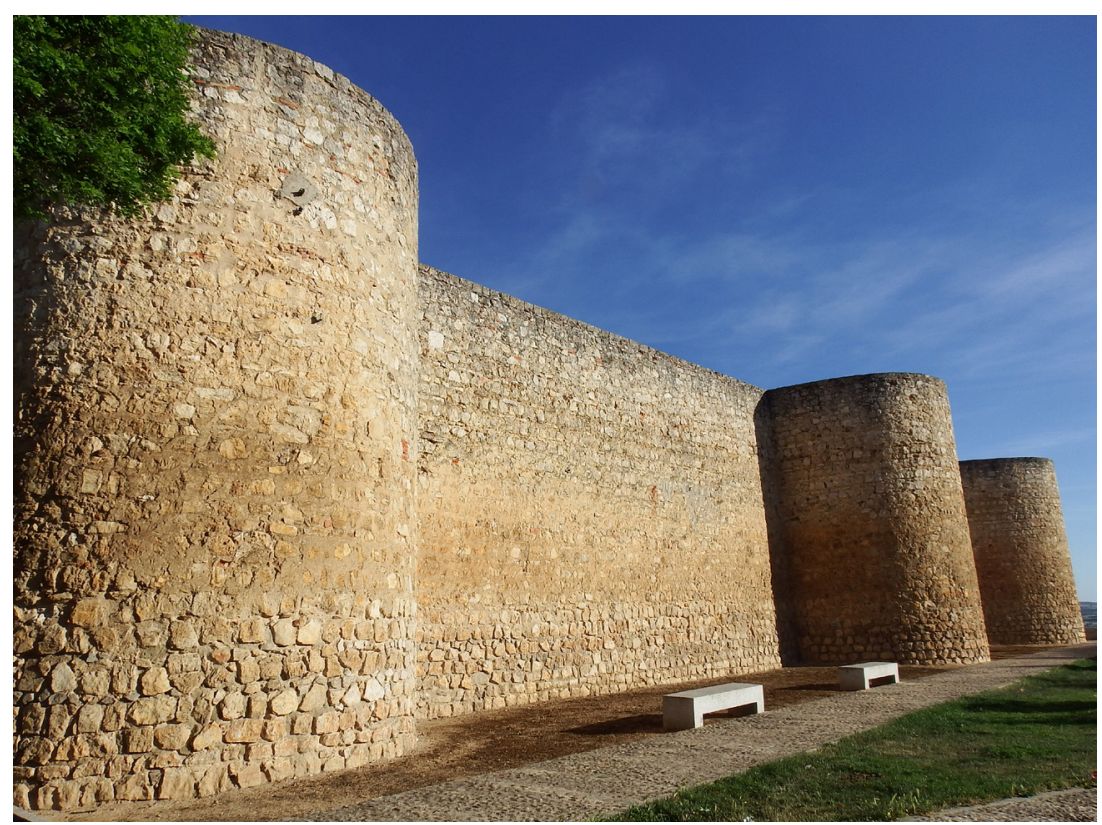

modo es muy complejo determinar si alguna de las partes 0 estructuras que conforman este edificio se edificaron en el periodo gótico. También ignoramos si con las reformas llevadas a cabo en el alcázar de Toro durante los siglos XIII, XIV y XV se llegó a dotar al edificio de alguna parte gótica reseñable que de haberse conservado hubiera tenido un gran interés para este estudio ${ }^{118}$.

El edificio fue utilizado por el monarca Juan II como residencia regia en las numerosas ocasiones que visitó su ciudad natal ${ }^{119}$.

\section{Las murallas}

Los distintos autores que han tratado sobre las murallas de Toro han aportado distintas propuestas sobre el número de recintos y su cronología. Gómez-Moreno señala la existencia de dos recintos. El primero de ellos apunta que es probable que se edificara a raíz de la organización de la ciudad por parte de Alfonso VII y los restos que se han conservado los relaciona con los de Villalpando y Belver ${ }^{120}$. Para el segundo no señala ninguna cronología aunque dice que era “...doble en extensión que la primitiva, a la que ciñe por lo llano, es, como la de Benavente, de

118 Estas reformas están recogidas por Cobos Guerra y Castro Fernández en COBOS GUERRA, F. y CASTRO FERNÁNDEZ, J. J. de, op. cit., 1998, p. 62.

119 CAÑAS GÁLVEZ, Francisco de Paula, El itinerario de la corte de Juan II de Castilla (1418-1454), Madrid, 2007, p. 89.

120 GÓMEZ-MORENO, M., op. cit., I, 1927 (1980), pp. 204-205. 
tapias de tierra con torres cuadradas, a distancia de cuarenta y cinco o cincuenta pasos una de otra, y grandemente aniquilada en razón de su fragilidad y del provecho que el destruirla reporta" ${ }^{121}$. Lobato Vidal igualmente señala la existencia de dos recintos ${ }^{122}$. El más antiguo considera que responde a los siglos XII y XIII y en línea con lo que ya dijo Gómez-Moreno observa en él una fisonomía semejante a la de los recintos de Villalpando y Belver de los Montes ${ }^{123}$. Según este autor carecía de cubos o torres de defensa y contaba, como todavía se puede observar en los fragmentos que se han conservado, con adarve y almenado. Rodeaba la ciudad antigua y tenía como accesos seis puertas y dos postigos. El segundo recinto lo data a mediados del siglo XIV y señala que se construyó para integrar los arrabales que habían ido surgiendo con el paso de los años. Navarro Talegón ${ }^{124}$ menciona primeramente una cerca que debió alzarse a raíz de la repoblación Ilevada a efecto por el monarca Alfonso III el Magno y de la que no se ha conservado ningún vestigio. Habla de un segundo recinto construido en las últimas décadas del siglo XII y primeras del XIII y una tercera y última cerca murada concluida en tiempos de Alfonso XI.

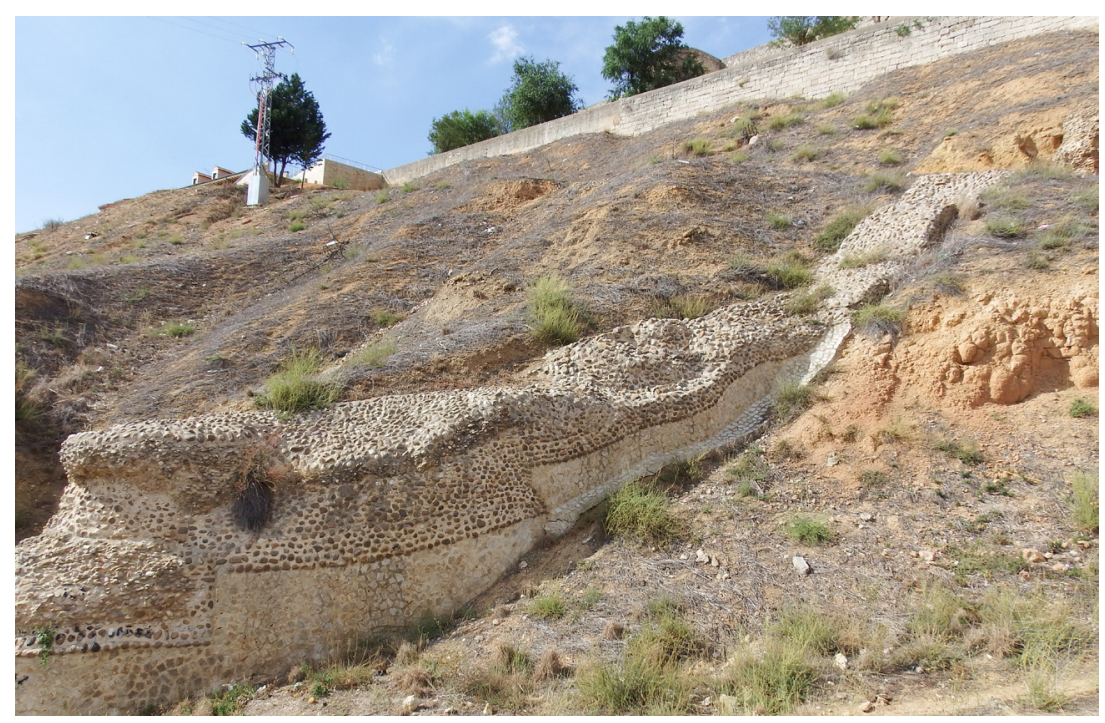

121 Ídem, p. 205.

122 LOBATO VIDAL, J.C., op. cit., 1997, pp. 101-102.

123 Este autor señala, como ya hicieran otros anteriormente, la probabilidad de que esta primera cerca siguiera el trazado hipotético de una cerca de época romana o prerromana, cuya existencia a día de hoy no ha podido demostrarse. LOBATO VIDAL, J.C., op. cit., 1997, p. 102.

124 NAVARro TALEGÓN, José, "Toro" en RODRÍGUEZ MONTAÑÉS, J. M., (coord.) Enciclopedia del Románico en Castilla y León. Zamora, Centro de Estudios del Románico, Aguilar de Campoo, 2002, pp. 215-216. 
En un estudio reciente, Cobos Guerra, Castro Fernández, y Canal Arribas consideran que durante el periodo medieval existió únicamente en la ciudad de Toro un recinto y que no fue hasta el siglo XVI cuando se edificó uno nuevo ${ }^{125}$. El primer recinto englobaba casi 21 hectáreas y se han conservado distintos fragmentos, compuestos de tapial de cal y canto, entre ellos, un tramo importante que conectaba el castillo con el puente bajando por la ladera (Fig. 91). Restos que por su funcionalidad y su fragmentación no pueden interpretarse desde el punto de vista del estilo artístico. La construcción, por tanto, de esta fortificación pertenece a un planteamiento de defensa de la frontera del reino de León que se llevó a cabo durante los siglos XII y XIII con características comunes desde el punto de vista tipológico y constructivo.

Del segundo recinto, que tenía una extensión considerablemente mayor que el primero y que estaba conformado por gruesos muros de tapial de cal y canto, nos e ha conservado nada.

\section{El puente Mayor}

El Puente Mayor o de piedra de la ciudad de Toro que salva las aguas del río Duero está situado al sur de la población, prácticamente cien metros por debajo de ella ${ }^{126}$ (Fig. 92). Aunque ha sufrido importantes intervenciones a lo largo de los siglos que han modificado, en parte, su aspecto original, se trata de una obra importante citada o tratada por todos aquellos estudiosos o historiadores que se han mostrado interesados por el patrimonio

125 COBOS GUERRA, Fernando, CASTRO FERNÁNDEZ, José Javier de y CANAL ARRIBAS, Rodrigo, Castros y recintos de la frontera de León en los siglos XII y XIII. Fortificaciones de tapial de cal y canto o mampostería encofrada, Valladolid, 2012, pp. 78-80 y 190-193.

126 Fruto del concurso "Los nueve secretos" convocado por la Fundación del Patrimonio Histórico de Castilla y León, el puente Mayor de Toro ha sido seleccionado para su restauración y puesta en valor. Actualmente dicha Fundación está redactando el plan director del Puente Mayor de Toro con el objetivo de marcar las bases para su posterior restauración. El importe de la redacción del plan director y de la redacción de los estudios documentales necesarios tienen un coste total de 84.000 euros que van a ser sufragados por la Fundación del Patrimonio Histórico de Castilla y León y por el Ayuntamiento de Toro. 
toresano y a su vez aparece incluida en numerosos catálogos relativos a puentes ${ }^{127}$.

Al igual que se ha comprobado en otros muchos puentes de la geografía nacional en el lugar en que se levanta este Puente Mayor de Toro debió existir uno anterior construido con toda probabilidad en época romana ${ }^{128}$. Así, al menos, lo evidencia la existencia de sillares almohadillados en algunas de las pilas y tajamares y que están labrados en un tipo de piedra diferente a la observada en el resto del puente. Navarro Talegón ha identificado aquellas zonas en las que se conservan restos de ese primitivo puente romano y a su vez ha deslindado la obra original perteneciente a finales del siglo XII y primer tercio del siglo XIII de las renovaciones que ha acusado ${ }^{129}$.

Su apariencia actual responde en lo esencial al estilo románico tardío y guarda grandes semejanzas con el puente de piedra conservado en la ciudad de Zamora, aunque la falta de uso en las últimas décadas haya sumido al puente de Toro en un estado lamentable (Fig. 93).

127 El estudio más riguroso y la bibliografía más amplia acerca de este puente puede consultarse en CHÍAS NAVARRO, Pilar y ABAD BALBOA, Tomás, Los caminos y la construcción del territorio en Zamora. Catálogo de Puentes, Salamanca, 2004, pp. $62-$ 71. No obstante, se señalan a continuación a algunos de los autores que han tratado sobre él por ser sus apuntes significativos. QUADRADO, J. M., y PARCERISA, F. J., op. cit., 1861 (1990), p. 95; FERNÁNDEZ DURO, C., op. cit., tomo I, 1883 (2003), p. 147; GÓMEZ-MORENO, M., op. cit., I, 1927 (1980), p. 205; VELASCO RODRÍGUEZ, Victoriano, Guía turística de la Provincia de Zamora, Zamora, 1961, pp. 193-194; CASAS Y RUIZ DEL ÁRBOL, Francisco, Motivos de Toro, Zamora, 1970, pp. 195198; NAVARRO TALEGÓN, J., op. cit., 1980, pp. 45-48; CHÍAS NAVARRO, Pilar y ABAD BALBOA, Tomás, Puentes de España, Madrid, 1994, pp. 98-99; ENRÍQUEZ DE SALAMANCA, Cayetano, Rutas del románico en la provincia de Zamora, Ediciones Castilla, 1998, p. 116; VASALLO TORANZO, Luis, Arquitectura en Toro (1500-1650) Instituto de Estudios Zamoranos "Florián de Ocampo", Diputación de Zamora, 1994, pp. 123-128; NIETO GONZÁLEZ, José Ramón, "El patrimonio arquitectónico" en AA.VV., El patrimonio histórico en el río Duero, Fundación "Rei Alfonso Henriques", Salamanca, 2001, p. 136; NAVARRO TALEGÓN, José, "Puente Mayor" en RODRÍGUEZ MONTAÑÉS, J. M., (coord.) Enciclopedia del Románico en Castilla y León. Zamora, Centro de Estudios del Románico, Aguilar de Campoo, 2002, pp. 263-266; LARRÉN IZQUIERDO, H. y PICHEL RAMOS, L., op. cit., 2010, p. 134.

128 Así lo afirman NAVARRO TALEGÓN, José, "Puente Mayor” en RODRÍGUEZ MONTAÑÉS, J. M., (coord.) Enciclopedia del Románico en Castilla y León. Zamora, Centro de Estudios del Románico, Aguilar de Campoo, 2002, p. 264; CHÍAS NAVARRO, P. y ABAD BALBOA, T., op. cit., 2004, p. 64. Otros autores, por el contrario, niegan con rotundidad la ascendencia romana de este puente. NIETO GONZÁLEZ, José Ramón, "El patrimonio arquitectónico" en AA.VV., El patrimonio histórico en el río Duero, Fundación "Rei Alfonso Henriques”, Salamanca, 2001, p. 136.

129 NAVARRO TALEGÓN, José, "Puente Mayor” en RODRÍGUEZ MONTAÑÉS, J. M., (coord.) Enciclopedia del Románico en Castilla y León. Zamora, Centro de Estudios del Románico, Aguilar de Campoo, 2002, p. 264-266. 


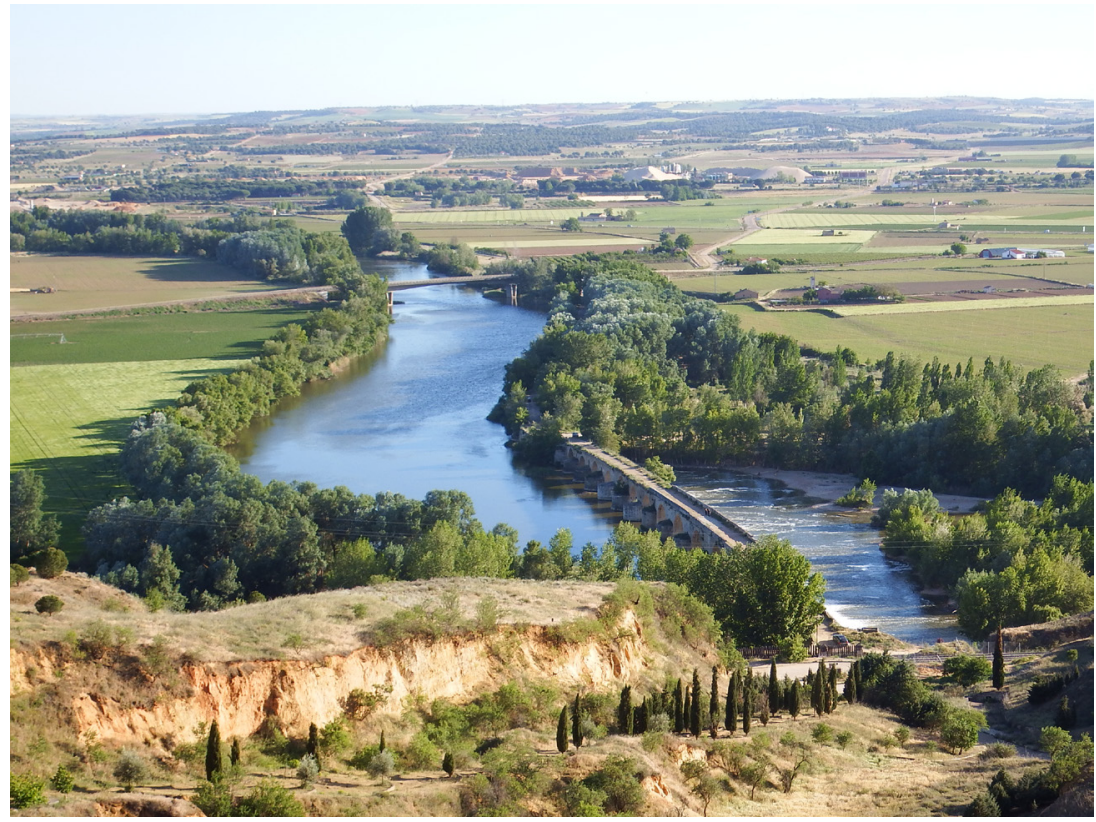

El puente Mayor de Toro está dividido en la actualidad en dos tramos perfectamente diferenciados. El primero de ellos, de grandes dimensiones, corresponde en su mayor parte a época medieval y es, por tanto, al que se le va a prestar atención. Arranca de la margen derecha del río Duero y está compuesto por diecisiete bóvedas. El segundo tramo es de dimensiones más reducidas y debió añadirse con posterioridad cuando el río varió su cauce. Entre ambos tramos se levantaba una torre medieval, hoy totalmente desaparecida, de planta cuadrada y que, como era común en los puentes de esta época, albergaba en su parte inferior una capilla en este caso bajo la advocación de Nuestra Señora de la Guía (Fig. 94).

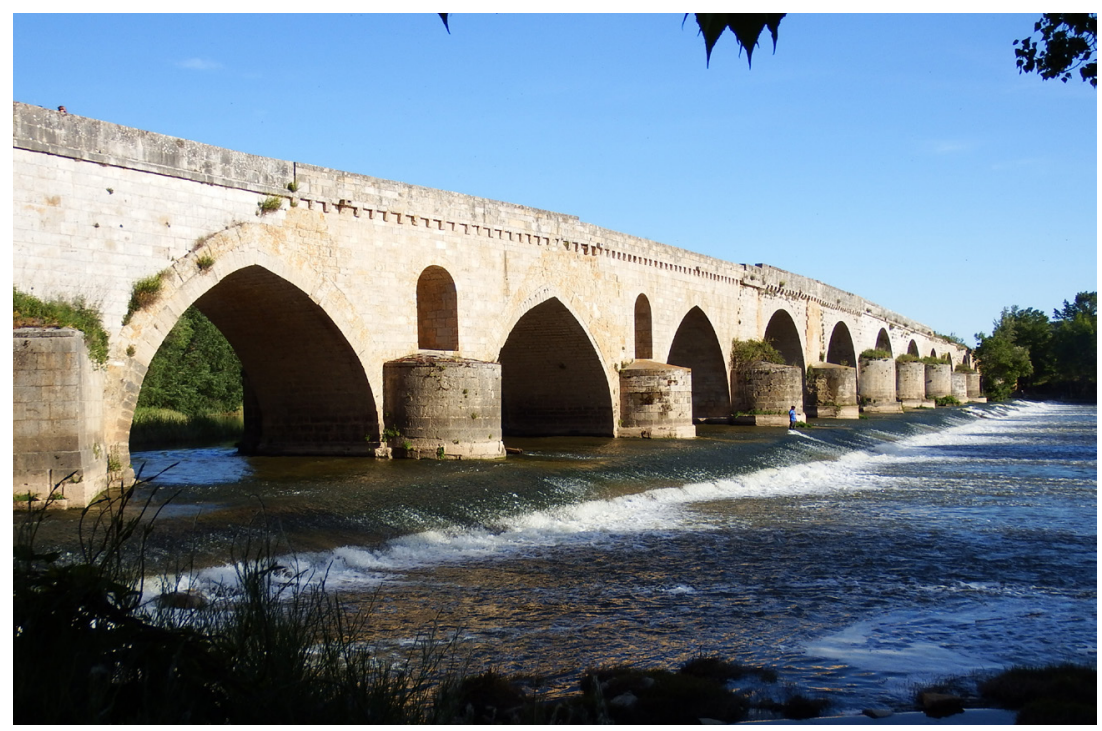




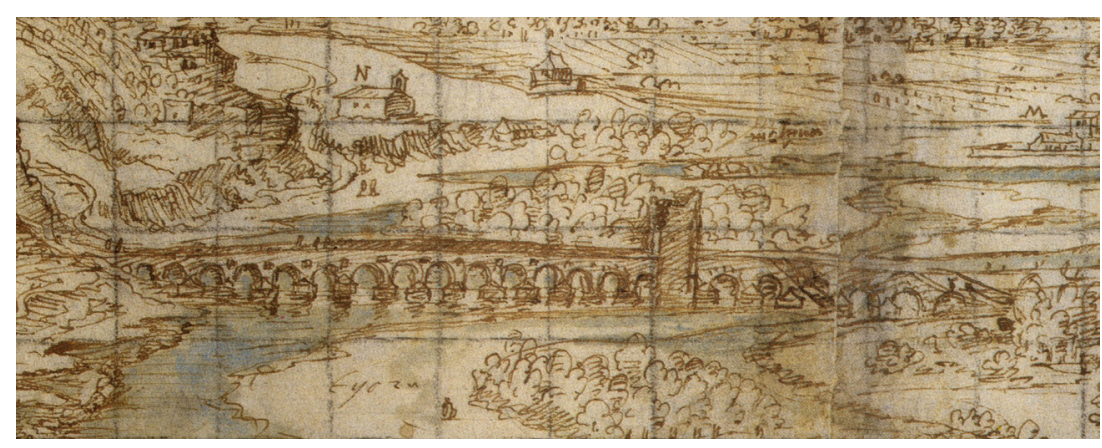

La fábrica actual del primero de los tramos, que es realmente el que constituye el puente denominado de piedra o Mayor, se remonta a época medieval aunque ha sido muy modificada a lo largo de los siglos. El momento concreto de la edificación fueron los años finales del siglo XII y las primeras décadas del siglo XIII, contemporáneo, por tanto, al puente homónimo de la ciudad de Zamora y a la remodelación del sistema defensivo de Toro. Esta cronología queda constatada en el concierto entre el pueblo salmantino de San Cristóbal de la Cuesta y el concejo de Toro del año 1194 en el que se citan las obras del puente ${ }^{130}$.

Tiene unas dimensiones considerables ya que supera en longitud los 400 metros y una anchura variable cuya media se establece en 6,75 metros. La plataforma descansa en 17 bóvedas, 6 en arco apuntado y, las restantes, de medio cañón, que salvan unas luces que oscilan entre los 6 y los 16 metros mientras que la rasante se eleva sobre su cauce cerca de 9 metros $^{131}$.

En toda su longitud se abrían, sobre las pilas, unos arquillos de aligeramiento, muchos de los cuales fueron cegados durante alguna de las reformas que afectaron al puente.

De las diecisiete bóvedas medievales de que consta el puente solamente siete están formadas por arcos apuntados (Fig. 95). Estas son, desde el norte hacia el sur, la primera, tercera, cuarta, quinta, decimocuarta, decimosexta y decimoséptima. En algunas de estas bóvedas apuntadas se observa la correspondencia del arco con la estructura original, pero en la mayoría es fácilmente
Fig. 94. Representación del puente medieval de Toro en el dibujo realizado por Wyngaerde

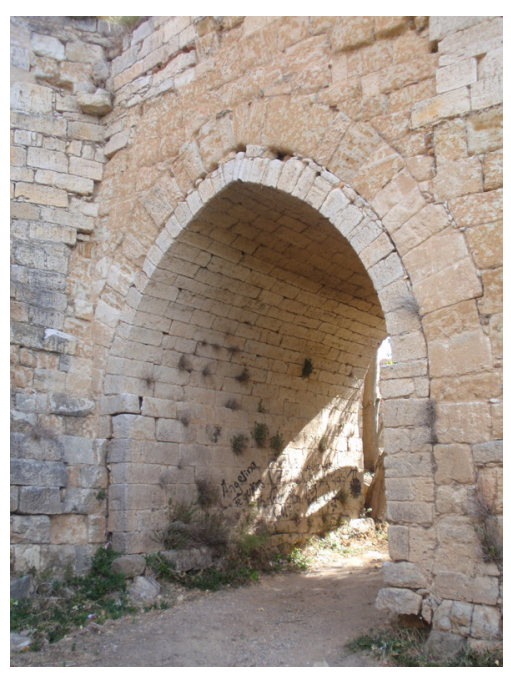

Fig. 95. Bóveda del puente medieval. Toro

130 Este concierto fue citado por todos los autores desde Floranes (FLORANES Y ENCINAS, Rafael de, Memorias para la historia de la ciudad y tierra de Toro, Valladolid 1994, p. 17) y transcrito por Navarro Talegón en NAVARRO TALEGÓN, J., op. cit., 1980, p. 45, nota 5.

131 Los datos técnicos los hemos tomado de CHÍAS NAVARRO, P., y ABAD BALBOA, T., op. cit, 1994, p. 99. 
perceptible cómo la bóveda original ha sido reforzada por una nueva que la reviste por completo.

Una vez más es difícil delimitar si la utilización del arco apuntado en este periodo de transición del siglo XII al XIII es consecuencia del cambio de estilo u obedece a unas razones técnicas por su mayor capacidad de sustentamiento respecto a la bóveda de medio cañón.

\section{Restos de otras fortificaciones}

Aparte de las ciudades de Zamora y Toro hubo otras poblaciones de la provincia que contaron con importantes defensas de las que se han conservado algunos testimonios. Es el caso de la ciudad de Benavente, que tuvo una posición marcadamente privilegiada desde el punto de vista estratégico durante los siglos XII y XIII ${ }^{132}$ pues se encontraba situada en plena frontera con Castilla $^{133}$ (Fig. 96). A la fortificación de Benavente solo podemos aproximarnos a través de la documentación gráfica que tenemos pues los testimonios materiales desaparecieron por completo ${ }^{134}$. Por un lado existe un Sello del Concejo de Benavente del siglo XIII

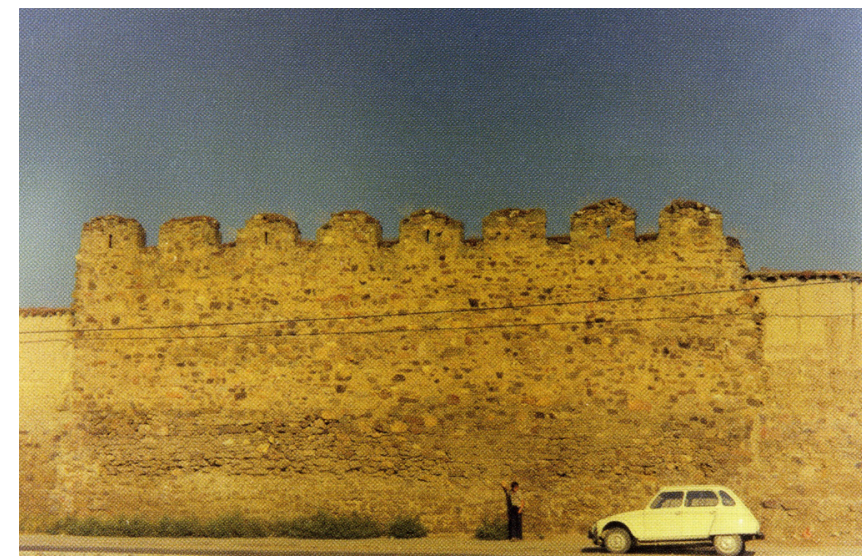

132 A finales del siglo XII y durante las primeras décadas del siglo XIII Benavente vivió una de sus etapas de mayor esplendor. FUENTES GANZO, Eduardo, Las Cortes de Benavente (El Siglo de Oro de una ciudad leonesa) Benavente: 1164-1230, Madrid, 1996.

133 GUTIÉRREZ GONZÁLEZ, José Avelino, Fortificaciones y feudalismo en el origen y formación del reino leonés (siglos IX-XIII), Universidad de Valladolid, Zaragoza, 1995, pp. 361-365.

134 Por ejemplo del castillo que fue construido entre los siglos XII y XIII en la zona meridional de la mota no se ha conservado absolutamente nada pues sobre ese lugar levantaron posteriormente los Pimentel su castillo-palacio. Tampoco ha llegado nada en pie de ninguno de los dos recintos amurallados que tuvo Benavente; el primero de ellos levantado en el siglo XII y el segundo en el XIV. LOBATO VIDAL, J.C., Castillos y murallas de la provincia de Zamora, Zamora, 1997, p. 35. 
realizado en cera prensada que posee un relieve en su anverso en el que se representa la villa medieval con el puente en primer término y todos los elementos que componían su fortificación ${ }^{135}$. La desaparición de todas estas estructuras hace que la visión que contiene este sello adquiera una enorme importancia pues nos aporta una vista aproximada de la ciudad tal y como era en el siglo XIII (Fig. 97). Tanto el tipo de arcos como algunos elementos ornamentales que se aprecian están en concordancia con los inicios del estilo gótico. Por otro lado contamos con una xilografía de 1841 que representa una de las puertas que se habría en la muralla de Benavente, hoy desaparecida, y que ya a mediados del siglo XIX presentaba un mal estado ${ }^{136}$. La misma portada en idéntico estado volvió a ser reproducida en un grabado de 1881 que fue publicado en la revista Zamora Ilustrada ${ }^{137}$. Esta puerta se abre en un fragmento de muralla edificado en sillería irregular y que ya en el momento de su publicación presentaba un acusado deterioro (Fig. 98). Se trata de un sencillo acceso de arco apuntado sin ornamentación en todo su desarrollo y con la línea de impostas señaladas por una casi imperceptible moldura. Las dovelas del arco y los sillares que conforman las jambas que generalmente suelen estar más cuidados en este caso también presentan piedras irregulares.

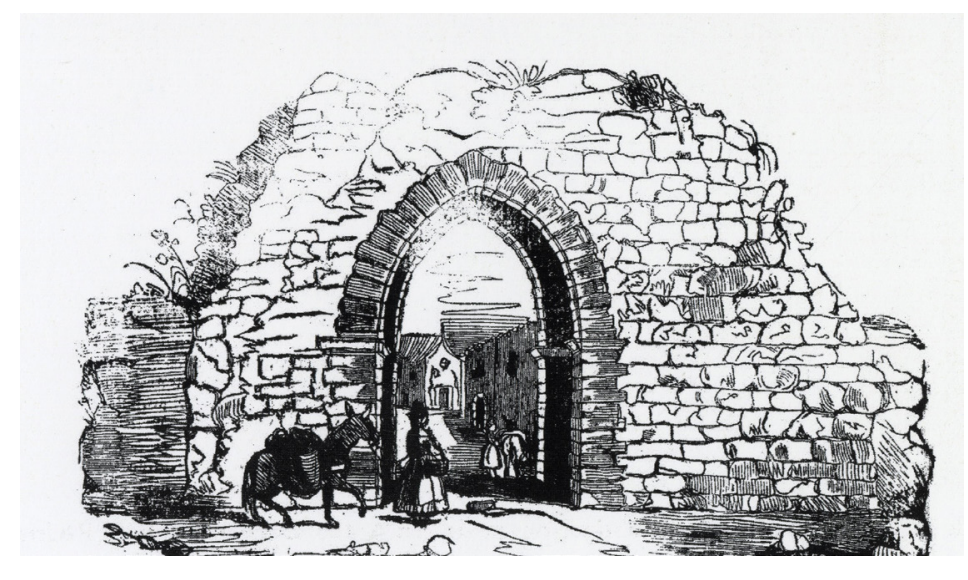

135 Este sello se conserva en el Archivo Diocesano de Astorga. AGUADO SEISDEDOS, Vidal, "Sello del Concejo de Benavente" en Catálogo de la exposición «Más vale volando» por el condado de Benavente, Centro de Estudios Benaventanos "Ledo del Pozo", Benavente, 1998, p. 89.

136 Esta xilografía fue publicada en el Semanario Pintoresco Español. 1841. Recientemente en REGUERAS GRANDE, Fernando y GONZÁLEZ RODRÍGUEZ, Rafael, Álbum de Benavente. Grabados, dibujos y fotografias históricas, Centro de Estudios Benaventanos «Ledo del Pozo», Zamora, 2013, p. 46.

137 AA.VV., "Antigua puerta de Benavente”, Zamora Ilustrada, tomo 1, n 19, Zamora 12 de julio de 1881 , pp. 1 y 6.

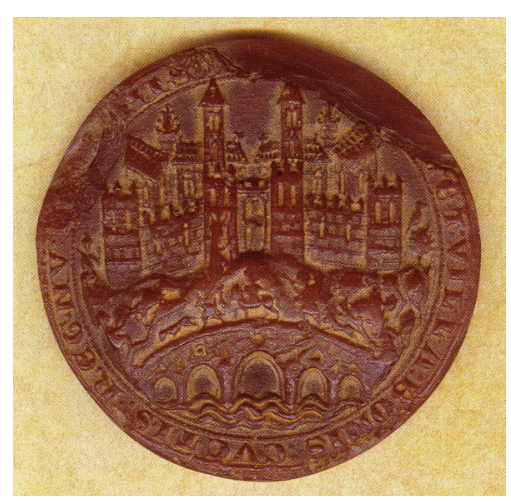

Fig. 97 Sello del Concejo de Benavente (Siglo XIII) 


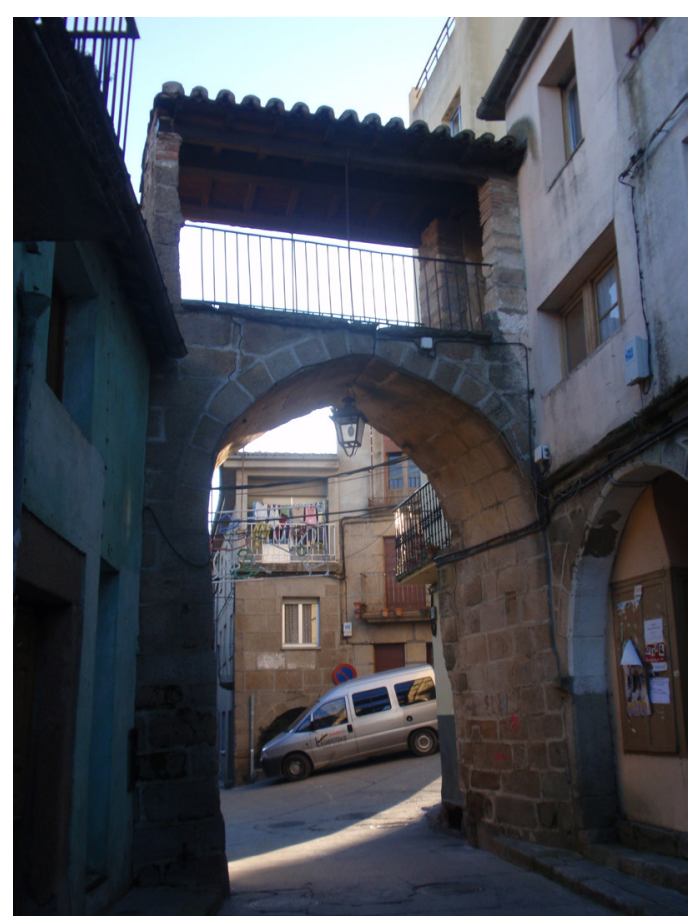

También Fermoselle durante la época medieval vivió un periodo de cierto esplendor como lo atestiguan los restos conservados en distintas partes de esta villa. De este modo subsisten todavía mínimos elementos de lo que fuera su Castillo, que por donación real perteneció a los obispos de Zamora ${ }^{138}$. Aunque la muralla ha desaparecido en casi su totalidad se puede reconstruir su trazado. Existen algunos restos visibles desde la carretera que bordea el pueblo levantados sobre un basamento rocoso. Estos consisten en un muro en el que se abre un gran arco apuntado con dovelas de considerable profundidad que salva una zona de terreno tremendamente irregular. Como elemento más destacado de la muralla se ha conservado una de las puertas que constituía uno de los accesos a la población. Rivera Lozano se refiere a ella como "El arco"139. Se trata de una puerta de gran sencillez y resuelta en arco apuntado sin solución de continuidad con las jambas al no estar explícita la línea de imposta (Fig. 99). Sobre ella se levanta un pequeño espacio rectangular techado de forma adintelada por un sencillo artesonado de madera y que actualmente simula una balconada. En origen pudo tener la función de tránsito a modo de adarve de la muralla. Ignoramos a que momento constructivo pertenece aunque es probable

138 Cuando Gómez-Moreno a principios del siglo XX visitó el lugar el castillo ya había desaparecido prácticamente por completo. GÓMEZ-MORENO, M., op. cit., I, 1927 (1980), p. 281.

139 RIVERA LOZANO, M., op. cit.,1996, p. 91. 
que responda al siglo XIII cuando esta villa comenzó a tener una cierta importancia y se edificaron el castillo y algunos templos de los cuales se han conservado de aquella época algunos restos en la actual iglesia de Nuestra Señora de la Asunción, que fue reformada tiempo después.

Igualmente Villalpando contó con un primer recinto amurallado que los estudiosos consideran se levantó durante el reinado de Fernando II y del que no se ha conservado nada. Sí han llegado a nuestros días algunos elementos que pertenecen al segundo recinto que debió edificarse casi con toda probabilidad en el siglo XIV y, por tanto, durante el gótico pleno. No obstante, es pertinente hacer una mención aquí, pues la finalidad de este tipo de estructuras hizo que mantuvieran durante largo tiempo los esquemas generales constructivos. De ahí que tanto la puerta de Santiago, como la parte medieval de la puerta de San Andrés, tengan un diseño muy semejante al de estructuras del mismo tipo levantadas a finales del siglo XII y primeras décadas del siglo XIII y pertenecientes a las fortificaciones de Zamora, Toro, Benavente y Fermoselle.

Aparte de la fortificación de ciudades, en la provincia de Zamora también se levantaron castillos durante estos momentos que fueron reformados en los sucesivos siglos y que hoy presentan un estado totalmente ruinoso. Es el caso de los castillos de Alba de Aliste y de Castrotorafe. 


\section{EL GÓTICO PLENO}





\section{EL GÓTICO PLENO}

\section{Notas históricas}

Este periodo que comprende los siglos XIII y XIV viene a coincidir con los reinados de Alfonso IX (rey de León entre 11881230), de su hijo Fernando III el Santo (rey de Castilla de 12171252 y de León de 1230 a 1252) que nació en la provincia de Zamora, y, posteriormente de Alfonso X el Sabio (1252-1284), Sancho IV (1284-1295), Fernando IV (1295-1312), Alfonso XI (1312-1350), Pedro I (1350-1366), Enrique II (1366-1367), Juan I (1379-1390) y Enrique III (1390-1406).

La situación histórica de Castilla en estos momentos fue bastante convulsa y de todo ello participaron las ciudades más destacadas de la provincia de Zamora que por diversos motivos fueron visitadas con cierta frecuencia por los monarcas.

Con respecto a las décadas precedentes se sucedieron algunas mejoras en el aspecto económico de tal modo que la agricultura y la ganadería experimentaron un cierto despegue. A ello habría que sumar la explotación de los numerosos molinos existentes y el auge comercial con la celebración de mercados, principalmente en Zamora, Toro, Benavente y Villalpando.

Sin embargo, la peste negra que afectó drásticamente a Europa durante el siglo XIV también tuvo su repercusión en la provincia de Zamora. La agricultura y la ganadería siguieron siendo las actividades principales; y es que la mayor parte de la población seguía residiendo en el campo, e, incluso, no podemos olvidar, que también muchos de los que residían en la ciudad, tenían como actividad principal el trabajo de la tierra. La ganadería lanar experimentó un fuerte crecimiento y los mercados siguieron celebrándose.

En el ámbito histórico fue muy relevante en la provincia de Zamora la entrega del señorío de Toro por parte de Sancho IV a su esposa María de Molina, que concedió numerosos privilegios a la ciudad y fue además la fundadora también en Toro del convento de San Ildefonso de la orden de Santo Domingo. También en 
las casas que María de Molina utilizó en Toro y que habían pertenecido anteriormente al obispo de Coria sirvieron como base para el convento de Santa Sofía de la orden premostratense.

Desde el punto de vista de las instituciones religiosas, en la diócesis de Zamora el papel más importante corresponde a la catedral que se había convertido en un foco cultural destacado, en gran medida determinado por las preocupaciones de su Cabildo $^{140}$. El segundo edificio en importancia de la diócesis era la colegiata de Toro. La pérdida de la mayor parte de la documentación del archivo de Zamora así como la desaparición en el incendio de 1761 del archivo municipal tornan compleja una valoración del edificio desde el punto de vista histórico, no obstante, el empaque y riqueza artística que presenta el templo hacen pensar que su vida religioso-cultural fue junto con la de la catedral la más activa de la provincia. Durante estos siglos estuvo regida por los siguientes obispos: Martín Rodríguez (1212-1237), Segundo Segundez (1238?), Pedro I (1239-1254), Suero Pérez de Velasco (1255-1286), Pedro II (1287-1302), Gonzalo Rodríguez Osorio (1303-?), Rodrigo I (1321-1339), Pedro Gómez Barroso (1341-1351?), Alonso Fernández de Valencia (1355-1365?), Martín Acosta (1365-1371), Álvaro I (1372-1395), Alonso Exea (1396-1403?), Juan III (?) y Alonso de Illescas (1405-1407). Las dos personalidades más relevantes desde el punto de vista religioso en la diócesis de Zamora durante este periodo fueron fray Juan Gil de Zamora ${ }^{141}$ y el obispo Suero. El primero, miembro de la orden franciscana, fue hombre de gran formación y autor de numerosas obras; el segundo fue también gran amante de la cultura y sabemos que poseyó una biblioteca de considerable importancia.

El siglo XIII también fue el siglo de esplendor de los grandes monasterios cistercienses de la provincia de Zamora cuya prosperidad se vio potenciada por el favor real a través de la concesión de numerosos privilegios. Han llegado a nuestros

140 Sobre la diócesis de Zamora en la segunda mitad del siglo XIII vid. SÁNCHEZ RODRÍGUEZ, Marciano, "La diócesis de Zamora en la segunda mitad del siglo XIII" en I Congreso de Historia de Zamora, t. III, Instituto de Estudios Zamoranos Florián de Ocampo, Zamora, 1989, pp. 147-171.

141 Acerca de la figura de Juan Gil de Zamora vid. FERRERO HERNÁNDEZ, Cándida, Juan Gil, Doctor y Maestro del Convento Franciscano de Zamora, (ca. 12411318), Zamora, 2006. 
días conservados en una buena parte los de Santa María de Moreruela y San Martín de Castañeda que fueron, sin duda, los más destacados de su época en la provincia.

Es este también el momento de la implantación y difusión en la provincia de Zamora de los conventos de órdenes mendicantes como queda confirmado por la documentación. Estos testimonios documentales permiten constatar la fundación de numerosos conventos a lo largo de los siglos XIII y XIV aunque lo que ha llegado de ellos a nuestros días sea realmente escaso y lo más antiguo pertenezca ya al siglo XIV.

De lo más significativo debió de ser el conjunto conventual de San Francisco en Zamora, que ha llegado muy mutilado debido a los distintos procesos desamortizadores que tuvieron lugar en el siglo XX. En relación con la implantación de estos conventos es necesario aludir al escandalo moral producido en el siglo XIII en el monasterio de dominicas de la ciudad de Zamora, que adquirió tal resonancia hasta el punto que a partir de aquel momento el papa Bonifacio VIII decidió ejercer un control férreo sobre las monjas enclaustradas en general ${ }^{142}$.

No podemos olvidar asimismo dos acontecimientos de índole espiritual (en gran medida hay que encuadrarlos dentro de la leyenda y tradición popular) que tuvieron una profunda impronta en nuestra provincia no solo en el terreno religioso y social sino también en el artístico. El primero de estos acontecimientos fue la aparición en el año 1260 bajo el obispado de don Suero Pérez de Velasco de los restos del que fuera arzobispo de Toledo San Ildefonso. Este hallazgo, de una enorme trascendencia, tuvo lugar durante unas obras de remodelación en la iglesia de San Pedro de la ciudad de Zamora. El otro acontecimiento religioso tuvo lugar unas décadas después y se encuentra relacionado con el monarca Sancho IV que se encontraba en Zamora y durante una jornada de caza en la que participó fue hallada una pequeña imagen de la Virgen entre unas hiniestas, lo que dio lugar a la edificación de un magnífico templo para acoger la imagen ${ }^{143}$.

142 Este complejo episodio ha sido estudiado en profundidad por Peter Linehan. LINEHAN, Peter, Las dueñas de Zamora. Secretos, estupro y poderes en la Iglesia española del siglo XIII, Ediciones Península, Barcelona, 1999.

143 El resumen histórico que hacemos en este capítulo tiene como base los estudios contenidos en el tomo I de Historia de Zamora publicado en el año 1995: VACA LORENZO, Ángel, "Población y poblamiento de Zamora en la Edad Media", 
La actividad arquitectónica religiosa en Zamora y su provincia durante los siglos XIII y XIV

En este marco histórico se encuentran las primeras manifestaciones del gótico pleno. Se acostumbra a denominar así al estilo artístico en el que las formas góticas alcanzan su madurez, superado el periodo inicial y anterior a los cambios que dieron lugar al gótico tardío. Los márgenes cronológicos para el desarrollo de esta modalidad son fluctuantes y han de utilizarse exclusivamente como relativos ${ }^{144}$. En la provincia de Zamora las formas del gótico pleno no aparecen en fecha anterior a mediados del siglo XIII y se prolongan durante la práctica totalidad del siglo XIV.

En correspondencia con el menor papel estratégico, político, social y económico que tuvo la provincia de Zamora durante este periodo la actividad constructiva decayó respecto a siglos anteriores y si a esto sumamos las perdidas ocasionadas por el paso del tiempo veremos que el catálogo de obras adscritas a este momento es escaso y fragmentario, ya que no conservamos ningún edificio completo y tan sólo han llegado a nuestros días elementos parciales. La práctica totalidad de las partes arquitectónicas que han sobrevivido pertenecen a la arquitectura religiosa, y aunque en un escaso número se puede citar algún ejemplo de arquitectura civil, especialmente las partes conservadas de un edificio de enorme importancia dentro del panorama arquitectónico de la Edad Media no sólo de la provincia de Zamora sino de todo el territorio castellano, como es la que fuera residencia del obispo de Coria en Toro y

pp. 431-475; VACA LORENZO, Ángel, “Agricultura y ganadería: Las actividades fundamentales de los zamoranos en la Edad Media”, pp. 477-504; IRADIEL, Paulino, "El desarrollo del comercio y de la industria: mercados, mercaderes y artesanos", pp. 505-541; MORETA VELAYOS, Salustiano, "La Sociedad Zamorana en los siglos X-XIII", pp. 543-585; CARBAJO MARTÍN, V.A., "La Sociedad Zamorana en los siglos XIV y XV", pp. 587-627; DIOS, Salustiano de, "Poder Político, Derecho e Instituciones", pp. 629-686; SÁNCHEZ HERRERO, José, "Historia de la iglesia de Zamora, siglos V al XV", pp. 687-753; MONTERO APARICIO, Domingo, "Arte medieval en Zamora”, pp. 755-821; HERNÁNDEZ VICENTE, Severiano, "Fuentes, Archivos y Documentos para la Historia medieval de las tierras de Zamora", pp. 823861. Los citados estudios aportan numerosa bibliografía complementaria que enriquece enormemente estos temas no solo en el ámbito relativo a nuestra provincia sino en un contexto más general.

144 La periodización para Francia es mucho más rica y allí los cambios se producen de forma más rápida como consecuencia de las transformaciones también en el pensamiento. 
que, desde hace siglos, forma parte del Monasterio de Santa Sofía de la misma localidad.

A lo largo del siglo XIII continuaron las obras en edificios como la Catedral en la que durante las primeras décadas del siglo XIII se habían producido los primeros síntomas del gótico y se concluyeron aquellos templos cuyas obras se habían iniciado en la segunda mitad del siglo XII, de modo que se vieron afectados también por el nuevo estilo.

A su vez, a lo largo de este mismo siglo XIII y del siglo XIV, en algunos de estos edificios religiosos se añadieron espacios o se hicieron obras que transformaron otros ya existentes.

Los escasos restos de edificios religiosos conservados adscribibles al periodo gótico pleno, aún a pesar de la parcialidad con que han llegado al momento presente aportan información interesante sobre lo que fue la actividad constructiva en aquella época, tanto en lo que se refiere a nuevas obras en iglesias ya existentes, como en lo relativo a la fundación y construcción de nuevas edificaciones.

A través de estos restos conservados encuadrables en los siglos XIII y XIV, he intentado establecer una relación de las formas arquitectónicas y de los detalles ornamentales utilizados en este momento como apoyo general para definir la secuencia y bases formales que rigieron en la arquitectura de esta época en la provincia de Zamora. Como elementos más destacados tenemos el arco apuntado y la bóveda de crucería.

El material utilizado en las partes de estos edificios que se han conservado es la piedra, que para los muros y bóvedas se ha empleado labrada de forma más o menos regular, aunque en diferentes tamaños, mientras que para las portadas o para los soportes se ha prestado un mayor cuidado, de tal forma que el acabado es más minucioso.

Por lo que respecta a los soportes, en la arquitectura religiosa, asistimos a la multiplicación progresiva de los fascículos como puede verse en los extremos de los restos de la cabecera del convento de San Francisco (Zamora) donde morirían los nervios de la bóveda que debió cubrir este espacio, ahora desaparecida, y donde descansaría también el arco triunfal. Sin embargo, en 
la arquitectura civil se pueden encontrar soportes cilíndricos a manera de columnas pero sin canon. Esta tendencia a colocar columnas que sostienen zapatas y como consecuencia una techumbre de madera en vez de arcos con bóvedas es probable que se deba a una reducción de costes en un periodo donde los recursos económicos escaseaban.

Aunque tenemos pocos ejemplos de capiteles, hay que tomar estos como significativos. El utilizado de forma más habitual es el que contiene en su decoración elementos vegetales más o menos naturalista con referencia a especies vegetales concretas aunque en algún caso persisten algunas formas monstruosas de origen románico (Fig. 100). Se incorpora el "ganchillo" (crochet) como elemento decorativo y aparecen también cabezas humanas en las que se observa la introducción de algunos elementos de la moda de la época, como ocurre en la capilla de la Majestad de la colegiata de Toro (Fig. 101). En algunas ocasiones los capiteles son sustituidos por sencillas molduras ornamentadas también con elementos vegetales.

El arco apuntado adquiere en este momento el desarrollo plenamente gótico, en muchos casos enriquecido con molduras de boceles y escocias. Es muy difícil establecer en el estado actual de nuestro conocimiento una estricta separación entre algunos arcos debido a la inexistencia de bases documentales que aporten una referencia precisa y porque determinadas formas se mantuvieron durante parte del siglo XIII y del siglo XIV.

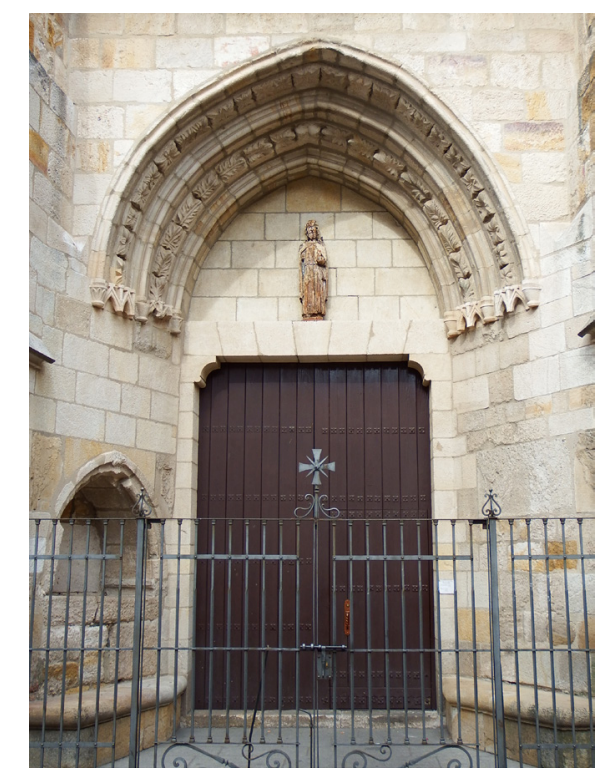

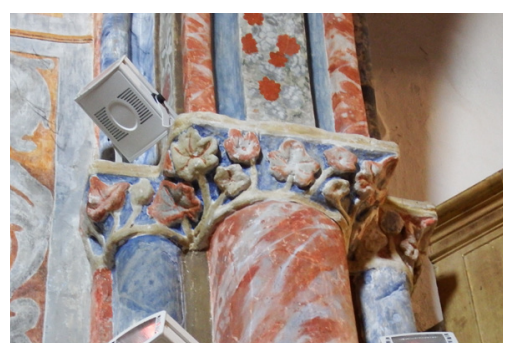

Fig. 100. Capiteles del arco de ingreso a la capilla mayor del monasterio de Sancti Spiritus. Toro

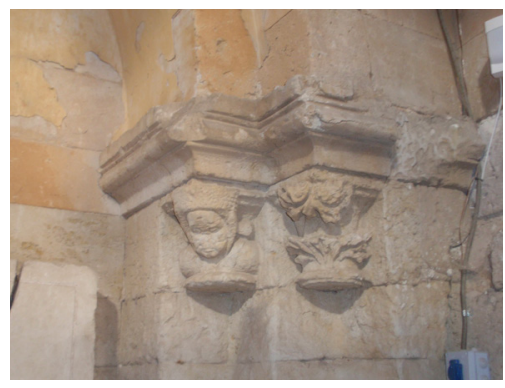

Fig. 101. Capiteles correspondientes al interior del muro norte de la capilla de la Majestad en la colegiata de Toro 

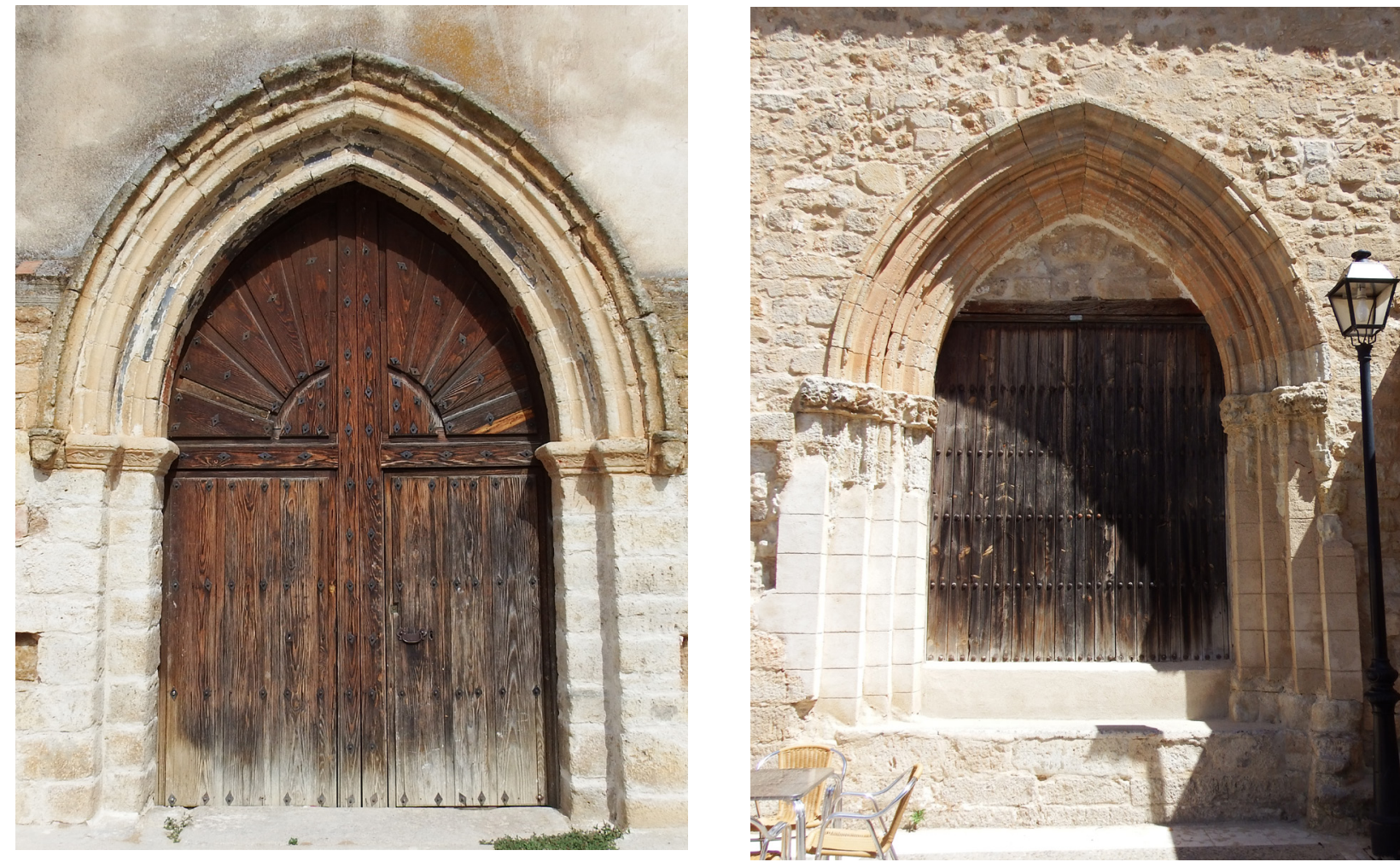

Este tipo de arco va a ser el elemento definidor de las portadas

Figs. 103 y 104. Portadas de la iglesia de San Pedro el Olmo y del convento de San lldefonso. Toro como puede observarse en el pórtico occidental de la colegiata de Toro, donde la portada gótica se encuentra ya perfectamente configurada (segunda mitad del siglo XIII). Este tipo de portada tiene su continuación en la portada meridional de la iglesia de Santa María la Real de la Hiniesta, ya del siglo XIV. Aunque no tenemos noticias documentales concretas, a partir de sus rasgos estilísticos pensamos que las arquivoltas de la portada occidental de la iglesia de San Juan de Puerta Nueva (Zamora) pertenecen también al siglo XIV (Fig. 102). Igualmente de este último siglo son las portadas de la antigua iglesia de San Pedro del Olmo (Toro) y la occidental del antiguo convento dominico de San Ildefonso, también de la ciudad de Toro, que son prácticamente los únicos elementos que de este momento se han conservado en estos edificios (Figs. 103 y 104). Menos elaboradas pero también correspondientes al siglo XIV son la portada norte de la iglesia del monasterio de Sancti Spiritus de Toro y el conjunto de puertas conservadas en torno a su claustro así como la portada sur de la capilla de la Majestad de la colegiata también de Toro (Fig. 105).

A pesar de la pobreza de los restos conservados de este periodo contamos, sin embargo, con la existencia de la portada 
de la Majestad de la colegiata de Toro y la portada de la iglesia de Santa María la Real de la Hiniesta que vienen a paliar esa escasez por su categoría extraordinaria y que hay que situarlas como pieza de primer interés durante este periodo del gótico pleno.

Los arcosolios pertenecientes a este periodo tienen un diseño semejante al de los arcos de las portadas citadas anteriormente con la rosca enriquecida con molduras y algunos trasdosados con chambrana. No obstante, existen otros en los que se acusa la tradición arcaizante que parece derivar de modelos cistercienses como los que se abren en el muro norte de la capilla de la Majestad de la colegiata de Toro, que fueron construidos a mediados del siglo XIII y muestran una dependencia absoluta de la arquitectura de décadas anteriores al estar configurados mediante un sencillo arco doblado y apuntado liso.

Apenas se han conservado en los edificios zamoranos ventanas que pertenezcan a este periodo y por ello los modelos característicos de vanos del gótico pleno son excepcionales. Tan sólo los vanos que rasgan los paños de la cabecera de la iglesia del convento de San Francisco de Zamora y dos situados en el tercer cuerpo de la torre de la iglesia de San Nicolás en Castroverde de Campos tienen diseños que pueden ser identificados como tales, con forma de lanceta (Figs. 106 y 107). De los pertenecientes a la iglesia de Castroverde de Campos, uno de ellos presenta la típica tracería gótica trilobulada y, el otro, formado por dos lancetas, tiene igualmente los tímpanos enriquecidos con tracería gótica trilobulada y sobre ellos una roseta.

Propio de este momento es el gran arco apuntado que se construyó durante la primera mitad del siglo XIV en la embocadura de acceso a la capilla mayor de la iglesia del monasterio toresano de Sancti Spiritus, que además apea en capiteles decorados con hojas carnosas (Fig. 108).

También, en las nuevas reestructuraciones que sufrieron las iglesias en su interior durante este periodo, el arco apuntado fue el elemento articulador del espacio como sucede en la iglesia de San Cipriano y en la de Santa María la Real de la Hiniesta. A su vez, y como puede constatarse en estos templos mencionados, el arco apuntado sería el utilizado exclusivamente en los arcosolios para albergar enterramientos durante este periodo.

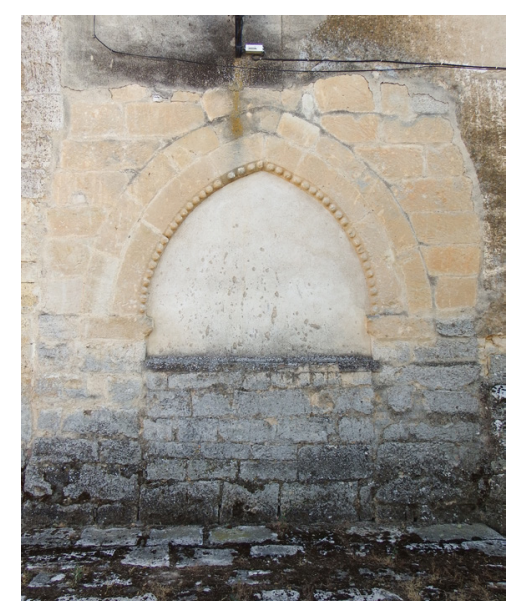

Fig. 105. Antigua puerta de acceso a la iglesia del monasterio de Sancti Spiritus. Toro

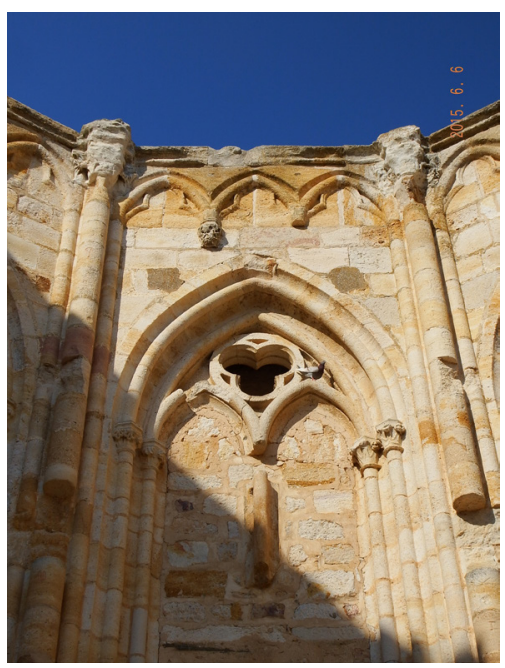

Fig. 106. Ventanal de la cabecera del convento de San Francisco. Zamora

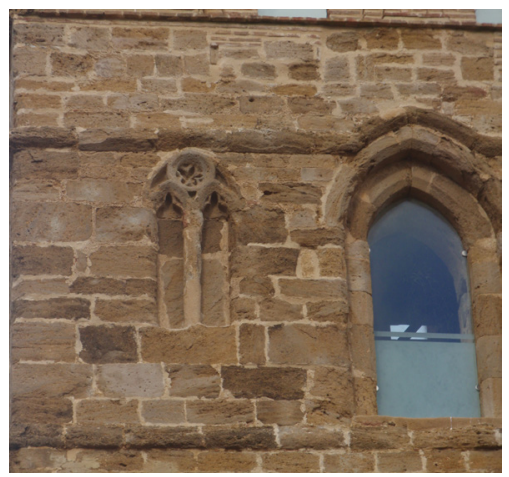

Fig. 107. Vanos en la torre de San Nicolás. Castroverde de Campos 


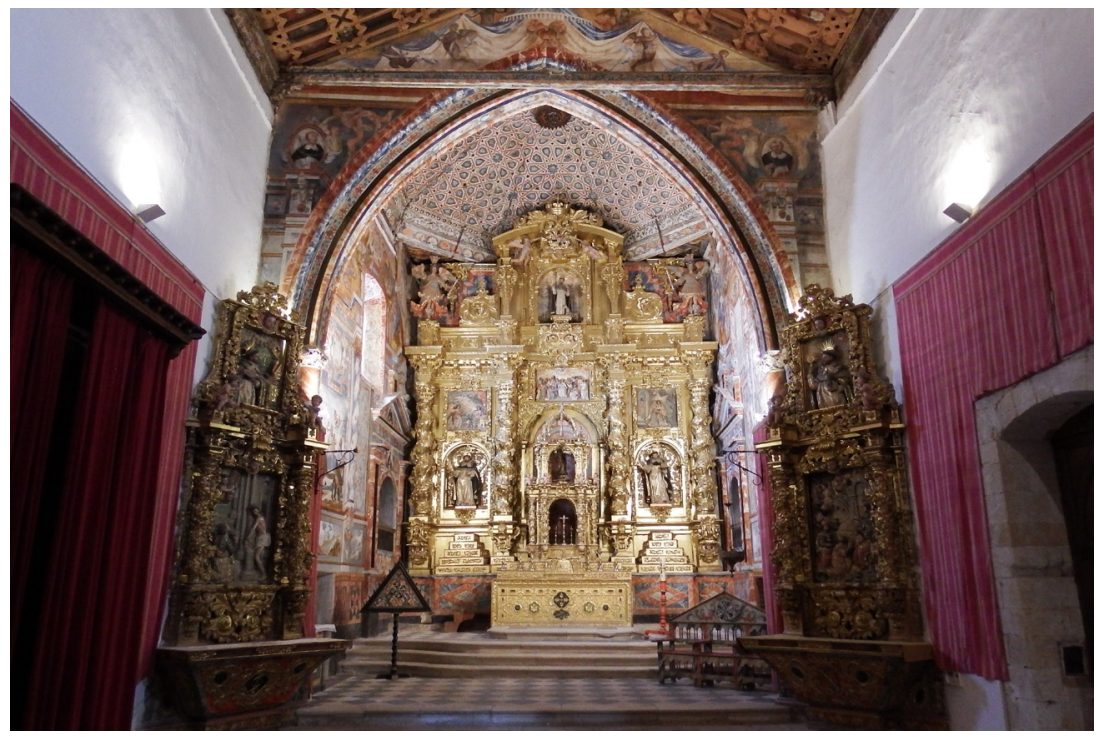

Pero el elemento principal definidor de la arquitectura gótica es la bóveda de crucería. Lamentablemente el análisis que podemos realizar es muy parcial al contar con pocos ejemplos. Sí podemos afirmar, que en fecha bastante avanzada, al menos, en algunas ocasiones, no se utilizó el arco formero sino que se construía apoyando los plementos sobre los muros de los edificios, como sucede con la bóveda de la actual capilla del Doctor Grado en la Catedral, que a pesar de algunas modificaciones responde a la segunda mitad del siglo XIII. Algunos nervios de la bóveda del pórtico de la Hiniesta plantean algunas dudas de datación aunque se ha querido ver en ellos un origen que se remonta al gótico pleno.

Respecto a la tipología de las construcciones realizadas en este momento no es posible generalizar ya que, como se ha señalado anteriormente, no se ha conservado ningún edificio completo levantado durante este periodo. Solamente contamos con restos, no muy numerosos y de edificios con funciones distintas lo que conlleva que cada uno de ellos plantee un tipo de problemática. De ahí que la labor que realizaremos a continuación consista en incidir en aquellas partes o elementos que han sobrevivido y que en la mayoría de los casos fueron fruto de intervenciones realizadas en construcciones románicas. $Y$ es que aunque este trabajo de investigación va dirigido al estudio de la arquitectura gótica, no obstante es necesario tener en cuenta el periodo constructivo románico, porque precisamente algunas de las manifestaciones del gótico pleno zamorano se produjeron como 
consecuencia de la evolución y remodelación que sufrieron algunas iglesias que se habían edificado principalmente durante la segunda mitad del siglo XII y el primer cuarto del siglo XIII. Comenzaremos por las que afectaron a la catedral de Zamora y a la colegiata de Toro.

\section{Obras en la catedral de Zamora}

Tenemos constancia documental y material de actuaciones llevadas a efecto en este periodo en la catedral de Zamora, tales como la edificación de la capilla, que actualmente conocemos como de San Juan Evangelista o del doctor Grado, así como también de la capilla de San Bernardo, ambas todavía existentes. Los problemas que plantea el estudio de estas capillas levantadas en los siglos XIII y XIV respectivamente son las importantes transformaciones que sufrieron durante el siglo $\mathrm{XVI}$ y por las cuales se vieron modificadas significativamente, sin bien se puede apuntar la existencia de estructuras y elementos pertenecientes al periodo gótico pleno.

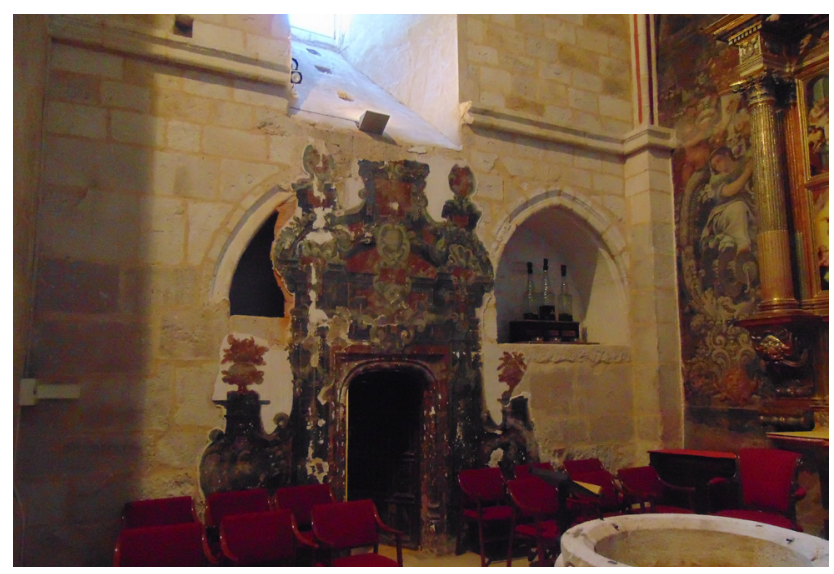

La primera de estas capillas fue edificada durante la segunda mitad del siglo XIII, ocupando un espacio cuadrangular en la prolongación del templo hacia el oeste a los pies de la nave de la Epístola. De aquel momento conserva la bóveda de crucería con nervios de ligadura y sin formeros, que fue reformada tiempo después, y dos lucillos sepulcrales que aparecieron en el transcurso de unas obras realizadas hace unos años ${ }^{145}$. Elementos ambos que no presentan ningún tipo de diferenciación con los 
diseños que se venían utilizando desde las primeras décadas del siglo XIII (Figs. 109 y 110).
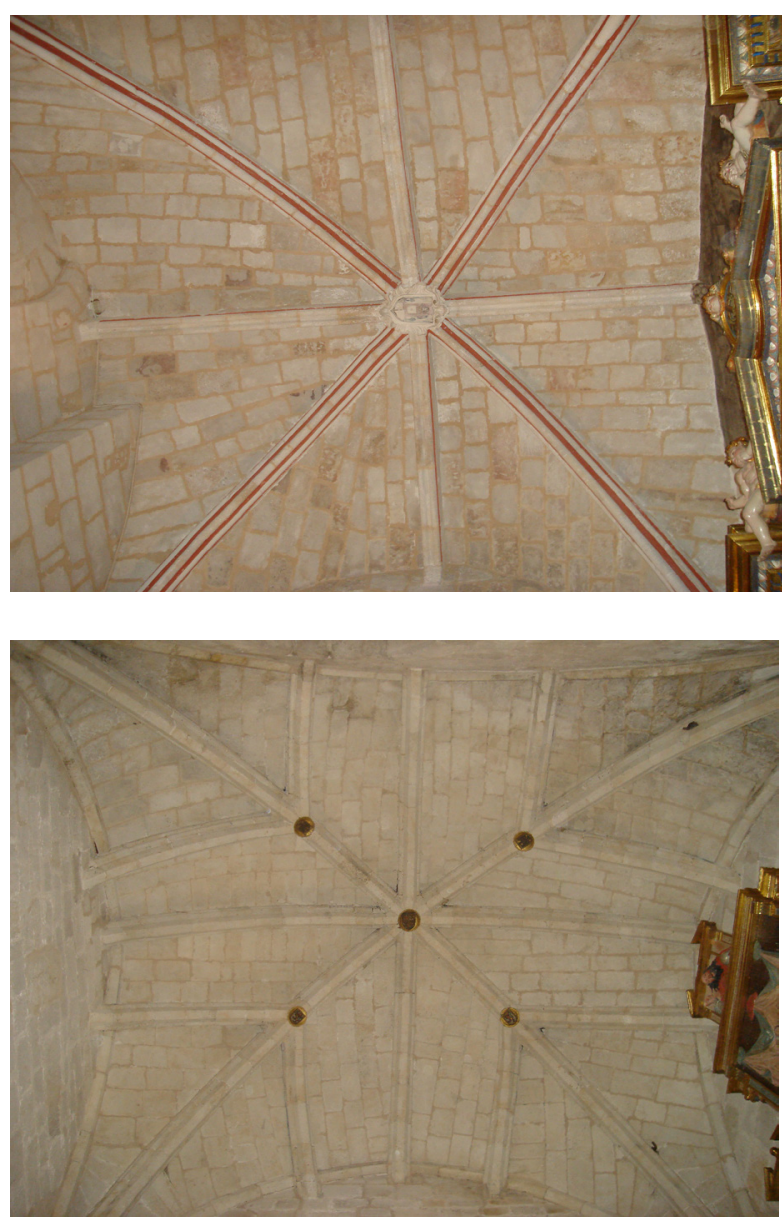

La capilla de San Bernardo, abierta al sur del primer tramo de los pies del lado de la Epístola, la mandó edificar, según consta en una de las lápidas que se encuentran en su interior, Alonso Fernández de Valencia, obispo de Zamora entre 1351 y $1365^{146}$. Se trata de un pequeño espacio cuadrangular, realizado en sillería y cubierto con bóveda de crucería de diseño inusual en la que los nervios dibujan una cruz central de brazos iguales y cuya cronología todavía es objeto de discusión (Fig. 111). Aunque en principio lo más lógico pudiera parecer relacionarla, bien con el fundador de la capilla Alfonso Fernández de Valencia y, por tanto, datarla en la segunda mitad del siglo XIV, o, quizá más bien, con las probables obras que llevó a cabo Juan de Valencia, nuevo propietario de la capilla a partir de 1421, la complejidad de su morfología ha dado lugar a que se haya propuesto como 
posible fecha de su construcción el siglo XVI. No hay un modelo exacto con el que pueda compararse. Sin embargo, la sección de sus nervaduras no reproduce el sistema formal empleado habitualmente en las bóvedas zamoranas del XVI. Por lo que respecta al original trazado en forma de cruz en el que unos nervios secundarios vienen a descansar contra los muros, fuera de la clave del arco formero, solamente ha sido posible encontrar un cierto paralelismo en la bóveda de la estancia superior de la antesacristía de la catedral de Santiago de Compostela realizada por Juan de Álava en el segundo cuarto del siglo XVI ${ }^{147}$. Por el contrario, si pertenecieron con toda probabilidad al momento de la fundación de esta capilla una serie de esculturas del siglo XIV que actualmente forman parte de la portada renacentista que se añadió en el siglo XVI. En la parte central la Virgen María impone la casulla a San Ildefonso en presencia de San Bernardo, patrono de la capilla y en los extremos el arcángel San Gabriel y la Virgen María de un grupo de la Anunciación.

Por último habría que señalar los dos arcosolios situados en el interior del templo, concretamente en su muro sur, y que han sido vaciados recientemente. Fechados a principios del siglo XV, sus motivos decorativos responden a modelos del gótico pleno (Figs. 112 y 113).

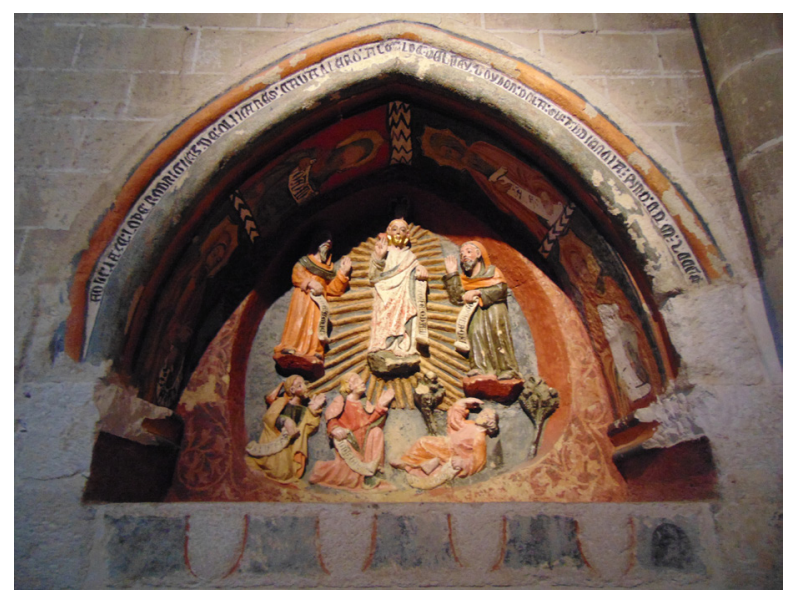

Fig. 112. Arcosolio de don Lope Rodríguez de Olivares. Catedral de Zamora

El arcosolio situado en el tramo más oriental, cerca del crucero, perteneció al alcaide del rey don Lope Rodríguez de Olivares como reza su cartela en la que se lee: AQUÍ IACE LOPE / ROD (RIGUEZ) DE OLIVARES / CAVALL (ER)O ALCAY/DE DEL RE(Y) E OYDOR / EN LA SVA AVDIEN/CIA. FINO AÑO / 1402. El frente de este arcosolio 
está ocupado por un relieve con el tema de la Transfiguración. Destaca la figura de Cristo en la parte central, rodeado de un haz de rayos y bendiciendo con la diestra. El intradós del arco está cubierto con pinturas murales que representan cuatro figuras de medio cuerpo que sostienen cartelas y que permiten identificar a dos de ellas como el rey David y el profeta Isaías.

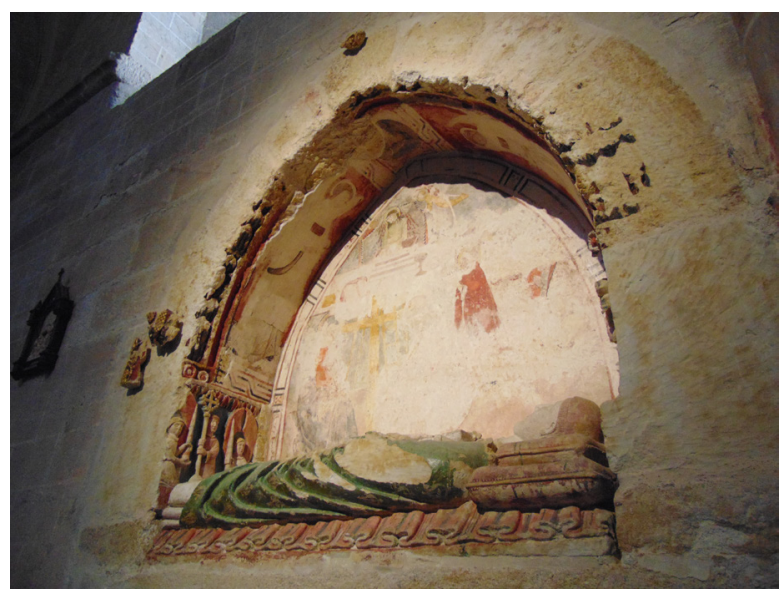

El arcosolio situado en la parte más occidental del muro, inmediato a la capilla de San Bernardo, perteneció al abad de Sancti Spiritus y canónigo de la catedral zamorana don Lope García. Su inscripción dice: AQVI IACE A LO(PE) / GARCIA ABBAD / DE S(ANCTI) SPIRIT(VS) Y CANO/NIGO DESTA S(ANTA) Y/GLESIA. FALLECIO / A 20 DE MAYO DE / 1409. La figura yacente del abad, caracterizada con vestiduras clericales, está dispuesta sobre un lienzo plegado ${ }^{148}$. El frente del arco y el intradós se encuentra policromado y en la parte inferior, tanto en la zona de los pies como de la cabeza de la representación del finado se labraron dos grupos escultóricos uno de los cuales está muy deteriorado.

\section{Obras en la colegiata de Toro}

Mucho más interesante resulta la última fase de las obras correspondientes a la colegiata románica de Toro desarrolladas durante la segunda mitad del siglo XIII y que consistieron en

148 Sin pretender ser exhaustivo, de la utilización de un lienzo plegado sobre el cual se dispone la figura yacente existen ejemplos en la provincia de Salamanca desde el siglo XIII. En la catedral de Ciudad Rodrigo puede observarse en el sepulcro de un obispo, obra del siglo XIII que está situado en un arco del crucero. En la catedral vieja de Salamanca sucede lo mismo en el sepulcro de García Ruiz ubicado en la capilla de Santa Bárbara y labrado en este caso en el siglo XIV. GÓMEZ-MORENO, Manuel, Catálogo Monumental de España. Provincia de Salamanca, 2 vols., Dirección General de Bellas Artes, Valencia, 1967, (edición facsímil, Salamanca, 2003), p. 323, lám. 434 y p. 121, lám. 59 . 
la edificación de una gran portada a occidente cobijada por un pórtico, que quedaron tiempo después incorporados en el interior de una capilla levantada durante el siglo XIII y parte del XIV. Interpretamos todo este conjunto, denominado pórtico de la Majestad, como uno de los espacios arquitectónico-escultóricos más significativos del gótico pleno en la provincia de Zamora ${ }^{149}$.

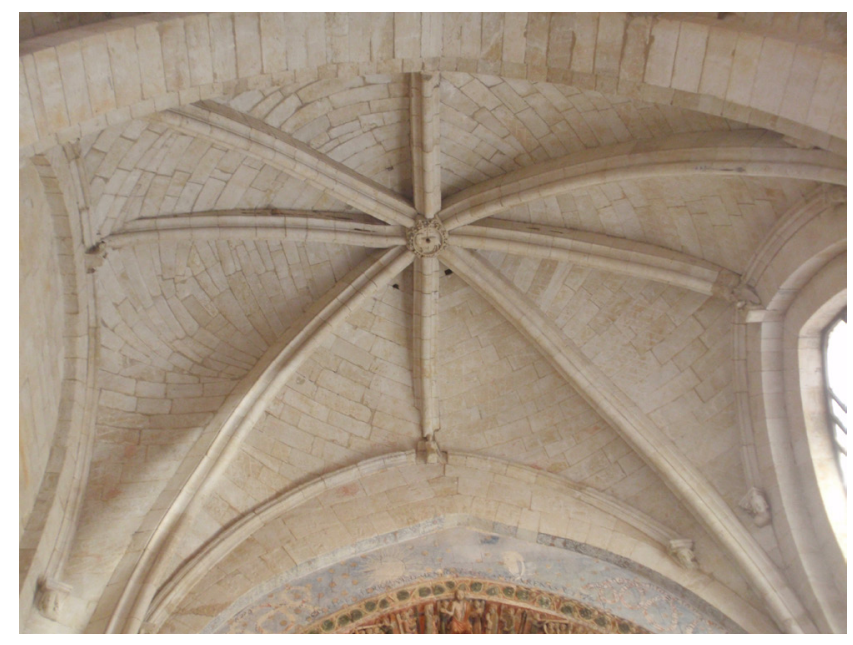

La bóveda de este pórtico es la última que se edificó en el templo y aunque es octopartita como las que pueden verse en los últimos tramos de las naves laterales presenta algunas particularidades respecto de aquellas ya que, en este caso, su sistema constructivo no es exactamente cupuliforme y además el aparejo de los plementos de la bóveda es independiente en cada uno de ellos, de modo que forman una especie de husos cóncavos (Fig. 114). En este caso y como sucedía en la bóveda que cubre en el templo el primer tramo hacia los pies del lado de la Epístola ya se han incorporado los formeros. Todo parece indicar que se trata de una variante española de las bóvedas aquitanas, de donde procede gran parte de la influencia ejercida en los edificios que se levantaron en el tercio superior de la Península Ibérica ${ }^{150}$. También solamente en este caso de la bóveda del pórtico encontramos ménsulas figuradas situadas en

149 Este pórtico y concretamente su portada han sido merecedores de multitud de estudios. Para más detalles puede consultarse la entrada correspondiente a la colegiata de Toro que figura en el catálogo donde también se desarrolla de manera más exhaustiva el proceso constructivo de la capilla que se construyó a los pies del templo y dentro de la cual quedó integrado el pórtico.

150 Así lo manifiesta Lambert para quien en el caso concreto de la colegiata de Toro es evidente la influencia proveniente de la arquitectura que se desarrolló en el suroeste francés, aunque en el caso toresano lo hiciese de forma menos acusada a como puede verse en la catedral Vieja de Salamanca o en la catedral de Ciudad Rodrigo. LAMBERT, Elie, El arte gótico en España. Siglos XII y XIII, Cátedra, Madrid, 1977, p. 70. 


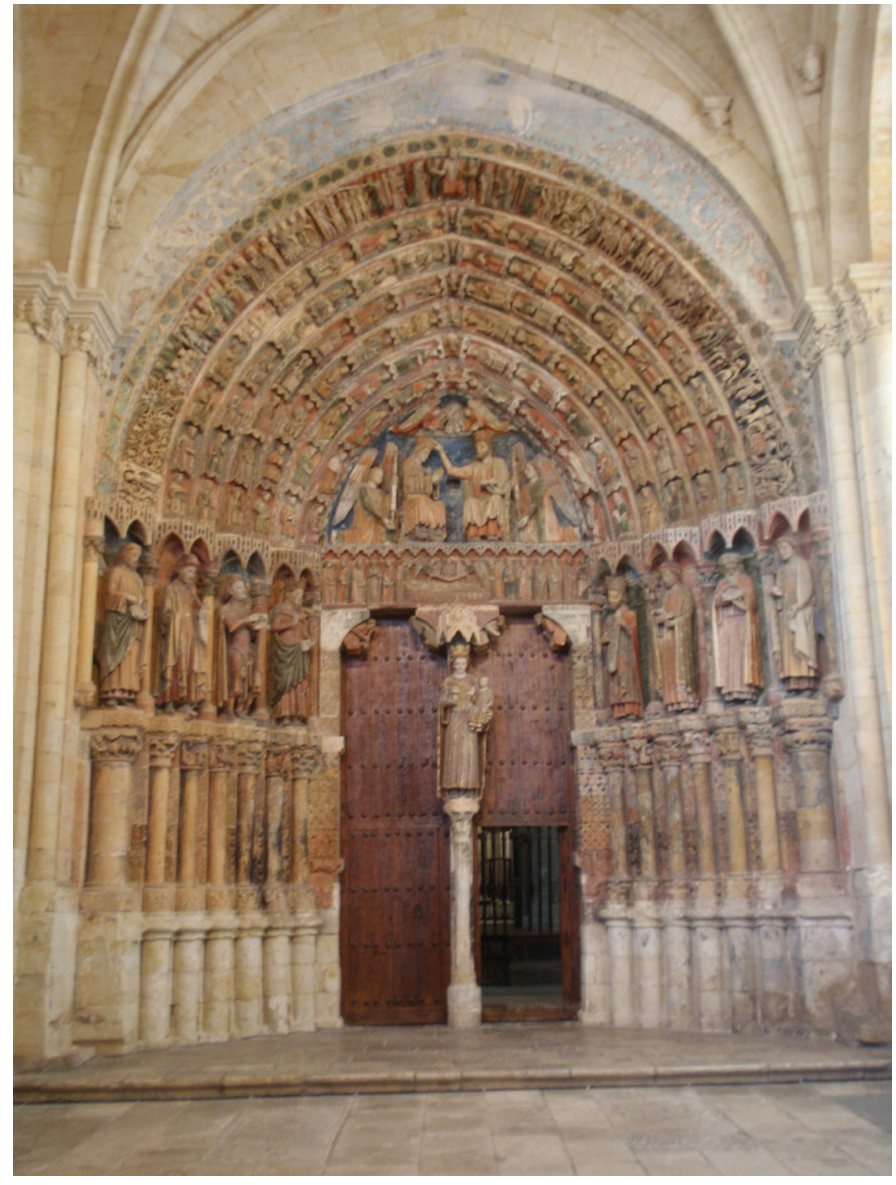

el arranque de los nervios, característica esta propia igualmente de la arquitectura que se desarrolló en el suroeste francés.

Por lo que se refiere a la portada, no vamos a insistir de manera detallada en el estudio de la misma por cuanto ha sido objeto ya de enorme atención por parte de los historiadores, sobre todo en lo que respecta a su escultura ${ }^{151}$; no obstante, sí incidiremos en su diseño arquitectónico y en aquellos elementos que la convierten en obra señera del gótico pleno zamorano (Fig. 115).

El esquema general de esta portada, en la que se ha querido ver parte románica y parte gótica, presenta no obstante una gran unidad de estilo que parece derivado de modelos franceses de la

151 QUADRADO, J. M ${ }^{\mathrm{a}}$ y PARCERISA, F. J., op. cit., 1861, (edición facsímil, Valladolid, 1990), p. 98; Catálogo de la Exposición Restauración de la portada de la Majestad de la Colegiata de Santa María la Mayor de Toro, Toro, The Samuel H. Kress Foundation, Junta de Castilla y León, El Viso, 1996; CHILLON, Bartolomé, La portada del Juicio Final de la Colegiata de Toro, Zamora, 1938; RUIZ MALDONADO, Margarita, "Reflexiones en torno a la portada de la Majestad. Colegiata de Toro (Zamora)" en Goya, n ${ }^{\circ} 283$, 1998; YARZA LUACES, J., op. cit., 1989. GÓMEZ-MORENO, M., op. cit., I, 1927 (1980), pp. 211-213; NAVARRO TALEGÓN, J., op. cit., 1980, pp. 106110; NAVARRO TALEGÓN, J., op. cit., 2005a, p. 57-86. 
segunda mitad del siglo XII (Senlis) y primera mitad del XIII (Laon y Chartes $)^{152}$ y, por lo tanto, plenamente góticos, aunque de una fase temprana. Este estilo tuvo su repercusión en Castilla, incluso en conjuntos de diseño todavía románico como es el caso de la portada occidental de la Basílica de San Vicente en Ávila, según ha señalado Navarro Talegón. ${ }^{153}$

Como en los modelos franceses, la puerta se expande hacia los lados por medio de un amplio abocinamiento formado por el derrame de las jambas y arquivoltas. También viene a coincidir con ellos, casi al pie de la letra, la organización arquitectónica de la misma ${ }^{154}$. El cuerpo inferior que actúan a modo de basamento está formado por una serie de siete gruesas columnas, con el fuste muy achaparrado y una simple moldura como capitel, en las que no se detectan rasgos estilísticos. Sobre ellas se levanta un segundo rango de columnas también en número de siete, pero, en este caso, con el fuste más delgado y esbelto, y provistas de basas y capiteles decorados con un repertorio temático de carácter vegetal, animal e historiado, que responden claramente al sistema formal gótico. Pertenecen igualmente al repertorio decorativo gótico los motivos que a modo de tapiz recubren los muros que respaldan este segundo rango de columnas (Fig 116).

Sobre cada capitel gótico hay un cimacio decorado con palmetas que, unidos entre sí, vienen a formar un friso corrido sobre el que apea una galería de estatuas, dispuestas cuatro a cada lado de la puerta, en hornacinas separadas por columnas y cubiertas por un dosel acastillado con su interior nervado. Estas estatuas forman parte del planteamiento unitario de la iconografía del portal dedicado a María. Son los reyes y profetas del Antiguo Testamento, que como antecesores y anunciadores de su misión, fundamentan los misterios marianos. Las dos esculturas de los nichos exteriores representan a dos ángeles,

152 Los ejemplos citados son la portada occidental de la Catedral de Senlis (ca. 1165-1170, la portada central de la fachada occidental de la catedral de Laon (ca 1200, muy restaurada) y portada central de la fachada norte de la catedral de Chartres (ca. 1210), las tres dedicadas igualmente al tema de la dormición y coronación de María (cf. WILLIAMSON, Paul, Escultura gótica. 1140-1300. Cátedra, Madrid, 1997, p. 58 y sig.)

153 NAVARRO TALEGÓN, José, La Colegiata de Toro, 2005, p. 58.

154 Una descripción más detallada de la decoración escultórica de la portada se recoge en la correspondiente ficha del catálogo de esta tesis (ver p. XXX) 


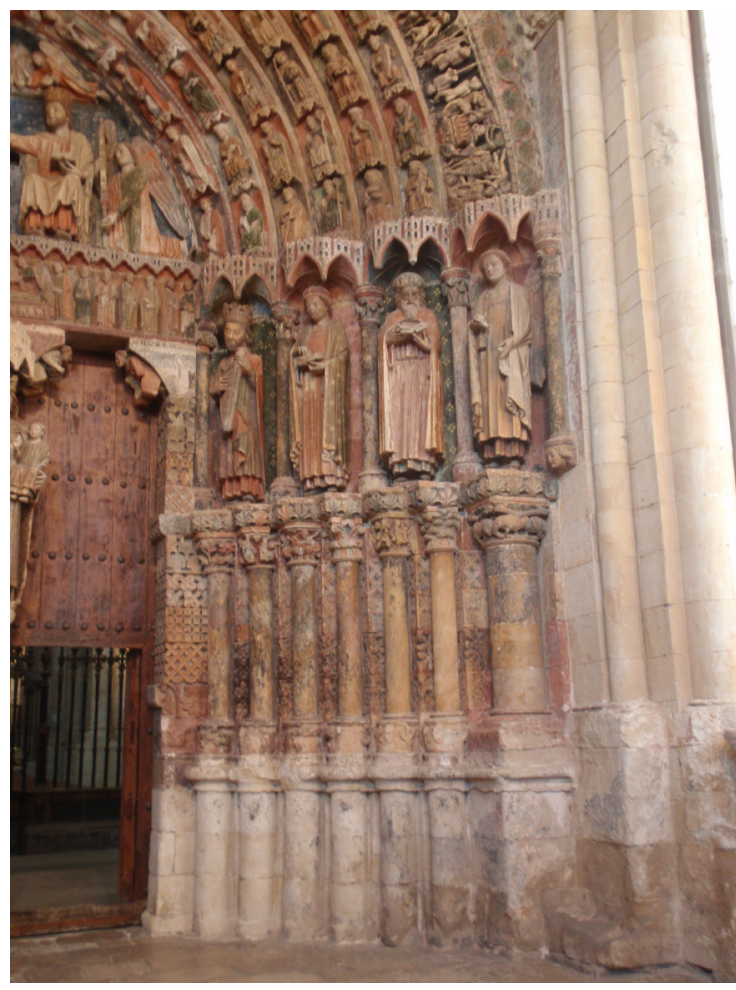

que han sido interpretados como el arcángel Gabriel portador de los mensajes de Dios a la Virgen, tanto en el momento de la Encarnación, como en el de su Tránsito.

La organización de la puerta responde asimismo a modelos propiamente góticos, en relación con lo francés pero también con ejemplos castellanos, como la portada del Sarmental de la catedral de Burgos. Como en ella el vano principal se encuentra dividido en dos por un parteluz en el que se asienta una imagen de la Virgen con el Niño, de pie sobre un capitel en forma de flor que le sirve de peana y que junto con el dosel acastillado situado sobre su cabeza, recrea un espacio ilusorio envolvente que aporta volumen a la escultura. Los dos vanos de acceso que se forman a ambos lados del parteluz, se cierran mediante un dintel, asentado en cuatro robustas mochetas de las que sobresalen figuras de músicos sentados en alto relieve.

De los modelos franceses góticos tempranos procede también la división del tímpano en dos registros, de los cuales el inferior es el dintel anteriormente referido, así como la temática iconográfica y la organización de las escenas. En el registro interior de Toro está representado el momento de la muerte de la Virgen rodeada por los apóstoles, a la vez que dos ángeles transportan al cielo la imagen de María. El tímpano propiamente 
dicho contiene el tema de la coronación de la Virgen María por su Hijo, flanqueados por ángeles turiferarios y ceroferarios. La configuración iconográfica del ciclo de la muerte, ascensión al cielo y coronación de María, con un sistema compositivo basado en la simetría axial tuvo su aparición en las catedrales góticas francesas de la segunda mitad del XII como Senlis y Laon y se difundió a Chartres y Paris. Con posterioridad, llegó a España como queda constatado tanto en el pórtico del Perdón de la catedral de Ciudad Rodrigo como en la fachada occidental de la catedral de León (Fig. 117).

En torno al tímpano hay seis arquivoltas que pretenden evocar la gloria de la que ya participa María (Fig. 118). En ella todo es orden. Las pequeñas figuras cobijadas por doseles y dispuestas en la dirección de las ramas del arco se agrupan de acuerdo con una jerarquía celeste. Más cerca del trono de Dios están los ángeles, seguidos en las órbitas inmediatas por lo que parece ser el colegio apostólico, por los santos mártires, por los santos confesores y obispos, por las santas mártires y por último por una serie de músicos que se han venido identificando con los veinticuatro ancianos del Apocalipsis.

La séptima arquivolta que remata el conjunto a modo de chambrana, no se encuentra en las portadas góticas clásicas. En ella está representado el Juicio Final mediante una serie de imágenes y escenas que en este caso siguen un trazado radial. Preside el tema Cristo, como hombre, ante el que interceden la Virgen y San Juan Evangelista. A su izquierda y derecha, respectivamente, se sitúan los condenados y los elegidos. La razón de su presencia en este conjunto puede ser interpretada como una reminiscencia románica, pero quizá más probablemente como una solución para ofrecer al espectador en un solo espacio los programas iconográficos del Juicio Final, y la Dormición y Coronación de María que se muestran de forma independiente en las grandes catedrales del XIII.

Los investigadores que han trabajado sobre esta portada coinciden en términos generales en la cronología, con pequeñas matizaciones de detalle. Para Gómez-Moreno encaja de lleno en lo parisién del siglo XIII ${ }^{155}$. Para Yarza debió de concluirse durante 


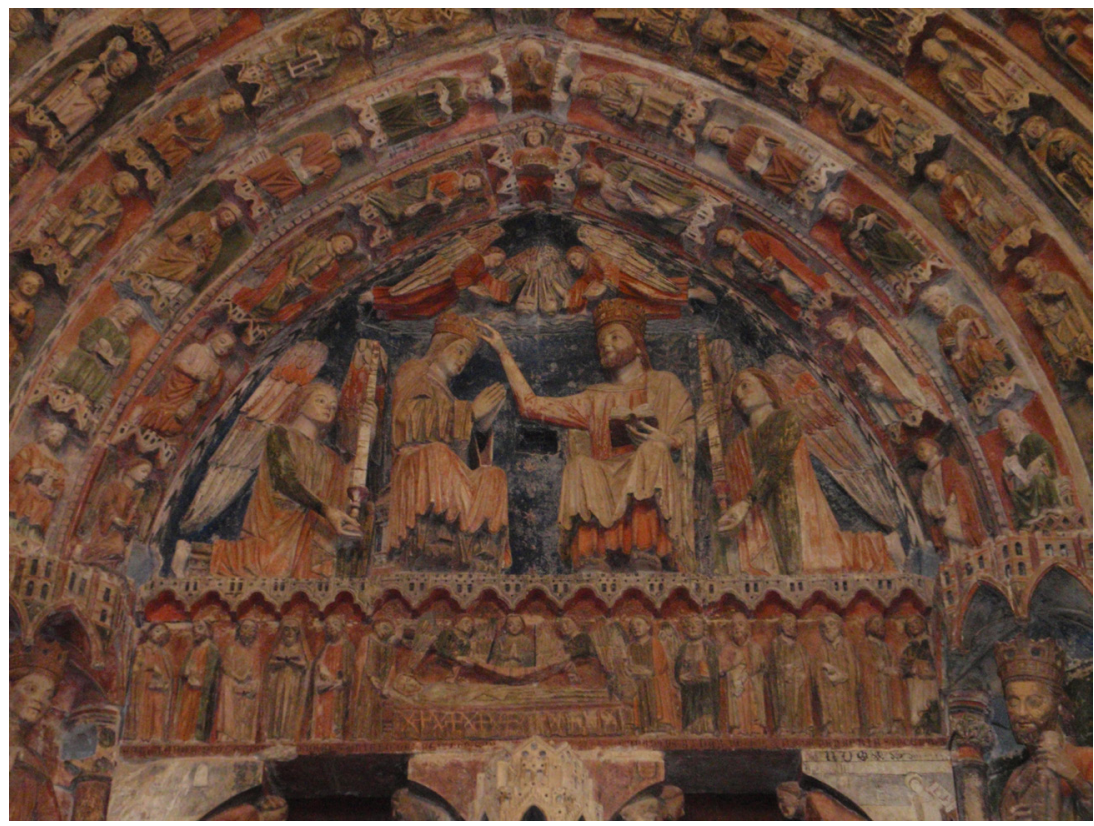

el último cuarto del siglo XIII ${ }^{156}$. Para Navarro Talegón la parte románica se levantaría durante el reinado de Fernando $1{ }^{157}$ y su terminación habría que atribuirla, de acuerdo con Yarza, a un impulso ocasionado por el favor regio de Sancho IV y María de Molina ${ }^{158}$. Ricardo Puente también señala una cronología aproximada a la dada por los anteriores estudiosos al fecharla durante el último cuarto del siglo XIII ${ }^{159}$.

Para compensar la carencia de noticias documentales relativas a la obra de arquitectura y escultura de la portada, se ha conservado un dato importantísimo que nos aporta el nombre del artista que dotó a la portada de su policromía original y el momento aproximado en que lo hizo. Lo sabemos por la inscripción conservada en la franja inferior del dintel y que dice: este : lauor : pinto : dom /// o : perez : criado : del : rei : don : sancho : ///// : mandado : de : aluar : perez : fiio : de : pedrarias : pcurador ${ }^{160}$. Si la portada como afirma la inscripción se policromó durante el reinado del rey Sancho IV (1284-1295)

156 YARZA LUACES, Joaquín, "La portada occidental de la colegiata de Toro y el sepulcro del doctor Grado, dos obras significativas del gótico Zamorano", SZ, Anejos 1, Arte Medieval en Zamora, 1989, p. 129.

157 NAVARRO TALEGÓN, J., op. cit., 2005, p. 57.

158 Ídem, p. 60.

159 PUENTE, Ricardo, Portadas medievales. La portada de la Majestad de Toro, Editorial Albanega, León, 2008, p. 22.

160 He seguido la trascripción realizada por José Navarro Talegón. NAVARRO TALEGÓN, José, La Colegiata de Toro, Junta de Castilla y León, 2005, p. 84. 


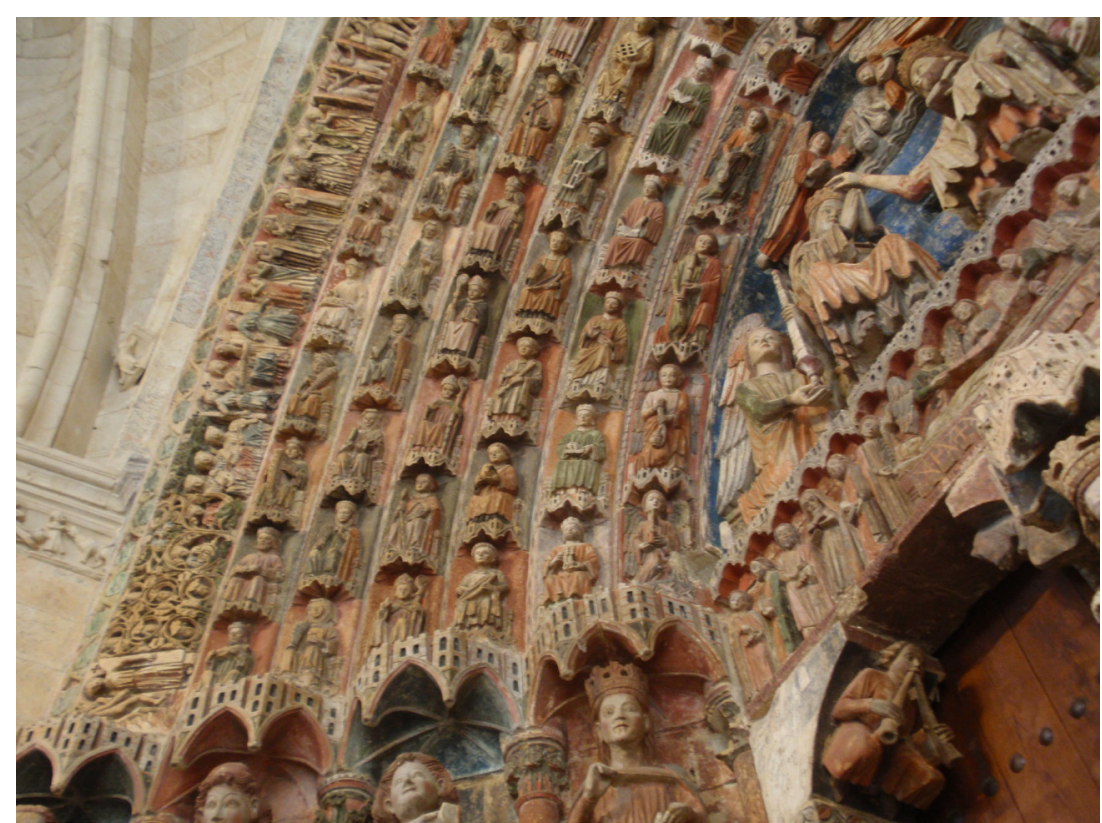

tenemos como fecha ante quem el año 1295, momento en el que a muy tardar la portada estaba concluida totalmente.

El estilo de las esculturas puede utilizarse asimismo como criterio para precisar el marco cronológico en que se llevaron a efecto las obras. La mayor parte de las imágenes participan de una forma de hacer homogénea, con excepción de la talla de los capiteles y las figuras de dos profetas en la jamba izquierda. El autor de éstas últimas obras parece influido por el llamado Maestro del Juicio Final de la catedral de León, a quien se debe el sepulcro del deán Martín Fernández $(+1250)$ y la portada que ha dado nombre a este escultor anónimo, para la que Franco Mata propone una fecha en torno a $1260-1270^{161}$. El resto de las imágenes responden a unas características muy definidas, con modismos formales quizá un poco arcaizantes pero relacionados en términos generales con la orientación estética del maestro del tímpano del Sarmental de la catedral de Burgos, cuya realización estima Karge en torno a $1240^{162}$. Esta corriente estilística que llega a Burgos procedente de Amiens se distingue por la utilización de volúmenes limpios, superficies planas y líneas ortogonales. El autor de las tallas de la portada de la Majestad de Toro lo traslada a términos muy convencionales,

161 FRANCO MATA, Ángela, Escultura gótica en León y provincia (12301530), Diputación León e Instituto leonés de Cultura, Salamanca, 1998, pp. 329-330.

162 KARGE, Henrik, La catedral de Burgos y la arquitectura del siglo XIII en Francia y España, Junta de Castilla y León, Valladolid, 1995, p. 106.
Fig. 118. Detalle de la portada de la Majestad. Colegiata de Toro 


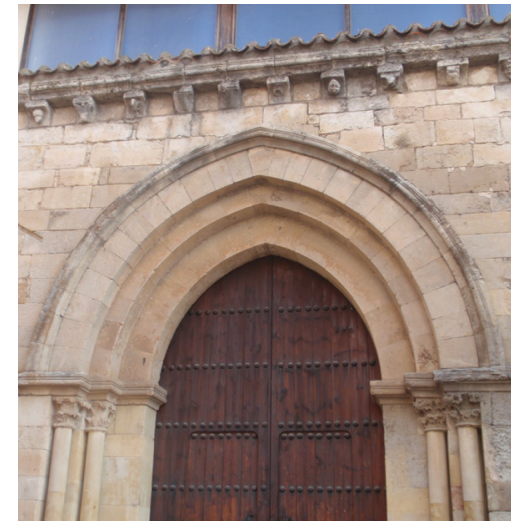

Fig. 119. Portada norte de la capilla de la Majestad. Colegiata de Toro en una concepción formal rígida que inmoviliza a las figuras. Los modismos que se repinten en su obra se reconocen también en un grupo de sepulcros de nobles castellanos realizados en torno al tercer cuarto del siglo XIII ${ }^{163}$.

Las referencias que ofrecen estas fechas hacen pensar que la portada estaría ya iniciada antes de la llegada al trono de Sancho IV, bajo cuyo reinado se daría por concluida la labor de talla y se procedería a su policromía.

Este pórtico quedó cerrado por la construcción de un recinto a lo largo de los siglos XIII y XIV dentro del cual quedó integrado el pórtico convirtiéndose la propia portada en el retablo mayor de este nuevo espacio que funcionó como capilla. Esta capilla, que se proyecta desde los pies del templo hacia occidente, es una de los espacios más interesantes de los edificados durante el gótico pleno y el que se conserva de manera más completa. Su fábrica responde a dos momentos constructivos claramente diferenciados como revelan sus portadas y los diferentes arcosolios que se abren a lo largo de sus muros norte y sur.

El inicio de la construcción comenzó por el muro norte como revela su portada resuelta en arco agudo trasdosado con chambrana y tripe arquivolta lisa, caracterizada en conjunto por una gran austeridad fruto de la influencia cisterciense (Fig. 119). En ella, sin embargo, además del evidente apuntamiento del arco, puede observarse algún elemento de modernidad como es

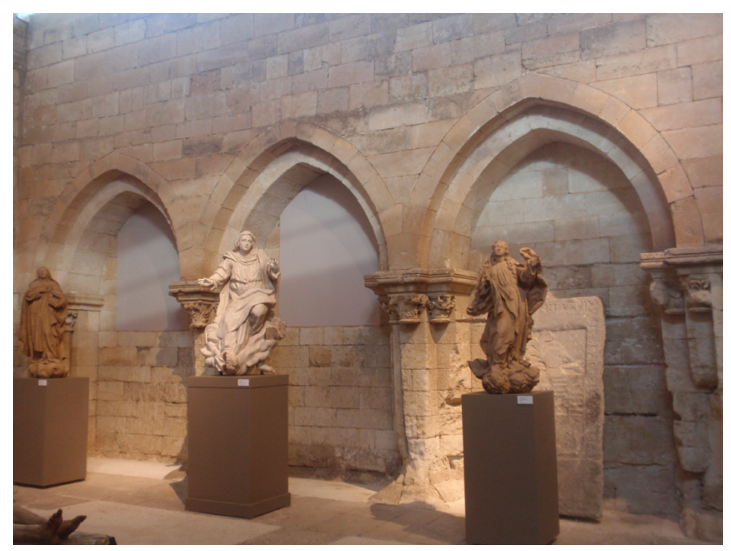

163 ARA GIL, Clementina Julia, "Un grupo de sepulcros palentinos del siglo XIII, Los primeros talleres de Carrión de los Condes: Pedro Pintor y Roi Martínez de Burueva", en Actas del II Curso de Cultura Medieval. Alfonso VIII y su época, Centro de Estudios del Románico, Aguilar de Campoó, 1992, p. 21-52. 
el tratamiento de las hojas que decoran los capiteles que habría que relacionar ya con el estilo gótico.

Lo mismo se puede decir de la sucesión de nichos que se abren a lo largo del interior de este mismo muro, que en esencia repiten el modelo de la portada, aunque en este caso se componen solamente de doble arquivolta, y de la decoración de los capiteles que está en línea igualmente con los de la propia portada, aunque en este caso a los motivos vegetales hay que añadir algunas cabezas o bustos humanos (Fig. 120).

Desde el punto de vista estilístico toda esta parte responde a mediados del siglo XIII.

Durante la segunda fase constructiva se levantó el muro sur y el hastial. La portada que se abre en este muro se encuentra en este caso un poco desplazada hacia el este (Fig. 121). En conjunto presenta una estructura semejante a la anterior ya que se compone igualmente de triple arquivolta y tuvo chambrana, aunque hoy está totalmente picada. Manifiesta una gran sobriedad en su estructura y un arcaísmo que llama evidentemente más la atención puesto que se realizó como señalaremos bastante tiempo después. En este caso, carece de decoración escultórica, no obstante, la molduración que poseen tanto las arquivoltas como las jambas revelan un momento constructivo posterior
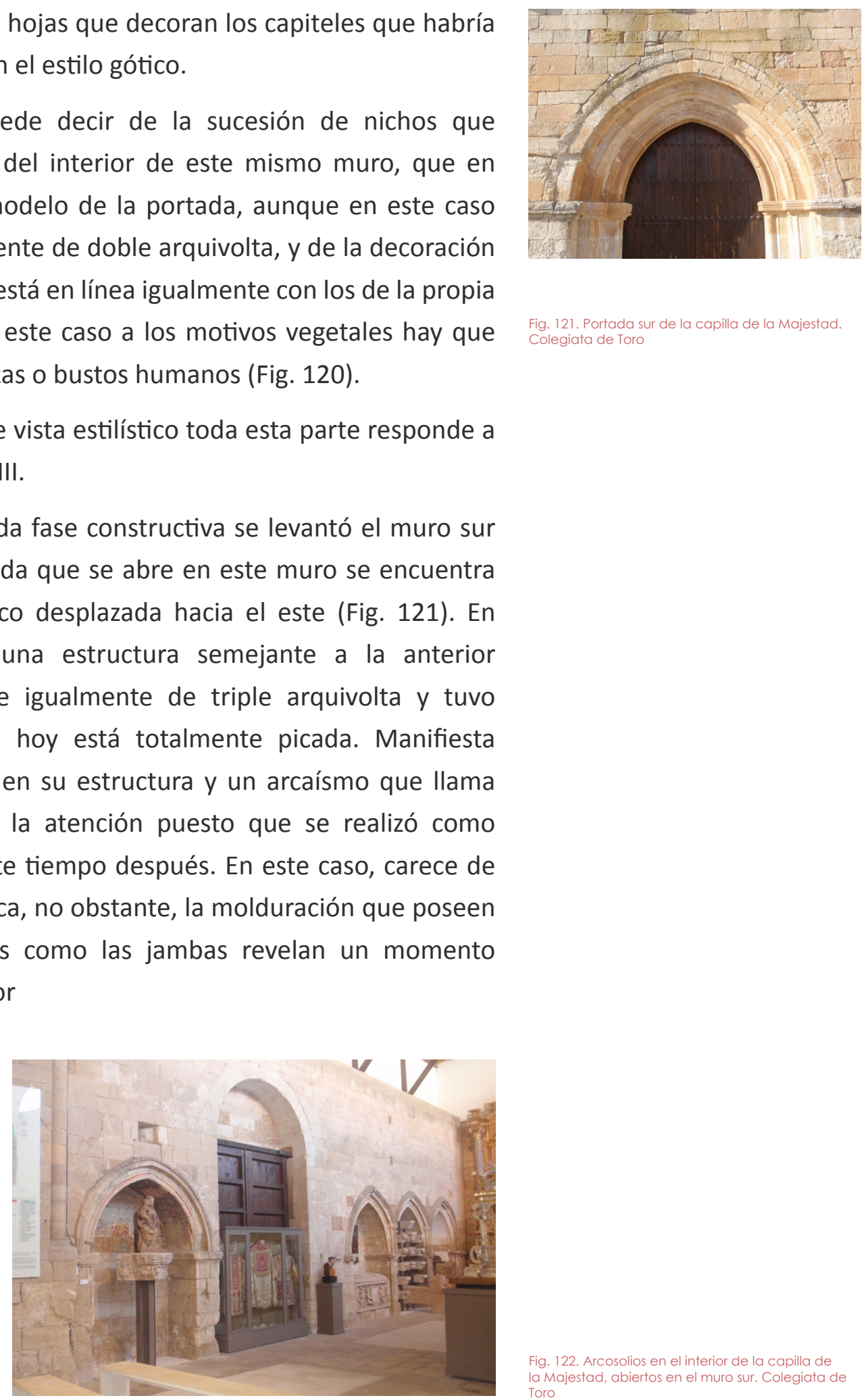

Fig. 121. Portada sur de la capilla de la Majestad.

Colegiata de Toro

Fig. 122. Arcosolios en el interior de la capilla de la Majestad, abiertos en el muro sur. Colegiata de Toro

También el interior de este muro está recorrido por una arquería de nichos ciegos con un nivel de elaboración mayor que los correspondientes al muro de enfrente (Fig. 122). En este caso el apuntamiento de los arcos es más evidente y el tipo de molduración así como las abrazaderas existentes entre los 
propios arcos remiten a una fecha posterior que podría situarse a mediados del siglo XIV.

El hastial no es visible al exterior por las edificaciones anejas y al interior gran parte de él está oculto por un retablo. Aun así se observa la parte superior de un vano achaflanado, doblado y apuntado.

Transformaciones en iglesias románicas. San Cipriano y Santa María la Nueva en Zamora y Santa María la Real de la Hiniesta

Durante los siglos XIII y XIV se intervino en algunas iglesias transformando su disposición original románica de tres naves en una estructura de nave única más acorde con la estética de los nuevos tiempos y, sobre todo, con la exigencia e influencia de las órdenes mendicantes que requerían de espacios despejados ${ }^{164}$. Con esta nueva estructura las iglesias ganaban en amplitud y luminosidad. Para resolver esta nueva disposición interna que afectó a las iglesias de San Cipriano, Santa María la Nueva y Santa María la Real de La Hiniesta ${ }^{165}$ se arbitraron soluciones distintas. En el caso de San Cipriano se dispusieron arcos diafragma doblados y apuntados que soportan una techumbre de madera, en Santa María la Nueva el nuevo espacio se articuló con arcos perpiaños doblados y apuntados que soportarían en origen cubiertas de madera aunque ahora hacen lo propio con bóvedas barrocas con lunetos y, en La Hiniesta, se voltearon arcos perpiaños apuntados que delimitan bóvedas sencillas de crucería. En los tres casos en los arcos transversales persiste la dobladura propia de la arquitectura románica. Aún así, la gran envergadura y luz de los mismos, como el objeto con el que fueron ejecutados que no fue otro que el de reestructurar la división interna de los templos y desligarlos de la penumbra románica-, hace que

164 Las reformas realizadas en el interior de las iglesias románicas fueron una constante generalizada. Se trató de sustituir espacios oscuros, propios de la arquitectura románica, por espacios más despejados y luminosos, que favorecieran el desarrollo de una nueva liturgia. Alguna de estas transformaciones tuvieron lugar en época medieval como sucedió en la iglesia de San Cipriano, aunque la gran mayoría de este tipo de intervenciones se llevaron a cabo en época moderna. Lo mismo sucedió en la ciudad de Toro.

165 En el caso concreto de la iglesia de Santa María la Real de la Hiniesta el edificio románico solamente contó con una nave que ignoramos si llegó a concluirse durante aquel periodo 
puedan presentarse como un claro antecedente de una nueva mentalidad que desembocaría en una arquitectura más esbelta, grácil y en la que la luz pasaría a convertirse en un elemento indispensable.

La iglesia de San Cipriano es una de las más antiguas de Zamora ya que su edificación debió iniciarse a finales del siglo XI. Por tanto, en conjunto es una iglesia románica que, sin embargo, sufrió una importantísima intervención a finales del siglo XIII o inicios del siglo XIV que alteró significativamente el edificio. En ese momento se sustituyó la disposición en tres naves del cuerpo de la iglesia por una sola nave organizada mediante dos arcos diafragma doblados y apuntados que soportan una sencilla techumbre de madera (Fig. 123). Igualmente en este mismo momento se abrió hacia el norte, en el tramo central de la nave, una capilla cuyo arco de acceso presenta las mismas características que los arcos diafragma mencionados. En el interior de esta capilla, en su muro norte se abren dos arcosolios en arco apuntado con la rosca con molduras que se extienden hacia las jambas. La línea de imposta también se encuentra señalada por molduras. Ambos arcosolios presentan un diseño semejante al que hemos visto en las portadas anteriormente citadas de la iglesia de San Pedro del Olmo y de la iglesia del convento de San Ildefonso, ambas en Toro. La diferencia en este

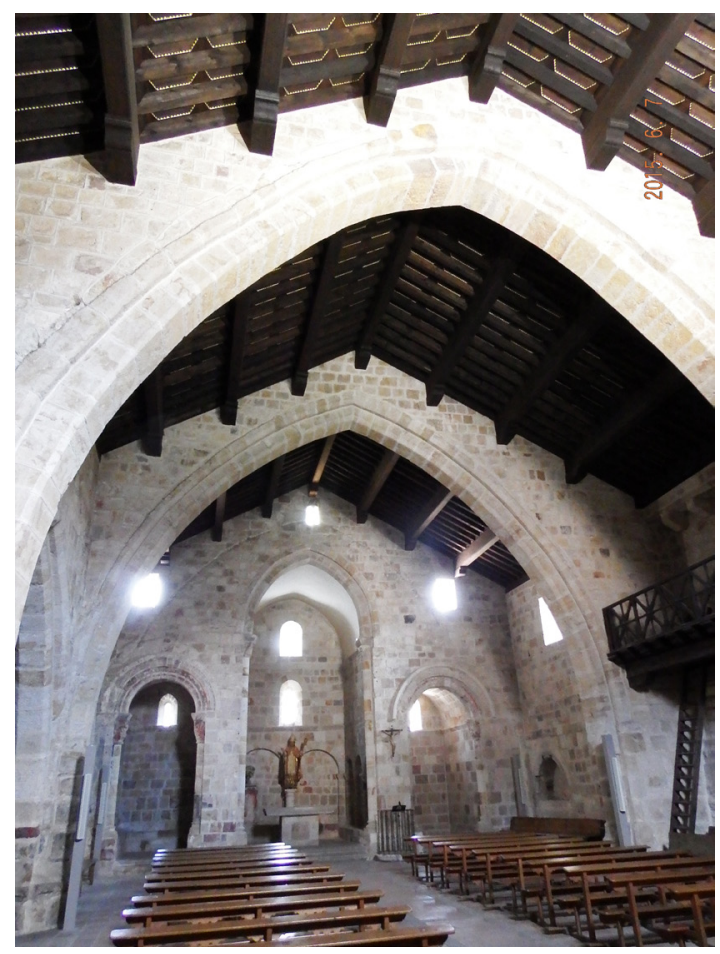


caso se observa en el propio molduraje y es que, mientras en las portadas toresanas éste se componía de molduras rectas que formaban ángulos, en los arcosolios de San Cipriano son todas ellas redondeadas, en forma de bocel lo que parece denotar un momento cronológico ligeramente anterior.

Al igual que la iglesia de San Cipriano la de Santa María la Nueva constituye uno de los templos románicos más antiguos de la ciudad. Su espacio interno se encontraba en origen dividido en tres naves que fueron transformadas en una sola muy probablemente a finales del siglo XIII o principios del siglo XIV.

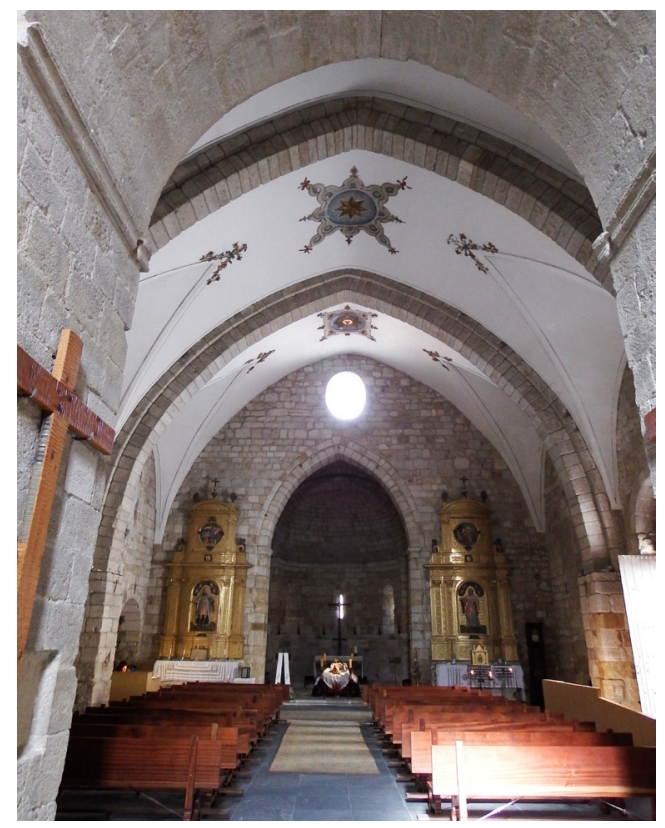

Para ello se voltearon arcos perpiaños doblados y apuntados que dejaron la nave estructurada en tres tramos (Fig. 124).

La iglesia de Santa María la Real de La Hiniesta constituye uno de los conjuntos arquitectónicos más interesantes de este periodo. Su origen y partes más antiguas se remontan al periodo románico tardío, aunque el edificio fue en gran medida reedificado durante los últimos años del siglo XIII y buena parte del siglo XIV amén de las numerosas reformas llevadas a cabo en los siglos subsiguientes ${ }^{166}$. Su arquitectura, a excepción de la portada occidental, como ya señalara Gómez-Moreno "poco mérito alcanza", no obstante, para este estudio es de un enorme 166 Una revisión reciente sobre este lugar y sobre la arquitectura de este edificio en relación con el monarca Sancho IV se encuentra en: GUTIÉRREZ BAÑOS, Fernando, Las empresas artísticas de Sancho IV el Bravo, Junta de Castilla y León, Burgos, 1997, pp. 122-127. 
interés por cuanto constituye uno de los escasísimos edificios de la provincia de Zamora que fue reconstruido con una única nave formada por tramos estrechos y alargados siguiendo el modelo que habían difundido las órdenes mendicantes durante el periodo correspondiente al gótico pleno. Estos tramos se cubrieron con bóvedas de crucería que solamente se han conservado en los dos tramos inmediatos a la cabecera, aunque a juzgar por los

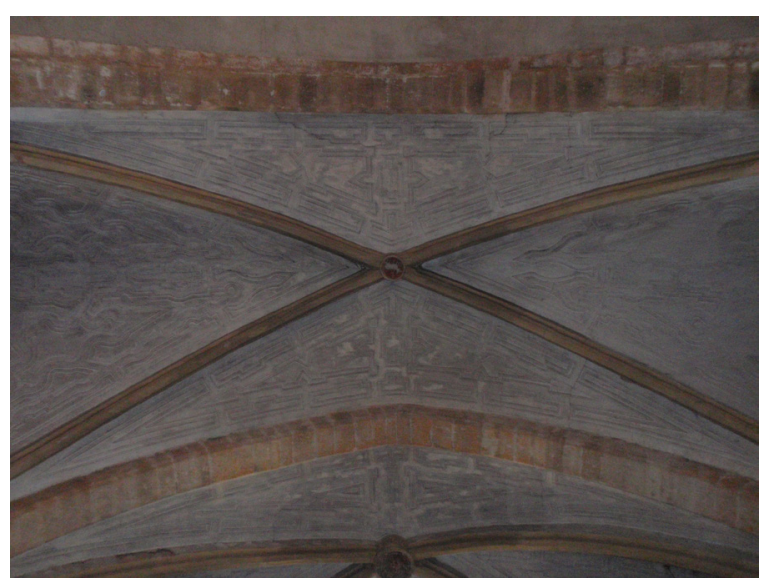

contrafuertes existentes en el exterior del edificio el resto de tramos de la nave debieron estar abovedados del mismo modo (Fig. 125).

También pertenecen a este periodo del gótico pleno sus dos portadas. La correspondiente al muro norte, y que en la actualidad se encuentra cegada, se compone de un amplio arco apuntado con la rosca decorada con molduras sin ornamentos del tipo habitual zamorano y con una sucesión de boceles y escotas rematadas mediante un guardapolvo que dan al arco un perfil ligeramente triangular (Fig. 126). Guarda unas ciertas semejanzas con la portada occidental del convento toresano de San Ildefonso y con la portada también occidental que se ha conservado de la iglesia de San Pedro del Olmo igualmente en la ciudad de Toro y a las que aludimos anteriormente. No obstante, estas últimas presentan un arco más reducido y un abocinamiento mucho más desarrollado de lo que puede verse en la portada de La Hiniesta. Curiosamente y fruto probablemente del conservadurismo de las formas (o de la reutilización de elementos de la iglesia románica ${ }^{167}$ ) la línea de imposta está definida mediante molduras propias de 167 El tipo de moldura que tiene la imposta de esta puerta es semejante a la que habitualmente se utiliza en los edificios hacia 1200 sin que por su simplicidad permita ir más allá en las deducciones. 


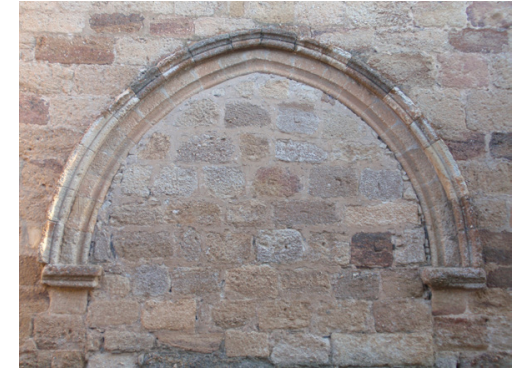

Fig. 126. Puerta cegada en el muro norte de la iglesia de Santa María la Real de La Hiniesta

principios del siglo XIII muy comunes en iglesias zamoranas de ese tiempo así como de la arquitectura cisterciense.

La portada meridional es, sin duda, la parte más destacada y conocida de este templo. Fue edificada durante las primeras décadas del siglo XIV de acuerdo con los patrones de la escultura de las grandes catedrales góticas del siglo XIII (Fig. 127).

Desde sus inicios, y según es habitual en la arquitectura del periodo clásico, este acceso al templo fue planteado como una fachada pórtico con un amplio derrame en los laterales. A diferencia de los portales del periodo gótico pleno en los que las arquivoltas son la prolongación de las jambas, en este caso las arquivoltas son muy estrechas y se organizan en torno al tímpano, mientras que las jambas se prolongan en la decoración esculpida de los muros del pórtico.

No sabemos con exactitud cómo era en origen el trazado del vano de esta portada que comunicaba con el templo ya que en el siglo XVIII fue objeto de una reforma, aunque sí consta, porque la documentación así lo refiere, que la puerta estaba dividida por un mainel que fue retirado precisamente en el año 1751. El documento dice que "costo quitar el poste que avía en la puerta principal de la yglesia y era impedimento a salir y entrar Nuestra Señora de hacer arco nuebo a dicha puerta...que lo hizo Francisco Ferrada maestro valenciano"168. Dicho mainel acogería según planteamiento de Rivera de las Heras la imagen de la Virgen con el Niño que actualmente se encuentra en el interior de la iglesia ${ }^{169}$. Ara Gil es de la misma opinión ${ }^{170}$.

Lo más relevante de la portada es, sin duda, su aspecto escultórico. El estilo de alguna de las piezas que la componen se reconoce también en otras obras de la zona, como la Virgen de la Calva de la catedral zamorana, los grupos de la Anunciación de Benavente y de la colegiata de Toro y la Virgen del Viso de la pequeña localidad de Bamba, lo que parece indicar la presencia de un artista de gran calidad, probablemente extranjero, que

168 A.H.D.Za., Parroquiales, 143 (13), cuentas de 1751, f. 12. Citado en RIVERA DE LAS HERAS, J. A., op. cit., 1997, p. 188, nota 36.

169 RIVERA DE LAS HERAS, J. A., op. cit., 1997, p. 188.

170 ARA GIL, Clementina Julia, "Virgen con el Niño" en Catálogo de la Exposición Remembranza. Las Edades del Hombre, Zamora. Zamora 2001, pp. 508-509. 


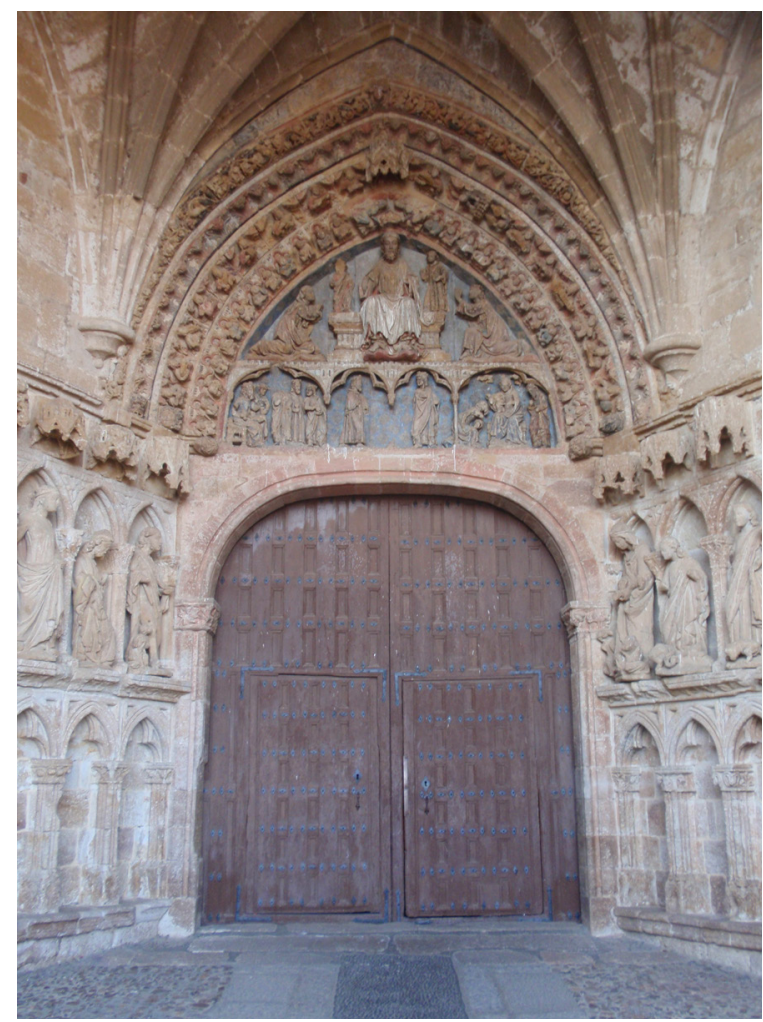

Fig. 127. Portada sur de la iglesia de Santa María la Real de la Hiniesta

trabajó en León y que lo hizo con posterioridad en Zamora y provincia ${ }^{171}$.

En origen esta portada esculpida estaría cobijada por una bóveda de crucería de la que sólo se ha conservado algunos tramos de nervios originales como queda evidenciado por la molduración que se empleó en ellos consistente en tres boceles (Fig. 128). Con la reforma llevada a efecto en el siglo XVI esta parte fue transformada de ahí que junto a esos nervios antiguos observemos otros con molduras propias del gótico tardío.

Todas estas obras que se hicieron en la iglesia de La Hiniesta, tanto en el interior (estructuración del cuerpo del templo en una sola nave dividida en tramos estrechos cubiertos por bóveda de crucería) como del exterior (portadas norte y sur), parecen responder a las reformas iniciadas en la época de Sancho IV y llevadas a efecto a lo largo del siglo XIV. Es probable que las obras concluyesen durante el tercer cuarto del siglo XIV y en este aspecto es preciso mencionar, aunque no sea objeto de este estudio, las pinturas murales góticas que se conservan detrás del retablo mayor decorando el testero de la capilla románica. Estas pinturas han sido cuidadosamente estudiadas por Gutiérrez 
Fig. 128. Bóveda de la portada sur de la iglesia de Santa María la Real de La Hiniesta

Fig. 129. Cabecera correspondiente a la nave norte de la iglesia de San Frontis. Zamora

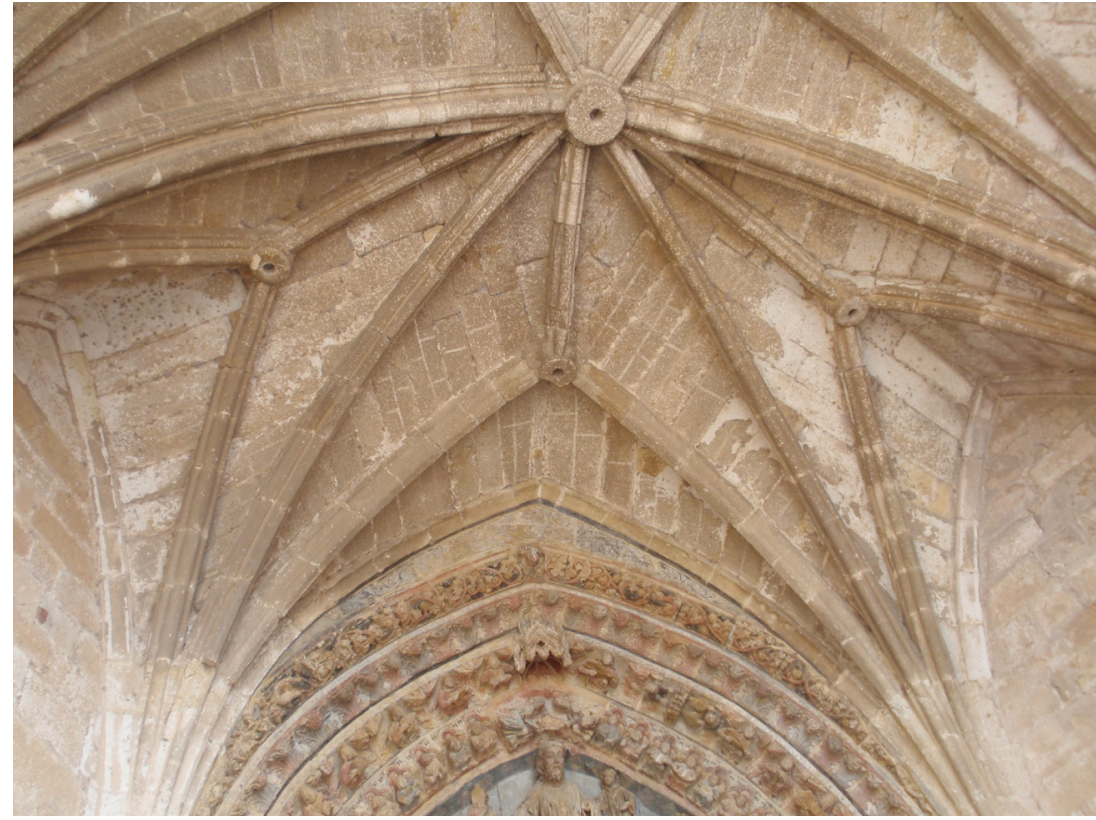

Baños que precisa para ellas una cronología ca. 1360-ca. 1370 172. Es lógico pensar que cuando estas pinturas fueron realizadas las reformas arquitectónicas del templo estaban ya finalizadas.

Por último cabe añadir la probable reforma que sufrió durante este periodo la iglesia de San Frontis de Zamora y que afectó a la cabecera correspondiente a la nave norte. El ábside poligonal que presenta, con contrafuertes en las esquinas para soportar los empujes de una bóveda de crucería que ignoramos si se construyó, remite a modelos góticos y podríamos datarlo, no sin reservas, en el siglo XIV e, incluso, en el XV (Fig. 129).

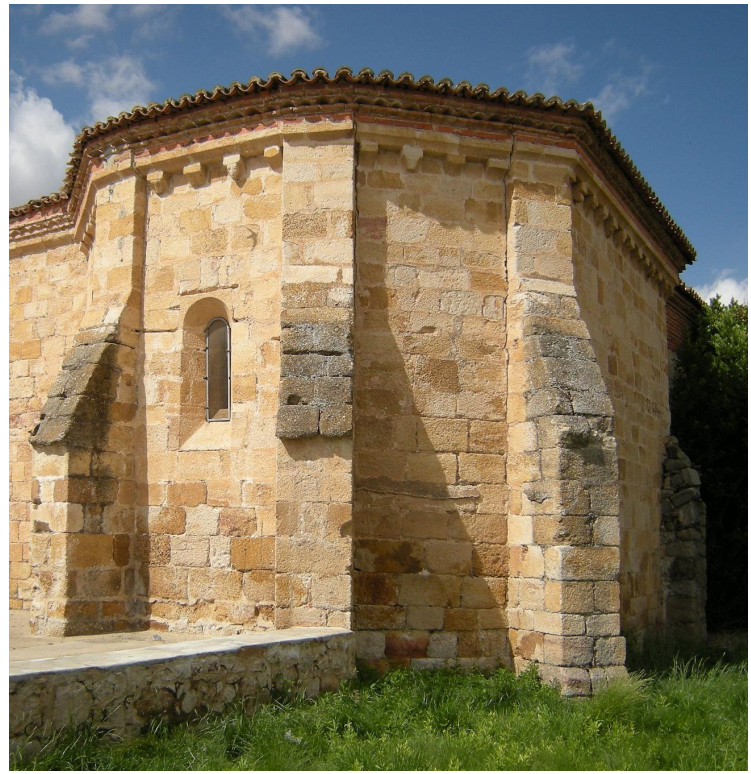

172 GUTIÉRREZ BAÑOS, Fernando, Aportación al estudio de la pintura de estilo gótico lineal en Castilla y León: Precisiones cronológicas y corpus de pintura mural y sobre tabla, II, Fundación Universitaria Española, Madrid, 2005, p. 83 


\section{La implantación de las órdenes mendicantes en Zamora y su provincia}

Uno de los fenómenos más característicos de la arquitectura del siglo XIII fue la implantación de casas por parte de las nuevas órdenes mendicantes. El nuevo sistema de vida religiosa aportado por estas órdenes tenía la capacidad de adaptarse a las nuevas condiciones de una sociedad que tiende a establecimientos urbanos. Las más significativas, debido al mayor desarrollo que tuvieron, fueron la Orden franciscana, fundada por el italiano Francisco de Asís (†1226) y, la Orden dominicana, fundada por el español Domingo de Guzmán (†1221). Lo que les unía, en lo fundamental, era la carencia de bienes raíces y, por lo tanto, la necesidad para su subsistencia de las limosnas de los fieles, la manifestación de pobreza y el acercamiento al pueblo a través de la predicación.

Estas órdenes aportaron una nueva forma de vida espiritual asociada. A diferencia de los benedictinos y cistercienses (las ordenes monásticas más extendidas en la época), los mendicantes, como se ha dicho, carecían de bienes raíces que les permitieran vivir aislados del mundo y dedicados plenamente a la oración. Por ello su actuación iba dirigida a la evangelización, de ahí que se establecieran en las ciudades y que posibilitaban el acceso del pueblo a sus iglesias, que contribuía a su sustento con las limosnas. Los miembros de estas mismas órdenes mendicantes, siguiendo el modelo de San Francisco, toman el nombre de frailes que proviene de la palabra latina frater, que significa hermano. Casi al mismo tiempo que se establecieron las comunidades masculinas lo hicieron las femeninas.

Lo que teóricamente en principio es muy claro, con el paso del tiempo se hace más complejo al producirse contaminaciones tanto desde el punto de vista de la organización como en los aspectos económico y terminológico.

Los edificios conventuales que estas órdenes levantaron en sus asentamientos diferían sustancialmente de los modelos dados por la arquitectura gótica de las catedrales, pese a estar ambas construcciones asentadas en la ciudad. Mientras que la catedral se había transformado mediante la altura, la luz y la riqueza ornamental en un espacio mágico que conseguía 
impresionar al fiel, las iglesias conventuales tenían como pretensión, únicamente, la de convertirse en un lugar apto para la predicación. Todo esto tuvo como consecuencia la configuración del espacio de las iglesias conventuales en una única nave con capillas entre contrafuertes o, en cualquier caso, quedaba de manifiesto la preferencia por un espacio diáfano que permitiese una perfecta visibilidad del presbiterio y del predicador ${ }^{173}$.

La popularidad que adquirieron las personalidades de San Francisco y Santo Domingo hizo que estas órdenes se multiplicaran. Esto no significa que no se edificaran edificios de otras órdenes, aunque sí es cierto que fueron muy superiores en número los conventos franciscanos y dominicos (masculinos y femeninos) que surgieron, estableciéndose en la práctica totalidad de ciudades y villas de importancia de toda la geografía española. Los núcleos de población más importantes de la provincia de Zamora no se distinguieron del resto del territorio peninsular en lo que respecta a la implantación de las órdenes mendicantes y fue lógicamente en la capital, que era la ciudad de mayor relevancia del entorno, donde se establecieron en mayor número las fundaciones de estas órdenes.

Sin embargo, aunque en la actualidad sólo han llegado a nuestros días las ruinas del convento de San Francisco de Zamora y del convento de San Ildefonso de Toro y algunos elementos integrados en el conjunto monástico de Sancti Spiritus de Toro, se conoce la existencia de otras muchas fundaciones de órdenes mendicantes que tuvieron lugar en los siglos XIII y XIV y que, por tanto, es probable que erigieran sus casas en estilo gótico aunque de acuerdo con los principios de austeridad de estas órdenes, lo que daría lugar a edificios modestos que con el paso del tiempo y muchas veces por estar ubicados en lugares poco propicios desaparecieron completamente. Sus comunidades por lo general se trasladaron a localizaciones más idóneas ${ }^{174}$.

173 No era nuevo este tipo de distribución interna; ya se había utilizado en la zona del mediodía en Francia durante el periodo románico. Lo que sí hicieron los mendicantes fue adoptar este tipo de plantas y así quedó reflejado desde muy pronto por parte de los franciscanos en Asís. GRODECKI, L., Arquitectura gótica, Madrid, 1989, pp. 90-96.

174 Esto sucedió con el convento de Santa María de los Villares perteneciente a la Orden de San Juan y establecido en la localidad zamorana de Fuentelapeña, que fue trasladado a la ciudad de Zamora en el siglo XVI. Juan Manuel Palacios ha situado en el siglo XIV la fundación, cronología que Pérez Monzón toma con reservas al no citar Palacios la fuente de la que extrajo ese importante dato. PALACIOS, Juan Manuel, La sagrada e ínclita Orden Militar de San Juan de Jerusalén (Orden de Malta) 
Tenemos noticia en la provincia de Zamora de distintas fundaciones de estas órdenes durante el gótico pleno, cuyos edificios primitivos desaparecieron completamente. En la ciudad de Zamora: el convento de Santo Domingo, el monasterio de Santa Clara, el monasterio de Santa María la Real de las Dueñas y el monasterio de Santa Marina. Solamente del convento de San Francisco a cuyo emplazamiento actual llegaron los religiosos en la segunda mitad del siglo XIII, tenemos testimonios materiales, algunos de los cuales y a pesar de su fragmentación, constituyen lo más destacado de nuestra arquitectura gótica plena.

En Benavente por ejemplo la orden de San Francisco se estableció en 1270 y la de Santo Domingo en el año 1276175. Desgraciadamente, de estos conjuntos conventuales en los que se debieron hacer obras significativas durante este periodo correspondiente al gótico pleno solamente se han conservado unos insignificantes restos del conjunto conventual de Santo Domingo ${ }^{176}$. Igualmente se establecieron en Benavente durante este periodo las ramas femeninas de estas órdenes mencionadas ${ }^{177}$. Las franciscanas lo hicieron en el siglo XIII y las dominicas en el siglo XIV, pero nuevamente nada se ha conservado de las casas que habitaron. En la ciudad de Toro también durante este periodo tuvieron lugar fundaciones monásticas que levantaron casas aunque de aquel momento los restos que se han conservado son muy escasos. Sabemos que el convento de Santa Clara estaba habitado en la segunda mitad del siglo XIII y que probablemente el convento de San Francisco debió fundarse también en la segunda mitad de este mismo siglo, que

y sus monasterios de religiosas en España, Logroño, 1977, p. 61; PÉREZ MONZÓN, Olga, "El convento de las Comendadoras de Zamora: El proyecto artístico del prior Sanjuanista Diego de Toledo", Anuario del Instituto de Estudios Zamoranos "Florián de Ocampo», Zamora, 1993, p. 229. Sobre la encomienda de Fuentelapeña y este convento vid. PÉREZ MONZÓN, Olga, Arte Sanjuanista en Castilla y León. Las encomiendas de la Guareña y su entorno geo-histórico, Valladolid, 1999, pp. 151-164.

175 LEDO DEL POZO, José, Historia de la nobilísima villa de Benavente con la antigüedad de su ducado, principio de su condado, sucesión y hazañas heroicas de sus condes, (Reedición hecha de la impresa en Zamora en el año 1853, por el Dr. Eugenio Llamas Valbuena), Salamanca, 1970, pp. 341-347.

176 FERNÁNDEZ RUIZ, Raquel del Carmen, Colección diplomática del monasterio de Santa Domingo de Benavente (1228-1390), Centro de Estudios Benaventanos «Ledo del Pozo», Salamanca, 2000.

177 LEDO DEL POZO, José, Historia de la nobilisima villa de Benavente con la antigüedad de su ducado, principio de su condado, sucesión y hazañas heroicas de sus condes, (Reedición hecha de la impresa en Zamora en el año 1853, por el Dr. Eugenio Llamas Valbuena), Salamanca, 1970, pp. 349-356. 


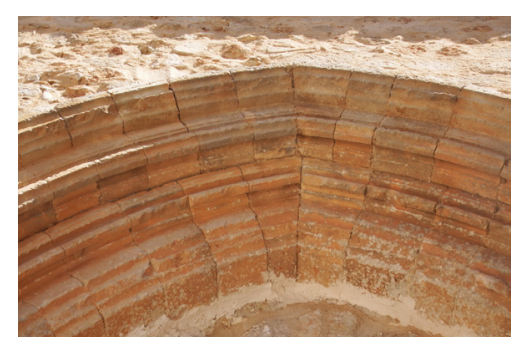

Fig. 130. Detalle de las arquivoltas de la portada occidental del convento de San Ildefonso. Toro

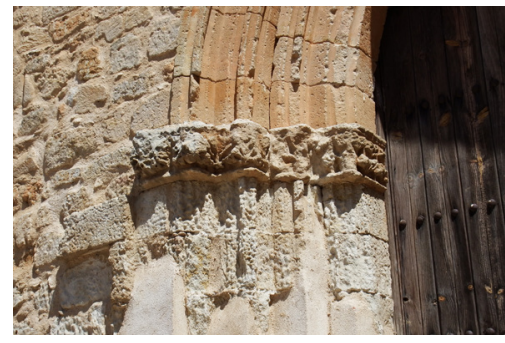

Fig. 131. Capiteles de la portada occidental del convento de San lldefonso. Toro el monasterio dominicano de San Ildefonso fue fundado en el año 1275 y que el monasterio de Sancti Spiritus, también de la orden dominica, fue fundado por doña Teresa Gil en 1307. Igualmente en la ciudad de Toro, pero al margen de las órdenes mendicantes, se estableció, concretamente en el año 1316, una comunidad de Premostratenses en una residencia cedida por María de Molina y que había pertenecido con anterioridad al obispo de Coria, donde es probable que las monjas hicieran algún tipo de obras de las que no ha llegado nada hasta nuestros días, pues lo conservado de este periodo responde a la residencia del obispo. De todas estas casas toresanas de religiosos y religiosas tan solo se han conservado algunos elementos del convento de San Ildefonso y del monasterio de Sancti Spiritus correspondientes al siglo XIV.

\section{Los restos conservados}

Del convento de San Ildefonso de Toro se ha conservado de este momento una sencilla puerta in situ que se ha venido relacionando con el acceso principal de la iglesia. Se trata de una portada abierta en un muro de mampostería, en parte reedificado después de la desamortización con materiales de deshecho del propio edificio, entre los que Navarro Talegón identificó, ya en su momento, tambores de columnas, pináculos, pedazos de basas o fragmentos de cornisas ${ }^{178}$. Consta de arco apuntado moldurado mediante pequeños boceles, listeles y escocias que se prolongan por las jambas y que presentan aún un deterioro más pronunciado que el que se aprecia en la rosca del arco. La línea de imposta está señalada mediante una franja con los extremos perfilados que acoge en su interior decoración de hojas características del gótico (Figs. 130 y 131). Navarro Talegón fecha esta portada en el siglo XIV ${ }^{179}$, opinión que comparte Vasallo Toranzo ${ }^{180}$. Esta misma cronología se ha dado también para la portada occidental de la antigua iglesia de San Pedro del Olmo, que se encuentra a escasa distancia de ella y con la que guarda una cierta similitud.

También se han conservado del convento de San Ildefonso algunos restos de una capilla funeraria. Gómez-Moreno apuntó

\footnotetext{
178 Ídem, p. 281.

179 Ídem

180 VASALLO TORANZO, L., op. cit., 1994, p. 309
} 


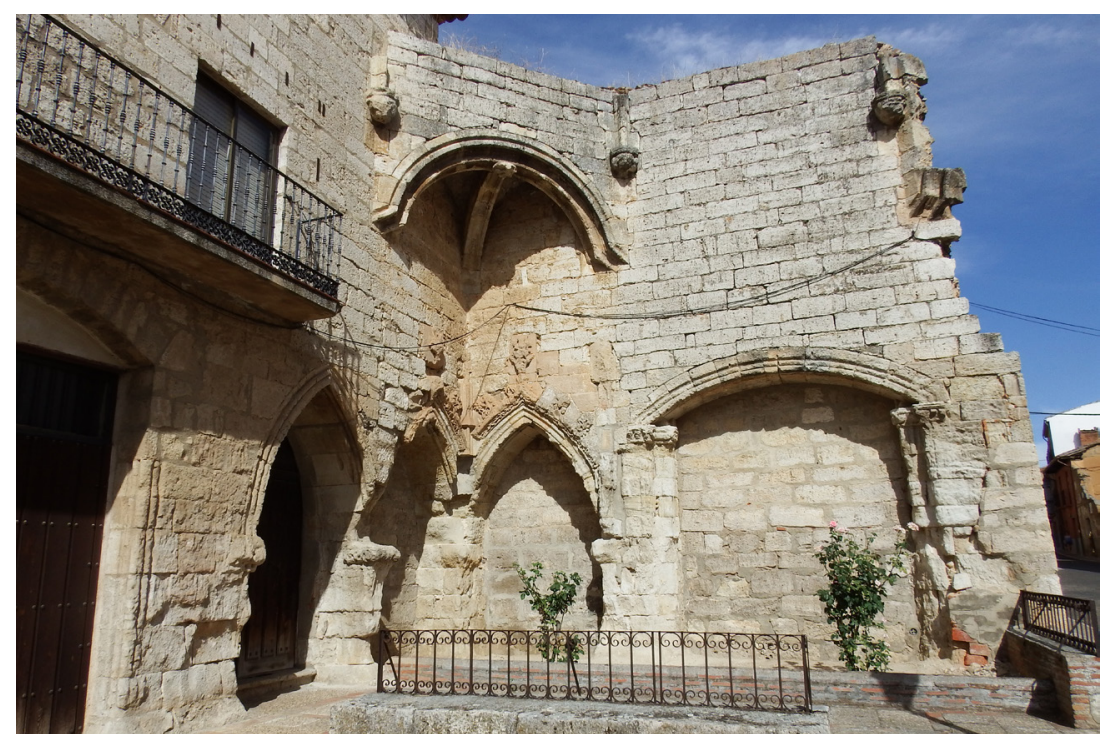

que éstos quizá pudieran haber pertenecido a la capilla que denomina de los Infantes, que acogió el enterramiento del infante Enrique, hijo de Sancho IV y de María de Molina, sin embargo el enterramiento de este infante estuvo ubicado en la desaparecida capilla mayor ${ }^{181}$. Estos restos consisten en dos fragmentos de muro integrados en una edificación moderna (Fig. 132). Su construcción es de cal y canto con revestimiento de sillería en su cara interna. En los muros se abren tres arcosolios y un arco ciego. Los tres arcosolios están resueltos mediante un arco de acusado apuntamiento. El primero de ellos presenta una arquivolta moldurada con un grueso bocel en la arista y con dos boceles de dimensiones más reducidas, a su vez flanqueados por dos pequeñas escocias, tanto en la rosca como en el intradós. $A$ pesar del gran deterioro de estas molduras da la impresión de que se prolongaban a lo largo de las jambas, interrumpidas, no obstante, por la faja decorativa que sigue la línea de imposta. Los otros dos lucillos están situados contiguos en el único ángulo conservado de esta capilla. Tienen el mismo diseño que el anterior aunque en este caso ambos han conservado parte de la chambrana o guardapolvo en forma de arco conopial que recorría el trasdós del arco. Ésta se componía de una escocia decorada con motivos vegetales flanqueada por dos boceles, más grueso el superior. A continuación de estos arcosolios se abre un amplio arco ciego de escarzano con la rosca moldurada mediante boceles y escocias como se ha visto en los anteriores y sin chambrana. Apoya lateralmente en dos pilares que tienen 


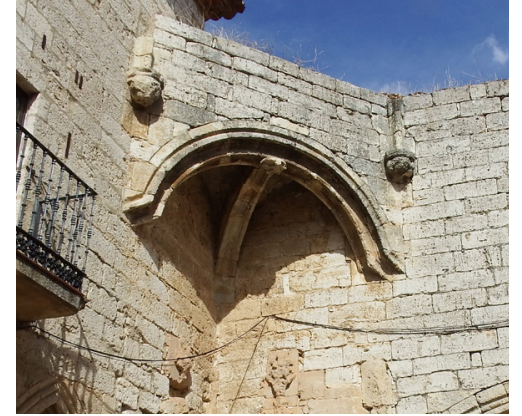

Fig. 133. Trompa. Restos del convento de San

lldefonso. Toro

a modo de capitel una franja decorada con rosetas que sigue la línea de imposta. Las jambas están reforzadas en el interior por otras dos pilastras adosadas a ellas de características semejantes, quizá para dar sustentación a las primeras dovelas de este gran arco.

La capilla de la que formaban parte estos arcosolios estaba cubierta por una bóveda sobre trompas según se deduce de la que se observa en la parte superior del ángulo todavía conservado y los escasos restos existentes de lo que fue otra trompa de las mismas características situados en el extremo de uno de los muros (Fig. 133). Gómez-Moreno relacionó estos arranques con los existentes en la capilla de Santa Bárbara, en el claustro de la catedral vieja de Salamanca ${ }^{182}$. La capilla de Santa Bárbara fue fundada en el año 1334 y guarda una estrecha similitud con la contigua capilla de Talavera de la que tomó inspiración para su arquitectura. La capilla de Talavera había sido sala capitular de la catedral salmantina con la advocación del Salvador hasta que a finales del siglo XV fue adquirida por el doctor Rodrigo Maldonado de Talavera. La arquitectura de esta capilla de los Talavera se ha venido datando a finales del siglo XII e, incluso, con más probabilidad a principios del siglo XIII ${ }^{183}$. Y sería más bien en esta última centuria donde se podría rastrear el origen de parte de la estructura de cubrición que debió de existir en la capilla de la iglesia conventual de San Ildefonso. Ignoramos si en San Ildefonso también se copió la magnifica bóveda esquifada de raigambre hispano-musulmana y de base octogonal que cubre la capilla de Talavera, aunque más bien nos inclinamos a pensar que no. Los restos de la capilla del convento de San Ildefonso que se conservan hablan de un espacio cuadrangular de algo más de ocho metros de lado, dimensiones aproximadamente idénticas a las que tiene la citada capilla de Talavera.

182 Ídem. También Nieto González apuntó que la cubierta desaparecida de este espacio pudiera haber sido semejante a la que tiene la capilla de Santa Bárbara situada en el claustro de la catedral vieja salmantina. NIETO GONZÁLEZ, José Ramón, SERRANO PIEDECASAS FERNÁNDEZ, L. y HERRERO PRIETO L. C., El patrimonio histórico en el río Duero, Fundación “Rei Alfonso Henriques”, Salamanca, 2001, p. 161.

183 TORMO Y MONZÓ, Elías, Salamanca: Las Catedrales (sobre estudios inéditos de D. Manuel Gómez Moreno), Madrid, p. 58; HERNANDO GARRIDO, José Luis, "Catedral Vieja de Santa María de la Sede" en RODRÍGUEZ MONTAÑÉS, J. M., (coord.) Enciclopedia del Románico en Castilla y León. Salamanca, Centro de Estudios del Románico, Aguilar de Campoo, 2002, p. 284. 


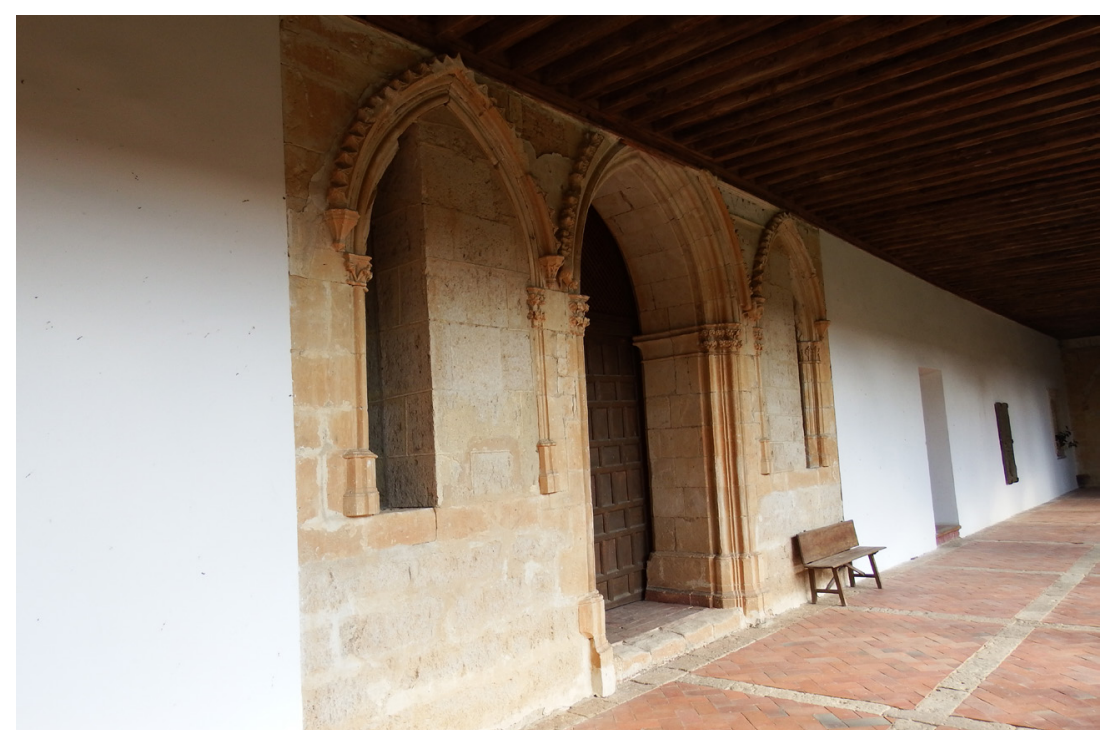

A falta de documentación sobre esta capilla funeraria es preciso establecer su cronología en función de los elementos arquitectónicos y ornamentales que presenta. Navarro Talegón la fecha en el siglo XIV, mientras que Vasallo Toranzo lo hace en el siglo XIV o principios del $X^{184}$. Desde el punto de vista arquitectónico nada habría que objetar a una cronología del siglo XIV, sin embargo, la decoración de los arcosolios situados en el rincón cuya chambrana adopta ya la forma de arco conopial decorado con una franja de motivos vegetales y con amplias hojas rizadas en el trasdós así como el florón que remata el conjunto pertenecen a modelos del siglo XV.

Del monasterio de Sancti Spiritus se han conservado, por un lado, una serie de portadas muy sencillas, resueltas en arco apuntado y desprovistas de decoración y, por otro, los vanos correspondientes a la antigua sala capitular mucho más elaborados. Este acceso a la antigua sala capitular se compone de una puerta flanqueada por dos ventanas según la tradición monástica que, en conjunto, muestra una significativa riqueza ornamental compuesta por distintas molduraciones así como elementos vegetales, animales y rostros humanos que se circunscriben a los capiteles y las chambranas que guarnecen los arcos (Fig. 134). La iglesia de este conjunto monástico también ha mantenido estructuras de la primera mitad del siglo XIV como son el primitivo acceso a la iglesia, situado en el muro norte y compuesto por un arco apuntado decorado con medias bolas
Fig. 134 Vanos correspondientes a la antigua sala capitular del monasterio de Sancti Spiritus. Toro

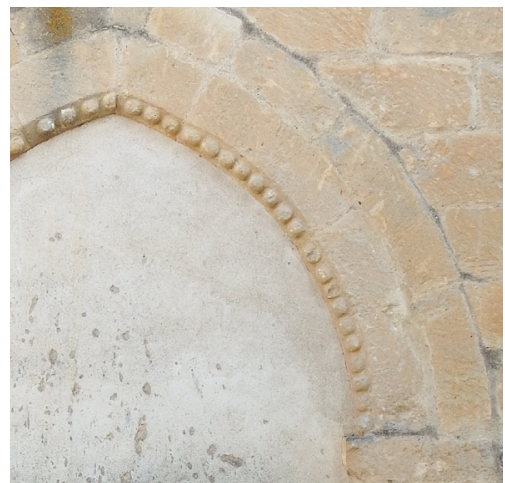

Fig. 135. Antiguo acceso a la iglesia del monasterio de Sancti Spiritus. Tor

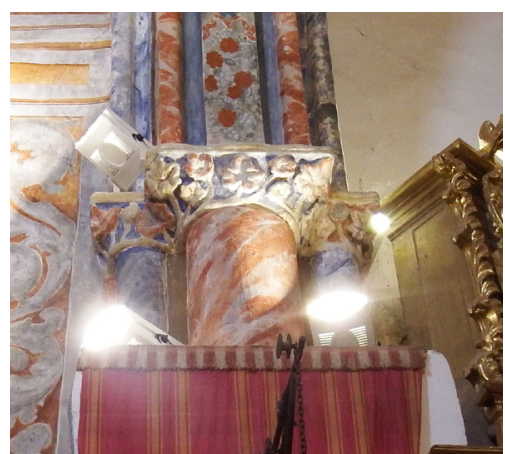

Fig. 36. Capiteles decorados con hojas en el vano de ingreso a la capilla mayor de la iglesia del monasterio de Sancti Spiritus. Toro 
y el gran arco de la embocadura de la cabecera que apoya en columnas con capiteles decorados con hojas (Figs. 135 y 136).

En Benavente se fundó en 1276 el convento de frailes de Santo Domingo, y a principios del siglo XIV, el de monjas de Sancti Spiritus, ambos pertenecientes a la orden dominica. De ninguno de estos conjuntos ha sobrevivido nada de esta época. En la misma ciudad se fundó hacia 1270 el convento de San Francisco y de una fecha aproximada parece ser también la fundación del Convento de Santa Clara. Ambos edificios de la orden franciscana fueron reconstruidos en el siglo XVII y de ellos, salvo documentos y algunos restos arqueológicos, no se conserva nada en la actualidad.

Precisamente el conjunto monumental más destacado por cuanto gran parte de su fábrica fue erigida durante el gótico pleno es el convento de San Francisco de Zamora situado en la margen izquierda del río Duero. Aunque haya que lamentar la pérdida de la mayor parte de sus edificios, todavía han llegado a nuestros días algunos restos que nos permiten formar una idea de lo que fueron originariamente. La lectura de la documentación escrita y la visualización de algunos documentos gráficos así como la importante labor arqueológica llevada a cabo en el solar del edificio con motivo de su reciente transformación en Fundación Rei Alfonso Enriques, aunque aportan una información muy reveladora, no llegan a ofrecernos datos suficientes para completar la planimetría del conjunto medieval ${ }^{185}$. A través del análisis pormenorizado de toda esta información conseguimos obtener un esbozo aproximado de cómo debió de ser y de las dependencias que lo conformaban.

La iglesia era un edificio sobresaliente, como dejó escrito uno de los historiadores de la orden, con unas dimensiones propuestas por Fernando Miguel Hernández de veintitrés por cuarentaidós metros $^{186}$. Con toda probabilidad constaría de una sola nave dividida en cuatro tramos. A su muro sur se encontraba

185 El propio equipo de arqueólogos así lo manifiesta en el Informe preliminar de la excavación arqueológica del convento de San Francisco (Zamora) al señalar que la intervención se desarrolló en una pequeña parte del conjunto del solar con catas insuficientes como para proponer una planimetría completa y rigurosa. MIGUEL HERNÁNDEZ, F., "Informe preliminar de la excavación arqueológica del Convento de San Francisco (Zamora)", en Anuario del Instituto de Estudios Zamoranos «Florián de Ocampo», Zamora, 1993, pp. 211-225.

186 MIGUEL HERNÁNDEZ, F., op. cit., 1993, p. 220. 


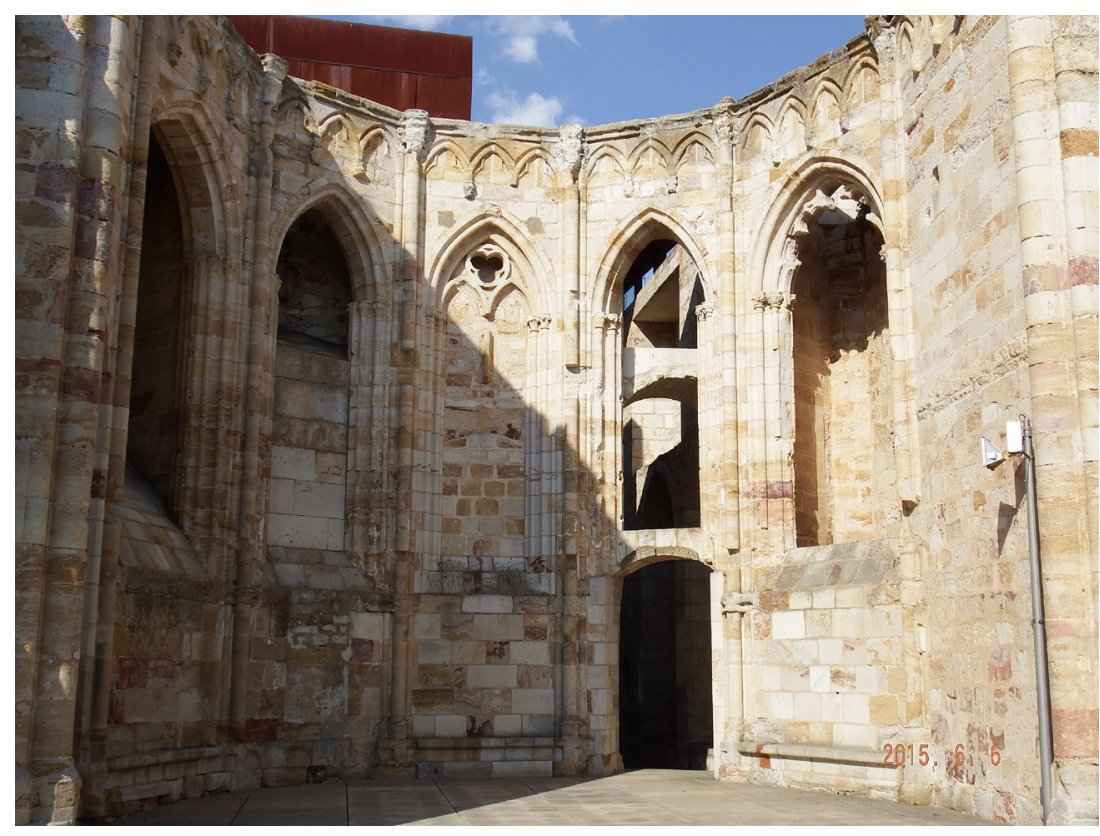

adosado el claustro edificado también en el siglo XIV y en torno a él las distintas dependencias propias de este tipo de casas conventuales. Con posterioridad y ya fuera del periodo gótico se edificó otro claustro y otras estancias que ampliaron el conjunto de manera considerable.

La cabecera de la iglesia de este convento de San Francisco de Zamora es la única parte de entre las que se han conservado que pertenece al siglo XIV (Fig. 137). Estos restos monumentales, aunque muy mutilados y desprovistos del abovedamiento de crucería que probablemente cubrió este espacio, presentan las características del gótico clásico, y a partir de ellos y junto con los testimonios documentales y arqueológicos conocidos podemos aseverar que dicho templo, en lo fundamental, respondía a la tipología propia de la arquitectura mendicante de ese momento.

El arco apuntado vuelve a ser el elemento definidor de todo este conjunto conventual. En este caso los vanos responden al modelo de ventana gótica que se generalizó en las catedrales francesas de la primera mitad del siglo XIII y que alcanzó una rápida difusión en Europa (Fig. 138). Cada una de las ventanas se abre en arco apuntado dividido en dos lancetas mediante un fina columnilla que actúa como mainel mientras que, la parte superior, a modo de tímpano, alberga un pequeño rosetón. Tanto las molduraciones a base de suaves boceles como la ornamentación de los capiteles de las columnas que separan las calles en que se divide el muro de esta cabecera como los
Fig. 137. Interior de la abecera del convento de San Francisco. Zamora

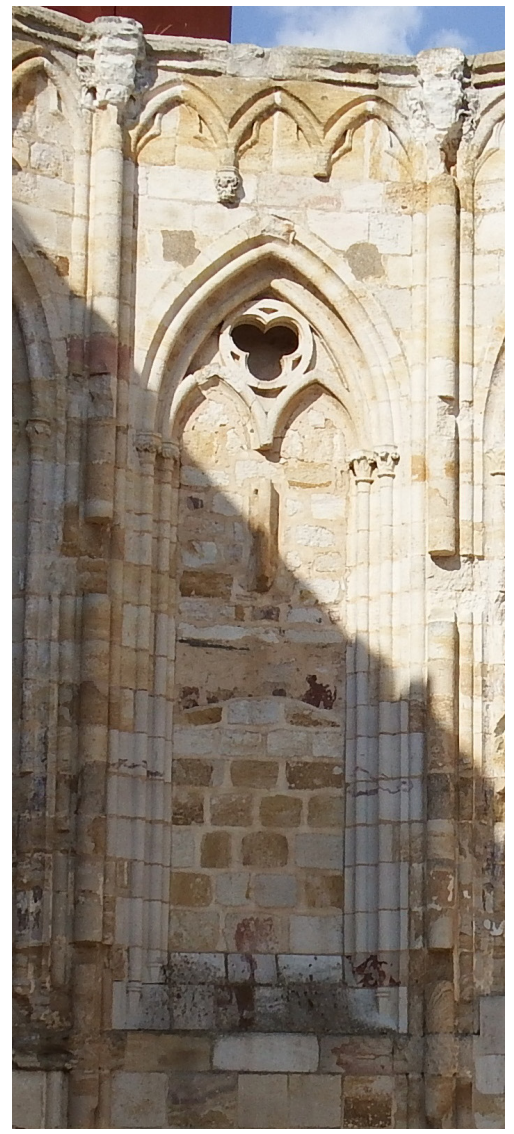

Fig. 138. Vano de la cabecera del convento de San Francisco. Zamora 
pequeños capiteles correspondientes a las columnillas de cada uno de los vanos presentan una decoración vegetal de acusada delicadeza y naturalismo en consonancia con lo propio del gótico pleno.

\section{La arquitectura civil durante los siglos XIII y XIV}

Como ocurre con la arquitectura religiosa, los restos arquitectónicos que han llegado a nuestros días de este periodo del gótico pleno pertenecientes al ámbito civil son realmente escasos y se reducen prácticamente a intervenciones en las fortificaciones. No obstante, no debe dejarse de lado el hecho de que en la provincia se haya conservado una obra de singular interés como es la casa o palacio del obispo de Coria en la ciudad de Toro de la que se hablará más tarde.

Por lo que se refiere a los elementos todavía existentes, en primer lugar, en función de su cronología, habría que señalar la edificación de parte del recinto amurallado de la ciudad de Zamora que fue ampliado durante los siglos XIII y XIV. Incluso contamos con una fecha exacta, año 1230, para datar la reconstrucción de una de las puertas del recinto amurallado: la puerta de Olivares. Sin embargo, la finalidad de estas estructuras nada aportan desde el punto de vista del estilo, de tal modo, que no ofrecen ningún elemento que pudiéramos valorar o que sirviera para establecer una evolución de las formas dentro de la arquitectura gótica civil. La propia puerta de Olivares se abre en un muro de sillería irregular mediante un sencillo arco de medio punto que apoya sobre jambas rectas. Tiene una simple moldura desornamentada hacia la línea de impostas. Al interior se abre un pequeño espacio abovedado en medio cañón con ausencia total de cualquier tipo de ornamentación o referencia estilística. También otros recintos amurallados como los correspondientes a Toro, La Bóveda de Toro y Villalpando fueron levantados o sufrieron importantes intervenciones durante el periodo gótico pleno. Al igual que sucede con las murallas zamoranas, en los escasos restos conservados de fortificación en estas otras poblaciones es difícil determinar el momento constructivo en base a sus rasgos estilísticos. Solamente en el caso concerniente a Villalpando, sus dos portadas conservadas, la de Santiago y la 
de San Andrés, ésta última muy modificada en el siglo XVI, dan cuenta de estructuras levantadas durante el gótico pleno pero que a su vez apenas modifican modelos cuyo origen se encuentra en el gótico inicial.

\section{Elementos pertenecientes a las casas del obispo de Coria}

La obra más importante de este momento, como ya se ha señalado, son las partes que se han conservado de la que fuera una antigua residencia urbana en la ciudad de Toro y que hoy día está integrada formando parte del monasterio premostratense de Santa Sofía. Se trata de la vivienda privada del obispo de Coria, don Alfonso, y que con posterioridad fue utilizada por la reina María de Molina. Aunque sabemos poco de los edificios civiles con función de residencia urbana en estos momentos, los elementos con que contamos en la actualidad de este palacio facilitan una aproximación a la estructura general de este conjunto y, más aún, puede servirnos para entender la organización interna de este tipo de edificios en aquellos tiempos. En líneas generales hablamos de una construcción simple con carácter de vivienda urbana fortificada a juzgar por la torre que acoge el acceso principal (Fig. 139). Esta torre, muy remodelada en la actualidad, presenta dos cuerpos de los cuales solamente el bajo pertenece al edificio primitivo. En él se encuentra integrada la portada de arco agudo, muy sencilla y emparentada con estructuras propias

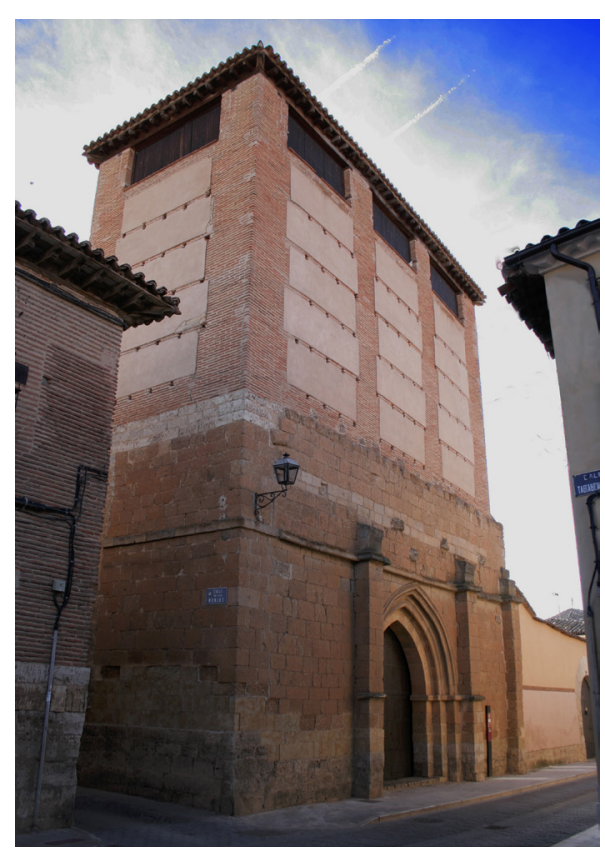




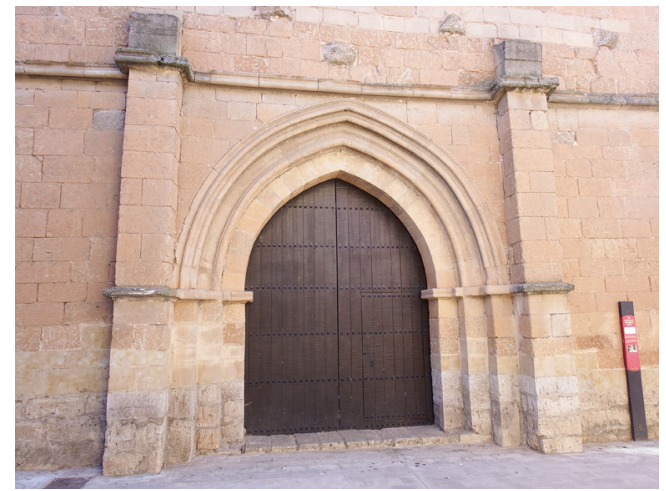

de la arquitectura cisterciense (Fig. 140). A pesar de que el diseño de esta puerta responde a formas propias de los primeros años del siglo XIII, habría que avanzar su cronología hasta mediados de esta centuria dado el carácter conservador de las formas en la provincia de Zamora. Esta portada da acceso a un zaguán alojado en el cuerpo bajo de la torre y alineado con el eje del pequeño patio que tiene su desarrollo a continuación. El patio denominado de la Cisterna tiene planta en forma de trapecio irregular y está bordeado por galerías abiertas cuya techumbre de madera, aunque muy reformada, permite reconocer la primitiva forma de alfarje sobre la que se disponía el tejado (Fig. 141). Las vertientes de éste confluyen hacia el interior del patio

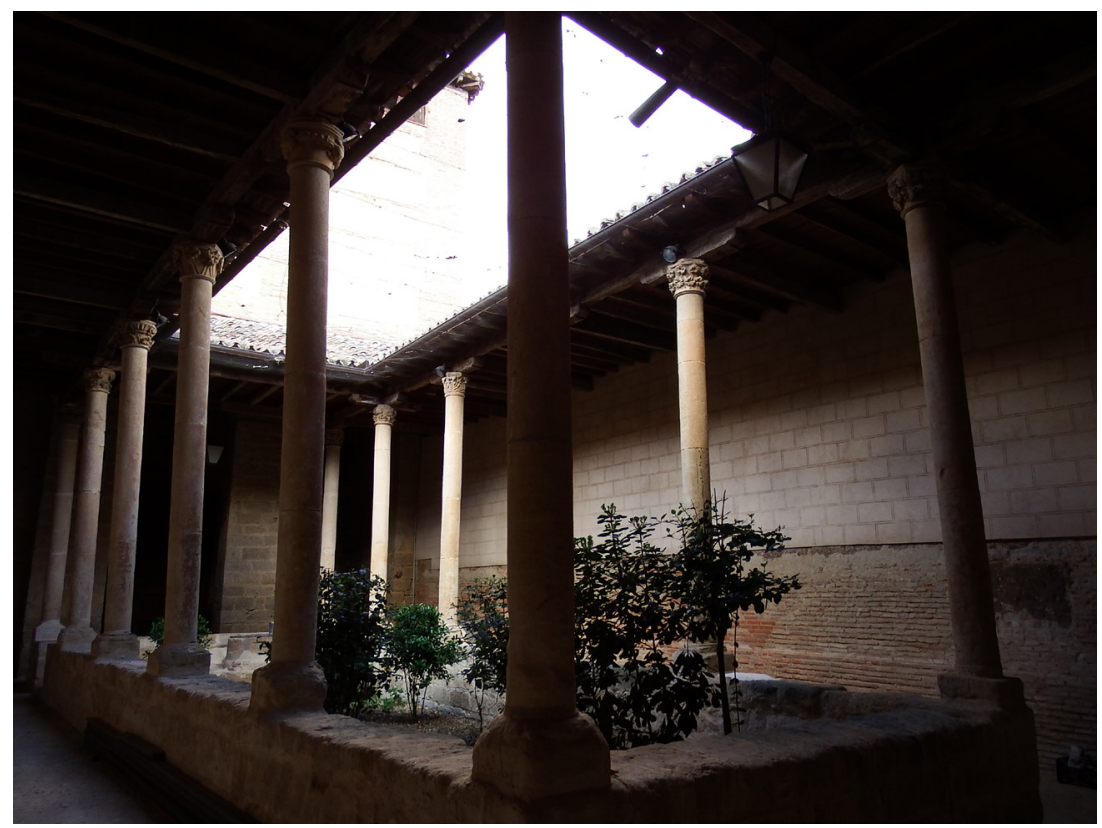

según la disposición en impluvium que posibilitaba aprovechar el agua que caía en su interior y que precisamente era recogida por la cisterna que se encuentra en uno de los ángulos y que es la que da nombre a este espacio. Los soportes de las cuatro galerías que conforman el patio están asentados sobre un podio 
a modo de antepecho bajo que no permite acceder al interior salvo en las partes donde existe una abertura. Estos soportes son cilíndricos en forma de columna pero sin canon y con capiteles fundamentalmente vegetales aunque también los hay figurados en los que se observan bustos humanos y animales fantásticos (Figs. 142, 143 y 144). Este tipo de ornamentación que tienen estos capiteles se dio igualmente en la arquitectura religiosa, de tal modo que, tanto en la capilla de la Majestad de la colegiata de Toro como en el crucero de la iglesia de Santa María del Azogue de Benavente, edificados poco tiempo antes, se encuentran motivos de similares características y tratamiento.

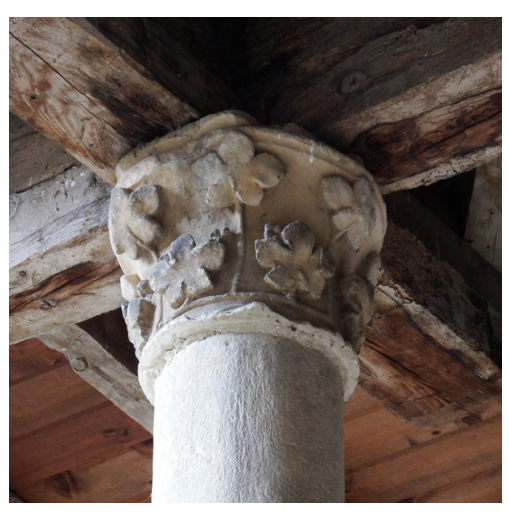

Fig. 142. Capitel del patio de la Cisterna. Monasterio de Santa Sofía. Toro

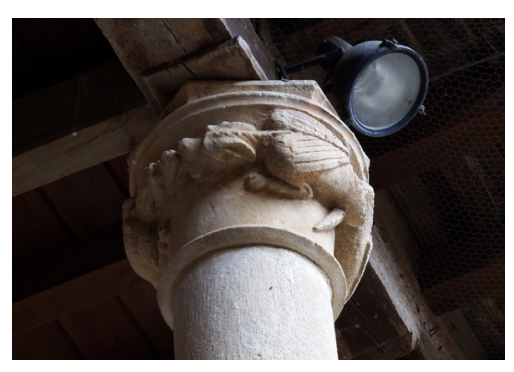

Fig. 143. Capitel del patio de la Cisterna. Monasterio de Santa Sofía. Toro

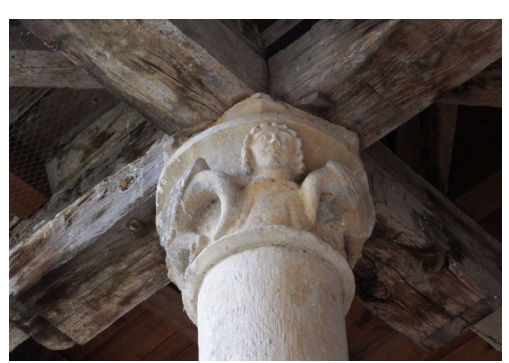

Fig. 144. Capitel del patio de la Cisterna. Monasterio de Santa Sofía. Toro 


\section{EL GÓTICO TARDÍO}





\section{EL GÓTICO TARDÍO}

\section{Notas históricas}

No fueron ajenos los reinos cristianos de la Península Ibérica y por extensión la provincia de Zamora a la profunda crisis que se vivió en Europa durante el siglo XIV, donde se sucedieron las guerras e, incluso, desde el punto de vista religioso, se produjo un cisma que dividió a la Iglesia manteniendo simultáneamente dos papas, uno en Roma y otro en la ciudad francesa de Aviñón.

La llegada al poder a mediados del siglo XIV de Enrique II, primer monarca de la dinastía de los Trastámara en los reinos de Castilla y León, no cambió mucho el panorama político respecto a las décadas anteriores ${ }^{187}$. Luchas internas (guerra fratricida con Pedro I el Cruel) y malas relaciones con los monarcas extranjeros (Aragón, Navarra y Portugal) fueron la tónica de los primeros años de su reinado aunque pronto consiguió una cierta estabilidad. El apoyo recibido de la nobleza de Castilla y León se vio recompensado por las numerosas concesiones que les otorgó y que hicieron que pasara a la historia con el sobrenombre de Enrique "el de las Mercedes". A Enrique II le sucedió su hijo Juan I, cuyo reinado no fue más tranquilo que el de su padre. Recordemos el enfrentamiento con los portugueses y su estrepitoso fracaso en la batalla de Aljubarrota. A partir de este momento Juan de Gante, Duque de Lancáster, que reclamaba la corona de Castilla, se dispuso a invadir su territorio apoyado por el rey de Portugal. En la defensa de la corona castellana jugaron un papel importante la ciudad de Zamora y algunas localidades pertenecientes hoy a su provincia como Benavente, Villalpando - Castroverde de Campos. Las complicaciones a las que se tuvo que enfrentar Juan de Gante favorecieron la firma de un acuerdo por el cual el heredero de la Corona de Castilla, Enrique, casaría con Catalina, hija del propio Juan de Gante. A la muerte de Juan I su hijo Enrique contaba tan solo con once años, por lo que se estableció un Consejo de Regencia. Una vez más se

187 Sobre los Trastámara vid. VALDEÓN BARUQUE, Julio, La Dinastía de los Trastámara, Madrid, 2006. 
trató de un reinado complejo que se vio truncado por la muerte de Enrique III cuando tenía veintisiete años. Le sucedió su hijo Juan II que había nacido en la ciudad de Toro. Finalmente, hay que mencionar por la relevancia del personaje y su vinculación igualmente con la ciudad de Toro a la reina consorte de Castilla doña Beatriz de Portugal, segunda esposa de Juan I, que pasó la última etapa de su vida en el monasterio de Sancti Spiritus de Toro donde se encuentra enterrada en un magnífico sepulcro de alabastro ${ }^{188}$. Con ella emigraron numerosos portugueses cuyos apellidos -Fonseca, Pereira, Sosa, Portocarrero, Deza o Tavera entre otros- se convirtieron en ilustres toresanos e importantes protagonistas de la época a los que se debe muchas de las fundaciones religiosa del siglo XV.

Si nos circunscribimos a nuestro ámbito geográfico, veremos que las semejanzas durante este periodo con lo que acontecía en Europa y en la Corona de Castilla, de la que era parte activa la provincia de Zamora, eran muchas. La crisis política, social, económica y demográfica que había caracterizado el siglo XIV prosiguió durante la mayor parte del siglo XV. Fueron, por tanto, habituales las pestes, las malas cosechas a la vez que se presentaba tremendamente dificultosa la cohesión social en un territorio como la provincia de Zamora que carecía de una mínima homogeneidad. Así lo pone de manifiesto Carbajo Martín que ha estudiado la sociedad zamorana durante los siglos XIV y XV'189. Una sociedad que en las últimas décadas se había transformado significativamente al dejar de ser eminentemente rural y surgir núcleos poblacionales ciertamente significativos. Aun así, como se apuntaba, las diferencias existentes entre la población seguían siendo enormes. En líneas generales podríamos reducirlo a los señores, civiles y eclesiásticos, dueños de la tierra y poseedores de importantes privilegios, que constituían un grupo reducido y, la gran mayoría, que la conformaban que eran aquellos que

188 Sobre la enorme relevancia de este personaje en el contexto político lusocastellano de los siglos XIV y XV puede consultarse OLIVERA SERRANO, César, Beatriz de Portugal. La pugna dinástica Avis-Trastámara, Consejo Superior de Investigaciones Científicas, CSIC, 2006.

189 En este periodo la provincia de Zamora estaba dividida en multitud de señoríos civiles y eclesiásticos a la vez que desde el punto de vista religioso su territorio dependía de seis diócesis. CARBAJO MARTÍN, V. A., "La sociedad zamorana en los siglos XIV y XV"en AA.VV., Historia de Zamora. De los orígenes al final del medievo, tomo I, Zamora, 1995, pp. 589-627. 
carecían de privilegios y estaban sometidos a los primeros como eran los campesinos, artesanos o comerciantes entre otros.

Los núcleos urbanos más significativos de la provincia siguieron siendo Zamora, Toro, Benavente y Villalpando.

Como fecha significativa para el arranque de este periodo histórico que se corresponde con el gótico tardío, podemos tomar como referencia la fecha de 1405 , año en el que nació, como se ha señalado con anterioridad, el monarca castellano Juan II en la ciudad de Toro. No sólo interesa para este estudio histórico la figura de Juan II por su nacimiento en tierras zamoranas y el establecimiento de su corte durante largos periodos de tiempo en las ciudades de Toro y Zamora, sino también por ser el padre del futuro Enrique IV y de la futura reina Isabel la Católica. En los problemas que se plantearon entre los hijos de Juan II por la sucesión, y su consecuente guerra civil, la ciudad y provincia de Zamora tuvieron un papel muy relevante ${ }^{190}$. Es por esto que, para abordar este periodo de la historia de España y la vinculación que la ciudad de Zamora tuvo en esta serie de acontecimientos, conviene clarificar una serie de aspectos.

Se ha comenzado destacando la figura de Juan II de Castilla, monarca que casó dos veces; la primera, con María de Aragón ${ }^{191}$ $y$, la segunda, con Isabel de Portugal. Del primer matrimonio le sobrevivió el futuro monarca Enrique IV, también conocido como Enrique el Impotente. Del segundo matrimonio nacieron dos hijos: la que sería reina Isabel la Católica y el príncipe Alfonso. El heredero de Juan II fue su primogénito Enrique, cuyo reinado como veremos estuvo lleno de sobresaltos. En aquellas luchas e intrigas contó siempre con el apoyo y la fidelidad de las ciudades de Zamora y Toro y de muchos de sus hombres más destacados. Tal fue así que el propio monarca Enrique IV el 9 de marzo de 1466 confirmaba los privilegios que los reyes don Pedro y don Enrique III habían concedido a la ciudad de Zamora y añadía que

190 Puede consultarse a este respecto FERNÁNDEZ DOMINGUEZ, José, La guerra civil a la muerte de Enrique IV. Zamora-Toro-Castronuño, Zamora, 1993 y FERNÁNDEZ-DOMÍNGUEZ PRIETO, Enrique, "Zamora en la encrucijada histórica de España y Portugal”, Stvudia Zamorensia, 3, Salamanca, 1982, pp. 25-62.

191 Con María de Aragón tuvo cuatro hijos, de los cuales, sólo sobrevivió Enrique IV; el resto, todas mujeres, apenas cumplieron uno o dos años. Catalina (1422-1424), Leonor (1423-1425) y María (1428-1429). 
a partir de ese momento se la intitulara como «Muy noble y muy leal $\rangle^{192}$.

El reinado de Enrique IV fue enormemente conflictivo. La falta de herederos de su primer enlace matrimonial con Blanca de Navarra le llevó a casarse en segundas nupcias con Juana de Portugal. De este último matrimonio nació la princesa Juana, que lejos de aportar estabilidad a la corona fue fuente de conflictos. $Y$ todo, por la creencia de que la señalada princesa no era hija del rey, sino de una relación adúltera de su esposa, la reina Juana de Portugal, con Beltrán de la Cueva ${ }^{193}$. Esta circunstancia hizo que Enrique IV cediera ante las presiones de los nobles nombrando como heredero a su hermano Alfonso. Pero el príncipe Alfonso falleció pocos años después, de tal modo que en esos momentos entra en escena Isabel, hermanastra de Enrique IV. Mediante el acuerdo al que llega con su hermano - conocido como Tratado de los Toros de Guisando- Isabel es nombrada heredera de Castilla por lo que su sobrina Juana, hija de su hermano Enrique IV, quedaba desplazada. Este acuerdo llevaba aparejados una serie de compromisos, entre ellos, se prohibía expresamente a Isabel la negociación de su matrimonio sin la previa autorización por parte del Rey. Sin embargo, Isabel, aprovechando la ausencia de su hermanastro se casó en Valladolid con Fernando, heredero de la corona aragonesa. Cuando la noticia llegó a oídos del monarca, éste jura de manera pública la legitimidad de su hija y la nombra heredera. Los nobles se encontraban en ese momento divididos, muchos de los que habían apoyado a Alfonso apoyan ahora a Isabel. Transcurren apenas cuatro años y el 11 de diciembre de 1474 fallece Enrique IV. Al día siguiente de la muerte del rey, Isabel se proclama en la ciudad de Segovia reina de Castilla y es a partir de este momento cuando estalla la guerra civil entre los partidarios, por un lado, de Juana y, por otro, de Isabel, hija y hermana del monarca recientemente fallecido, respectivamente. La guerra que había comenzado en 1475 se prolongó hasta 1479.

192 FERNÁNDEZ DOMINGUEZ, J., op. cit., Zamora, 1993, pp. 130-131.

193 Beltrán de la Cueva, favorecido por el monarca Enrique IV, ocupó altos cargos en la Corte. Cierto, o no, a Beltrán de la Cueva se le acusó de haber mantenido relaciones con la reina Juana de Portugal y de ser el verdadero padre de la princesa Juana. De ahí, que la hija de los Reyes haya pasado a la historia con el sobrenombre de la Beltraneja. 
De parte de Juana se encontraban Portugal, Francia y un buen número de la nobleza castellana; de parte de Isabel estaba un nutrido grupo de nobles, así como varias de las ciudades más importantes de los reinos de Castilla y de León (Segovia, Burgos, Valladolid, Salamanca, León...). Zamora y Toro se declararon contrarias a las pretensiones de Isabel.

Poco a poco Isabel fue incrementando sus apoyos y obtuvo un éxito incontestable con la victoria de la batalla de Peleagonzalo, en las inmediaciones de Toro, que tuvo lugar el 1 de marzo de 1476. Esta batalla asestó un gran golpe al ejercito portugués, fortaleciendo de manera extraordinaria a la reina Isabel. El conflicto aún se dilató algunos años más, hasta que el 4 de septiembre de 1479 el rey de Portugal y los Reyes Católicos firmaron el tratado de Alcaçovas, en la localidad portuguesa de ese mismo nombre. En dicho tratado, entre otros muchos aspectos, quedaron de manifiesto el reconocimiento de Isabel como reina de Castilla por parte del rey de Portugal, así como el concierto matrimonial de la hija mayor de los Reyes Católicos con el heredero al trono portugués.

Toro había permanecido fiel al monarca portugués hasta que finalizó la guerra civil. No sucedió lo mismo con Zamora, que en un primer momento se mantuvo dividida y fue sucesivamente conquistada por uno y otro bando hasta que comenzó a mostrar un apoyo decidido a los Reyes Católicos, de tal forma, que las gentes procedentes de la ciudad de Zamora, fueron fundamentales para la victoria en Peleagonzalo. Finalizada la guerra, dicho apoyo entusiasta se vio recompensado, en lo simbólico, por la franja verde que Fernando el Católico añadió a la Seña Bermeja (nombre con el que se conocía la bandera del concejo) y, en lo económico, por la creación de una feria llamada del Botijero.

En definitiva podría afirmarse que uno de los periodos más convulsos de la historia de España y, concretamente de la historia de Castilla, tuvo lugar durante la segunda mitad del siglo XV. La ciudad de Zamora, que había tenido un menor protagonismo durante los siglos precedentes, volvió a gozar durante el último tercio del siglo XV de una situación estratégica privilegiada, no recordada desde tiempos de la reconquista. Y aunque los Reyes 
Católicos con sus conquistas y fortalecimiento del poder lograron un gobierno en cierto modo estable a raíz de la muerte de Isabel la Católica en 1504 se originarán nuevas disputas por el control del gobierno.

No podemos olvidar como hechos de gran relevancia que tuvieron como testigo tierras zamoranas, por un lado, la firma de la concordia entre Felipe el Hermoso y Fernando el Católico el 26 de junio de 1506 en Villafáfila ${ }^{194}$ y por otro, la celebración de Cortes durante estas primeras décadas del siglo XV en diversas ocasiones en las ciudades de Toro y Zamora.

Como señalamos anteriormente, desde el punto de vista de la organización eclesiástica, la diócesis de Zamora apenas sufrió variaciones significativas hasta el siglo XIX. Los obispos que la gobernaron a lo largo del siglo XV y durante los primeros años del XVI fueron Juan de Illescas (1395-1403), Alfonso de Illescas (1403-1413), Diego Gómez de Fuensalida (1413-1424), Pedro Martínez (1425-1438), Juan de Mella (1440-1465), Rodrigo Sánchez de Arévalo (1465-1467), Juan de Meneses (1468-1493), Fray Diego de Deza (1494, que fue trasladado el mismo año a Salamanca), Diego Meléndez Valdés (1494- 1506) y Antonio Acuña (1507-1526) 195 .

A Juan de Mella, fray Diego de Deza y Diego Meléndez Valdés les prestaremos más adelante una atención especial por su destacadísima actividad promotora en el campo de las artes $y$, concretamente por lo que a nuestro interés respecta, de la arquitectura. Del resto solamente destaca el obispo Antonio de Acuña del que realizaremos a continuación una breve semblanza que pone de manifiesto la importancia que tuvo este prelado desde el punto de vista histórico.

Antonio de Acuña había nacido en el año 1459 y gobernó la diócesis de Zamora durante buena parte del primer cuarto del

194 El personaje principal para que este hecho tuviese lugar en la provincia de Zamora fue el conde de Benavente, favorable a Felipe el Hermoso, que lo acogió en Puebla de Sanabria, Benavente y lo acompañó a Villafáfila. Elías Rodríguez Rodríguez ha tratado en profundidad la importancia de esta Concordia de Villafáfila. RODRÍGUEZ RODRÍGUEZ, E., "La Concordia de Villafáfila. 27 de junio de 1506", Cuadernos de investigación, $\mathrm{n}^{\circ}$ 26, Instituto de Estudios Zamoranos «Florián de Ocampo», Zamora, 2006.

195 RAMOS DE CASTRO, G., op. cit., 1982, p. 556; GARCÍA MARTÍNEZ, J., Historia de la Santa Iglesia Catedral de Zamora, Zamora, 1904, pp. 157-159. 
siglo XV|196. Su carrera eclesiástica dio inicio con el desempeño del cargo de arcediano de Valpuesta hasta que el papa Julio Il lo nombró obispo de Zamora sin que la Corte le hubiera propuesto. Más que por su labor religioso-cultural destacó por su implicación en los temas políticos. Planteó innumerables conflictos desempeñando el cargo de obispo y apoyó con gran entusiasmo el alzamiento de las comunidades en Castilla. Años después de que las tropas reales dieran por concluido este episodio en Villalar, el obispo Acuña fue encarcelado y ajusticiado en el castillo de Simancas.

Esta breve introducción a la situación histórica durante el gótico tardío en Zamora no debe concluir sin hacer un comentario acerca de la aportación que la propia ciudad de Zamora y su provincia hicieron a la empresa americana ya que ésta fue harto significativa ${ }^{197}$. En el ámbito eclesiástico años antes de que se llevara a cabo el descubrimiento del Nuevo Mundo, fray Diego de Deza (dominico nacido en Toro) ponía todo su empeño desde su posición privilegiada en la corte y en la universidad de Salamanca- para que los reyes tomaran en consideración la propuesta que les hacía Cristóbal Colón. Junto a fray Diego de Deza, tuvo una enorme importancia, ya en los primeros años transcurridos después del descubrimiento, el también toresano Juan Rodríguez de Fonseca. Éste había nacido en 1451 en el seno de una de las familias más notables y poderosas de la ciudad. Fue obispo de Badajoz, Córdoba, Palencia y Burgos, pero lo que más interesa destacar es su cargo como Delegado de los Reyes en los asuntos de Indias ${ }^{198}$.

196 Para aproximarse a la figura de este obispo de Zamora así como también al periodo histórico en el que vivió, vid. PÉREZ, J., La revolución de las Comunidades de Castilla 1520-1521, Madrid, 1977; GUILARTE, A. M., El obispo Acuña. Historia de un comunero, Valladolid, 1979; FERNÁNDEZ, L., "El obispo comunero, don Antonio de Acuña, defensor de los bienes de la mitra zamorana (1509-1518)" en Hispania Sacra, vol. XXXVI, Madrid, 1984, pp. 485-508; GUILARTE, A. M., Obispo Acuña, Caja de Ahorros Popular de Valladolid, 1984

197 Para el acercamiento y comprensión de la importancia que tuvieron los zamoranos en el periodo previo, durante y posterior a la conquista de América, vid. AA.VV., Jornadas sobre Zamora, su entorno y América, Instituto de Estudios Zamoranos «Florián de Ocampo», Diputación de Zamora, 1992. También LORENZO, Eufemio, "Protagonismo de los zamoranos en América en el siglo XVI" en I Congreso de Historia de Zamora, t. III, Instituto de Estudios Zamoranos Florián de Ocampo, Zamora, 1989, pp. 531-538.

198 Sobre el papel destacado que Juan Rodríguez de Fonseca tuvo a fines del XV y principios del XVI en relación con la recién conquistada América, vid. FERNÁNDEZPRIETO DOMÍNGUEZ Y LOSADA, E., "Don Juan Rodríguez de Fonseca, Delegado Regio en los asuntos de Indias 1493-1524" en Jornadas sobre Zamora, su entorno 
Consumado el descubrimiento y puesta en marcha la conquista de aquel inmenso territorio fue necesario proceder a la evangelización ${ }^{199}$. En el primer grupo de franciscanos que embarcaron hacia América se encontraba fray Toribio de Motolinía, o de Benavente, haciendo clara referencia a su lugar de origen ${ }^{200}$.

En el ámbito civil, de entre los nacidos en la ciudad de Zamora y que ayudaron en la conquista de América, estuvieron Antonio de Carvajal y Diego de Mazariegos, ambos bajo las órdenes de Hernán Cortés en la conquista de México. En el Perú y a las órdenes de Francisco Pizarro se encontraba Alonso de Mercadillo. También participaron en la conquista de la empresa americana Diego de Ordás, natural de Castroverde de Campos y hombre valioso en la conquista de México y, Alonso de Briceño, benaventano que estuvo en el Perú junto a Pizarro. Pero quizás el más reconocido sea Diego de Losada, que nació en 1511 en Rionegro del Puente y fundó las ciudades venezolanas de Caracas y Maracaibo ${ }^{201}$.

Igualmente en el ámbito civil hubo zamoranos que desempeñaron cargos importantes, baste recordar a Francisco de Ceínos, relator y fiscal en el Consejo de Indias de 1526 a 1530.

Pero fueron muchos más los zamoranos que unieron sus lazos con América en el transcurrir de los siglos, siendo en número

y América, Instituto de Estudios Zamoranos «Florián de Ocampo», Diputación de Zamora, 1992, pp. 259-266.

199 El papa Alejandro VI a través de la bula Inter Coetera había concedido a los Reyes Católicos y sus sucesores "todas y cada una de las islas y tierras predichas y desconocidas que hasta el momento han sido halladas por vuestros enviados y las que se encontrasen en el futuro y que en la actualidad no se encuentren bajo el dominio de ningún otro señor cristiano" y les exhortaba para que "haciendo todas las debidas diligencias del caso, destineis a dichas tierras e islas varones probos y temerosos de Dios, peritos y expertos para instruir en la fe católica e imbuir en las buenas costumbres a sus pobladores y habitantes".

200 La figura de fray Toribio está glosada en los siguientes estudios: AGUADO SEISDEDOS, V., "Fray Toribio de Benavente (Motolinía) el hombre y el contexto regional" en Jornadas sobre Zamora, su entorno y América, Instituto de Estudios Zamoranos «Florián de Ocampo», Diputación de Zamora, 1992, pp.383-406; BAUDOT, G., Utopía e Historia en México, Espasa-Calpe, Madrid, 1983. Sobre su participación en la fundación de la ciudad de Puebla de los Ángeles vid. FERNÁNDEZ RUIZ, Raquel del Carmen, "Fray Toribio de Benavente y Puebla de los Ángeles", Brigecio, $\mathrm{n}^{\circ} 1,1989$, pp. 141-153.

201 MATILLA TASCÓN, A., "Diego de Losada y otros destacados zamoranos en el Descubrimiento y Colonización de América" en Jornadas sobre Zamora, su entorno y América, Instituto de Estudios Zamoranos «Florián de Ocampo», Diputación de Zamora, 1992, pp. 187-200. 
mayor, los hombres de iglesia, ya que muchos de los nacidos en estas tierras llegaron a ser obispos al otro lado del océano.

\section{La arquitectura religiosa durante el gótico tardío}

Aunque una vez más es complejo delimitar un periodo artístico entendemos por gótico tardío, al menos en la provincia de Zamora, el arte desarrollado durante el siglo XV y el primer tercio del siglo $X \mathrm{VI}^{202}$. En modo alguno se trata de una etapa homogénea en cuanto a actividad constructiva, diseños y formas empleadas. Es por ello que estableceremos dos momentos que nos permitan entender mejor la actividad edificadora llevada a cabo. Por un lado comenzaremos analizando los dos primeros tercios del siglo $\mathrm{XV}$, que apenas nos han legado testimonios arquitectónicos $y$, por otro, estudiaremos la importantísima cantidad de obras realizadas durante el último tercio del siglo XV y el primero del siglo XVI.

La actividad arquitectónica durante los dos primeros tercios del siglo XV

Como había sucedido en los siglos precedentes, durante los dos primeros tercios del siglo XV la actividad constructiva fue débil como lo demuestran las escasas referencias que tenemos a edificios de este momento y más aun los mínimos elementos que han llegado a nuestros días que no nos permiten realizar valoraciones en cuanto a la evolución del estilo y de las formas.

De este modo contamos solamente con dos testimonios, totalmente distintos entre sí, pero ambos acusadamente significativos. Por un lado, y fruto de las reformas que sufrieron las iglesias románicas con el paso de los siglos, tenemos, correspondiente a este periodo, la mitad superior de la fachada occidental de la iglesia de San Juan de Puerta Nueva. En ella se abrió un enorme ventanal de tracería gótica que dotó de

202 El concepto de gótico tardío está plenamente asumido por los historiadores del arte al menos desde principios del siglo XIX. Fue el conde Arcisse de Caumont el que en sus escritos estableció dentro del periodo gótico un momento que fue el flamígero (equiparable a gótico tardío) término que después fue rechazado y sustituido por el de gótico tardío) término que después fue rechazado y sustituido por el de gótico tardío que no implica connotaciones estilísticas. BIALOSTOCKI, Jan, "Le gothique tardif: désaccords sur le concept", Information d' Histoire de l'Art, $\mathrm{n}^{\circ}$ 3, Mai-Juin 1968, pp. 106-128. 


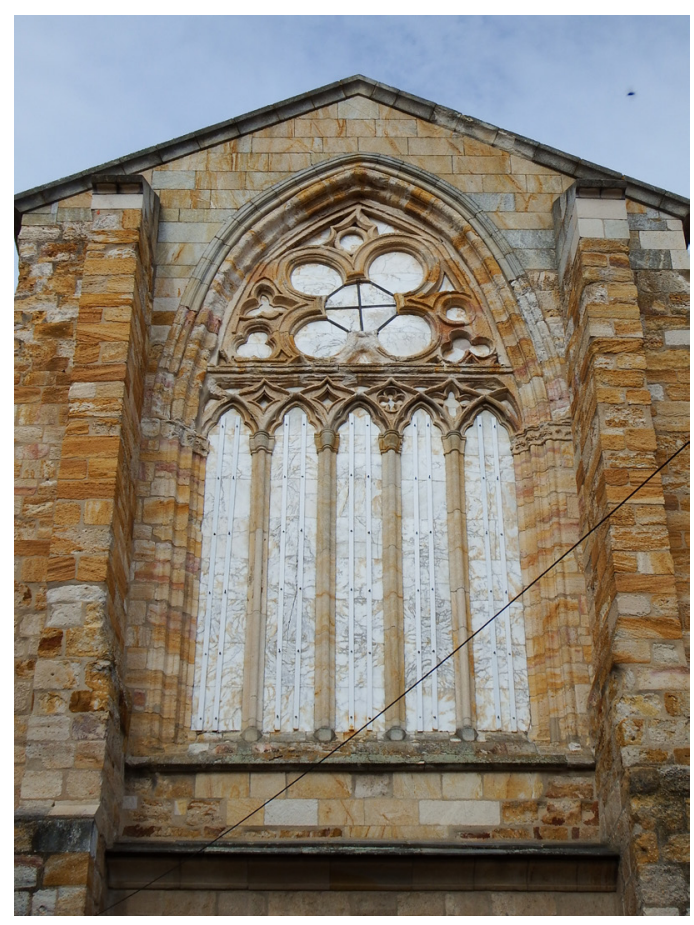

una cierta luminosidad el interior del templo (Fig. 145). Se trata de una "ventana maestra", tipo de vano que se había utilizado con anterioridad en la arquitectura europea y se había difundido sobre todo a través de modelos ingleses. Su diseño se corresponde con lo que se viene denominando gótico flamígero. Uno de los elementos que caracterizan este momento es el arco conopial, cuya fuerte presencia en la arquitectura europea tuvo lugar ya a partir del siglo XIV; sin embargo, su uso en Castilla no se generaliza hasta el primer tercio del siglo $X^{203}$. En Zamora lo encontramos por vez primera en esta ventana. Las pocas referencias a esta ventana la han situado sin un fundamento crítico en el siglo XIV, y es cierto que la estructura general del ventanal responde en efecto a los modelos de ese momento, pero la reiterada utilización del arco conopial en su diseño hace sospechar que pudiera pertenecer ya a la primera mitad del siglo XV. La carencia de datos documentales, no obstante, no permite afinar de forma precisa en su cronología 204.

Por otro lado contamos con los restos de un edificio que se levantó de nueva planta en la ciudad de Toro con función de

203 Este tipo de arco que tiene forma de quilla invertida se compone de cuatro centros, dos interiores y dos exteriores. Fue uno de los más utilizados durante el periodo gótico tardío. En la provincia de Zamora lo vamos a encontrar en vanos (puertas y ventanas) y en sepulcros.

204 Lo que sí está bajo nuestro punto de vista equivocada es su adscripción al siglo XIII otorgada por Rivera de las Heras. RIVERA DE LAS HERAS, José Ángel, Por la catedral, iglesias y ermitas de la ciudad de Zamora, Edilesa, León, 2001, p. 121.
Fig. 145. Vano del hastial de la iglesia de San Juan de Puerta Nueva. Zamora 


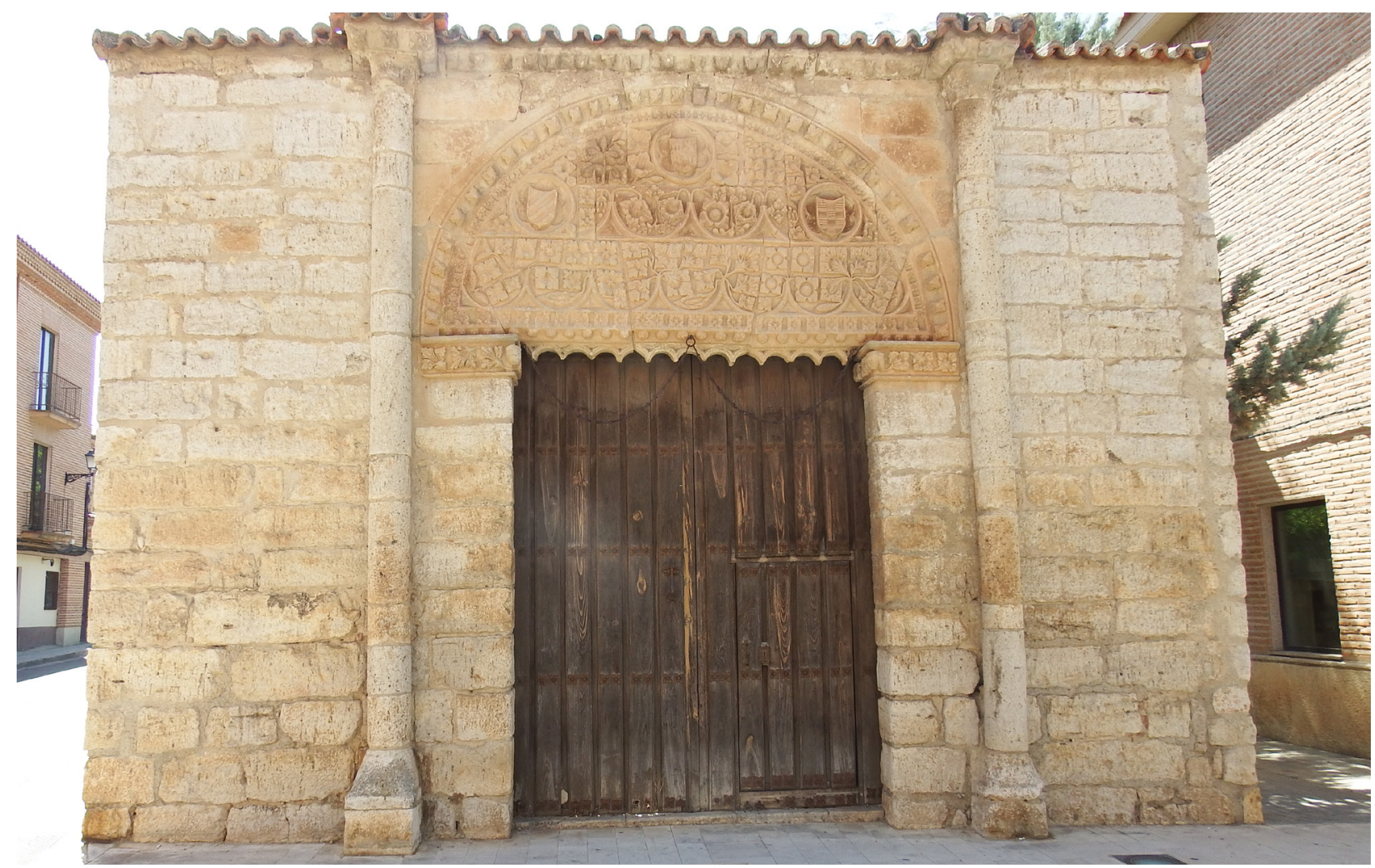

residencia y, probablemente, sobre unas casas anteriores. Se le conoce comúnmente como Palacio de las Leyes aunque también es denominado como de los Ulloa o de los marqueses de Santa Cruz de Aguirre (Fig. 146). Actualmente, y como consecuencia de un terrible incendio sucedido el día 15 de agosto de 1923, que destruyó la mayor parte del conjunto palacial, solamente queda en pie la fachada principal. Su portada con un enorme tímpano en arco de medio punto constituye el único ejemplo del estilo gótico internacional en la provincia de Zamora. El arco de medio punto tuvo un cierto uso durante la primera mitad del siglo XV, sobre todo en la arquitectura retablística, como se puede ver en el retablo mayor de la catedral vieja de Salamanca ejecutado entre 1430 y 1450 por los hermanos Delli.

La actividad arquitectónica durante las décadas finales del siglo XV y las primeras del siglo XVI

El peso político, económico y social de una ciudad se ve reflejado en su arquitectura. Zamora, después de la época de la reconquista en la que se había convertido en firme baluarte frente al enemigo y, como consecuencia de ello, en punto estratégico del reino cristiano recientemente formado, cayó en el olvido hasta 
que, a finales del siglo XV, volvió a recobrar una considerable importancia. Por tanto, el parón constructivo existente durante buena parte del siglo XIII, el siglo XIV y aproximadamente los dos primeros tercios del siglo XV, dio paso a una actividad edificadora que se desarrolló durante las últimas décadas de este último siglo y las primeras del XVI y que transformó de manera significativa muchos templos de la ciudad y de la provincia así como se emprendió la edificación de otros de nueva planta ${ }^{205}$. También en la provincia se ha constatado un fuerte incremento de la actividad constructiva en estos momentos, que como veremos, en la mayor parte de los casos, se tratará de intervenciones en edificios ya existentes.

Imprescindible fue durante este periodo la labor de mecenazgo ejercida fundamentalmente por algunos miembros distinguidos de la iglesia y de la nobleza. En la ciudad de Zamora destacaron don Juan de Mella y don Diego Meléndez Valdés, ambos obispos de la ciudad. Aunque ninguno de ellos residió en Zamora durante el desempeño de su función episcopal, ambos acometieron obras arquitectónicas de una cierta envergadura. Don Juan de Mella encargó en la ciudad de Zamora una capilla dedicada a San Ildefonso a los pies del templo catedralicio. Bajo el episcopado de Diego Meléndez Valdés se acometieron importantes obras tanto en el templo catedralicio como en la iglesia de San Ildefonso. Otros personajes como el doctor Juan de Grado, fray Diego de Deza o los propios condes de Benavente jugaron igualmente un papel destacado en el patrocinio de importantes obras en la provincia de Zamora.

\section{Los promotores}

Juan de Mella ${ }^{206}$ había nacido en Zamora en el año de 1397 en el seno de una familia noble. Su padre, Fernando de Mella

205 MONTERO APARICIO, D., "Arte medieval en Zamora" en AA.VV., Historia de Zamora. De los origenes al final del medievo, tomo I, Zamora, 1995, pp. 796 y 797.

206 En las publicaciones señaladas a continuación existe una breve biografía de este importante prelado nacido en Zamora. ANTONIO, N., Bibliotheca Hispana Vetus, tomo II, libro 10, capítulo X, p. 283; FERNÁNDEZ-PRIETO DOMÍNGUEZ Y LOSADA, E., Nobleza de Zamora, C.S.I.C., Madrid, 1953, p. 849; RAMOS DE CASTRO, G., op. cit., 1982, p. 319; SÁNCHEZ HERRERO, J., "Historia de la iglesia de Zamora. Siglos $\mathrm{V}$ al XV" en AA.VV., Historia de Zamora. De los origenes al final del medievo, tomo I, Zamora, 1995, p. 732. En el catálogo de la exposición Remembranza —organizada por la Fundación "Las Edades del Hombre" y que tuvo lugar en la catedral de Zamora- 
desempeñó los cargos de notario de la curia episcopal y escribano de número de la ciudad de Zamora. Cursó estudios en el Colegio de San Bartolomé de la Universidad de Salamanca, donde se doctoró y llegó a ser catedrático. Pronto recibió sus primeros cargos eclesiásticos al ser nombrado sucesivamente Arcediano de Madrid, Deán de Coria y Auditor de la Rota.

La vida de Juan de Mella dio un giro importantísimo cuando Diego de Anaya, obispo de Salamanca, decidió enviarle, para resolver unos asuntos, a Roma, ciudad que nunca abandonaría. En Roma continuó su ascendente carrera. En 1440, Eugenio IV le nombró obispo de León, diócesis de la que no tomó posesión. También en el mismo año fue nombrado obispo de la ciudad de Zamora. Años después, concretamente el 17 de diciembre de 1456, el papa Calixto III le nombró Cardenal Presbítero. Murió el 13 de octubre de 1467 siendo obispo de Zamora aunque nunca residió en su diócesis ${ }^{207}$. Fue sepultado en el Hospital de Santiago de los Españoles en Roma hasta que a finales del siglo XIX sus restos fueron trasladados a la iglesia de Montserrat en la misma ciudad. Su epitafio publicado por Enrique Fernández-Prieto dice lo siguiente: «Jo de Mella Genere Hispano Famil. Ingenva, Caesarii At pontifio Juris Consvltiss. Lavr. In Damaso Pres. Card. Zamorem. Sacrvm. Vix. An. LXX. Obiit. XIII. Octobr. A Salvte Nra. MCCCCLXVII. Pont. Max. Pavli II. An Qvarto.»²08.

Este prelado ordenó la edificación de la capilla de San Ildefonso a los pies del templo catedralicio para que sirviera de panteón familiar. El original diseño de nervaduras utilizado para cubrir los dos tramos de crucería de esta capilla, poco usual en la provincia de Zamora y relativamente infrecuente en el resto de España, la convierten en un espacio enormemente interesante.

hay una descripción realizada por Domínguez Casas del Árbol genealógico de la familia del Cardenal Mella. DOMINGUEZ CASAS, R., "Árbol genealógico de la familia del Cardenal Mella” en Catálogo de la exposición Remembranza. Las Edades del Hombre, Catedral de Zamora, Zamora, 2001, pp. 464-467.

207 Dos años antes de su muerte fue nombrado obispo de Sigüenza, diócesis de la que acabó renunciando antes de tomar posesión debido a la oposición que le mostró el Cabildo.

208 FERNÁNDEZ-PRIETO DOMÍNGUEZ Y LOSADA, E., op. cit., 1953, p. 849. En el apéndice fotográfico de este texto de Fernández-Prieto Domínguez y Losada se incluye una imagen realizada por él del sepulcro del Cardenal Mella. 
Don Diego Meléndez Valdés ${ }^{209}$, hijo de Rodrigo Valdés y Mariana de Porres, nació en Zamora en 1446. Su padre Rodrigo de Valdés desempeñó distintos cargos al servicio de los monarcas Juan II y Enrique IV; su hermano, Francisco de Valdés, jugó un papel importante durante la guerra de sucesión, ya que, siendo alcaide de la torre del puente de Zamora, permitió el acceso a la ciudad - partidaria del monarca portugués Alfonso $\mathrm{V}-$ de Fernando de Aragón. Este hecho fue decisivo a la hora de decantar la victoria de Isabel de Castilla sobre su sobrina Juana la Beltraneja.

En el año 1482 Meléndez Valdés fue enviado por los Reyes Católicos a Roma con el fin de tratar una serie de asuntos, entre los cuales figuraban los nombramientos de una serie de obispos. En todo se siguió la pauta marcada por los reyes a excepción de lo que respectaba al nombramiento del obispo de Salamanca. Los monarcas habían designado para ese puesto al prior del monasterio jerónimo de Nuestra Señora de Prado. Sin embargo, el Pontífice se apartó de la voluntad real y nombró obispo de Salamanca al propio Meléndez Valdés. Los reyes no lo aceptaron, de tal modo que Meléndez Valdés no llegó nunca a tomar posesión de la diócesis salmantina. Posteriormente, en 1493, y con la anuencia de todas las partes, fue nombrado obispo de Astorga y, un año después, de Zamora, aunque no residió en ninguna de las dos ciudades durante su episcopado. Al igual que sucediera con Juan de Mella, su vida transcurrió en Roma donde desempeñó el cargo de Escritor Apostólico del Papa Alejandro VI. No hay constancia hasta mayo de 1505 de quien estuvo directamente al cargo de la diócesis durante su episcopado. Sí se sabe, sin embargo, que a partir de ese momento el obispo nombra a Antonio Meléndez Valdés, prior de la Iglesia de Zamora, provisor oficial y vicario general del obispado con plenos poderes para que pueda conferir beneficios y le represente en su oficio pastoral $^{210}$.

209 En las publicaciones señaladas a continuación existe una breve biografía de este importante prelado nacido en Zamora. FERNÁNDEZ-PRIETO DOMÍNGUEZ Y LOSADA, E., op. cit., 1953, pp. 876-877; SÁNCHEZ HERRERO, J., "Historia de la iglesia de Zamora. Siglos V al XV" en AA.VV., Historia de Zamora. De los orígenes al final del medievo, tomo I, Zamora, 1995, p. 734. 
Diego Meléndez Valdés falleció en 1506 y fue sepultado en la capilla de San Ildefonso, fundada por él en el Hospital de Santiago de los Españoles en Roma, hasta que, a finales del siglo XIX, sus restos fueron trasladados a la iglesia de Montserrat en la misma ciudad. Su epitafio, publicado por Enrique Fernández-Prieto, dice lo siguiente: «Didacvs ExValdes Asturum patria pontificatuvq Zamora qvvm se moritvrvm ASSIDVE meditaretur vivens-Hos svo cadaveri statvit monvmentvm-Visit annis prope LX oblit XXVII Decebr MDVI-Die XI mensis septembris M.D.I. pontificatv maximi Alexandri Valentin anno decimo cvm magistratvm domvs eivs exerceret ${ }^{211}$

Como ya se ha apuntado anteriormente bajo el episcopado de don Diego Meléndez Valdés se acometieron importantes obras tanto en el templo catedralicio como en la iglesia de San Ildefonso. En el primero se sustituyó la cabecera románica por una más esbelta gótica, se levantaron la hoy conocida como sacristía vieja y algunas pequeñas capillas y se talló el magnífico coro. En el segundo fue transformado el espacio interno en su totalidad, de tal modo, que la iglesia de San Ildefonso, que hasta entonces había contado con tres naves, pasó a tener una sola. También se intervino en el ábside mayor de este último edificio dividiéndolo en altura mediante una pequeña bóveda con el objeto de colocar sobre ella las urnas con los cuerpos santos de Ildefonso y Atilano.

Juan de Grado ${ }^{212}$, cuya fecha exacta de nacimiento se ignora, aunque algunas referencias con las que contamos indican que debió de ser en la década de 1440, también estuvo estrechamente vinculado a la catedral de Zamora. Sus orígenes como revela su apellido proceden del Concejo asturiano de Grado. Primeramente se instaló en Salamanca donde residió gran parte de su familia y donde se casaron sus hermanas. Allí también fue

211 FERNÁNDEZ-PRIETO DOMÍNGUEZ Y LOSADA, E., op. cit., 1953, p. 877. En el apéndice fotográfico de este texto de Fernández-Prieto Domínguez se incluye una imagen realizada por él el sepulcro del obispo don Diego Meléndez Valdés.

212 Sobre la figura del doctor Juan de Grado vid. BRÍO MATEOS, Asterio Miguel del y BRÍO CARRETERO, Clara del, El canónigo doctor Juan de Grado. Biografía de un clérigo medieval, Madrid, 1987 y DEL BRÍO CARRETERO, Clara, "El doctor Juan de Grado: centenario y revisión" en Anuario del Instituto de Estudios Zamoranos «Florián de Ocampo», Zamora, 2005, pp. 315-323; YARZA LUACES, J., "La portada occidental de la Colegiata de Toro y el Sepulcro del Doctor Grado: dos obras significativas del gótico zamorano", Stvdia Zamorensia, (Anejos 1), Arte Medieval en Zamora, Universidad de Salamanca, 1988, pp. 131-132. 
donde alcanzó el grado del bachiller y donde, probablemente, obtuvo el de doctor, pues como señala Clara del Brío, a su padre se le cita en alguna ocasión como "maestro" e, incluso, parece que un tío suyo llegó a ser catedrático de la Universidad de Salamanca ${ }^{213}$. Es probable que completara sus estudios en Roma, ciudad donde él mismo declara en su testamento que estuvo ${ }^{214}$. Con posterioridad se instalaría en Zamora donde adquirió un gran número de propiedades tales como fincas, dehesas, casas, pajares, palomares, cortinas, prados, etc., la mayor parte de ellas en la villa de Fresno de Sayago.

Aunque no deje de ser más que una mera anécdota sabemos por la documentación que fue excomulgado por ponerle la mano encima a fray Pablo, monje de Valparaíso. El doctor Grado como abad comendatario del monasterio de Valparaíso se había opuesto rotundamente a la reforma de la Orden que desde hacía décadas trataban de imponer un número de monjes. Finalmente triunfaron los reformistas y el mencionado fray Pablo fue elegido el primer abad trienal. Poco tiempo después el doctor Juan de Grado fue absuelto de la excomunión que se le había impuesto ${ }^{215}$.

Ostentó dentro del ámbito eclesiástico, entre otros, los cargos de canónigo de la catedral de Zamora y abad del monasterio de Valparaíso. También atesoró un importante patrimonio y poseyó una biblioteca ciertamente significativa que donó a la catedral.

Desde el punto de vista del patrocinio nos interesa enormemente la dotación de la capilla de San Juan Evangelista de la catedral de Zamora, que transformó y que acoge su sepulcro. Fue titular de los beneficios simples correspondientes a las iglesias de Guijuelo y San Juan de Pelabiano, ambas pertenecientes a la diócesis de Salamanca, así como también de la iglesia de San Miguel de Fresno de Sayago, con sus anejos de San Juan de Piñuel y Santa María Magdalena de Figueruela de Sayago, en la diócesis de Zamora. Ignoramos si emprendió algunas obras o reformas en aquellos templos donde tuvo la titularidad, como hemos señalado, de los beneficios simples, a excepción de la

213 DEL BRÍO CARRETERO, Clara, op. cit., Zamora, 2005, p. 320.

214 Véase el testamento completo en BRÍO MATEOS, Asterio Miguel del y BRÍO CARRETERO, Clara del, op. cit., 1987, pp. 96-105.

215 BRÍO MATEOS, Asterio Miguel del y BRÍO CARRETERO, Clara del, op. cit., Madrid, 1987, pp. 17-18. 
iglesia de San Miguel en Fresno de Sayago de la que ha llegado a nuestros días la cabecera con los escudos de este personaje en dos de las ménsulas que reciben los nervios de la bóveda ${ }^{216}$. Otorgó testamento pocas semanas antes de su muerte que tuvo lugar el 22 de octubre del año $1507^{217}$.

Fray Diego de Deza nació en Toro en el año 1443218. Este fraile de la orden de Santo Domingo fue uno de los personajes más destacados de su época. A lo largo de su vida desempeñó numerosísimos cargos, tanto en la corte -en 1486 fue nombrado tutor del príncipe Juan, primogénito de los Reyes Católicos y, con posterioridad, capellán mayor, confesor real y Gran Canciller de Castilla-, como en la vida eclesiástica, donde dirigió las diócesis, primero, de Zamora y, posteriormente, de Salamanca, Jaén, Palencia y, ya por último, de Sevilla, ciudad esta última de la que fue nombrado arzobispo en 1504. En el año 1523 fue nombrado arzobispo de Toledo, sede episcopal de la que no llegaría a tomar posesión pues falleció poco tiempo antes. Desempeñó también el cargo de Inquisidor General de Castilla y León y mantuvo una excelente relación con Cristóbal Colón hasta el punto de que intercedió por él ante los Reyes Católicos. No olvidaría el marino la gran ayuda prestada y así en una carta dirigida a su hijo Diego y fechada el 21 de diciembre de 1504 dice refiriéndose a Deza “..., que fue causa que sus Altezas oviesen las Indias y que yo quedase en Castilla, que ya estaba yo de camino para fuera..." ${ }^{219}$.

En su ciudad natal patrocinó la construcción de la iglesia de San Sebastián de los Caballeros que fue edificada sobre una anterior en la que se ha supuesto que tuvo lugar su bautismo. También prestó fray Diego atención especial a las diócesis de las que fue obispo reformando algunos edificios e incrementando el patrimonio de numerosos templos. En Palencia, por ejemplo, de cuya diócesis fue obispo dotó al templo catedralicio de objetos para el culto y enriqueció los espacios que estaban concluidos y precisaban ornamentación. De entre todo ello lo

216 No obstante en su testamento tuvo un recuerdo dejó mandas para todas las iglesias de sus beneficios.

217 A. H. P. ZA., carpeta 1, exp. 32 .

218 Sobre fray Diego de Deza vid. CONTARELO Y VALLEDOR, A., Fray Diego de Deza. Ensayo biográfico, Madrid, 1902

219 Cristóbal Colón. Textos y documentos completos (Prólogo y notas de Consuelo Varela), Alianza Editorial, Madrid, 1982, p. 320. 
más sobresaliente, sin duda, es el magnífico retablo, ya de estilo renacentista, realizado a su costa para la primitiva capilla mayor de la catedral, en el que se encuentran labradas las armas del prelado ${ }^{220}$.

En Benavente fueron sus condes quienes mayores atenciones dedicaron a la villa y así durante este periodo que abarca el gótico tardío ampliaron significativamente su castillo-palacio e hicieron importantes reformas en la iglesia de Santa María la Mayor. El condado de Benavente se remonta al año 1398 cuando Enrique III otorgó el título nobiliario a Juan Alonso Pimentel, de origen portugués ${ }^{221}$. Casi un siglo después, el 28 de enero del año 1473, Enrique IV eleva el condado de Benavente a ducado, de tal forma que el propietario del título en aquel momento, Rodrigo Alonso Pimentel se convirtió a partir de ese momento en IV conde y I duque de Benavente. Este noble junto con su hijo don Alonso Pimentel, V conde y II duque de Benavente patrocinaron la construcción y transformación de importantes edificios fundamentalmente en su ciudad pero también hicieron lo propio en otras villas de su propiedad como Puebla de Sanabria.

Don Rodrigo Alonso Pimentel ${ }^{222}$, nacido hacia 1441, mantuvo una estrecha relación con los distintos monarcas hospedándolos en sus casas en varias ocasiones. El viajero alemán Jerónimo Münzer en su visita a Benavente a finales del siglo XV lo describió así: “El señor de esta tierra es don Rodrigo, conde de Benavente; él y el duque de Sevilla (sic por Medina Sidonia) son más poderosos y más ricos que el mismo rey de España. Posee el conde muchas y grandes villas, y como recompensa de las guerras que sostuvo

220 SAN MARTÍN PAYO, Jesús, "El retablo mayor de la catedral de Palencia. Nuevos datos", Publicaciones de la Institución Tello Téllez de Meneses, 10, Palencia, 1953, pp. 299-306; PLAZA SANTIAGO, Javier de la, "Retablo mayor" en Catálogo de la Exposición Memorias y Esplendores. Las Edades del Hombre. Palencia, Salamanca, 1999, pp. 111-115.

221 Existen diversos estudios sobre el condado de Benavente y la figura de sus condes en distintos periodos. Para profundizar en ello pueden consultarse los siguientes: BECEIRO PITA, Isabel, El condado de Benavente en el siglo XV, Centro de Estudios Benaventanos «Ledo del Pozo» (C.E.C.E.L.-C.S.I.C.), Salamanca, 1998 y SIMAL LÓPEZ, Mercedes, Los condes-duques de Benavente en el siglo XVII. Patronos y coleccionistas en su villa solariega, Centro de Estudios Benaventanos «Ledo del Pozo» (C.E.C.E.L.-C.S.I.C.), Benavente, 2002. Esta última publicación recoge toda la bibliografía existente relacionada con este aspecto.

222 Sobre don Rodrigo Alonso Pimentel vid. LEDO DEL POZO, José, Historia de la nobilísima villa de Benavente (edición facsímil de la obra publicada en Zamora en 1853), Centro de Estudios Benaventanos «Ledo del Pozo», Salamanca, 2000, pp. 271281. 
contra los moros, concedióle el Papa la mitad de los diezmos de sus estados, así como la colación de todos los beneficios. El tiempo atrás estuvo en lucha con los reyes de Castilla, que nunca lograron reducirle a la obediencia, y él es también de sangre real”223. Casó con María Pacheco. Su patrimonio pronto se vio acrecentado con la villa de Puebla de Sanabria y Portillo (1465) y la de Castromocho (1470). Falleció en el año 1499. Entre otras actuaciones destaca la profunda intervención realizada en su castillo de Benavente y la edificación del castillo de Puebla de Sanabria, localidad esta que como Benavente era de su propiedad.

Don Alonso Pimentel ${ }^{224}$, nacido hacia 1470 , hijo de don Rodrigo, también tuvo estrechas relaciones con los monarcas castellanos y alojó en su residencia de Benavente a Felipe el Hermoso. Desde el punto de vista de las artes don Alonso Pimentel siguió remodelando y engrandeciendo su residencia benaventana, construyendo entre otros espacios la torre del Caracol, único testimonio conservado, mandó hacer importantes reformas en la iglesia de Santa María del Azogue y fundó en el año 1517 el Hospital de Nuestra Señora de la Piedad, todo ello en la ciudad de Benavente. Fuera de la provincia de Zamora, concretamente en la ciudad de Valladolid, mandó edificar un magnífico palacio cuyo aspecto original conocemos a través de una acuarela realizada por Carderera en 1836 225 . Importantísimo resulta el inventario que dejó el conde a su muerte y que puede consultarse dentro de los fondos del Archivo Histórico Nacional

223 GARCÍA SIMÓN, Agustín, Castilla y León según la visión de los viajeros extranjeros. Siglos XV-XIX, Salamanca, 1999, p. 353.

224 Sobre don Alonso Pimentel vid. LEDO DEL POZO, José, Historia de la nobilísima villa de Benavente (edición facsímil de la obra publicada en Zamora en 1853), Centro de Estudios Benaventanos «Ledo del Pozo», Salamanca, 2000, pp. 281286.

225 Aunque los terrenos donde se construyó este palacio fueron adquiridos por el IV conde y I duque don Rodrigo Alfonso Pimentel en el año 1475 lo cierto es que el edificio fue levantado durante el primer cuarto del siglo XVI por su hijo don Alonso Pimentel. El palacio, que se conserva en la actualidad desprovisto de alguno de sus elementos más interesantes, acoge la Biblioteca Pública de Valladolid. Acerca del edificio puede consultarse: GARCÍA CHICO, E., "El palacio del conde de Benavente" en Boletín de la Real Academia de la Purísima Concepción de Valladolid, 1946, pp.1330; MARTÍN GONZÁLEZ, Juan José, La arquitectura doméstica del Renacimiento en Valladolid, Valladolid, 1948, pp. 124-131; URREA, Jesús, Arquitectura y Nobleza. Casas y palacios de Valladolid, Valladolid, 1996, pp. 41-45; VASALLO TORANZO, Luis, "La casa del conde de Benavente en Valladolid, un frustrado palacio al servicio de Carlos V", en MÍNGUEZ CORNELLES, V.M., Las artes y la arquitectura del poder, 2013, pp. 829-842. 
de Madrid procedentes de la Casa de Osuna ${ }^{226}$. En él se detallan a fecha de 16 de junio de 1530 los bienes que eran de su propiedad, entre los que cabe destacar un listado de los libros que componían su biblioteca particular ${ }^{227}$.

A los grandes promotores anteriormente mencionados hay que sumar otros que patrocinaron obras de menor envergadura como fue el caso de don Pedro López de Peralta, Chantre de la catedral de Zamora que intervino en la localidad de El Perdigón, donde mandó edificar una capilla funeraria anexa al templo parroquial y se construyó un palacio, y el canónigo de la catedral de Zamora don Alonso de Valdivieso a quien se debe la edificación de la iglesia de la Asunción de la Virgen de Villaralbo.

\section{Las obras}

Aunque, como ya se ha señalado, existe en este periodo una mayor actividad constructiva que en etapas anteriores, lo cierto es que, ni se tradujo en obras completas de este momento (salvo excepciones), ni siquiera de empaque salvo en alguna contada ocasión. En cambio hay, por un lado, obras de acomodación estilística en templos ya existentes que estuvieron dirigidas principalmente a la sustitución de su antigua cabecera románica por una gótica tardía, o se añadieron espacios tales como capillas de carácter funerario, sacristías o pórticos. Por otro lado se iniciaron nuevos templos que solamente en casos excepcionales llegaron a concluirse. La práctica totalidad de ellos fueron comenzados, como por otra parte venía siendo tradicional, por la cabecera, de ahí que se de la circunstancia de que sea precisamente este espacio prácticamente el único que por cronología pueda ser adscrito a este momento.

Es por ello que, dentro de todo el conjunto de elementos arquitectónicos que se han conservado de este periodo, vayamos a distinguir entre las reformas, transformaciones o construcción de espacios en templos ya existentes y los edificios levantados de nueva planta. 
Transformaciones góticas y obras de ampliación durante las últimas décadas del siglo XV y las primeras del XVI en edificios religiosos ya existentes

Por lo que se refiere a las transformaciones de las cabeceras de los templos, la intervención más significativa del momento fue el cambio de la cabecera románica de la catedral de Zamora por una cabecera gótica, obra concluida por el obispo Meléndez Valdés durante el reinado de los Reyes Católicos (Fig. 147). También muy significativa fue la importantísima transformación que sufrió la iglesia de San Ildefonso por encargo del mismo obispo, y que también afectó a su cabecera. No obstante, lo verdaderamente sustancial de la reforma emprendida por Meléndez Valdés en este último templo consistió en cambiar su distribución interna románica, que hasta el momento se organizaba mediante tres naves, y dejarlo en una sola cubierta por tramos estrechos de bóvedas de crucería que otorgaba al edificio una mayor diafanidad.

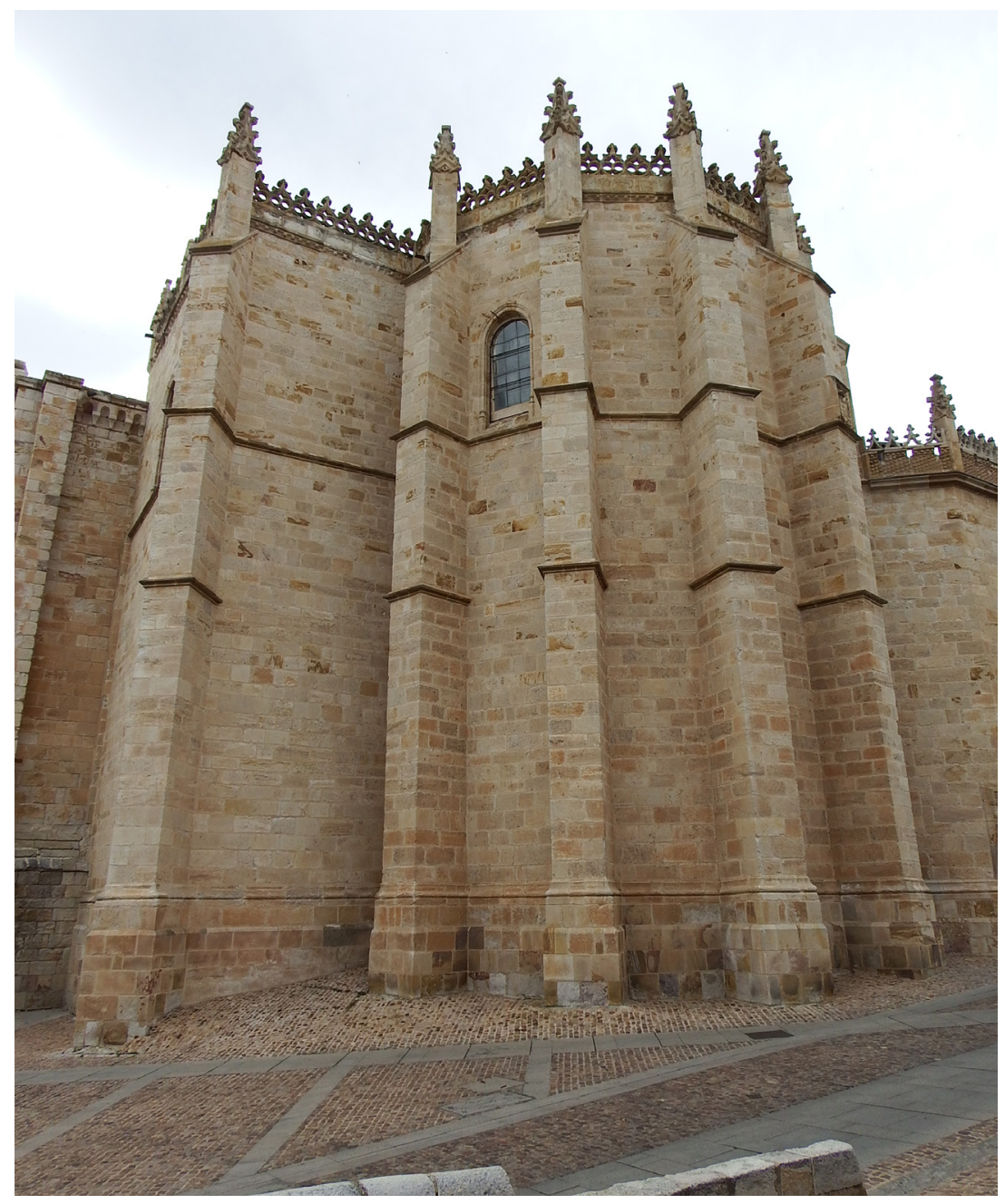


Al margen de las obras de gran empeño, llevadas a cabo por el promotor citado anteriormente, en Zamora y su provincia hubo otra serie de actividades que responden a construcciones más modestas como por ejemplo la sustitución de la cabecera románica de la iglesia de San Leonardo (Zamora) por una de diseño gótico durante las primeras décadas del siglo XVI. Esta nueva cabecera consta de una sola capilla de planta poligonal cubierta por una bóveda de crucería que tiene un juego de nervios de una cierta riqueza. Lo mismo sucedió en la iglesia parroquial de Nuestra Señora de la Asunción de Venialbo donde a finales del siglo XV o principios del siglo XVI fue sustituida la cabecera románica, en este caso por una cabecera gótica de grandes proporciones (Fig. 148).

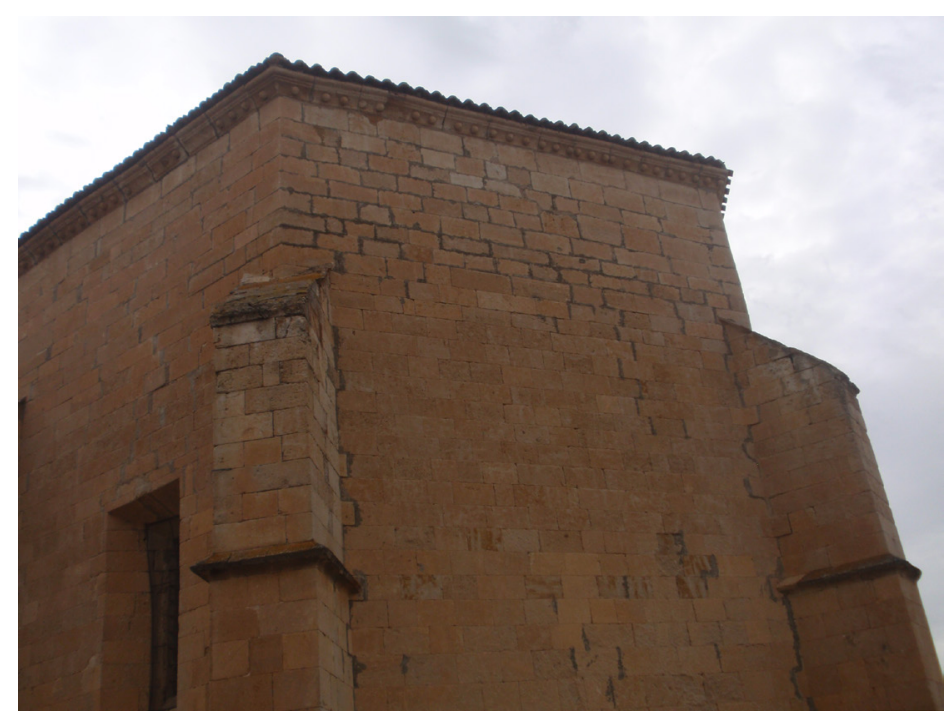

Igualmente fue transformado durante este periodo el cuerpo de la iglesia parroquial de la Asunción de Nuestra Señora en Fermoselle, que fue dividido durante el primer cuarto del siglo $\mathrm{XVI}$ en cuatro tramos mediante tres arcos perpiaños ligeramente apuntados.

Otro elemento destacable fue la construcción de pórticos para cobijar las entradas principales de templos pertenecientes a la transición del románico al gótico, como fue el caso del correspondiente a la iglesia de la Asunción de Nuestra Señora en Fermoselle o la ampliación del pórtico, ya existente, de la iglesia de Santa María la Real de La Hiniesta (Fig. 149). En ambos casos la edificación tuvo lugar en tiempos de los Reyes Católicos. 
Fig. 149. Pórtico de la iglesia de Santa María la Rea de La Hiniesta

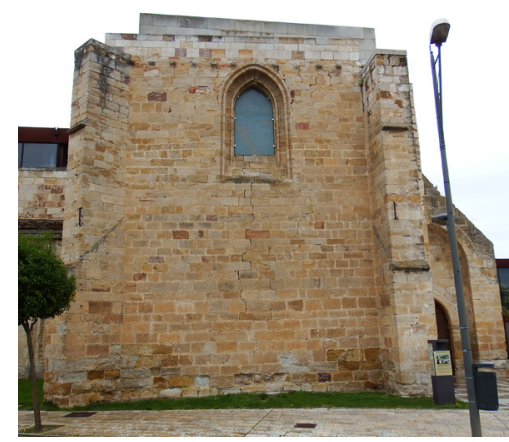

Fig. 150. Exterior de la capilla de los Ocampo. Convento de San Francisco. Zamora

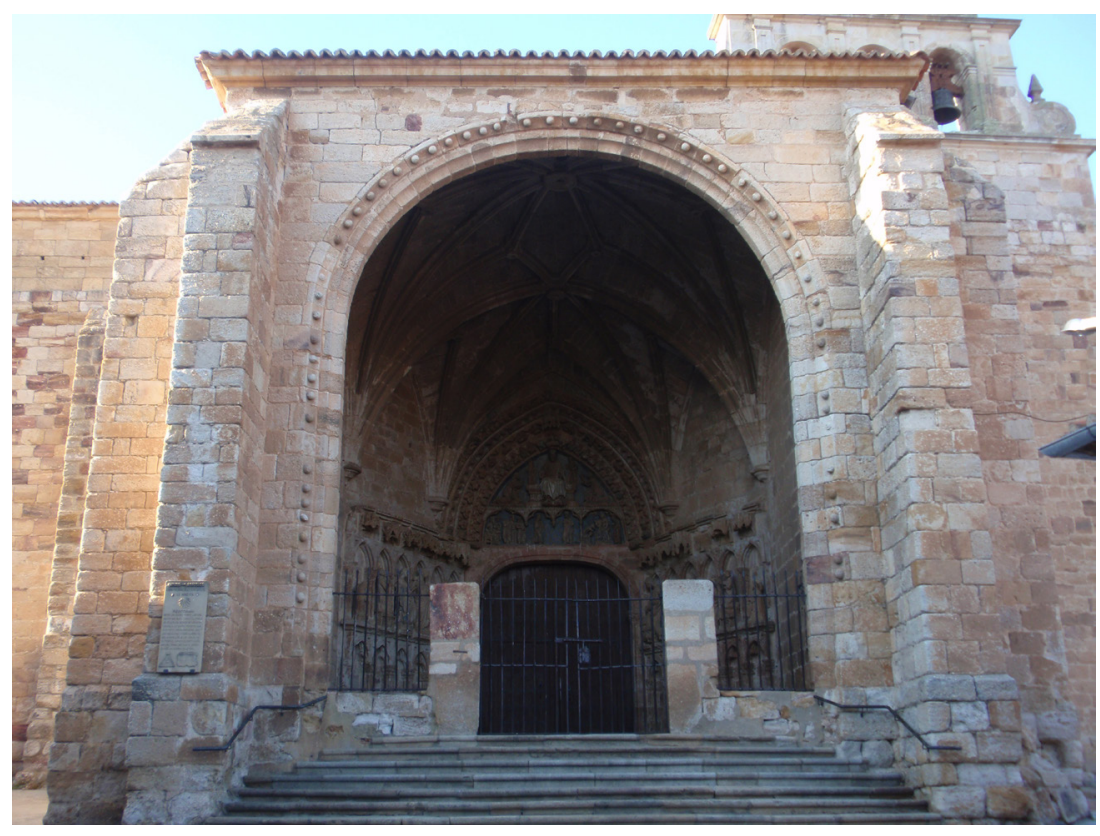

Pero el aspecto que ha dejado una mayor impronta es el que se refiere a la creación de un amplio número de espacios edificados o remodelados en este momento, la mayoría de ellos con funciones de capillas funerarias de una cierta entidad. De este modo en la ciudad de Zamora se construyeron la capilla de los Ocampo y la capilla de los Escalante, en el convento de San Francisco; la capilla de Juan de Vega, en la iglesia de Santa María de la Horta; la capilla de la Soledad, en la iglesia de Santa Lucía y la capilla de la Virgen de Fátima, en la iglesia de San Vicente (Fig. 150). En Toro contamos con la capilla de los Tapia, en la iglesia de San Lorenzo el Real; en El Perdigón, con la capilla del Chantre, situada en el templo parroquial advocado en San Félix $y$, en Montamarta, con la capilla abierta en el muro sur de la iglesia de Santa María del Castillo (Figs. 151 y 152). Junto a estas capillas funerarias y de características muy semejantes a ellas en cuanto a las dimensiones y a los elementos estructurales que las componen contamos con la antesacristía y sacristía vieja de la catedral de Zamora y con la sacristía de la capilla de San Juan Evangelista también en el edificio catedralicio.

De menor entidad son otros espacios contemporáneos a los anteriores, algunos de ellos también pertenecientes al ámbito funerario. Se encuentran en la ciudad de Zamora, concretamente en la catedral y en las iglesias de Santiago del Burgo y San Leonardo. 
Por último tenemos constancia de importantes obras en algunos edificios que han desaparecido totalmente como es el caso del convento de San Francisco de Toro en el que intervino en la década de 1520 el reputado arquitecto Juan de Álava ${ }^{228}$. El maestro planteó una capilla mayor muy similar a otras que ya había trazado compuesta por un tramo recto rectangular rematado en ochavo. Lamentablemente el plano de este edificio que se ha conservado del siglo XVIII en el Archivo de la Diputación de Zamora no contiene dibujadas las bóvedas aunque la presencia de contrafuertes parece indicar que pudieron existir. Al menos así ocurre en otras cabeceras diseñadas por este autor en las que, no obstante, los contrafuertes tienen la disposición habitual en contraposición a como ocurría en la cabecera del convento franciscano de Toro donde, como ya reparó Castro Santamaría, los contrafuertes que debieran situarse en diagonal en las esquinas del testero, están colocados perpendicularmente a los muros oblicuos del ochavo.

Lo mismo ocurre con el también convento de San Francisco de Benavente que llegó a ser en su día uno de los más destacados de entre aquellos que conformaban la provincia franciscana de Santiago y del que lamentablemente no se ha conservado nada ${ }^{229}$. Su fundación se ha establecido en torno a 1270 y el patronato que sobre él ejercieron los condes de Benavente lo convirtieron en un centro religioso de primer orden. Este edificio acogió el panteón de los condes de Benavente hasta que entroncaron con la casa de Osuna. Poco se sabe de este edificio a lo largo de la Edad Media. Todo apunta, sin embargo, que la iglesia fue reconstruida durante la primera mitad del siglo XV, pues a juzgar por lo dictado en su testamento en el año 1440 por Rodrigo Alfonso Pimentel parece que quedaba poco para la finalización de las obras ${ }^{230}$. El claustro estaba en obras a finales del siglo XV, pues el IV conde, don Rodrigo dejó dicho en su testamento que

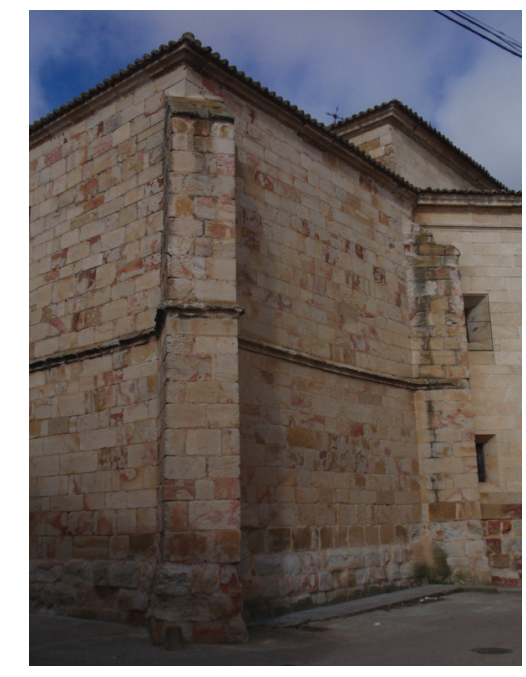

Fig. 151. Exterior de la capilla del Chantre en la iglesia parroquial de El Perdigón

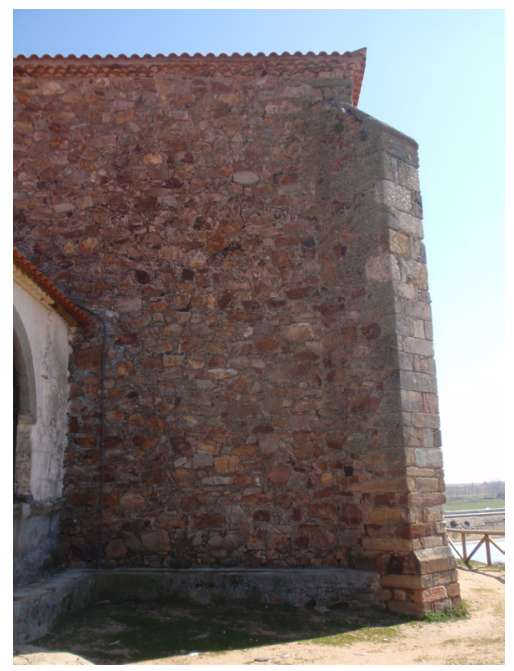

228 CASTRO SANTAMARÍA, Ana, Juan de Álava. Arquitecto del renacimiento, Salamanca, 2002, pp. 354-355.

229 Sobre las labores de urgencia llevadas a cabo para documentar los vestigios existentes en el solar que había ocupado el convento de San Francisco vid. DOMINGUEZ BOLAÑOS, Alonso, "Intervención de urgencia en el convento de San Francisco (Benavente)", Anuario del Instituto de Estudios Zamoranos «Florián de Ocampo», Zamora, 1988, pp. 125-138.

230 CARDIÑANOS BARDECI, Inocencio, "El convento de San Francisco de Benavente y su reconstrucción en el siglo XVII", Anuario del Instituto de Estudios Zamoranos «Florián de Ocampo», Zamora, 1992, p. 243. 
se concluyera al modo en que su abuelo, don Rodrigo Alonso Pimentel, II conde, había señalado que se hiciese en el citado testamento de 1440. Las obras se habían iniciado en vida de este segundo. De principios del siglo XVI y aunque muy general pero revelador, es el testimonio de Antoine Lalaing que vio el edificio en 1501: "Al pie de la ciudad, hay un bellísimo claustro de San Francisco, fundado por San León, compañero de San Francisco, allí canonizado, muerto el año de la Encarnación divina 1236. Allí también yacen los antecesores del actual conde. Su padre yace en el coro; su tumba, de cerca de tres pies de alta, es lisa y cubierta por un rico paño de terciopelo carmesí. Y la iglesia está muy bien adornada y decorada. Visto todo ello, se volvieron a despedir de dicho conde, que les ofreció caballos y gentes, para conducirlos a su destino" ${ }^{231}$. Carecemos de testimonios materiales y documentales del edificio correspondientes al periodo gótico ${ }^{232}$.

\section{Edificios levantados de nueva planta durante las últimas} décadas del siglo XV y las primeras del XVI

De este periodo de la arquitectura correspondiente a las últimas décadas del siglo XV y primeras del siglo XVI no se ha conservado en la ciudad de Zamora, en lo que al aspecto religioso se refiere, ningún edificio o parte de él realizado ex novo.

231 GARCÍA SIMÓN, Agustín, Castilla y León según la visión de los viajeros extranjeros. Siglos XV-XIX, Salamanca, 1999, p. 357.

232 Sí existe documentación exhaustiva de los proyectos fechados en 1681 que se realizaron para la reconstrucción de la misma en el siglo XVII consistentes en diez planos conservados en el Archivo Histórico Nacional de Madrid con plantas y secciones, alzado exterior y planta y alzado del panteón de los condes. El primero de los proyectos está firmado únicamente por Juan de Setién Güemes, el segundo está firmado nuevamente por Juan de Setién Güemes y Antonio de Carasa, Juan de Tejedor Lozano y Francisco Cassuso. El tercer y último proyecto lo firman Felipe Berrojo de Isla y Pedro Ezquerra de Toras. Parece que el proyecto que se llevó a cabo fue el segundo. Todo este material ha sido estudiado y publicado por: TOVAR MARTíN, Virginia, "Proyectos para la iglesia del convento de San Francisco de la villa de Benavente (Zamora)" en Boletín del Seminario de estudios de Arte y Arqueología, tomo XLII, Universidad de Valladolid, 1976, pp. 463-469; CARDIÑANOS BARDECI, Inocencio, "El convento de San Francisco de Benavente y su reconstrucción en el siglo XVII" en Anuario del Instituto de Estudios Zamoranos «Florián de Ocampo», Zamora, 1992, pp. 239-252. El edificio fue incendiado por los franceses y restaurado con posterioridad. Finalmente, y a pesar del interés de la comunidad y el propio conde por salvarlo, el monasterio acusó los estragos de la desamortización y quedó suprimido. Sirvió un tiempo como cárcel y con posterioridad entró en un proceso de degradación que lo llevó a la ruina total. Los últimos restos que se conservaban, que se correspondían con algunos muros del templo, fueron demolidos definitivamente en el mes de julio de 1987. 


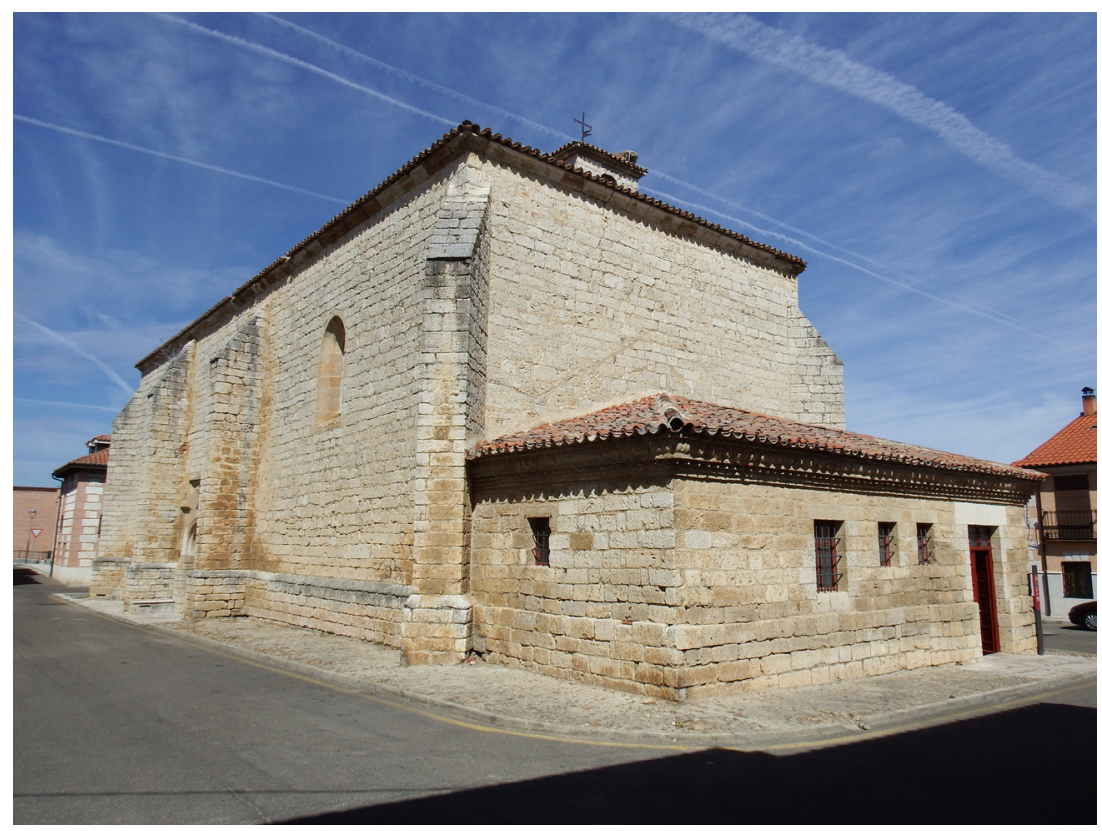

Fig. 153. Iglesia de San Sebastián de los Caballeros.

Sin embargo, en la ciudad de Toro sí contamos con algún ejemplo de edificios construidos completamente de nueva planta en el periodo aludido como es el caso de la iglesia de San Sebastián de los Caballeros (Fig. 153). También, y aunque no se concluyera hasta tiempo después, se comenzó a construir en este momento la iglesia de Santo Tomás Cantuariense (Fig. 154). En ambos casos se trata de redificaciones sobre templos anteriores.

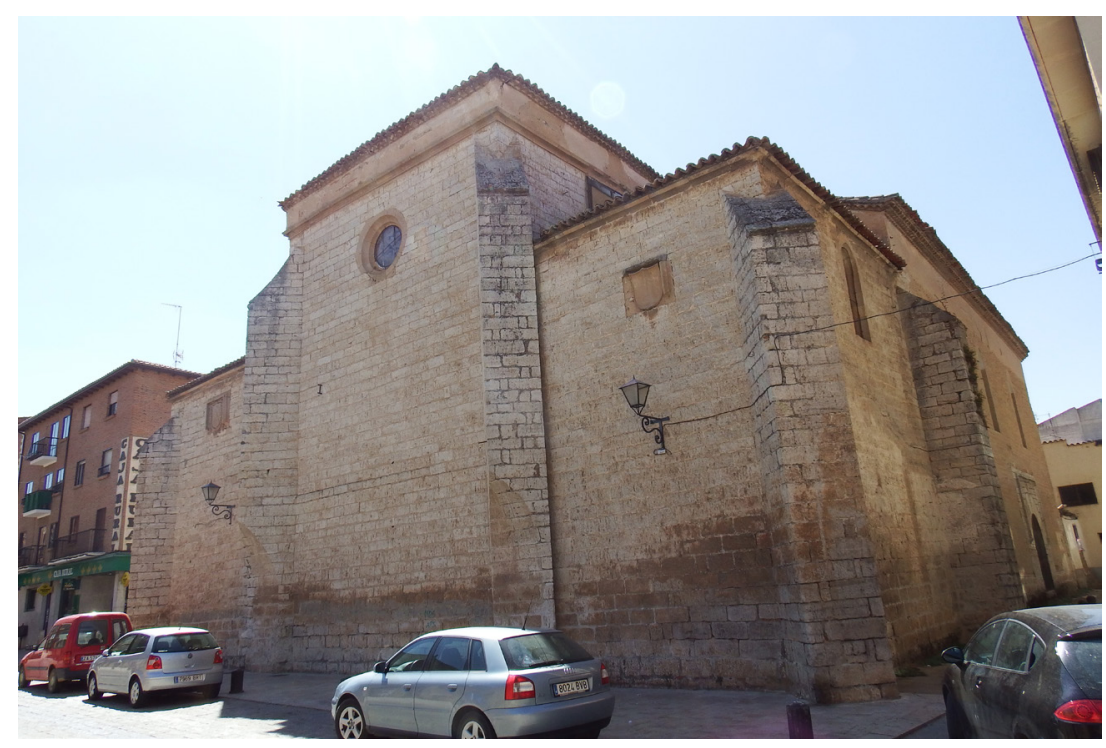

En el resto de la provincia hay que señalar excepcionalmente la iglesia parroquial de Ayoó de Vidriales de notables proporciones y edificada en su conjunto a finales del XV y principios del XVI (Fig. 155). Igualmente de nueva planta se comenzaron a levantar 
Fig. 155. Iglesia parroquial de Ayoó de Vidriales

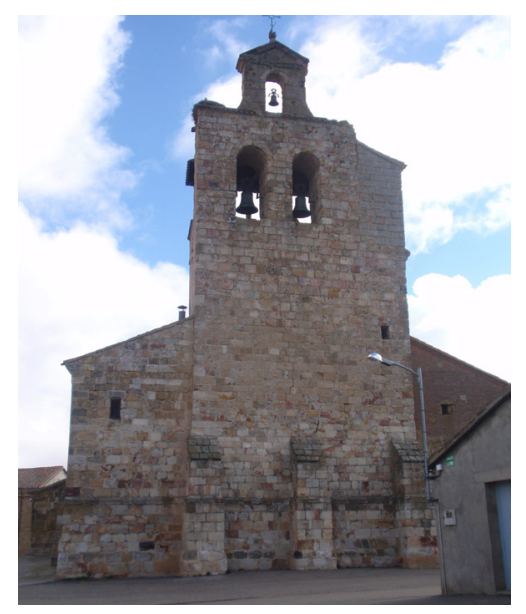

Fig. 156. Iglesia parroquial de El Perdigón

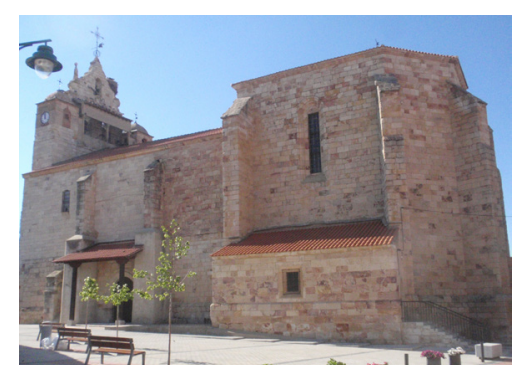

Fig. 157. Iglesia parroquial de Villaralbo

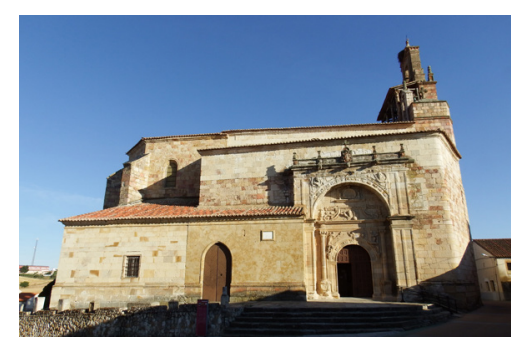

Fig. 158. Iglesia parroquial de Morales del Vino

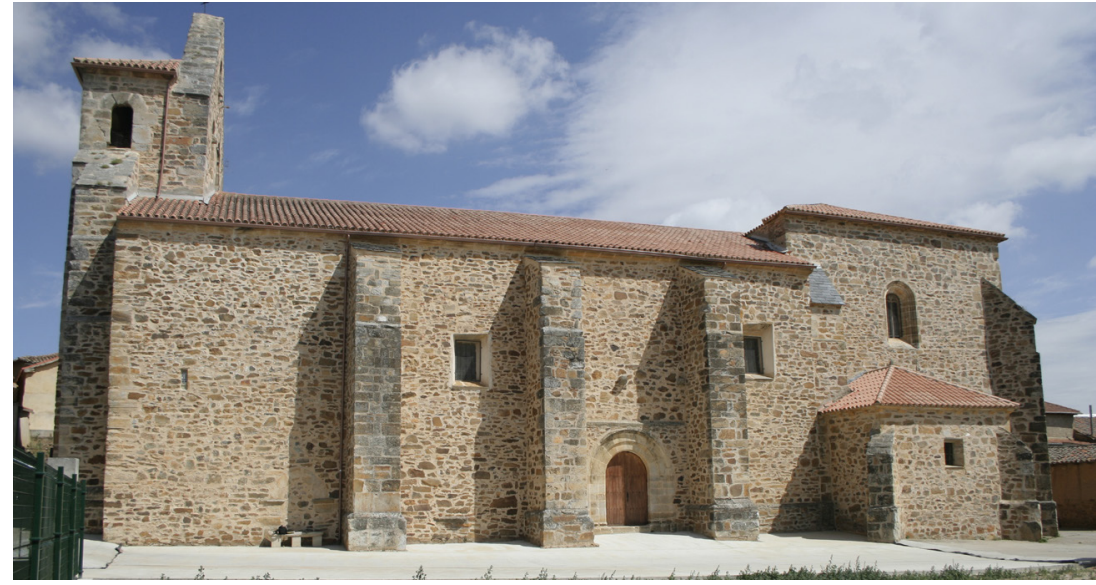

durante las primeras décadas del siglo XVI las iglesias de San Félix en El Perdigón, de la Asunción de Nuestra Señora en Villaralbo, de Santa María Magdalena en Corrales del Vino (en este caso de nueva planta pero sobre un templo anterior del que se ha conservado el cuerpo bajo de la torre), de la Asunción en Morales del Vino y de Nuestra Señora de la Asunción en Villamor de los Escuderos, cuyas fábricas en buena medida corresponden a estos momentos aunque las obras se prolongaron hasta la segunda mitad de esa misma centuria (Figs. 156, 157 y 158). También alguna de ellas, como fue el caso de la parroquial de El Perdigón, sufrió reformas posteriores, fundamentalmente durante el siglo XVIII, que desvirtuaron el aspecto que había tenido cuando se edificó en tiempos de los Reyes Católicos.

Es por ello que, en algunos de estos edificios de nueva planta, nuestra atención se ciña únicamente a la cabecera debido a que es la parte del templo que puede ser adscrita por cronología y estilo a este periodo que hemos denominado gótico tardío. En su práctica totalidad estas estructuras arquitectónicas que se van a estudiar presentan un planteamiento, distribución y organización plenamente góticos. Esto afecta tanto a la arquitectura religiosa como civil, observándose tan sólo y de manera muy débil, la introducción de elementos renacientes en el aspecto decorativo.

Los elementos arquitectónicos de las obras gótico-tardías: problemas de cronología

Aunque durante este periodo la arquitectura en Zamora y su provincia tuvo un importante desarrollo que, en gran medida, viene a coincidir con las obras de gran empeño patrocinadas o 
relacionables con Mella y Meléndez Valdés entre otros, lo cierto es que prácticamente siempre estuvo caracterizada por una gran austeridad y lejos, por tanto, del marcado desarrollo, en cuanto a "riqueza ornamental" se refiere, que encontramos en otros lugares. Sin embargo, el repertorio formal y los elementos decorativos que definen la arquitectura del gótico tardío en el marco geográfico que estamos estudiando, aunque sean escasos, ayudan a la hora de realizar una aproximación cronológica de edificios que son tan difíciles de fechar. Y esto fundamentalmente por carecer en muchos casos de noticias concretas que permitan datar con precisión estos espacios. Se han conservado, no obstante, algunos datos documentales que aportan a estas obras una cronología, que aunque no pueda ser tomada como la fecha en la que se concluyó la construcción de un determinado espacio, sí son indicativos de un momento cercano. Es por lo tanto muy necesario en la clasificación cronológica de las obras de este momento atender no sólo a los datos documentales sino a la evidencia estilística que aporta la propia construcción.

Las referencias documentales que poseemos indican que las obras patrocinadas por el cardenal Mella en la catedral de Zamora debieron comenzar poco tiempo después de su fundación acontecida en el año 1464, aunque no finalizarían al menos hasta el primer cuarto del siglo XVI. Las Ilevadas a cabo en el mismo edificio con el objeto, entre otras cosas, de sustituir su cabecera románica por una nueva de estilo gótico es probable que se desarrollaran durante su mandato y que en 1505 estuvieran finalizadas pues en la clave principal de este espacio se colocó un gran escudo de los Reyes Católicos. En la iglesia de San Ildefonso de la ciudad de Zamora, cuya remodelación fue también ordenada por el obispo Meléndez Valdés, se conserva una inscripción en la que se constata que las obras se habían comenzado antes de 1496 lo que viene a corroborar la cronología apuntada para la catedral pues las afinidades estilísticas, principalmente en las bóvedas que se voltearon en ambos edificios, están fuera de toda duda. En 1495 nos consta que Juan de Vega y su mujer fundaron su capilla en la iglesia de Santa María de la Horta, sin embargo, su bóveda con combados parece responder a unas décadas posterior. En el arco de ingreso a la capilla de la Soledad de la iglesia de Santa Lucía de Zamora se ha conservado una cartela

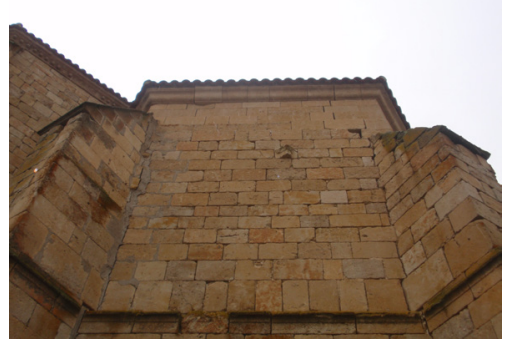

Fig. 159. Exterior de la cabecera de la iglesia parroquial de Corrales del Vino

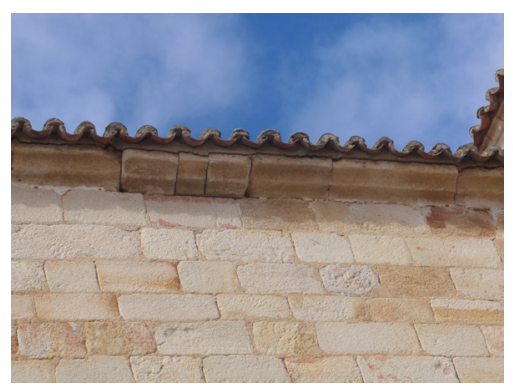

Fig. 160. Exterior de la capilla del Chantre en la iglesia parroquial de El Perdigón 


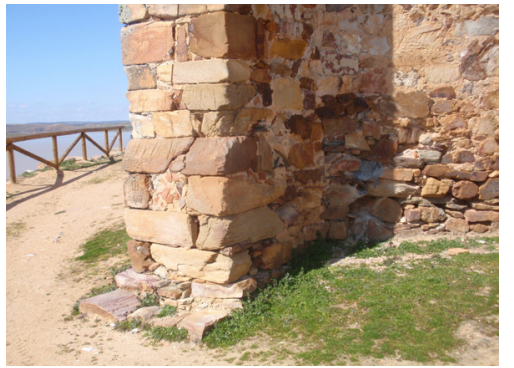

Fig. 161. Detalle del exterior de la capilla meridional de la iglesia de Santa María del Castillo. Montamarta

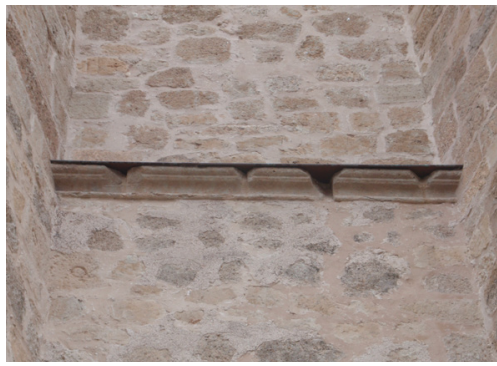

Fig. 162. Detalle del exterior de la cabecera de la iglesia parroquial de Villamor de los Escuderos

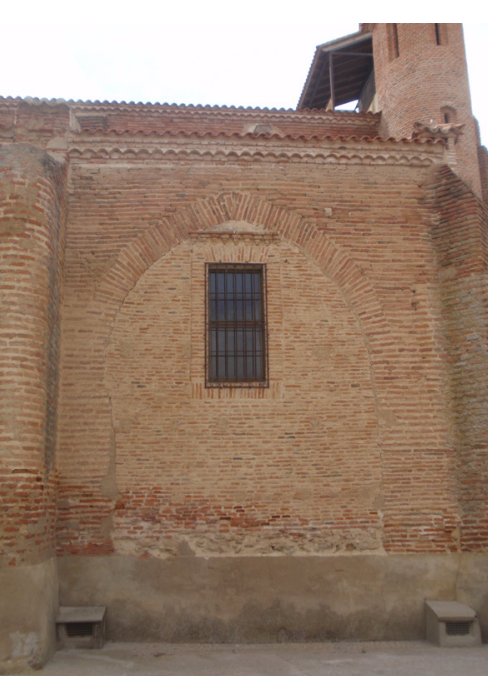

Fig. 163. Iglesia parroquial de Villafáfila fechada en 1522 en la que se dice que dicha capilla la hizo Antón Hernández y su mujer Benita Lozana. La bóveda de esta capilla es muy semejante a la que cubre la capilla de Juan de Vega y, probablemente, la fecha de 1522 pueda convenir a ambas. Por último sabemos que don Diego López obtuvo el 18 de enero de 1501 licencia para poder edificar su capilla privada en la iglesia de San Félix de El Perdigón, cuyos rasgos estilísticos ciertamente responden al primer cuarto del siglo XVI.

Para los espacios de los que no se ha conservado absolutamente ninguna referencia documental tendremos que acudir a la hora de establecer una cronología hipotética a la relación que presentan con los elementos estructurales y decorativos de otros edificios del momento de los que sí se han conservado datos.

\section{Análisis formal de los elementos arquitectónicos}

\section{Materiales}

El material utilizado en las obras llevadas a cabo durante este periodo siguió siendo la piedra de sillería que, por lo general, está bien trabajada como puede verse en las cabeceras de la catedral, de la iglesia de San Leonardo (Zamora), de las parroquiales de Corrales del Vino y Morales del Vino así como también en la capilla del Chantre de la iglesia de San Félix de El Perdigón entre otras obras (Figs. 159 y 160). En ocasiones la piedra bien labrada en sillería se utiliza solamente en los contrafuertes como sucede en la capilla abierta hacia el sur en la iglesia de Santa María del Castillo en Montamarta (Fig. 161). Otras veces se prestó un menor cuidado en el trabajo de la piedra aunque los sillares mantienen una cierta regularidad. Por último, en algún caso se utilizó la mampostería: capilla aludida de Montamarta y cabecera de la iglesia de Nuestra Señora de la Asunción de Villamor de los Escuderos (Fig. 162).

Solamente existe un caso en el que se utilizó un material distinto a la piedra y fue en la iglesia de Santa María de Villafáfila edificada en ladrillo en estilo gótico (Fig. 163). 


\section{Planimetría y configuración interior}

En la actividad artística que se realiza a partir de finales del XV tuvieron un papel muy importante las transformaciones de las viejas cabeceras románicas con ábsides circulares en otras con diseños poligonales con contrafuertes en las esquinas separando los distintos paños al gusto de la época. Las dos obras que iniciaron este tipo de transformaciones fueron el templo catedralicio y la iglesia de San Leonardo (Zamora). Pero también en ese momento comenzó la edificación de iglesias de nueva planta cuyas obras se prolongaron en el tiempo aunque sus cabeceras, que fueron las primeras partes que se levantaron, vienen a coincidir en diseño con las erigidas en sustitución de las románicas. Esta es la razón por la cual uno de los elementos característicos del gótico tardío va ser el trazado de las cabeceras al que vamos a dedicar especial atención procediendo a continuación al análisis de sus particularidades arquitectónicas.

Estas cabeceras en los casos de mayor relieve arquitectónico suelen constar de tres capillas como sucede en la catedral o en las iglesias de Corrales del Vino y de Santo Tomás Cantuariense de Toro. En otros casos como en San Leonardo (Zamora), en Nuestra Señora de la Asunción (Venialbo) o en San Sebastián de los Caballeros (Toro) se optó por la cabecera única, bien porque el templo anterior de época románica constara de una sola nave que no se modificó como ocurrió en la primera iglesia citada, bien porque se edificó así ex profeso como fue el caso de la segunda. El diseño utilizado con mayor frecuencia es aquel en el que el ábside poligonal con las esquinas reforzadas por contrafuertes va precedido por un tramo presbiterial recto que, en ocasiones, alcanza un desarrollo importante como sucede en la mayor parte de los casos. Esto no es óbice para que en edificios sencillos (iglesia de San Sebastián de los Caballeros), en capillas secundarias (evangelio y epístola de la catedral) e, incluso, en iglesias como la toresana de Santo Tomás Cantuariense de triple cabecera puedan existir plantas simplemente rectangulares.

Por lo que al resto de espacios se refiere, capillas funerarias fundamentalmente, adoptan por lo general una estructura sencilla: se trata — salvo en el caso de la capilla de San Ildefonso de la catedral y la capilla del deán Diego Vázquez de Cepeda del 
convento de San Francisco (esta última capilla de fecha muy avanzada dentro del siglo XVI) que presentan un amplio trazado rectangular - de espacios modestos de planta cuadrangular en los que a pesar de estar construidos la mayoría de ellos en pleno siglo XVI se aprecia una clara dependencia de la estética del gótico tardío. Estas estructuras arquitectónicas, que, a veces son sencillas, en ocasiones están enriquecidas por sepulcros de empaque que le dan al espacio la caracterización típica de la época.

La integración de estos ámbitos funerarios en el lugar donde se encuentran se produce de distinta forma. Por un lado, algunas capillas adaptaron espacios ya existentes en los templos acotándolos y transformándolos para esta nueva función. Así ocurrió con la capilla de los Escalante y la capilla de los Ocampo, ambas en el convento de San Francisco, con la capilla de Juan de Vega en la iglesia de Santa María de la Horta y con la capilla del Doctor Grado en la catedral. Por otro lado, otras capillas surgieron como edificaciones de nueva planta anexas a templos ya existentes. De este modo nacieron, en la ciudad de Zamora, la capilla de San Ildefonso en la catedral y la capilla de la Virgen de Fátima en la iglesia de San Vicente y, en la provincia, la capilla de los Tapia en la iglesia de San Lorenzo el Real en Toro, la capilla del Chantre en la iglesia de San Félix en El Perdigón o la capilla de la iglesia de Santa María del Castillo en Montamarta.

Aunque contamos con escasos ejemplos, otro aspecto importante fue el tratamiento que se le dio a la estructura del cuerpo de los templos durante este periodo. Por un lado tenemos las iglesias de San Sebastián de los Caballeros de Toro, de la Asunción de Nuestra Señora de Villaralbo y de San Félix de El Perdigón cuyo cuerpo de naves fue edificado de nueva planta en el primer tercio del siglo XVI; por otro, la iglesia de la Asunción de Nuestra Señora de Fermoselle y las iglesias zamoranas de San Ildefonso y San Juan de Puerta Nueva, construcciones románicas cuya nave fue transformada en estos momentos. La característica común a todas ellas es la creación de espacios despejados como venía siendo la norma desde el siglo XIII, aunque durante el gótico pleno se había preferido mayoritariamente el uso de arcos diafragma que soportaban techumbres de madera. De 
este modo, salvo en los casos de la parroquial de El Perdigón y de la iglesia de San Juan de Puerta Nueva, se optó por la nave única separada por arcos fajones apuntados que van dividiendo la nave en tramos, dos en el caso de San Sebastián de los Caballeros y cuatro en la parroquial de Fermoselle y en la iglesia zamorana de San Ildefonso. Se aparta de esta organización, como señalábamos, la iglesia de San Félix de El Perdigón y la de San Juan de Puerta Nueva que articulan el espacio mediante dos grandes arcadas longitudinales que establecen tres naves. No obstante, sí se consigue la espacialidad pretendida al dotar de una mayor amplitud a la nave central y al voltear esas amplias arcadas que apenas restan visibilidad a la integridad del conjunto. Ignoramos el tratamiento que se le concedió a las separaciones de los distintos tramos que conforman la nave de la iglesia parroquial de Villaralbo puesto que en el siglo XVIII fue totalmente remodelada.

Por tanto, en base a las estructuras conservadas, hemos constatado que lo habitual para la articulación del cuerpo de naves de las iglesias durante este periodo correspondiente al gótico tardío fue el uso de arcos que soportaban cubiertas de madera y solo en el caso de la iglesia toresana de San Sebastián de los Caballeros se optó por el abovedamiento en crucería.

También durante este periodo se edificó el pórtico de la iglesia de la Asunción de Nuestra Señora en Fermoselle y se amplió el pórtico, ya existente, de la iglesia de Santa María la Real de La Hiniesta, que nada añaden desde el punto de vista del diseño y de la estructura a lo señalado anteriormente al hablar de las cabeceras y de las capillas.

\section{Exteriores}

Por lo que se refiere a su exterior, todas estas estructuras (cabeceras, capillas y pórticos fundamentalmente) responden por lo general a una elaboración sencilla y se mantiene en todas ellas una configuración muy semejante. Tanto las capillas como las cabeceras y los propios pórticos tienen generalmente en la parte inferior un saliente a modo de basamento que recorre todo su perímetro y una serie de contrafuertes, habitualmente 
Fig. 164. Exterior de la cabecera de la iglesia parroquial de Villamor de los Escuderos

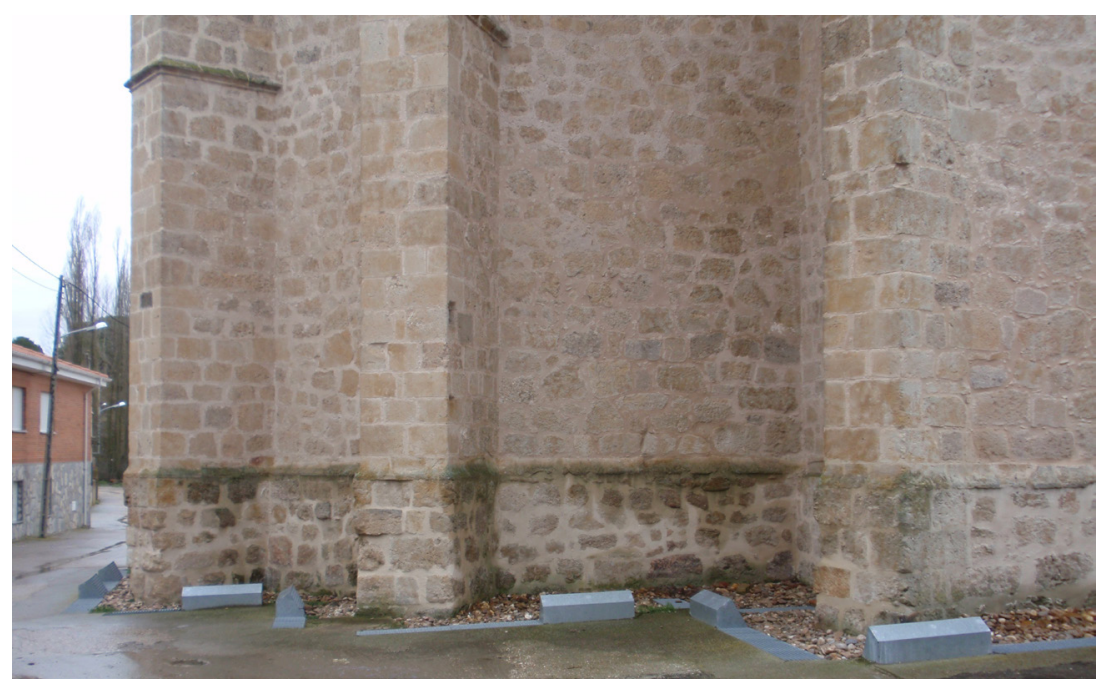

en disposición diagonal y situados en las esquinas de los muros separando los distintos paños (Figs. 164 y 165). Por lo general, estos contrafuertes recorren prácticamente toda la altura del edificio muriendo en chaflán. Es también común que estos contrafuertes tengan unas molduras a modo de vierteaguas que, bien, en unos casos, sólo le afectan a ellos, bien, en otros, se prolongan a lo largo de toda la estructura creando divisiones en horizontal. Sólo en alguna ocasión como sucede en el pórtico de la iglesia de La Hiniesta la disposición de los contrafuertes no se ha realizado en diagonal como hemos visto que es costumbre en la arquitectura tardogótica, sino que se disponen paralelos a los muros del templo a modo de pilastras que enmarcan el espacio. Esta disposición se generalizó en el segundo cuarto del siglo XVI.

En lo que atañe a los remates de estas construcciones, observamos en prácticamente todas ellas un sencillo friso sin más decoración que suaves molduras, salvo en la capilla de la Epístola y en la capilla Mayor correspondientes a la cabecera de la iglesia parroquial de Corrales del Vino y en la cabecera de la iglesia de Nuestra Señora de la Asunción de Venialbo que llevan como elemento decorativo las medias bolas tan características del reinado de los Reyes Católicos pero que remiten a la decoración románica de medias bolas o besantes. Como única excepción que se aparta de la sencillez aludida contamos en la ciudad de Zamora con la crestería que remata la cabecera de la catedral con pináculos y tracerías flamígeras. Bajo ella se desarrolla una molduración con una escocia central que va decorada con las medias bolas ya aludidas. Un diseño prácticamente idéntico se 


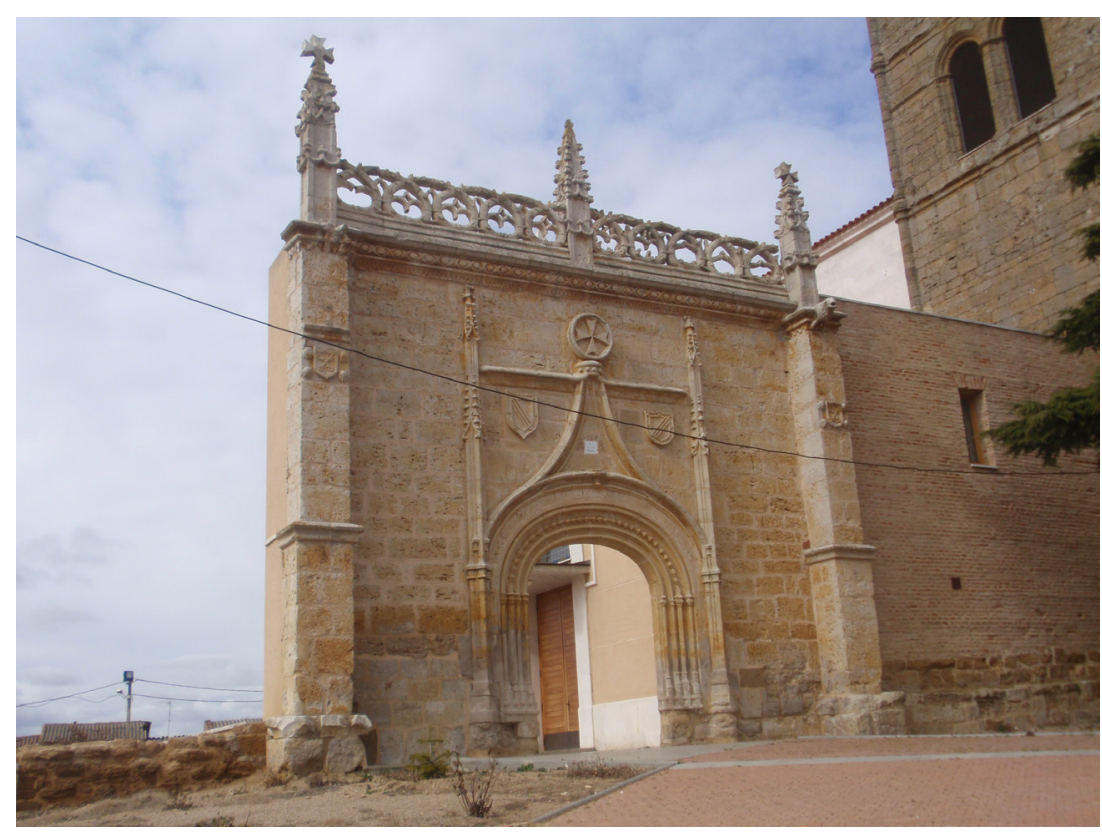

encuentra rematando el coro de este edificio también a modo de crestería. En la provincia podemos hablar también de una única excepción constituida en este caso por la portada sur de la iglesia de San Vicente Mártir de Villar de Fallaves dotada de una interesante crestería con hermosos pináculos en su recorrido (Fig. 166).

Es frecuente el uso de otros elementos propios de este momento como son los escudos enmarcados por alfiz como sucede en la cabecera de la catedral de Zamora, en la iglesia de San Sebastián de los Caballeros de Toro o en la capilla del Chantre de la iglesia parroquial de El Perdigón (Figs. 167 y 168). Pero, sin duda, en el exterior de estos espacios el mayor impacto decorativo lo constituyen los vanos (puertas y ventanas) de las que se hablará en su apartado correspondiente.

\section{Soportes}

Al tratarse en la mayoría de los casos de pequeños espacios cuadrangulares los soportes independientes prácticamente no existen de ahí que solo podamos referirnos a pilares adosados a los muros, bien sustentando los arcos en las embocaduras de las cabeceras bien con la misma función en puertas y ventanas. Existen únicamente dos ejemplos en los que también hay pilares adosados en los rincones de las capillas como apeo de los nervios de la bóveda. Es el caso de la capilla de los Ocampo en
Fig. 166. Antigua portada de la iglesia de Villar de Fallaves

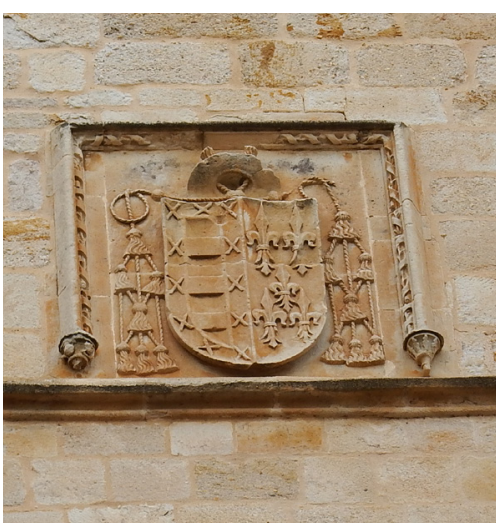

Fig. 167. Armas de Meléndez Valdés en la cabecera de la catedral de Zamora

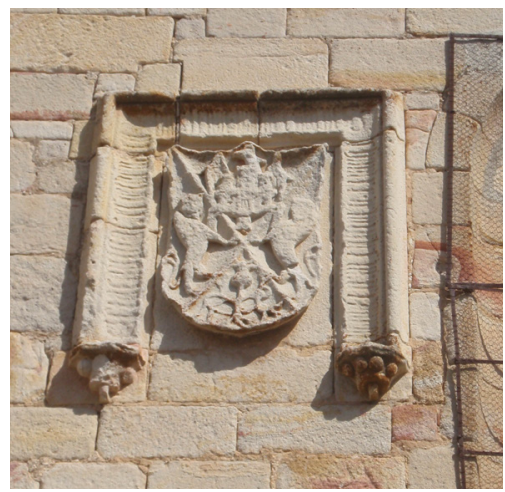

Fig. 168. Armas del Chantre en la capilla que patrocinó en la iglesia de San Félix. El Perdigón 


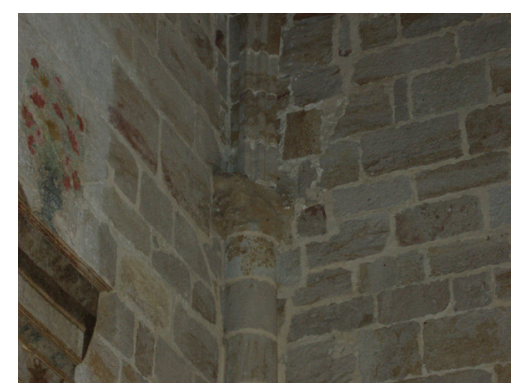

Fig. 169. Capilla de los Ocampo en el convento de San Francisco. Zamora

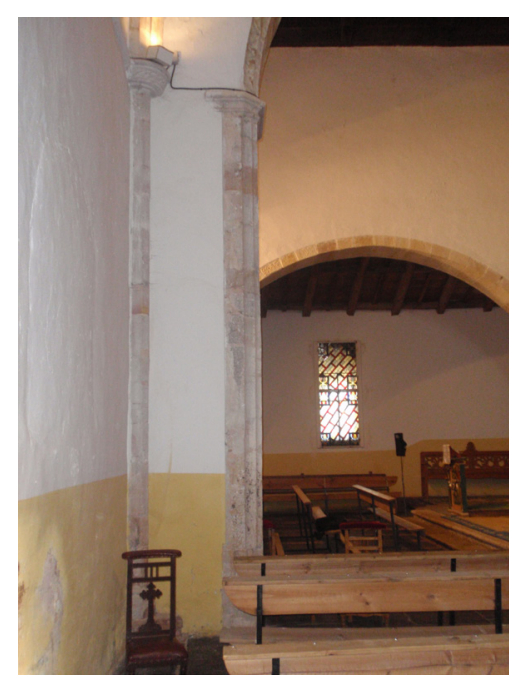

Fig. 170. Capilla meridional de la iglesia de Santa María del Castillo. Montamarta

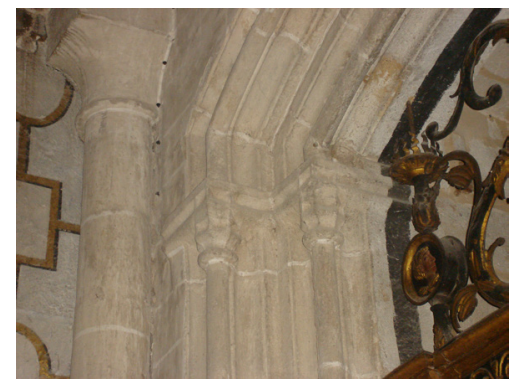

Fig. 171. Detalle de la portada de la actual capilla de San Juan Evangelista en la catedral de Zamora

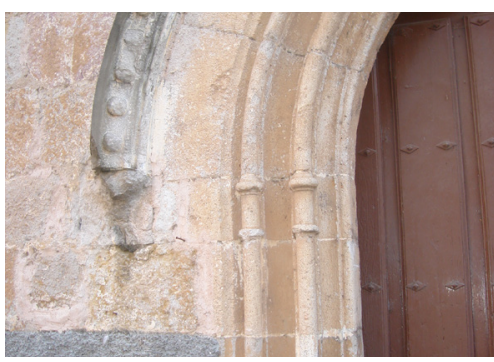

Fig. 172. Detalle de la actual portada de comunicación a las huertas en el convento de el convento de San Francisco de Zamora donde son simplemente columnas con su capitel correspondiente, mientras que en la capilla de la iglesia de Santa María del Castillo en Montamarta más que un pilar adosado propiamente dicho hay que definirlo como una sencilla moldura que cubre el ángulo (Figs. 169 y 170). En todos los demás casos los nervios de las bóvedas descansan en ménsulas.

Estos soportes en muchas ocasiones mantienen un valor independiente de tal forma que aparecen caracterizados como un pilar compuesto formado por pedestal, basas, fuste y capitel. El pedestal tiene en todos los casos un marcado desarrollo y su diseño suele tener sección poligonal aunque lógicamente no todos sus lados son visibles. En otras ocasiones, como sucede en las puertas del trascoro de la catedral o en la portada de la capilla del deán Diego Vazquez de Cepeda en el convento de San Francisco, tienen diseño curvo. Sobre el pedestal se asienta la basa compuesta por un juego de volúmenes creado por molduras superpuestas que le confieren un carácter movido con entrantes y salientes característico de la arquitectura de este momento. Le sigue el fuste que actúa a modo de jamba y que posee por lo general una molduración a base de escocias y boceles. Estos últimos asemejan finas columnillas que arrancan de los pedestales y basas mencionadas con anterioridad y rematan, en unos casos, en sencillas molduras a modo de capitelitos como sucede en la portada de acceso a la capilla del doctor Grado de la catedral o en la portada que comunica actualmente con las huertas del convento de Santa Marina de Zamora y, en otros, en capiteles propiamente dichos muy ornamentados pero también de tamaño muy reducido (Figs. 171 y 172).

\section{Ménsulas}

Las nervaduras de las bóvedas apean en su gran mayoría en ménsulas de diseños variados situadas en los ángulos. Algunas de ellas mantienen un fuerte apego a la tradición gótica claramente reconocible por su diseño de perfil poligonal y por la profusión de molduras de que están dotadas. Ejemplo de ello tenemos en las ubicadas en la capilla del Santo Sepulcro del convento de San Francisco (Zamora) o en el pequeño espacio previo al acceso 
a la nave de la iglesia de San Sebastián de los Caballeros de Toro (Figs. 173 y 174). Otras presentan un trazado semicircular, influenciado ya por los nuevos modelos renacentistas, pero en las que se mantiene, por lo general, todavía una ornamentación puramente gótica a base de hojarasca y animalillos. Es el caso de las ubicadas en la nave y cabecera de la iglesia de San Sebastián de los Caballeros de Toro y también de las correspondientes a la cabecera de la iglesia parroquial de Venialbo (Figs. 175 y 176). Pero a pesar de la existencia de ménsulas como las mencionadas, de trazado y ornamentación fundamentalmente goticista, lo cierto es que el modelo más común en estos últimos años del siglo XV y primeros del XVI es la ménsula de perfil semicircular moldurado con boceles y escocias desprovistas de ornamentación, todo ello en clara consonancia ya con el nuevo estilo. No es extraño que, en ocasiones, la escocia central de este tipo de ménsulas vaya enriquecida con elementos que se revelan como evidentes indicios de la introducción de los repertorios decorativos renacentistas. Las encontramos, sin ningún tipo de decoración en sus molduras, en la antesacristía y sacristía de la catedral de Zamora y en los pequeños espacios ya mencionados de la catedral e iglesia de San Leonardo y, provistas de hojas de laurel y acanto, en la capilla de la Soledad de la iglesia de Santa Lucía y en la capilla de Juan de Vega de la iglesia de Santa María de la Horta.

Uno de los repertorios de ménsulas más amplios y donde se han conservado ejemplos de todos los tipos anteriormente descritos se encuentra en la iglesia de Santa María Magdalena de Corrales del Vino (Fig. 177).

Como sucede con otras estructuras las particularidades en el diseño y elementos decorativos de estas ménsulas ofrecen un sistema serial en sus formas que ayudan a establecer la evolución del estilo.

\section{$\operatorname{Arcos}$}

En esta etapa del gótico tardío se utiliza una gran variedad de arcos, en unos casos, funcionales y, en otros, de carácter ornamental. En las embocaduras de las capillas se sigue usando

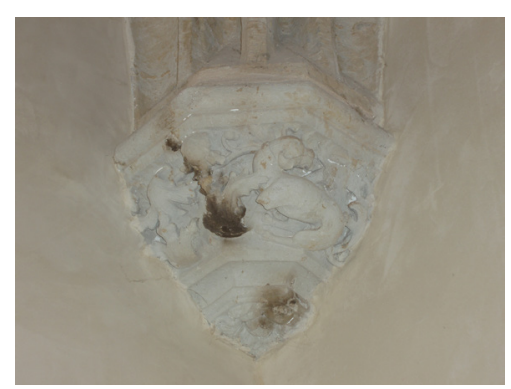

Fig. 173. Ménsula de la capilla del Santo Sepulcro en el convento de San Francisco. Zamora

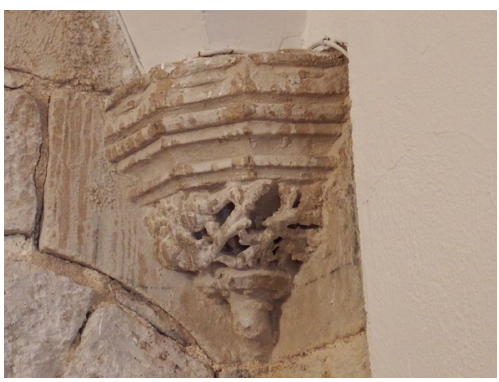

Fig. 174. Ménsula de la iglesia de San Sebastián de los Caballeros. Toro

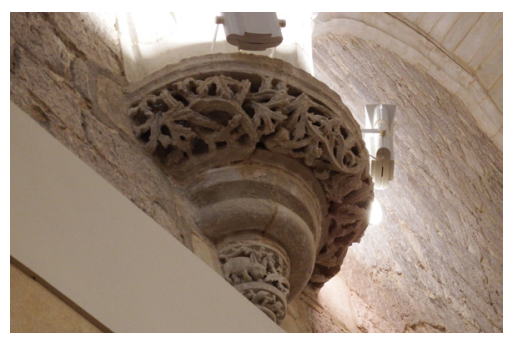

Fig. 175. Ménsula de la iglesia de San Sebastián de los Caballeros. Toro

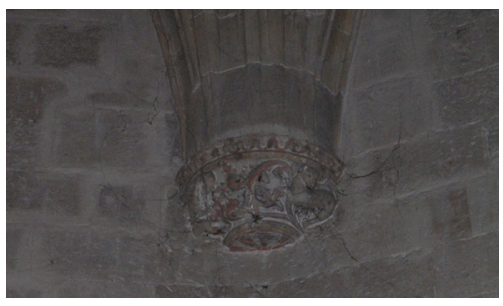

Fig. 176. Ménsula de la capilla mayor de la iglesia parroquial de Venialbo 


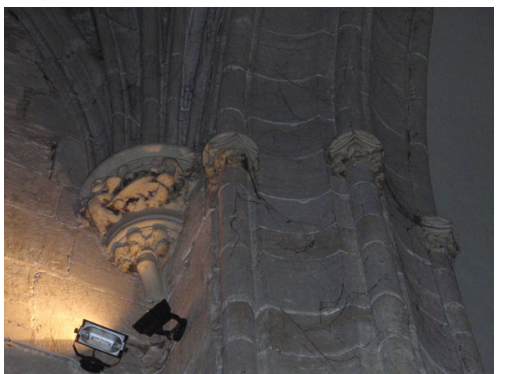

Fig. 177. Ménsulas de la cabecera de la iglesia parroquial de Corrales del Vino

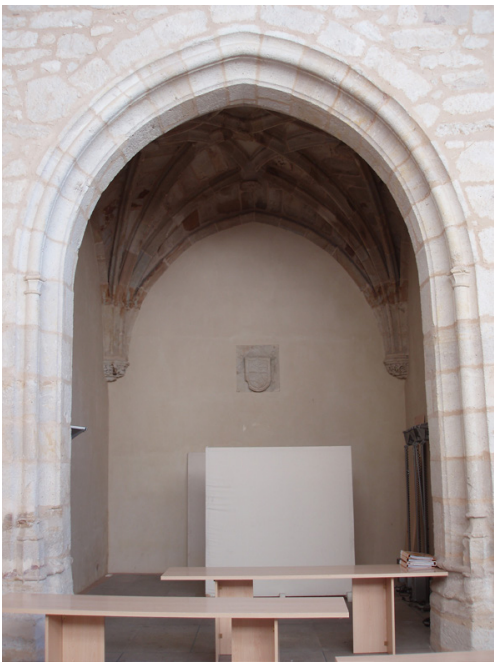

Fig. 178. Vano de acceso a la capilla del Santo Sepulcro en el convento de San Francisco. Zamora

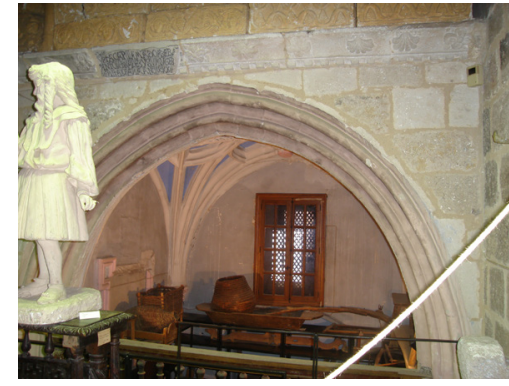

Fig. 179. Vano de acceso a la capilla de la Soledad en la iglesia de Santa Lucía. Zamora preferentemente el arco apuntado de tradición gótica por su funcionalidad. Lo encontramos en la embocadura de las capillas de La Bóveda de Toro, del Santo Sepulcro en el convento de San Francisco (Zamora), de la capilla de la iglesia de Santa María del Castillo de Montamarta, de la capilla de la Soledad en la iglesia de Santa Lucía, de la capilla Mayor de San Leonardo (Zamora) y en las embocaduras de las cabeceras de las iglesias de la Asunción de Morales del Vino, de Nuestra Señora de la Asunción de Venialbo y de Santa María Magdalena de Corrales del Vino (Figs. 178 y 179). Lo vemos además en diversos ventanales o en arcosolios como es el caso de los situados en la capilla de los Ocampo del convento de San Francisco de Zamora (Figs. 180 y 181).

Muy utilizado también y ya propio de este momento es el arco carpanel que podemos encontrar en pequeñas puertas interiores como en el acceso a las sacristías de la catedral de Zamora, en el acceso al lavabo de la sacristía vieja, en el acceso a la sacristía de la capilla del doctor Grado y en las puertas situadas en el trascoro, todas ellas también en la catedral, o en portadas principales de gran importancia como en el acceso occidental de la iglesia de La Hiniesta, en la antigua puerta del crucero de la iglesia conventual de San Francisco (Toro) y en la iglesia de la Asunción de Morales del Vino (Figs. 182 y 183). De forma excepcional, en las puertas del cerramiento del coro de la catedral de Zamora se utilizó un dintel adovelado en forma de arco carpanel. Aunque la abertura es en dintel, no se trata de una construcción adintelada propiamente dicha (Fig. 184).

Otros tipos de arco que se utilizan de forma más ocasional son el arco trilobulado (portada norte de la capilla del Deán Diego Vázquez de Cepeda en el convento de San Francisco de Zamora y que décadas después se repitió en la portada sur de la iglesia de la Asunción de Grijalba de Vidriales), el arco rebajado (acceso occidental del pórtico de la iglesia de La Hiniesta y accesos norte y oeste de la iglesia de San Sebastián de los Caballeros de Toro), el arco escarzano (acceso a las capillas catedralicias del doctor Grado y del cardenal Mella), y el arco conopial que a pesar de ser el más representativo del gótico tardío ha tenido una acogida relativamente limitada en la arquitectura gótica religiosa zamorana (portada sur de la iglesia de San Vicente Mártir de Villar 

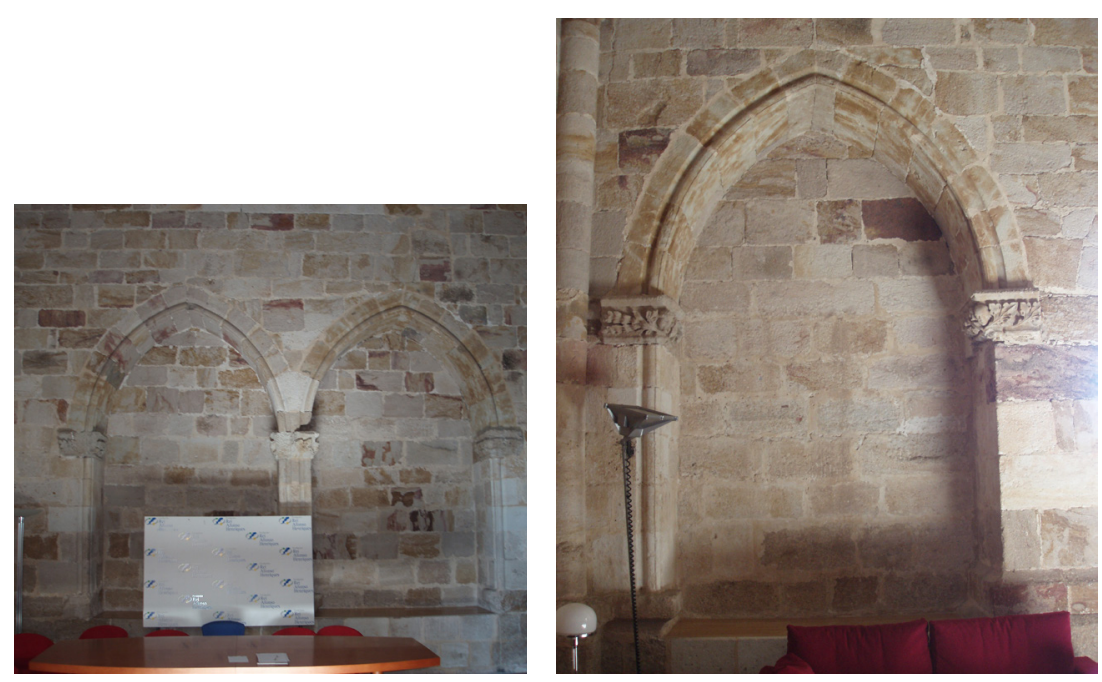

de Fallaves, portada suroccidental de la iglesia de Santa María de Villafáfila, chambrana de la antigua portada perteneciente al convento de San Ildefonso (Toro), hornacina sobre el acceso meridional de la iglesia de la Asunción de Morales del Vino, hornacina de la fachada occidental de la iglesia de la Asunción de Nuestra Señora de Fermoselle y trascoro de la catedral donde se ha utilizado el arco lobulado rematado en un conopio) (Figs. $185,186,187$ y 188). Un caso especial es la portada de acceso a la capilla de San Ildefonso o del cardenal Mella de la catedral de Zamora, renacentista en la mayor parte de los elementos que la configuran, si bien el arco que delimita el tímpano y que se alza sobre el dintel de la puerta tiene trazado conopial aunque está flanqueado por roleos vegetales simétricos y por hacheros.

Por último, durante este primer tercio del siglo XVI comenzó a utilizarse, tanto en las portadas como en las ventanas, el arco de medio punto que, a partir de este momento, adquiere especial protagonismo, asociado en muchos casos al alfiz, elemento que la arquitectura gótica anteriormente había incorporado ocasionalmente a su repertorio. Ejemplos de utilización del arco de medio punto en los inicios del siglo XVI lo tenemos en la puerta de acceso a la iglesia de convento toresano de Santa Sofía y en la actual puerta de entrada a las huertas del convento de Santa Marina en Zamora (Fig. 189).

\section{Bóvedas}

Donde se puede apreciar un mayor sentido de continuidad de las formas góticas y, por tanto, se acusa de forma más directa Figs. 180 y 181. Arcosolios en el interior de la capilla
de los Ocampo del convento de San Francisco. Zamora

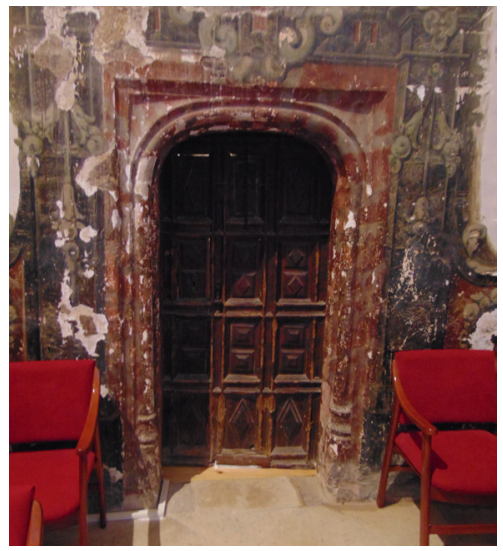

Fig. 182. Puerta de acceso a la sacristía de la capilla del doctor Grado. Catedral de Zamora

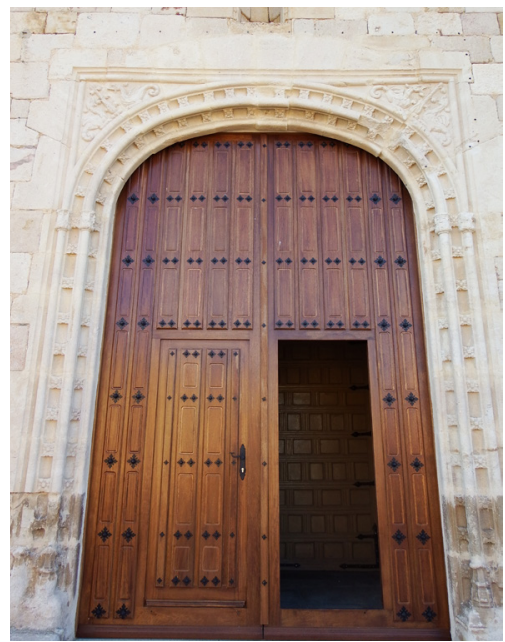

Fig. 183. Portada sur de la iglesia parroquial de Morales del Vino 


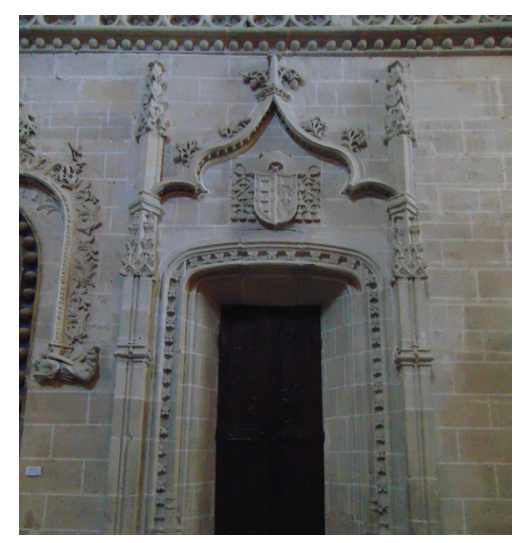

Fig. 184. Puerta en el trascoro de la catedral de Zamora

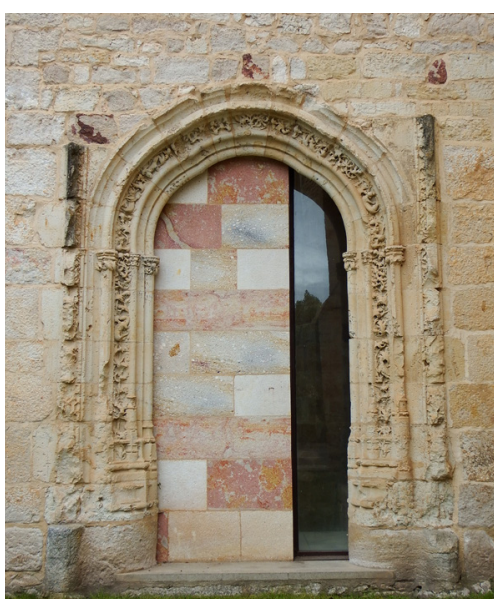

Fig. 185. Puerta de la capilla del Deán en el convento de San Francisco. Zamora

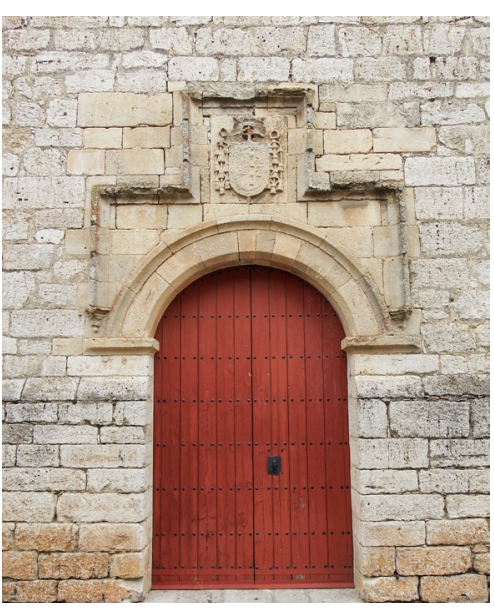

Fig. 186. Portada de la iglesia de San Sebastián de los Caballeros. Toro la pervivencia de este estilo es en el sistema de cubierta que se utilizó principalmente y que no fue otro que la bóveda de crucería.

La bóveda de crucería, cuyo trazado en este momento se enriquece respecto a las bóvedas del periodo anterior mediante terceletes y otros nervios secundarios o de ligadura, fue empleada para cubrir espacios diferentes tales como cabeceras, capillas y pórticos. Presentan una cierta variedad en su diseño y algunas de ellas están dotadas de una gran originalidad en la organización de las nervaduras. Pero quizá lo que confiere homogeneidad a todas ellas sea la característica disposición de las molduras de sus nervios de forma triangular, consistente en dos molduras cóncavas continuadas de desigual tamaño que se estrechan hasta concluir en un vértice achaflanado. Es el tipo de molduración que, como ya hemos dicho, se generalizó en la arquitectura zamorana del gótico tardío y cuyo uso se prolongó durante gran parte del siglo XVI con ligeras variantes y que delata la construcción tardía de muchas bóvedas cuyo trazado venía utilizándose desde hacía siglos. Los formeros, que alivian a los muros del peso de la bóveda, tienen el mismo diseño y mantienen, en la mayoría de los casos, un perfil apuntado. No obstante, en los más tardíos se fue optando progresivamente por un trazado en arco de medio punto.

Este diseño que presentan los sistemas abovedados levantados en esta época en la provincia de Zamora, fue también empleado de forma idéntica en el desarrollo de un número limitado de arcos de acceso a la capilla mayor, como es el caso de los correspondientes a las iglesias de la Asunción de Morales del Vino y de San Martín de Tours de Peñausende y también del que comunica la nave del Evangelio con su capilla correspondiente en iglesia de Santa María Magdalena de Corrales del Vino.

Por lo que se refiere al trazado de las bóvedas, la tipología comprende desde el tipo más sencillo en el que solamente se utilizan los nervios cruceros, hasta las bóvedas de crucería enriquecidas con combados. También a finales del siglo XV y principios del XVI se utilizaron una serie de bóvedas en la catedral y en la iglesia de San Ildefonso (Zamora) cuyos nervios no se cruzan en el centro y en las que podemos observar diseños 
realmente interesantes. Por último, al final de este periodo cronológico en el que se desarrolla la arquitectura gótica tardía aparecieron las primeras bóvedas con nervios combados.

\section{Crucería simple}

En este marco, el tipo de bóveda más elemental como acaba de señalarse es la bóveda de crucería simple, cuyo cruzamiento de nervios, en varias ocasiones, está ornado con una clave muy sencilla. La encontramos, por lo general, cubriendo espacios reducidos y sencillos $y$, en algunas ocasiones, simplemente pequeños habitáculos de uso indeterminado, como es el caso de los ubicados en la catedral en torno a la cabecera y, con clara función de capilla funeraria, como sucede en los conservados en la iglesia de Santiago del Burgo y de San Leonardo (Figs. 190 y 191). Este tipo de bóveda compuesta únicamente de nervios cruceros también fue utilizado en ámbitos de mayor entidad como son las capillas del Evangelio y de la Epístola de la iglesia toresana de Santo Tomás Cantuariense y en las cabeceras de las iglesias parroquiales de Pereruela y Mogátar así como en el primer tramo de la nave de la parroquial de Malillos (Figs. 192 y 193). La base fundamental para la datación tardía de estas bóvedas de trazado simple cuando se carece de documentación es la sección de sus nervios.

Durante este periodo también se utilizó la bóveda octopartita de la que contamos con dos ejemplos. La primera de ellas se encuentra cubriendo la sacristía de la capilla de San Juan Evangelista o del doctor Grado de la catedral de Zamora. La segunda cubre la cabecera de la iglesia parroquial de Malillos (Figs. 194 y 195). En este último caso, los nervios de ligadura, que

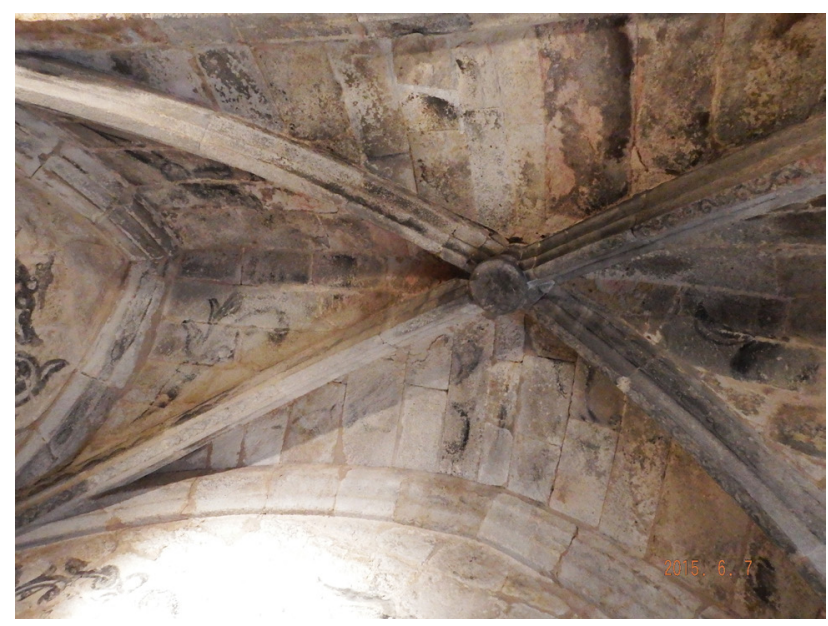

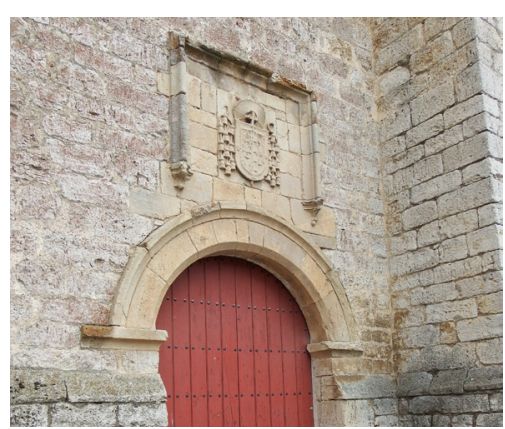

Fig. 187. Portada de la iglesia de San Sebastián de los Caballeros. Toro

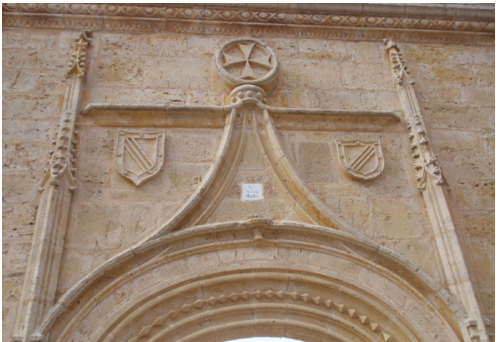

Fig. 188. Detalle de la antigua portada de la iglesia parroquial de Villar de Fallaves

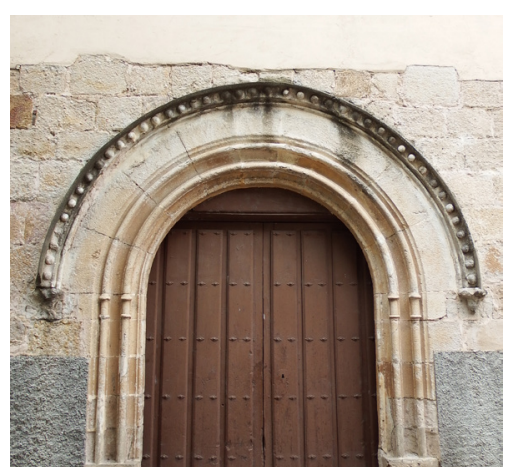

Fig. 189. Actual portada de acceso a las huertas del convento de Santa Marina. Zamora 


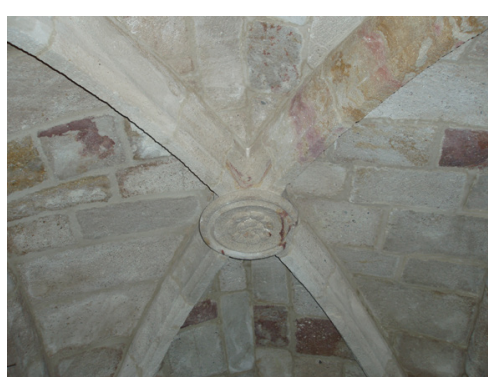

Fig. 191. Bóveda de la cabecera de la nave norte de la iglesia de San Leonardo Zamora

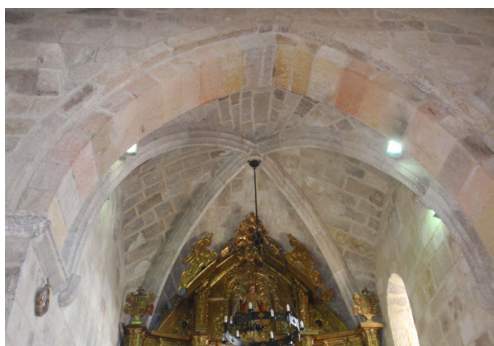

Fig. 192. Bóveda de la cabecera de la iglesia

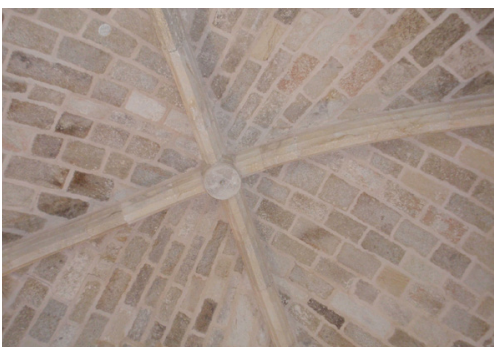

Fig. 193. Bóveda de la cabecera de la iglesia parroquial de Mogátar

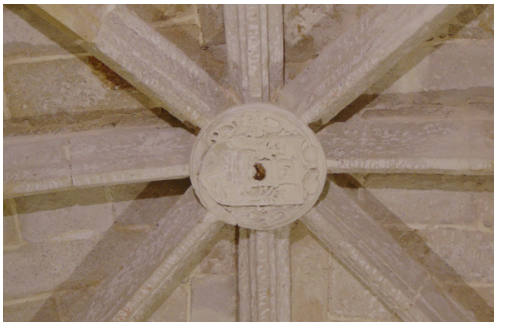

Fig. 194. Bóveda de la sacristía de la capilla de San Juan Evangelista. Catedral de Zamora habitualmente mueren en la clave de los formeros, desembocan sobre el propio muro.

\section{Bóvedas de terceletes}

La aparición de los terceletes dio lugar a una bóveda de crucería que se convirtió en el tipo más comúnmente utilizado desde finales del siglo XV en la arquitectura religiosa de la ciudad de Zamora y su provincia, prolongándose su uso, en buena medida, durante gran parte del siglo XVI, en algunos casos, con ligeras variantes. Este tipo se empleó para cubrir la capilla de los Ocampo en el convento de San Francisco (Zamora), la antesacristía y la sacristía vieja de la catedral de Zamora, la capilla de la Virgen de Fátima de la iglesia de San Vicente (Zamora), la capilla del Chantre de la iglesia de San Félix en El Perdigón, la cabecera de la iglesia de San Martín de Tours de Peñausende, la capilla mayor de la iglesia de Santo Tomás Cantuariense en Toro y los dos tramos de la nave y la cabecera de la iglesia de San Sebastián de los Caballeros también en Toro (Figs. 196, 197 y 198). En el caso concreto de la capilla de los Ocampo del convento de San Francisco se utilizaron nervios de ligadura que unen las claves de los terceletes con las claves de los formeros (Fig. 199). El uso de esta particularidad, que no presenta ninguna de las restantes bóvedas citadas, fue frecuente durante el segundo cuarto del siglo XVI en las bóvedas de crucería con terceletes que cubren algunas cabeceras de iglesias situadas en la comarca de Benavente y los Valles.

Este tipo de bóveda de crucería con terceletes y cinco claves se encuentra por vez primera según señaló ya el arquitecto francés Viollet le Duc cubriendo el crucero de la catedral de Amiens $(c a .1260-1270)^{233}$. En España hubo que esperar un tiempo de tal modo que según Gómez Martínez es probable que la primera bóveda de este tipo que se ha conservado sea la que cubre el crucero de la catedral de Toledo, muy probablemente levantado durante la segunda mitad del siglo XV. El mismo estudioso señala la bóveda trazada por Egas Coeman para el lucillo funerario de Alonso de Velasco en el monasterio cacereño de Guadalupe (ca.1467) como la más antigua de este tipo en España de la que se

233 Recogido por Gómez Martínez en GÓMEZ MARTÍNEZ, J., op. cit., 1998, p. 80. 
tiene documentación ${ }^{234}$. En Zamora y provincia a excepción de la bóveda que cubre la capilla de los Ocampo en el convento de San Francisco y que plantea serias dudas en cuanto a su cronología, pues podría situarse a finales del XV-principios del XVI, el resto de las bóvedas que se han conservado de crucería con terceletes y cinco claves fueron levantadas en el siglo XVI.

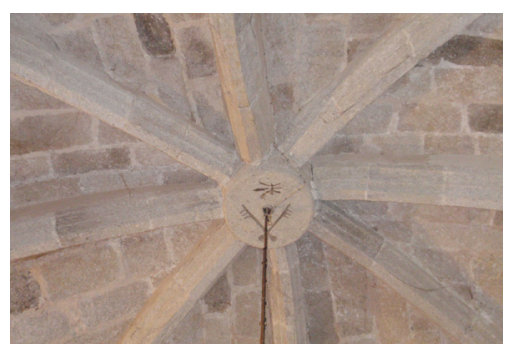

Bóvedas sin cruceros y con figuras poligonales en el centro

Hacia 1500 comienza a aparecer en Zamora una serie de bóvedas de crucería, de trazado más complejo $-y$, en cierto modo, original, para lo que se venía haciendo en la ciudad y en la provincia-cuya particularidad es que, en ellas, los nervios cruceros son sustituidos por dobles nervios que se abren y forman en el espacio central de la bóveda un cuadrado o un rombo. Contamos con ejemplos sencillos pero muy bien planteados como las bóvedas de la capilla de San Ildefonso en la catedral de Zamora ${ }^{235}$, en las que la desaparición de la clave polar da lugar a un grupo de claves secundarias en torno a un espacio central despejado (Figs. 200 y 201). Existen también diseños más complejos en los que se mantiene igualmente una figura geométrica en el centro pero, en este caso, atravesada por los nervios de ligadura que se cruzan en el centro, marcado por una clave. A esta última modalidad responden las bóvedas de las capillas laterales de la cabecera de la catedral y las bóvedas de la nave de la iglesia de San Ildefonso (Zamora). Idéntico diseño al que observamos en las bóvedas de las capillas laterales de la catedral zamorana tiene la capilla hornacina del lado del Evangelio del convento de Santo Tomás de Ávila, que se viene atribuyendo a Juan Guas²36. También diseño muy parecido a éstas últimas mencionadas, aunque en este caso carente de contraterceletes, tiene la capilla hornacina del lado del Evangelio del monasterio jerónimo de Santa María del Parral, obra que, una vez más, se debe a Guas.

234 Ídem, p. 79, fig. 126 y p. 80.

235 De idéntico trazado a la bóveda correspondiente al tramo del testero de la capilla de San Ildefonso de la catedral de Zamora es la bóveda que cubre el ábside de la iglesia de Santa María del Azogue de Puebla de Sanabria, aunque en este último caso la bóveda es probable que corresponda ya al segundo cuarto del siglo XVI. La única diferencia existente entre ambas es que la primera se adapta a una planta cuadrangular mientras que la segunda lo hace a un polígono.

236 GÓMEZ MARTÍNEZ, J., op. cit., 1998, p. 158.

Fig. 195. Bóveda de la cabecera de la iglesia parroquial de Malillos

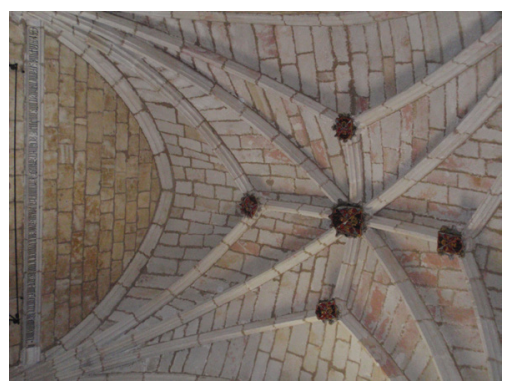

Fig. 196. Bóveda de la capilla del Chantre en la iglesia parroquial de El Perdigón

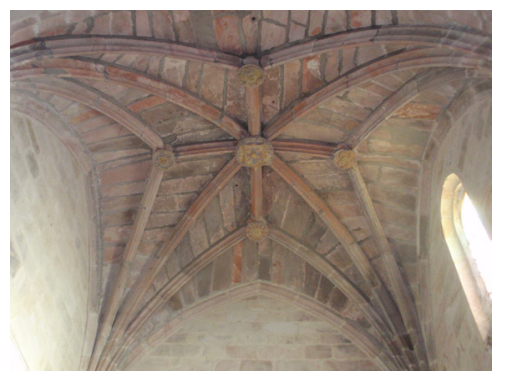

Fig. 197. Bóveda de la capilla mayor de la iglesia parroquial de Peñausende

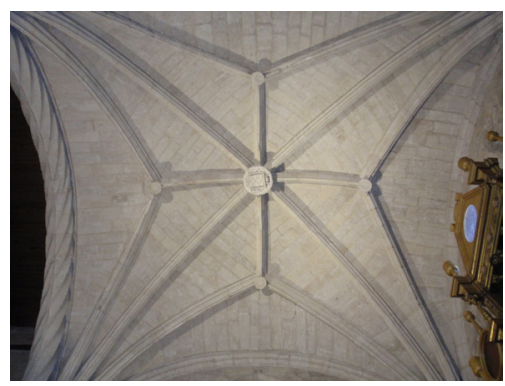

Fig. 198. Bóveda de la capilla mayor de la iglesia de Santo Tomás. Toro 


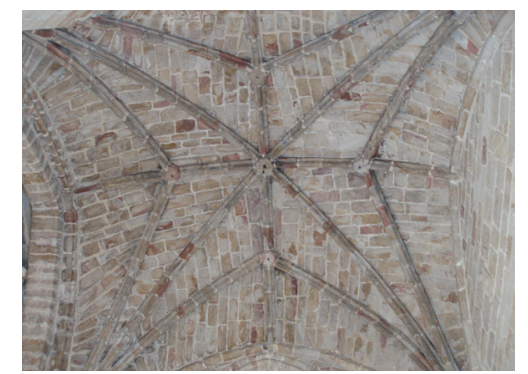

Fig. 199. Bóveda de la capilla de los Ocampo en el convento de San francisco. Zamora
En este mismo grupo se puede incluir también la bóveda que cubre la capilla del Evangelio de la iglesia de Corrales del Vino. Como en las anteriores, los nervios no se cruzan en el centro, sino que forman un diseño geométrico irregular y complejo (Fig. 202). De todos modos es probable que esta bóveda fuera construida algún tiempo después pero todavía dentro del primer tercio del siglo XVI.

Este tipo de diseño de bóveda de crucería es de procedencia centroeuropea, donde comenzó a utilizarse a partir de mediados del siglo XIV dentro de las nuevas modalidades de abovedamiento propias del gótico tardío en las que los nervios cruceros tienden a desaparecer cobrando importancia los terceletes que dejan desahogado el centro de la bóveda evitando la clave central. Es un tipo de bóveda que parece relacionada con la actuación de la familia de los Parler durante la segunda mitad del siglo XIV y como referencia pueden servir las bóvedas de la catedral de
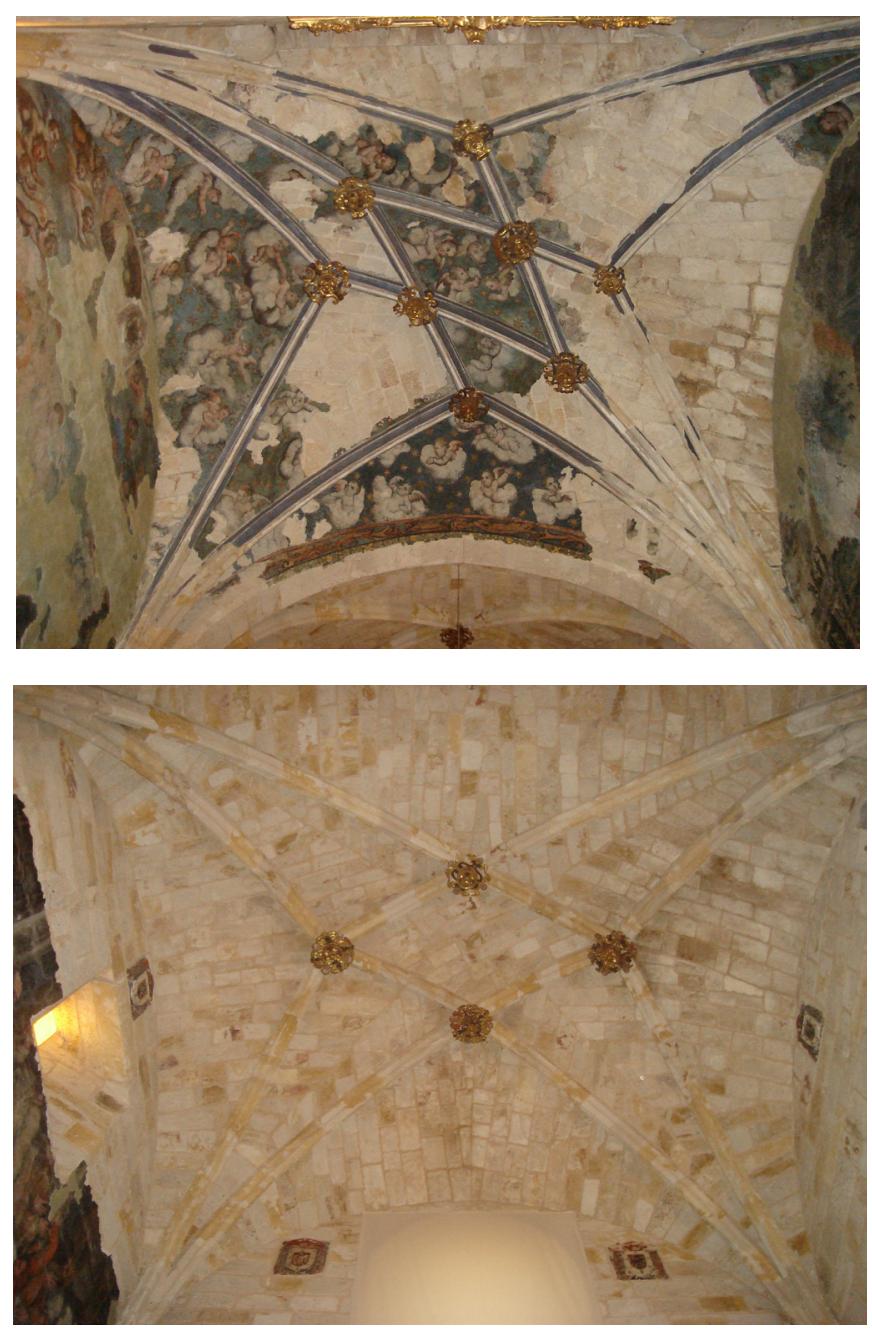


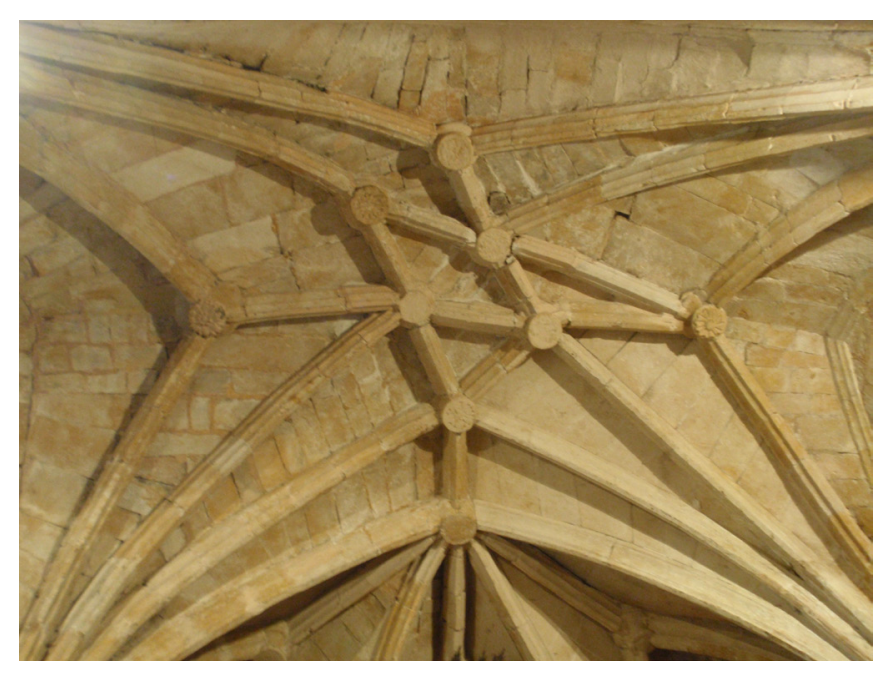

Praga, obra de Peter Parler. Esta forma se mantiene y continúa en uso a lo largo del siglo XV y buena parte del XVI, como se recoge en esquemas contenidos en libros de cantería alemanes y en dibujos del propio Alberto Durero ${ }^{237}$.

La introducción en España es un poco más tardía y por lo que se conoce hasta ahora fue el arquitecto Juan Guas y su círculo más cercano quienes contribuyeron a su implantación. Juan Guas trabajó durante veinte años en la catedral de Segovia que se encontraba situada junto al Alcázar y de la que solamente se ha conservado su claustro que fue trasladado en el año 1524 al lugar donde se levanta el actual edificio catedralicio diseñado por los Hontañón ${ }^{238}$. En el ángulo NO del claustro segoviano se conserva una bóveda prácticamente idéntica a la que cubre el primer espacio de la capilla de San Ildefonso de la catedral de Zamora (Fig. 203). Existe, no obstante una pequeña diferencia entre la citada bóveda de Segovia y la zamorana ya que esta última carece de las dos ramas centrales en una de las diagonales. Para Javier Gómez Martínez, que ha estudiado las bóvedas de crucería en el gótico español durante la Edad Moderna, no cabe duda de que este trazado, utilizado por vez primera en España por Juan Guas, responde a modelos europeos que se mantienen hasta el último tercio del siglo XVI como queda patente en el Steinmetzbuch o libro de cantería conocido como "Álbum de Francfort" donde aparece recogido ${ }^{239}$. El mismo Gómez Martínez afirma que este 237 GÓMEZ MARTÍNEZ, J., op. cit., 1998, pp. 81 y 83.

238 Acerca de la vinculación de Juan Guas con la catedral de Segovia véase LÓPEZ DÍEZ, María B., "Juan Guas en la Catedral de Segovia", Archivo español de arte, tomo 79, nº 315, 2006, pp. 299-306.

239 GÓMEZ MARTÍNEZ, J., op. cit., 1998, pp. 83-84.
Fig. 202. Bóveda de la capilla del Evangelio de la iglesia parroquial de Corrales del Vino. Zamora

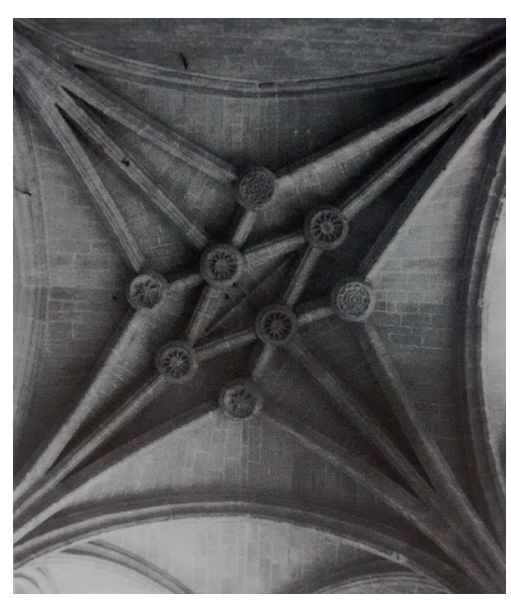

Fig. 203. Bóveda del claustro de la catedral de Segovia

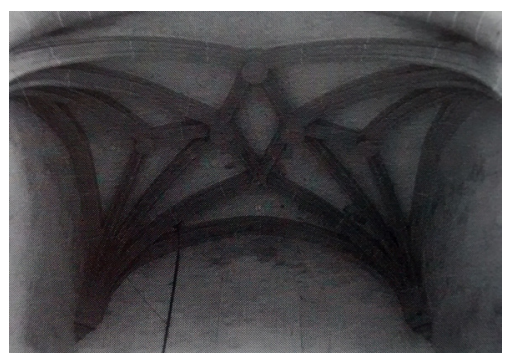

Fig. 204. Bóveda de la iglesia conventual de San Francisco. Medina de Rioseco 
trazado solamente cuenta con otro ejemplo en España localizado lógicamente en la órbita toledana, en concreto cubriendo uno de los tramos occidentales de la iglesia de San Juan Bautista en Auñón, provincia de Guadalajara ${ }^{240}$. En este trabajo aportamos un nuevo ejemplo de este tipo tan interesante y tan escaso en la arquitectura española.

Una variante de este tipo de bóveda en las que la desaparición de la clave polar da lugar a un grupo de claves secundarias en torno a un espacio central despejado se encuentra en el segundo tramo de la citada capilla de San Ildefonso de la catedral zamorana. Como en el caso anterior también hay que relacionarlo directamente con Juan Guas que lo utilizó asimismo en el claustro del convento toledano de San Juan de los Reyes. No obstante, Guas crea un cuadrado central con un giro de 45 grados como consecuencia de la bifurcación de las ogivas en ángulo recto mientras que en el caso de la bóveda de la capilla de San Ildefonso la figura creada en el centro en torno al polo es un rombo. La base de este último diseño fue utilizada y enriquecida por Juan de Badajoz el Viejo en el pórtico occidental de la catedral de Oviedo. El modelo fue de nuevo utilizado en Castilla, en este caso por Juan Gil de Hontañón y es lógico pensar que este maestro lo retomaría probablemente con ocasión de la edificación de la nueva catedral de Segovia y, sobre todo, con

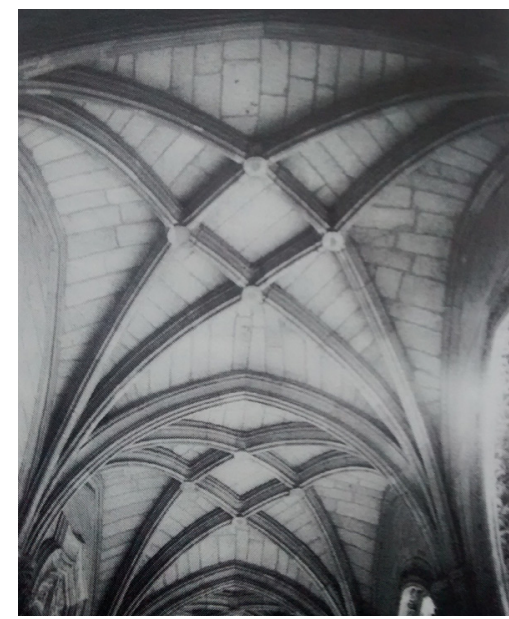
Fig. 205. Bóvedas del claustro de San Juan de los
Reyes. Toledo el conocimiento que a este maestro le proporcionó el claustro antiguo de la citada catedral. Concretamente se sirvió de este diseño, aunque añadió terceletes en dos de los laterales, en la iglesia conventual de San Francisco de Medina de Rioseco (Fig. 204) en la provincia de Valladolid (entre 1491 y 1520) y, con algunas variantes, nuevamente recurrió a él en el claustro de la catedral de Palencia (1505-1516) ${ }^{241}$.

La cronología de estas bóvedas está supeditada a los maestros citados. No conocemos modelos previos a los utilizados por Juan Guas, con lo que habría que acudir a las fechas que aporta la bóveda del ángulo NO del claustro de la catedral de Segovia, donde trabajo desde 1472 hasta 1491 y las bóvedas del claustro de San Juan de los Reyes en Toledo (Fig. 205), del último cuarto

240 Ídem, p. 83.

241 GÓMEZ MARTÍNEZ, J., op. cit., 1998, pp. 83 y 85. 
del siglo XV, para tener una referencia antequem. La actividad de Juan de Badajoz el Viejo en Oviedo tuvo lugar entre 1500-1512 y según la cronología aceptada por Javier Gómez las bóvedas de este tipo realizadas por Juan Gil de Hontañón en Medina de Rioseco se fechan entre 1491 y 1520 y las del claustro de la catedral de Palencia entre 1505 y 1516. Si a esto añadimos los elementos renacentistas que presentan las claves de las bóvedas de la capilla de San Ildefonso en ningún caso podríamos hablar, para las bóvedas zamoranas de este modelo, de una fecha anterior a finales del siglo $\mathrm{XV}$ y, muy probablemente, en torno ya a 1500 .

Bovedas complejas de terceletes con nervaduras rectas

Los diseños más ricos de bóvedas de nervios rectos son aquellas en las que el esquema básico de crucería con terceletes se ve enriquecido por la presencia de otros nervios secundarios que dibujan figuras más o menos complejas. Están relacionadas con algunas del grupo anterior, como las que cubren las capillas

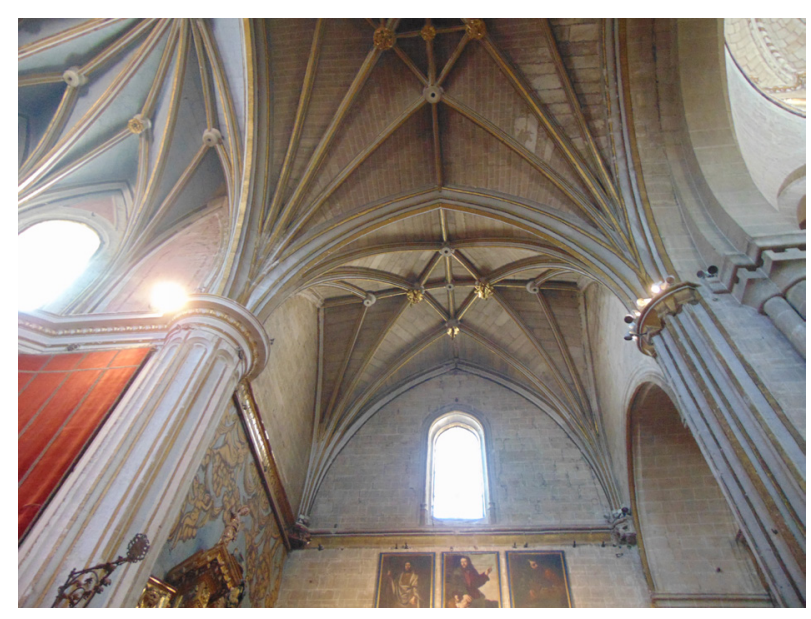

laterales de la cabecera de la catedral de Zamora y el ábside central y la nave de la iglesia de San Ildefonso (Zamora), ambas obras patrocinadas por el obispo Meléndez Valdés, y que, aunque muy semejantes a las de este grupo, carecen de nervios cruceros (Figs. 206 y 207).

La bóveda que cubre el tramo presbiterial de la cabecera de la catedral es el ejemplo más sobresaliente de este tipo (Fig. 208). Está configurada mediante nervios cruceros, nervios de ligadura 


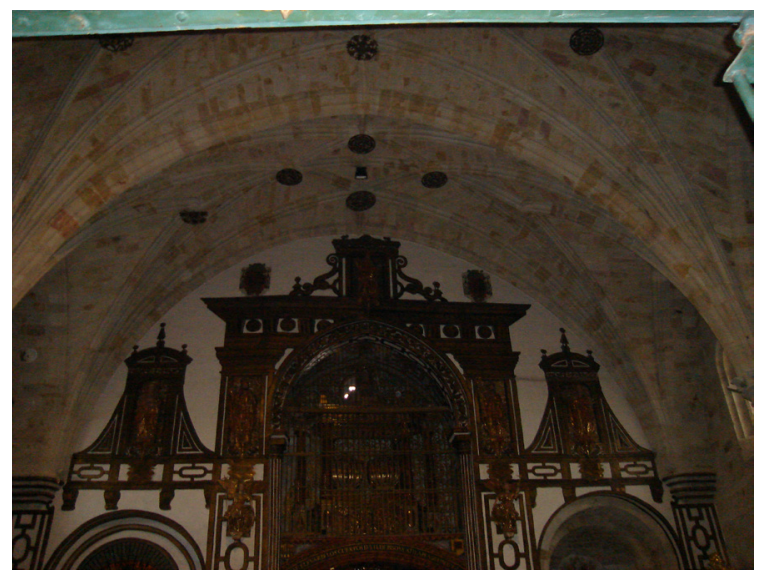

y otros nervios secundarios de trazado recto que enlazan los nervios cruceros, dibujando un cuadrado en torno a la clave polar y, otro, tangente a los vértices del anterior, que lo dobla en superficie y que une las claves de los terceletes ${ }^{242}$. En la provincia se utilizó, años después, un esquema similar a este que cubre el tramo presbiterial de la catedral de Zamora para cubrir el crucero de la iglesia parroquial de Villamor de los Escuderos, cuya traza se debe a Juan Gil de Hontañón. No obstante, en este caso de Villamor de los Escuderos se utilizaron ya nervios combados.

Nuevamente habría que vincular este diseño con el maestro Juan Guas. Así, la duplicación y rotación del cuadrado tal y como lo vemos en el tramo recto central de la capilla mayor de la catedral de Zamora fue utilizado por el propio Guas en el claustro de la catedral de Segovia cerrado en 1479 y en el cimborrio del

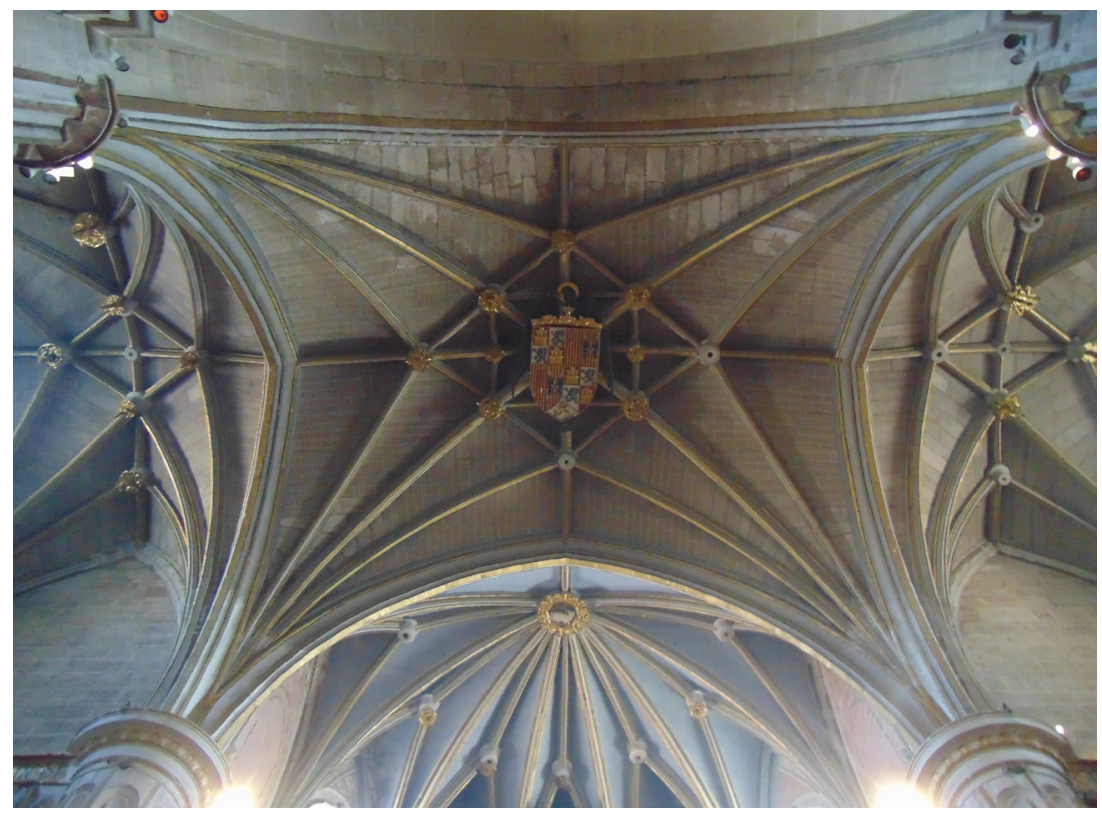

242 Véase la ficha correspondiente a la catedral de Zamora en la que se hace una valoración del origen de este diseño y se apunta su posible autor. 
convento toledano de San Juan de los Reyes que debía estar cerrado en $1486^{243}$. Con posterioridad, lo vemos también en la capilla mayor del hospital de San Sebastián de Córdoba (15131526) atribuida a Simón de Colonia. Igualmente fue utilizado, como se ha señalado, por Juan Gil, cuya dependencia del propio Guas y de su taller está fuera de toda duda.

Tiempo después Rodrigo Gil de Hontañón utilizaría con cierta frecuencia estos diseños empleados en las bóvedas de la cabecera de la catedral de Zamora. Por ejemplo en la iglesia de San Pedro ad Víncula de Villavieja (Salamanca), datada a partir de 1550 y cuya fábrica se atribuye desde antiguo a este maestro ${ }^{244}$. Concretamente es el tramo presbiterial de este templo el que está cubierto con una bóveda de diseño idéntico al utilizado en el mismo espacio de la Catedral.

En la capilla que se prolonga hacia el sur en la iglesia de Santa María del Castillo de Montamarta se utilizó una bóveda de crucería con terceletes a la que se añadieron unos nervios rectos que forman un octógono en torno a la clave central (Fig. 209). Este mismo diseño, pero con las nervaduras que forman el octógono flexionadas, llegaría a tener poco tiempo después una enorme presencia en nuestra arquitectura. En la provincia de Zamora se utilizó por ejemplo a mediados del siglo XVI para cubrir el crucero de la iglesia de Santa María del Azogue en Puebla de Sanabria (Fig. 210).

En alguna de estas bóvedas el tercelete se desvirtúa porque la ligadura que va a la clave se bifurca en dos dando lugar a un complejo diseño geométrico como ocurre en la bóveda de la capilla de la epístola de la iglesia parroquial de Corrales del Vino. Esta bifurcación del nervio que debería unir la clave del tercelete será una forma generalmente adoptada en las bóvedas de combados.

Dentro de este mismo tipo de bóveda compuesta por nervaduras únicamente rectas y con nervios cruceros, contamos también con un diseño más sencillo que se encuentra cubriendo el pórtico que se añadió en el lado sur de la iglesia de la Asunción

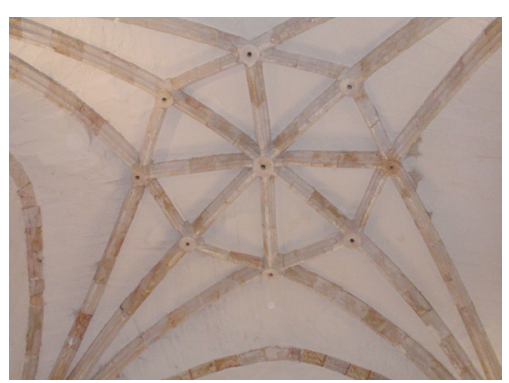

Fig. 209. Bóveda de la capilla meridional de la iglesia de Santa María del Castillo. Montamarta

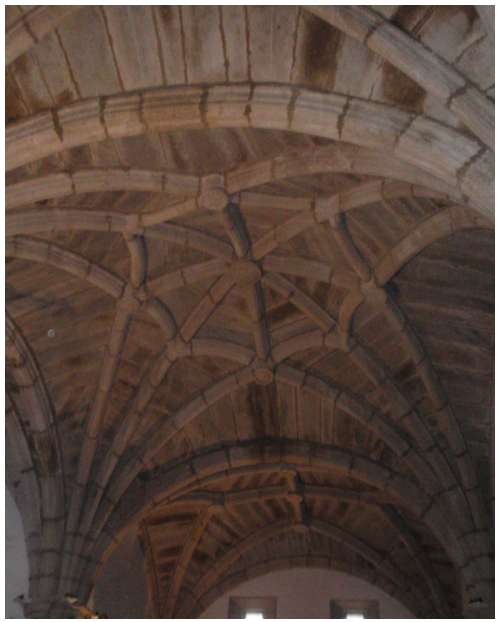

Fig. 210. Bóveda del crucero de la iglesia de Santa

María del Azogue. puebla de Sanabria

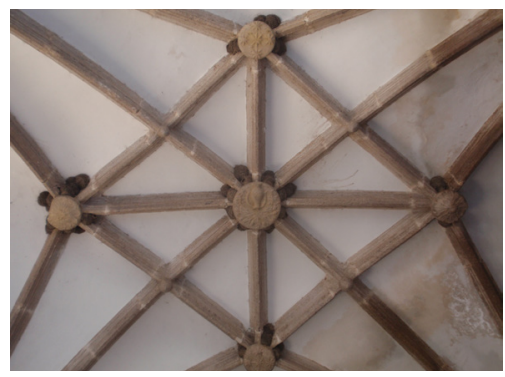

Fig. 211. Bóveda del pórtico de la iglesia parroquial de Fermoselle

243 GÓMEZ MARTÍNEZ, J., op. cit., 1998, p. 72, fig. 105. 


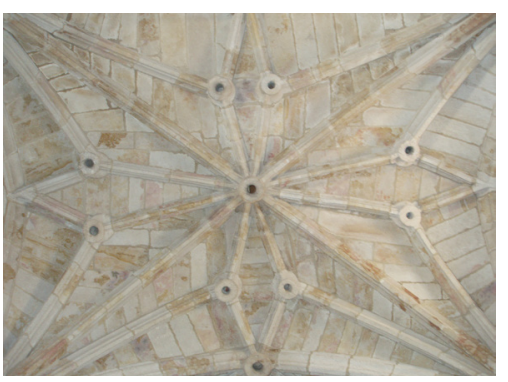

Fig. 212. Bóveda de la cabecera de la iglesia de San Leonardo. Zamord

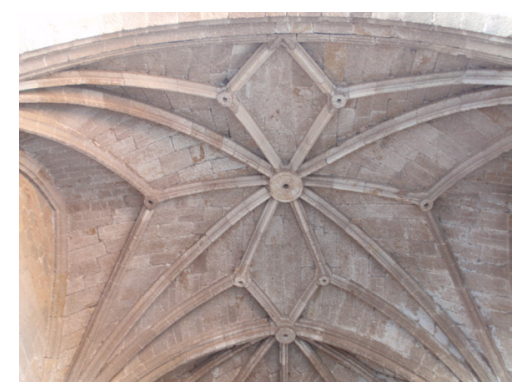

Fig. 213. Bóveda del pórtico sur de la iglesia parroquial de La Hiniesta de Nuestra Señora de Fermoselle (Fig. 211). Se trata de una bóveda de crucería con terceletes, cuyas claves están unidas por nervios secundarios rectos que forman un cuadrado en torno a la clave polar. Este cuadrado central está dividido a su vez por ligaduras que parten de las claves de los terceletes. Esta bóveda fue realizada durante el primer tercio del siglo XVI.

Por último hay que señalar que, al menos en la provincia de Zamora, mientras que las bóvedas de terceletes se mantuvieron a lo largo de mucho tiempo durante el siglo XVI, los diseños de nervaduras rectas no se prolongaron más allá del primer tercio de ese mismo siglo.

\section{Bóvedas estrelladas}

Existen dos bóvedas con una composición puramente estrellada y de diseño muy semejante. En ellas quedan perfectamente delimitadas por un gran arco la bóveda que cubre el tramo recto de la que hace lo propio con el cierre poligonal. La primera de estas bóvedas corresponde a la cabecera de la iglesia de San Leonardo (Zamora) y la segunda al pórtico que se añadió en el sur de la iglesia de Santa María la Real de la Hiniesta (Figs. 212 y 213). En ambos casos la parte correspondiente al polígono está dividida en planta en tres triángulos equiláteros con un abovedamiento en terceletes cada uno de ellos. En el tramo recto observamos una diferencia, y es que mientras en la iglesia de San Leonardo la bóveda está dividida por los nervios cruceros en cuatro espacios triangulares con dos bóvedas de terceletes cada uno de ellos, en La Hiniesta, cuya bóveda está igualmente dividida, presenta solamente los dobles terceletes en los laterales mayores y solamente uno en los menores. Como ejemplos de bóvedas con un esquema muy parecido a las mencionadas podemos citar las que cubren las cabeceras de las iglesias de El Salvador de La Poveda en la provincia de Soria y de Nuestra Señora de la Asunción de Cogeces del Monte en la provincia de Valladolid, edificadas ya avanzado el siglo XVI.

Bóvedas de ábside 
El empleo en la provincia de Zamora del ábside poligonal cubierto por bóveda de crucería fue bastante habitual y más concretamente el uso de la bóveda de crucería estrellada formada por la compartimentación mediante terceletes de las bovedillas generadas entre los nervios que convergen en la clave.

El ábside de mayor riqueza es el correspondiente a la catedral de Zamora, dividido en siete paños con sus correspondientes siete bovedillas internas con un tercelete cada una de ellas (Fig. 214). En este caso existe una nota distintiva respecto a los demás ábsides conservados y es que los nervios principales no

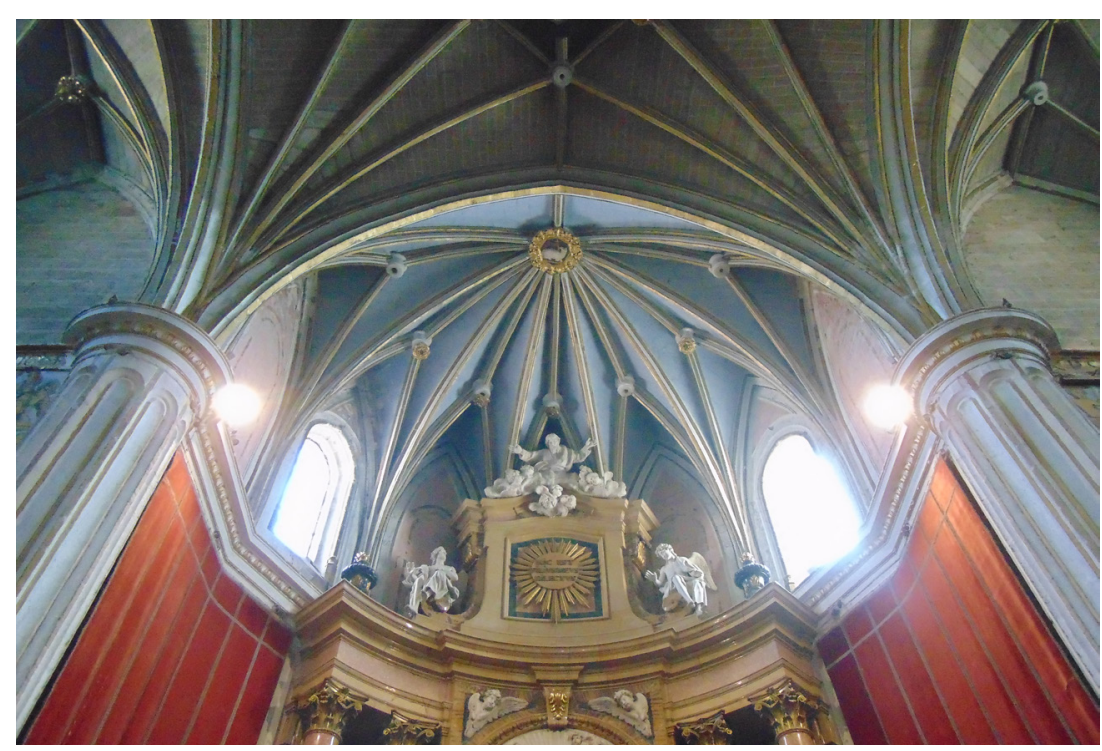

convergen en la clave principal del arco de separación con el tramo presbiterial, como ocurre en otros ejemplos de la provincia como en la iglesia de San Leonardo (Zamora) y en la parroquial de La Hiniesta, que salvo esta particularidad en lo demás son del todo semejantes al catedralicio.

Existen, no obstante, casos especiales en cuanto que tienen diseños únicos. El primero lo encontramos en la bóveda que se levantó en la iglesia de San Ildefonso durante el obispado de Melendez Valdés para dividir en dos alturas el ábside románico (Fig. 215). Se trata de una pequeña bóveda con un diseño muy particular que contiene nervios cruceros que dan lugar a una clave central bien definida. Otra serie de nervios crean claves secundarias al cruzarse con los cruceros. Por último existen otros nervios que mueren al topar con los cruceros creando una clave en ese mismo lugar. Todas estas nervaduras apean en ménsulas
Fig. 214. Bóveda de la capilla mayor de la catedral de Zamora

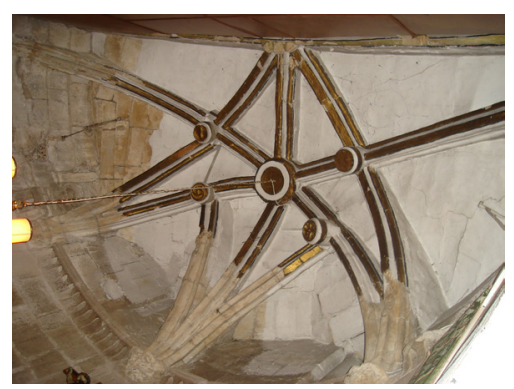

Fig. 215. Bóveda en el ábside de la iglesia de San lldefonso. Zamora 


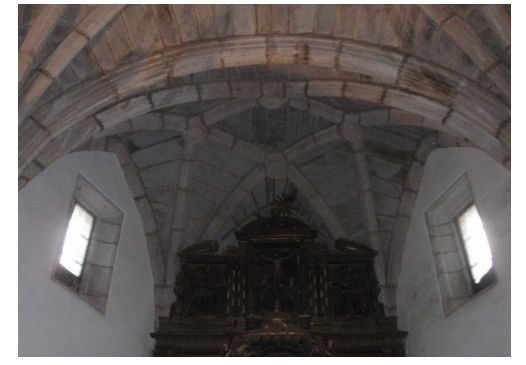

Fig. 216. Bóveda de la capilla mayor de la iglesia parroquial de Puebla de Sanabria con decoración gótica situadas sobre un friso clásico de estrías. El otro caso se corresponde con el diseño de la bóveda que cubre el ábside de Villamor de los Escuderos donde se ha utilizado un esquema semejante al de las bóvedas de la capilla de San Ildefonso de la catedral de Zamora y, más concretamente, al ábside de la iglesia parroquial de Puebla de Sanabria (Fig. 216). No obstante, en el caso de Villamor de los Escuderos existe un nervio de espinazo que va desde la clave del arco triunfal hasta la parte central del testero del ábside cruzando de este modo la figura romboidal que se crea en la parte central de la bóveda y no dejándola libre como ocurre en los ejemplos citados de la catedral y Puebla de Sanabria.

Por último, si bien la capilla de la epístola de Corrales del Vino podría incluirse dentro de esta modalidad, las que cubren la capilla mayor y nave del evangelio de la misma iglesia forman un todo con la bóveda del tramo presbiterial de modo que se incluyen en el apartado siguiente.

\section{Fusión de bóvedas de ábside y tramo presbiterial}

A la vez que se realizan los diseños que acabamos de señalar encontramos otras bóvedas en las que se origina una fusión entre el trazado de la bóveda del ábside y el tramo presbiterial. En esta interferencia se producen múltiples variantes en las que aparecen diseños complejos en torno a la clave polar.

Dentro de este tipo de bóvedas hay que señalar especialmente dos ejemplos en los que esta fusión de la bóveda del ábside

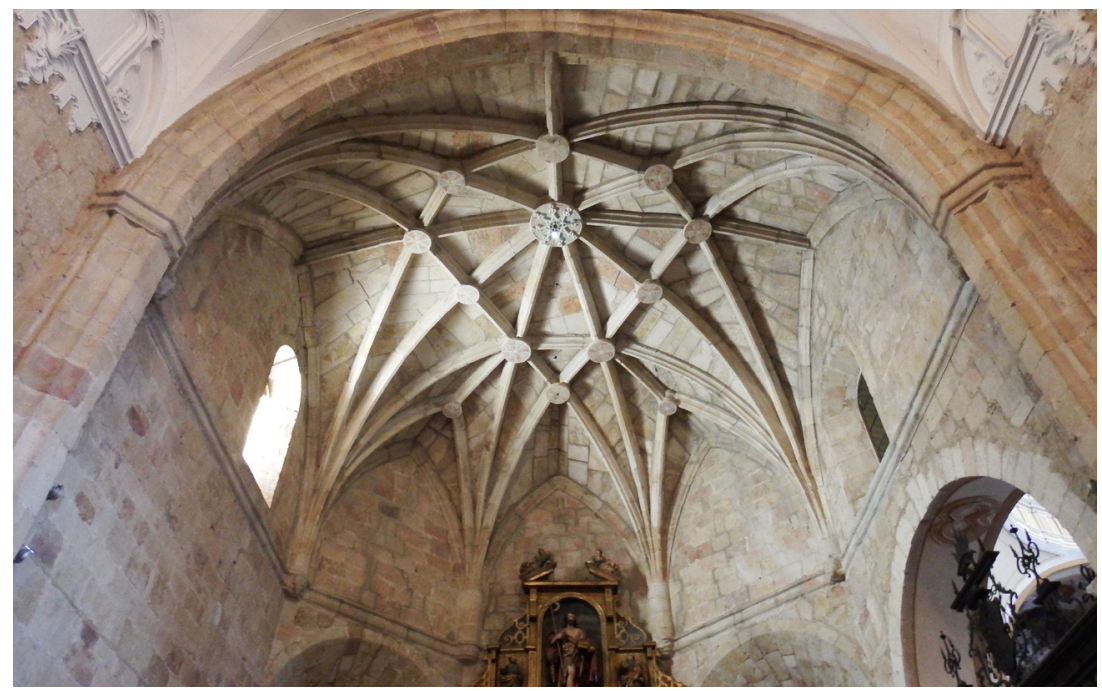




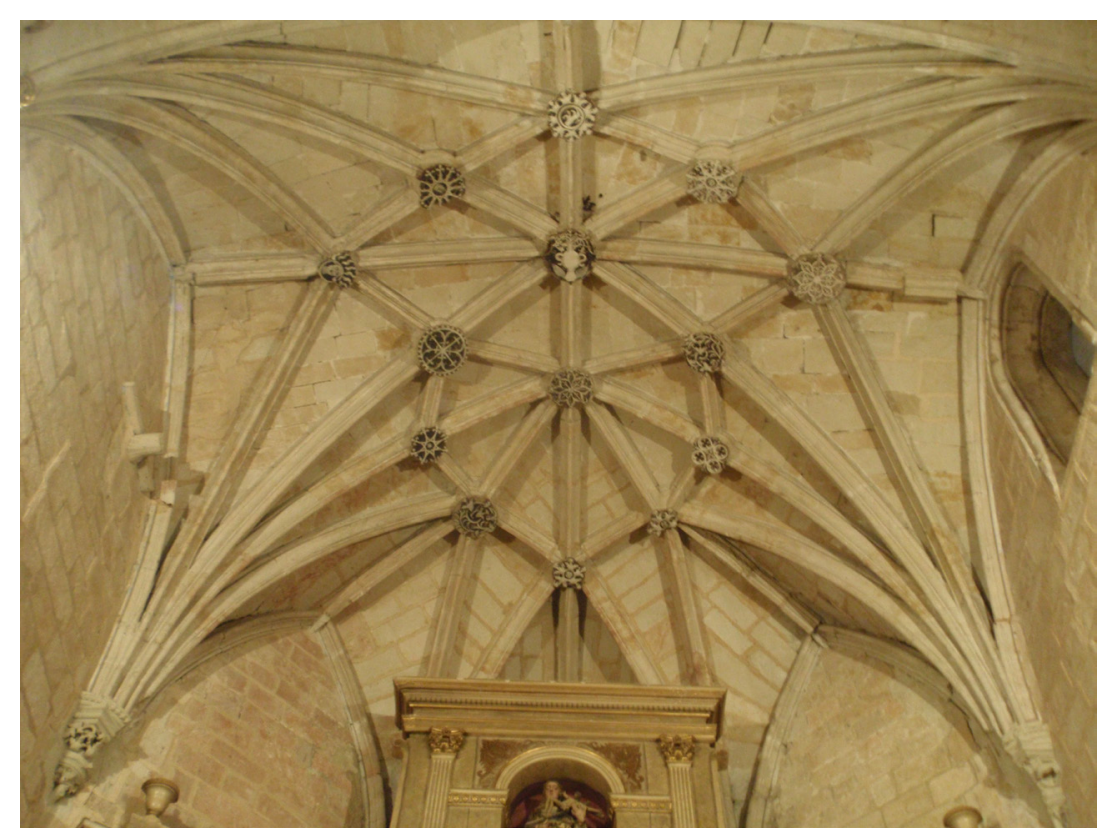

con la del tramo presbiterial da lugar ópticamente a un diseño común. Esto es especialmente visible en las capillas mayores de las iglesias parroquiales de Morales del Vino y de Corrales del Vino así como también en la capilla del Evangelio de esta última, si bien este caso podría clasificarse también como bóveda de ábside.

Por lo que respecta a las capillas mayores de Morales del Vino y de Corrales del Vino las nervaduras son rectas y con diseños complejos a partir de un esquema de crucería estrellada con ligaduras a las claves de los formeros y figuras poligonales en torno a la clave central configuradas mediante nervios rectos (Figs. 217 y 218 ).

Ambos casos responden a construcciones de época de los Reyes Católicos y se pueden fechas en los primeros años del siglo $\mathrm{XVI}$.

\section{Bóvedas de combados}

El tipo más evolucionado de bóveda de crucería en la provincia de Zamora es el que incorpora ya nervios combados. Es complejo establecer mediante una cronología concreta el momento en el que en España se introdujeron los nervios curvos en la bóveda de crucería ${ }^{245}$. Durante el último cuarto del siglo XV es probable

245 Aunque algunos autores denominan combados a los nervios rectos que dibujan una figura poligonal generalmente en torno a la clave central nosotros utilizaremos el término combado para referirnos exclusivamente a los nervios curvos. Los diccionarios
Fig. 218. Bóveda de la capilla mayor de la iglesia parroquial de Corrales del Vino 
que se realizaran algunas bóvedas en las que pudo incluirse algún elemento curvo como es el caso de las bóvedas de la nave de la iglesia de San Vicente de Plasencia, consagrada en 1487, en las que aparece un pequeño círculo alrededor de la clave central ${ }^{246}$. El espacio que sirve de atrio a la actual capilla del Condestable de la catedral de Burgos está cubierto por una bóveda de crucería con nervios combados que dibujan una especie de burbuja en torno a la clave central. Rico Santamaría ${ }^{247}$ la considera concluida antes de 1488. Elena Martín ${ }^{248}$ señala que es de suponer que se trate de la primera bóveda con nervios combados en una construcción burgalesa cuya cronología en cualquier caso debe ser anterior al cerramiento de la capilla del Condestable que tuvo lugar en el año 1494. También en este momento se introducen nervios curvos en la bóveda situada en el ángulo NE del claustro de la catedral de Segovia (1472-1491). Esta bóveda, trazada por Juan Guas, está compuesta de cuatro círculos en torno a la clave central ${ }^{249}$. Diseño parecido, aunque más evolucionado, utilizó Simón de Colonia en el claustro del monasterio de Oña (1495-1503). No obstante, se considera que la bóveda más antigua de crucería con combados que se ha conservado en España es la que cubre el crucero de la catedral de Palencia. Al menos con combados que se desarrollan por la totalidad de la bóveda y que no se limitan simplemente a meros nervios curvos en el entorno de las claves. Así lo puso de manifiesto Hoag que fechó esta bóveda de la catedral palentina en 1497 y que aunque la relaciona con un diseño de Simón de Colonia, su ejecución la atribuyó a Bartolomé de Solórzano ${ }^{250}$. Zalama Rodríguez considera como factible lo

de términos arquitectónicos definen la palabra "combado" en este sentido: PANIAGUA, José Ramón, Vocabulario básico de arquitectura, Cuadernos de Arte Cátedra, Madrid, 1985, p. 104, "En la bóveda estrellada, dícese en general de cada uno de sus nervios curvos". Esta significación se encuentra también en los diccionarios oficiales de la lengua española: MOLINER, María, Diccionario de uso del español, Madrid, 1998, p. 685, en la entrada combado: "De forma curva".

246 HOAG, John D., Rodrigo Gil de Hontañón. Gótico y renacimiento en la arquitectura española del siglo XVI, Madrid, 1985, p. 29.

247 RICO SANTAMARÍA, Marcos, La catedral de Burgos: Patrimonio del Mundo, Vitoria, 1985, p. 316

248 MARTÍN MARTÍNEZ DE SIMÓN, Elena, Arquitectura religiosa tardogótica en la provincia de Burgos (1440-1511), Tesis Doctoral, inédita, defendida el 16-12-2013, Universidad de Burgos, pp. 209 y 238-39 dibujo y fotografía.

249 Bóvedas muy semejantes a esta segoviana las encontramos en el claustro de la catedral de Palencia, cuya traza e inicio de las obras se debe a Juan Gil de Hontañón, lo que una vez más constata la dependencia de este maestro de modelos de Juan Guas.

250 HOAG, J. D., op. cit., 1985, pp. 29 y 31. 
dicho por Hoag y, por tanto, aunque Bartolomé de Solórzano fuera maestro de la fábrica de la catedral de Palencia cuando se cierra el crucero, un diseño tan innovador es mucho más probable que pudiera deberse a Simón de Colonia ${ }^{251}$. Martínez la atribuye a Bartolomé de Solórzano ${ }^{252}$. Gómez Martínez ha fijado documentalmente el año 1496 como la fecha exacta en la que se cerró el crucero de la catedral de Palencia ${ }^{253}$. Para este último autor es plenamente asumible la atribución a Simón de Colonia, el único arquitecto en la España del momento capaz de trazar una bóveda con esas características. Por último, Rumoroso Revuelta, que ha estudiado la figura de Bartolomé de Solórzano, incide

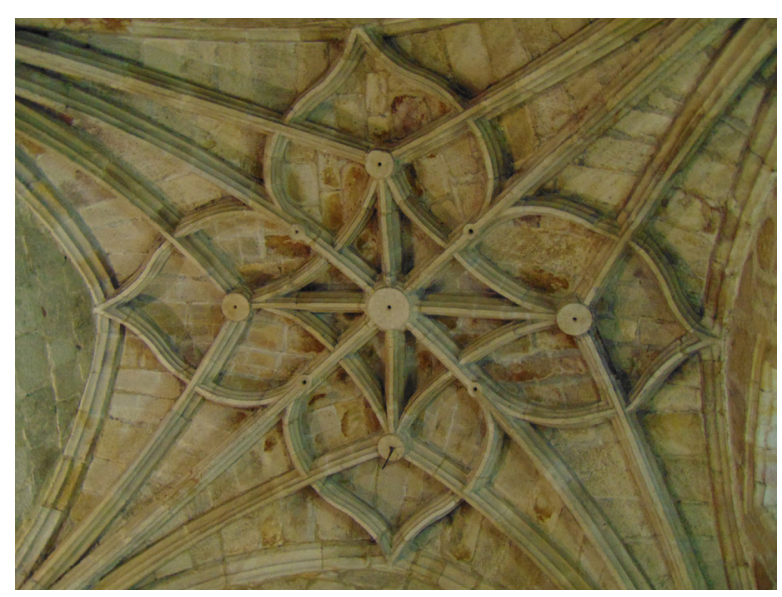

Fig. 219. Bóveda de la capilla de Juan de Vega en la iglesia de Santa María de la Horta. Zamora

en la falta de documentación que vincule a Simón de Colonia con Palencia y, en concreto, con su catedral ${ }^{254}$. Por el contrario, la documentación existente habla de Bartolomé de Solórzano relacionándolo directamente con las obras del crucero.

En Zamora las bóvedas con nervios curvos más antiguas que se han conservado están compuestas de nervios cruceros, terceletes en los que se bifurca el nervio que habría de confluir en la clave y combados que diseñan arcos conopiales. El resultado es una gran flor cuadripétala que, en ocasiones, acoge en su interior una figura geométrica cuadrangular de lados curvos en torno a

251 ZALAMA RODRÍGUEZ, Miguel Ángel, La arquitectura del siglo XVI en la provincia de Palencia, Palencia, 1990, pp. 172-173.

252 MARTÍNEZ, Rafael, La arquitectura gótica en la ciudad de Palencia 1165-1516, 1988, pp. 125-126.

253 GÓMEZ MARTÍNEZ, J., op. cit., 1998, p. 92.

254 RUMOROSO REVUELTA, "Bartolomé de Solórzano: maestro de obras de la catedral de Palencia” en AA. VV., Los últimos arquitectos del Gótico (Begoña Alonso Ruiz Coord.), Madrid, 2010, pp. 375-377. 
la clave central. Fue éste un tipo de bóveda muy común que se utilizó en Zamora y provincia desde el primer tercio del siglo XVI en adelante y que parece responder tanto a diseños de los Egas como de Juan Gil de Hontañón o del propio Simón de Colonia cuya bóveda mencionada para el crucero de la catedral de Palencia presenta en esencia el esquema general de las que veremos en Zamora. En el crucero del Hospital Real de Granada ${ }^{255}$, construido

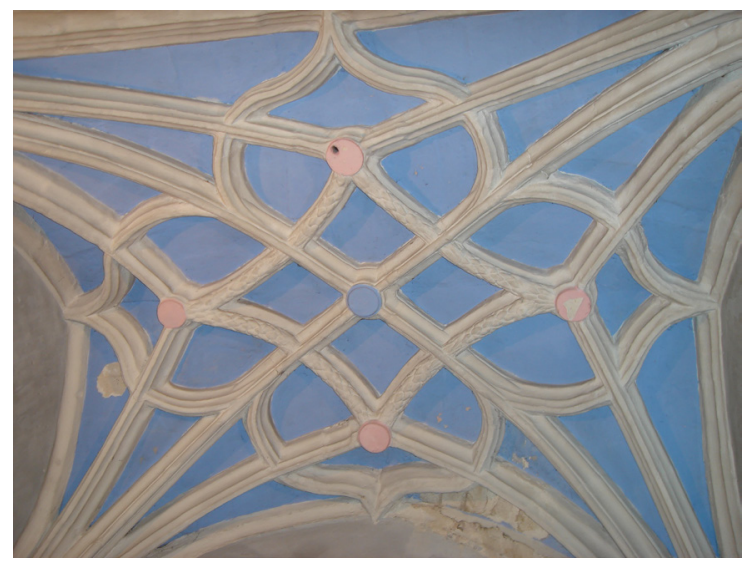

entre 1511 y 1526 y cuyas trazas se atribuyen a Enrique Egas ${ }^{256}$, se conserva una bóveda prácticamente idéntica a algunas de las que tenemos en Zamora y provincia. Igualmente, semejantes diseños utilizó Juan Gil de Hontañón, por ejemplo, para cubrir diversos tramos de las naves laterales de la catedral de Segovia.

En la ciudad de Zamora y provincia las dos bóvedas más antiguas que se conservan de este tipo y que son las primeras que incorporan los nervios combados en este ámbito geográfico se encuentran en la capilla de Juan de Vega en la iglesia de Santa María de la Horta y en la capilla de la Soledad en la iglesia de Santa Lucía (Figs. 219 y 220). Ambas se levantaron durante el primer tercio del siglo XVI y guardan una curiosa semejanza de trazado con la bóveda que cubre la capilla de la Epístola de la iglesia parroquial de Corrales del Vino, aunque en este último caso todas las nervaduras sean rectas. Parece probable que, en bóvedas como la referida de Corrales del Vino, se pueda rastrear el origen del tipo de bóveda que estamos tratando.

255 FÉlEZ LUBELDA, C., El Hospital Real de Granada, Granada, Universidad, 1979, pp. 93-95. 
Este tipo de bóveda de crucería con nervios combados gozó de una gran aceptación y como consecuencia de ello fue muy utilizada en el resto de España, en muchas ocasiones, como sucede también en la provincia de Zamora, ya durante la segunda mitad del siglo XVI. Gran parte de esa aceptación se debió a la difusión ejercida por Rodrigo Gil de Hontañón, quien se sirvió de este modelo con sus variantes en diversas obras como, por ejemplo, en la catedral nueva de Salamanca y en la catedral de Segovia.

En la provincia de Valladolid contamos con numerosos ejemplos semejantes a este tipo de bóveda al que estamos aludiendo. En la propia ciudad observamos una bóveda similar cubriendo la capilla Sacramental de la iglesia de El Salvador, levantada durante la primera mitad del siglo XVI257. En la provincia fue utilizada en uno de los tramos de la Capilla del Conde de Rivadavia en la iglesia de Santa María de Villabrágima, en los tramos de la nave central de la iglesia de San Pedro en Alaejos así como en el primer tramo de la nave hacia los pies de la iglesia

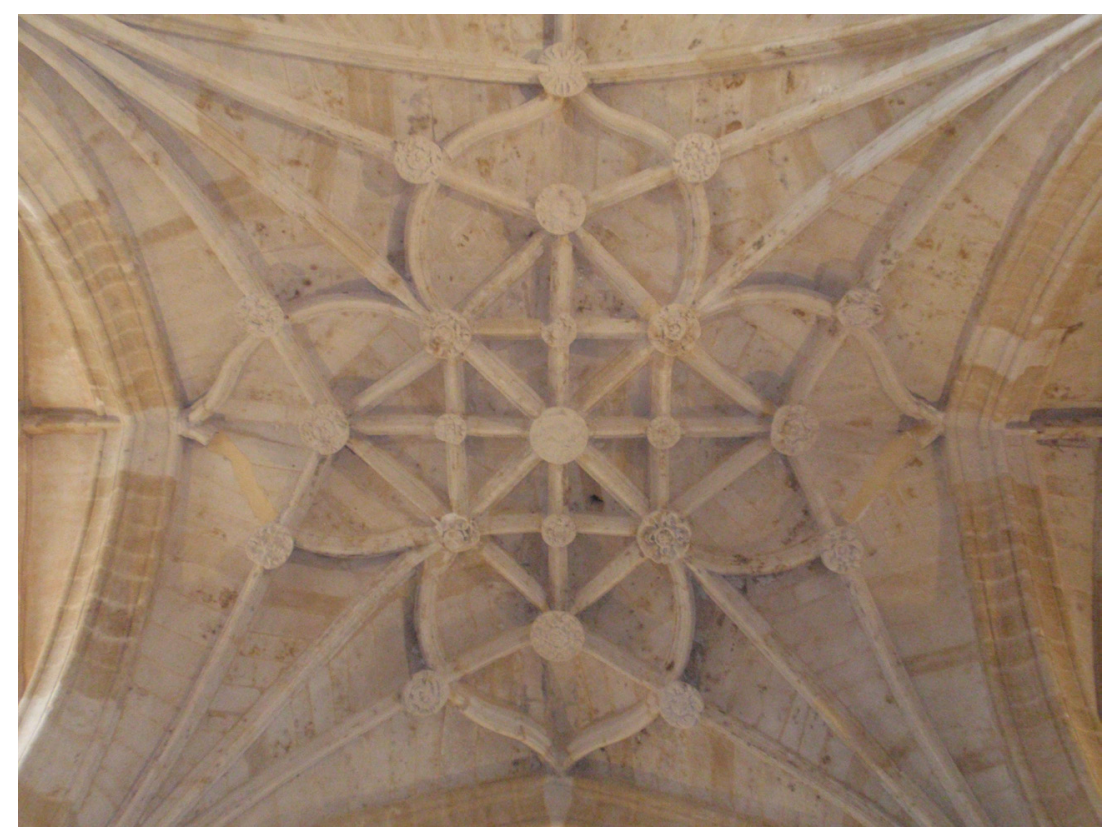

Fig. 221. Bóveda del tramo central del crucero de la iglesia parroquial de Villamor de los Escuderos

de Santa María Magdalena en Medina del Campo ${ }^{258}$. Igualmente

257 MARTÍN GONZÁLEZ, Juan José y URREA FERNÁNDEZ, Jesús, "Monumentos Religiosos de la ciudad de Valladolid (Catedral, parroquias, cofradías y santuarios)" en Catálogo Monumental de la Provincia de Valladolid, Tomo IV, parte primera, Institución Cultural Simancas, Valladolid, 1985, pp. 29-30.

258 Esta iglesia perteneciente al monasterio de MM. Agustinas de la localidad vallisoletana de Medina del Campo utilizó este tipo de bóveda en el primer tramo del templo hacia los pies tanto en el espacio bajo que actúa de sotocoro como en el espacio 
Fig. 222. Bóveda de la capilla del Santo Sepulcro en el convento de San Francisco. Zamora

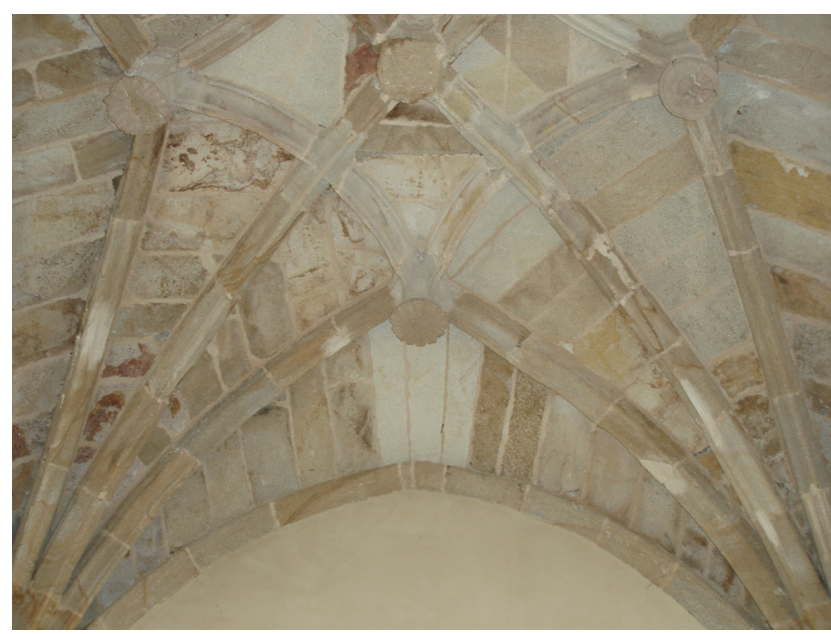

en la capilla mayor de la ermita de Nuestra Señora del Villar en Laguna de Duero la bóveda es muy similar, aunque en este caso y como sucede también en la capilla de la Soledad de la iglesia de Santa Lucía la figura romboidal del centro carece de nervios rectos que unan sus ángulos como se observa en la bóveda de la capilla de Juan de Vega y en el resto de las citadas.

Al tiempo que se levantaron las citadas bóvedas de La Horta y Santa Lucía trazó Juan Gil de Hontañón las bóvedas correspondientes a la cabecera y el crucero de la iglesia parroquial de Villamor de los Escuderos (Fig. 221). La más compleja es la que cubre el tramo central del crucero que reproduce en parte el modelo del que venimos hablando solo que, además, introduce en torno a la clave central el juego del cuadrado girado dentro de otro cuadrado que le dobla en superficie. El resto de bóvedas con combados que utiliza Juan Gil en la cabecera de Villamor cubren espacios rectangulares y constan de terceletes, nervios de ligadura a las claves de los formeros y una figura ovalada compuesta por nervios curvos. Podríamos, por tanto, considerar a Juan Gil como uno de los principales introductores del combado en la arquitectura de nuestra provincia.

Otro tipo de bóveda de crucería con nervios curvos se ha conservado en la "sacristía" o "capilla del Santo Sepulcro" de la capilla del deán Vázquez de Cepeda en el convento de San Francisco. Fue levantada durante el primer tercio del siglo XVI y aunque más sencilla que las anteriormente citadas, se trata igualmente de una bóveda de crucería compuesta de cruceros,

superior. Ambas se levantaron durante la segunda mitad del siglo XVI de ahí que sus claves estén profusamente decoradas con labores plenamente renacientes. 
terceletes en los que se bifurca el nervio que habría de dirigirse hacia la clave polar, dando lugar a una figura romboidal de lados curvos en torno a dicha clave central (Fig. 222). Este diseño de las nervaduras que configuran esta bóveda se mantendrá en las décadas subsiguientes como queda de manifiesto en las bóvedas gemelas que cubren la sacristía de la antigua iglesia monástica de San Martín de Castañeda. En este caso, aunque el trazado de los nervios sea el mismo, presentan un perfil acusadamente más plano y ornamentos totalmente renacentistas que las situarían cronológicamente en el segundo tercio del siglo $\mathrm{XVI}^{259}$.

Por lo que respecta a la plementería, el material utilizado más comúnmente fue la piedra, en muchos casos muy bien trabajada como se ve en las bóvedas de la cabecera de la catedral de Zamora o en los mismos espacios de la iglesia toresana de Santo Tomás Cantuariense, por señalar dos ejemplos (Fig. 223). Una plementería más descuidada se observa en los dos tramos de bóveda que cubren la capilla de San Ildefonso de la catedral de Zamora y en la bóveda de la capilla de los Ocampo en el convento de San Francisco también de la ciudad de Zamora (Fig. 224). Se trata en ambos casos de bóvedas que podrían pertenecer a finales del siglo XV.

No tenemos referencias de bóvedas de ladrillo durante los años finales del siglo XV y los primeros del XVI. Hay que esperar, por tanto, a un momento avanzado de este último siglo para encontrar bóvedas cuya plementería y, en algún caso, las nervaduras, fueron construidas en este material.

\section{Vanos}

La mayor parte de los vanos, ya sean puertas o ventanas, son muy sencillos, pero se pueden distinguir dos orientaciones en cuanto al planteamiento de su estructura. En unos casos, el sistema constructivo utilizado es el tradicionalmente empleado

259 Este tipo de diseño que presentan las bóvedas de la sacristía de la iglesia del antiguo monasterio de San Martín de Castañeda y la capilla del Santo Sepulcro del antiguo convento de San Francisco (Zamora) fue utilizado con ligeras variantes en distintas ocasiones por Juan de Álava. Por ejemplo en las bóvedas del claustro de la catedral de Santiago de Compostela y en las bóvedas que cubren los dos tramos de la capilla del Colegio Fonseca de la misma ciudad gallega. Curiosamente Juan de Álava fue el autor de la traza del desaparecido monasterio de San Jerónimo de Zamora, que se encontraba ubicado a escasos metros del mencionado convento de San Francisco.
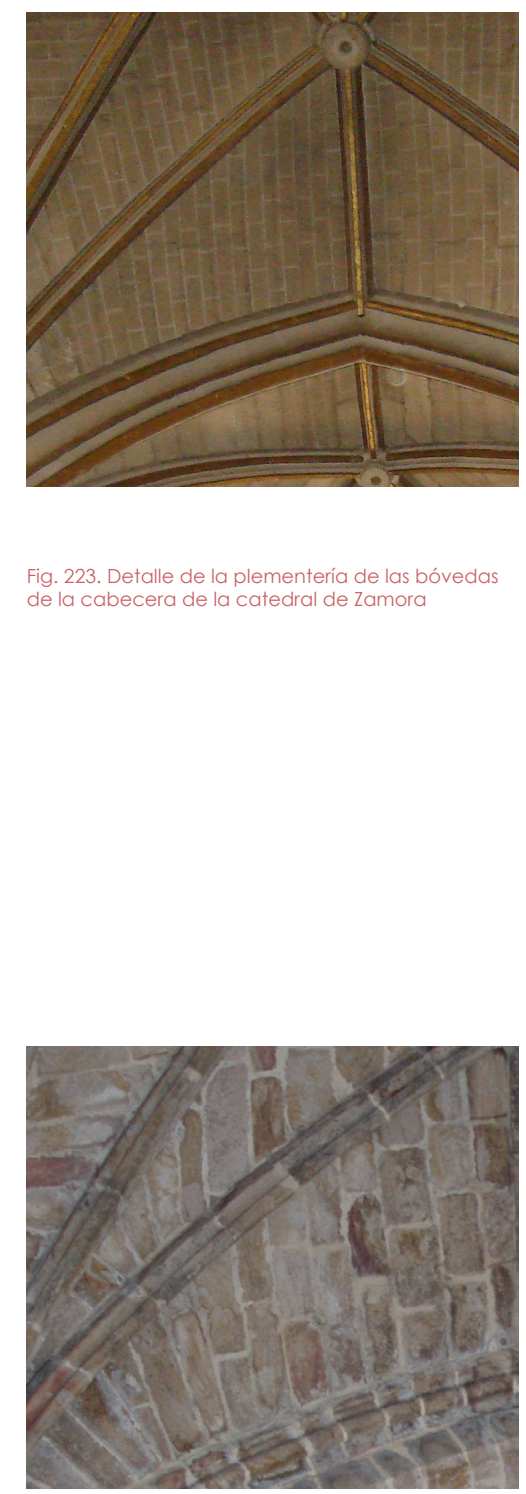

Fig. 223. Detalle de la plementería de las bóvedas de la cabecera de la catedral de Zamora

Fig. 224. Detalle de la plementería de la bóveda de la capilla de los Ocampo en el convento de San Francisco. Zamora 


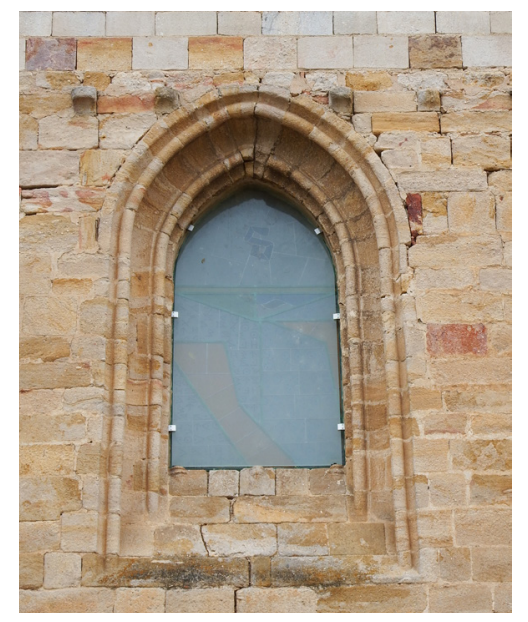

Fig. 225. Vano de la cabecera de la catedral de zamora

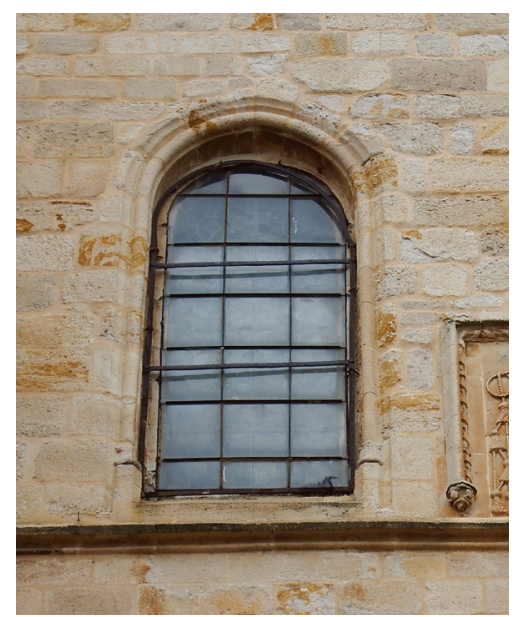

Fig. 226. Vano de la sacristía vieja de la catedral de Zamora en el gótico clásico en el que se observa una separación clara entre los elementos sustentantes y el arco, mediante la línea de imposta. Sin embargo, en otros casos se opta por una estructura más en consonancia con los principios del gótico tardío en los que se pierde la independencia de los elementos a favor de la prolongación de las formas, sin que exista solución de continuidad entre las jambas y el arco. Continuidad que se mantendrá en la arquitectura de buena parte del siglo XVI. De entre los muchos ejemplos que podríamos citar señalamos el ventanal abierto en la capilla de los Ocampo del convento zamorano de San Francisco, el ventanal de la capilla mayor de la iglesia toresana de Santo Tomás Cantuariense o los vanos que se abren en la cabecera y sacristía vieja de la catedral de Zamora y en el muro sur del tramo recto presbiterial de la iglesia de la Asunción de la Virgen de Villaralbo (Figs. 225 y 226).

Existen también casos en los que en un mismo vano conviven ambas formulas. De este modo podemos observar cómo en la puerta de la capilla del deán Vázquez de Cepeda o en el acceso a las huertas del monasterio de las Marinas hay molduras que, sin solución de continuidad, se prolongan por todo el vano mientras que, otras, generalmente en forma de bocel a modo de columnillas, se interrumpen hacia la línea de imposta mediante molduras horizontales o pequeños capiteles.

\section{Puertas}

Desde el punto de vista tipológico no existe un modelo de puerta que se repita, sino que cada una de ellas posee un diseño diferente. Sin embargo, hay que señalar que en las que pertenecen a la reforma emprendida en la catedral en el reinado de los Reyes Católicos se observan rasgos afines.

A pesar de que la simplicidad es la tónica dominante en la arquitectura religiosa gótica zamorana y de que, en la mayoría de los casos, las puertas tienen una decoración compuesta a base de sencillas molduras, se puede citar algún ejemplo de portadas decorativas. Es el caso del antiguo acceso por el crucero al convento dominico de San Ildefonso (Toro) - hoy trasladado al hastial occidental de la iglesia de San Julián de los Caballeros-, 


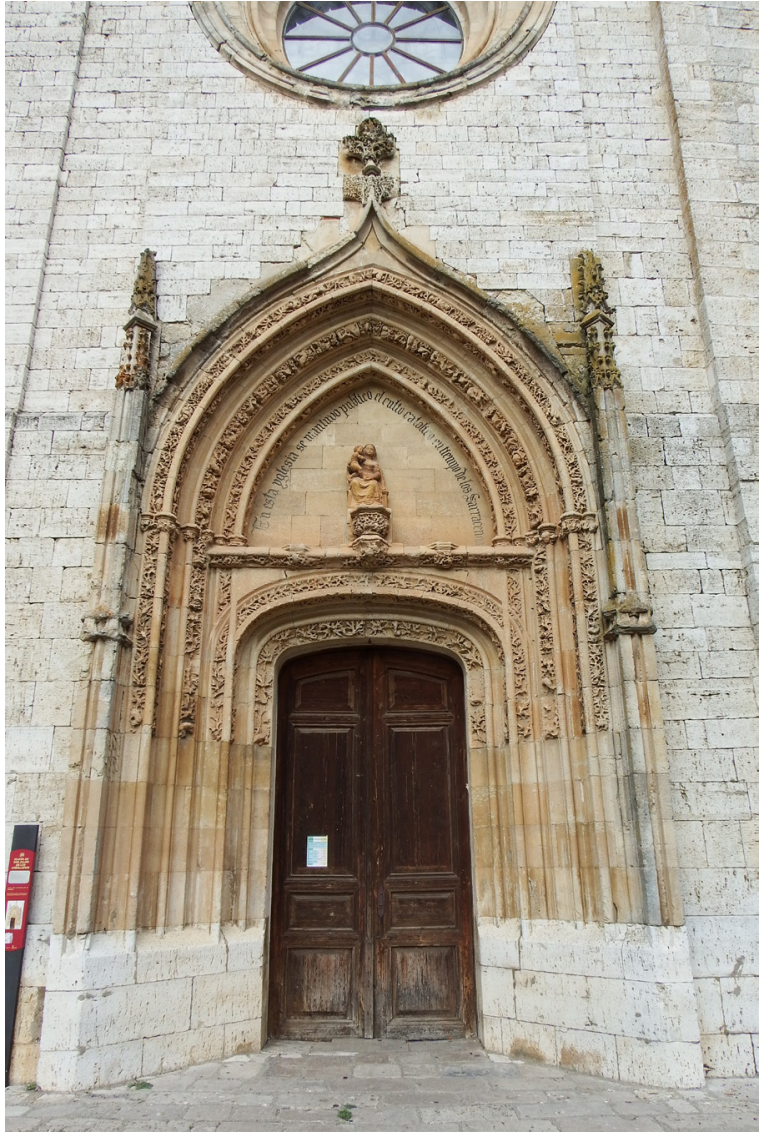

que presenta un carácter monumental enmarcada por dos pequeños contrafuertes rematados en pináculos y en el que se combinan el arco carpanel del vano que permite el acceso y las arquivoltas de trazado apuntado que se proyectan flanqueando el tímpano (Fig. 227). La última de estas arquivoltas va contorneada por una chambrana que se levanta en forma de arco conopial y en cuya cúspide se ha colocado un florón. Sobre el arco carpanel y sirviendo de base al tímpano existe una moldura horizontal que establece una división clara entre las jambas y el arco. De entre todas las conservadas es la portada de este periodo donde se despliega el mayor número de ornamentos y el repertorio es más amplio. Lo componen fundamentalmente tallos, hojas y figuras humanas y animales. Desde antiguo se ha establecido la relación de esta portada con la de los Novios de la catedral de Palencia con la que guarda enormes semejanzas en el diseño ${ }^{260}$.

También como portada decorativa contamos con la que se abre en el muro sur de la iglesia parroquial de Villar de Fallaves para cuya realización se siguió como modelo las portadas de la iglesia de Santa María de Medina de Rioseco (Fig. 228).
Fig. 227. Actual portada occidental de la iglesia de San Julián de los Caballeros

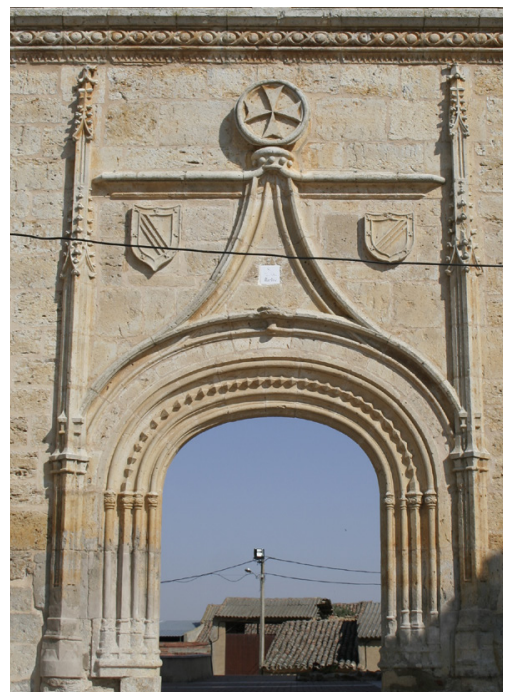

Fig. 228. Antigua portada de la iglesia parroquial de Villar de Fallaves 


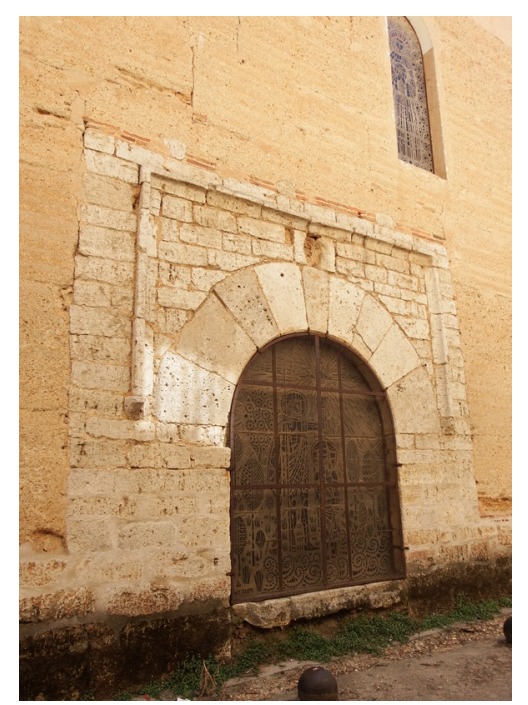
Fig. 229. Portada de la iglesia de Santo Tomás
Cantuariense. Toro

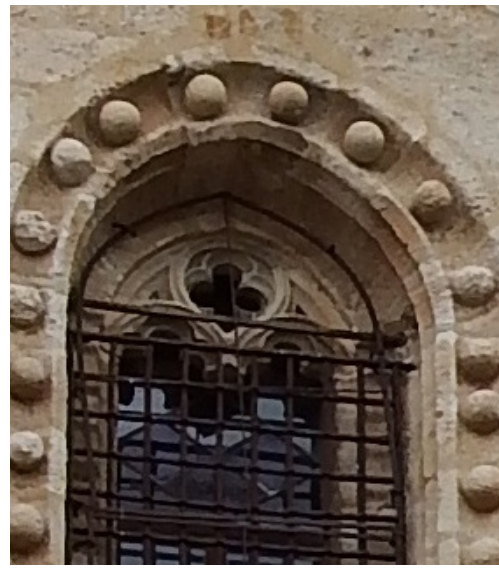

Fig. 230. Detalle del vano de la sacristía vieja de la catedral de Zamora
Otro ejemplo es la puerta de la capilla del deán Vázquez de Cepeda en el convento de San Francisco, que lleva una escocia continua de profusa ornamentación que contornea todo el perfil de la puerta cuyo arco tiene diseño trilobulado. Los modelos más ricos en cuanto a trazado se encuentran en las puertas situadas en el trascoro de la catedral como corresponde a una obra de gran empeño patrocinada por el obispo Meléndez Valdés en el marco de transformaciones emprendidas en el templo en este periodo. Enmarcadas por un arco conopial y pináculos, los motivos ornamentales que presentan todas estas puertas en general consisten en molduras y decoración vegetal como hojarasca calada, animalillos y medias bolas, elemento decorativo este último como ya dijimos característico de la arquitectura románica y que se retomó precisamente en época de los Reyes Católicos. En algunos casos encontraremos también rosetas de cuatro pétalos.

Por último, habría que señalar, que durante estas primeras décadas del siglo XVI comienza a introducirse un modelo de portada en arco de medio punto totalmente liso y formado por grandes dovelas que se proyecta hacia las jambas, igualmente lisas, sin solución de continuidad. El único elemento decorativo que presentan es el alfiz que enmarca el arco. Como ejemplos de este tipo de portada, que fue también de uso frecuente en la arquitectura civil, podemos citar las dos de la iglesia toresana de Santo Tomás Cantuarense (Fig. 229).

\section{Ventanas}

Por lo que se refiere a las ventanas, es muy común la utilización de un tipo de vano abocinado de trazado apuntado y en ocasiones en medio punto compuesto todo él de una sucesión de escocias y sin solución de continuidad entre las jambas y el arco.

Solamente algunas ventanas están enriquecidas con maineles y tímpanos perforados por tracerías o algún otro motivo ornamental. Sucede esto en el correspondiente a la sacristía vieja de la catedral de Zamora, que lleva ornamentada con medias bolas la escocia continuada que lo delimita y ha perdido el pilar o columnilla que actuaría de parteluz, y 
en el vano abierto en el muro meridional de la capilla que se proyecta hacia el sur en la iglesia de Santa María del Castillo en Montamarta, de trazado en medio punto, muy abocinado, con sencillas tracerías y carente, como el anterior, de mainel por no haberse conservado (Figs. 230 y 231). También en medio punto $y$, en este caso, de dimensiones muy estrechas es el vano que se abre en el muro sur correspondiente al tramo presbiterial de la iglesia de la Asunción de Nuestra Señora de Villaralbo. Posee un pequeño tímpano con una sencilla tracería flamígera. Un mayor desarrollo y profusión ornamental, pero dentro de la modestia que caracteriza la arquitectura gótica zamorana, poseen el óculo y ventanal abiertos en la capilla mayor de la iglesia de Santo Tomás Cantuariense en Toro, ambos enriquecidos con tracerías flamígeras (Figs. 232 y 233).

Lo habitual fue que estos vanos se abrieran en el muro sur para iluminar las cabeceras y algunas capillas.

\section{Decoración}

Los elementos decorativos que hemos visto en la arquitectura durante este periodo se circunscriben al contorno de algunos arcos, ya correspondan a portadas, ventanales o arcosolios; a las cornisas, que generalmente están compuestas por sencillas molduras; a las cresterías y, por último, a los capiteles, línea de impostas, ménsulas y claves. En la mayoría de los casos todos estos ornamentos están en plena consonancia con los diseños tardogóticos vigentes en aquel momento. Solamente en algunos de ellos se observa la incorporación de motivos renacentistas cuya paulatina introducción no produce estridencias.

La mayor parte de las molduras que hemos visto tienen forma de escocia y bocel y se encuentran desprovistas de decoración. No obstante, hay casos en los que las molduras cóncavas se ven adornadas o bien por motivos de tallos vegetales formando ondulaciones y provistos, en unos casos, de hojarasca calada, entre la cual, en ocasiones, se reconocen animalillos e, incluso, algunas personas, como se puede ver en las portadas de la capilla del Deán en el convento de San Francisco y en la portada del antiguo convento de San Ildefonso de Toro (Figs. 234 y 235). En

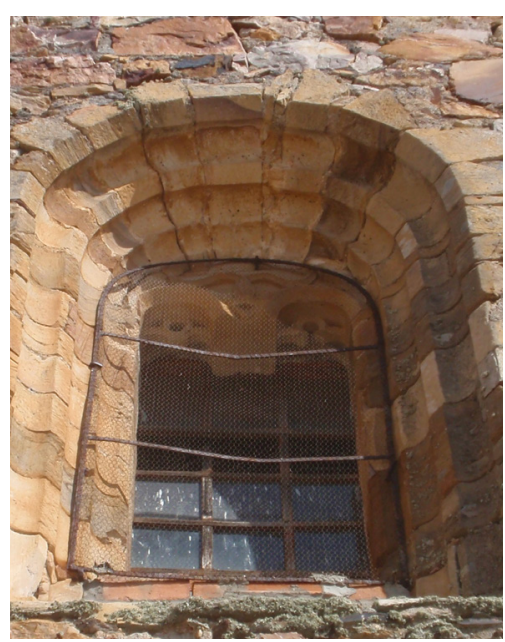

Fig. 231. Vano abierto en la capilla meridional de la iglesia de Santa María del Castillo. Montamarta

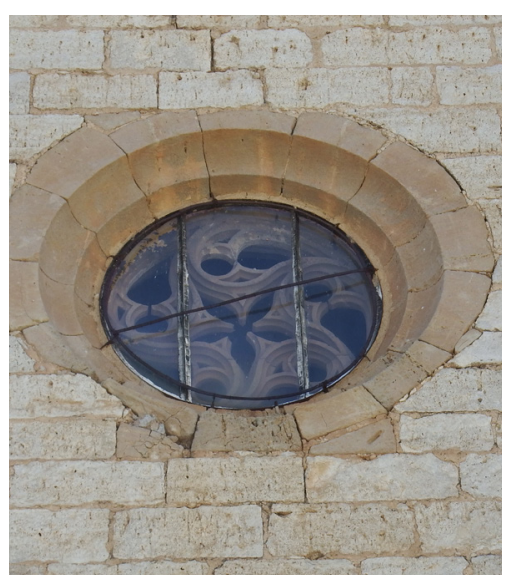

Fig. 232. Óculo abierto en la capilla mayor de la iglesia de Santo Tomás Cantuariense. Toro

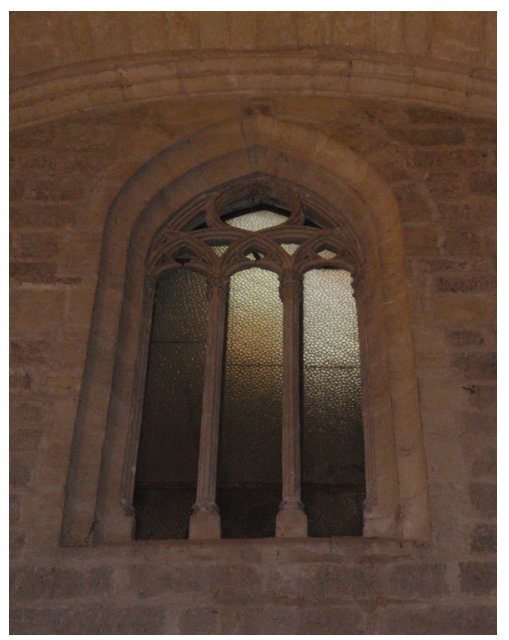

Fig. 233. Vano en la capilla mayor de la iglesia de Santo Tomás Cantuariense. Toro 


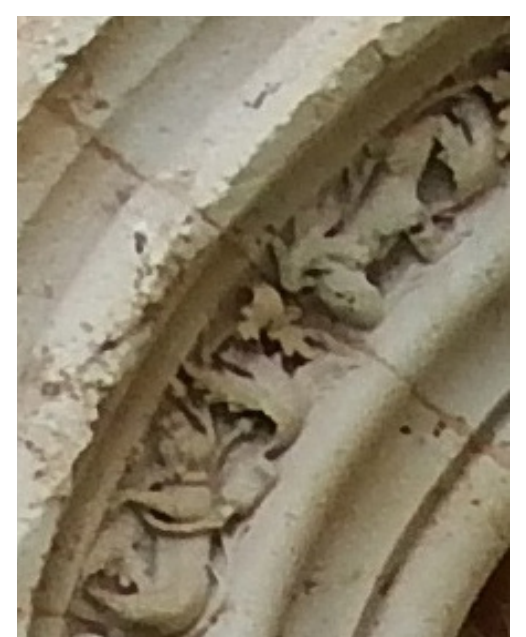

Fig. 234. Detalle de la portada de la capilla del Deán en el convento de San Francisco. Zamora

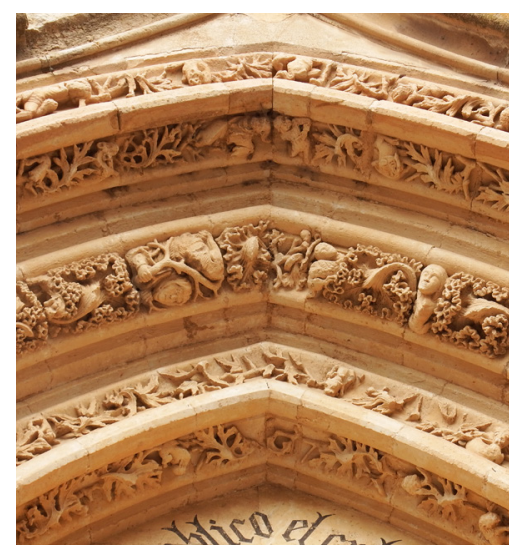

Fig. 235. Detalle de la ectual portada occidental de la iglesia de San Julián de los Caballeros

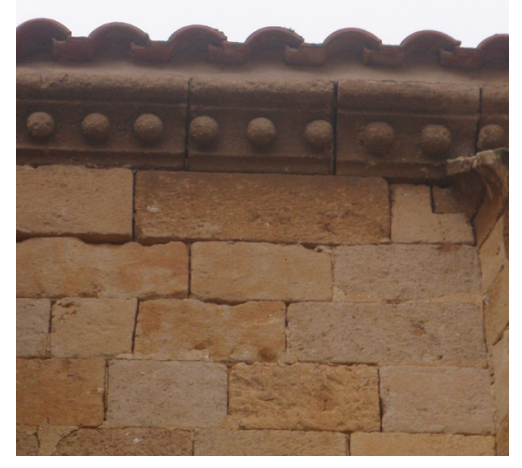

Fig. 236. Detalle de la cornisa de la cabecera de la iglesia parroquial de Corrales del Vino otros casos, el tallo vegetal está simplemente rodeado por una cinta como ocurre en uno de los capiteles de la capilla sur de la iglesia de Santa María del Castillo de Montamarta. Otro elemento ornamental que se repite con cierta frecuencia es la serie de medias bolas que, en ocasiones, se sitúan en las ménsulas que dan apeo a los nervios de las bóvedas y habitualmente en la rosca de los arcos, como sucede, tanto hacia el interior como hacia el exterior, del vano de la sacristía vieja de la catedral de Zamora, en el arco central del trascoro de la catedral y en la escocia que trasdosa el amplio vano que sirve de acceso al pórtico de la iglesia de La Hiniesta. También se utilizaron en las cornisas de las cabeceras de las iglesias parroquiales de Corrales del Vino y Venialbo (Figs. 236 y 237). A su vez, la decoración con medias bolas la encontramos en la chambrana de la actual portada hacia las huertas del convento zamorano de Santa Marina. En menor medida se utilizaron las rosetas compuestas de cuatro u ocho pétalos con botón central que se encuentran en la portada sur de la iglesia de la Asunción de Morales del Vino, en la portada de la iglesia de San Pedro Apóstol de San Pedro de Ceque, en uno de los capiteles de la capilla aludida del templo de Santa María del Castillo de Montamarta y delimitando las grandes arcadas que configuran el cuerpo de la iglesia de San Félix de El Perdigón (Figs. 238 y 239).

También en las cresterías se concentran un gran número de elementos decorativos. Conservamos dos, la que remata la cabecera de la catedral de Zamora y la que remata la fachada sur de la iglesia parroquial de Villar de Fallaves. La primera de ellas está ornamentada con motivos flamígeros mientras que para la segunda se utilizó un tronco que va entrelazándose creando una decoración calada propia también del momento (Figs. 240 y 241).

Los capiteles, cuando los hay, por lo general y con escasas excepciones, son de pequeño tamaño y evolucionan poco a poco dando paso a sencillas molduras horizontales que tienden a desaparecer conforme se introduce el renacimiento. Los capiteles de mayor entidad forman parte de los arcosolios que se abren en el interior de la capilla de los Ocampo del Convento de San Francisco de Zamora. Tienen formas muy cuadráticas y en ellos se han labrado algunos rostros y, fundamentalmente, grandes hojas 
(Fig. 242). Pero, como precisábamos, mayoritariamente van a ser utilizados pequeños capitelitos profusamente ornamentados que se ajustan a finas molduras en forma de bocel dispuestas en los vanos, ya sean ventanas, portadas o funcionen como accesos a capillas. Tal es el caso de los correspondientes a la portada norte de la capilla del Deán del Convento de San Francisco, a la antigua portada del convento de San Ildefonso de Toro o los situados en los vanos de acceso a la capilla mayor y capilla de la Epístola del templo parroquial de Corrales del Vino (Figs. 243 y 244).

También en algún caso se decora la línea de imposta como sucede en las correspondientes a los arcosolios de la mencionada capilla de los Ocampo en el convento de San Francisco donde se concentran elementos ornamentales fundamentalmente vegetales aunque también hay presencia de algunos rostros humanos.

Respecto de las ménsulas, un gran número de ellas mantienen ornamentaciones propias del último gótico. Es el caso de las correspondientes a la cabecera de la catedral de Zamora, a la capilla mayor y de la epístola de la iglesia de Santa María Magdalena de Corrales del Vino, de la capilla del Santo Sepulcro del convento de San Francisco (Zamora) y a las situadas tanto en la cabecera como en los tramos de la nave de la iglesia de San Sebastián de los Caballeros de Toro y en la cabecera de la iglesia de Venialbo. En ellas abunda la decoración a base de hojarascas y animalillos circunscrita en su mayoría a la banda central y en algún caso como sucede en algunas de la cabecera de la catedral de Zamora podemos observar ángeles con pliegues muy envolventes.

Las claves, durante este periodo que, en lo fundamental, se corresponde con el reinado de los Reyes Católicos, tienen tamaño reducido y un aspecto muy sencillo. Su trazado en todos los casos es circular y suelen carecer de ornamentación, pero seguramente porque ha desaparecido, o no llegaron a colocarse las claves de madera dorada y policromada que en ese momento se superponían a las de piedra. Existen ejemplos de claves en las que se labraron elementos decorativos en la piedra como en la clave central del actual lavabo de la sacristía vieja de la catedral que se compone de roseta central de cuatro pétalos rodeada de

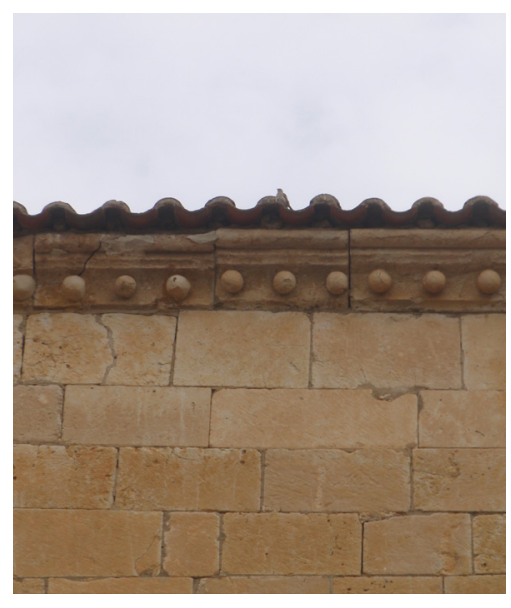

Fig. 237. Decoración de medias bolas en la cornisa de la cabecera de la iglesia parroquial de Venialbo

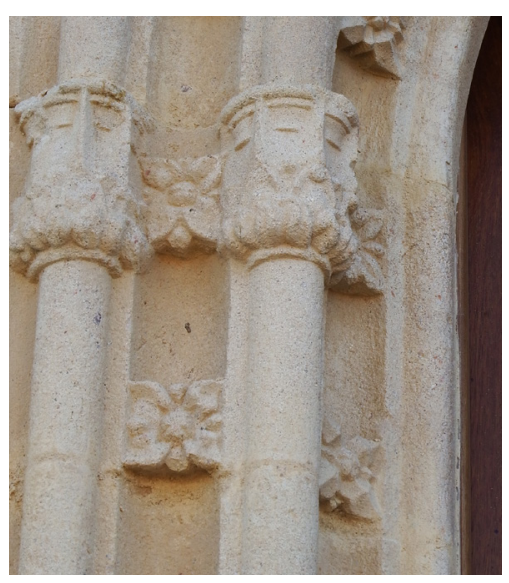

Fig. 238. Decoración de rosetas en la portada sur de la iglesia parroquial de Morales del Vino

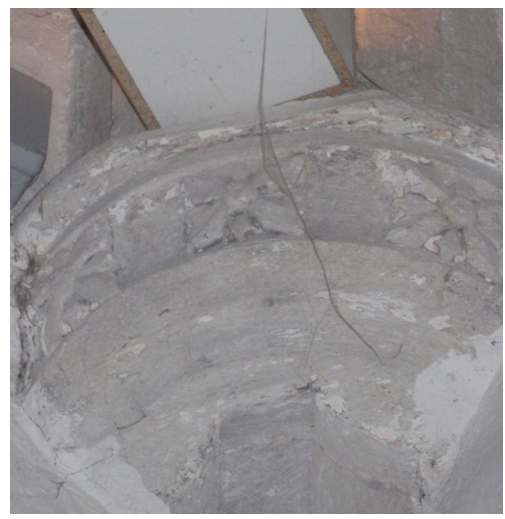
Fig. 239. Decoración de rosetas en la capilla de la
iglesia de Santa María del Castillo en Montamarta 


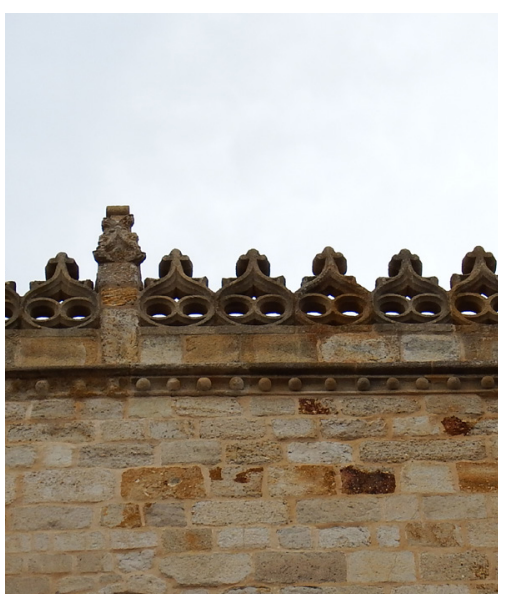

Fig. 240. Crestería de la cabecera de la catedral de Zamora

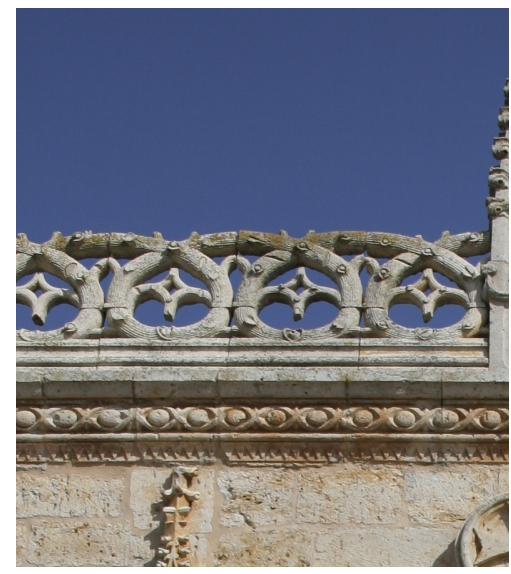

Fig. 241. Crestería de la portada decorativa de la iglesia parroquial de Villar de Fallaves

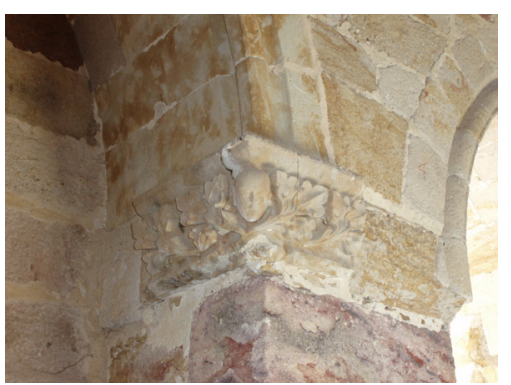

Fig. 242. Detalle de los arcosolios abiertos en la capilla de los Ocampo en el convento de San Francisco. zamora un tallo vegetal con hojas (Fig. 245). Cuando se han conservado los apliques de madera en las claves, la decoración adquiere un desarrollo considerablemente mayor que en las pétreas, según puede verse en las situadas en las bóvedas de las capillas que componen la cabecera de la catedral y en las bóvedas de los tramos de la nave de la iglesia de San Ildefonso, obras, ambas, pertenecientes a las reformas de Meléndez Valdés. Por último, en la reforma que se hizo a finales del siglo XV en la capilla mayor de la iglesia de San Lorenzo el Real de Toro por parte de don Sancho de Castilla para acoger los enterramientos de sus padres, don Pedro de Castilla y doña Beatriz de Fonseca, se colocó una bóveda con nervios de yeso en la que se encajaron unas grandes claves de madera que se decoran con escudos heráldicos (Fig. 246). Aunque el espacio ha sido tremendamente modificado en época reciente y se eliminaron esas bóvedas de yeso, se conservan sus claves que constituyen las piezas de este tipo más sobresalientes de la provincia de Zamora ${ }^{261}$.

En las bóvedas de las naves de los templos y en los espacios patrocinados por mecenas (capillas funerarias fundamentalmente), es común que éstos ordenaran labrar sus armas en la clave central. Lo vemos, entre otros lugares, en la iglesia de San Sebastián de los Caballeros de Toro, edificio erigido por mandato de fray Diego de Deza, en la sacristía de la capilla funeraria catedralicia del doctor Grado, donde campean las armas de este canónigo y en la capilla del Chantre de la iglesia de San Félix del Perdigón donde se repite en sus claves el escudo del fundador don Pedro López de Peralta (Figs. 247 y 248). Es probable que en la clave correspondiente a la bóveda de la capilla del lado del evangelio de la iglesia toresana de Santo Tomás Cantuarense estuviesen labradas las armas de los Melena, la familia que se ha supuesto ostentaba el patronazgo de este lugar ${ }^{262}$. No obstante, no deja de ser más que una conjetura pues el enorme deterioro que acusa el escudo impide ir más allá.

261 De esta transformación que sufrió a finales del siglo XV la cabecera de esta iglesia toresana únicamente se conserva in situ el sepulcro de Pedro de Castilla y Beatriz de Fonseca, obra destacadísima de la escultura funeraria gótica en nuestra provincia.

262 VASALLO TORANZO, L., op. cit., 1994, p. 263. 


\section{Talleres locales en el gótico tardío zamorano}

En la provincia de Zamora se pueden distinguir desde finales del periodo gótico tardío y hasta las décadas centrales del siglo $\mathrm{XVI}$, aparte de las relaciones ya mencionadas con los grandes maestros de rango nacional, edificios que guardan en su diseño general o en algunos elementos particulares relaciones muy estrechas ${ }^{263}$.

Uno de los grupos con evidentes vínculos formales está constituido por los cercanos templos parroquiales de Morales del Vino y Corrales del Vino donde la semejanza de los apoyos en forma de cilindro y del propio entablamento de la capilla mayor del primero de estos edificios con los existentes en la capilla del Evangelio del segundo, que cronológicamente parecen responder al segundo cuarto del siglo XVI, hace pensar que en ambas interviniera el mismo maestro. Más evidente es la relación entre las iglesias de San Juan Bautista en Casaseca de las Chanas y la Asunción de la Virgen en Arcenillas donde la concepción general de estos templos está resuelta de forma similar. Ambos conservan del periodo gótico tardío la cabecera mientras que el cuerpo dividido en tres naves por grandes columnas está ya plenamente acorde con el estilo renacentista. En ambos a los pies se instaló un coro y sotacoro, aunque solamente en Casaseca de las Chanas alcanzó gran protagonismo al tener unas mayores dimensiones y a la vez estar los dos espacios cubiertos por bóvedas de crucería con combados.

Otro grupo de iglesias con evidentes conexiones es el formado por tres parroquiales de la comarca de Sayago. En concreto se corresponde con las iglesias de Santa Eufemia de Pereruela, Santa María Magdalena de Malillos y Nuestra Señora de la Natividad de Mogátar. Se trata de edificios modestos de una sola nave con cabecera cuadrangular aunque construidos en piedra de sillería. En todos los casos el paso desde la nave a la cabecera se produce a través de un gran arco apuntado que descansa en pilastras muy bajas salvo en el caso de Pereruela donde adquieren mayor altura. El empleo de la bóveda de crucería se reduce a cubrir el espacio de las cabeceras a excepción de la iglesia de Malillos,
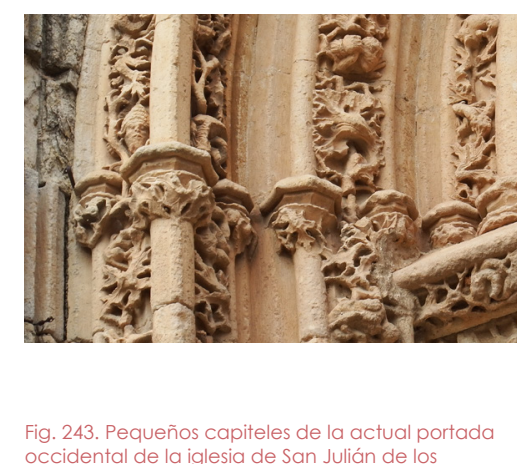
occidental de la iglesia de San Julián de los Caballeros

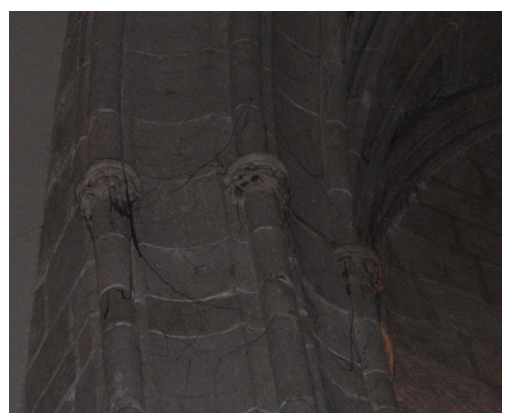

Fig. 244. Pequeños capiteles en la cabecera de la iglesia parroquial de Corrales del Vino

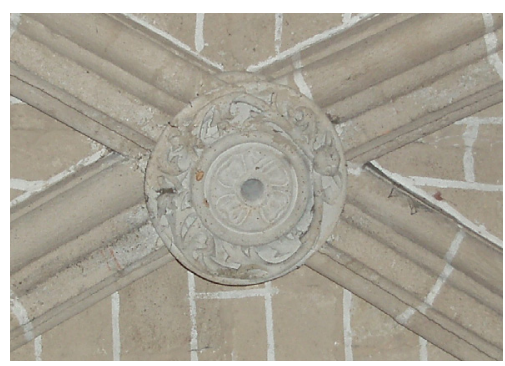

Fig. 245. Clave del lavabo de la sacristía vieja de la catedral de Zamora

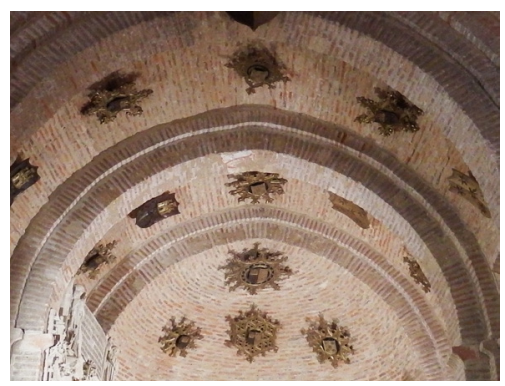

Fig. 246. Claves conservadas en la iglesia de San Lorenzo el Real. Toro 


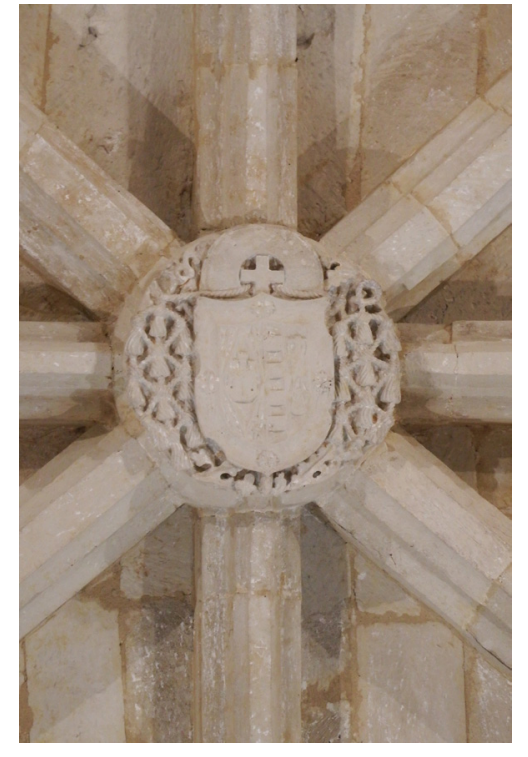

Fig. 247. Armas del doctor Grado en la sacristía de su capilla funeraria en la catedral de Zamora

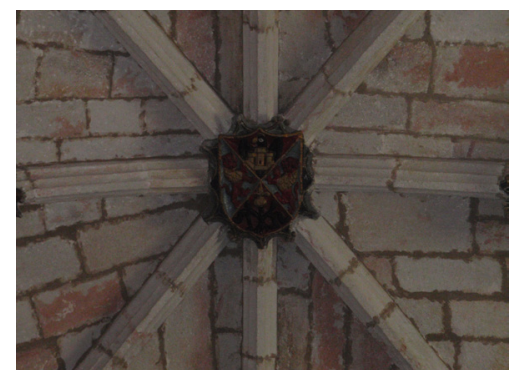

Fig. 248. Armas del Chantre don Pedro López en su capilla de la iglesia parroquial de El Perdigón que además la utilizó para cubrir el primer tramo de la nave lo que no es habitual ni siquiera en el resto de la arquitectura de la provincia de Zamora.

Estos templos guardan grandes semejanzas entre sí tanto en la concepción general arquitectónica como en las soluciones empleadas para organizar y cubrir los espacios. El sistema constructivo que se ha utilizado en todas estas bóvedas es prácticamente idéntico y siempre siguiendo modelos muy sencillos. De crucería simple son las que cubren las cabeceras de Pereruela y Mogátar y el primer tramo de la nave de Malillos y, octopartita, la correspondiente a la cabecera de Malillos. En ninguna de ellas se emplearon los formeros, lo que convierte este arcaísmo en una particularidad de la arquitectura de la zona.

Como conclusión podríamos pensar en la presencia de un taller de canteros modestos y todavía dependientes de soluciones propias de finales del gótico que ellos mantuvieron en estas iglesias rurales en las que trabajaron durante las primeras décadas del siglo XVI. 



\section{La arquitectura civil durante el gótico tardío}

La actividad artística de carácter civil desarrollada durante el periodo del gótico tardío, al igual que sucediera, como se ha visto, en la arquitectura religiosa de este mismo momento, fue relativamente fecunda si atendemos a los edificios o partes de edificios, que se han conservado, así como a aquellos de los que, aunque han desaparecido totalmente, se tiene constancia de su construcción en las últimas décadas del siglo XV y las primeras del XVI.

En el desarrollo de esta arquitectura fue decisivo el impulso dado por los Reyes Católicos y la nobleza. La nobleza asentada en la ciudad de Zamora e, incluso, en la provincia no tuvo la entidad de la existente en otras zonas del territorio peninsular. De hecho, salvo los condes de Benavente y los condes de Alba de Aliste, que se convirtieron en los grandes representantes de la nobleza zamorana, el resto podría encuadrarse como baja nobleza local, dedicada, en lo fundamental, a ocupar cargos en el gobierno municipal ${ }^{264}$. También tuvo cierta relevancia la actividad promovida por algunos personajes que desempeñaron cargos eclesiásticos.

Todos estos personajes pertenecientes a la alta clase social sintieron la necesidad de remodelar o edificar de nuevo sus residencias, lo que dio lugar a una actividad en la construcción de casas principales que se tradujo en un periodo pujante para la provincia y, especialmente, para las ciudades de Zamora y Toro, como ya se indicó en la arquitectura religiosa.

Dentro de la arquitectura conservada de este momento se puede hacer una división de los edificios a partir de su funcionalidad. Primeramente se hará referencia a los castillos, que en unos casos se reforman y, en otros, se edifican de nueva planta, fundamentalmente durante el último tercio del siglo XV. A continuación se hablará, por un lado, de una arquitectura

264 Sobre la baja nobleza de Zamora durante los siglos XV y XVI, vid. CARBAJO MARTÍN, V. A., "La baja nobleza de Zamora en la alta edad moderna. Oficios y gobierno municipal. Siglos XV y XVI" en Actas del I Congreso de Historia de Zamora. Medieval y Moderna, tomo III, Instituto de Estudios Zamoranos «Florián de Ocampo», Diputación de Zamora, 1991, pp. 615-619. 
doméstica a la que pertenecerían los palacios de cierto empaque de las grandes familias así como las casas de la baja nobleza $y$, por otro, de las intervenciones de mejora de la ciudad de Zamora, emprendidas fundamentalmente por orden de los Reyes Católicos y que se materializaron en la construcción de un Ayuntamiento, y en la intervención y remodelación de las murallas, el puente, la Plaza Mayor y algunas calles ${ }^{265}$. Por último se abordará la arquitectura hospitalaria, que aunque igualmente ha llegado muy mermada, tuvo durante este periodo una presencia muy significativa.

De algunas de estas obras se han conservado testimonios más o menos completos que son de gran interés para el conocimiento, aunque sea parcial, de la arquitectura que se desarrolló en la provincia de Zamora a finales del siglo XV y, sobre todo, a principios del siglo XVI.

\section{Los castillos}

A partir de mediados del siglo XV se aprecia en la provincia de Zamora un cierto incremento de la actividad constructiva de castillos, tanto de nueva planta como de actualización y reconstrucción de fortalezas ya existentes. La finalidad de este tipo de edificaciones hizo que sus elementos constitutivos estuviesen supeditados a la defensa, por lo que los criterios utilizados para su clasificación atienden principalmente a formalismos de carácter técnico. No obstante, en alguno de ellos y casi excepcionalmente, se han conservado detalles muy puntuales que, en el momento actual, permiten establecer relaciones estilísticas con la arquitectura civil y religiosa de su época. El hecho de que se incluyan en este estudio se debe a que son estructuras levantadas durante el periodo gótico y, sin duda, imprescindibles para entender los aspectos sociales e históricos de aquel momento en la provincia de Zamora. Con ellos, además, se completa el corpus arquitectónico que se cataloga.

265 RAMOS DE CASTRO, G., op. cit., 1978a, pp. 39 y 51; GUTIÉRREZ GONZÁLEZ, J. A., "Las fortificaciones de la ciudad de Zamora. Estudio arqueológico e histórico" en Cuadernos de investigación «Florián de Ocampo», $\mathrm{n}^{\circ}$ 6, Diputación de Zamora, 1990, pp. 56-58; CARBAJO MARTÍN, V. A., “Obras públicas” en Catálogo de la exposición CIVITAS. MC. Aniversario de la Ciudad de Zamora, Junta de Castilla y León y Caja España, Zamora, 1993, p. 96, ficha 19. 


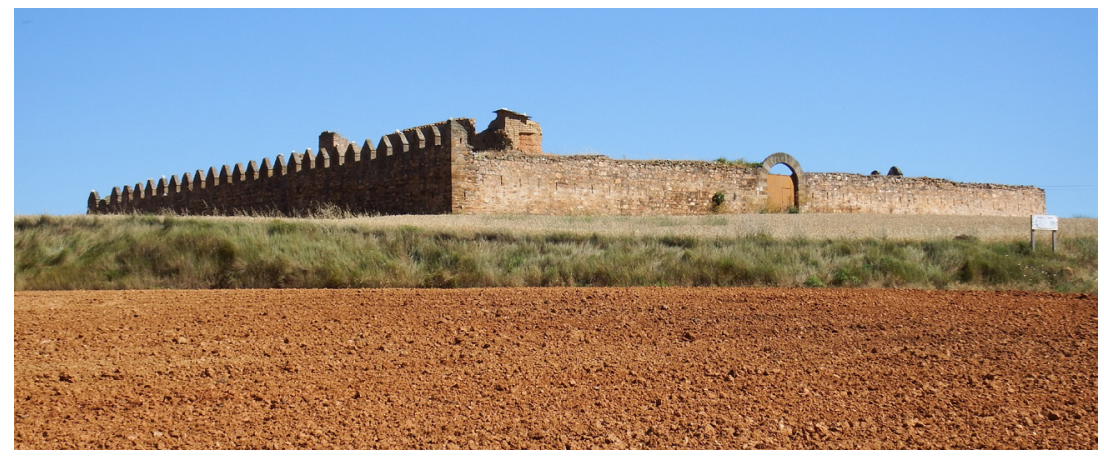

Su número no es especialmente significativo y su estado de conservación muy deficiente con excepción de los de Villalonso, en las cercanías de Toro, y el de Puebla de Sanabria. Del castillo de Granucillo se conserva, en relativo buen estado, únicamente su recinto exterior de planta cuadrangular, edificado en el siglo XV, con sus muros rematados en almenas (Figs. 249 y 250). Otros, como el castillo de Alba de Aliste, el de El Asmesnal, el de Villalpando y el de Castrotorafe, que habían sido edificados mucho antes, se reformaron igualmente en el siglo XV e, incluso, durante el siglo $\mathrm{XVI}$, pero en la actualidad se encuentran en estado ruinoso y en un proceso de deterioro de difícil solución.

El material utilizado en estos edificios de la provincia de Zamora fue siempre la piedra, que en los castillos de Villalonso y Puebla de Sanabria presenta una labra muy cuidada, mientras que en los castillos de Granucillo, Alba de Aliste, Castrotorafe, Villalpando y El Asmesnal se optó por la mampostería y, solamente en partes puntuales, se utilizó piedra de sillería.

Desgraciadamente la mayoría de las dependencias internas de estos castillos, edificadas con materiales menos sólidos que la piedra empleada para sus muros, se perdieron con el paso del tiempo y no han llegado testimonios documentales de ellas.

Los castillos de Villalonso y Puebla de Sanabria son edificios de tamaño medio y sólida edificación y, como se ha dicho, también los que han conservado sus estructuras en mejor estado.

El de Villalonso fue edificado en la segunda mitad del siglo XV, por Juan de Ulloa, casado con María Sarmiento (Fig. 251). Los escudos de armas de ambos cónyuges se encuentran labrados encima de la portada de acceso al recinto. Juan de Ulloa participó en la guerra de sucesión castellana del lado portugués y murió durante la contienda. Requisada la fortaleza por los 


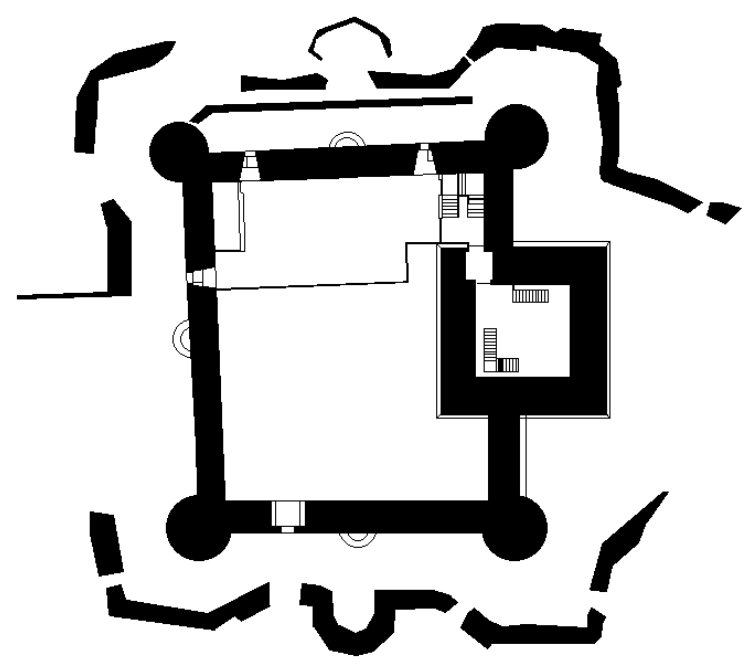

Fig. 251. Planimetría del castillo de Villalonso. Larrén Izquierdo y Pichel Ramos, 2010, p. 140.

Reyes Católicos, finalmente fue restituida a María Sarmiento, su esposa. El hijo de ambos, Diego Sarmiento, que participó en contra del Emperador durante la guerra de las Comunidades, momento en que se fabricó la barrera artillera, fue condenado y se le incautaron gran parte de sus bienes, entre ellos, este castillo. A cambio de una importante suma de dinero fue perdonado y recuperó la plaza de Villalonso.

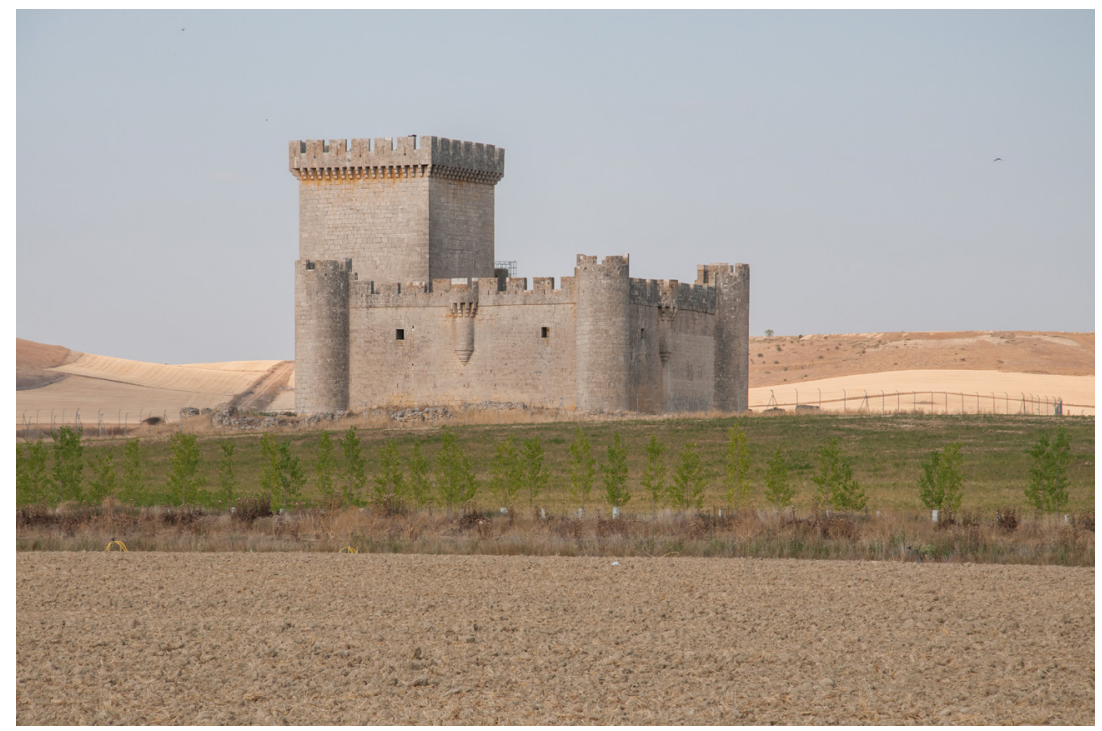

El castillo está ubicado en una amplia llanura (Fig. 252). Tiene planta cuadrangular con torres circulares en las esquinas y una poderosa torre del homenaje situada en el centro del muro norte, y reservada como suele ser habitual a vivienda del señor. Contó en su día con foso y barrera artillera que abrazaba la fortaleza propiamente dicha en todo su perímetro y que ha desaparecido casi completamente. La construcción del castillo 


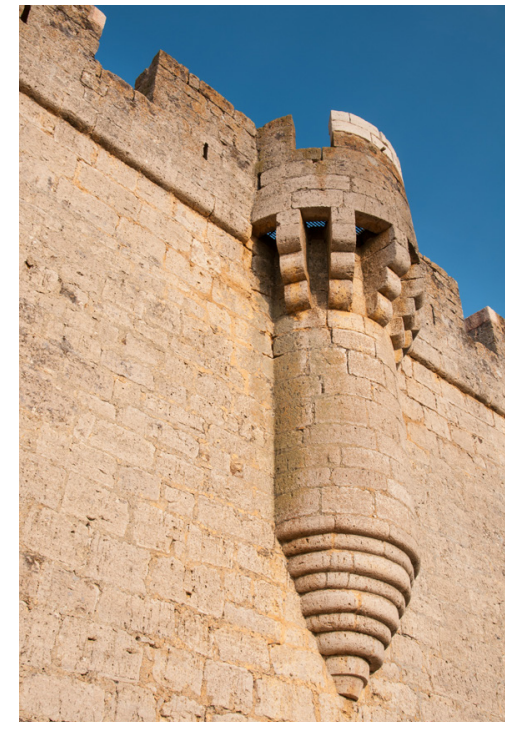

Fig. 253. Garitón del castillo de Villalonso data de la segunda mitad del siglo XV. Con posterioridad se añadió la barrera de la que apenas se han conservado restos ${ }^{266}$.

Cooper agrupó los castillos señoriales en la Corona de Castilla por maestros de obras y escuelas estilísticas y este de Villalonso lo estudia junto con el de Portillo (Valladolid) y Ampudia (Palencia) ${ }^{267}$; todos ellos con una planimetría y una torre del homenaje muy semejante. Como característica propia a los tres, menciona la situación de las garitas en el medio de los paños del edificio en vez de en las esquinas, y la similitud de los matacanes y adarves (Fig. 253). A pesar de todas estas similitudes afirma que no es posible adjudicar la autoría de estos tres castillos a un mismo maestro. Por su parte Cobos Guerra y Castro Fernández lo incluyen dentro de un grupo tipológico al que denominan "Castillos Señoriales de la Escuela de Valladolid", en el que engloban una serie de castillos con unas mismas particularidades atendiendo a su traza y disposición y entre los que también se encuentran los de Portillo, Torrelobatón, Fuensaldaña y Villafuerte, entre otros ${ }^{268}$.

El castillo de Puebla de Sanabria se levanta, a diferencia del de Villalonso, en lo alto de la población sobre un cerro rocoso en una posición estratégica más favorable (Fig. 254). Al parecer, en el lugar que hoy ocupa había existido anteriormente una torre llamada de los Losada, posiblemente del siglo XIV, pero fue en la segunda mitad del siglo XV y a instancias del IV conde de Benavente, cuando el castillo fue redificado y tomó su actual aspecto $^{269}$. De planta cuadrangular con torres, en su mayor parte circulares, tanto en las esquinas como en la parte central de

266 En el Informe Técnico realizado para la Fundación del Patrimonio Histórico de Castilla y León se apunta que algunos de los cambios que sufrió este castillo para adaptarlo a un mejor funcionamiento militar pudieron realizarse con motivo de la Guerra de las Comunidades. Informe Técnico de la Excavación, control arqueológico y lectura de paramentos del proyecto de rehabilitación del Castillo de Villalonso (Zamora) elaborado por Aratikos Arqueólogos, S.L., p. 86.

267 COOPER, Edward, Castillos señoriales de Castilla de los siglos XV y XVI, vol. 1, Fundación Universitaria Española, Madrid, 1980, pp. 242-248.

268 COBOS GUERRA, Fernando y CASTRO FERNÁNDEZ, José Javier de, "Los castillos señoriales de la Escuela de Valladolid: una tipología arquitectónica para un grupo social" en Actas del congreso Medievalismo y neomedievalismo en la arquitectura española, Ávila, 1990, pp. 147-162; COOPER EDWARD, Castillos señoriales en la Corona de Castilla, vol. I. 1, Junta de Castilla y León, Salamanca, 1991, p. 41.

269 Cobos Guerra y De Castro Fernández han planteado la posibilidad de que la actual torre del homenaje se levantara reaprovechando una torre anterior, probablemente la de los Losada, pero de tal forma que quedó engullida en la nueva construcción. Como consecuencia de ello hoy únicamente puede observarse lo edificado a finales del siglo 


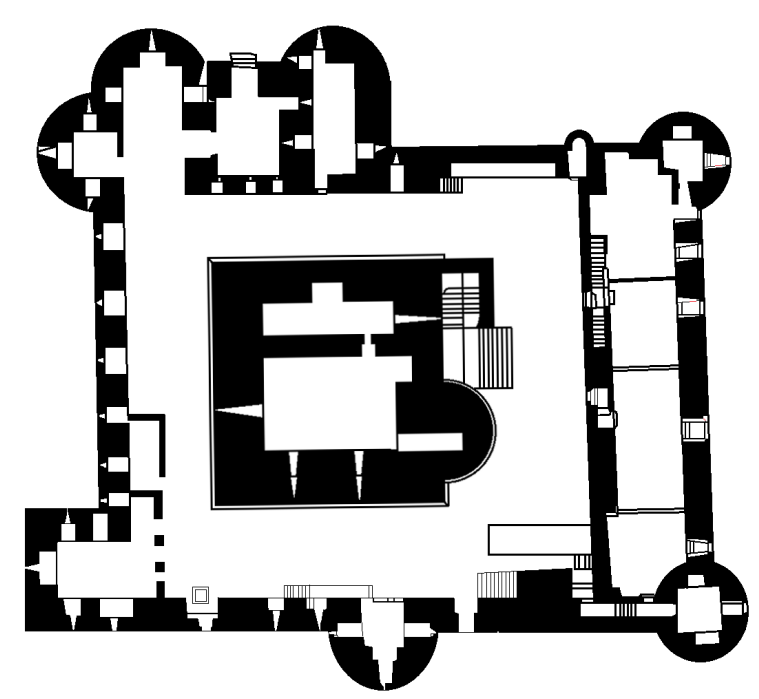

dos de sus lados, presenta la particularidad de tener la torre del homenaje exenta en el centro del patio de armas. Esta misma disposición tiene también el ruinoso castillo de El Asmesnal, situado como el de Puebla de Sanabria en una zona cercana a la frontera con Portugal (Fig. 255). Cooper señala que este tipo de castillo conformado por un torreón en la parte central rodeado de un recinto cuadrangular fue común durante el siglo XV en la frontera con Navarra, aunque se difundió por el resto de Castilla como lo evidencia, entre otros, el propio castillo de Puebla de Sanabria que él cita ${ }^{270}$.

El aspecto más relevante de la construcción de este castillo

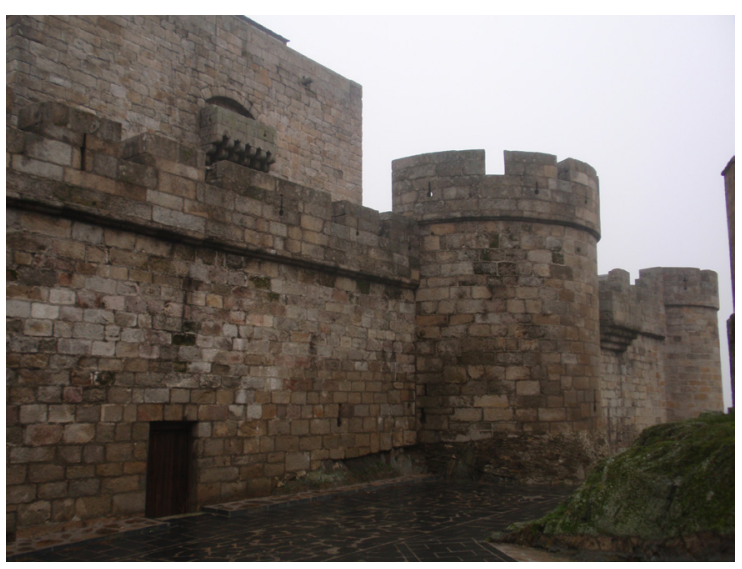

de Puebla de Sanabria está en relación precisamente con "la torre nueva" (torre del homenaje) que las fuentes documentales citadas por Cooper atribuyen al cantero Juan de Herrada o de

XV. COBOS GUERRA, Fernando y CASTRO FERNÁNDEZ, José Javier de, Castilla y León. Castillos y Fortalezas, Edilesa, León, 1998, pp. 224-225.

270 COOPER, Edward, Castillos señoriales en la Corona de Castilla, vol. I. 1, Junta de Castilla y León, Salamanca, 1991, pp. 40-41.
Fig. 254. Planimetría publicada por Cobos Guerra y De Castro Fernández, 1998, p. 224 (Arch. J.C. y L. Báez y San José, 1981) 
Fig. 256. Planimetría del castillo de El Asmesnal. Larrén Izquierdo y Pichel Ramos, 2010, p. 12

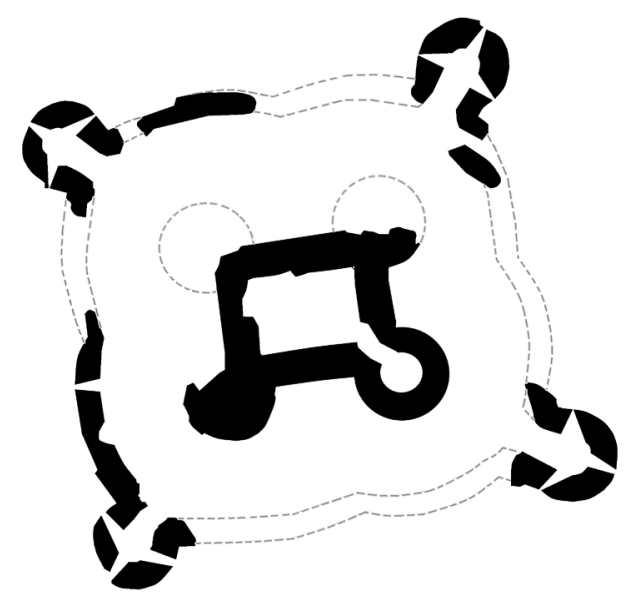

Rada ${ }^{271}$. El mismo autor señala que la obra en conjunto de esta fortaleza, patrocinada por don Rodrigo Pimentel, IV conde de Benavente, fue realizada entre 1477 y 1482. Los escudos del conde y su mujer, María Pacheco se encuentran labrados en el edificio.

A pesar del estado totalmente ruinoso del castillo de El Asmesnal ${ }^{272}$, cuyos restos actuales habría que datar en el siglo $\mathrm{XV}$, puede distinguirse en él una disposición semejante al de Puebla de Sanabria ${ }^{273}$. Un recinto exterior con cubos en las esquinas protegía la torre principal de mayor altura y dividida en dos plantas, que se levantaba en el centro y tenía planta cuadrada reforzada igualmente por cubos en las esquinas (Fig. 256). La planta superior de esta torre principal o torreón

271 COOPER, Edward, Castillos señoriales en la Corona de Castilla, vol. 1.2, Junta de Castilla y León, Salamanca, 1991, p. 475.

272 El castillo de El Asmesnal, actualmente de propiedad privada, se levanta en una dehesa perteneciente al municipio de Alfaraz en la comarca de Sayago. Sobre el lugar a mediados del siglo XVIII vid. CARNERO FELIPE, Ramón Manuel, “Asmesnal, antes villa, ahora dehesa", El Correo de Zamora, 28-3-84, p. 10. Este autor señala que en el año 1751 la tercera parte del castillo se encontraba ya caído. La villa que se asentaba en este lugar junto con el castillo era propiedad en aquel momento del marqués de Palacios y de la marquesa de Cardeñosa.

273 Gómez-Moreno que lo visitó en los inicios del siglo XX señala que existía ya a principios del siglo XIII cuando era conocido como Almeslal. La descripción que dejó de él es muy somera pues se encontraba ya enormemente destrozado. GÓMEZMORENO, M., op. cit., I, 1927 (1980), p. 299. Por su parte Pérez Sánchez en un artículo publicado en El Correo de Zamora considera que fue levantado a principios del siglo XVI sobre una edificación de época románica de la que quedaría el talud de los cimientos realizado con sillares labrados. PÉREZ SÁNCHEZ, Celedonio, "El castillo de Amesnal", El Correo de Zamora, 26-2-84, p. 9; Larrén Izquierdo y Pichel Ramos, que recogen el edificio en su obra Bienes culturales de la provincia de Zamora, señalan como cronología siglo XIII-XV. LARRÉN IZQUIERDO, Hortensia y PICHEL RAMOS, Luis, Bienes culturales de la provincia de Zamora, Zamora, 2010, p. 12. Lobato Vidal, que remonta su origen al siglo X, considera que la mayor parte de lo conservado en la actualidad obedece a la reconstrucción que sufrió a el edificio en el siglo XV. LOBATO VIDAL, J.C., Castillos y murallas de la provincia de Zamora, Zamora, 1997, p. 25. 
se encontraba cubierta con una bóveda de cañón de la que todavía subsisten algunos restos. Esta reforma, que podría datarse en la segunda mitad del siglo $\mathrm{XV}$, puede atribuirse a don Pedro Rodríguez de Ledesma, que gozó de las encomiendas de Castrotorafe y Peñausende y poseyó un destacado señorío en torno a El Asmesnal274. Esta fortaleza desempeñó un papel importante durante las guerras con Portugal en la segunda mitad del siglo XV en favor de Fernando el Católico, que fue apoyado decididamente por Pedro Rodríguez de Ledesma y sus hermanos García y Fernando 275 .

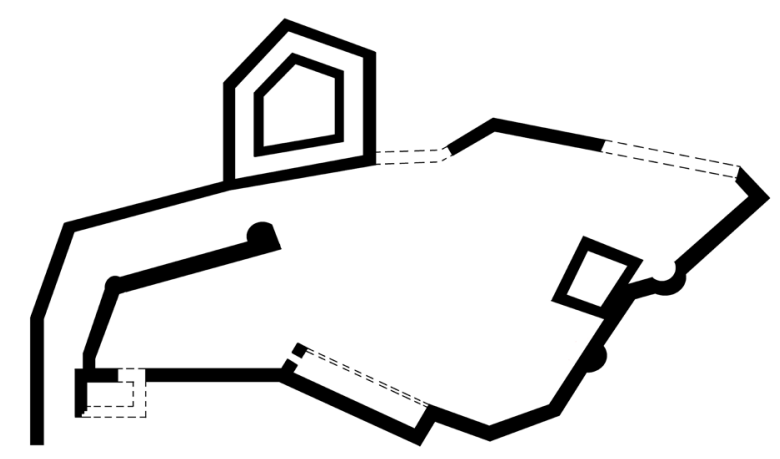

El castillo de Alba de Aliste también permanece totalmente en ruinas y su proceso de deterioro se ve favorecido por su situación en una comarca pobre de la provincia de Zamora lejos de cualquier centro turístico relevante (Fig. 257). La planta del castillo presenta trazado completamente irregular motivado por su adaptación al terreno (Fig. 258). Aproximadamente tiene 80 por 30 metros y los restos conservados parecen responder a periodos constructivos distintos. Está edificado en lo fundamental en mampostería de cantos pizarreños que fueron extraídos muy probablemente según Lobato Vidal de las canteras del cercano pueblo de Fonfría ${ }^{276}$. Como han señalado ya los autores que han

274 Sobre Pedro Rodríguez de Ledesma vid. VASALLO TORANZO, Luis, "Casa llamada de los Momos" en Zamora Año de 1850. Cuaderno de vistas de Zamora tomadas del natural y ejecutadas por Don José María Avrial y Flores (Coord. Pérez Martín, Sergio y Martín Bailón, Marco Antonio), Zamora, 2013, p. 237.

275 FERNÁNDEZ-DOMÍNGUEZ PRIETO, Enrique, "Zamora en la encrucijada histórica de España y Portugal”, Stvudia Zamorensia, 3, Salamanca, 1982, p. 37; SAINZ SAIZ, Javier, Rutas por la provincia de Zamora, Zamora, 2007, pp. 167-168; LARRÉN IZQUIERDO, Hortensia y PICHEL RAMOS, Luis, Bienes culturales de la provincia de Zamora, Zamora, 2010, p. 12; LOBATO VIDAL, J.C., Castillos y murallas de la provincia de Zamora, Zamora, 1997, p. 25.

276 LOBATO VIDAL, J.C., Castillos y murallas de la provincia de Zamora, Zamora, 1997, p. 15. 


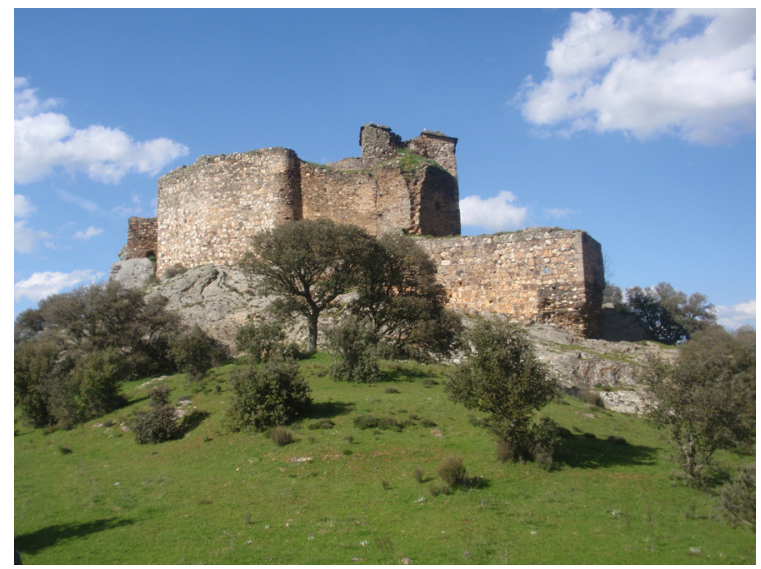

tratado sobre el edificio, en lo fundamental se podría reducir el proceso constructivo o, más bien los testimonios que se han conservado, a dos momentos ${ }^{277}$. Por un lado, a los siglos XII-XIII pertenecería el grueso de la fortaleza con los dos recintos y las dos torres; por otro, durante una importante intervención que tuvo lugar durante el siglo XV se levantó la puerta con el revellín y el primer baluarte y se reformó la torre principal, de planta cuadrada dividida en tres cuerpos.

El castillo de Castrotorafe, a 4 kilómetros de San Cebrián de Castro, está situado en el extremo noroccidental de lo que fue en su día un poblado medieval que se encontraba en una zona llana en la margen izquierda del río Esla, aunque con una caída abrupta hacia el propio río (Fig. 259).

Sus orígenes se remontan al año 1129, cuando el rey Alfonso VII concede fuero al concejo de Castrotorafe aunque la repoblación definitiva no tuvo lugar hasta el reinado de su hijo Fernando II, que en 1176 dona la villa a la Orden de Santiago ${ }^{278}$.

277 PINILLA GONZÁLEZ, Jaime, "Dos castillos zamoranos", Stvdia Zamorensia, I, Universidad de Salamanca, Salamanca, 1980, p. 59; GÓMEZ-MORENO, Manuel, Catálogo Monumental de España. Provincia de Zamora, 2 vols., Ministerio de Instrucción Pública y Bellas Artes, Madrid, 1927, (edición facsímil, Editorial Lebrija, León, 1980), p. 255; A.A.V.V., Patrimonio arqueológico y monumental en el embalse del Esla (Zamora). Tramo. Bretó de la Ribera-Ricobayo, Instituto de Estudios Zamoranos «Florián de Ocampo», Zamora, 2001, p. 168.

278 FERRERAS FINCIAS, Francisco Javier, "Castrotorafe (Zamora): conservación y ruina de la fortaleza santiaguista, 1494-1736" en Actas del Primer Congreso Nacional de Historia de la construcción, Madrid 19-21 de septiembre de 1996, Madrid, 1996, pp. 203-209; COBOS GUERRA, Fernando y CASTRO FERNÁNDEZ, José Javier de, Castilla y León. Castillos y Fortalezas, Edilesa, León, 1998, pp. 78-79; COBOS GUERRA, Fernando, CASTRO FERNÁNDEZ, José Javier de y CANAL ARRIBAS, Rodrigo, Castros y recintos de la frontera de León en los siglos XII y XIII. Fortificaciones de tapial de cal y canto o mampostería encofrada, Valladolid, 2012, pp. 84-86 y 166-169; ÁLVAREZ ORTIZ, Pilar, Historia de la Villa y Castillo de Castrotorafe, Salamanca, 2002. Esta última publicación recoge abundante bibliografía sobre esta villa y su castillo. 


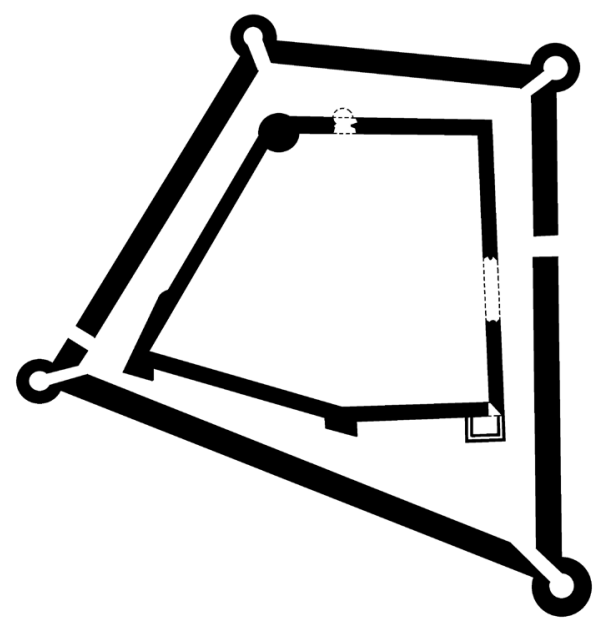

Durante la guerra de sucesión castellana, y concretamente en el año 1475 , el monarca portugués Alfonso $V$ tomó la villa pero no pudo hacerse con su castillo. De pocos años después se conserva una descripción muy interesante pues permite hacerse una idea del estado de todo el conjunto. La descripción fue realizada por los visitadores Francisco Martínez de Almaguer y Alonso de Esquivel, que fueron recibidos por el alcaide Francisco Treslago el martes 25 de noviembre de 1494. En aquel momento el comendador, que se encontraba ausente, era don Enrique Enríquez de Guzmán. La descripción relatada por los visitadores dice así:

"Y luego entramos en la villa en la cual cabran bien si poblada estoviese 400 vecinos poco mas o menos aunque a la sazón no ay mas en ella de 15 vecinos y con ellos y con los de la tierra con hidalgos y pecheros somos informados que ay 250 vasallos.

Esta dha villa los muros della estan todos aportillados y segun fuemos informados nos dijeron quel señor rey de Portugal los mando derrocar son los muros de piedra mampuesta y algunos petriles de tapial.

Llegamos a la fortaleza que esta junto con el río que se llama Esla la qual dha fortaleza tiene una cava acia la villa no muy honda y della a la puerta de la barrera salio el dho alcaide e nos metio por la mano en la dha fortaleza e se salio fuera della e tomamos posesion de la dha fortaleza.

Visitamos la dha fortaleza la qual antes que entro en ella hacia la villa estaba una cava no muy honda y una puente de madera por do entramos a la fortaleza entramos en la barrera la cual
Fig. 259. Planimetría del castillo de Castrotorafe. Pinilla González, 1980, p. 62. 
cerca toda la fortaleza hacia el río e hacía la villa la cual es muy buena e harto ancho los muros y harto ancha de muro de piedra mampuesta toda y algunos petriles de tapia e otros de piedra mampuesta toda y algunos petriles de tapia e otros de piedra mampuesta e almenas tiene e los traveses muy buenos cubos los que le hace menester e sus troneras en toda la dha barrera.

Entramos en la dha fortaleza la cual esta muy bien reparada y los muros della muy buenos y bien reparados y de piedr mampuesta y pues esta muy bien reparada y como deve y por no alargar no se dice por menudo las cosas della.

Visitamos el aposentamiento de la dha fortaleza y entramos en una sala que en el esta en la cual esta una chimenea e en la dha sala una ventana con una reja de hierro que sale al río y en la dha sala una camara con una reja de hierro que sale al río y en ella un retrete y par de el retrete una escalera que sube a lo alto que esta encima del aposentamiento todo esto suso dho esta muy bien reparado nuevamente hecho lo cual todo diz que mando hacer el dho comendador todo el otro aposentamiento de grano e basticimiento y bestias esta bien reparado tejado con teja e todo ello lo uno y lo otro de madera basta" 279 .

A finales del siglo XV como se especifica en esta descripción la villa estaba muy poco poblada, pues de los cuatrocientos vecinos que podía acoger solamente vivían quince. Con el tiempo, al ir perdiendo la importancia estratégica que tuvo en su día se agravó la situación hasta el punto que a finales del siglo XVII todo este conjunto había sido abandonado. A pesar de que lo conservado del castillo son ruinas, impresionan por la monumentalidad que todavía hoy presentan.

Los elementos arquitectónicos que constituyen el castillo de Castrotorafe y que permanecen en pie responden a distintas épocas y su cronología ha quedado delimitada por Cobos Guerra y De Castro Fernández ${ }^{280}$. De este modo la muralla urbana que sirvió para acotar en dos de sus flancos el castillo pertenecería a los siglos XII y XIII, el castillo se levantó en el siglo XIV y la barrera se edificó en la segunda mitad del siglo XV. Durante la segunda mitad de este siglo XV, además de la construcción de la 279 COBOS GUERRA, F. y CASTRO FERNÁNDEZ, J. de, op. cit., 1998, p. 78. 280 Ídem, p. 79 
barrera, también se habían hecho importantes reparaciones en el conjunto del castillo, como queda reflejado en la descripción anteriormente citada en la que los visitadores dan cuenta del buen estado que presentaba. A principios del siglo XVI continuaron las obras y se construyeron nuevas salas, corredores y una panera ${ }^{281}$.

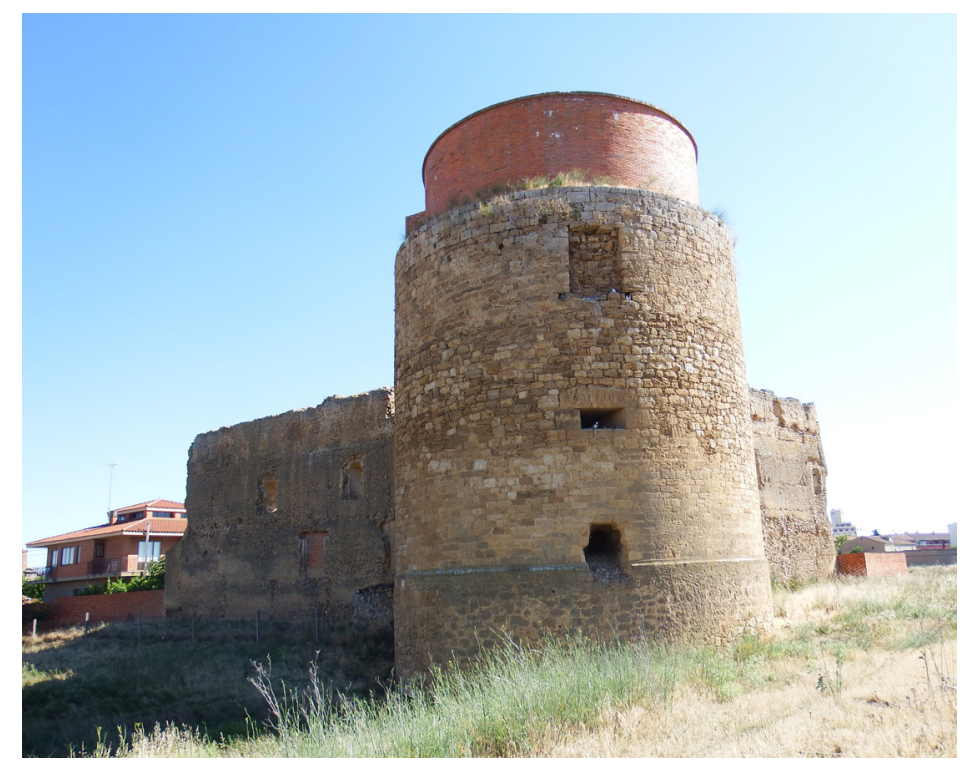

Los restos existentes actualmente del castillo de Villalpando pertenecen al edificio que mandó construir don Iñigo de Velasco, Condestable de Castilla, y que tenía planta cuadrada con un potente cubo edificado en sillería y situado en la esquina noroeste ${ }^{282}$. Aparte de este cubo se conservan dos lienzos de muro, no obstante, en ellos, al igual que sucede en el cubo, los vanos que se observan pertenecen a época moderna (Fig. 260).

Como se ha dicho anteriormente, en algunos de estos castillos se han conservado pequeños detalles constructivos que dan testimonio de su pertenencia al periodo gótico. En el castillo de Villalonso los únicos restos que se conservan con características de estilo son el arco apuntado que da acceso al patio de armas y algunos arcos escarzanos correspondientes a los vanos; en el castillo de Puebla de Sanabria son numerosos los arcos escarzanos y conopiales conservados en distintas partes del edificio. 


\section{El castillo-palacio de los Pimentel en Benavente}

Un caso particular, a medio camino entre los castillos y los palacios urbanos, es el castillo-palacio de Benavente, residencia de los Pimentel, condes de la localidad que les dio el título y del que en la actualidad únicamente se conserva la denominada Torre del Caracol. Aunque su origen tuvo lugar en la Edad Media como elemento puramente defensivo de la ciudad junto con las murallas, con el paso del tiempo fue perdiendo ese carácter, de tal forma que a finales del siglo XV y principios del XVI se convirtió en una de las residencias más espléndidas de Europa, admirada por todos aquellos que la conocieron y, en especial, por los viajeros extranjeros que dejaron constancia, en los escritos que relataban sus itinerarios, de la grandeza del edificio y de la suntuosidad de sus estancias ${ }^{283}$.

De finales del siglo $X V$, en época de don Rodrigo Alonso Pimentel IV conde (1461-1499), existe un testimonio realmente significativo que constituye la primera descripción detallada del castillo según se encontraba en aquel tiempo. Se debe al viajero alemán Jerónimo Münzer y dice: "La fortaleza de Benavente es de las mejores y más bellas del reino castellano, y exceptuando las de Granada y Sevilla no hay en toda España ninguna otra que con ésta pueda ser comparada. Álzase en la cima de un montículo que esta fuera de la ciudad; su forma es cuadrada; flanquea cada uno de los cuatro ángulos una robusta torre; rodéala un foso y la protege una muralla sólidamente fortificada. En el interior tiene un patio, también cuadrado; capilla, salas y cámaras adornadas con figuras de diversas clases; áureos artesonados, columnas de mármol, todo, en suma, cuanto puede concurrir a la mayor suntuosidad de la ornamentación. Al pie del montecillo en que se yergue la fortaleza, corre el río Órbigo. En los sótanos hay profusión de bóvedas, arcos, cuadras, etc., pero todo tan intrincado, que quien entra allí se cree estar en el seno de un laberinto. Tiene una larguísima galería en rampa que va a dar al río, por la que llevan a abrevar a los caballos, y tantas estancias para molinos, depósitos de aguas y otros menesteres que, sin verlo, no es posible formar cabal idea. De mí puedo asegurar que

283 Los testimonios aportados por los viajeros de época posterior están recogidos en la ficha de este estudio dedicada al edificio. 
no conozco otro castillo que tales subterráneos ni con tal riqueza en las habitaciones que alumbra el sol.

El conde, que es hombre magnífico y liberal, no estaba allí a la sazón; pero el castellano o alcaide, como se dice en lengua española, nos enseñó personalmente cuanto había de notable. Su señor es aficionadísimo a toda suerte de animales; vimos nueve leones y otros dos que con un lobo comían tranquilamente en la misma jaula, en la cual entró un negro de Etiopía que comenzó a acariciarlos, de lo que las bestias parecían mostrarse muy complacidas: ioh milagros del trato, que logra que las mismas fieras se tornen mansas con quien las halaga! Según me dijo el alcaide, gástase al año mil quinientos ducados en la alimentación de aquéllas. Ha pocos años tuvieron también un elefante, pero se murió por no poder resistir los fríos del invierno.

Aunque es mucho más lo que pudiera escribir acerca de este castillo, quiero omitirlo en gracia de la concisión; añadiré tan sólo que el panorama que se descubre desde lo alto de la fortaleza por la parte que da al río es bello en grado sumo, porque desde allí se alcanza a ver toda la comarca» ${ }^{284}$.

Pocos años después, en 1501, visitó Benavente Antoine de Lalaing, cuyo testimonio deja constancia de la gran hospitalidad que ofrecía don Alonso Pimentel V conde (1499-1530) a sus huéspedes. Describe el castillo como un edificio de numerosos aposentos muy bien arreglados, amplio salón y galerías de ricos materiales. No duda en calificarlo como uno de los castillos más exquisitos de España. También hace alusión Lalaing a los espacios denominados El Jardín y El Bosque.

El relato de Antoine Lalaing dice: «Y el jueves, les invitó por un caballero a que fuesen a ver dos bellísimos parques cerca de su palacio, uno de los cuales estaba lleno de liebres, varias de las cuales son blancas, y había allí un camello, y al extremo un jardín y un cuerpo de edificio. El otro parque, a un cuarto de legua de allí, está lleno de ciervos y de gamos, de venados y de corzos. El hombre encargado de ello les da de comer dos veces al día. Estos animales están tan acostumbrados a él que, al oir

284 El texto completo de Münzer y otros textos de viajeros que visitaron Benavente y conocieron su castillo pueden consultarse en GARCÍA SIMÓN, Agustín, Castilla y León según la visión de los viajeros extranjeros. Siglos XV-XIX, Salamanca, 1999, pp. 353-366. 
sonar su corneta, acuden a comer delante de él. Al extremo de cuyo parque hay un cuerpo de edificio, conteniendo dos galería y tres o cuatro habitaciones, cuyos artesonados están muy bien tallados y dorados, y llenos de otras pinturas muy agradables. Allí les envió un buen almuerzo. Luego envió a don Juan de Pimentel, su tío, caballero antiguo, que en su tiempo había servido al duque Carlos de Borgoña, y a su hermano bastardo, al encuentro de ellos, que los llevaron a comer al castillo con el conde, que les obsequió muy bien. E hizo, después de comer, tocar varios buenos instrumentos. Luego les enseñó su casa de alto abajo. Hay allí dos galerías muy bien talladas y doradas por encima; las columnas son algunas de alabastro, otras de mármoles, otras de jaspes, otras de piedra de toque. Junto a esas galerías hay un salón de quince a dieciséis pies de ancho, y de ochenta de largo, abierto por un lado sobre el río, hacia el camino de Galicia, el más suntuoso que se pueda ver; en la entrada del cual dos colmillos de elefante sostienen el arco. Allí vieron ocho o diez habitaciones muy bien arregladas, cuyos artesonados están muy bien tallados y todos dorados. Nada digo de la capilla; no me preguntéis si está bien arreglada; su bóveda está, mejor de lo que se sabría decir, tallada y muy ricamente dorada, y también pintada como no es posible mejor. Abajo hay leones y leopardos, y otras bestias. En suma: es uno de los más exquisitos castillos de España. Los fosos están todos ampliamente construidos, y está rodeado por muy gruesas torres bien erguidas y provistas de buenos salientes; $y$, si lo alto estuviese abatido, no sería posible tomarlo, por lo hueco de abajo» ${ }^{285}$.

Estas descripciones, que informan en general de la magnificencia del edificio, son más de elogio y sorpresa ante lo que se veía que un análisis pormenorizado que pudiese servir para conocer su distribución. No obstante, aportan datos importantísimos para el conocimiento de una gran residencia de finales de la Edad Media y tienen la particularidad de ser el único testimonio escrito del castillo antes de las reformas que lo transformaron en el siglo XVI. A los textos anteriormente citados hay que añadir el pleito que se ha conservado y que interpuso doña María Pacheco, viuda de don Rodrigo Pimentel, IV conde 
de Benavente, a su hijo don Alonso Pimentel, $\mathrm{V}$ conde ${ }^{286}$. Las declaraciones testificales en él incluidas resultan imprescindibles para conocer el edificio a finales del siglo XV y principios del siglo XVI. Existe igualmente documentación relativa a la fase tardía del castillo-palacio de Benavente donde se constata la importante actividad de consolidación, reforma y ampliación que se llevaron a cabo en el edificio por los diferentes condes de Benavente y especialmente Rodrigo Alonso Pimentel, IV conde, y Alonso Pimentel, $\mathrm{V}$ conde.

En razón de estos testimonios y documentos $y$, aunque el aspecto exterior del edificio en gran medida siguiese siendo el de una fortificación encaramada en lo más alto de la villa y amurallado, salvo en la parte oeste que daba al río, lo cierto es que su carácter a finales del siglo XV y principios del XVI era más residencial, con lujosas cámaras en su interior y dotado de grandes jardines que lo convertían en un lugar de vivienda y descanso de los condes.

Esta magnificencia en lo arquitectónico a lo que hay que sumar los jardines y casas de campo para el recreo y la caza, además del gusto por los animales exóticos traídos de otros continentes, podía ser en aquel momento prácticamente excepcional en las residencias nobiliarias de España, sin embargo, existen testimonios de antecedentes muy notables en algunas residencias cortesanas de Europa ${ }^{287}$. En ningún modo, por tanto, se puede hacer una equivalencia con el resto de residencias señoriales de finales de la Edad Media en la provincia de Zamora, pues se trata

286 AHN. Sección Nobleza. Toledo. Osuna. $478^{2} 4^{31}$. (Este pleito ha sido citado por Cooper, Beceiro Pita y por González Rodríguez, Regueras Grande y Martín Benito. COOPER, Edward, Castillos señoriales en la Corona de Castilla, vol. 1.2, Junta de Castilla y León, Salamanca, 1991, pp. 471-473. BECEIRO PITA, Isabel, "La fortaleza de Benavente en el siglo XV", Brigecio, VII, 1997, pp. 185-204; GONZÁLEZ RODRÍGUEZ, Rafael, REGUERAS GRANDE, Fernando y MARTÍN BENITO, José Ignacio, El Castillo de Benavente, Centro de Estudios Benaventanos «Ledo del Pozo», Salamanca, 1998, p. 42)

287 Quizás el ejemplo más paradigmático lo encarnó, durante la primera mitad del siglo XV, el Duque de Berry que llegó a ser uno de los coleccionistas más importantes de la historia. Poseía un gran número de castillos con espléndidos jardines y animales exóticos. Conocemos gran parte de su modo de vida y la imagen de algunas de sus residencias a través de las bellísimas miniaturas que decoran Las muy ricas horas del Duque de Berry, el manuscrito iluminado más importante de los que se realizaron en su tiempo. Las muy ricas horas del Duque de Berry: con las 131 miniaturas facsímiles a todo color del manuscrito del Musée Condé de Chantilly, prefacio de Rogelio Buendía; textos de Jean Longnon y Raymon Cazelles (traducidos del francés por Adela R. Vargas), Madrid, Casariego, 1989. 
de un edificio excepcional que solo podría compararse con las grandes residencias nobiliarias españolas y europeas.

Este esplendor que vivió la villa de Benavente y su palacio durante todo el siglo XVI se evaporó cuando los condes se trasladaron como el resto de la alta nobleza española a la Corte. De ahí que, durante los siglos XVII y XVIII, el palacio entró en una decadencia paulatina que le afectó de manera inexorable ${ }^{288}$. A esto hay que añadir el incendio que sufrió en enero de 1809 durante la guerra de la Independencia y el acusado deterioro progresivo que padeció durante todo el siglo XIX. A finales del año 1898 los restos que se conservaban fueron adquiridos en subasta por don Telesforo Benito León, vecino de Benavente, a la Casa de Osuna, en cuyo título había quedado incorporado el condado de Benavente. Don Telesforo pagó por los restos del antiguo castillo la cantidad de 23.000 pesetas e inmediatamente después los cedió al Ayuntamiento por esta misma cantidad a pagar en seis plazos ${ }^{289}$. El espacio ocupado por estas construcciones desaparecidas fue utilizado por el Ayuntamiento para extender los jardines públicos.

Durante los últimos años del siglo XIX y las primeras décadas del siglo XX el castillo fue desmontado y su piedra reutilizada ${ }^{290}$. Testimonio de la degradación del castillo son las numerosas fotografías, dibujos y grabados que se han conservado desde finales del siglo XIX. En este proceso de desmantelamiento sufrido por el edificio durante la primera mitad del siglo XX intervino Arthur Byne (1884-1935) ${ }^{291}$ que trabajaba en España

288 SIMAL LÓPEZ, Mercedes, Los condes-duques de Benavente en el siglo XVII. Patronos y coleccionistas en su villa solariega, Centro de Estudios Benaventanos «Ledo del Pozo» (C. E. C. E. L. - C. S. I. C.), Benavente, 2002

289 Sobre la venta de la fortaleza vid. GONZÁLEZ RODRÍGUEZ, Rafael, REGUERAS GRANDE, Fernando y MARTÍN BENITO, José Ignacio, El Castillo de Benavente, Centro de Estudios Benaventanos «Ledo del Pozo», Salamanca, 1998, pp. 116-119.

290 Todo el proceso de degradación al que fue sometido el castillo palacio de los condes de Benavente está expuesto de forma pormenorizada en la ficha correspondiente del catálogo.

291 Arthur Byne fue un arquitecto formado en Pensilvania que se convirtió en un estudioso del arte español de cierto prestigio. Con el paso de los años él y su mujer se decantaron por el coleccionismo a la vez que trabajaban como marchantes. Está considerado uno de los máximos responsables de la salida de una gran cantidad de obras de arte español con destino a coleccionistas privados y museos de los EE.UU. 
como marchante de arte al servicio del magnate de la prensa norteamericana William Randolph Hearst (1863-1951) ${ }^{292}$.

Lo actualmente conservado es una parte muy pequeña de lo que fue este conjunto monumental descrito por los viajeros y del que todavía, aunque arruinado, llegó a ver a principios del siglo XX Gómez-Moreno, quien incluyó en su Catálogo Monumental correspondiente a la provincia de Zamora fotografías del estado ruinoso que presentaba el edificio; una de ellas de la puerta principal del castillo que ya por entonces no se conservaba. Este autor describe las partes desaparecidas en los siguientes términos: "El castillo yérguese en lo más prominente de hacia el sur. Es irregular en su disposición y no tan grande y espléndido como el fausto de sus moradores hacía imaginar; pero ha de considerarse que no resta sino el esqueletaje de un cuerpo al que cien años han ido arrancando miembros desde su incendio por los franceses, y llegará no lejana fecha en que todo desaparezca. Le cercan tres lienzos: el uno en curva, de suroeste a noreste, $y$ dos rectilíneos por el norte y el oeste, conservando tres torres de ángulo, más o menos deterioradas, y otra hacia el sureste, que parece fueron macizas, y todo ello hecho de tapicería como la cerca de la villa. En el promedio del muro de hacia el oeste abríase la puerta primitiva, en forma de arco agudo, con tres roscas desligadas de ladrillos finos y desiguales entre gruesos tendeles de mortero blanco; la tercera rosca más bien parece ser arranque de una bóveda de cañón que se extendería por fuera. En el lienzo septentrional queda una ventanilla arqueada, hecha igualmente de ladrillo.

Por allí mismo se hizo puerta, quizá bajo el segundo conde D. Rodrigo, no muy entrado el siglo XV, defendiéndola con una gran torre de mampostería, antemuro y ancho foso, que se salva con un puente hecho con sillares marcados, despojo de algún edificio románico. La puerta del antemuro forma un arco carpanel con molduras de poco gusto; encima se ostentarían dentro de familia adinerada. Con el paso de los años se convertiría en uno de los magnates más importantes de la prensa americana, de tal modo, que llegó a controlar multitud de periódicos, revistas y cadenas de radio. Su fortuna y su interés por el patrimonio le llevaron a adquirir multitud de obras de arte medievales con intención de decorar sus mansiones californianas de entre las que destacaba la denominada La Cuesta Encantada. Uno de sus proyectos que nunca llegó a realizarse fue la creación de un Museo de Arte Medieval en San Francisco. Sobre la vida de este personaje vid. NASAW, David, HEARST. Un magnate de la prensa, Tusquets, Barcelona, 2005. 
un recuadro las armas de los Pimenteles, y a los lados surgen pequeños cubos, ligados por arriba con una bóveda escazana que cobija la puerta. Otra interior es casi de medio punto y con algunas molduras del propio estilo" 293.

Por último resulta muy interesante la cantidad de restos de azulejería y yeserías que encontró Gómez-Moreno durante su recorrido entre los escombros del castillo y de los que también da constancia de manera exhaustiva ${ }^{294}$.

De la intervención llevada a cabo por Byne, por la cual adquirió en 1929 una serie de elementos arquitectónicos del interior del castillo-palacio, ha quedado testimonio documental, gracias al cual se sabe que pagó por ellos 28.000 dólares y que salieron con destino a Nueva York. A pesar de lo interesantes que puedan a priori resultar estos datos en relación al estudio del castillo palacio de Benavente, se verá a continuación que plantean algunos interrogantes y que como consecuencia no son del todo fiables. Conocemos estos elementos arquitectónicos gracias a los dibujos que de ellos realizó Byne y que se conservan actualmente en la biblioteca biblioteca del C. W. Post Center de la Long Island University [CWP], Nueva York, Nueva York ${ }^{295}$. Están incorporados en la ficha de inventario del tomo 76, pp. 44 a 46 en la que se incluyen los siguientes datos:

S/B LOT \#284 - ART.\#1

VARIOUS DECORATIVE STONE ELEMENTS

FROM THE CASTLE OF BENAVENTE, SPAIN

SPANISH GOTHIC XV CENTURY

Consisting of Stone portals, various Windows, a carved

Vaulted Ceiling, and carved Label Moulding.

Acquired from Arthur Byne, of Madrid, Spain, 9/19/29.

293 GÓMEZ-MORENO, M., op. cit., I, 1927 (1980), p. 258.

294 Ídem, pp. 259-260

295 Citado por MERINO DE CÁCERES, José Miguel, “Algunos datos sobre el traslado a los Estados Unidos de determinadas piezas arquitectónicas del castillo de Benavente", Brigecio (Revista de Estudios de Benavente y sus tierras), núm. 3, Centro de Estudios Benaventanos «Ledo del Pozo», 1993, p. 220, nota 13. 
Los citados dibujos, que llevan consigo algunos datos técnicos, fueron exhumados en su momento por Merino de Cáceres ${ }^{296}$. Cuando Byne adquirió estas piezas y las dibujó se encontraban la mayoría desmontadas y fuera de su primitivo emplazamiento, según él mismo relata en una carta de 26 de abril de 1929 dirigida a Julia Morgan arquitecta de Hearst ${ }^{297}$, de modo que sus indicaciones están ya condicionadas por la falta de precisión en cuanto a la localización.

Merino de Cáceres publicó los dibujos realizados por Byne que consisten en un dibujo que representa una portada, otro que representa la sección y planta de una bóveda y uno último en el que se observan varios elementos como una portada, ventanales decorados con tracerías y un escudo rodeado de una inscripción. Están realizados en hojas numeradas de la número dos a la cuatro, lo que ya hizo sospechar a Merino de Cáceres que originariamente existiera una más con el número uno. Los motivos representados corresponden a elementos arquitectónicos y decorativos del castillo, que fueron vendidos por piezas y pasaron a enriquecer las colecciones de arte de Hearst ${ }^{298}$. Cuando Byne hizo estos dibujos anotó en ellos datos de interés como son las dimensiones de lo representado así como el número de piezas que lo componían, si bien las referencias respecto a la procedencia concreta de las mismas es poco precisa, de modo que no es posible determinar donde estaban todos estos elementos arquitectónicos y si pertenecieron a un mismo espacio. Con la venta de parte de la colección de Hearst en 1940 se perdió el rastro de los elementos recogidos en estos dibujos por eso el testimonio que ellos representan es especialmente valioso.

En la hoja número dos está representada una portada gótica en ligero arco apuntado, compuesto de baquetones y escotaduras que se prolongan por las jambas tras una breve interrupción de

296 MERINO DE CÁCERES, J. M., op. cit., 1993, pp. 211-225. Con posterioridad, en el año 2012, parte de este estudio, sin aportaciones nuevas, se incorporó en MERINO DE CÁCERES, José Miguel y MARTÍNEZ RUIZ, María José, La destrucción del patrimonio artístico español. W. R. Hearst: «El gran acaparador», Cátedra, Madrid, 2012, pp. 475-482.

297 MERINO DE CÁCERES, J. M., op. cit., 1993, p. 220.

298 Sobre la destrucción y despojo del castillo de Benavente vid. MARTÍNEZ RUIZ, María José, La enajenación del patrimonio en Castilla y León (1900-1936), Junta de Castilla y León, 2008, I, pp. 353-357; II, pp. 501-503, láms. 65, 66, 67 y 68. 


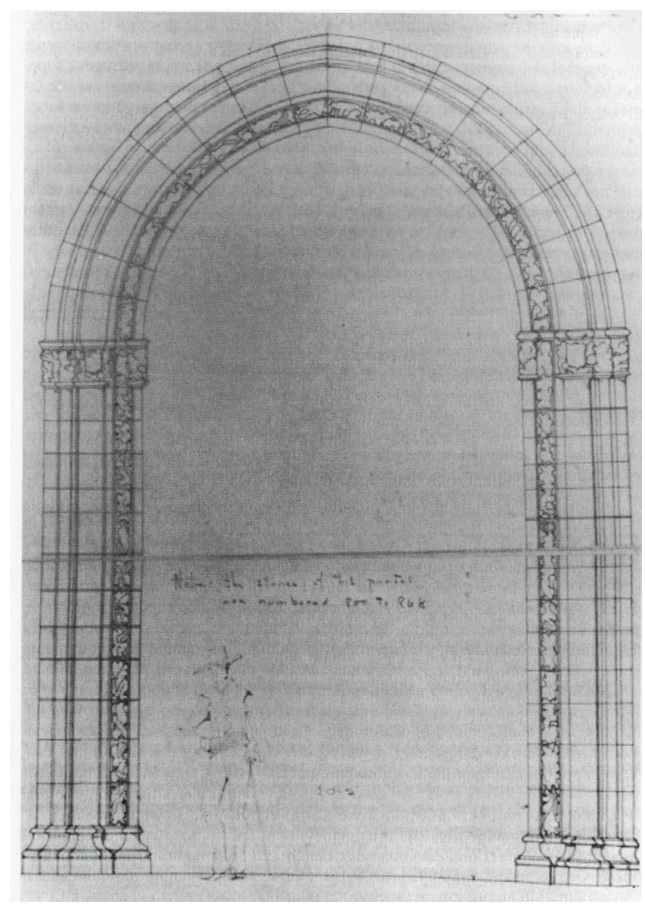

un friso decorado con hojarasca y escudetes que sigue la línea de imposta (Fig. 261). Las molduras de las jambas descansan en pequeñas basas elevadas sobre pedestales. A su vez, la banda interior de la rosca del arco muestra una labor ornamental de motivos vegetales calados que se prolonga sin solución de continuidad a lo largo de las jambas. Según Byne las dimensiones de la portada eran de 3,10 metros de luz por 7 metros de altura. A juzgar por los elementos que aporta el dibujo esta portada puede corresponder a la reforma llevada a efecto por el $V$ conde de Benavente durante las primeras décadas del siglo XVI. EI texto que acompaña a este dibujo hace constar que las piedras de dicha puerta (hay que entender que al ser desmontada) se numeraron de la ochocientos a la ochocientos sesenta y ocho. Por lo tanto el número de piezas que compusieron esta portada era de sesenta y nueve ${ }^{299}$.

En la hoja número tres están representadas la planta y sección de una bóveda de crucería con combados que cubría un pequeño espacio a juzgar por las dimensiones reseñadas: 3 , 75 metros por 3, 95 metros (Fig. 262). Se trata de una bóveda de crucería con terceletes y combados que dibujan una flor cuadripétala con los extremos en forma de arco conopial. El diseño está configurado por la gran clave central decorada 


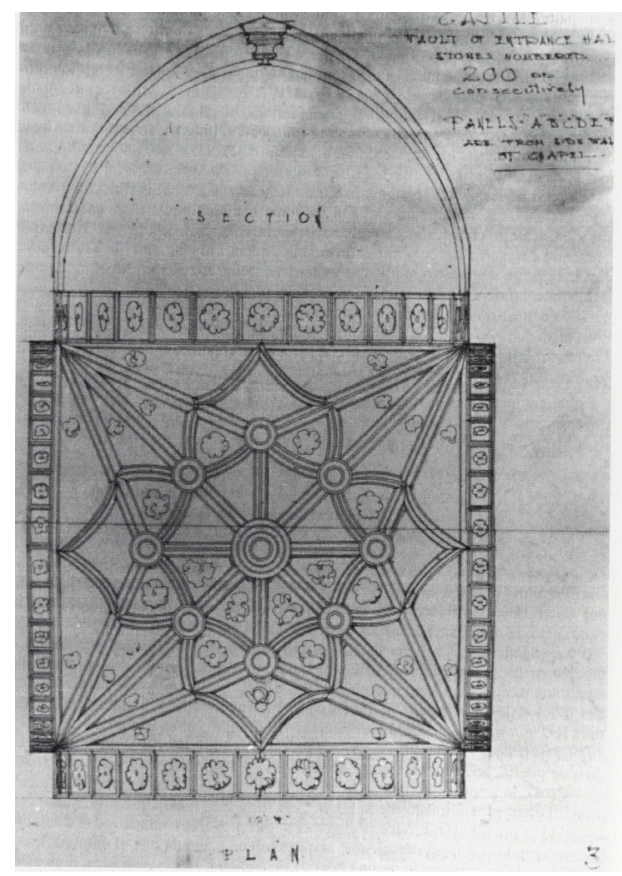

con molduras en círculos concéntricos, de la que parten ocho nervios radiales que concluyen en otras claves secundarias. Estas claves están emplazadas en los vértices de un octógono de nervios cóncavos cuyas caras forman la base de una corona de triángulos que dan lugar a una estrella de ocho puntas. A partir de ellas, los nervios convergen en las esquinas hacía una probable ménsula y en el centro de las cuatro caras en arcos conopiales cuya cúspide se dirige hacia la clave de los fajones. El dibujo muestra que los plementos en su mayor parte iban decorados con rosetas. A partir de los testimonios aportados por Byne sabemos que esta bóveda estaba construida en piedra y que estuvo formada por doscientas piezas numeradas en orden consecutivo. En los estudios relativos a estos dibujos se clasifica a esta bóveda como obra gótica sin definir su cronología ${ }^{300}$. En realidad este tipo de bóveda con nervios combados que dibujan una flor cuadripétala en torno a la clave central y que acoge una figura poligonal comenzó a darse, con sus distintas variantes a finales del primer tercio del siglo XVI. En Zamora se conservan dos bóvedas de idéntico trazado en las cabeceras de la iglesia de San Andrés. Sin embargo, parece más conveniente relacionarla directamente, como ya hiciera Regueras Grande, con la bóveda de la capilla del Hospital de Benavente y con las bóvedas de la nave central de la iglesia de Santa María del Azogue también 
de Benavente, en ambos casos patrocinadas por el $\mathrm{V}$ conde de Benavente ${ }^{301}$. Incluso por los detalles decorativos que se aprecian en el dibujo podría vincularse, como hiciera Javier Martínez con las bóvedas de la nave de la iglesia de Santa María del Azogue, con los maestros yeseros Corral de Villalpando o con alguno de los artistas que siguieron su senda ${ }^{302}$.

Este dibujo de la mencionada bóveda va acompañado por un texto en la parte superior derecha que dice que se trata de la bóveda del vestíbulo de entrada. Su reproducción literal es: "CASTLE" / VAULT OF ENTRANCE HALL / STONES NUMBERED / 200 ON / CONSECUTIVELY / PANELS "A" "B" "C" " $D$ " "E" "F" / ARE FROM SIDE WALLS / OF CHAPEL" ${ }^{303}$. En este texto se hace referencia también a unos paneles procedentes de las paredes laterales de la capilla identificados por las letras A, B, C, D, E y F, que no aparecen en los dibujos bajo estas siglas, a no ser que hagan referencia a las seis ilustraciones de la página siguiente.

Aunque se ha señalado que esta bóveda perteneció a la capilla del palacio, Regueras Grande lo ha puesto en cuestión, ya que en el pleito citado con anterioridad se alude a la existencia en la residencia de los condes de Benavente de tres capillas, de las cuales ninguna llegó a estar cubierta por una bóveda de nervios góticos ${ }^{304}$.

La hoja número cuatro incluye seis detalles arquitectónicos correspondientes a vanos, molduras y ornamentos (Fig. 263). El primero de estos detalles es un arco ligeramente rebajado con un perfil escalonado, que el autor se ha cuidado de reflejar en una sección. En el momento de ser desmontada esta pieza debía de encontrarse ya descontextualizada porque en la leyenda aclaratoria se duda de que fuese una puerta o una ventana ${ }^{305}$. Por su trazado y características este vano puede responder a lo construido en el siglo XVI. El dibujo número dos pertenece a un

301 GONZÁLEZ RODRÍGUEZ, R., REGUERAS GRANDE, F. y MARTÍN BENITO, J. I., op. cit., 1998, p. 75.

302 GÓMEZ MARTÍNEZ, J., op. cit., 1998, p. 182.

303 MERINO DE CÁCERES, J. M., op. cit, p. 224.

304 GONZÁlEZ RODRÍGUEZ, R., REGUERAS GRANDE, F. y MARTÍN BENITO, J. I., op. cit., 1998, p. 73.

305 "PORTAL OR WINDOW/These moldings are numbered 400 to 696 inclusive". (Ibidem). 
arco de diseño más rico, cuyo trazado carpanel alberga en su interior tres vanos lobulados, de los cuales el central tiene un desarrollo mayor. El espacio del tímpano comprendido entre los arcos se encuentra enriquecido con tracería flamígera. La inscripción que figura al pie declara que en aquel momento existía otro panel semejante ${ }^{306}$. Byne deja constancia también, mediante el dibujo de las secciones, de dos tipos de molduras de los que hace constar que se habían conservado cien pies de cada una de ellas ${ }^{307}$. El siguiente dibujo representa un vano correspondiente a una ventana, al parecer de pequeño tamaño $(0,94 \mathrm{~m})$, según las indicaciones de medida aportadas

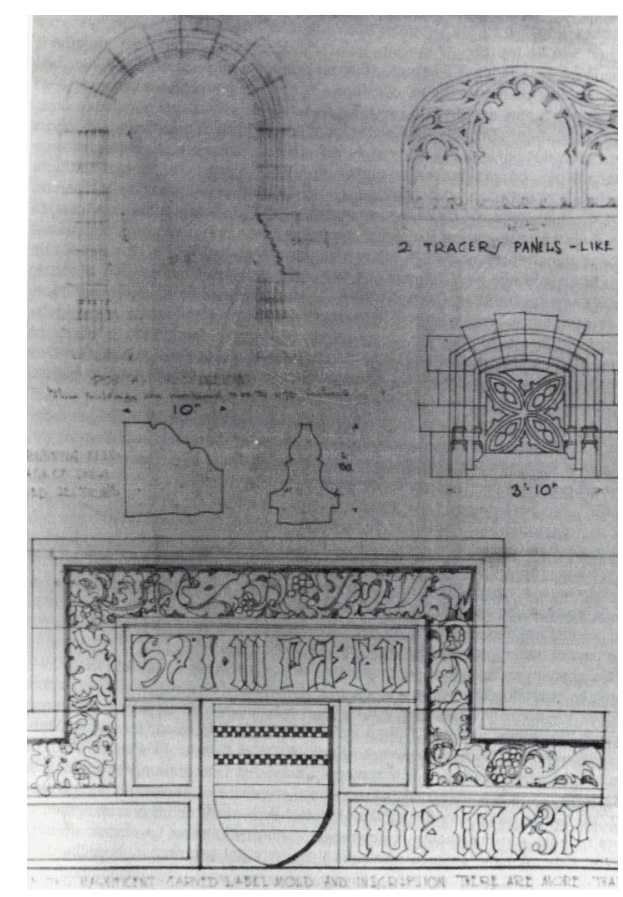

por Byne ${ }^{308}$, con diseño en arco rebajado y molduras a base de boceles y escocias que se prolongan a lo largo de las jambas a modo de columnillas y mueren en pequeñas basas anilladas sobre pedestales. Su luz está ornamentada con una celosía de tracería flamígera en forma de flor cuadripétala.

El tercio inferior de esta página está ocupado por el dibujo de un fragmento del friso ornamental que contiene una inscripción en letras góticas y un escudo de armas. Debajo del mismo Byne escribió que de ese magnífico friso epigráfico quedaban más de

306 “2 TRACERY PANELS LIKE THIS”. (Ibidem).

307 “100 RUNNING FEET OF EACH OF THESE MOLDED SECTIONS”. (Ibidem).

308 “3’10””. (Ídem). 
cien pies y que estaba fechado en $1475^{309}$. La inscripción dice: "Esta capilla es del onrado cavallero: de: almazan: alcaide de la: fortaleza: de: Atienza: y de la Señora Doña Elvira de Morales la cual mandaron facer e se hizo el año de M e CCCC e XXV años. E aqui se pusieron las armas de sus linajes las de Sotomayor las de la señora de Morales. Alavado Ntro. Señor Jhu Xpo por siempre amen $^{\prime 310}$. Como ya señaló Merino de Cáceres, el propio Byne debajo de la traducción al ingles de la inscripción anotó: "En la misma capilla estuvo un altar dedicado a San Luis Obispo (de Tolosa)" y "Nota: la referida fortaleza de Atienza es el primitivo nombre de Benavente" ${ }^{311}$. Respecto a la inscripción, el mismo Byne aporta indicaciones en la carta de 9 de junio dirigida a Julia Morgan en la que se expresa en la siguiente forma: "Adjunto a la presente puede usted encontrar el texto en español de la inscripción gótica del castillo de Benavente. Su interpretación ha de resultar ciertamente problemática, ya que no estoy seguro de que esté completa. Igualmente envío una traducción al inglés. ¡Es interesante pensar que en esta capilla había un altar dedicado a San Luis Obispo!"312. Esta desconcertante inscripción, junto con las anotaciones del propio Byne, hace que se planteen numerosas dudas y que haya, por tanto, que tomar con relativa cautela todos estos datos, que como señaló Merino de Cáceres son más que discutibles a pesar de que en apariencia las informaciones se muestren como absolutamente reveladoras. En primer lugar existe una contradicción entre la fecha de 1475 que Byne hace figurar al pie del dibujo y la de 1425 que él mismo recoge en la transcripción completa de la inscripción enviada a Julia Morgan. A ello se suma la alusión a una capilla dedicada a San Luis Obispo de la que no existe referencia documental alguna y, sobre todo, la falsa afirmación de que Atienza es el primitivo nombre de Benavente.

Todas estas incongruencias hacen pensar incluso, como así han señalado quienes han estudiado estos documentos, que quizá estos elementos arquitectónicos no procedan del castillo 309 "OF THIS MAGNIFICENT CARVED LABEL MOLD AND INSCRIPTION THERE ARE MORE THAN 100 FT. / DATED 1475 / Frieze stones are numbered 100 to 176 inclusive". Ibidem.

310 MERINO DE CÁCERES, J. M., op. cit, p. 220.

311 Ídem.

312 Ídem. 
palacio de Benavente. Las razones que podrían justificarlo van desde la suposición de que las anotaciones hubieran sido hechas sin demasiada precisión, de que se tratara de una mera confusión debido a la cantidad ingente de obras que Hearst adquirió en España, o incluso de una artimaña del propio Byne para vender mejor estas piezas. Aunque no sirva como prueba definitiva, fue habitual durante el siglo XX anotar en las actas de la Comisión Permanente $\mathrm{y}$ del concejo las obras o ventas realizadas en relación con el edificio, sin embargo, nada consta de lo adquirido por Arthur Byne ${ }^{313}$.

En el caso de proceder de Benavente, habría que fechar estos elementos, a excepción de la bóveda dibujada en la hoja número 3 y del vano en arco de medio punto rebajado representado en la hoja número 4, en la primera mitad del siglo XV, concretamente se podría tomar como referencia el año de 1425 contenido en la inscripción a la que se ha aludido con anterioridad. Serían, por tanto, elementos pertenecientes a obras realizadas bajo el mandato del II conde don Rodrigo Alfonso Pimentel (14201440). Por lo que respecta a la bóveda ya se ha dicho que no parece anterior a finales del primer tercio del siglo XVI y el vano de medio punto dibujado en la hoja número 4 tampoco parece anterior al siglo XVI. Estaríamos hablando en este caso de obras patrocinadas por el V conde don Alonso Pimentel (1499-1530).

Desgraciadamente se ignora el paradero de estas piezas que pudieron pertenecer al castillo- palacio de Benavente. En el

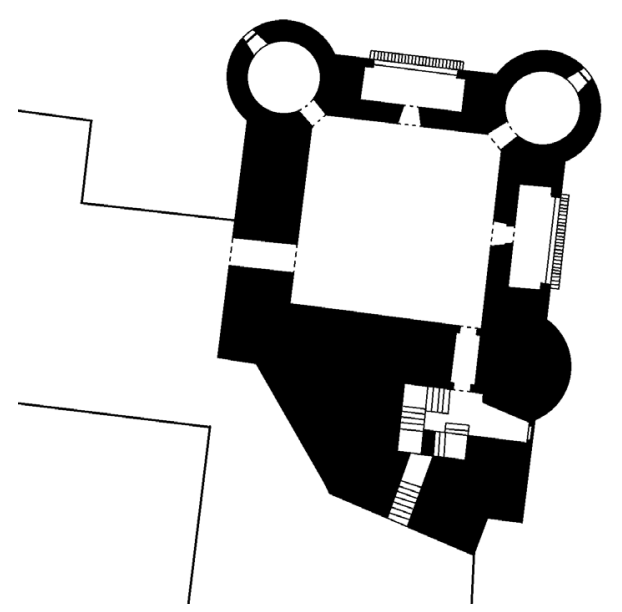




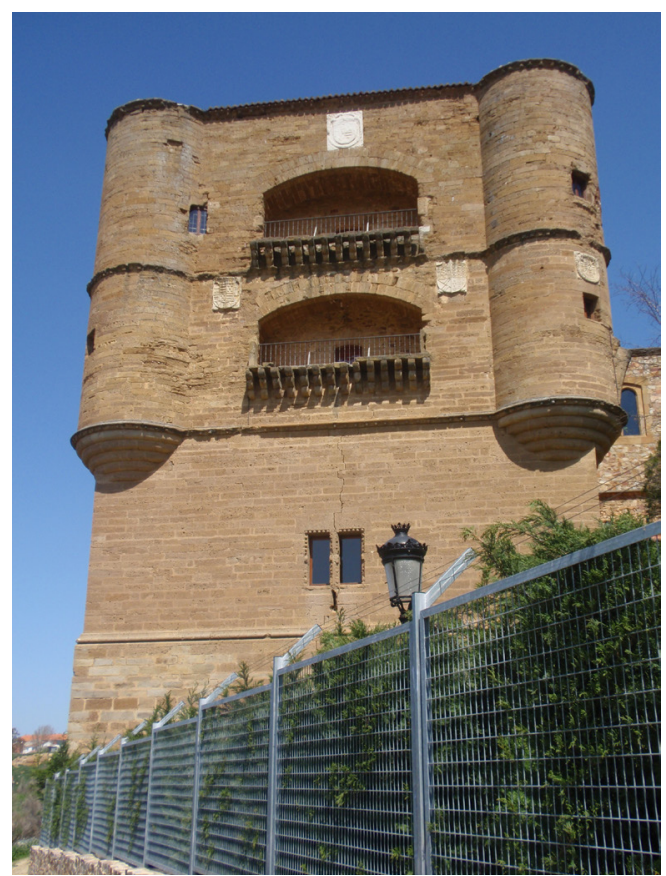

inventario que citamos con anterioridad se anotó "9, 997.00" lo que parece indicar que se vendieron a lo largo del siglo XX en alguna subasta ${ }^{314}$.

En la actualidad, como se ha mencionado anteriormente, la única parte arquitectónica que se conserva del antiguo castillopalacio de los condes de Benavente es la denominada torre del Caracol, que aparece en la gran mayoría de representaciones existentes sobre el castillo (Fig. 264). Fue declarada Monumento Nacional en el año 1931 cuando la demolición de este gran edificio era ya un hecho. Se trata de una poderosa torre de diecisiete metros de lado edificada en buena piedra de sillería y dividida al exterior por molduras en cuatro cuerpos (Fig. 265). La primera de estas molduras que separa los dos cuerpos inferiores es muy sencilla y carece de decoración. Las molduras que marcan la división de los restantes cuerpos tienen forma de escocia y van decoradas en un caso con medias bolas, en otro con puntas de diamante y en el último, que sirve de remate al torreón, por conchas. Los dos cuerpos inferiores son prácticamente macizos; solamente dos vanos cuadrangulares interrumpen el muro. Uno de estos vanos, dividido por un parteluz en dos ventanas rectangulares, presenta una escocia en la mayor parte de su contorno con decoración de bolas. Al interior la decoración, en este caso a base de puntas de diamante, se circunscribe solamente al parteluz. Pero la parte 
más interesante del torreón son sus dos cuerpos superiores, que se encuentran flanqueados en las esquinas por torrecillas de estructura semejante a los garitones angulares tan comunes en las fortalezas medievales. Estos garitones van asentados sobre ménsulas encabalgadas en forma de anillos concéntricos, forma que también se observa como apeo de los balcones en una de las torres de la antigua residencia que los propios condes de Benavente poseían en Valladolid ${ }^{315}$. Entre estas torrecillas y en dos de sus cuatro lados se abre, en cada cuerpo, una amplia balconada en arco escarzado (Fig. 266). Estos grandes balcones que permiten bellas vistas sobre el paisaje están apoyados en una sucesión de grandes ménsulas encabalgadas o de perfil

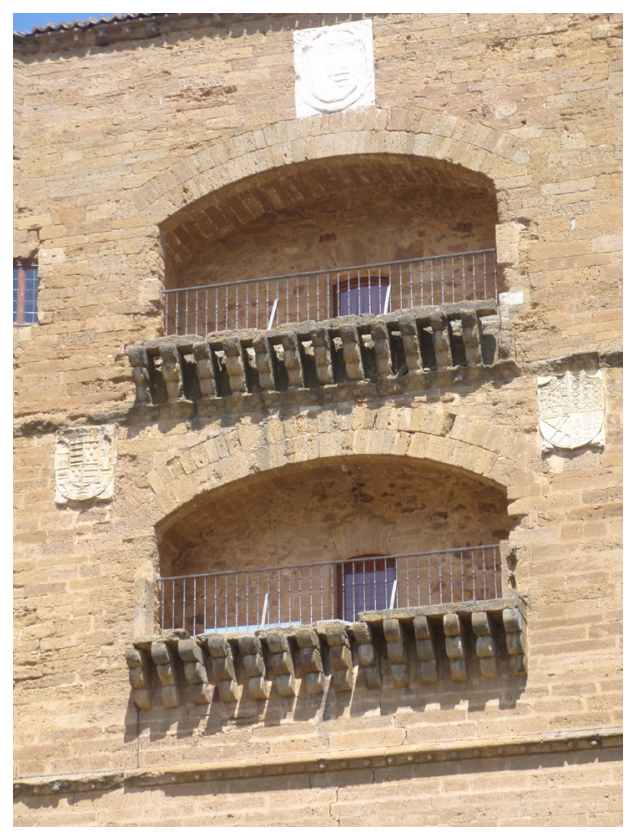

trilobulado, a modo de matacanes ${ }^{316}$. La semejanza que estos balcones presentan con los del castillo de Puebla de Sanabria mandado edificar por el IV conde de Benavente ya fue advertida por Edward Cooper ${ }^{317}$. Varios escudos correspondientes al $\mathrm{V}$ 


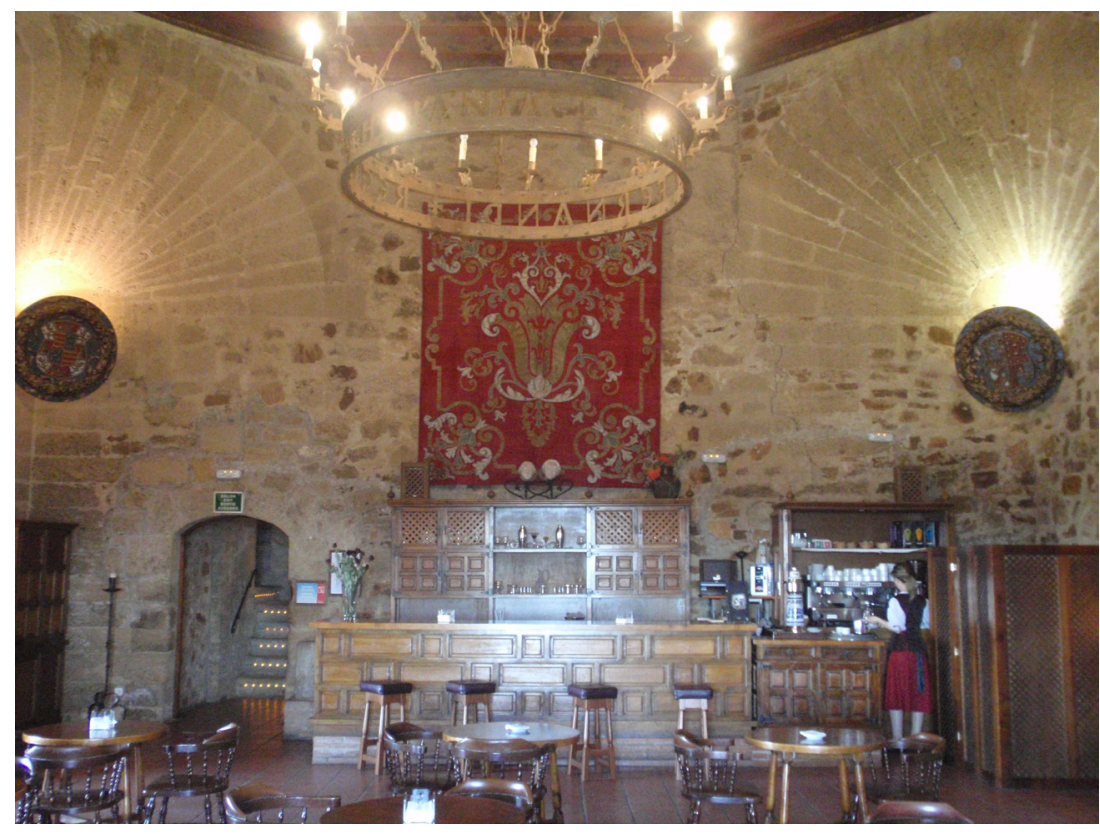

conde y su mujer están encastrados en diversas partes del muro de estos cuerpos superiores.

El interior del torreón está dividido actualmente en dos cuerpos. El correspondiente a la parte inferior acoge la cafetería del Parador Nacional de Turismo y tiene planta cuadrada que se transforma, en altura, en octógono mediante cuatro grandes trompas de ángulo para sostener una armadura de madera octogonal (Fig. 267). En él se ha utilizado mayoritariamente la mampostería y en determinadas zonas la piedra de buena sillería. Se accede a esta sala a través de dos pequeñas entradas cuyo vano está resuelto en arco escarzano y también dos pequeños ventanales abiertos igualmente en arco escarzano y embutidos en una gran estructura abocinada con el mismo tipo de arco. Todo ello, accesos y vanos, permite constatar el enorme grosor que tiene el muro. Estos desornamentados elementos arquitectónicos propios de la arquitectura militar no ofrecen datos de estilo que permitan matizar la fecha más allá de la cronología general de principios del siglo XVI.

Otros testimonios más consistentes de la decoración del palacio son los elementos arqueológicos descubiertos en la torre del Caracol y en su entorno, durante la década de 1960, con ocasión de las obras realizadas en este lugar para convertirlo en Parador Nacional de Turismo. Estos elementos tienen las mismas características que los vistos y descritos por Gómez-Moreno a principios del siglo XX cuando visitó el lugar. 
Actualmente se encuentran expuestos a la vista del público y consisten en azulejería, dos cabezas de yeso góticas y una serie de pedazos de yeserías mudéjares con diseños flamígeros ${ }^{318}$. Elementos muy comunes y muy del gusto de la época para la decoración de palacios.

Como se ha insistido ya, los testimonios escritos, la documentación gráfica y las partes que se han conservado tanto arquitectónicas como decorativas del castillo palacio de Benavente ponen de relieve que se trataba de un edificio de extraordinaria magnitud y riqueza. Su complejidad radica en los arreglos que sufrió a lo largo de distintas épocas y, fundamentalmente, durante la primera mitad del siglo XVI cuando el renacimiento ya se había introducido en Castilla. Algunos elementos o estructuras se pueden situar cronológicamente en el siglo XV. Es el caso de los restos de yeserías y azulejos y también de las dos cabezas humanas a las que se ha aludido anteriormente y que podrían responder al igual que la mayor parte de lo representado en los dibujos de Byne a obras emprendidas por el II conde don Rodrigo Alfonso Pimentel (1420-1440). Así lo determinan sus diseños y ornamentaciones que evidencian su pertenencia a una fase del estilo gótico muy avanzada.

No obstante, y aunque todas las referencias con que contamos en relación a las obras adquiridas por Hearst y fruto de las anotaciones de Byne, las sitúan cronológicamente en el siglo XV, habría que hacer alguna precisión. Si bien la gran mayoría de los restos que se han mencionado encajan por estilo con el siglo $\mathrm{XV}$, no así la bóveda de crucería cuyos nervios combados y los casetones correspondientes al intradós de los cuatro arcos que la enmarcan corresponden a modelos empleados en la provincia de Zamora avanzado el siglo XVI. En el caso que esta estructura perteneciese al castillo de Benavente es probable que se debiese a las reformas que emprendió en el edificio durante su mandato el $\mathrm{V}$ conde don Alonso Pimentel (1499-1530) al que se debe la construcción de la torre del Caracol. 


\section{La arquilectura doméstica}

Como se ha visto ya, en la provincia de Zamora existen pocas referencias de arquitectura doméstica durante los siglos XIII, XIV y buena parte del $\mathrm{XV}$, bien porque la actividad edificadora no debió ser muy intensa, bien igualmente porque muchas de estas construcciones se han perdido. Hay que esperar hasta el reinado de los Reyes Católicos para que la provincia de Zamora recupere el apogeo que había perdido durante tan largo tiempo.

En este periodo, correspondiente a finales del siglo XV y principios del XVI, el tipo de vivienda de la nobleza tomó características diferentes de lo que había sido usual en los siglos precedentes, en que la residencia preferida por los nobles fue la casa fuerte torreada. Esta nueva etapa del gótico tardío representa, por lo tanto, una clara ruptura con la anterior. A partir de la consolidación como monarcas de los Reyes Católicos y su control de la nobleza comienzan a predominar las casas llanas, es decir de perfil apaisado, sin torres salientes y abiertas con múltiples ventanas. A este momento pertenecen la mayor parte de casas y palacios que se han conservado en la provincia de Zamora. La recuperación de la actividad arquitectónica no cesó con el fallecimiento de los Reyes Católicos sino que se prolongó durante buena parte del siglo $\mathrm{XVI}$, manteniendo largo tiempo una tendencia conservadora de las formas góticas.

No obstante, la arquitectura doméstica en las ciudades más destacadas de la provincia de Zamora, durante el reinado de estos monarcas y años después, no alcanzó el desarrollo que obtuvo en otras ciudades del entorno. Aun así, se han conservado, aunque en la mayoría de los casos de forma muy fragmentaria, algunos palacios urbanos de principios del siglo XVI, alguno de los cuales se comenzó a edificar a finales de la centuria anterior.

Las residencias de menor entidad pertenecientes a familias acomodadas de la burguesía, fundamentalmente de las ciudades de Zamora y Toro, han Ilegado aun en peor estado. Es habitual que las fachadas se encuentren muy transformadas $y$ a veces incorporadas a otros edificios. De sus interiores conservamos algunos soportes, que en algunos casos parecen haber llegado a nuestros días in situ y en otros fuera de contexto. La inexistencia 
de escudos en algunas de estas casas no permite conocer quienes fueron los propietarios.

La condición social de la nobleza se expresaba exteriormente a través de la apariencia de sus casas en el entorno de la ciudad. El primer problema que se plantea a la hora de abordar su estudio es el de las denominaciones. A todos estos edificios de los que trataremos, cuya función era la de residencia familiar, se les menciona en la documentación medieval y, sobre todo, a partir de finales del siglo XV, momento del que se conservan un mayor número de testimonios escritos, con los términos "casa" o "casas", y significativamente con el de "casas principales" para contraponerlas a las "accesorias" que se adosaban a ellas. El nombre de "casas" tenía en aquel tiempo un significado muy general y no quiere indicar, en ningún modo, que se estuviera haciendo referencia a edificios sencillos o menores, ya que en muchos casos, este término era utilizado cuando se aludía a las residencias de los reyes.

Los valores simbólicos en estas construcciones se concentraban en los elementos y espacios más significativos: fachada, zaguán, patio, escalera y salón. Indudablemente el elemento principal era la fachada pues a través de ella se manifestaba de manera abierta y directa la importancia del linaje ante toda la ciudadanía; de ahí que los frentes inicien en esta etapa un proceso de engrandecimiento y engalanamiento que continuará por más de un siglo. Los edificios más sencillos potenciarán solamente la portada, en la que se labraban las armas del propietario; mientras que los más ricos se veían ennoblecidos con numerosos vanos, galerías, escudos y multitud de elementos decorativos. El zaguán daba acceso a la vivienda a modo de vestíbulo, antecediendo al patio en torno al cual se articulaban las estancias. En una de las crujías se abría el acceso a la escalera noble que comunicaba las dos plantas del edificio. En la segunda planta se encontraba habitualmente el salón.

De este tipo de vivienda nobiliaria sólo un número relativamente escaso ha llegado a nuestros días en Zamora y su provincia, aunque hay que suponer la existencia de muchas más, perdidas por los avatares del tiempo. Prácticamente todas estas residencias están localizadas en las ciudades de 
Zamora, Benavente y Toro; solamente una de ellas está ubicada en la pequeña población de El Perdigón, lo que se explica por la vinculación que su promotor, Chantre de la catedral de Zamora, tenía con este pequeño pueblo de la provincia. Estas construcciones, después de profundas intervenciones, tienen en la actualidad un uso diferente del original. Por ello es sumamente compleja su valoración.

Para el estudio de estos edificios nos serviremos de los elementos conservados, en la mayor parte muy escasos, junto a las noticias que se tienen de otros ya desaparecidos, en el intento de reconstrucción del tipo de residencia que imperaba en la época.

No obstante el título general de "casas" que se puede aplicar a este tipo de arquitectura, parece conveniente, establecer una diferencia entre los "palacios", así calificados por la nomenclatura actual y que se corresponden con grandes residencias nobiliarias que se manifiestan bajo un aspecto de monumentalidad y de ornamento, y las residencias de menores pretensiones, pero de cierta importancia, levantadas por la nobleza local, de las que conservamos restos escasísimos a las que corresponde mejor denominar "casas nobles urbanas" y que seguramente siguieron de forma modesta el modelo palacial.

\section{Los palacios}

A pesar del estado fragmentario que presentan en la actualidad las residencias nobiliarias, que han llegado a nuestros días, pertenecientes a un periodo que se viene a corresponder aproximadamente con el reinado de los Reyes Católicos, contamos con suficientes elementos para tratar de definir el tipo de palacio de aquella época. Aunque no alcancen la envergadura de los grandes palacios de este momento existentes en otras ciudades, sí al menos, presentan una organización externa semejante $y$, en base a los testimonios conservados, hacen suponer que el interior de ellos tenía un desarrollo similar ${ }^{319}$.

319 Marías realiza un estudio de la arquitectura palaciega desde finales del siglo XV y gran parte del siglo XVI, incidiendo en los cambios que se van produciendo al mantenerse algunos elementos propios de la tradición gótica con incorporaciones de un lenguaje nuevo proveniente de Italia. Este autor hace distintas observaciones sobre las piezas que componen el edificio, entre ellas el patio y algunas de sus partes más 
Todos estos palacios tienen una amplia fachada principal, con o sin torres, y algunos mantienen un zaguán que da acceso a la parte principal del edificio, un patio articulado en dos alturas $y$, en algún caso, se ha conservado la escalera original de "rincón de patio" que comunicaba los dos cuerpos.

Referido a la propia edificación el rasgo más característico de estas construcciones es la progresiva eliminación de los aspectos que hasta poco antes les había convertido en casa-fuerte para apostar por edificios más elegantes, con una planimetría cuadrangular, y abiertos hacia la ciudad.

De ahí que un aspecto fundamental a destacar en la arquitectura palacial de este momento sea la importancia que se concede a la fachada del palacio. Esta importancia se ve reforzada por el deseo de crear delante de estas residencias amplias plazas que faciliten una buena perspectiva del edificio y, como consecuencia, dejen constancia de la categoría del propietario, cuyo escudo, generalmente de grandes dimensiones, suele estar labrado en un lugar privilegiado. Los propios nobles se van a encargar de ello. De este modo en la ciudad de Zamora don Pedro Rodríguez de Ledesma derruyó unas casas para crear la plaza que se encuentra delante de la que fue su residencia, el palacio de los $\operatorname{Momos}^{320}$ y aunque ya respondiendo a un modelo más propio del renacimiento, el III conde de Alba de Aliste, don Diego Enríquez de Guzmán decidió la apertura de dos grandes plazas delante de las fachadas norte y oeste de su espléndida residencia. Don Francisco Ramírez de Noreña que disponía en Zamora de unos terrenos en los barrios bajos aprovechó la plaza existente de Santa Lucía para potenciar la visualización de su Palacio del Cordón. En Toro por ejemplo el palacio de los condes de Requena tenía una de sus fachadas a la plaza de San Francisco y el palacio del Chantre de El Perdigón todavía mantiene una amplia plaza delante de su fachada principal.

El conocimiento de la distribución interna de estos palacios plantea algunas dificultades debido a la carencia en nuestra

destacadas como la capilla y la escalera. MARÍAS, Fernando, El largo siglo XVI. Los usos artísticos del renacimiento español, Madrid, 1989, pp. 365-385. 
provincia de obras completas de esta época que pudieran servir como modelo. No obstante, edificios como el antiguo palacio de los condes de Villalonso de Toro y el de los condes de Alba de Aliste de Zamora, que mantienen gran parte de su estructura, así como otros elementos pertenecientes a otras residencias que se han conservado, pueden servirnos de base para aproximarnos y ofrecer una visión lo más completa posible de los palacios nobiliarios de finales del siglo XV y principios del siglo XVI en la provincia de Zamora. Palacios de esta época en Castilla nos sirven igualmente en esta aproximación a la distribución interna que tuvieron estos edificios y que no debía ser muy diferente de unos a otros. En líneas generales se puede decir que en la parte baja se encontraba el zaguán, las habitaciones del servicio, y otras que servían de lugar de almacenaje. En la parte alta se encontraban las habitaciones principales, de las que destacaba el salón, que era la pieza más suntuosa. En la parte trasera del edificio se encontraban las cocinas y a veces también las habitaciones destinadas al servicio. En ocasiones existían corredores abiertos principalmente hacia el sur.

Durante el primer tercio del siglo XVI, los rasgos que definieron el palacio urbano en época de los Reyes Católicos, se mantienen, aunque con la incorporación progresiva de las formas renacentistas. Las obras conservadas de este momento se localizan una vez más en las ciudades de Zamora y Toro.

Uno de los aspectos representativos de los palacios de este periodo gótico tardío que perduraron de épocas anteriores fue la torre, que en este momento era vista como un símbolo de poder. Existe algún ejemplo conocido de actuaciones de los Reyes Católicos para que los nobles abatieran las torres de sus casas, ya que eran frecuente causa de disturbios, luchas y querellas ${ }^{321}$. No hay constancia de que aquí en Zamora ocurriera lo mismo, pero sí tenemos conocimiento, al menos, del conflicto que se generó en la ciudad por la edificación de torres en el palacio de los condes de Alba de Aliste, que es uno de los pocos palacios que ya en esta época estuvieron torreados o que al menos mantienen, aunque ligeramente, ese elemento residual de las antiguas fortificaciones 
medievales. Lo mismo ocurrió en Valladolid a principios del siglo XVI cuando el V conde de Benavente inició la construcción de lo que sería una de las residencias más espléndidas de la ciudad. El temor de los ciudadanos de que el conde edificase una fortaleza tuvo como consecuencia la apertura de una investigación que finalmente permitió que el palacio se construyese como estaba proyectado $^{322}$.

El resto de partes, zaguán, patio y escalera viene a coincidir con lo que ya se ha visto en otros edificios, aunque en este caso del palacio de los condes de Alba de Aliste los motivos decorativos hay que relacionarlos más con los repertorios del primer renacimiento.

Los palacios conservados o los elementos estructurales que todavía perviven de ellos son: en la ciudad de Zamora, el palacio de los Momos (fachada principal) y el palacio del Cordón (fachada principal), a los que habría que añadir el palacio de los marqueses de Villagodio, que ha llegado a nuestros días muy transformado pero del que se conserva un grabado de Parcerisa que, aunque no abarca la totalidad de la edificación, permite reconocer en él una de las construcciones más significativas de la arquitectura perteneciente al gótico tardío de la ciudad de Zamora. De la ciudad de Toro permanecen el antiguo palacio de los condes de Villalonso (conserva gran parte de su estructura de tal forma que es el que ha llegado en forma más completa), hoy monasterio de las Comendadoras Mercenarias, el palacio de los condes de Requena (mantiene el patio aunque transformado), el palacio de Bustamante (las dos portadas y los nueve pilares ochavados del patio) y las casas de doña Teresa de las Cuevas, barragana de don Alonso de Fonseca, Obispo de Osma (bastante transformadas mantienen elementos en la fachada y el patio), denominadas tradicionalmente como palacio de don Fernando de Fonseca o del Obispo ${ }^{323}$. Con excepción de los ejemplos citados en Zamora y Toro, durante las últimas décadas del siglo XV y primeras del XVI sólo cabe señalar en la provincia, por un lado, la gran residencia nobiliaria que se localiza en el pueblo de El Perdigón y que se 322 URREA, Jesús, Arquitectura y nobleza. Casas y palacios de Valladolid, Valladolid, 1996, p. 41. 
conoce como palacio del Chantre (algunos elementos en su fachada principal como el escudo y la decoración de dos vanos) $y$, por otro, el prácticamente desaparecido conjunto palaciego de los condes de Benavente en esta villa zamorana del mismo nombre del que solamente permanece en pie la denominada torre del Caracol.

En cuanto al material empleado para la construcción de estos edificios, tenemos como única referencia los elementos que de ellos han pervivido y que se reducen fundamentalmente, como se acaba de señalar, a sus fachadas y, en algún caso concreto, al patio, construidos en piedra de buena sillería, labrada con especial atención en el enmarque de las portadas, vanos y esquinas del propio edificio, así como en las arcadas y elementos ornamentales desplegados por el patio. Desconocemos el tipo de material utilizado en el resto de la edificación, aunque es probable que se tratara de materiales menos nobles como se puede observar en algunos palacios de la ciudad de Toro que reservaron la piedra para la puerta, las estructuras del patio y la escalera, y el resto del edificio lo construyeron en ladrillo.

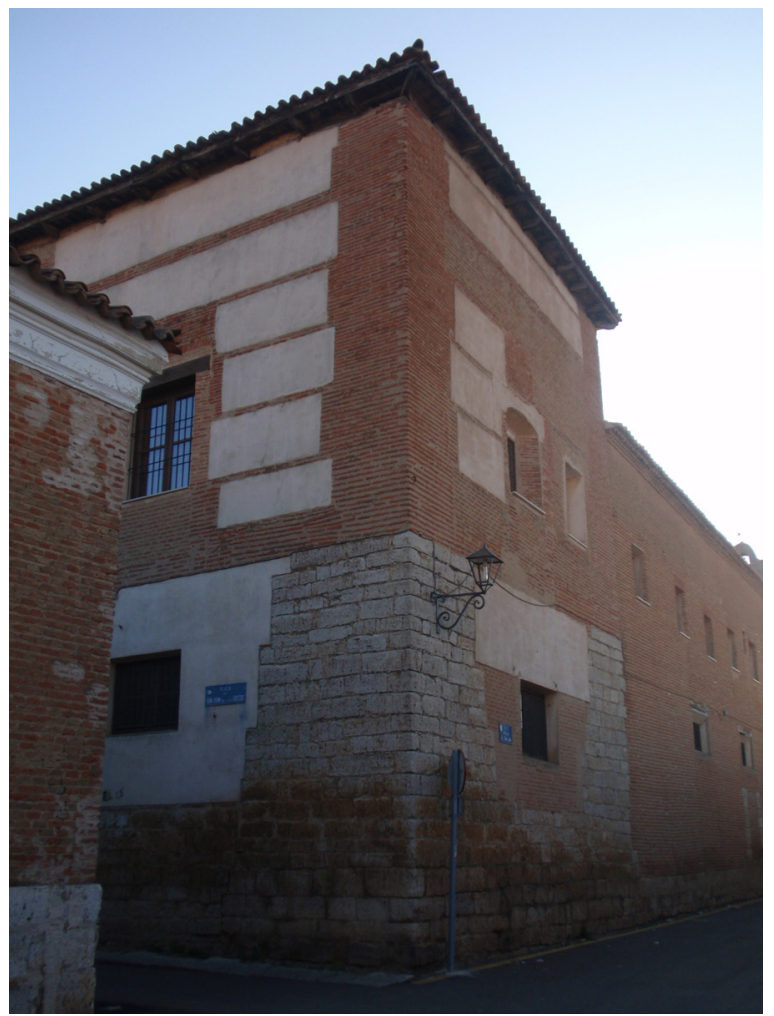




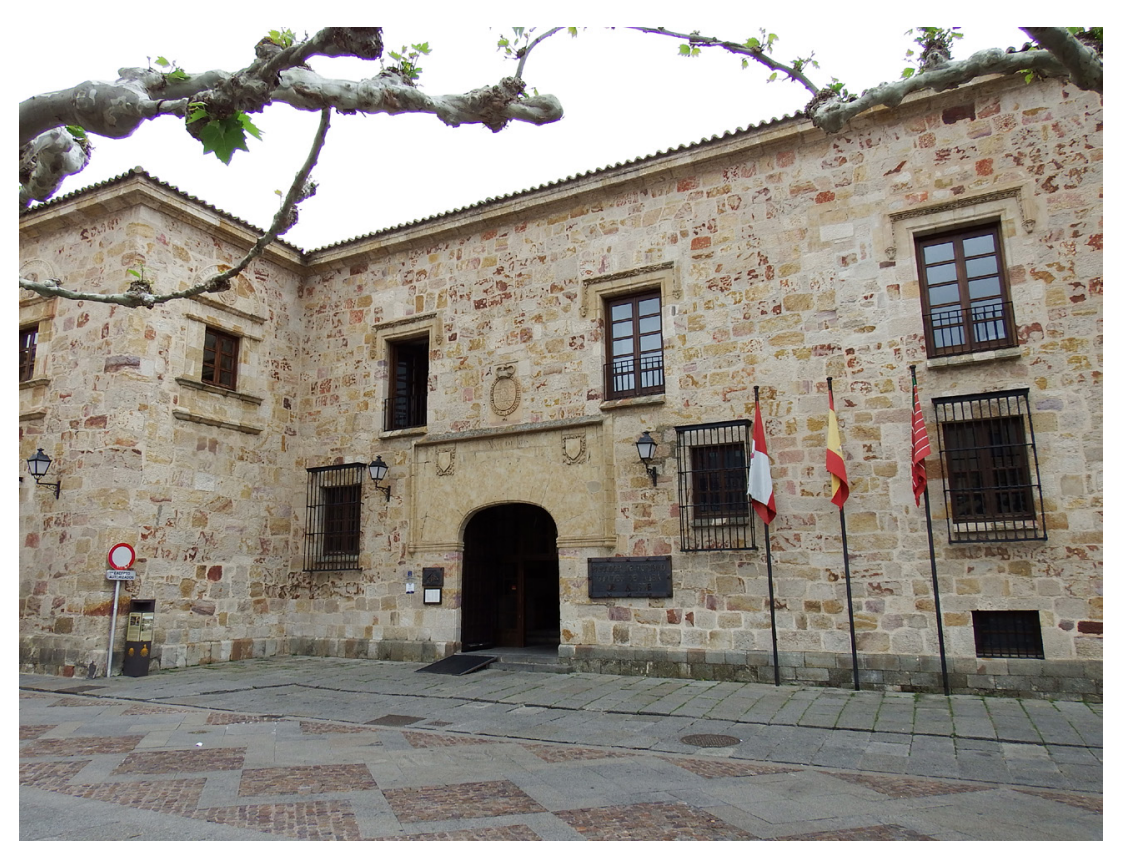

La fachada

Al ser el elemento más significativo de la vivienda es el que se ha conservado en la mayor parte de los casos y el que contiene, por lo general, el despliegue decorativo más destacado, así como los detalles simbólicos.

Tiene una composición en horizontal que puede incorporar en su estructura una o dos torres, habitualmente bajas, con la finalidad de potenciar los extremos de la propia fachada. No podemos olvidar, que la torre o torres, tenían un valor simbólico muy importante en la vivienda del noble. Quizás en Zamora no alcanzaron el desarrollo que en otros lugares, pero existen testimonios de su presencia en la fachada de algunos edificios palaciegos, lo que demuestra que no estuvieron excluidas de su arquitectura. Es el caso del palacio de los condes de Villalonso en Toro, que con toda probabilidad tuvo su fachada flanqueada por dos torres de las cuales solamente queda parte de una de ellas en uno de los ángulos (Fig. 268). También en Toro estuvo torreado el palacio de los condes de Requena, con una torre principal y otra más pequeña. Pero el caso más significativo de la ciudad de Toro, por cuanto ha llegado a nuestros días, es el palacio de los Cossío o de los marqueses de Castrillo, que mantiene como propio del último gótico, tanto la composición de la fachada flanqueada por torres, como la portada principal resuelta en arco escarzano enmarcado por un alfiz y en cuyo espacio interior se colocaron tres escudos y una inscripción que se encuentra
Fig. 269. Palacio de los condes de Alba de Aliste. Zamora 


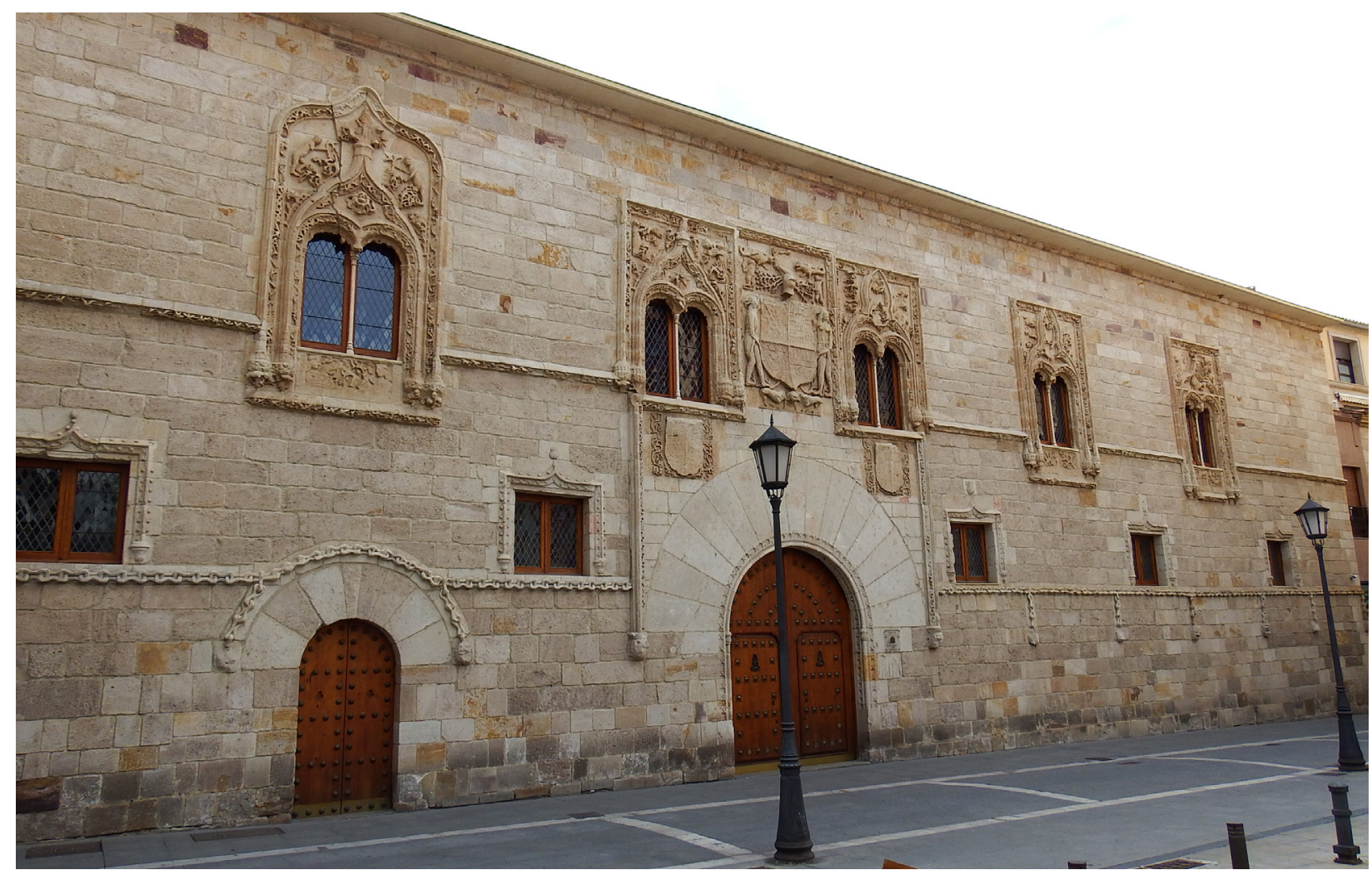

Fig. 270. Fachada del conocido como palacio de los Momos. Zamora muy deteriorada. En la ciudad de Zamora el palacio de los condes de Alba de Aliste mantuvo este elemento residual de fortificación ya en pleno siglo XVI en un edificio en el que además se empezaban a manifestar de manera contundente los influjos del renacimiento (Fig. 269). Son, por tanto, casos excepcionales, pues las iniciativas promovidas por los Reyes Católicos, a las que se ha aludido con anterioridad, tuvieron como consecuencia la eliminación de las torres fuertes, que había sido uno de los elementos característicos de las residencias señoriales durante la Edad Media.

La organización de la fachada principal de estas residencias suele estar articulada en dos plantas y rematada en una cornisa moldurada, en algún caso con adornos. En ella se abre la portada principal de acceso y excepcionalmente, en el caso del palacio de los Momos de Zamora, además, una puerta de servicio de menores dimensiones (Fig. 270).

La portada principal, en la totalidad de estos palacios, se encuentra desplazada respecto del eje central de la fachada hacia la izquierda del espectador y, en algún caso, como sucedía en la residencia de los marqueses de Villagodio de Zamora y a juzgar por el grabado de Parcerisa, este desplazamiento era aun mayor 


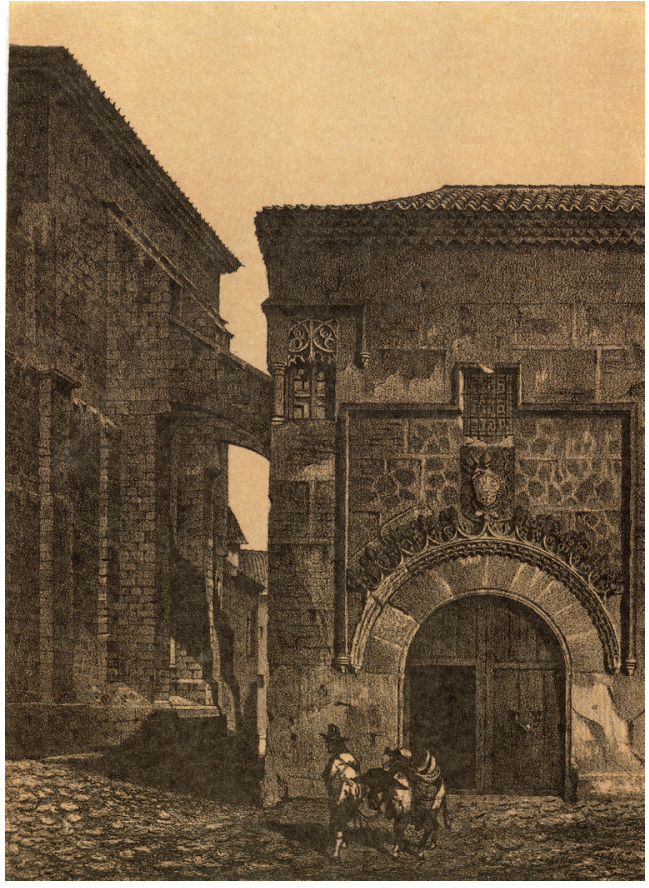

(Fig. 271). El tipo de arco más utilizado es el de medio punto; así se observa en los dos accesos del palacio de los Momos, en el grabado que recoge la desaparecida portada de acceso del palacio de los marqueses de Villagodio, en el palacio de Bustamante de Toro y, cabe la posibilidad que así fuera también, en la portada del palacio del Cordón de Zamora. Sin embargo, para la portada del antiguo palacio de los condes de Villalonso se prefirió un acceso resuelto mediante un arco con forma carpanel en el trasdós y que dibuja un arco conopial con las aristas achaflanadas en el intradós, por tanto, un diseño en conexión con la arquitectura gótica tardía (Figs. 272 y 273). La utilización del arco carpanel y escarzano también fue común a este periodo en las portadas de los palacios toresanos como se constata en el palacio de los Monroy o de los Samaniego y en el de Cossío o de los marqueses de Castrillo respectivamente. Igualmente hay que señalar que común a muchas de estas portadas fue el encuadramiento en alfiz, que en algunos casos se ha perdido.

En las fachadas de estos palacios urbanos se abren, por lo general, un significativo número de vanos, localizados fundamentalmente en el piso noble y que posibilitaban una amplia luminosidad de las estancias que se encontraban situadas en esa zona. En ocasiones se trataba de vanos geminados como sucede en el piso noble del denominado palacio de los Momos y como sucedía también en el palacio de los condes de Alba de
Fig. 271. Grabado de Parcerisa que recoge la fachada del palacio de los marqueses de Villagodio. Zamora

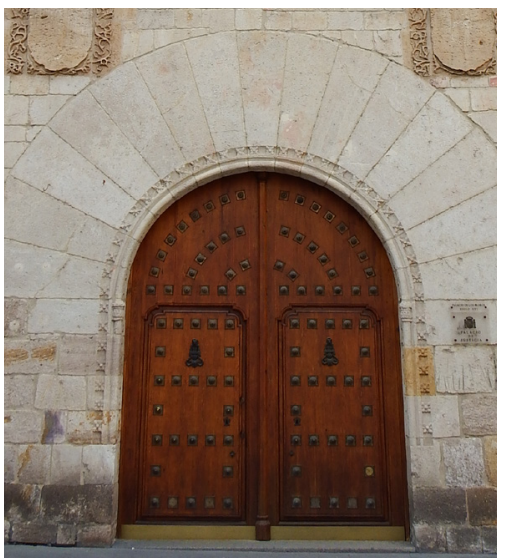

Fig. 272. portada principal del conocido como palacio de los Momos

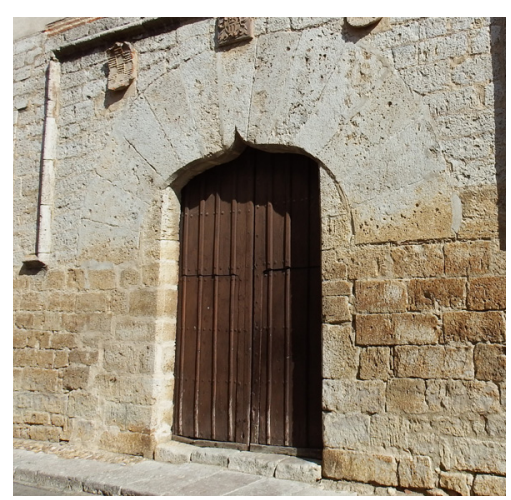

Fig. 273. Portada del antiguo palacio de los condes de Villalonso. Toro 


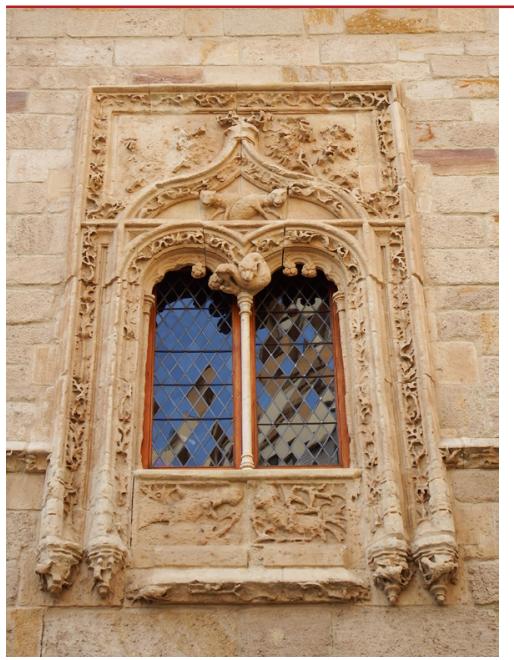

Fig. 274. Ventanal del piso noble del conocido como palacio de los Momos. Zamora

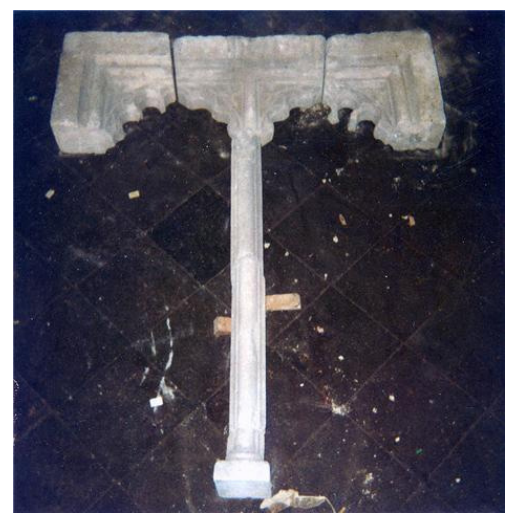

Fig. 275. Antiguo vano del palacio de los condes de Alba de Aliste

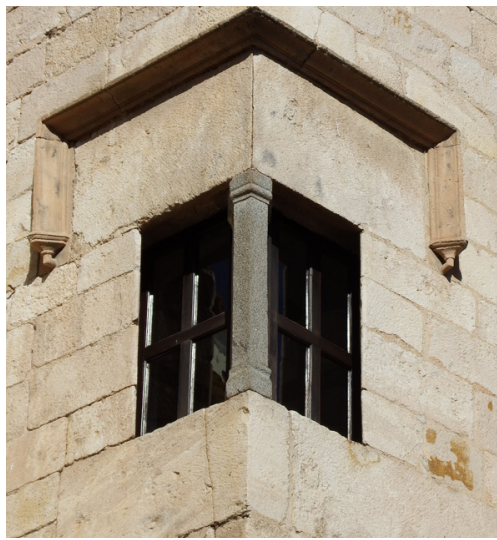

Fig. 276. Vano en esquina del conocido como palacio del Cordón. Zamora
Aliste en el que existió al menos un vano geminado que hoy se conserva desmontado en el Museo de Zamora (Figs. 274 y 275). También en alguno de estos palacios existió un tipo de vano que se conoce como "ventana en esquina", muy frecuente en la arquitectura palacial española a partir de 1500 y que permite la visión hacia dos calles distintas. Dos son las conservadas en la arquitectura doméstica de nuestra provincia: una, muy sencilla, situada en su emplazamiento original, el palacio del Cordón; y, otra, muy ornamentada, que procede del palacio de los marqueses de Villagodio y, en la actualidad, forma parte de la colección permanente del Museo Provincial de Zamora. En ambos casos, un mainel situado en el ángulo hace geminado el correspondiente vano (Figs. 276 y 277 ).

Tanto en las portadas como en los vanos es donde se van a concentrar la mayor parte de los elementos decorativos y simbólicos, cuyo análisis, unido al del diseño arquitectónico, permite constatar en este tipo de edificios, construidos en gran parte en el siglo XVI, la convivencia de elementos propios de la arquitectura gótica con elementos que van a ir introduciendo paulatinamente el renacimiento. La fachada más suntuosa del grupo corresponde al palacio de los Momos, sin comparación con las otras conservadas cuya decoración se reduce prácticamente a los elementos heráldicos.

La heráldica fue uno de los elementos más destacados en la arquitectura civil zamorana de este momento, como lo era también en todo el ámbito hispánico. Especial atención se concede al escudo de la familia propietaria que se ubica en el lugar más visible de la fachada, pues es el elemento parlante que manifiesta el poder y la clase social a la que pertenecen sus moradores. Generalmente los escudos están ubicados en las enjutas del arco de la portada principal (palacio de Bustamante de Toro) y en algún caso sobre la clave de este mismo arco (antiguo palacio de los marqueses de Villagodio, palacio del Cordón). En ocasiones se optó por situarlos tanto en las enjutas como sobre la cúspide del arco (palacio de los condes de Villalonso, palacio de los Momos). Solamente en el caso del palacio del Chantre de El Perdigón el escudo se colocó en la propia fachada sin guardar ningún tipo de alineación respecto a la portada. Generalmente 


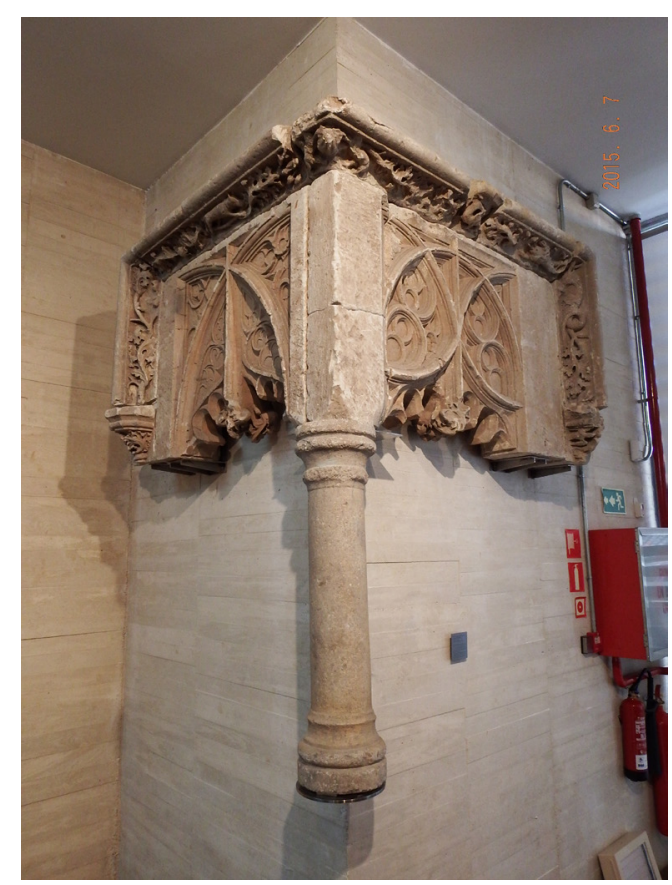

tienen tamaño reducido aunque su situación en un lugar tan destacado del edificio les hace perfectamente visibles. En el caso del palacio de los Momos, del Cordón y en buena medida del palacio del Chantre, adquieren una gran presencia de tal forma que se convierten en el elemento de mayor entidad de todo el edificio. Como particularidades se pueden señalar la disposición en diagonal del correspondiente al palacio del Cordón (habitual en el momento, recordemos los escudos de los Condestables en su capilla en la catedral de Burgos) o la presencia de salvajes, en nuestro caso flanqueando el escudo principal del palacio de los Momos (Figs. 278 y 279), y que también encontramos, por ejemplo, en la misma capilla del Condestable, en la de los Vélez de la catedral de Murcia o en la capilla del convento de Santa Clara de Medina de Pomar (Burgos) ${ }^{324}$.

El programa heráldico como historia y virtudes de la familia se prolonga habitualmente en una parte más íntima como es el patio. Así se manifiesta en los palacios toresanos de los condes
Fig. 277. Ventana de esquina del antiguo palacio de los marqueses de Villagodio. Zamora

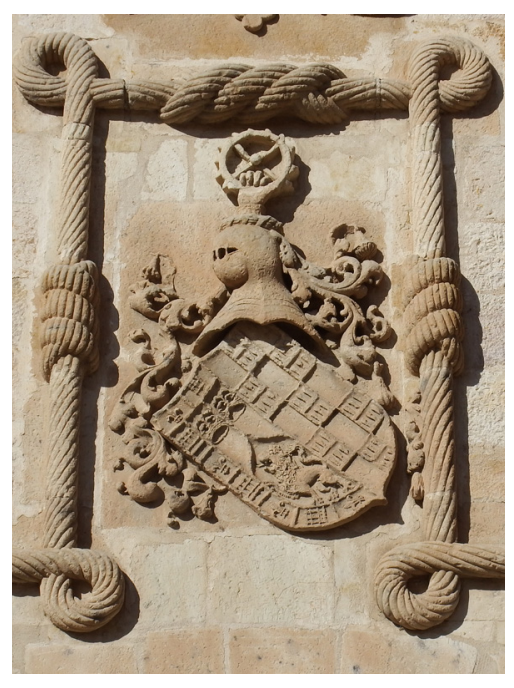

Fig. 278. Escudo de la fachada del conocido como palacio del Cordón. Zamora 


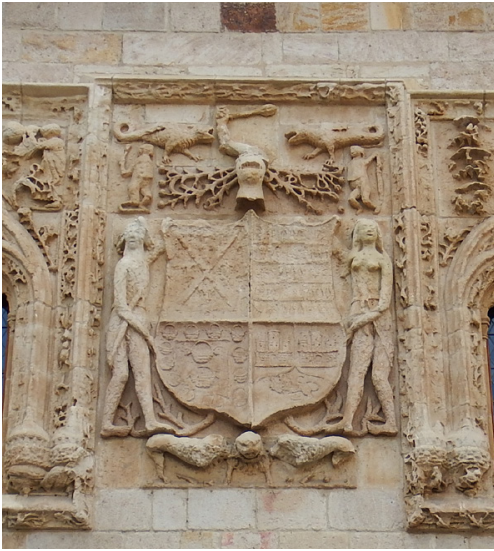

Fig. 279. Escudo de la fachada del conocido como palacio de los Momos. Zamora

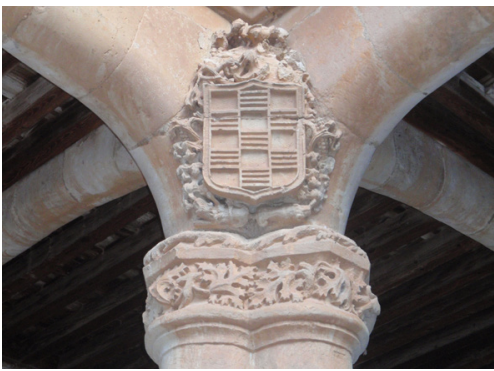

Fig. 280.. Heráldica en el patio del antiguo palacio de los condes de Villalonso. Toro de Villalonso y de los condes de Requena y en el palacio de los condes de Alba de Aliste de Zamora (Figs. 280 y 281).

En algunas de las fachadas nobles existen también otras manifestaciones simbólicas propias del momento como son el cordón y la cadena (Figs. 282 y 283). El más utilizado fue sin duda el cordón, que en Zamora encontramos en la fachada del palacio edificado por Francisco Ramírez de Noreña, denominado comúnmente como Palacio del Cordón. En Castilla hay numerosos ejemplos en los que este motivo se encuentra decorando una fachada, que indica la vinculación de los propietarios con la orden franciscana ${ }^{325}$. Por lo que se refiere al palacio zamorano su explicación es evidente, pues sus promotores profesaban una gran devoción a esta orden. Francisco Ramírez, el fundador, no sólo llevaba el nombre del santo de Asís, sino que, como ya señaló Vasallo Toranzo, dejó dispuesto en la fundación de su mayorazgo su deseo de que en caso de no tener descendencia su casa se convirtiese en un convento de monjas de la Tercera Regla y bajo la advocación de Santa María de la Memoria ${ }^{326}$. A ello se suma la fundación, también en la ciudad de Zamora, del beaterio de franciscanas terciarias de Santa Isabel, que llevó a cabo su segunda mujer, Catalina de Meneses ${ }^{327}$.

La cadena fue empleada en Zamora en la fachada del palacio de los Momos, quizá como un mero motivo decorativo sin mayores pretensiones ${ }^{328}$.

325 De entre todos ellos destacamos especialmente el palacio del Cordón del Condestable de Castilla, Pedro Fernández de Velasco, en la ciudad de Burgos que constituye el edificio de mayor significación de los levantados en esta ciudad a finales de la Baja Edad Media. Existía una especial predilección hacia la orden de San Francisco por parte de los Condestables y sus familiares, que justifica la colocación del cordón en la fachada. PAYO HERNANZ, René-Jesús, "Burgos" en Casas y palacios de Castilla y León Jesús Urrea (Dir.), Junta de Castilla y León, Valladolid, 2002, p. 54.

326 VASALlO TORANZO, L., "La casa del Cordón de Zamora" en Actas del segundo Congreso de Historia de Zamora, tomo II, Zamora, 2007, p. 584.

327 LORENZO PINAR, Francisco Javier, "El convento zamorano de Nuestra Señora de la Concepción en la época moderna: siglo XVII" en Actas del Primer Congreso Internacional sobre la Orden Concepcionista, vol II, León, 1990, p. 287. Luis Vasallo (VASALLO TORANZO, L., "La casa del Cordón..., op. cit., 2007, p. 584) recoge estas apreciaciones.

328 Hernández Redondo relaciona la inclusión de la cadena, separando los dos cuerpos del patio del Colegio de San Gregorio, con la orden dominica a la que pertenecía su fundador. Aunque no sea un atributo muy frecuente en determinadas ocasiones es posible encontrarla en la iconografía de este Santo. Curiosamente, y sin pretender establecer paralelismos, el fundador del conocido como palacio de los Momos de Zamora, don Pedro Rodríguez de Ledesma, fundó su capilla funeraria en el convento de Santo Domingo de Zamora. HERNÁNDEZ REDONDO, José Ignacio, "El Colegio de 


\section{Distribución interna: zaguán, patio, habitaciones y escalera}

Como ocurría en los siglos anteriores no se ha conservado ningún palacio en su disposición original completa, aunque sí contamos con algunos ejemplos que mantienen en pie buena parte de su estructura arquitectónica. Estos testimonios materiales que han llegado a nuestros días parecen indicar que en ellos se mantuvo la configuración de los palacios edificados tiempo atrás y que constaban de zaguán y un patio en torno al cual se disponían una serie de habitaciones. Este esquema se mantuvo en líneas generales en las construcciones de este tipo que se llevaron a cabo en las décadas finales del siglo XV y en las primeras del siglo XVI. No obstante, en este momento, el claustro adquiere una mayor prestancia por generalizarse la superposición de dos galerías con antepechos decorados y adornos en las enjutas así como la construcción de una escalera monumental que enlazaba ambas plantas.

\section{Zaguán}

Por lo general el zaguán de estos edificios es un espacio sin grandes pretensiones arquitectónicas y artísticas que sirve de elemento de comunicación entre el acceso principal que da al exterior y el patio. Estas puertas de comunicación se encuentran descentradas entre sí, de tal modo que mantienen de esta forma la concepción propia de la Edad Media que a la vez que permitía una mayor intimidad favorecía en el pasado la defensa de la casa. Tan solo se han conservado los zaguanes del palacio de don Fernando de Fonseca, o del Obispo de Toro, y del palacio de los conde de Alba de Aliste de Zamora. El correspondiente al palacio del Obispo de Toro posee grandes dimensiones y tiene un recorrido quebrado para acceder al patio, como era habitual durante la Edad Media. El perteneciente al palacio de los condes de Alba de Aliste está bastante reformado, pues fue planteado igualmente con un recorrido quebrado pero posteriormente se transformó y se abrió otro acceso alineado con el correspondiente de la entrada principal.
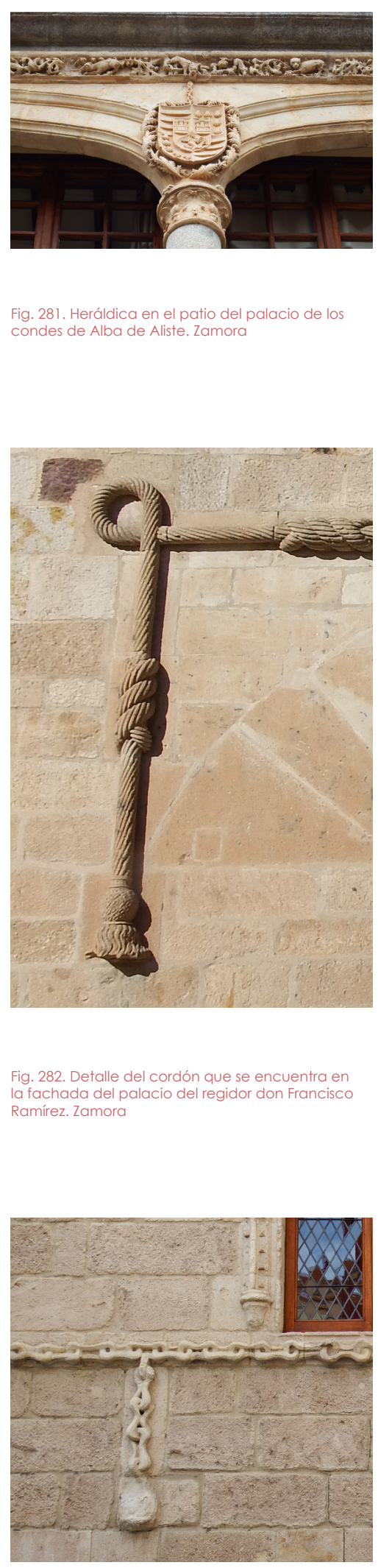

Fig. 281. Heráldica en el patio del palacio de los condes de Alba de Aliste. Zamora

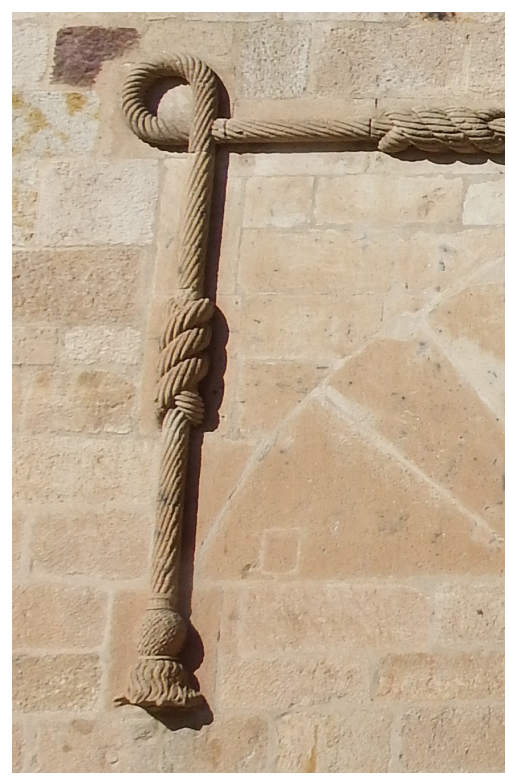

Fig. 282. Detalle del cordón que se encuentra en a fachada del palacio del regidor don Francisco Ramírez. Zamora Fig. 283. Detalle de la cadena que se despliega
por la fachada del conocido como palacio del Cordón. Zamora 


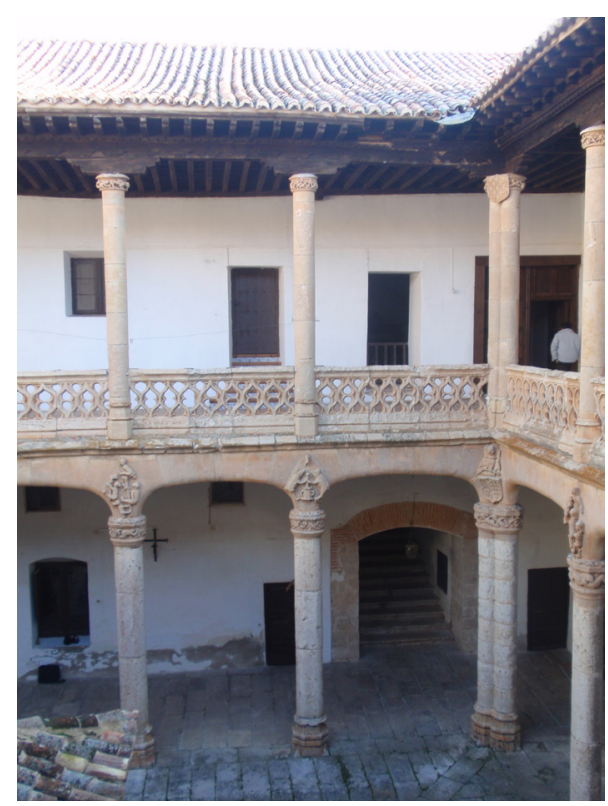

\section{El patio}

El patio, desaparecido en muchos casos, era otro de los elementos fundamentales de estos palacios urbanos. Los que han llegado a nuestros días aportan la información necesaria para el estudio y el análisis de esta parte del edificio. Los más significativos por cuanto han conservado prácticamente íntegra su estructura son los correspondientes al palacio de los condes de Vilallonso de Toro y al palacio de los condes de Alba de Aliste de Zamora; también en esta última localidad se encuentran los patios de los palacios de don Fernando de Fonseca o del Obispo y de los condes de Requena, que aunque han sufrido transformaciones importantes mantienen en lo esencial su estructura (Figs. 284, 285 y 286). Muchas más remodelaciones sufrió el palacio de Bustamante de Toro aunque los nueve pilares ochavados conservados en su pequeño patio y el brocal del pozo pertenecen a la edificación gótica de finales del siglo XV.

Teniendo como base los edificios conservados, los patios poseían planta cuadrangular con galerías en los cuatro lados, salvo en el caso concreto del palacio del Obispo en Toro que solamente presenta galerías en tres de sus lados, como sabemos, por otra parte y a través de la documentación, que sucedía en el también toresano palacio de las Leyes, que había sido edificado unas décadas antes. 


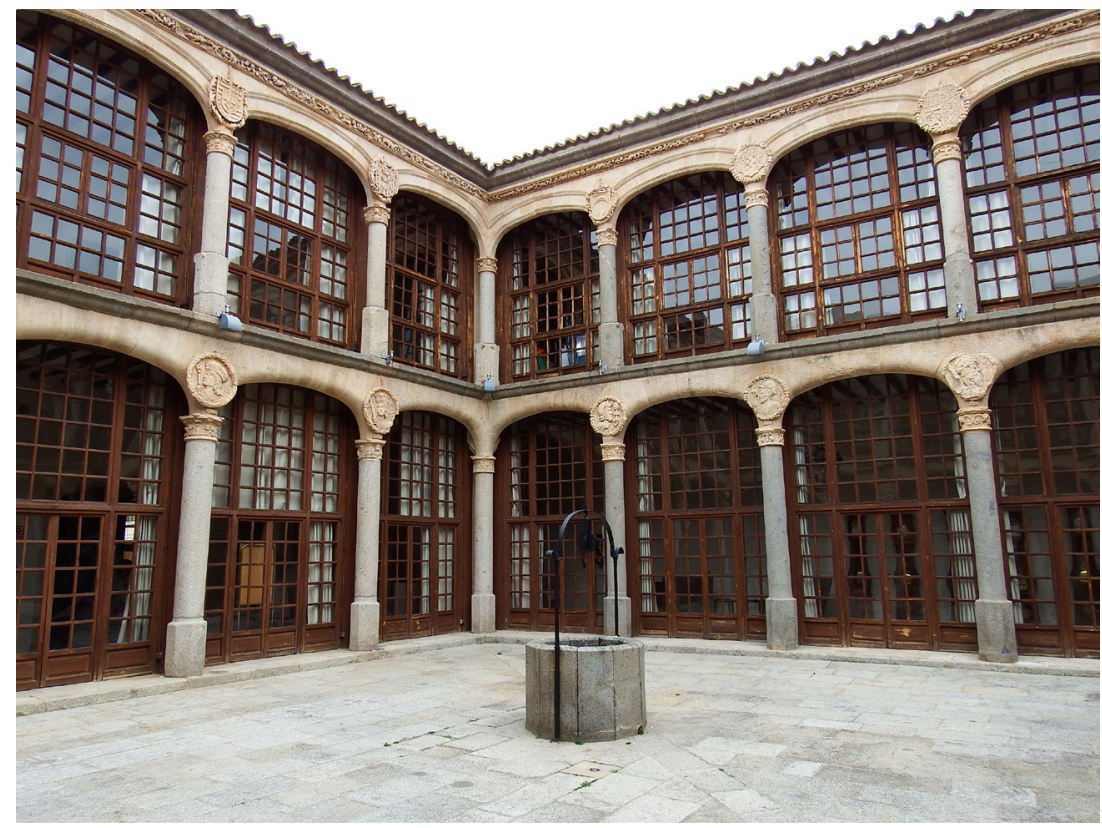

Todos estos patios se organizaban en dos alturas aunque de forma distinta. Por un lado contamos con algunos cuya parte baja se encuentra articulada mediante una galería compuesta de pilares ochavados con zapatas que soportan vigas de madera mientras que en la parte superior hay un cuerpo sencillo y cerrado en el que se abren ventanales, que pertenece por lo general a reformas posteriores; tal es el caso del palacio Episcopal de Zamora y del palacio de Bustamante de Toro. La misma organización tiene la galería al vergel del antiguo palacio de los condes de Villalonso, aunque en este caso no se trate de un patio sino como señalamos de una galería que se abre hacia el oriente.

Por otro lado existen patios de un mayor empaque arquitectónico y ornamental que organizan su cuerpo bajo mediante arquerías mientras que para el cuerpo alto se utilizaron pilares con zapatas que sostienen vigas de madera. Así ocurre en los palacios toresanos de los condes de Villalonso y de los condes de Requena. En otros casos, como en el palacio de los condes de Alba de Aliste de Zamora los dos cuerpos se abren al patio mediante galerías de arcos carpaneles. Lo mismo sucede en el actual claustro del monasterio de las Dueñas de Zamora, edificio que nació como hospital y que permite constatar la utilización de estructuras idénticas en la arquitectura civil tanto de carácter público como privado. Del palacio de Villalonso habría que destacar los antepechos correspondientes al piso superior, que
Fig. 285. Patio del palacio de los condes de Alba de Aliste. Zamora 


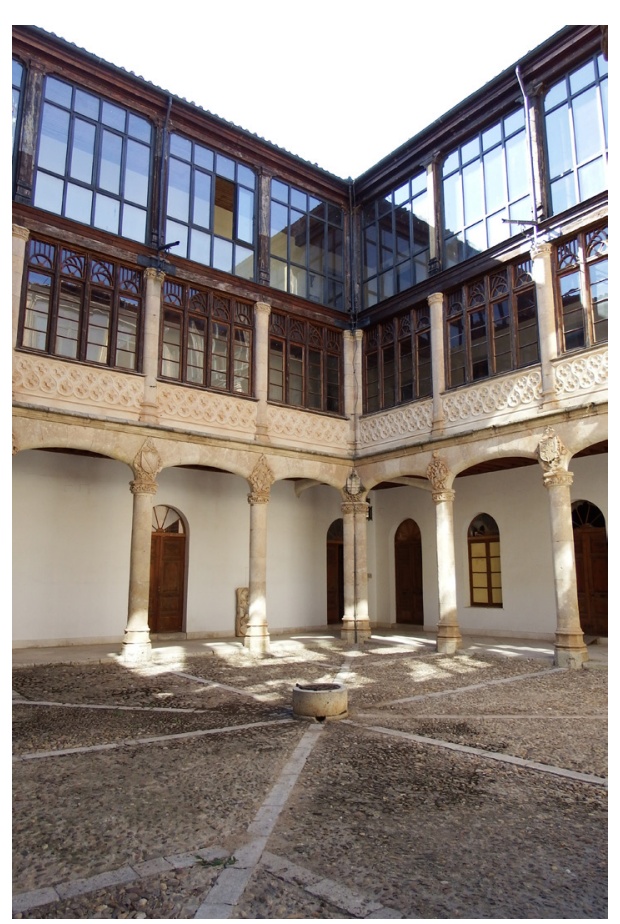

es donde se concentran, junto a los capiteles y los escudos o escenas situados encima de ellos, los motivos decorativos. Por el contrario, en el palacio de los condes de Alba de Aliste y en el monasterio de las Dueñas este tipo de ornamentación situada en la confluencia de las arcadas ha sido sustituida por medallones, ya claramente renacentistas, aunque en algunos de los correspondientes al palacio de los condes de Alba de Aliste se aprecien todavía motivos claramente góticos. En este mismo palacio se reconocen igualmente detalles ornamentales góticos en las ménsulas de las que arrancan los arcos que sostienen la techumbre en los rincones del claustro alto.

La configuración general de este tipo de estructuras en época de los Reyes Católicos se mantuvo con posterioridad, de tal forma, que en el señalado palacio de los condes de Alba de Aliste o en el actual monasterio de las Dueñas, que nació como edificio civil, lo que se hizo fue probablemente repetir en pleno siglo XVI modelos ya existentes.

En las paredes de las galerías de los patios han quedado huellas de sencillas puertas que indican la existencia de habitaciones en su perímetro. Estas habitaciones en la práctica totalidad de los casos han desaparecido y, cuando no, sufrieron transformaciones importantes como sucedió con el salón principal, el zaguán y la cochera del antiguo palacio de los condes de Villalonso que 
fueron convertidos en iglesia por la comunidad de religiosas que se asentó en el edificio a mediados del siglo XVII. No obstante, y a pesar de todo ello, se ha conservado el espacio con el artesonado original del salón principal del palacio situado sobre el zaguán y la cochera de este palacio toresano ${ }^{329}$.

\section{El pozo}

El pozo ha sido una estructura imprescindible que permitía de forma sencilla el abastecimiento de agua para el consumo humano o de animales. Fue muy habitual su ubicación en los claustros de monasterios y conventos así como en los patios de los palacios y con anterioridad en las fortalezas de cualquier condición y lugar. Su parte más destacada es el brocal que evitaba la caída al interior del propio pozo de objetos o personas y que es el elemento que posee una entidad arquitectónica, que dentro de su sencillez, en ocasiones, acusa los rasgos que caracterizan un estilo artístico. El único brocal que se ha conservado de este periodo en la arquitectura civil de la provincia de Zamora es el perteneciente al antiguo palacio de los condes de Villalonso de Toro, hoy convento de Comendadoras Mercedarias (Fig. 287). No obstante existe otro muy semejante también en la ciudad de Toro, concretamente en el claustro principal del convento de San José (Madres Carmelitas). Este convento fue fundado a finales del siglo XVI y edificado durante el siglo XVII lo que indicaría que, en este caso, el brocal gótico aludido debió de pertenecer a otro edificio del que ignoramos su carácter civil o religioso.

\section{La escalera}

A finales del siglo XV fue muy común en los claustros y patios palaciegos la presencia de una escalera que comunicaba los dos pisos de la vivienda. Estaba emplazada en las edificaciones que rodean las galerías del patio, y comúnmente se encontraba oculta ocupando un pequeño espacio, por lo general, en un ángulo de las mismas, ya que su finalidad era únicamente comunicar
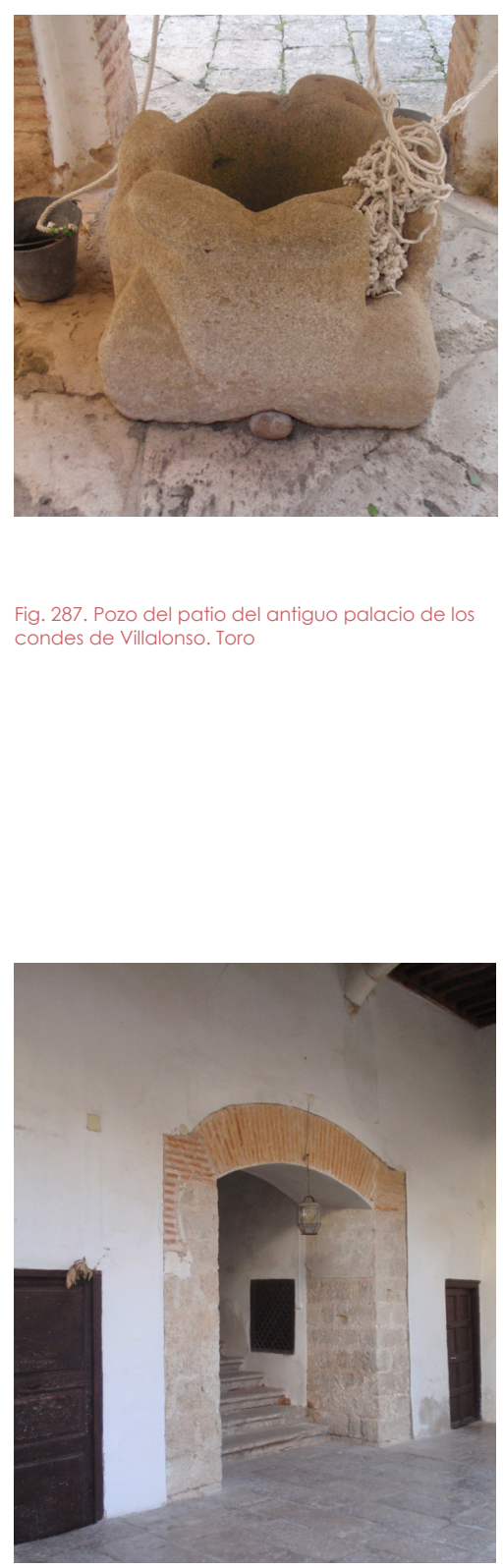


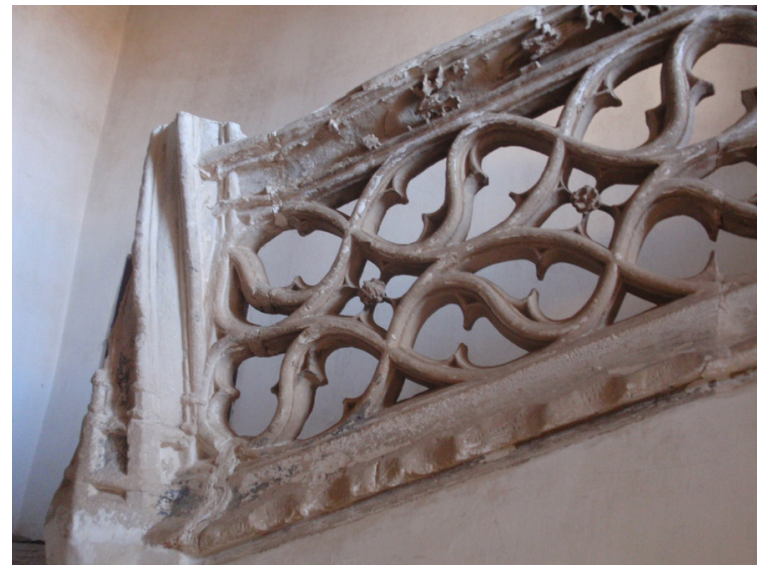

las dependencias bajas del edificio con las situadas en la parte alta. De entre las que tienen un carácter monumental, el tipo más antiguo es el denominado de ida y vuelta, formado por dos tramos con un descansillo y cuya única iluminación consistía en la que entraba por el vano de acceso en el piso bajo y el de salida en el superior. Se ha apuntado por parte de Marías Franco la posibilidad de que se tratase de una creación española a finales de la Edad Media ${ }^{330}$. Martínez Montero ha señalado como ejemplos de este tipo en la arquitectura civil castellana la escalera del castillo de Villanueva de Cañedo (1476-1490) en la provincia de Salamanca, las desaparecidas del palacio de los Duques de Maqueda en Torrijos (1482-1503) en la provincia de Toledo, la de la casa del Cordón de Burgos (1484-1497), las del colegio Mayor de Santa Cruz de Valladolid (1486-1491) y del colegio de San Gregorio de Valladolid (1488-1496), la de la casa-palacio de los Vivero en Valladolid (1490-1500), la del Hospital madrileño de la Concepción de Nuestra Señora (1499-1507) y, en la provincia de Zamora, la correspondiente a la casa de los condes de Villalonso de Toro $(1489)^{331}$.

La desaparición de muchos de los interiores de las grandes residencias urbanas que se levantaron en las localidades más destacadas de la provincia de Zamora, especialmente en las propias ciudades de Zamora y Toro, no permite hacer un estudio pormenorizado de las escaleras monumentales que debían comunicar la planta baja con la planta superior en este tipo de 1983, p. 167. 
edificios en la zona a la que se circunscribe este estudio. El único ejemplo conservado de esta época es la escalera del antiguo palacio de los condes de Villalonso de Toro, hoy Convento de la Purísima Concepción y deSan Cayetano de Madres Comendadoras Mercedarias (Figs. 288 y 289). Esta escalera se encuentra situada en la esquina noreste del patio y desde el punto de vista de la clasificación tipológica ${ }^{332}$, atiende a las características siguientes: se trata de una escalera interior de caja abierta aunque de dimensiones reducidas, cuyo espacio está cubierto con un único artesonado de madera. Posee un antepecho de motivos flamígeros calados, único caso conservado en la provincia de Zamora.

Por su localización y estructura se puede denominar como escalera claustral de dos tramos, entre los cuales hay un pequeño descansillo. La especial significación que posee esta escalera de Villalonso viene dada por ser uno de los primeros ejemplos en los que se utiliza la caja abierta, en la que ambos tramos están cubiertos por una única techumbre de madera, frente a la caja cerrada, con los tramos individualizados y cubiertas independientes que era tradicionalmente el tipo común de la arquitectura bajomedieval. Es, por tanto, un ejemplo ciertamente evolucionado pues adquiere una monumentalidad

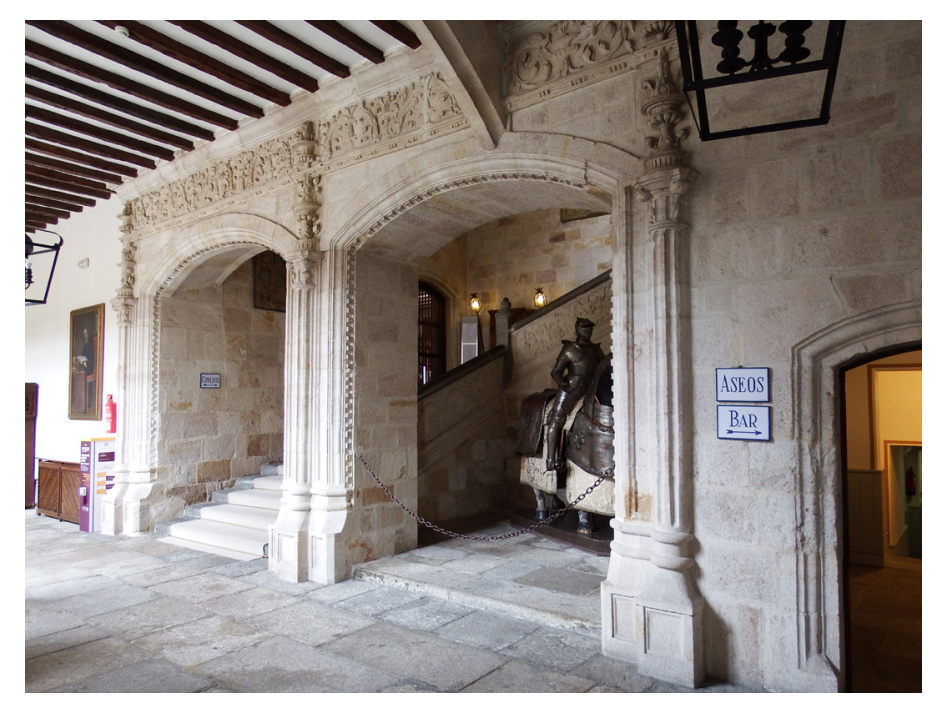

Fig. 290. Escalera monumental del palacio de los condes de Alba de Aliste

332 Seguimos la clasificación aportada por Martínez Montero que se fundamenta a su vez en las clasificaciones que la historiografía ha venido estableciendo en las últimas décadas. Este autor recoge abundante bibliografía sobre la escalera, fundamentalmente de época renacentista. MARTÍNEZ MONTERO, Jorge, La escalera en la arquitectura civil del siglo XVI en las provincias de Burgos y León, Universidad de León, León, 2009, pp. 27-31. 
significativa. Se ha relacionado con la perteneciente al Colegio de San Gregorio de Valladolid ${ }^{333}$, edificio cuya construcción se había iniciado en 1488, aunque lo verdaderamente reseñable, como indicó ya Vasallo Toranzo, es que esta pieza toresana es anterior en el tiempo, pues el palacio debía estar construido, al menos en lo fundamental, en el año 1489, como se desprende de la lectura del testamento de María Sarmiento, propietaria del edificio ${ }^{334}$.

Con los años y la irrupción del Renacimiento la escalera hispana evolucionó progresivamente ganando en amplitud, ornamentación, luminosidad y prestancia. En la provincia de Zamora existe un ejemplo excepcional y sobresaliente donde se percibe el cambio estructural a la vez que estilístico. Es la escalera del palacio de los condes de Alba de Aliste en la ciudad de Zamora, que podría datarse en las postrimerías del primer tercio del siglo XVI (Fig. 290). Tiene configuración claustral de caja abierta, con la embocadura en arco escarzano y compuesta por tres tramos En este caso su concepción y ornamentación, que se concentra en la cara que da al patio y en el desarrollo de la balaustrada, son ya plenamente renacentistas. No obstante la presencia del arco escarzado revela todavía débitos del último gótico.

\section{El salón}

El salón generalmente estaba situado en el primer piso con ventanas hacia la fachada principal. Era la estancia más suntuosa de la casa y poseía una o dos chimeneas. Su planta por lo común era rectangular y solía estar cubierta con artesonado de madera. Los testimonios documentales hablan de interiores decorados con tapices, que en España fueron muy demandados. Recordemos la colección que poseía el conde de Alba de Aliste cubriendo algunos muros de su palacio zamorano, de los cuales algunos se conservan hoy día en la catedral de Zamora.

En la provincia de Zamora solamente conservamos un ejemplo y no completo. Se trata del salón del antiguo palacio de los condes

333 MARÍAS, F., op. cit., 1989, p. 132.

334 VASALLO TORANZO, L., op. cit., 1994, p. 175; VASALLO TORANZO, Luis, "Zamora" en Casas y palacios de Castilla y León Jesús Urrea (Dir.), Junta de Castilla y León, Valladolid, 2002, pp. 342-343. 
de Villalonso en Toro, que desde el siglo XVII, al convertirse el edificio en un convento de Mercedarias, fue integrado en la iglesia. La comunidad de religiosas necesitaban de un lugar para la oración y lo que hicieron fue desmontar el techo del zaguán y caballerizas del palacio de tal forma que ganaron altura y el artesonado del salón que se ubicaba encima de ellos pasó a ser el techo de la nueva iglesia. Este alfarje original permite en este caso saber cómo estaba cubierto un salón palaciego en la segunda mitad del siglo XV.

\section{Decoración}

La decoración que poseen estas residencias urbanas se ajusta a los modelos utilizados en la arquitectura religiosa de la época, como cardinas con animales, cabezas de clavos, puntas de diamante y medias bolas. Destacan igualmente los motivos flamígeros que en la arquitectura religiosa habíamos visto prácticamente reducidos a los vanos y que en la arquitectura palaciega están presentes, a parte de en los vanos, en los antepechos de los patios y de las escaleras.

La decoración, en general, se concentra, como ya se ha dicho, en las fachadas, fundamentalmente en torno a las portadas y los vanos que, en algunos casos, como sucede en la fachada del palacio de los Momos de Zamora y en la ventana perteneciente al antiguo palacio de los marqueses de Villagodio de la misma ciudad y hoy conservada en el Museo de Zamora, adquieren un carácter ornamental más destacado (Figs. 291 y 292). En los palacios de los condes de Villalonso y de los condes de Requena de Toro la decoración se concentra en las bandas que a modo de capitel adornan la parte superior de las columnas y los pilares, en los salmeres de los arcos y en los antepechos del cuerpo superior de los patios (Figs. 293 y 294). También las escaleras fueron soporte habitual de elementos decorativos, aunque la única conservada con motivos de esta época es la correspondiente al palacio de los condes de Villalonso.

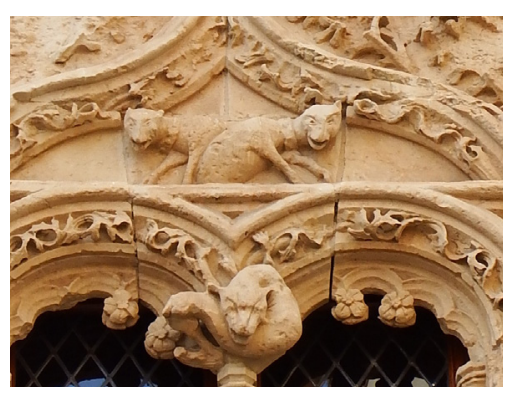

Fig. 291. Detalle de la decoración de la fachada del conocido como palacio de los Momos. Zamora

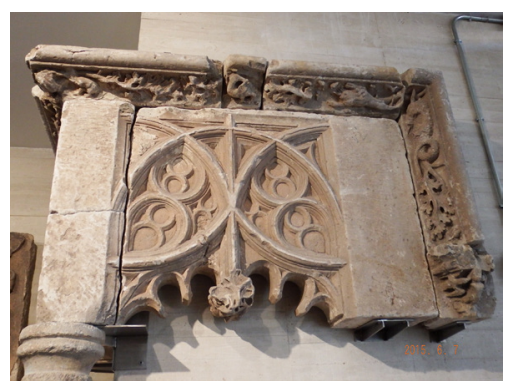

Fig. 292. Detalle de la antigua ventana del palacio de los marqueses de Villagodio. Zamora

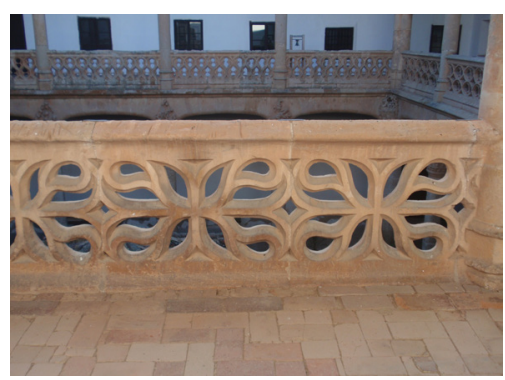

Fig. 293. Detalle de los antepechos del piso superior del antiguo palacio de los condes de Villalonso.
Toro

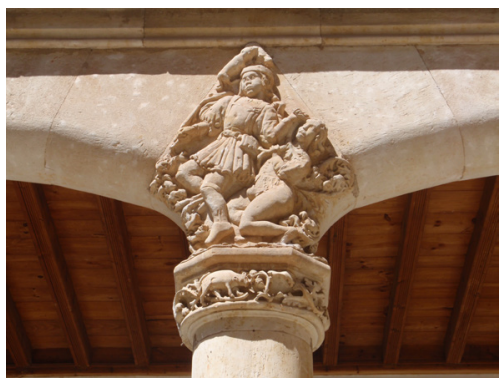

Fig. 294. Decoración de los salmeres del cuerpo bajo del patio del palacio de los condes de Requena. Toro 


\section{La casa noble urbana}

Si como acabamos de ver los palacios que se levantaron durante este periodo que se corresponde con el periodo gótico tardío han llegado de forma parcial, peor suerte aun corrió la casa noble urbana de las que se han conservado exclusivamente algunas portadas, en muchos casos, muy desfiguradas e incorporadas a edificios actuales, así como pilares con basas y capiteles descontextualizados y distribuidos por diversos lugares. Estos edificios, en su mayoría ubicados en las ciudades de Zamora y Toro, al parecer se encontraban alineados con la calle. Cronológicamente habría que encuadrar estas edificaciones en dos momentos constructivos: uno, que se correspondería con el reinado de los Reyes Católicos y cuyo diseño y ornamentación está plenamente enraizado con la arquitectura del gótico tardío y, otro, posterior, que abarcaría el segundo y tercer cuarto del siglo $\mathrm{XVI}$, y en el que lo gótico pervive o convive con diseños ya puramente renacentistas. Es imposible ofrecer una descripción fundamentada del interior de estas casas a causa de la desaparición prácticamente total de sus estructuras.

\section{Las portadas}

La parte que ha persistido preferentemente de la estructura de las casas urbanas es la portada. Constituyen el elemento más representativo de la fachada y, probablemente, en muchos casos, el único que se construyó en piedra de sillería, motivo por el cual se ha mantenido en pie. En el casco antiguo de las ciudades de Zamora y Toro existen varias incorporadas a edificios posteriores, algunos de ellos de reciente construcción.

A juzgar por lo conservado se trata de portadas sencillas reducidas a un simple arco de medio punto, carpanel e, incluso, de medio punto rebajado, pero en todos los casos con grandes dovelas que dan lugar a una rosca de marcado desarrollo. Este amplio dovelaje que las caracteriza se encuentra en ocasiones resaltado con molduras en el intradós o en el trasdós. En algún caso como sucede en la casa 1 de la calle dela Antigua de Toro el intradós del arco está ornamentado con medias bolas, decoración característica y común durante el reinado de los Reyes Católicos. 
Alguna de estas puertas como es el caso de la situada en la Rúa de los Notarios de Zamora, muy cerca de la Plaza de la Catedral, está resuelta en arco carpanel con una moldura en forma de bocel que se prolonga por las jambas y, como es común en esta época, muere antes de llegar a la línea del pavimento. Este bocel está tímidamente interrumpido justo en el arranque del arco por dos molduras aboceladas dispuestas horizontalmente que quieren ser un recuerdo del capitel gótico. De características muy semejantes es la portada de la casa toresana sita en la calle Odreros.

Otras portadas están enmarcadas por un alfiz, elemento muy común de la arquitectura gótica civil zamorana, aunque también se utilizara con frecuencia en la arquitectura religiosa. Es el caso de la portada de la antigua casa del obispo de Oviedo que al poco tiempo de ser construida se trasladó e incorporó a un edificio conventual anexo a la iglesia de Santa María de la Horta, de ahí

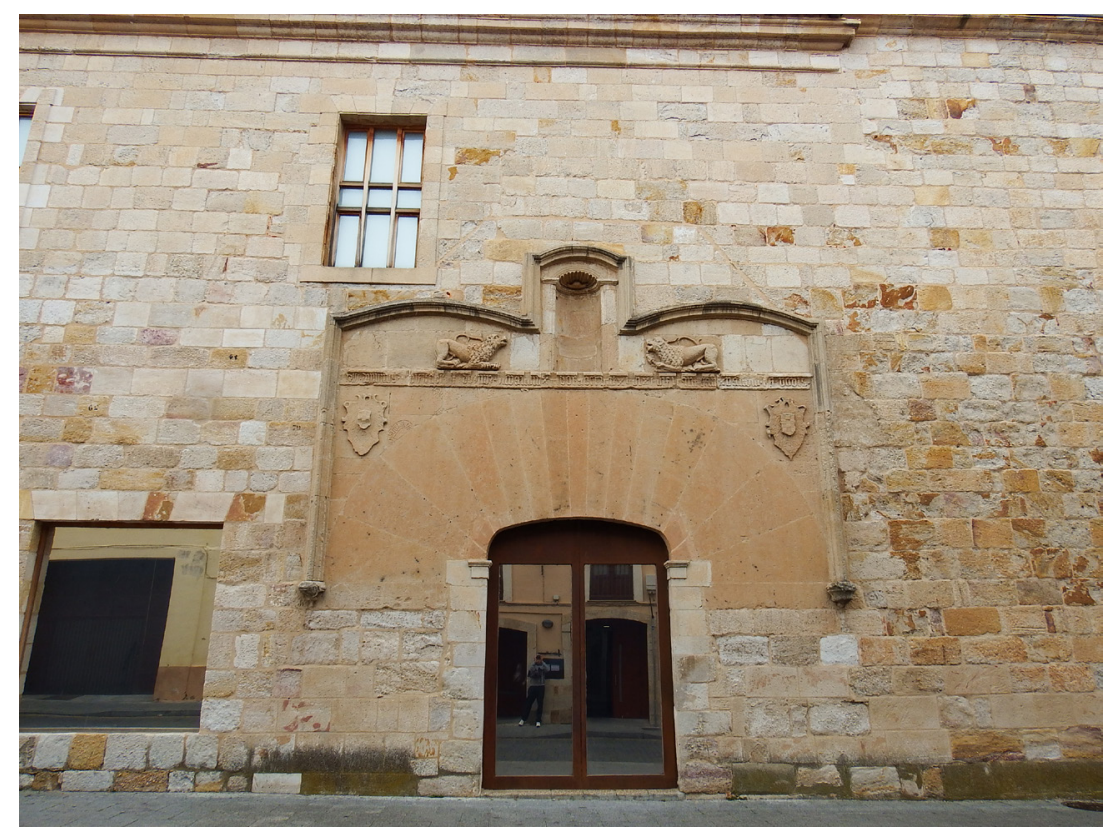

que su lectura haya que hacerla con cierta cautela (Fig. 295). A pesar de sus transformaciones se trata de uno de los ejemplos más interesantes tanto por su desarrollo como por los elementos que la integran. También la puerta parcialmente conservada de la Calle de los Baños de Zamora, resuelta en arco rebajado, conserva algunos fragmentos del alfiz de sección angulosa. Las ménsulas en que remata el alfiz tienen una sección poligonal semejante a las vistas en la arquitectura religiosa de esta ciudad. En la ciudad de Toro son muy numerosas las portadas que se han
Fig. 295. Antigua portada de la casa del obispo de Oviedo 


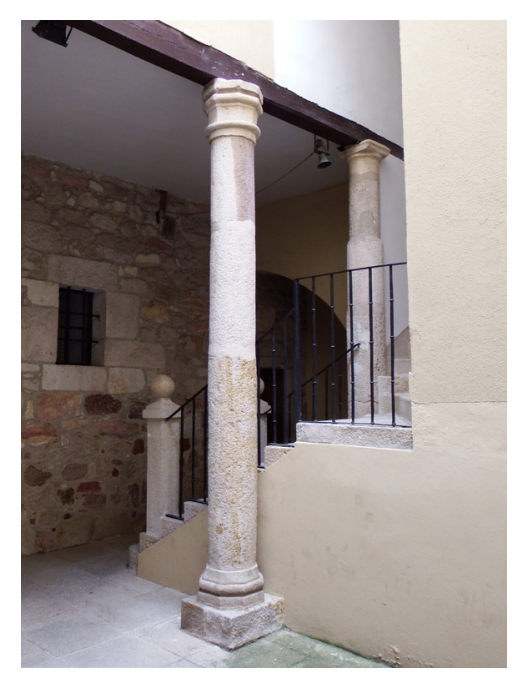

Fig. 296. Pilar situado en el zaguán del convento

del Tránsito

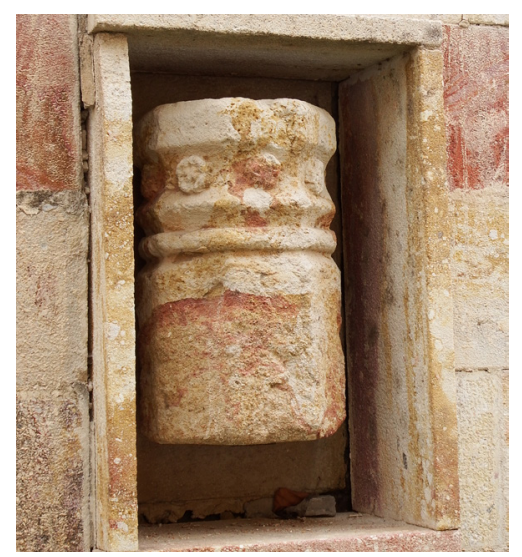

Fig. 297. Resto de un pilar expuesto en San Martín. conservado del siglo XVI distribuidas por su casco antiguo en las que se utilizó como enmarque del arco el alfiz. En muchos casos el alfiz arranca de ménsulas de diseño gótico.

Un caso particular es la portada situada al final de la calle Balborraz. Está resuelta en arco carpanel, ligeramente retranqueada respecto a su encuadramiento rectangular que, en cierto modo, podría interpretarse como un deseo de mantener el alfiz. Conserva en la parte superior del encuadramiento unas inscripciones góticas muy deterioradas.

Este tipo de portadas en las que pervive en cierto modo la tradición gótica se mantuvo durante buena parte del siglo XVI, aunque conforme fueron pasando los años, los arcos carpaneles, escarzanos o de medio punto rebajados fueron utilizándose en menor medida en favor del arco de medio punto.

\section{Otros restos}

Se han conservado algunos testimonios que hacen suponer la existencia de posibles patios en las casas nobles y que es preciso valorar por la utilidad que tienen en el intento de reconstrucción ideal de este tipo de vivienda.

Estos testimonios se reducen a una serie de pilares, muchos de ellos descontextualizados, que debieron pertenecer, en base a estructuras equiparables vistas en palacios y que se han conservado in situ, a patios de casas de la nobleza local o, incluso, a algún palacio significativo, ya desaparecido. De ahí que pueda generalizarse la idea de que en la vivienda zamorana de cierta importancia el patio era un elemento posiblemente muy común.

El caso más destacado en la ciudad de Zamora es el patio del palacio episcopal, que mantiene gran parte de su estructura original y que conserva, por tanto, un buen número de estos elementos en su lugar primitivo. El resto de lo conservado en la ciudad de Zamora son pilares aislados $y$, en muchos casos, descontextualizados o, simplemente, fragmentos de ellos. Se encuentran en el Mesón de la calle Balborraz, en el establecimiento hostelero de la Plazuela de San Miguel 3, en el portal que da acceso al convento del Corpus Christi (en este caso todos tienen fuste circular y solamente son góticos el capitel y 


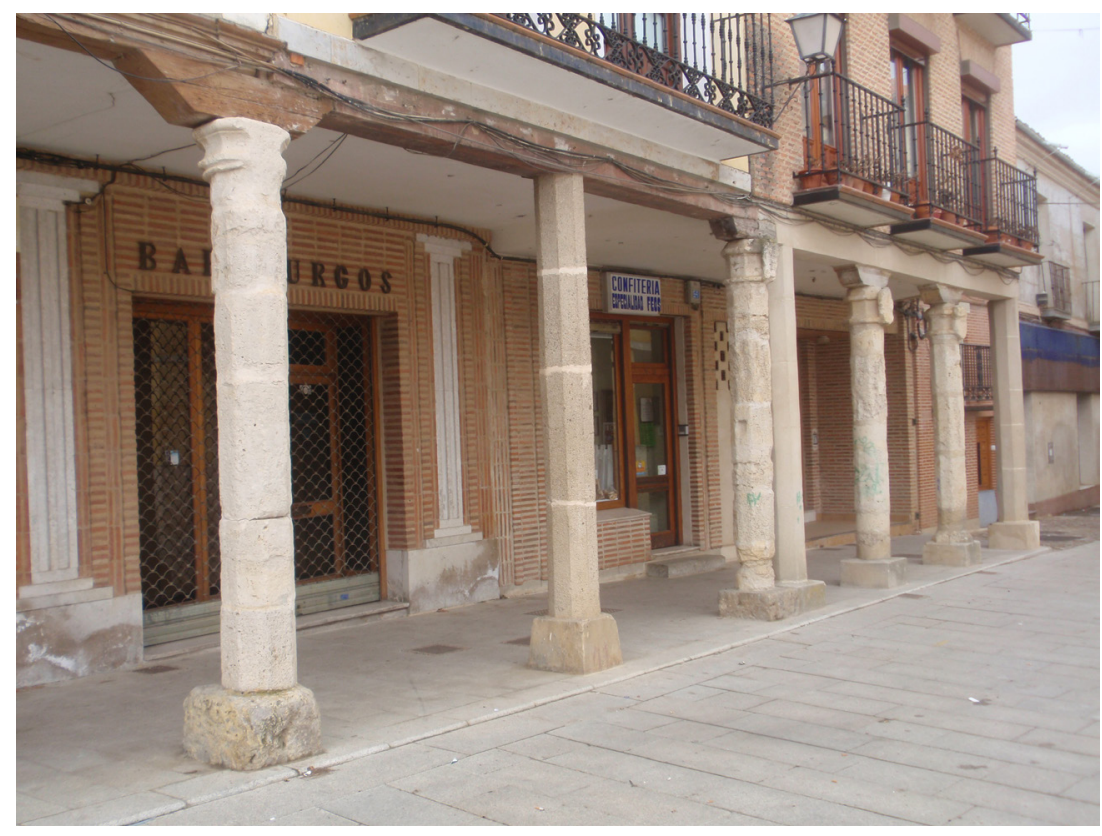

la basa de uno de los pilares situado al suroeste y el capitel del pilar situado al noreste; en cambio los restantes son totalmente renacentistas), en el Ayuntamiento Viejo, en la Alhóndiga del Pan, en dependencias de la Cofradía de Jesús Nazareno, en el Archivo Histórico Provincial, y, por último, existen una serie de fragmentos expuestos en la plaza de San Martín y que se encontraron a raíz de las obras realizadas en este lugar durante la construcción del aparcamiento (Figs. 296 y 297). En la provincia, por ejemplo, existen soportes semejantes en la Plaza Mayor de Villalpando (Fig. 298).

Este tipo de soporte tiene unas características que se repiten en todos los casos y es el más común de la arquitectura de finales del siglo XV y principios del siglo XVI en Zamora y provincia ${ }^{335}$. Suele estar asentado sobre un pedestal por lo general cúbico. El fuste tiene sección octogonal con capitel y basa de diseño también poligonal. Solamente los soportes que se encuentran en el portal que da acceso al convento del Corpus Christi, los dos situados en el local de la Plazuela de San Miguel 3 y uno de los conservados en el Archivo Histórico Provincial de Zamora, aunque mantienen el capitel y basa con formas poligonales, presentan un fuste de sección circular. La decoración de los capiteles, que generalmente es sencilla, está compuesta de una

335 También pilares de este tipo fueron utilizados en la arquitectura religiosa como puede verse en el portal de acceso a la iglesia de Santa María y Santa Catalina de Roncesvalles de Toro. En este caso se incluyeron como elemento ornamental las medias bolas.
Fig. 298. Columnas de los soportales de la Plaza Mayor de Villalpando 
serie de molduras entre las que no falta un amplio collarino y una escocia central. Uno de los capiteles hallados durante las obras en la plaza de San Martín se distancia de esta concepción al llevar la cesta adornada con rosetas. Los correspondientes a la Plaza Mayor de Villalpando llevan en el frente labrado un escudo.

Como se ha señalado hay que suponer que la mayoría de estos soportes pertenecieron a patios desaparecidos de casas urbanas que organizaban sus dependencias en torno a él como sucedía en los palacios. También es posible que alguno de ellos proceda de edificios públicos que pudieran contar con alguna galería e incluso patio o, como en el caso de Villalpando, que sirvieran para la configuración de los soportales de algunas plazas.

\section{Obras públicas}

A juzgar por las referencias que se conservan, durante el reinado de los Reyes Católicos se realizaron diversas obras en la ciudad de Zamora que contribuyeron a un claro mejoramiento de la urbe ${ }^{336}$. Se hicieron arreglos en las murallas, en el puente, en las calles y se levantaron algunos edificios como el Ayuntamiento Viejo ${ }^{337}$. De forma más puntual se intervino en algunos lugares de la provincia de Zamora.

Una de las escasas estructuras arquitectónicas correspondiente a la muralla de Zamora que se puede encuadrar cronológicamente por sus elementos decorativos dentro de este periodo es el desaparecido coronamiento de la puerta de Zambranos o de doña Urraca, que es perceptible en un lienzo de grandes dimensiones que se conserva en el muro norte del presbiterio de la iglesia de San Antolín de Zamora. Así al menos lo advirtió Gómez-Moreno ${ }^{338}$, que fue el primero en relacionarlo

336 Sobre este aspecto vid. LADERO QUESADA, Manuel Fernando, “Aproximación al proceso de transformaciones urbanísticas en Zamora en el tránsito de la Edad Media a la Edad Moderna", en I Congreso de Historia de Zamora, t. III, Instituto de Estudios Zamoranos Florián de Ocampo, Zamora, 1989, pp, 565-577.

337 A.H.P.Za.Secc. Munic. Zamora. A.4.1 (provisional). En este documento (datado en 1506-1508) se da cuenta de los ingresos y los gastos para las obras del puente, muros, almenas y puertas de la ciudad. Citado por CARBAJO MARTÍN, C. M., "Obras públicas" en Catálogo de la exposición CIVITAS. MC. Aniversario de la Ciudad de Zamora, Junta de Castilla y León, Caja España, Zamora, 1993, p. 96.

338 GÓMEZ-MORENO, M., op. cit., I, 1927 (1980), p. 86. 
con la citada puerta de la muralla ${ }^{339}, y$, posteriormente, Ramos de Castro $^{340}$, Gutiérrez González ${ }^{341}$, Ferrero Ferrero ${ }^{342}$ y Lorenzo Arribas $^{343}$ que han valorado esta representación de igual modo. La pintura es obra anónima de finales del siglo XVII o principios del siglo XVIII y Ileva por título Traslado de Nuestra Señora de San Antolín o de la Concha a Zamora y su jura como patrona de la ciudad. Esta pintura sirvió para la realización de un grabado publicado en 1881 en la revista Zamora Ilustrada bajo el título Puerta del Palacio de Doña Urraca ${ }^{344}$. En la misma revista y en el mismo año se publicó otro grabado del estado que presentaba la puerta en 1881 bajo el nombre Arco de las ruinas del Palacio de Doña Urraca en la que el aspecto era prácticamente idéntico al que tiene hoy día ${ }^{345}$. De mediados del siglo XIX es el dibujo de Avrial titulado Restos del palacio de Doña Urraca que reproduce en primer plano los restos que se conservaban en aquel momento de esta puerta de la muralla que, por otra parte, son en esencia los que se conservan en la actualidad ${ }^{346}$. La fotografía tomada por J. Laurent entre 1860-1886 desde el mismo ángulo utilizado por Avrial para su dibujo en 1850 constata la fidelidad con que fue representada por el dibujante ${ }^{347}$.

339 La puerta de doña Urraca también conocida como puerta de Zambranos pertenece al primer recinto amurallado de la ciudad. Está compuesta de dos cubos semicirculares que flanquean una puerta de medio punto con bóveda de cañón. Su construcción responde a las primeras décadas del siglo XIII. GUTIÉRREZ GONZÁLEZ, J. A., op. cit., 1990, pp. 21 y 48 .

340 RAMOS DE CASTRO, G., op. cit., 1978a, p. 28.

341 GUTIÉRREZ GONZÁLEZ, J. A., op. cit., 1990, p. 18.

342 FERRERO FERRERO, Florián, “Traslado de Nuestra Señora de San Antolín o de la Concha a Zamora y su jura como patrona de la ciudad" en Catálogo de la Exposición Remembranza. Las Edades del Hombre, Zamora, 2001, p. 230.

343 LORENZO ARRIBAS, Josemi "Restos del palacio de Doña Urraca" en AA.VV., Zamora Año de 1850 (Sergio Pérez Martín y Marco Antonio Martín Bailón (Coord.)), Zamora, 2013, p. 227.

344 ÁLVAREZ MARTÍNEZ, U., "Nuestro Grabado" en Zamora Ilustrada, Diputación de Zamora, tomo I, n 22, Grab., p. 1.

345 ÁLVAREZ MARTÍNEZ, U., "Nuestro Grabado" en Zamora Ilustrada, Diputación de Zamora, tomo I, nº 15, Grab., p. 1.

346 AA.VV., Zamora Año de 1850 (Sergio Pérez Martín y Marco Antonio Martín Bailón (Coord.)), Zamora, 2013, lám. 29.

347 LAURENT, Jean, "Zamora. 436. Murallas y portillo, con la casa de doña Urraca" en España artística y monumental. Viaje instructivo y reseña histórica de todas las bellezas arquitectónicas, antiguas y modernas de la Península, con la descripción de cada una de ellas en sus diferentes estilos y épocas, tomo 2, Barcelona, Seguí, [192?], $\mathrm{n}^{\mathrm{o}} 24$. 
Es muy probable, como ya han apuntado los autores mencionados, que la representación contenida en el lienzo de la iglesia de San Antolín, recoja la conocida actualmente como Puerta de doña Urraca pues lo conservado hoy de ella guarda una gran semejanza con los dos tercios inferiores de la puerta que se representó en la citada pintura. Ha perdido, sin embargo, el tercio superior o coronamiento que sería lo ejecutado durante el gótico tardío.

De esta puerta se conserva actualmente la parte correspondiente al siglo XII, es decir los dos tercios inferiores formados por dos torreones de forma circular flanqueando un acceso en arco de medio punto. En la pintura de la iglesia de San Antolín se observa claramente cómo estos dos torreones tenían un mayor desarrollo en altura y se encontraban rematados en chapitel. La parte superior, de la que con toda probabilidad da testimonio la pintura, no existe. Aunque en ella la mayoría de vanos que se aprecian presentan formas cuadrangulares y pertenecen a reformas realizadas ya en época barroca, existen una serie de elementos que habría que relacionar con el gótico

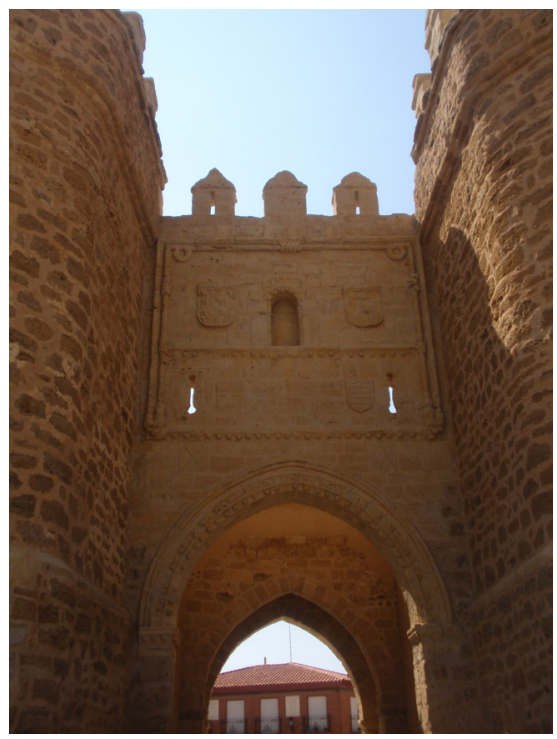

final como son los alfices que enmarcan los escudos situados sobre los vanos de la torre occidental y los arcos lobulados o tetrafoliados que son visibles en dos de las caras de la parte superior de la torre que se encuentra más hacia el este. 
En la provincia de Zamora se intervino durante el primer tercio del siglo XVI en el recinto amurallado de Villalpando; concretamente en la puerta medieval de San Andrés que se renovó de tal forma que fue transformada en un acceso

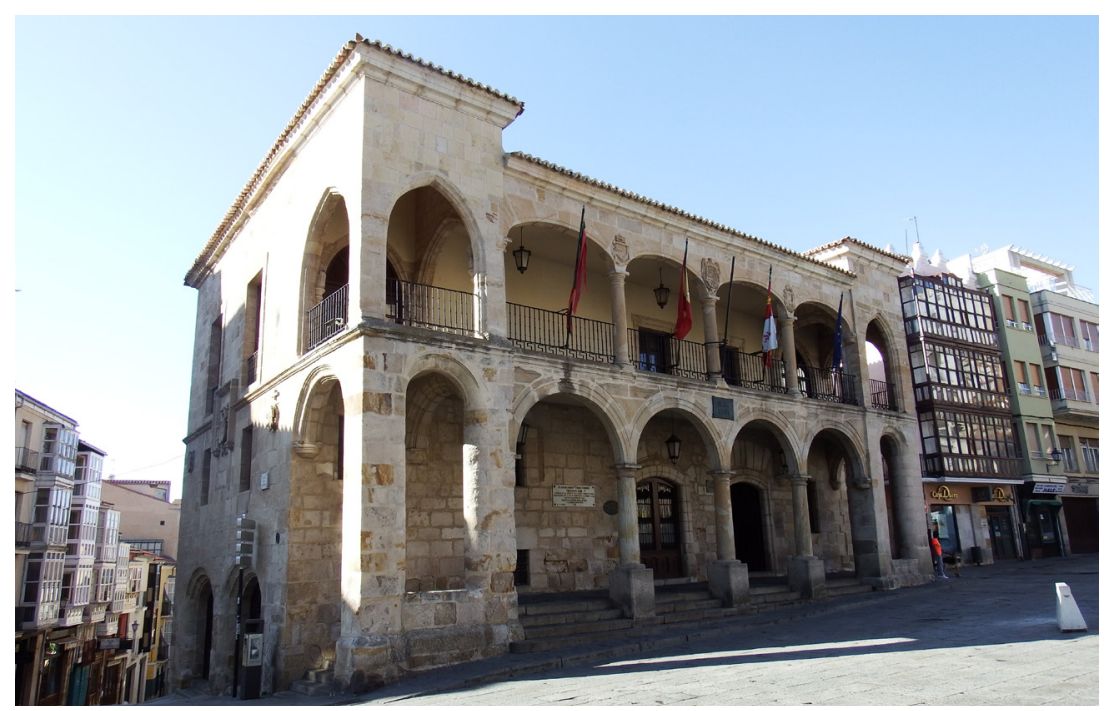

monumental y decorativo. Destaca en ella la presencia de un cordón franciscano, escudos de armas, motivos geométricos y las medias bolas tan recurrentes en la arquitectura civil y religiosa de este momento (Fig. 299).

Algo semejante sucedió en la villa de Benavente donde según señala Lobato Vidal fue levantada sobre la puerta original de Santiago una nueva a finales del siglo XV o principios del XVI, actualmente desaparecida pero que conocemos a través de fotografías antiguas ${ }^{348}$. Esta puerta, que pertenecía a un segundo recinto amurallado que rodeaba el castillo-palacio de Benavente, constituía la entrada principal a la residencia de los condes, y como ya destacó el autor mencionado guardaba semejanzas con la puerta de San Andrés de Villalpando.

Como edificio civil, aunque muy transformado, se ha conservado el antiguo Ayuntamiento ${ }^{349}$ de la ciudad de Zamora que sigue las pautas, en lo esencial, de este tipo de edificios en tiempos de los Reyes Católicos y del que conservamos como noticia de enorme relevancia el nombre del maestro encargado

348 LOBATO VIDAL, J.C., op. cit., 1997, p.36

349 En breve se va a proceder al traslado de la Policía Municipal al edificio que albergó en su momento al Banco de España y en este edificio denominado Ayuntamiento viejo se va a instalar un museo dedicado a la figura del escultor zamorano Baltasar Lobo. 
de la obra en los inicios de la edificación (Fig. 300). Se trata de un edificio que está organizado mediante una gran fachada con soportales que da hacia la actual plaza Mayor cerrándola por su lateral sur. En su día cuando se realizó la obra original esta localización ya constituía uno de los puntos más destacados y transitados de la ciudad. Todo el edificio se encuentra tremendamente transformado como queda reflejado en su evolución arquitectónica a través de los siglos y que conocemos por testimonios, planos y numerosas fotografías. No obstante, su fachada oriental todavía conserva gran parte de la estructura original con una serie de escudos. Interesantísimos resultan los restos existentes en la galería superior que confirman la existencia, sino de bóvedas de crucería, sí al menos de la intención de llevarlas a cabo, lo que constituiría el único ejemplo de arquitectura civil del que tenemos constancia de este tipo de elementos ${ }^{350}$.

Los elementos ornamentales que posee se reducen a los escudos existentes en el frente y en las fachadas este y sur.

\section{Arquilectura hospitalaria}

Los hospitales, alberguerías o casas de acogida para peregrinos, transeúntes o personas del lugar faltos de recursos fueron muy comunes en Europa desde el siglo XII ${ }^{351}$. La mayoría de estas fundaciones hospitalarias se debieron a la Iglesia, que ponía así en práctica una de sus funciones primordiales como era la caridad atendiendo a los necesitados ${ }^{352}$. Así, muchas

350 Lo más reciente sobre la Plaza Mayor y el antiguo ayuntamiento en VASALLO TORANZO, Luis. "Origen y desarrollo de la Plaza Mayor de Zamora. Siglos XV y XVI". En HERNÁNDEZ LUIS, José Luis (ed.). Sic vos non vobis. Colección de estudios en honor de Florián Ferrero. Zamora: Ministerio de Educación, Cultura y Deporte-Junta de Castilla y León-UNED-ACAL-IEZ Florián de Ocampo, 2015 (publicación electrónica en preparación), pp. 385-406.

351 De entre la abundante bibliografía general sobre arquitectura hospitalaria vid. LEISTIKOW, Dankwart, Edificios hospitalarios en Europa durante diez siglos. Historia de la arquitectura hospitalaria, C.H. Boehringer Sohn, Ingelheim am Rhein, Alemania, 1967. Más recientemente pueden consultarse las obras de Rosende Valdés y Félez Lubelza que recogen abundante bibliografía sobre arquitectura hospitalaria. ROSENDE VALDÉS, Andrés A., El Grande y Real Hospital de Santiago de Compostela, Madrid, 1999; FÉLEZ LUBELDA, Concepción, El Hospital Real de Granada. Los comienzos de la arquitectura pública, Granada, 2012.

352 Sánchez Herrero a través de la documentación revisada ha constatado la existencia de hospitales en la diócesis de Zamora desde el siglo XII hasta el siglo XVI. En su opinión la mayor parte de ellos debieron ser fundados durante el siglo XV y no pasarían probablemente de ser viviendas particulares reconvertidas en albergues asistenciales. 
cofradías y monasterios contaron con un espacio para atender a estas personas. También se debe la fundación de hospitales a las órdenes militares (especialmente la Orden Hospitalaria de San Juan) y a algunos gremios o particulares.

Es indudable, que a pesar de la terminología empleada para definir estas instituciones asistenciales, su objeto durante la Edad Media no fue otro que el de casas de acogida y de atención muy primaria, ya que, quienes regentaban estos lugares, carecían mayoritariamente de conocimientos médicos. También escaseaban los recursos, de ahí que la dotación de estos lugares fuese muy limitada.

La situación estratégica de la ciudad de Zamora y su provincia, atravesada por importantes caminos de comunicación entre los que destacaba la Vía de la Plata, y la existencia de ciudades tan importantes como lo fueron Toro y Benavente, hizo que las fundaciones hospitalarias a lo largo de la Edad Media fueran muy cuantiosas $^{353}$. En Zamora durante este periodo habían estado en funcionamiento el Hospital de San Julián o de los Pelliteros (desde el siglo XII), el Hospital Santo Espíritu (desde el siglo XIII), el Hospital de San Lázaro (desde el siglo XV), el Hospital de Santa Victoria (desde el siglo XV), la Hospedería-Hospital de Nuestra Señora del Caño (desde el siglo XV), el Hospital Santa María de los Mozos (desde el siglo XV), el Hospital de San Juan de Acre (fundado en el siglo XV), el Hospital de la Sarna (desde el siglo $X V$ ?) y el Hospital de los Ciento o de San Ildefonso (desde el siglo $X V)$. Estos hospitales no debían de tener demasiada entidad pues en el siglo XVI y XVII se fundaron el Hospital de Sotelo y el Hospital de la Encarnación que dejaron definitivamente resueltas las necesidades de la ciudad en este aspecto.

SÁNCHEZ HERRERO, José, "Las instituciones eclesiásticas de la diócesis de Zamora durante la Edad Media, siglos VII al XV" en Civitas. MC Aniversario de la Ciudad de Zamora, Catálogo de exposición, Zamora, 1993, p. 58.

353 Lamentablemente la mayor parte de edificios con esta funcionalidad han desaparecido. Un catálogo exhaustivo de ellos a lo largo de la Vía de la Plata puede consultarse en AA.VV., Historia hospitalaria de la Vía de la Plata (José Luis Perona Larraz. Dir.), Salamanca, 2009, pp. 212-271. Los hospitales de la ciudad de Toro han sido recogidos por Navarro Talegón y Vasallo Toranzo. NAVARRO TALEGÓN, J., op. cit., 1980, pp. 71-90; VASALLO TORANZO, L., op. cit., 1994, pp. 151-168. Desde el punto de vista de la historia de la diócesis de Zamora como un lugar donde se desarrollaron multitud de actividades benéfico-asistenciales vid. SÁNCHEZ HERRERO, José, "La Diócesis de Zamora, hogar de vida cultural y benéfico asistencial" en AA.VV., Ciclo de Conferencias. Enero 2002. XI Centenario de la Fundación Diócesis de Zamora. 5 octubre 2001-26 mayo 2002, Zamora, 2002, pp. 52-66.
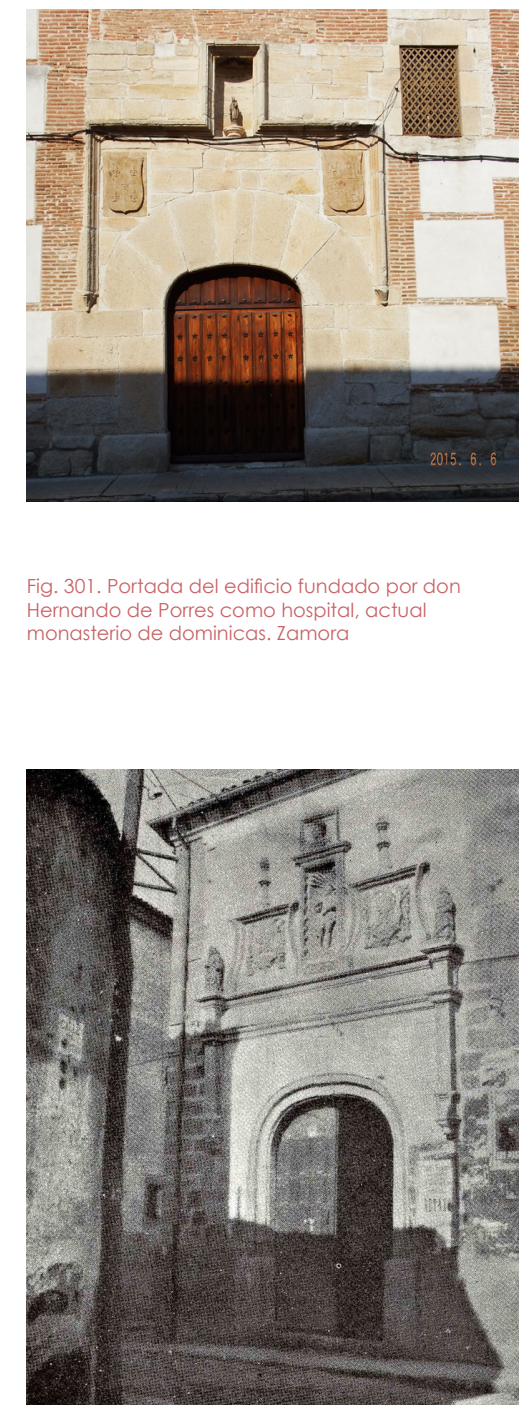

Fig. 301. Portada del edificio fundado por don Hernando de Porres como hospital, actual monasterio de dominicas. Zamora

Fig. 302. Portada del desparecido hospital de Sotelo. Zamora

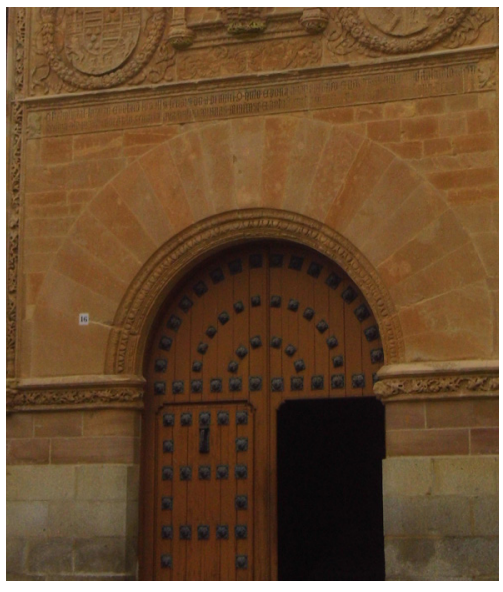

Fig. 303. Portada del hospital de la Piedad. Benavente 


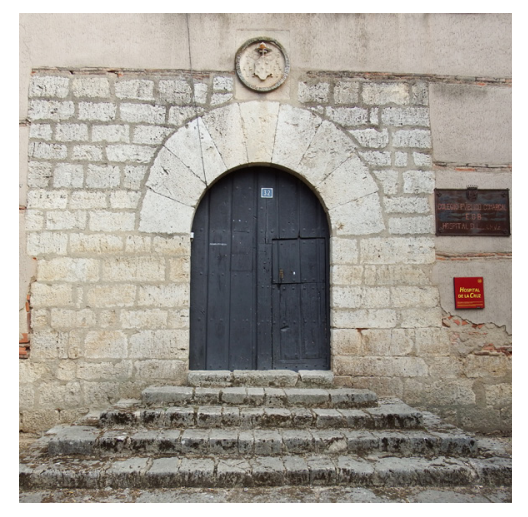

Fig. 304. Portada del hospital de la Asunción y dos Santos Juanes. Toro

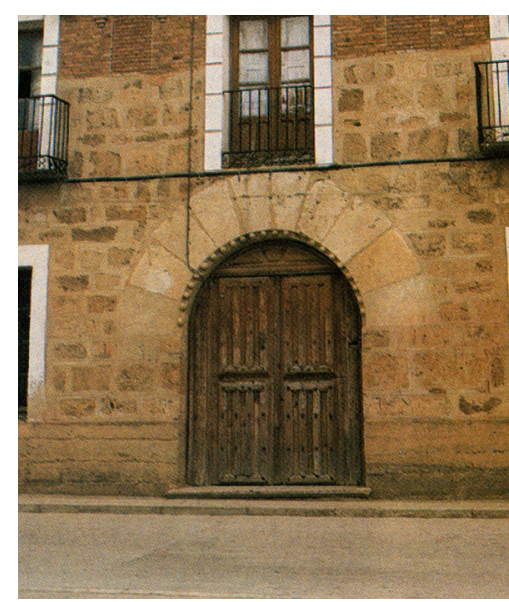

Fig. 305. Portada del hospital del Espíritu Santo. Villalpando
Después de la ciudad de Zamora, Benavente era la localidad situada en la Vía de la Plata con un mayor número de lugares de acogida o pequeños hospitales durante la Edad Media. Algunos de los más significativos fueron el Hospital de San Juan Bautista (del que se tienen noticias desde principios del siglo XIV), el Hospital de San Antón (fundado en el siglo XIV), el Hospital de la Santa Cruz (del siglo XV), la Ermita y Hospital de San Lázaro (cuyas primeras noticias se datan en el siglo XV), la Ermita Hospital de San Roque (con noticias desde principios del siglo XVI) y el Hospital de la Piedad (fundado a principios del XVI), que es el único que ha llegado a nuestros días. Otros núcleos de población mucho menos significativos contaron algún tipo de alberguería u hospital por estar situados en Vía de la Plata, aunque de ellos nada se ha conservado y las escasísimas noticias documentales que tenemos no permiten establecer en la mayoría de los casos el momento de la fundación. En el siglo XVI Toro llegó a contar con dieciséis hospitales, la mayoría de ellos fundados en época medieval ${ }^{354}$. Estos eran el Hospital de San Antonio Abad (con restos del siglo XIII), el Hospital de Santa María de Roncesvalles (fundado en época medieval), el Hospital de Palomino (fundado a principios del XV), el Hospital de San Blas (se ignora la fecha de fundación), el Hospital de la Antigua (fundado en el siglo $X V$ ), el Hospital de Párraga (fundado en el siglo XV), el Hospital de Pecador (documentado en el siglo XIV), el Hospital de la Asunción y dos Santos Juanes (fundado a principios del XVI) y otros de los que se tienen escasas referencias como es el caso de los hospitales de San Pedro del Olmo, del Rastro, de San Julián, de la Higuera, de Rematados, de Roncesvalles, de Rocamador y del Sepulcro. Otros núcleos de población importantes en estos momentos eran Villafáfila, que llegó a tener cuatro hospitales (los de San Pedro, de Nuestra Señora de Villarigo, de la Cofradía de la Santa Vera Cruz y el de San Juan) y Villalpando con cinco (San Lázaro, Santa María la Nueva, Santa María de Rocamador, la Santísima Trinidad y Sancti-Spiritus) ${ }^{355}$. La fundación hospitalaria más antigua en la provincia de Zamora parece corresponderse,

354 VASALLO TORANZO, L., op. cit., 1994, p. 152, nota 320.

355 Respecto a los hospitales de Villafáfila vid. RODRÍGUEZ RODRÍGUEZ, Elías, "Los Hospitales de Villafáfila en los siglos XVI-XVIII" en en Anuario del Instituto de Estudios Zamoranos "Florián de Ocampo», Zamora, 2000, pp. 431-446. Respecto a los hospitales de Villalpando vid. CALVO LORENZO, Luis, Historia de la villa de Villalpando, Zamora, 1981, pp. 90-92. 


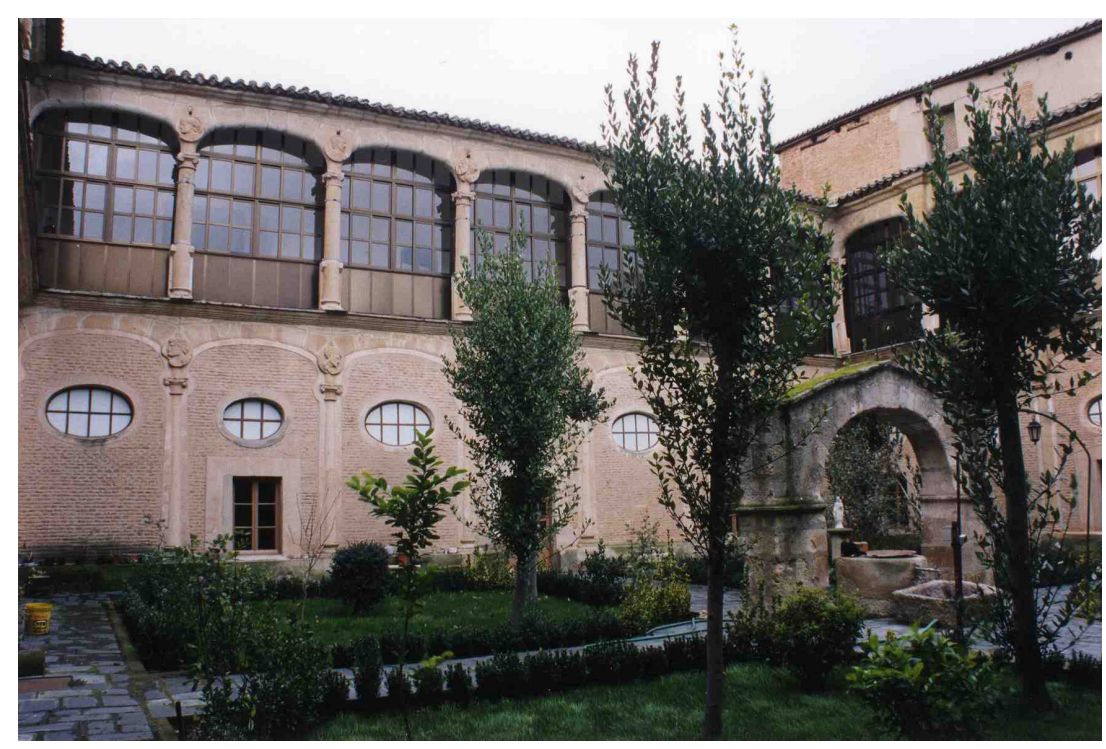

como ya señalara José Sánchez Herrero, con la alberguería que hubo anexa al templo románico del Santo Sepulcro en la ciudad de Zamora y que se remonta a finales del siglo XII ${ }^{356}$.

De todos los hospitales mencionados apenas se han conservado unos pocos y ninguno anterior al siglo $\mathrm{XVI}$, por lo que no es posible un estudio científico y evolutivo de su arquitectura. Es probable que durante los siglos XIII, XIV y XV este tipo de instituciones se instalaran en espacios modestos de arquitectura sobria que no participaría del estilo del momento sino que estaría supeditada a la mera funcionalidad. En otras ocasiones se aprovecharían espacios ya existentes anexos a un templo o edificio monacal. A esto se une la fundación de grandes hospitales en el siglo XVI que dejó sin función a los de menor entidad que, por otro lado, hacía ya tiempo que estaban muy faltos de recursos además de estar mal gestionados siguiendo un modelo medieval que estaba totalmente agotado. Todo ello trajo como consecuencia la desaparición de las fundaciones hospitalarias medievales, conocidas solo a través de referencias documentales.

No obstante, en los escasos edificios hospitalarios construidos durante el primer tercio del siglo XVI que han llegado a nuestros días $\mathrm{o}$, de los que al menos tenemos testimonio visual a través de fotografías, se perciben claramente estructuras y elementos característicos de la arquitectura gótica tardía, por lo que, al 


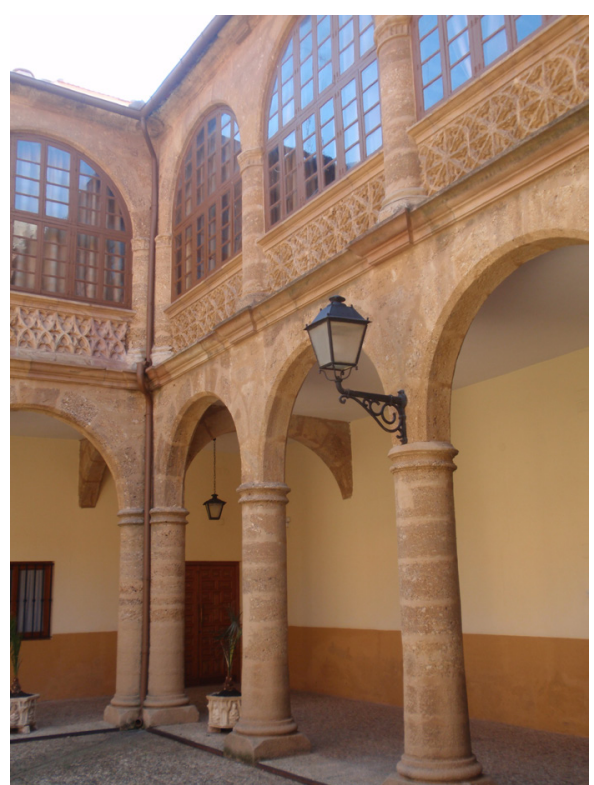

menos durante este periodo, podemos hacer una valoración aproximativa de sus rasgos generales.

En gran medida estos edificios hospitalarios edificados a principios del siglo XVI son producto de un nuevo concepto de hospital que impusieron los Reyes Católicos con el objeto de que fueran más efectivos y prácticos. Indudablemente el modelo que ellos introdujeron, proveniente de Italia, y que se plasmó en los hospitales reales de Santiago de Compostela (1499) y Granada (1511), y también en el de Santa Cruz fundado en Toledo (1504) por el Cardenal Mendoza, necesitaba de un comitente acorde con la magnitud de estos edificios. Lo que se hizo, por tanto, fue adaptar la estructura de uno de los cuatro claustros que estos grandes hospitales tenían previsto, lo que dio como consecuencia que estos hospitales se pareciesen más a la arquitectura palaciega de la época. No obstante y en cierto modo, la estructura del claustro y la aparición de una capilla, fundamental en edificios de este tipo, en cierto modo recoge a menor escala los nuevos planteamientos de arquitectura hospitalaria que se estaba imponiendo en la Península desde finales del siglo $\mathrm{XV}^{357}$.

Los edificios hospitalarios de la provincia de Zamora de finales de la Edad Media y principios del Renacimiento de los que ha llegado testimonio material o gráfico son: en la ciudad de Zamora, el actual monasterio dominico de las Dueñas (edificado 


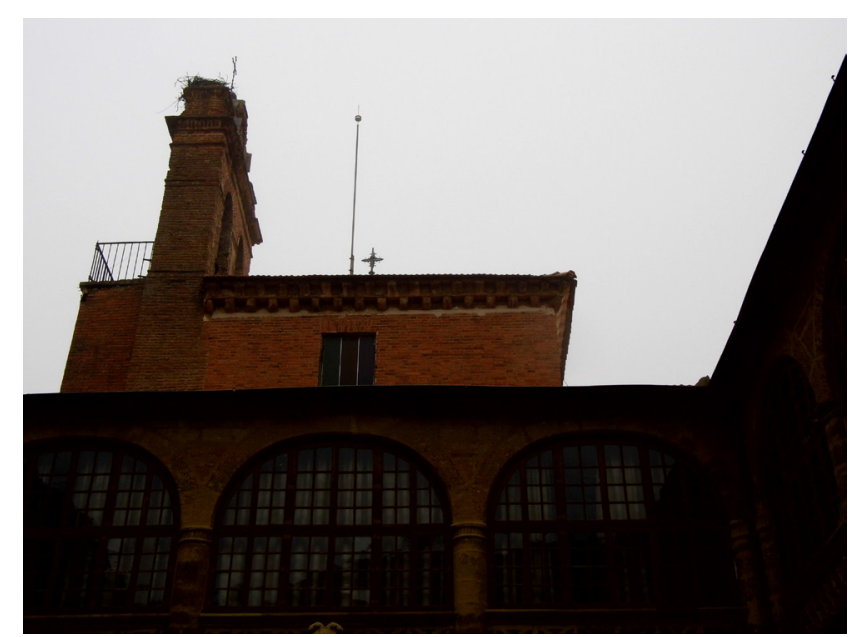

en origen como hospital), el Hospital de Sotelo (desaparecido en el siglo XX); en la ciudad de Toro, el Hospital de la Asunción y dos Santos Juanes (conocido como del Obispo); en la ciudad de Benavente, el Hospital de la Piedad; y, en Villalpando, el Hospital del Espíritu Santo.

Aunque ninguno se conserva en su integridad, es más, algunos han sido muy transformados como sucede con hospital fundado por don Hernando de Porres y Monroy, caballero de la Orden de San Juan, actual monasterio de dominicas, podemos hacer algunas apreciaciones.

En primer lugar, y por lo que respecta a la apariencia exterior, en todos ellos se enfatizó la portada, labrada en buena sillería, frente al resto de la edificación que está construida en mampostería o en ladrillo. Para el acceso se utilizó bien el arco carpanel como sucede en el actual monasterio de dominicas de Zamora y en el desaparecido Hospital de Sotelo, también de la capital, bien el arco de medio punto, como es el caso del Hospital de la Piedad de Benavente, el Hospital del Obispo de Toro y el Hospital del Espíritu Santo en Villalpando (Figs. 301, 302, 303, 304 y 305$)$.

Los elementos que de estas portadas guardan todavía una vinculación directa con la arquitectura gótica tardía son el amplio dovelaje utilizado, el uso del alfiz en alguna de ellas y la presencia de elementos tales como las medias bolas. A estos elementos se suman otros absolutamente ya propios del primer renacimiento.

Respecto del interior y a juzgar por los tres testimonios conservados, el actual monasterio de dominicas Dueñas de 


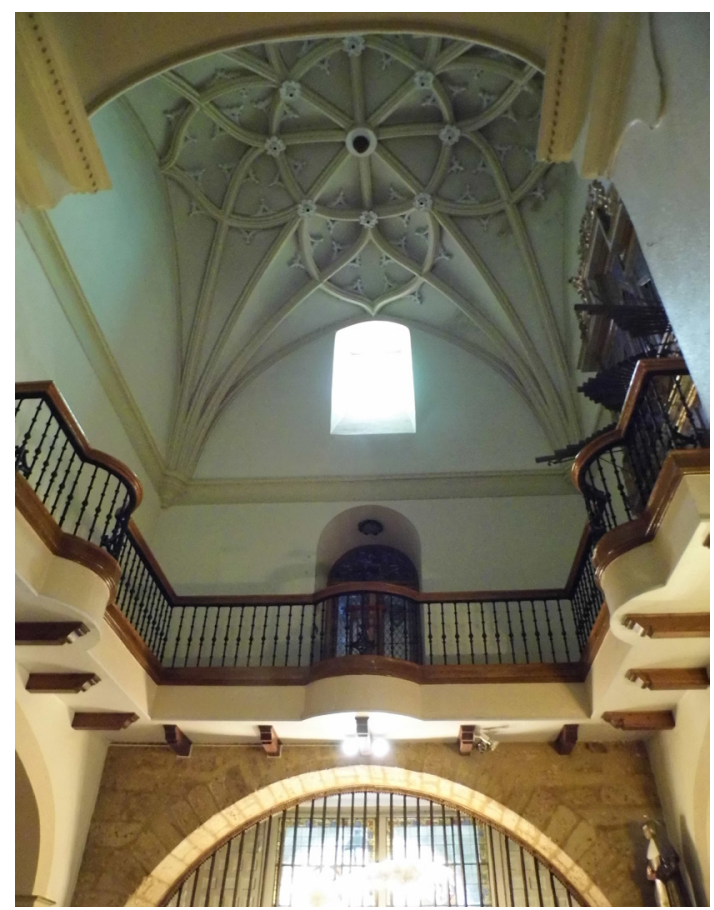

Zamora, el Hospital de la Piedad de Benavente y el Hospital del Obispo de Toro, se componía de un patio central cuadrangular articulado en dos alturas (Figs. 306 y 307). En el caso del actual monasterio dominicano configura sus dos pisos con arcos carpaneles, el Hospital de la Piedad lo hace con arcos de medio punto también en sus dos cuerpos y el hospital toresano con pilares cilíndricos que sostienen vigas de madera mediante zapatas, de considerable mayor altura en el cuerpo bajo que en el alto. En conjunto estos patios manifiestan ya una clara dependencia del primer renacimiento; tan sólo los antepechos del patio del hospital benaventano mantienen diseños de tradición flamígera.

Por último, especial importancia tuvo en estos edificios la capilla, elemento esencial ubicado en un lugar privilegiado. Conservamos la correspondiente al Hospital de la Piedad, cuya parte original tiene planta cuadrangular y se encuentra edificada en ladrillo (Fig. 308). Sobresale por encima del patio y su interior está cubierto por una bóveda de crucería estrellada donde abundan los nervios combados y la ornamentación ya de tipo renacentista (Fig. 309). Por el tipo de bóveda que presenta, debió levantarse avanzado ya el siglo XVI. De la capilla del Hospital Sotelo de Zamora, que fue derruida junto con el propio hospital en la segunda mitad del siglo XX contamos con alguna fotografía aunque la información que aporta sea limitada, ya que 


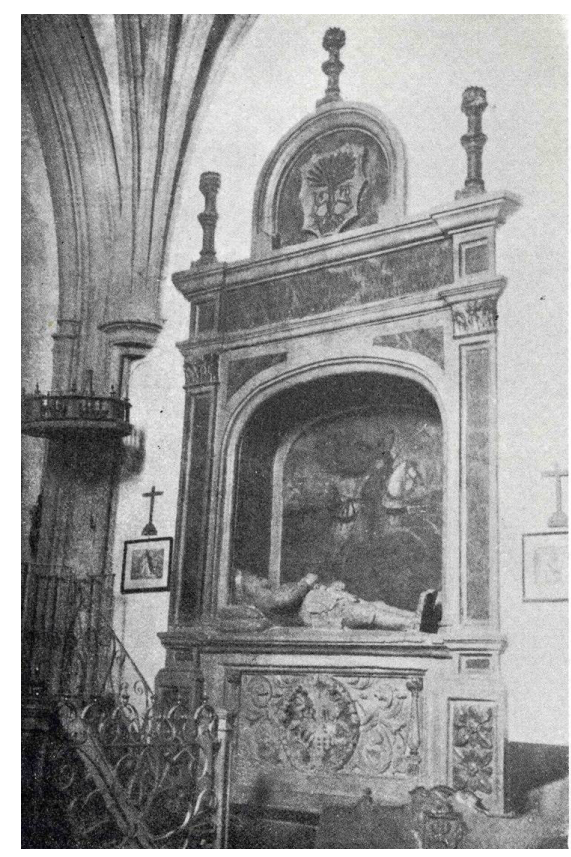

Fig. 310. Interior de la capilla del desaparecido hospital de Sotelo. Zamora

únicamente permiten imaginar sus cubiertas góticas a partir de los arranques de las mismas (Fig. 310). Más interesante resulta la descripción que de ella hizo Gómez-Moreno señalando " La capilla es a modo de iglesia; su nave se cubre con armadura de par y nudillo, que pudo tener lazo en su renovado almizate, y la cabecera sustenta bóveda de crucería gótica, pero con filateras de gusto romano"358. Esta bóveda es probable que fuese de la misma época o quizás un poco anterior que la bóveda de la capilla del Hospital de la Piedad.

Como conclusión podemos apuntar que la arquitectura hospitalaria que se hizo para fines sociales durante las primeras décadas del siglo XVI tomó como referencia los modelos palaciales. A pesar de no haberse conservado muchos ejemplos todo apunta en esa dirección. El tipo de portada, la configuración del edificio en torno a un patio de doble altura, así como la ornamentación, no difieren de los palacios coetáneos. Baste citar, como ejemplo, en este aspecto el patio del hospital fundado por Hernando de Porres y el patio del palacio de los conde de Alba de Aliste, ambos configurados mediante arcos carpaneles en dos alturas con medallones situados en la confluencia de los arcos. Tan sólo la capilla, que en los palacios debió de ser un espacio más modesto, tiene en estos edificios de carácter asistencial una presencia más destacable. 


\section{LAS PERVIVENCIAS DEL GÓTICO EN LA EDAD MODERNA}





\section{LA PERVIVENCIA DEL GÓTICO EN LA EDAD MODERNA}

\section{Notas históricas}

A lo largo del siglo XVI la importancia de la ciudad de Zamora y su provincia en el conjunto de España fue tan escasa como lo había sido en los siglos precedentes, si exceptuamos el breve periodo transcurrido entre los últimos años del siglo XV y los primeros del siglo $\mathrm{XVI}$, en el que se vivió un cierto apogeo al que se ha hecho referencia en el apartado anterior. Por tanto, Zamora, pero también Toro, Benavente y demás villas que habían tenido un destacado protagonismo en algunos acontecimientos históricos sucedidos en nuestro país, quedaron relegadas en favor de otras localidades. Aun así, la ciudad de Zamora debido a su importante situación geográfica y estratégica, jugó un papel significativo en la contención de las aspiraciones portuguesas. Debido a esta situación privilegiada tanto en la ciudad de Zamora como en su provincia se encontraba un amplio destacamento del ejército que mermaba sobremanera los recursos económicos de que disponían los zamoranos, ya que eran éstos los que tenían que hacer frente a los gastos de mantenimiento generados por aquellos ${ }^{359}$.

No se sucedieron, por tanto, en la ciudad de Zamora y su provincia grandes acontecimientos históricos de importancia a lo largo de estos dos últimos tercios del siglo XVI que tomamos como marco general cronológico para este apartado. Tan sólo son destacables la boda de la infanta Juana, hija del Emperador Carlos V, con el príncipe Juan de Portugal, que tuvo lugar en la ciudad de Toro en 1552 y, la visita que realizó Felipe II a Zamora en 1556, para encomendarse a los patronos de la diócesis (San Atilano) y de la ciudad (San Ildefonso) antes de partir para Inglaterra con motivo de su boda con la reina María Tudor.

Respecto a la población de la ciudad de Zamora, ésta fue incrementándose de manera muy destacada hasta mediados de siglo, momento en el que comenzó un marcado declive. De tal 
forma que, si a principios del siglo XVI la ciudad había contado con casi cuatro mil habitantes, en la década de 1560 se había doblado esta cifra para, a finales de la centuria, acabar contando con poco más de cinco mil quinientos ${ }^{360}$.

La situación económica, que había comenzado a recuperarse a lo largo del siglo XV, siguió dando muestras de fortalecimiento durante el siglo XVI. En la ciudad sus habitantes seguían viviendo fundamentalmente de la industria textil y del comercio con las zonas limítrofes ${ }^{361}$. La provincia seguía siendo eminentemente agrícola $^{362}$.

En el aspecto religioso no existió ningún cambio sustancial en la pequeña diócesis de Zamora en lo que se refiere a su extensión. Los obispos que gobernaron la diócesis durante este periodo fueron Francisco de Mendoza (1527 o 1528 -1536), Pedro Manuel de Castilla (1536-1546), Antonio del Águila (1547-1560), Álvaro de Moscoso (1561-1564), Manuel de la Cerda (15651572), Rodrigo de Castro (1573-1576), Diego de Simancas (15781583), Juan Ruiz de Agüero (1584-1595) y Fernando Suárez de Figueroa (1596-1608).

Las pervivencias del gótico en la Edad Moderna: la arquitectura religiosa

Con las intervenciones llevadas a cabo en Zamora en torno a 1500 sobre la arquitectura civil -favorecidas en gran parte por los Reyes Católicos y la nobleza local-, y las que sufrieron algunos edificios religiosos como el catedralicio, acabó de configurarse la ciudad en la forma y extensión que mantuvo hasta el siglo XIX. También, como se ha visto, fueron destacables las obras realizadas durante aquel periodo en otras ciudades como Toro, 360 RUEDA FERNÁNDEZ, J.C., FERNÁNDEZ VECILLA, J.F., y VELASCO MERINO, E., "La población zamorana, siglos XVI-XIX" en AA.VV., Historia de Zamora. La Edad Moderna, tomo II, Diputación de Zamora, Zamora, 1995, pp. 249339.

361 ALBA LÓPEZ, J.C., "La industria y el comercio en la edad moderna" en AA.VV., Historia de Zamora. La Edad Moderna, tomo II, Diputación de Zamora, Zamora, 1995, pp. 147-215.

362 Para profundizar en el análisis de la agricultura de Zamora durante el siglo XVI vid. ÁLVAREZ VÁZQUEZ, A., "La agricultura de Zamora en la época moderna” en AA.VV., Historia de Zamora. La Edad Moderna, tomo II, Diputación de Zamora, Zamora, 1995, pp. 113-143. 
Benavente o Villalpando. No obstante, la actividad constructiva prosiguió, y pasadas las primeras décadas del siglo XVI en la ciudad de Zamora y en otros muchos núcleos de población de la provincia se acometieron reformas en edificios ya existentes a la vez que se construyeron otros muchos de nueva planta. Entre estos últimos encontraremos edificaciones tanto religiosas como de carácter civil.

Del mismo modo que el gótico había hecho su aparición tardíamente y de manera lenta, debido fundamentalmente al arraigo de las formas románicas, este nuevo estilo echó raíces muy pronto y se prolongó durante un espacio de tiempo muy amplio dificultando la introducción del renacimiento en estado puro. Así, durante las décadas finales del siglo XV y las primeras del XVI, se mantuvieron en los edificios estructuras y ornamentaciones principalmente góticas a las que se fueron incorporando fundamentalmente elementos decorativos renacentistas. Pero poco tiempo después, superadas las primeras décadas del siglo, el grueso de los edificios comenzó a tener una configuración y ornamentación propia del renacimiento aunque se mantuvo, sin embargo, el recuerdo gótico que se ciñó casi exclusivamente a los abovedamientos, para los que se siguió utilizando la bóveda de crucería que adquirió en estos momentos una mayor elaboración y ornamentación. En algunos casos también se siguió utilizando el tipo de soporte en forma de pilar fasciculado propio de la arquitectura gótica tardía. A ello hay que añadir la presencia del alfiz, que aunque de origen mudéjar había sido utilizado habitualmente en la arquitectura civil y religiosa del periodo gótico tardío y se mantiene con frecuencia en muchos edificios de esta época. No obstante habría que señalar que la separación entre la arquitectura gótica tardía propiamente dicha y aquella en la que los elementos góticos son una mera pervivencia es difícil de establecer de manera lineal. De ahí que en este apartado hayamos clasificado algunos edificios teniendo en cuenta que determinadas características que presentan son del gótico tardío, y muy difícil de precisar la fecha de su construcción.

En conclusión podemos afirmar que la proyección de modelos góticos, incluso fuera de época, fue habitual en la provincia de Zamora, en gran medida, favorecida por la introducción de forma 
desigual del Renacimiento en nuestra geografía y su implantación parcial que favoreció su convivencia con formas y elementos góticos que tardaron mucho tiempo en desaparecer. Lo que realizaremos, por tanto, es un análisis de los elementos que, de acuerdo con la definición general del estilo, pertenecerían al gótico. Elementos que encontramos fuera de la época en la que los estudios encuadran este estilo y en edificios que son, en algunos casos, ya principalmente renacentistas y que en las publicaciones sobre la arquitectura de nuestra provincia se califican como edificios de estilo Renacimiento ${ }^{363}$.

\section{Los promotores}

Durante este periodo los personajes de mayor relieve social, fundamentalmente de la ciudad de Zamora, patrocinaron la construcción de edificios religiosos (iglesias y monasterios), hospitales y residencias palaciegas. De este modo el comendador de la Orden de Santiago Alonso de Sotelo fundó en el año 1526 en la ciudad de Zamora el Hospital de Sotelo del que solamente han llegado a nuestros días testimonios documentales y gráficos. El capitán Antonio de Sotelo Cisneros, compañero de Hernán Cortés en la aventura de América, se encargó de la edificación de un nuevo templo dedicado a San Andrés en Zamora, que fue levantado en el mismo lugar en el que había existido una iglesia románica advocada en el mismo santo y de la que los escasos restos que permanecieron en pie fueron incorporados al nuevo edificio. Igualmente en la ciudad de Zamora, en este caso en la margen izquierda del río Duero, don Hernando de Porres y Monroy, caballero de la Orden de San Juan, mandó levantar hacia 1541 un edificio que la historiografía actual considera que fue edificado en origen como hospital.

A su vez la nobleza local, sobre todo la correspondiente a las ciudades de Zamora y Toro, erigió residencias palaciegas, algunas

363 Puede consultarse a este respecto algunos trabajos sobre maestros cuyas obras son principalmente de estilo Renacimiento aunque es fácil reconocer en ellas todavía algunas particularidades propias del estilo gótico tardío. HOAG, John D., Rodrigo Gil de Hontañón. Gótico y renacimiento en la arquitectura española del siglo XVI, Madrid, 1985; CASASECA CASASECA, Antonio, Rodrigo Gil de Hontañón (Rascafría, 1500-Segovia, 1577), Junta de Castilla y León, Salamanca, 1988; CASTRO SANTAMARÍA, Ana, Juan de Álava. Arquitecto del renacimiento, Salamanca, 2002; ALONSO RUIZ, Begoña, Arquitectura tardogótica en Castilla: los Rasines, Universidad de Cantabria, 2003. 
de ellas de cierto empaque. En Benavente siguieron siendo sus condes los artífices de las intervenciones más destacadas que se produjeron en la ciudad, como fue el caso de las obras acometidas tanto en su espléndido castillo-palacio como en la iglesia de Santa María del Azogue. Igualmente fundaron y patrocinaron la construcción del Hospital de la Piedad, que en lo fundamental se había edificado durante el primer tercio del siglo XVI.

La actividad arquitectónica religiosa zamorana y sus aspectos conservadores durante los dos últimos tercios del siglo XVI

Los edificios que se construyeron a lo largo del siglo XVI aceptaron progresivamente la influencia renacentista, pero muy mediatizada por la pervivencia de las formas góticas ${ }^{364}$. No obstante, y debido a la época tan avanzada del siglo XVI en que se construyeron, el número de elementos referenciales góticos es muy limitado, según puede deducirse a partir de los ejemplos conservados.

Por lo que se refiere a la arquitectura monástica el periodo de renovación espiritual vivido en la ciudad de Zamora en el siglo XVI dio lugar a nuevas fundaciones que, en unos casos, levantaron nuevos edificios y, en otros, adaptaron casas o palacios ya existentes. Estas comunidades, durante este siglo, vivieron una etapa de apogeo y es lógico pensar que esa intensa actividad espiritual tuviera su reflejo en el terreno constructivo, aunque poco de ello haya llegado a nuestros días. Hemos ido viendo a lo largo de este estudio cómo la práctica totalidad de los edificios construidos por las diversas comunidades, durante el periodo en el que se desarrolló la arquitectura gótica, no se han conservado, salvo escasas excepciones ya citadas. De la misma forma ha desaparecido también la mayor parte de los edificios monásticos construidos durante el siglo XVI. Hay que lamentar especialmente la pérdida del notable conjunto arquitectónico de los Jerónimos de Zamora en el que intervino Juan de Álava y del que apenas se conservan algunos testimonios gráficos, literarios y unos pocos elementos materiales descontextualizados que no pertenecen al estilo objeto de este estudio. Han desaparecido 
igualmente las edificaciones de las comunidades femeninas de franciscanas de San Bernabé, Santa Marta y Santa Paula, que también nacieron a lo largo del siglo $\mathrm{XV|}{ }^{365}$, aunque en este caso carecemos de datos para valorar la entidad de su arquitectura. En otros casos, comunidades que tenían a sus espaldas varios siglos de historia, a lo largo del siglo XVI trasladaron su residencia a un nuevo edificio. Así sucedió con la comunidad de las dominicas que pasó a ocupar el edificio patrocinado por don Hernando de Porres y Monroy, ya citado.

En la provincia de Zamora la pérdida de edificios monásticos y conventuales fue igual de dramática. Como ejemplo podemos citar el convento de San Francisco de Toro, que ha desaparecido completamente pero en el que consta que durante las primeras décadas del siglo XVI se reconstruyó la capilla mayor de la iglesia bajo la dirección de Juan de Álava ${ }^{366}$. En Benavente tampoco se ha conservado el monasterio de los Jerónimos que fue edificado durante un momento muy avanzado del siglo XVI y en el que intervinieron Pedro de Ybarra y Miguel de Ibarbia ${ }^{367}$.

La desaparición, por tanto, casi total de estos edificios ha mermado de manera decisiva el patrimonio de nuestra provincia y nos ha privado, de este modo y una vez más, de un conocimiento pleno de la arquitectura levantada durante este periodo. Hay que lamentar, por tanto, la perdida de construcciones monásticas del siglo XVI y de edificaciones más antiguas que fueron reformadas durante este siglo y de las que apenas se conserva algún testimonio gráfico o literario. Entre los factores que ocasionaron estas pérdidas circunscritas, en gran medida, a la ciudad de Zamora, aunque también localizados como acabamos de señalar en Toro y Benavente, se encuentran sobre todo las diversas

365 No tenemos constancia, debido a la escasez de documentación y a la inexistencia de restos conservados de los citados monasterios desaparecidos de San Bernabé, Santa Marta y Santa Paula (a excepción de la portada perteneciente hoy al monasterio de Santa Marina y que en su día formaría parte del monasterio de Santa Marta), de que presentaran en su arquitectura elementos que respondieran a la tradición gótica y que pudieran analizarse como una pervivencia.

366 Se ha conservado un plano del siglo XVIII que permite conocer el trazado de la planta de esta capilla que constaba de un ábside ochavado precedido de un tramo recto rectangular y cuatro contrafuertes. Desgraciadamente el sistema de cubrición no fue dibujado en el plano y, por tanto, ignoramos el diseño que tuvieron las bóvedas. CASTRO SANTAMARÍA, A., op. cit., 2002, pp. 354-355. 
desamortizaciones que, por ejemplo, hicieron desaparecer en su práctica totalidad tanto el monasterio mencionado de los Jerónimos como el de San Benito, ambos en la ciudad de Zamora.

Ajustando el análisis a la arquitectura conservada se puede afirmar que la tradición gótica perduró en Zamora y su provincia incluso durante la segunda mitad del siglo XVI. Las formas góticas se mantuvieron en esta época tan avanzada, fundamentalmente, en las bóvedas y, en menor medida, en los soportes. Por el contrario, en las ménsulas y, sobre todo, en las portadas, es donde se encuentran frecuentemente los diseños y ornamentaciones puramente renacentistas. El ejemplo quizás más claro en el que se optó por esa simbiosis tan característica de nuestra arquitectura en la que conviven el gótico y el renacimiento es la iglesia de San Andrés (Zamora), construida durante el tercer cuarto del siglo XVI.

Pero, aunque en la mayor parte de las estructuras arquitectónicas que se levantaron de nueva planta en este momento, ya fueran iglesias completas, capillas funerarias o renovación de cabeceras, se mantuvo la presencia de elementos góticos en convivencia con las formas renacentistas, sin embargo es interesante destacar los cambios que se aprecian en los modelos estructurales del gótico tardío debido a la nueva interpretación de las formas.

Por otro lado también se construyeron y transformaron nuevos edificios en los que apenas se puede intuir un recuerdo de la arquitectura gótica. Así sucedió con el hospital fundado por Hernando de Porres y Monroy, que se adaptó como Monasterio de Dominicas. Este edificio, que acusó grandes obras durante el siglo XVI, muestra una clara dependencia de los gustos renacentistas $y$, tan solo el uso del arco carpanel en ambos cuerpos de su actual claustro con el intradós en bocelón a la manera salmantina, puede interpretarse como una voluntad de mantener estructuras que habían sido muy habituales en las décadas anteriores. Baste recordar el patio del palacio de los condes de Villalonso en Toro donde en el último cuarto del siglo XV se había empleado la misma solución. 
En función de estos limitados espacios conservados se pueden realizar algunas apreciaciones. Por una parte, se mantuvo la práctica de configurar el interior de los templos, como sucede en la iglesia de San Andrés de Zamora, mediante una sola nave articulada con arcos diafragma de sección aguda. Esto sucede, fruto probablemente de la tradición existente en Zamora que había transformado las tres naves, que algunas iglesias habían tenido en origen, en una sola. Así había ocurrido en las iglesias de Santa María la Nueva y de San Cipriano durante los siglos XIII y XIV en pleno gótico y, mucho más tarde, en las de San Antolín, San Vicente y Santa Lucía. También en la provincia esta transformación de un templo románico de tres naves en una sola se llevó a cabo en la iglesia parroquial de Fermoselle, en este caso ya durante la época de los Reyes Católicos.

Los sistemas abovedados correspondientes a las cabeceras de las iglesias y de alguna capilla mantienen la bóveda de crucería a la que se le han incorporado los combados, de tal forma, que se muestran enriquecidas y, en algunos casos, aparecen dotadas de una cierta complejidad. De entre ellas cabe destacar la perteneciente a la iglesia zamorana de San Andrés por cuando se trata de una doble cabecera de un gran desarrollo que constituye el mayor despliegue de nervaduras de esta segunda mitad del siglo XVI en nuestra provincia. Podemos añadir igualmente la bóveda de la capilla de San Pablo en la Catedral, las bóvedas del cuerpo de naves de la iglesia de Santa María del Azogue de Benavente o la bóveda de la cabecera de la iglesia del convento de Santa Clara de Toro por citar solo algunos ejemplos en los que se mantuvo la estética goticista en un periodo avanzado del siglo XVI.

Por el contrario, en los soportes se tiende claramente hacia una estética renacentista ya desde el entorno de 1500. Así puede verse en las pilastras circulares y acanaladas pertenecientes a la reforma llevada a efecto en tiempos del obispo Meléndez Valdés en la cabecera de la catedral de Zamora y, en las pilastras con la misma sección, que se utilizaron en el cuerpo de la iglesia de San Ildefonso de Zamora. Pero si en estos dos casos aún, por lo que respecta a las basas, se observa un evidente regusto gótico, en la iglesia de San Andrés el soporte va a encontrarse ya dentro 
de una concepción totalmente renacentista. Y no solamente los soportes, sino también los vanos que se abren en el muro que renuncian al arco apuntado para pasar al arco de medio punto, lo que es plenamente comprensible pues entre las reformas emprendidas por Meléndez Valdés y la nueva edificación de la iglesia de San Andrés había transcurrido algo más de media centuria.

Por último las portadas de la Capilla de San Pablo y de la Capilla de San Ildefonso, ambas en la Catedral pertenecen a una concepción prácticamente renacentista aunque mantienen algunos elementos de tradición gótica como el arco carpanel en la primera y el arco escarzano y un remate en conopio en la segunda. El resto de portadas levantadas durante esta época como pueden ser la occidental de la iglesia de San Andrés (Zamora) o la portada sur de la iglesia de Villamor de los Escuderos están caracterizadas en todo su desarrollo por una organización y ornamentación totalmente renacentista.

\section{Análisis formal de los elementos arquitectónicos}

Como hemos venido señalando las formas góticas se mantuvieron en la arquitectura zamorana durante gran parte del siglo XVI aunque fueron perdiendo valor conforme pasaban los años y el renacimiento se iba consolidando. Si hasta las primeras décadas del siglo XVI las estructuras y elementos ornamentales respondían claramente a los modelos generalizados durante el gótico tardío, poco a poco y tras un periodo en el que ambos estilos convivieron por igual, el gótico fue dando paso al renacimiento. De este modo y como hemos señalado, a partir del primer tercio del siglo XVI, el renacimiento se adueñó de los elementos sustentantes y de la decoración y, solamente, en las cubriciones de los espacios, se mantuvo la bóveda de crucería.

\section{Materiales}

Por lo que se refiere a los paramentos, en buena medida se siguió utilizando la piedra labrada en buena sillería como vemos en algunas de las partes que se edificaron en este momento en las iglesias parroquiales de Villamor de los Escuderos, Corrales 


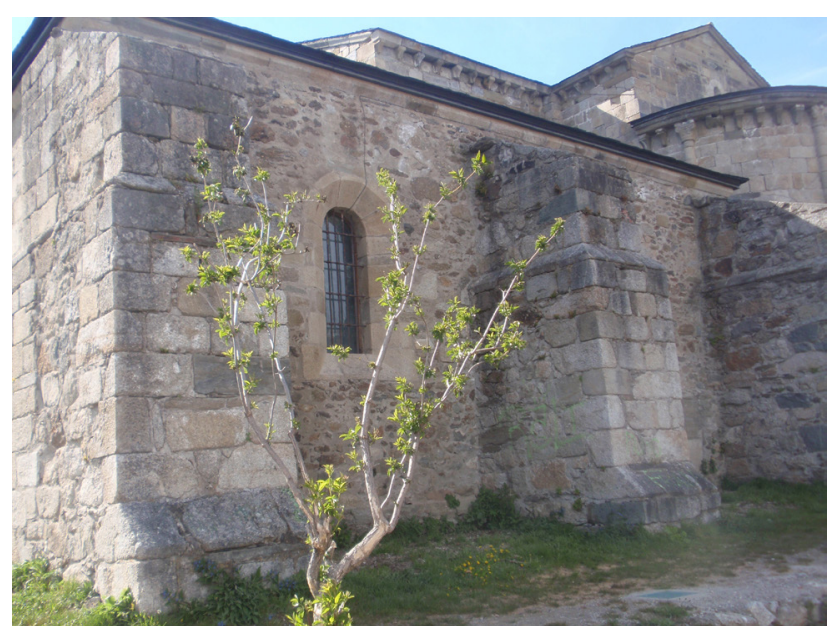

del Vino, Casaseca de las Chanas, Fuentesaúco o Villar del Buey. En otras ocasiones, como sucedió en parte de la sacristía del monasterio de San Martín de Castañeda o en las cabeceras de las parroquiales de Algodre y Bretó de la Ribera, se optó por la mampostería (Fig. 311). El ladrillo tuvo un uso más limitado aunque fue, por ejemplo, el material principal empleado para la construcción de la iglesia parroquial de Santa María de Villafáfila (Fig. 312). Fue más común el uso del ladrillo para la plementería de las bóvedas como especificaremos más adelante. El yeso se reservó para las nervaduras o elementos decorativos de algunas bóvedas como sucede en la iglesia de Santa María de Villafáfila, en la iglesia de Santa María del Azogue de Benavente y en la bóveda que cubre la capilla del Hospital de la Piedad también

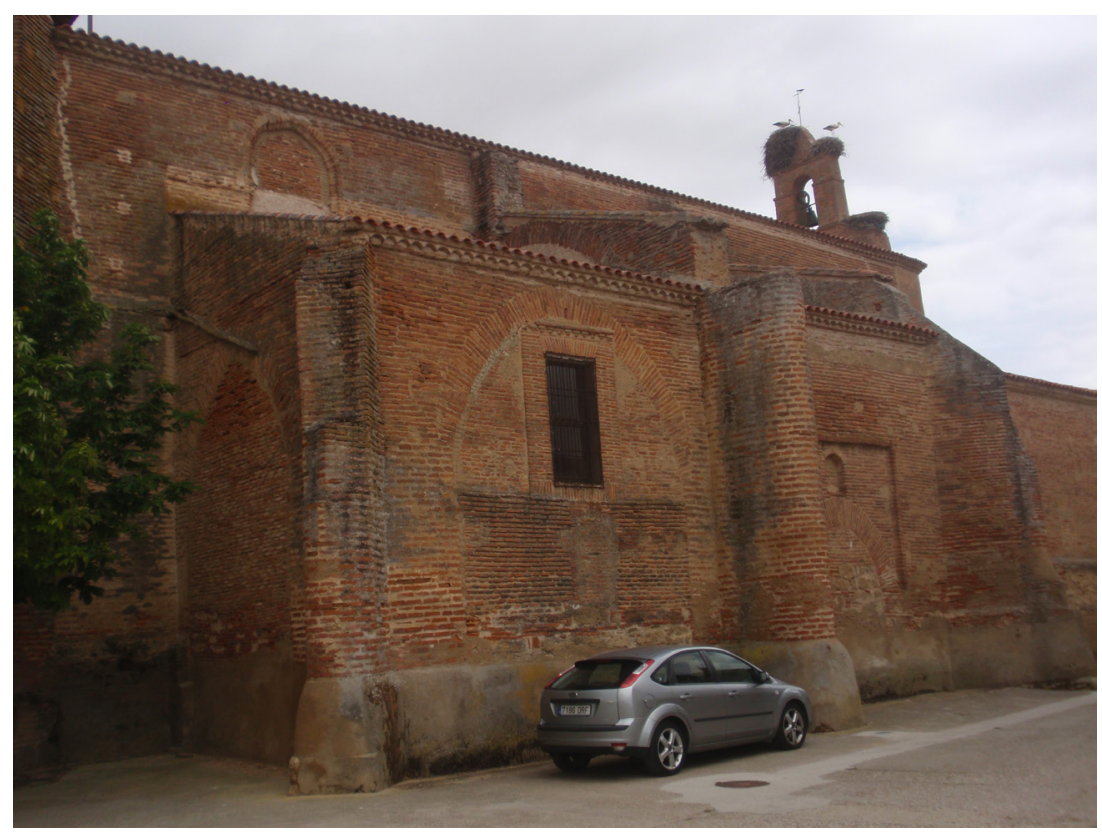

Fig. 311. Sacristía de la iglesia monástica de San Martín de Castañeda 


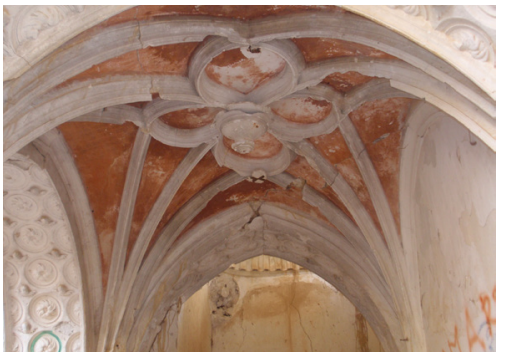

Fig. 313. Bóveda situada a los pies del lateral del Evangelio de la antigua iglesia parroquial de Quintanilla del Monte

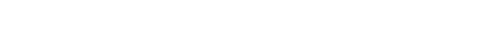

de Benavente o en las bóvedas ruinosas de la antigua iglesia parroquial de Quintanilla del Monte (Fig. 313).

\section{Planimetría y configuración interior}

Por lo general se tiende hacia grandes espacios despejados. En los templos de proporciones más modestas su cuerpo se organizó mediante una nave con fajones apuntados o de medio punto separando los distintos tramos. En unas ocasiones se trataba de templos anteriores que fueron reformados en estos momentos y, en otros casos, de construcciones de esta época. Cuando los templos adquieren mayor monumentalidad, como sucede en las parroquiales de Morales del Vino, Corrales del Vino, Casaseca de las Chanas o Arcenillas, el cuerpo de las iglesias se dividió en tres naves mediante grandes arcadas paralelas a ellas que descansan en pilares o columnas y que a su vez crean un amplio espacio diáfano (Fig. 314). También se utilizaron los arcos diafragma en sentido transversal o en sentido longitudinal para sostener una cubierta de madera, como dijimos que sucedía en la iglesia de San Andrés de Zamora (Fig. 315).

La cabecera de las iglesias mantuvo durante largo tiempo el trazado que se había utilizado de forma habitual en la arquitectura gótica tardía y que consistía, bien, en un amplio tramo recto presbiterial con remate poligonal y contrafuertes en las esquinas, bien, en un simple espacio cuadrangular también con contrafuertes en las esquinas dispuestos en diagonal. Así lo vemos en la parroquial de Casaseca de las Chanas, templo

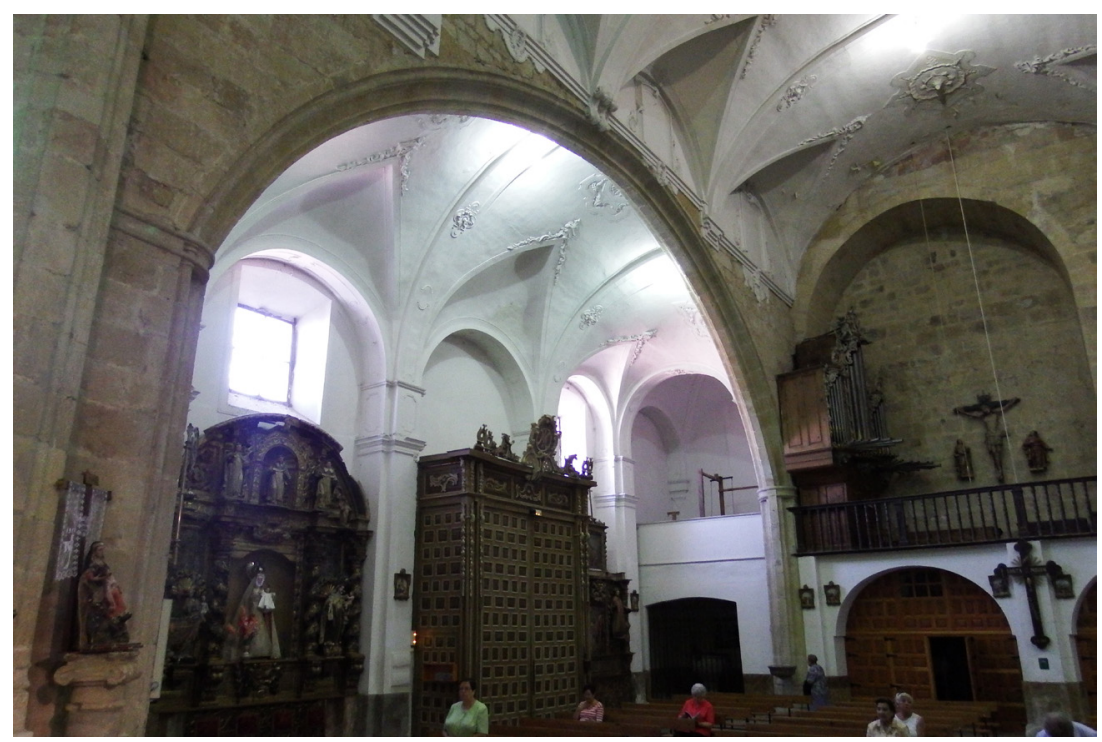




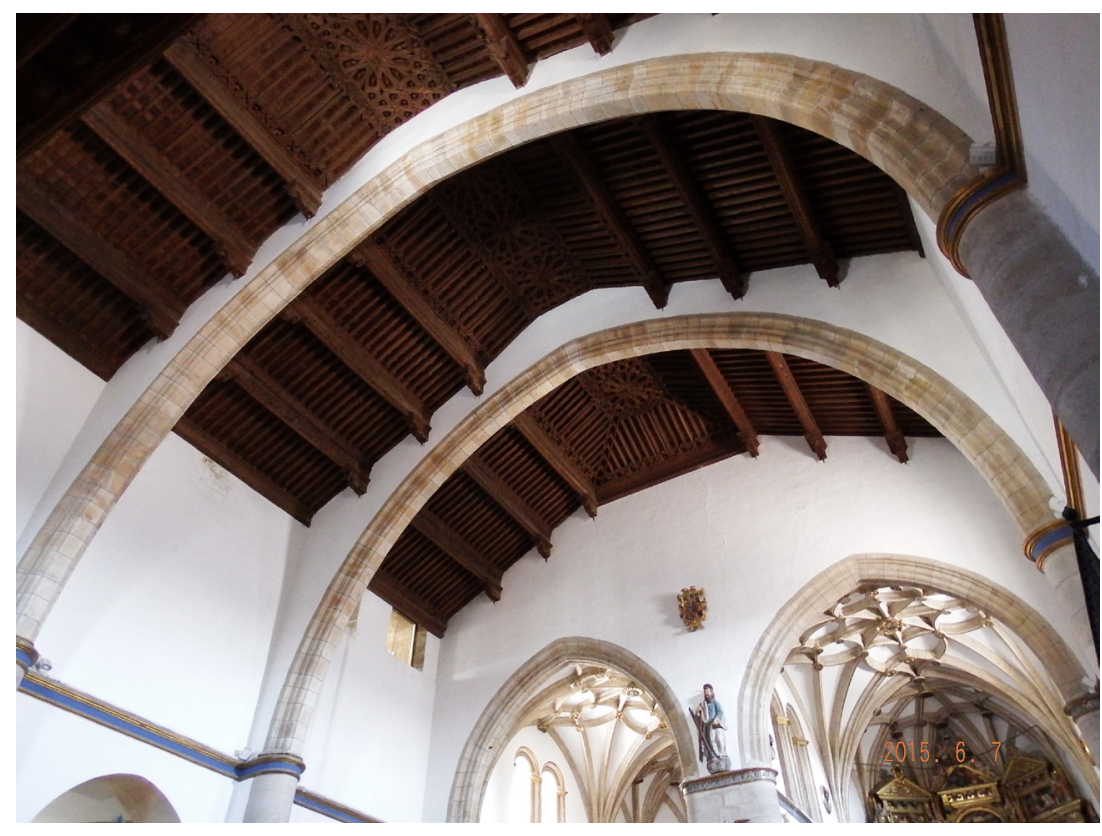

levantado durante la segunda mitad del siglo XVI, o en la iglesia parroquial de Bretó de la Ribera (Fig. 316). Sin embargo, al tiempo que se realizaban éstas se construyen otras con ligeras variantes que afectan a la disposición de los contrafuertes que, en este caso, se colocaron paralelos al muro, de tal forma que parecen pilastras que lo enmarcan a modo de cantoneras. Es el caso de las cabeceras de las iglesias parroquiales de Valdespino y de Algodre (Figs. 317 y 318). También aparecieron nuevos diseños como el utilizado para la cabecera de la iglesia de Santa María del Castillo en Fuentesaúco con su parte inferior recta y transformada por medio de trompas en semicírculo en su parte superior. Igualmente se diseñó el presbiterio con forma semicircular para la iglesia de la Asunción de Nuestra Señora en Villamayor de Campos (Fig. 319).

\section{Exteriores}

Como venía sucediendo en los periodos anteriores el exterior de los edificios que se levantan en estos momentos responde, por logeneral, a una elaboración sencilla. Asíse observa, por ejemplo, en las cabeceras de los templos correspondientes a este momento que mantienen algunas de las particularidades que venían caracterizando a este tipo de espacios desde finales del siglo XV como son el tratamiento a modo de basamento de su perímetro inferior, el recuerdo de los contrafuertes que,
Fig. 315. Interior de la iglesia de San Andrés. Zamora

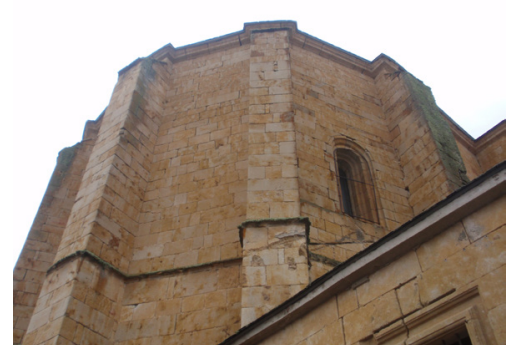

Fig. 316. Cabecera de la iglesia parroquial de Casaseca de las Chanas

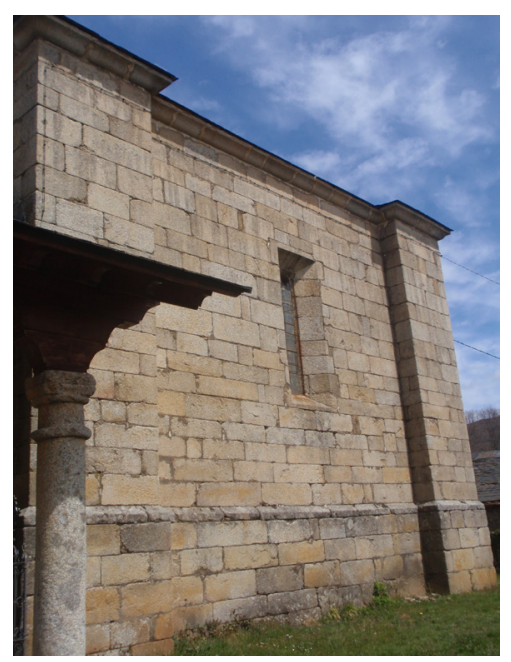

Fig. 317. Cabecera de la iglesia parroquial de valdespino 


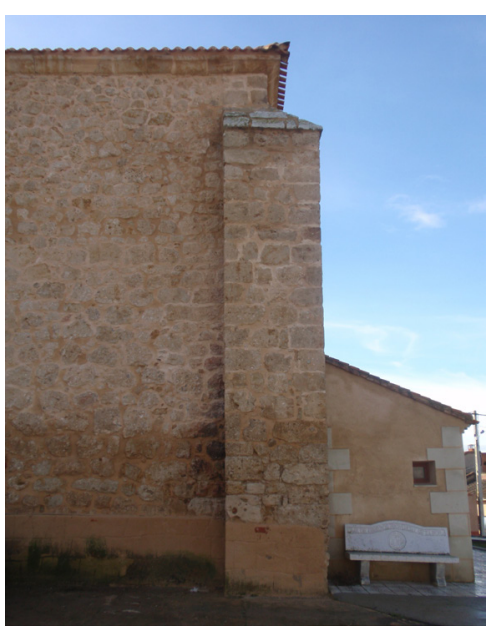
Fig. 318. Exterior de la cabecera de la iglesia
parroquial de Algodre

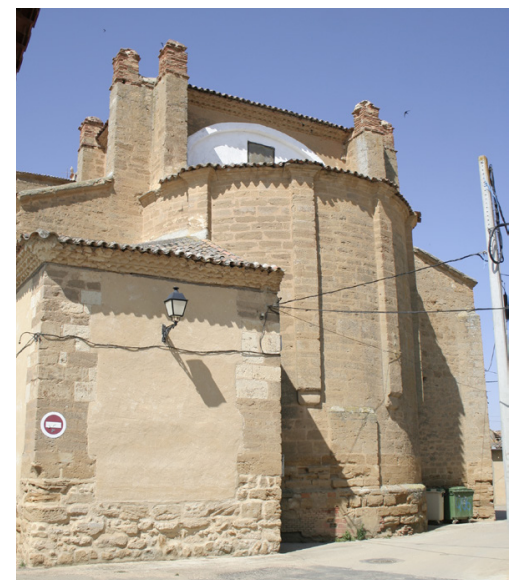

Fig. 319. Exterior de la cabecera de la iglesia parroquial de Villamayor de Campos

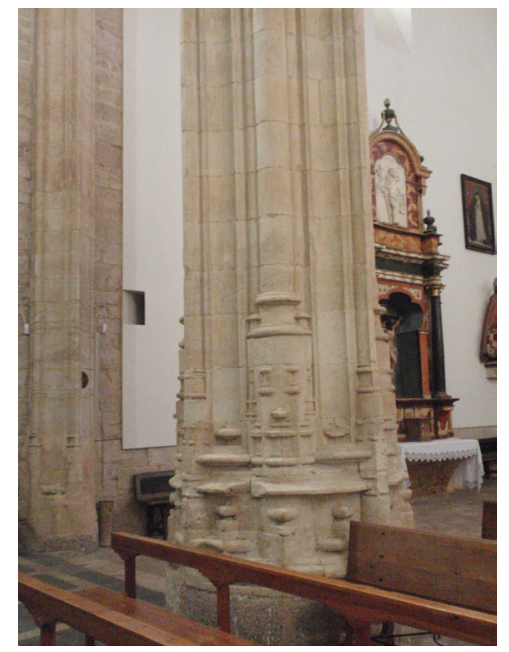

en el caso de la iglesia parroquial de Villamayor de Campos, se han convertido ya en pilastras, que no arrancan del suelo, y la división en horizontal mediante una moldura que, como sucedía en muchas ocasiones, abarca a los contrafuertes.

No obstante se construyeron edificios de una cierta entidad en los que se recurrirá principalmente a formas renacentistas aunque se mantenga en ellos algunos recuerdos góticos. La parte más sobresaliente y elaborada de su exterior se corresponde con las portadas en las que como se señala se empleó mayoritariamente un lenguaje plenamente renaciente.

\section{Soportes}

En los elementos sustentantes, en la práctica totalidad de los casos, se ha perdido ya todo recuerdo gótico. Fundamentalmente se utilizan pilares o columnas de trazado clasicista o semicolumnas adosadas en las que se ha sustituido el capitel por sencillas molduras circulares. No obstante, hay algún ejemplo muy significativo de soportes en los que se mantiene el esquema general gótico como sucede en los pertenecientes a la iglesia de San Julián de los Caballeros de Toro, donde se puede apreciar la multiplicidad de molduras y el pedestal formado por distintas basas a diversas alturas que había sido tan habitual unas décadas antes (Fig. 320). Esta obra se debe a Rodrigo Gil de Hontañón, que aunque en lo fundamental podría decirse de él que fue un arquitecto del Renacimiento, el caso es que siguió utilizando en muchas de sus obras algunos elementos estructurales góticos que en la iglesia toresana de San Julián de los Caballeros se reducen como acabamos de señalar a los soportes y arcadas que articulan el espacio del edificio.

También en las ménsulas que sirven de apoyo a los nervios de las bóvedas se optó claramente por diseños y ornamentaciones renacentistas. La mayor parte de ellas son muy sencillas y están enriquecidas por simples molduras circulares; otras están más elaboradas, pero siguen igualmente modelos totalmente renacentistas. 


\section{$\operatorname{Arcos}$}

El uso del arco apuntado se prolongó durante mucho tiempo de tal forma que, en algunos de los templos que hemos mencionado con anterioridad y que se edificaron durante la segunda mitad del

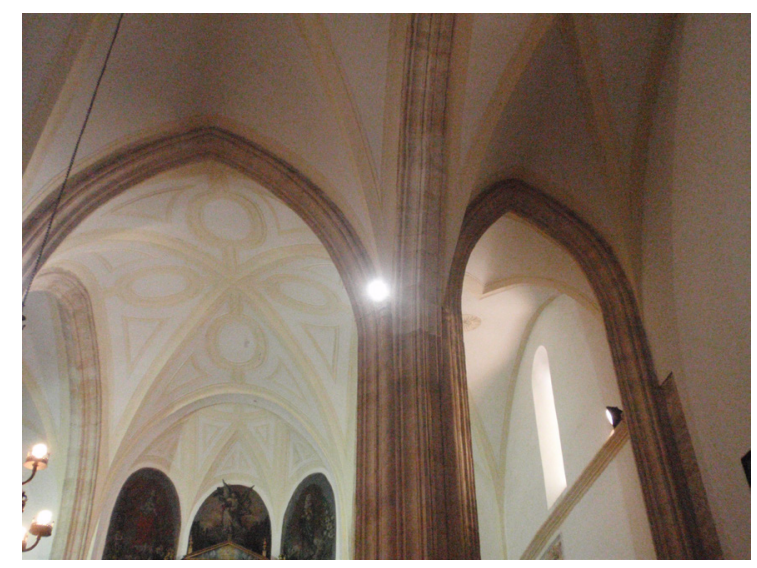

Fig. 321. Interior de la iglesia de San Julián de los Caballeros. Toro

siglo XVI, se mantuvo. Lo vemos, por ejemplo, en gran parte de la configuración interna de la iglesia de San Julián de los Caballeros de Toro, en los accesos a la doble cabecera de la iglesia de San Andrés de Zamora, en el acceso a la capilla de los Hurtado de la misma iglesia, en el acceso a la cabecera de la iglesia parroquial de Casaseca de las Chanas y en el acceso al espacio superior situado a los pies de este último edificio (Figs. 321 y 322). Hay, no obstante, que puntualizar que prácticamente en todos ellos las molduras y la decoración carecen de motivos estructurales u ornamentales góticos.

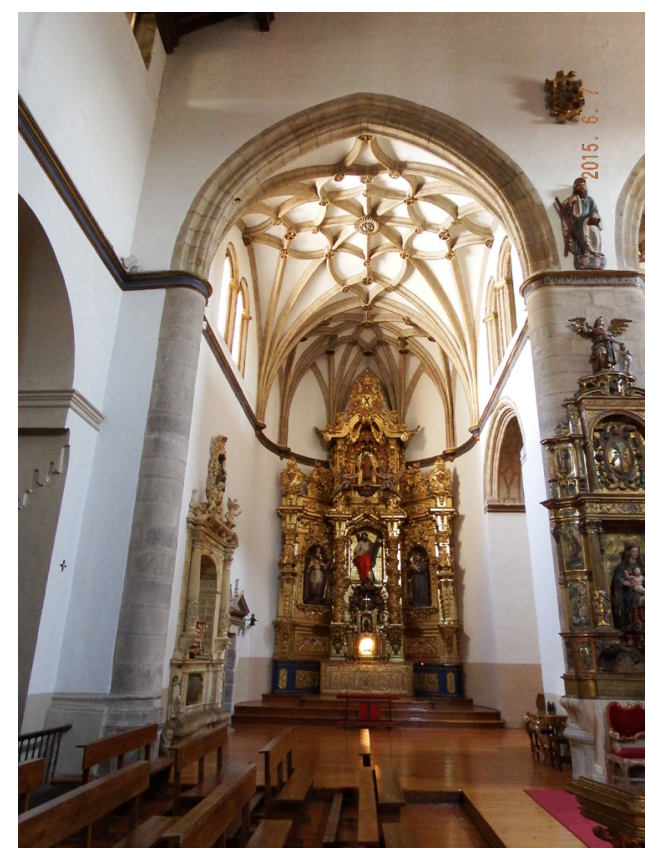




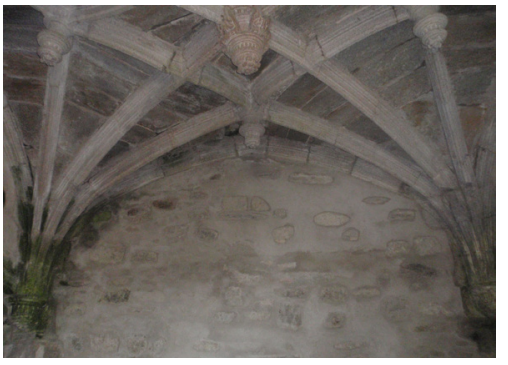

Fig. 323. Sacristía de la iglesia monástica de San Martín de Castañed

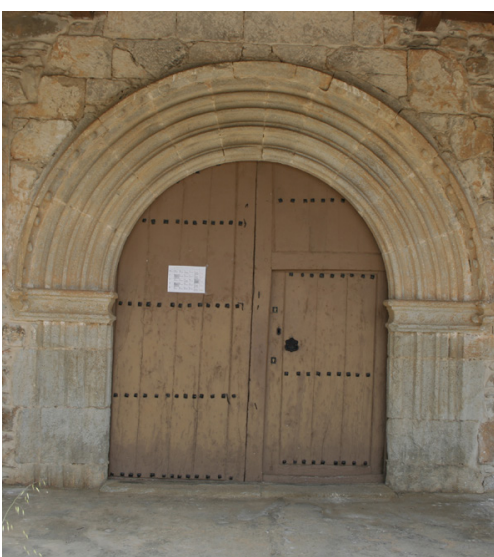

Fig. 324. Portada de la iglesia parroquial de Carracedo de Vidriales

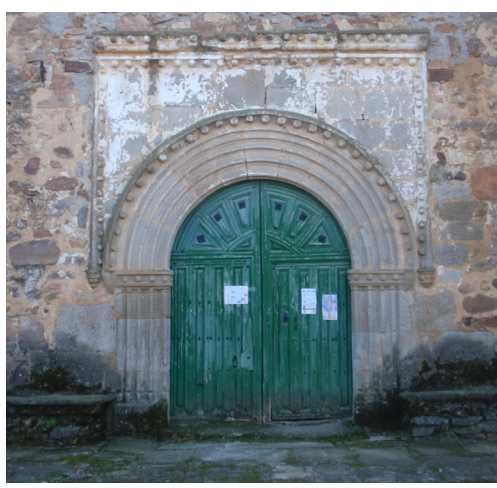

Fig. 325. Portada de la iglesia parroquial de Cunquilla de Vidriales
Pero al contrario de lo que sucediera durante el periodo anterior donde encontramos una cierta variedad de arcos, en este momento y al margen del arco apuntado, el protagonismo corresponde al arco de medio punto que se utiliza en las portadas, en las ventanas y configurando las naves y el acceso al presbiterio de algunos templos.

Hay que señalar, sin embargo, que excepcionalmente se utilizó el arco tudor en la sacristía del monasterio de San Martín de Castañeda (Fig. 323).

\section{Portadas}

El arco de medio punto, cuya utilización en las portadas se había hecho sentir ya en la fase tardía del gótico, tuvo una difusión importante en las décadas centrales del siglo XVI y especialmente en algunas iglesias situadas en los valles del Tera y de Vidriales ${ }^{368}$. Las portadas correspondientes a este ámbito geográfico de la provincia de Zamora parecen mostrar en su configuración una cierta voluntad de retorno al románico debido a la incorporación de molduras en forma de arquivoltas y el uso como elemento decorativo de medias bolas o besantes en la rosca. Sin embargo en ellas, existen también basas, molduras y ornamentaciones góticas. Estas portadas en casi todos los casos están enmarcadas por un alfiz que, ocasionalmente, está igualmente decorado con medias bolas. No se puede olvidar que el alfiz es un elemento decorativo muy utilizado, principalmente en la arquitectura civil de finales del siglo XV y principios del XVI, y que el motivo decorativo de las medias bolas se recupera y utiliza también con frecuencia en ese mismo momento hasta convertirse en uno de los elementos que definen el Ilamado "estilo Reyes Católicos". Como ejemplo de este tipo de portadas pueden citarse las de las iglesias de San Miguel de Carracedo de Vidriales, San Miguel de Cunquilla de Vidriales, Santiago Apóstol de Moratones de Vidriales, la Inmaculada Concepción de Pozuelo de Vidriales, San Miguel de Sítrama de Tera, la Asunción de Cubo de Benavente,

368 La arquitectura religiosa tardogótica de esta zona, en especial las portadas correspondientes a sus templos, ha sido estudiada por Rubén Fernández Mateos. FERNÁNDEZ MATEOS, Rubén, "A propósito de varias portadas tardogóticas de los valles del Tera y Vidriales (Zamora)" en CODEX AQVILARENSIS. Cuadernos de Investigación del Monasterio de Santa María la Real, Aguilar de Campoo (Palencia), 2009, pp. 80-106. 
San Pelayo de Quintanilla de Urz y San Pedro Apóstol de San Pedro de la Viña (Figs. 324, 325 y 326). La localización en un ámbito geográfico muy concreto de estas portadas así como la reiteración de otros elementos hace pensar en la existencia de un taller de cantería que repite los mismos motivos en distintas localidades. De esta particularidad hablaremos más adelante en el apartado titulado Talleres locales durante los dos últimos tercios del siglo XVI.

En el resto de la provincia de Zamora también encontramos portadas con esta misma composición de vano con arco de medio punto y enmarcado por alfiz. Así lo vemos, por ejemplo, en la portada sur de la iglesia de San Antolín de Zamora, en la portada sur de la iglesia de la Asunción de Nuestra Señora de Villamayor de Campos y en la portada norte de la iglesia parroquial de Tardobispo $^{369}$ (Fig. 327).

El uso evidente de reminiscencias del último gótico en estas portadas podría justificarse por tratarse de templos de menor entidad y de pequeñas poblaciones fuertemente ancladas en la tradición y a las que no llegó en este momento de manera directa el renacimiento en estado puro. Sí encontramos, por el contrario, portadas monumentales que responden plenamente al estilo renacentista en templos de mayor empaque, en los que trabajaron maestros que asimilaron pronto el nuevo estilo.

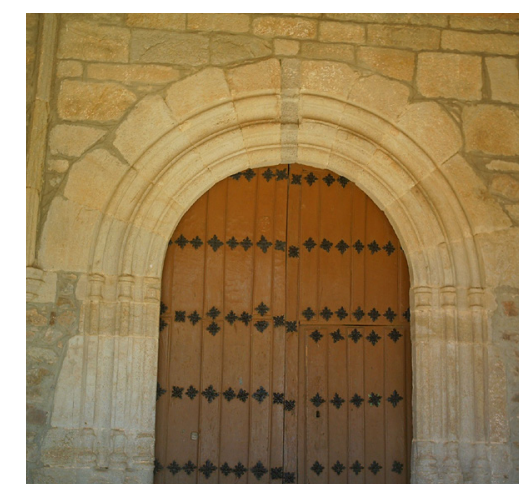

Fig. 326. portada de la iglesia parroquial de Quintanilla de Urz

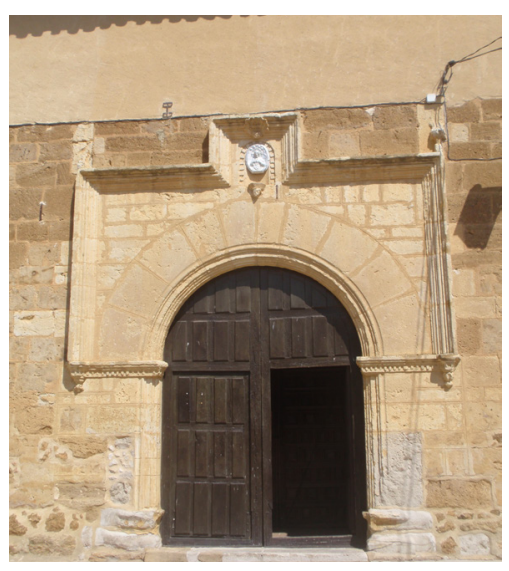

\section{Ventanas}

Ya hemos visto cómo a finales del gótico tardío comenzó a ser común en los vanos la pérdida de independencia de los elementos a favor de la prolongación de las formas, sin que exista solución de continuidad entre las jambas y el arco. Esto se generalizó en las siguientes décadas de tal forma que desaparecieron prácticamente por completo los capiteles e impostas. A su vez los vanos pertenecientes a este momento, que se corresponde, en lo fundamental, con los dos últimos tercios del siglo XVI, son sencillos, se resuelven en medio punto y están compuestos de molduras en forma de escocia de diverso

369 En el caso particular de la portada septentrional de la iglesia parroquial de Tardobispo, advocada en El Salvador, hay que señalar que las obras llevadas a cabo en el edificio durante el periodo barroco hicieron necesario la construcción de un contrafuerte que oculta prácticamente en su totalidad uno de los brazos del alfiz. 


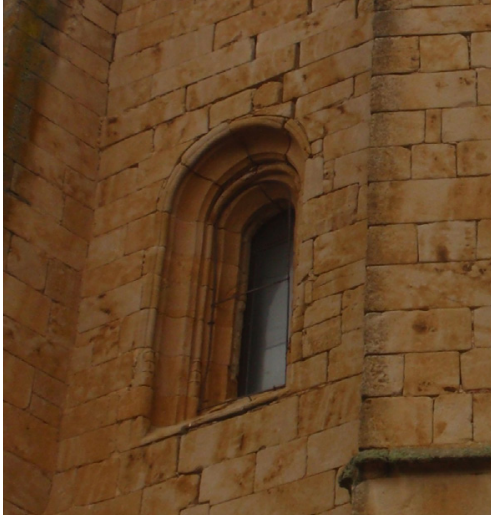

Fig. 328. Vano abierto en la cabecera de la iglesia parroquial de Casaseca de las Chanas

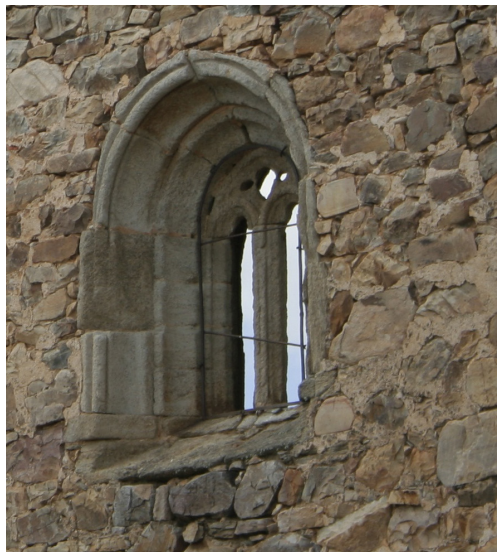

Fig. 329. Ventana abierta en la cabecera de la antigua iglesia de Santa Marina. Tardemézar tamaño, molduras rectas y, en menor medida, otras en forma de bocel. Como ejemplo podemos citar el vano situado en el ábside de la cabecera de la iglesia de San Juan Bautista de Casaseca de las Chanas cuyo único recuerdo gótico se observa en las pequeñas basecitas de las que arrancan los boceles (Fig. 328). El vano que se abría en la cabecera de la iglesia de Bretó de la Ribera, hoy tapiado, y los que se encuentran en el muro sur del cuerpo de la iglesia de Villamor de los Escuderos, aunque siguen en parte el esquema de los anteriores, se presentan totalmente desprovistos de elementos decorativos y su traza emparenta más con los diseños renacentistas.

Existen algunos vanos, situados mayoritariamente en el muro sur de las cabeceras de los templos, que mantienen en los tímpanos, en época muy avanzada del siglo XVI, diseños que habían sido comunes décadas antes. Con cierta frecuencia los vanos conservan la división mediante un mainel central que sostiene dos arquillos que, en la mayor parte de los casos, son de medio punto. El tímpano puede estar ocupado por una forma circular perforada o decorado ocasionalmente con sencillas tracerías de motivos flamígeros. Ejemplo de ello encontramos en el vano abierto en el muro sur de la cabecera de la iglesia parroquial de Arcenillas y en los dos existentes en el muro sur del cuerpo de naves de la iglesia parroquial de la vecina localidad de Casaseca de las Chanas. La utilización de tracerías flamígeras en los vanos fue relativamente común en la comarca de Benavente y los Valles como puede verse en la ruinosa iglesia de Santa Marina de Tardemézar y en las parroquiales de Granucillo y Grijalba de Vidriales (Fig. 329).

\section{Bóvedas}

Durante gran parte del siglo XVI la bóveda de crucería se siguió utilizando con diseños variados que habían incorporado los nervios combados. Partiendo de la bóveda gótica sencilla, que encontraremos en algunas ocasiones, se tiende progresivamente hacia diseños complejos y, en cierto modo, fantasiosos, pero que, en ningún caso, alcanzaron la grandilocuencia y complejidad existente en otros lugares de nuestra geografía. Aunque con menos frecuencia que las bóvedas con combados, también se 
utilizaron aquellas que se componen únicamente de nervaduras rectas, fundamentalmente fue así en la comarca de Benavente y los Valles donde es curioso comprobar que durante el segundo tercio del siglo XVI se repitió continuamente un mismo tipo de bóveda sencilla, de terceletes que, a diferencia de lo que ocurría en otras comarcas o en las localidades más importantes de la provincia como Zamora, Toro y la propia ciudad de Benavente, no utilizó nunca los combados.

Por último, en alguna ocasión se utilizaron nervaduras superpuestas a bóvedas que estructuralmente o son de arista, como ocurre en la iglesia de Santa María del Azogue en Benavente, o de cúpulas rebajadas, como las correspondientes a la capilla de San Pablo de la catedral de Zamora y a la capilla mayor de la iglesia de San Juan de Puerta Nueva.

En cuanto al diseño de las nervaduras todavía se mantiene en ocasiones la doble escocia rematada mediante una moldura plana, si bien fue más habitual el uso de molduras rectas fileteadas que le confieren al nervio un mayor grado de angulosidad. Este tipo de moldura fileteada se generalizó en nuestra arquitectura en el segundo tercio del siglo XVI.

Bóveda de crucería simple. Como venía sucediendo en las décadas anteriores, la bóveda más sencilla utilizada durante el segundo tercio del siglo XVI fue aquella compuesta únicamente por nervios cruceros. Tenemos ejemplos cubriendo una capilla situada en el lado de la epístola de la iglesia de Santa María del Azogue (Benavente) y en la sacristía de Moratones. En estos casos la referencia para fecharlas proviene del tipo de molduración de sus arcos, así como de su implantación en el edificio correspondiente.

Bóvedas octopartitas. En una ocasión encontramos la bóveda octopartita, que fue empleada en la cabecera de la iglesia de Santo Tomás de Benegiles (Fig. 330). Aunque se puede ver como una recurrencia a formas del pasado, lo cierto es que en estos momentos fue reinterpretada siguiendo los esquemas del gótico 
Fig. 330. Bóveda de la capilla mayor de la iglesia parroquial de Benegiles

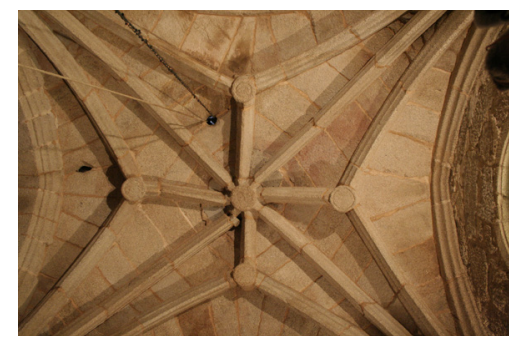

Fig. 331. Bóveda del segundo cuerpo de la torre de la iglesia parroquial de Villar del Buey

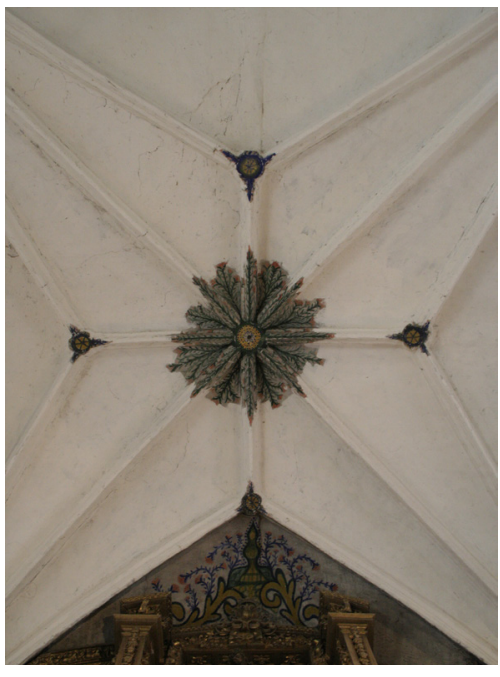

Fig. 332. Bóveda de la capilla mayor de la iglesia parroquial de Quintanilla de Urz

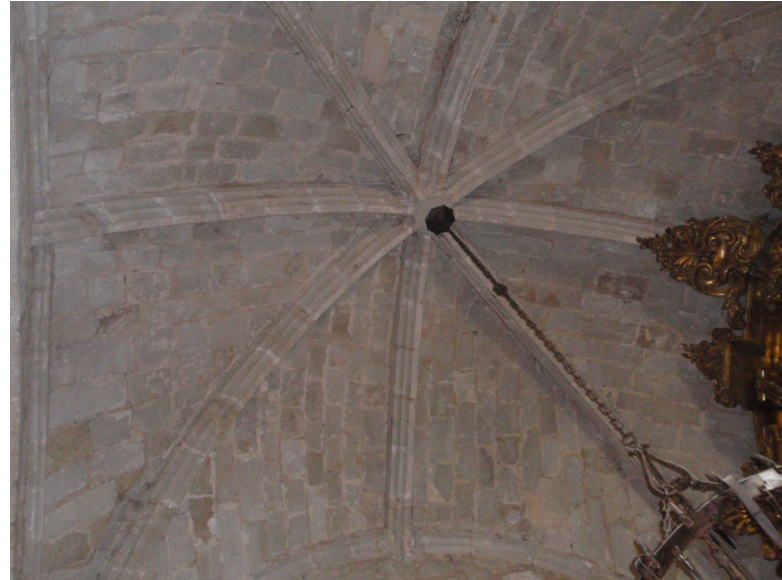

tardío lo que queda manifiesto en la forma en que se dispuso la plementería y en el perfil que poseen las nervaduras.

Bóveda de crucería con terceletes y bóveda de crucería con terceletes y nervios de ligadura. Uno de los tipos de bóveda más utilizados durante gran parte del siglo XVI fue la bóveda de crucería con terceletes, cuyo uso había sido muy común durante el periodo gótico tardío. Se encuentra en la sacristía situada en el lado de la Epístola de la iglesia parroquial de Fuentesaúco (con toda probabilidad cubría el espacio gemelo del lateral del Evangelio), en la capilla de la Virgen de Fátima de la iglesia de San Vicente (Zamora), en el sotacoro alto de la parroquial de Villar del Buey, en las capillas laterales de la parroquial de Villamayor de Campos y en las cabeceras de Cunquilla de Vidriales, Tardemézar y Quintanilla de Urz (Figs. 331 y 332). Igualmente se siguieron utilizando las bóvedas de crucería con terceletes y nervios de ligadura hasta las claves de los perpiaños y formeros como habíamos visto ya décadas antes en la capilla de los Ocampo del convento de San Francisco de Zamora que constituye la más antigua de este tipo que se ha conservado en la provincia de Zamora. De este periodo tenemos ejemplos en la capilla de los Hurtado de la iglesia de San Andrés de Zamora y en una dependencia alta de este mismo templo (Fig. 333). Dentro de la provincia de Zamora el empleo de este tipo de bóveda de crucería con terceletes y nervios de ligadura fue bastante frecuente en la comarca de Benavente y los Valles. Allí la encontramos cubriendo, por ejemplo, las cabeceras de los templos parroquiales de Grijalba de Vidriales o Quiruelas 


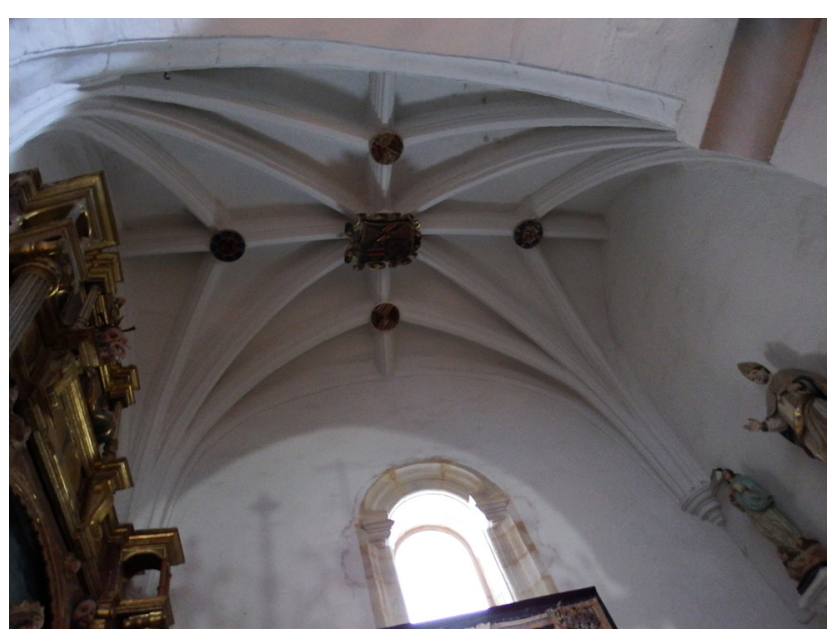

de Vidriales (Fig. 334). Existe un último ejemplo cubriendo el sotacoro bajo de la parroquial de Villar del Buey.

Bóvedas de crucería reticuladas. Existe otro tipo de bóveda con nervaduras rectas, $y$ en este caso sin terceletes, que forman una retícula en la parte central, con ocho claves en torno a la polar y de la que tenemos dos ejemplos. Se trata de las bóvedas que cubren las cabeceras de los templos parroquiales de Valdespino y Asturianos, ambas localidades pertenecientes a la comarca sanabresa ${ }^{370}$. La falta de datos concretos en estos dos casos nos impide establecer una cronología exacta, no obstante, el análisis del conjunto de los elementos arquitectónicos que integran estos edificios nos permite considerar que estas bóvedas fueron realizadas en el segundo cuarto del siglo XVI (Fig. 335). Ello se ve corroborado por la cronología dada a algunas bóvedas de la provincia de Valladolid que poseen una configuración idéntica a éstas o con alguna ligera variante y que se establece igualmente en el segundo cuarto del siglo XVI ${ }^{371}$. E, igualmente, por otras de la provincia de Palencia y León ${ }^{372}$.

370 Los tramos correspondientes a las naves de las iglesias parroquiales de Paramio y San Román de Sanabria, ambas poblaciones pertenecientes a la comarca sanabresa, poseen una cubierta de madera realizada en el siglo XX que copia el diseño que tiene la bóveda que cubre la cabecera de la iglesia de la cercana localidad de Valdespino, con claves actualizadas.

371 Estas bóvedas se encuentran en la iglesia parroquial de la Asunción de Geria, en la iglesia parroquial de Santa Eulalia en Matilla de los Caños, o en la iglesia parroquial de la Asunción en Villanubla (HERAS GARCÍA, Felipe, Arquitectura religiosa del siglo XVI en la primitiva diócesis de Valladolid, Diputación provincial de Valladolid, 1975 , p. 106, figura 10, p. 135, figura 14 y p. 309, figura 41).

372 En la provincia de Palencia estas bóvedas se encuentran en la iglesia de Nuestra Señora del Tovar de Meneses de Campos, en la iglesia de San Juan de Paredes de Nava, en la iglesia de San Miguel de Piña de Campos y en la iglesia de San Cipriano
Fig. 333. Bóveda de la capilla de los Hurtado. Iglesia de San Andrés. Zamora

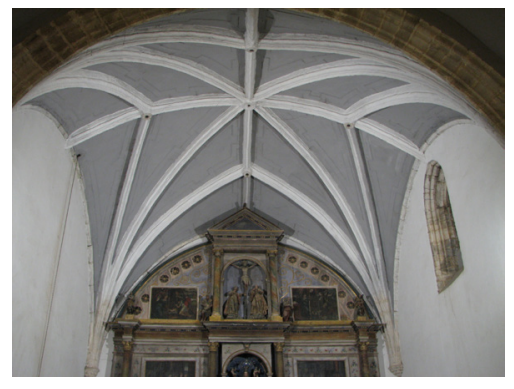

Fig. 334. Bóveda de la capilla mayor de la iglesia parroquial de Quiruelas de Vidriales 

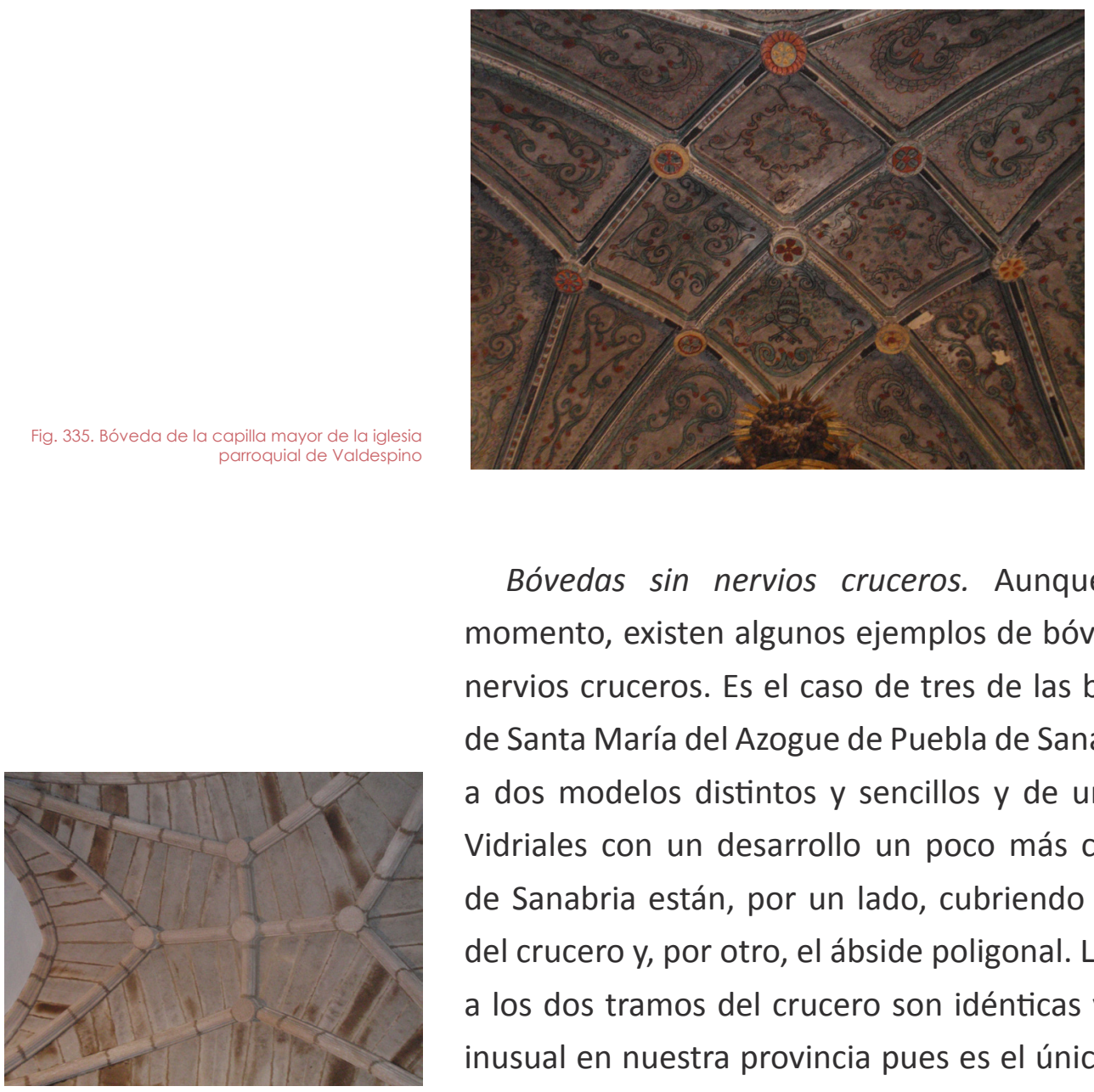

Bóvedas sin nervios cruceros. Aunque escasos en este momento, existen algunos ejemplos de bóvedas de crucería sin nervios cruceros. Es el caso de tres de las bóvedas de la iglesia de Santa María del Azogue de Puebla de Sanabria que responden a dos modelos distintos y sencillos y de una en Carracedo de Vidriales con un desarrollo un poco más complejo. En Puebla de Sanabria están, por un lado, cubriendo los tramos laterales del crucero y, por otro, el ábside poligonal. Las correspondientes a los dos tramos del crucero son idénticas y constituye un tipo inusual en nuestra provincia pues es el único caso (Fig. 336). Se trata de una bóveda, cuyo trazado parece provenir de la habitual de terceletes a la que se hubiera despojado de los cruceros. Puebla de En ella los nervios conforman una estrella de cuatro puntas con cinco claves unidas mediante nervios de ligadura. La que cubre el ábside de esta misma iglesia de Puebla de Sanabria, sin embargo, repite el diseño de una de las bóvedas de la capilla de San Ildefonso de la catedral de Zamora, concretamente aquella

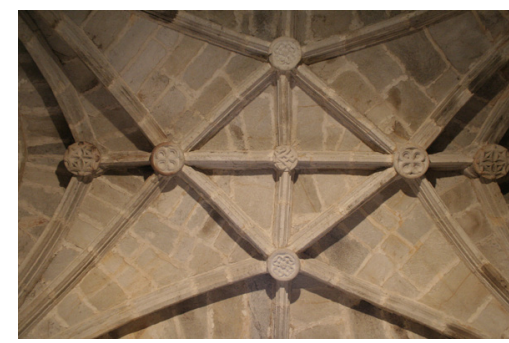

Fig. 337. Bóveda de la sacristía de la iglesia parroquial de Carracedo de Vidriales en la que las nervaduras se abren dejando libre la parte central en la que se forma una figura romboidal.

En la iglesia parroquial de Carracedo de Vidriales la bóveda que carece de nervios cruceros se encuentra cubriendo el espacio rectangular alargado que conforma la sacristía (Fig. 337). Posee un diseño basado en las bóvedas de las capillas laterales de la cabecera de la catedral de Zamora y se trata de una bóveda de

de Pedraza de Campos. ZALAMA RODRIGUEZ, Miguel Ángel, La arquitectura del siglo XVI en la provincia de Palencia, Palencia, 1990, pp. 155 planta, 186 planta, 189 planta y 223 planta. De la provincia de León puede citarse como ejemplo la Basílica de Nuestra Señora de la Encina de Ponferrada que comenzó a edificarse en la segunda mitad del siglo XVI según diseño de Juan de Albear. 
crucería de terceletes compleja con contraterceletes en los lados menores.

La localización de estas bóvedas en una parte de la provincia de Zamora que depende eclesiásticamente de la diócesis de Astorga lleva también a pensar en un influjo directo de la catedral astorgana pues en ella se utilizaron bóvedas carentes de cruceros.

Bóvedas con nervaduras rectas y combados que dibujan una forma en torno a la clave central.

El grupo más numeroso de bóvedas de crucería es el integrado por aquellas en las que se emplearon los nervios combados. Bóvedas estas últimas, que habían hecho su aparición en la provincia de Zamora durante el primer tercio del siglo XVI y que con el tiempo van adquiriendo una mayor complejidad en su diseño sirviéndose del uso de la curva y la contracurva, lo que daría lugar a la aparición de múltiples variantes.

El primer modelo de bóveda con nervios combados que tenemos es aquel en el que éstos se circunscriben únicamente a la creación de una figura en torno a la clave central. Los ejemplos más sencillos, por tanto, son aquellos en los que sobre una base de bóveda de crucería con terceletes se dibuja una forma circular en forma de láurea en torno a la clave central, tal y como se observa en las capillas laterales de la iglesia de San Juan de Puerta Nueva de Zamora o en la cabecera de la iglesia de San Antolín (Figs. 338 y 339), también de Zamora ${ }^{373}$.

Igualmente ocurre esto, aunque en este caso la figura en torno a la clave central toma forma de octógono con cada uno de los lados curvados, en el crucero de la iglesia de Santa María del Azogue de Puebla de Sanabria. El modelo más antiguo de esta bóveda lo encontramos en la capilla de la Visitación de la catedral de Burgos que constituye el primer trabajo que realizó Juan de Colonia en Castilla (1440-1442) y que vincula los trabajos abovedados de este templo de Puebla de Sanabria con
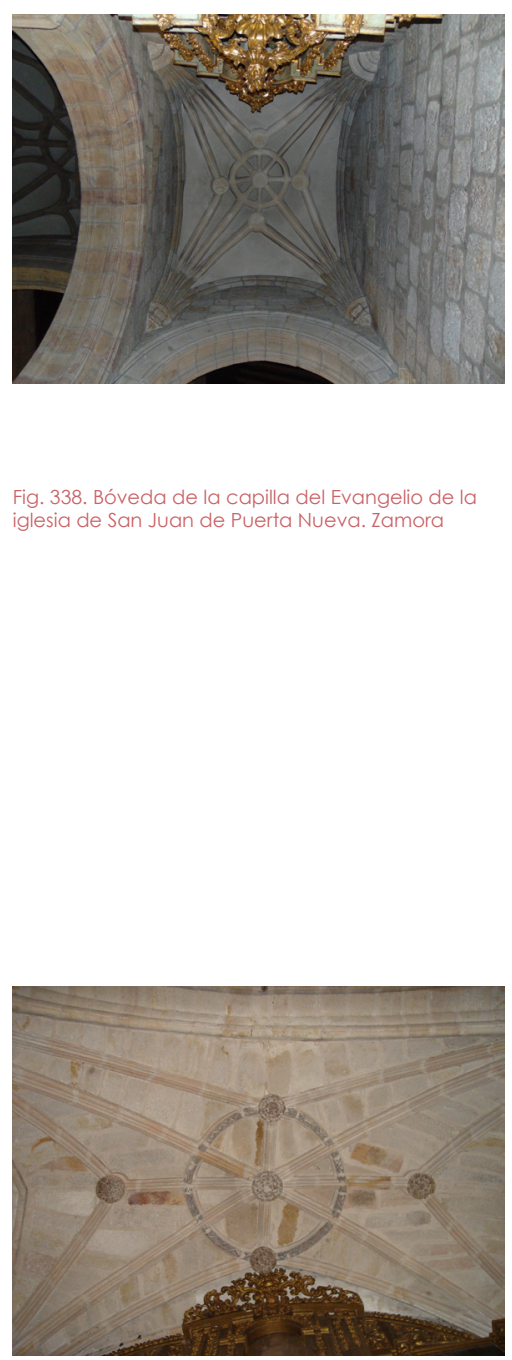
la arquitectura alemana ${ }^{374}$. Años después se utilizó este modelo para cubrir los tramos de la nave de la iglesia del monasterio de San Salvador de Oña (Burgos) aunque en esta ocasión con nervios de ligadura a las claves de los formeros y con los nervios, que conforman el octógono, rectos. Recordemos que este conjunto monástico del que no se conocen datos documentales sobre su autoría se ha puesto siempre en relación con Juan de Colonia y su hijo Simón, documentado este último como autor de la fuente del claustro ${ }^{375}$. En la iglesia parroquial de San Juan Bautista, también de la localidad de Oña y a escasos metros el monasterio, hay dos bóvedas semejantes igualmente con nervios de ligadura, una de ellas presenta los nervios que conforman el octógono rectos, la otra, combados.

Este tipo de bóveda de crucería fue muy común durante el segundo tercio del siglo XVI, empleando indistintamente, para la figura que se crea en torno a la clave central, nervios rectos 0 , como sucede en este caso de Puebla de Sanabria, combados ${ }^{376}$. Es probable que a Puebla de Sanabria la influencia llegase a través de Astorga a cuya diócesis pertenecía esta localidad zamorana y donde se había utilizado idéntico diseño para cubrir la segunda bóveda hacia los pies tanto en el tramo de la Epístola como en el del Evangelio de su catedral.

En la provincia de Zamora contamos con dos bóvedas de diseño semejante, aunque en ambos casos los nervios correspondientes a la figura que rodea la clave central son rectos. En ambos casos su cronología es ligeramente anterior respecto a la bóveda de la iglesia de Santa María del Azogue de Puebla de Sanabria. La primera de ellas cubre la capilla meridional de la iglesia de Santa María del Castillo de Montamarta y la segunda el tramo presbiterial de la iglesia parroquial de Morales del Vino, aunque

374 Sobre este arquitecto vid. GARCÍA CUETOS, María Pilar, "En los límites de la sombra como arquetipo historiográfico. La llegada de Juan de Colonia y su aportación a la arquitectura tardogótica en Castilla" en Los últimos arquitectos del Gótico, Madrid, 2010, pp. 70-146.

375 En la actualidad se atribuye la iglesia a Fernando Díez de Presencio, pero en cualquier caso se señala que la deuda de este maestro de obras con Juan de Colonia es evidente.

376 Sin ánimo de ser exhaustivo podemos señalar, por ejemplo, que en la provincia de Soria fue muy común el uso de este tipo de bóveda quizá debido a su significativa presencia en el claustro de la catedral de El Burgo de Osma. En la mayoría de los casos se utilizaron en época avanzada del siglo XVI. 
en este último caso se han incorporado nervios de ligadura que en Puebla de Sanabria no aparecen.

En otras bóvedas existe una bifurcación del nervio que debería de unir la clave del tercelete con la clave polar de tal forma que se crea en torno a ella una figura cuadrangular con los brazos flexionados. Este tipo de composición de los nervios ha sido denominado por Gómez Martínez como "el diseño fluido de Juan de Álava", por haber sido utilizado con cierta frecuencia por dicho maestro ${ }^{377}$. Son bóvedas muy planas que parecen reflejar influencia inglesa de finales del gótico. En Zamora lo encontramos, por un lado, en la capilla del Santo Sepulcro del convento de San Francisco, muy próximo al desaparecido monasterio de San Jerónimo, cuyas trazas dio precisamente el propio Juan de Álava. Por otro lado, a este mismo diseño responden también los dos tramos de bóveda que cubren la sacristía del monasterio de San Martín de Castañeda en la comarca zamorana de Sanabria (Fig. 340).
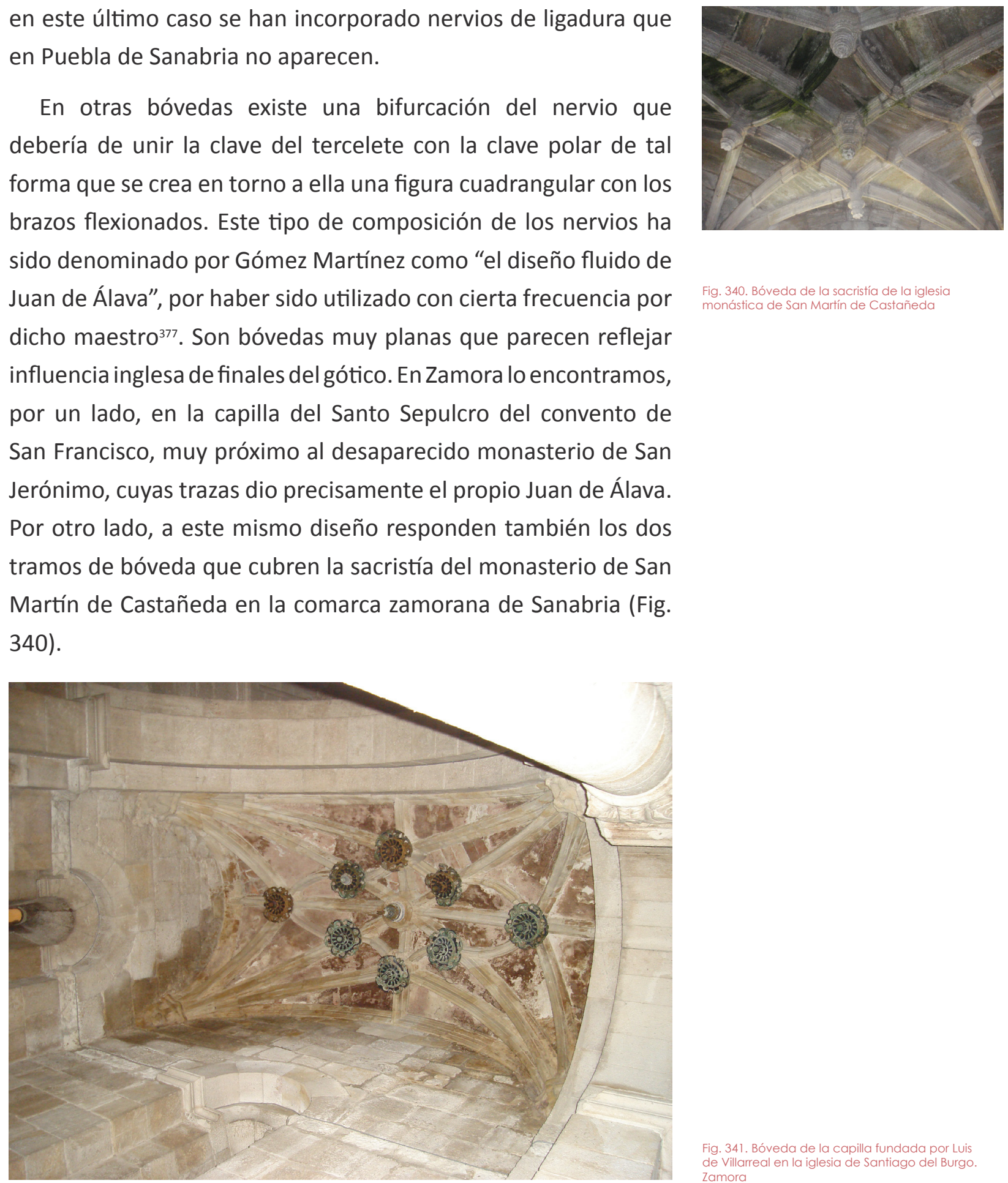

Fig. 340. Bóveda de la sacristía de la iglesia monástica de San Martín de Castañeda

Fig. 341. Bóveda de la capilla fundada por Luis de Villarreal en la iglesia de Santiago del Burgo. Zamora

En el caso de la capilla situada a los pies del lado del evangelio de la iglesia de Santiago del Burgo de Zamora la bóveda es de crucería con terceletes y tiene una serie de nervios curvos uniendo las claves de éstos y otras secundarias, de tal forma que se crea una figura ovoidal en torno a la clave central (Fig. 341). Bóvedas de idéntico trazado a éste de Santiago del Burgo utilizó 
Juan Gil para cubrir tanto el tramo presbiterial como los tramos laterales del crucero de la iglesia de Villamor de los Escuderos (Zamora). Su hijo Rodrigo Gil emplearía en diversas ocasiones bóvedas con un esquema semejante.

Bóvedas de terceletes complejas con combados. Este tipo de bóveda de crucería con terceletes y combados que dibujan un esquema floral de cuatro pétalos en torno a la clave central fue muy utilizado en la arquitectura española del siglo XVI, y en la ciudad de Zamora y en su provincia existen numerosos ejemplos. No obstante, y aunque el diseño básico se repite, en algunos casos se enriquece y da lugar a variantes. Encontramos en Zamora ejemplos en el primer tercio del siglo XVI aunque fue durante el segundo tercio cuando este tipo de trazado alcanzó su mayor difusión, en muchos casos repitiendo o variando ligeramente el esquema general. Recordemos que en la ciudad de Zamora durante el primer tercio del siglo XVI este modelo se

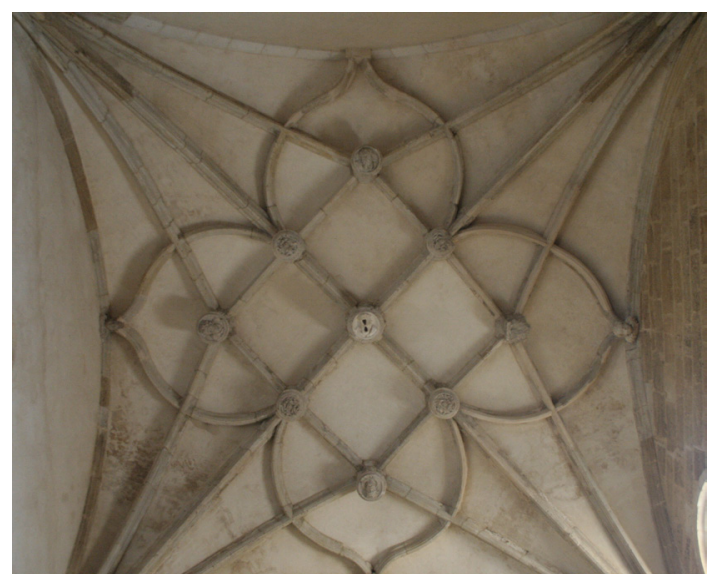

encuentra en las capillas funerarias de las iglesias de La Horta y Santa Lucía, posiblemente de acuerdo con un diseño que había utilizado Juan Gil de Hontañón en el tramo central del crucero de la iglesia parroquial de Villamor de los Escuderos y que después generalizó su hijo Rodrigo ${ }^{378}$. A la transición entre el primer tercio y el segundo del siglo XVI parecen responder la bóveda que cubre la cabecera de la iglesia de San Vicente Mártir de Villar de Fallaves y la de la bóveda de la capilla de los Tapia situada en la iglesia de San Lorenzo de Toro, ambas mencionadas ya en 378 CORTÓN DE LAS HERAS, María Teresa, La construcción de la catedral de Segovia (1525-1607), 3 vols., Universidad Complutense, 1990; RODRIGUEZ GUTIÉRREZ DE CEBALLOS, Alfonso, Las catedrales de Salamanca, Everest, Madrid, 1978. 


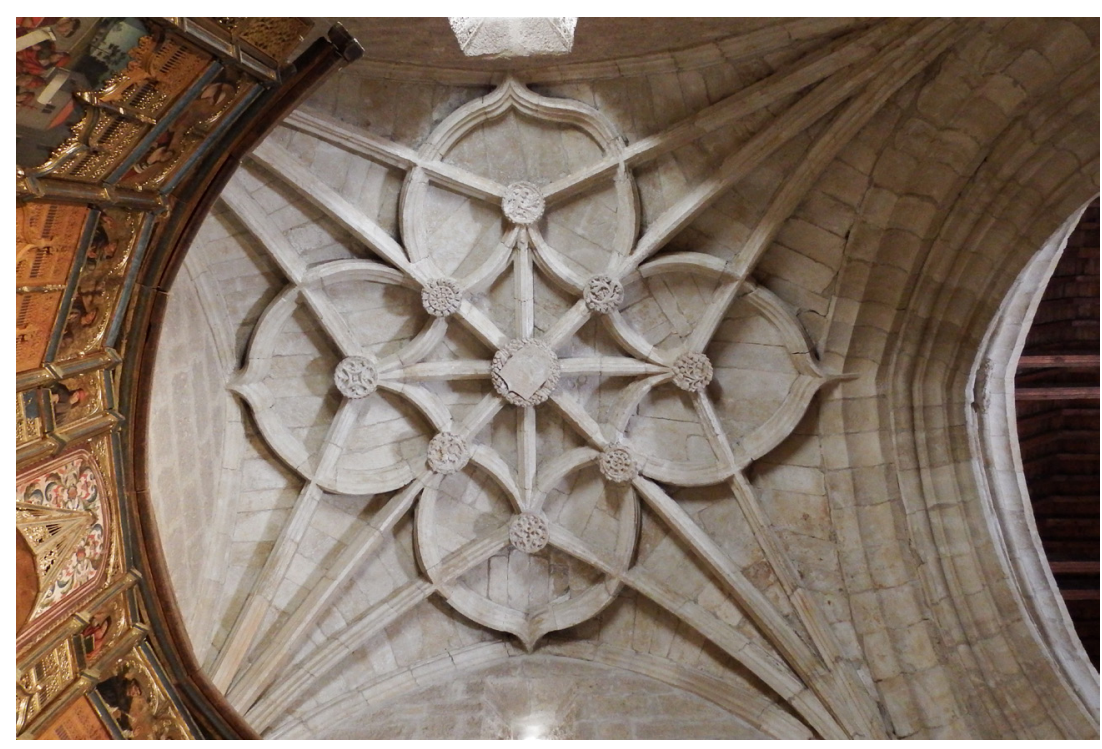

el capítulo anterior correspondiente al gótico tardío (Figs. 342 y 343). En el primer caso el cuadrado generado en torno a la clave polar tiene los brazos rectos mientras que en el segundo cada brazo del cuadrado está compuesto por dos tramos flexionados. Posteriormente, en un periodo cronológico tan avanzado como la segunda mitad del siglo XVI, se volvió a utilizar este mismo modelo de bóveda en la provincia de Zamora, en la cabecera de la iglesia de Santa María de Belén de Algodre, en la cabecera de Nuestra Señora de la Asunción de Bretó de la Ribera y en las dos alturas del primer tramo hacia los pies de la iglesia parroquial de San Juan Bautista en Casaseca de las Chanas (Figs. 344 y 345). En Algodre y Bretó de la Ribera se utilizó el cuadrado con los brazos rectos mientras que en las bóvedas de Casaseca de las Chanas están flexionados. También en la iglesia de San Andrés se utilizó este mismo tipo de bóveda para cubrir las dos grandes capillas gemelas que configuran la cabecera del templo aunque en este caso la figura creada en torno a la clave polar es un octógono de lados flexionados. Idéntico diseño posee la bóveda dibujada por Byne y que se ha supuesto perteneciente a alguna estancia del castillo de Benavente. La capilla del Hospital de la Piedad de Benavente repite esta composición con la particularidad de que los nervios mayores de los terceletes están flexionados a lo que se suma que la figura que dibuja en torno a la clave polar es, en este caso, un gran círculo (Fig. 346). En la capilla mayor de la iglesia parroquial de Villafáfila se mantiene el esquema de flor cuadripétala, pero en este caso no existe ninguna nervadura que una los terceletes, lo que no suele ser habitual,
Fig. 343. Bóveda de la capilla de los Tapia en la iglesia de San Lorenzo el Real. Toro

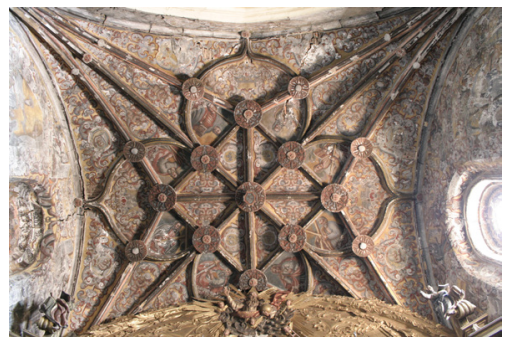

Fig. 344. Bóveda de la capilla mayor de la iglesia parroquial de Bretó de la Ribera

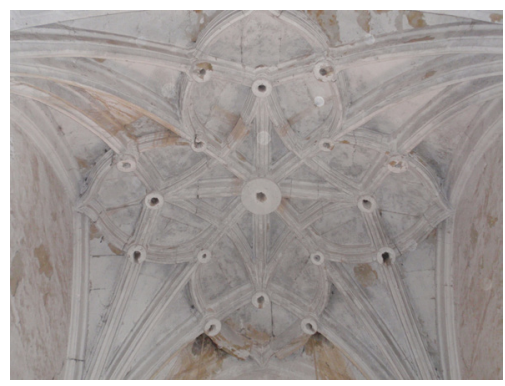

Fig. 345. Bóveda situada en la prolongación hacia os pies de la iglesia parroquial de Casaseca de las Chanas 


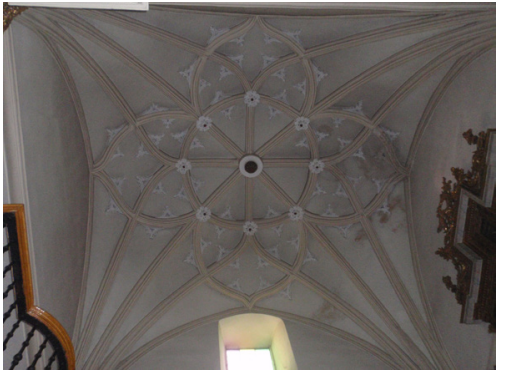

Fig. 346. Bóveda de la capilla del hospital de la Piedad. Benavente

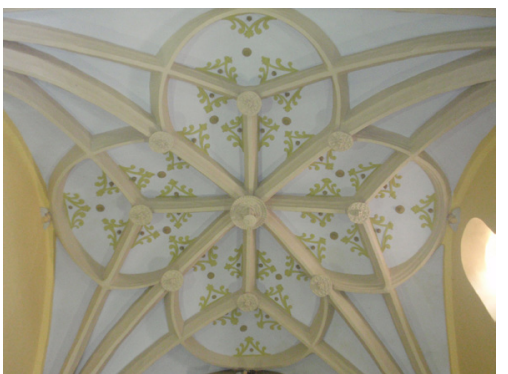

Fig. 347. Bóveda de la capilla mayor de la iglesia parroquial de Villafáfila

pues en la provincia de Zamora solamente encontramos otro caso, la bóveda de la torre de la iglesia de San Nicolás en Castroverde de Campos (Figs. 347 y 348). Hay que señalar que tanto las nervaduras de la bóveda de la capilla del Hospital de la Piedad de Benavente como la mencionada de la parroquial de Villafáfila y las correspondientes a la nave central de la iglesia de Santa María del Azogue de Benavente de las que se tratará en el siguiente epígrafe son las únicas de la provincia que se enriquecieron con caireles de yesería en el centro de cada tramo. Esta decoración de caireles en las bóvedas de crucería había sido utilizada durante el periodo gótico tardío fuera de la provincia de Zamora. Pueden servir de ejemplo las bóvedas de la capilla de la Concepción o de Santa Ana en la catedral de Burgos obra iniciada por Juan de Colonia y concluida por su hijo Simón. El propio Simón de Colonia se serviría también de ellos en el claustro del monasterio de San Salvador de Oña (Burgos). En pleno siglo XVI los conocidos yeseros Corral de Villalpando utilizaron este tipo de ornamentaciones con cierta frecuencia como lo evidencian, por ejemplo, la bóveda de la capilla mayor de la catedral de Palencia y la bóveda de la capilla mayor y del crucero del convento de la Magdalena de Medina del Campo.

Es probable que las obras de los Corral de Villalpando, de ascendencia zamorana como declara el topónimo de su apellido, fuesen tomadas como referencia por los artífices que trabajaron en Benavente y Villafáfila y también por los que intervinieron en la antigua iglesia parroquial de Quintanilla del Monte. Aunque los restos de las bóvedas que han permanecido en pie de esta última iglesia no tienen caireles, conservan una serie de labores en yesería perfectamente relacionables con los Corral. De hecho el modelo de este tipo de bóveda -empleado en la nave central de Santa María del Azogue de Benavente, en la capilla del Hospital de la Piedad también de Benavente, en la capilla mayor de Santa María de Villafáfila y quizás en el coro de la antigua iglesia de la Asunción de la Virgen de Quintanilla del Monte- cuyos nervios combados dibujan una flor cuadripétala en torno a la clave central, y cuyo origen y desarrollo ya explicamos en el apartado 


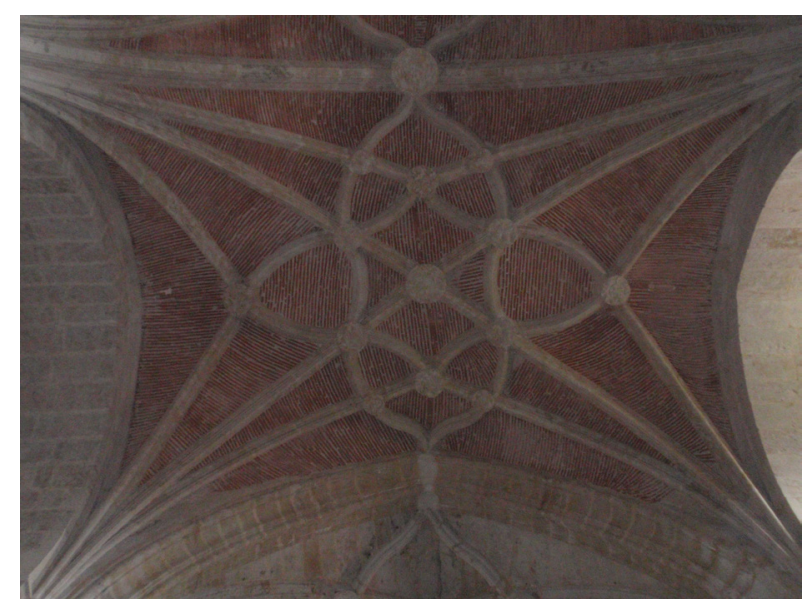

Fig. 349. Bóveda de uno de los tramos de la nave de la iglesia parroquial de Villamor de los Escuderos

anterior, fue la utilizada con preferencia por los hermanos Corral de Villalpando ${ }^{379}$.

Las bóvedas que cubren los tres tramos de la nave de la iglesia de Villamor de los Escuderos, correspondientes a la obra realizada por Rodrigo Gil de Hontañón, como continuación de la cabecera y crucero trazados por su padre, mantienen el esquema floral de cuatro pétalos con figura de seis lados curvos en torno a la clave central, con la particularidad de que la compartimentación mediante terceletes está enriquecida por la presencia de nervios curvos que bifurcan el brazo que debería dirigirse hacia la clave (Fig. 349).

El diseño que adopta todo este grupo de bóvedas, independientemente de sus variantes, fue sin duda el más utilizado en la arquitectura zamorana durante buena parte del siglo XVI.

Bóvedas con nervios combados pero no de crucería. Algunas bóvedas tardías responden a sistemas constructivos propios del renacimiento, como la bóveda de arista o la cúpula rebajada casi plana. No obstante se decoraron con un sistema de nervios que reproducen modelos góticos con cruceros, terceletes y combados que aporta una cierta riqueza de curvas y contracurvas. Las bóvedas correspondientes a la capilla catedralicia de San Pablo y al ábside central de la cabecera de la iglesia de San Juan de Puerta Nueva (Figs. 350 y 351), constructivamente son cúpulas muy rebajadas, casi planas, decoradas ambas con un diseño 


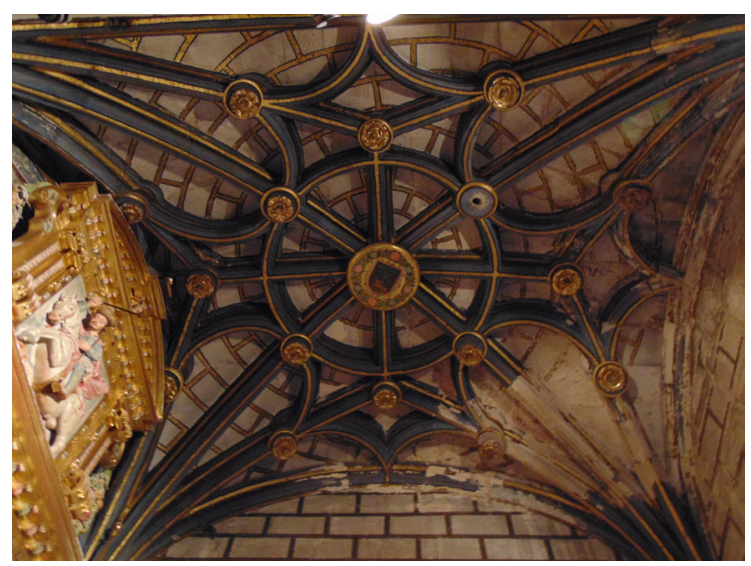

semejante de nervios cruceros, terceletes y combados que dibujan una cruz de brazos cóncavos y puntiagudos dispuestos a partir de un círculo en torno a la clave central ${ }^{380}$. En ambos casos los formeros tienen trazado semicircular. Fuera de la provincia de Zamora se conservan bóvedas de similares características a estas mencionadas en la catedral de Astorga (León), en la iglesia del convento de la Concepción (Valladolid) o en la iglesia de Nuestra Señora de la Asunción en Cordovilla La Real (Palencia). Cronológicamente habría que situar la construcción de la bóveda de la capilla de San Pablo de la Catedral de Zamora durante el segundo cuarto del siglo XVI, momento en el que se levantaron las restantes bóvedas citadas y, momento, por tanto, en el que este modelo se difundió por gran parte de la geografía española.

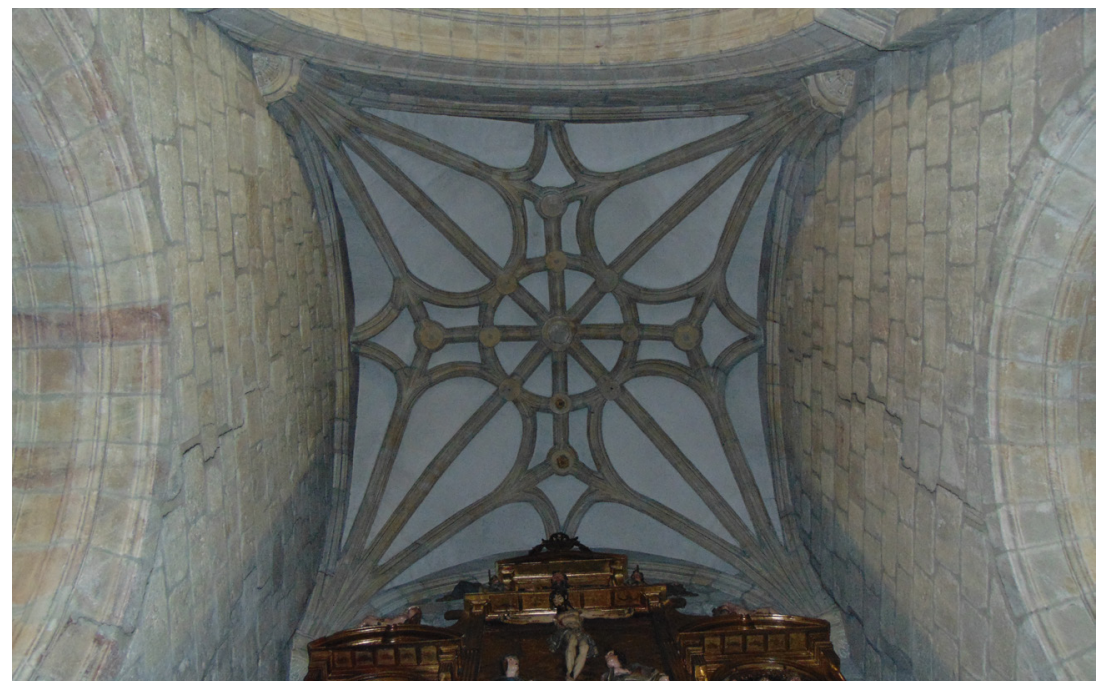

En la cabecera de la iglesia del convento de Santa Clara en Toro el tipo de bóveda es de arista pero presenta un sistema

380 Recordemos que, aunque la actual bóveda de la capilla mayor de la iglesia de San Juan de Puerta Nueva data de la segunda mitad del siglo XVI, se levantó copiando el modelo que ejecutó Rodrigo Gil de Hontañón en la década de 1530. 


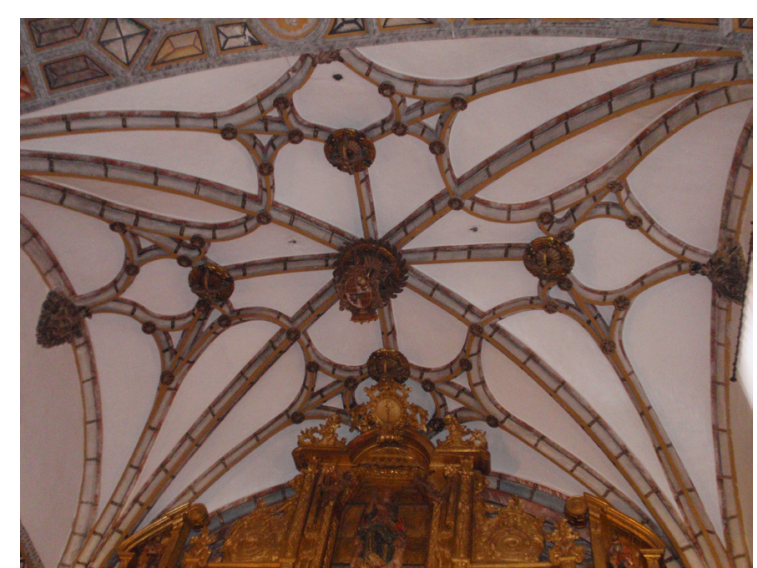

de nervaduras decorativas muy semejante al de las bóvedas anteriormente descritas con la diferencia de que carece del círculo que rodea la clave polar (Fig. 352). Este trazado de nervios empleado en la cabecera del convento toresano se encuentra en bóvedas de crucería en la arquitectura española durante el segundo tercio del siglo XVI. De este modo bóvedas idénticas o muy semejantes se utilizaron en el último tramo hacia los pies de la iglesia del convento de la Concepción de Valladolid, en la cabecera de la iglesia de Nuestra Señora de la Asunción de Bercero (Valladolid), en la cabecera de la iglesia de Nuestra Señora de la Asunción de Cabezón de Pisuerga (Valladolid) o en el tramo central del crucero de la iglesia de San Miguel de Piña de Campos (Palencia), por poner solo algunos ejemplos de localidades relativamente cercanas.

Las bóvedas que cubren las naves de la iglesia de Santa María del Azogue de Benavente, igualmente de arista, cuentan asimismo con nervios combados que reproducen diseños florales (Fig. 353).

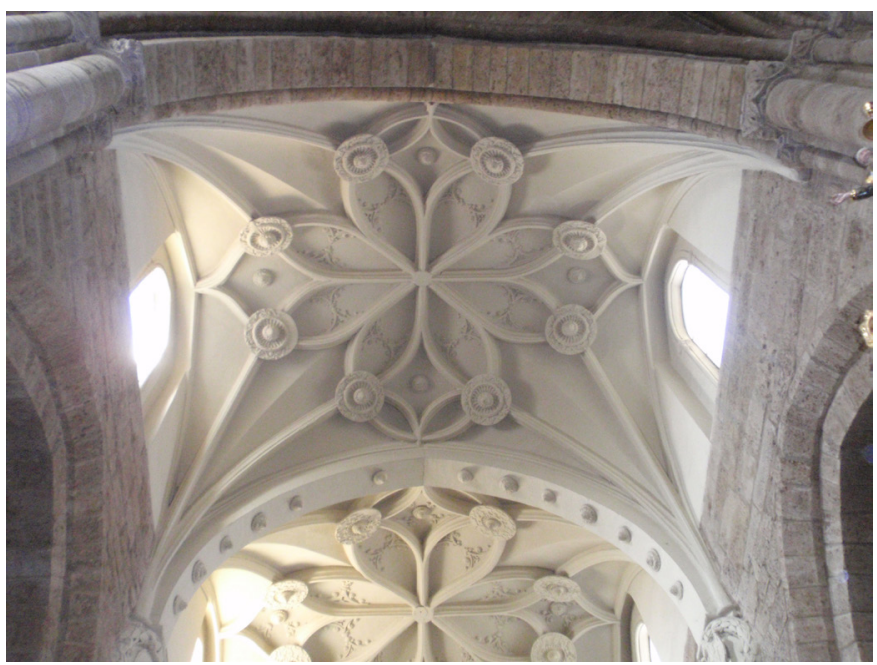

Fig. 352. Bóveda de la capilla mayor de la iglesia conventual de Santa Clara. Toro 
Podemos concluir señalando que en este caso se trata de la utilización de elementos góticos con un criterio puramente ornamental y no constructivo.

\section{Plementería}

El estudio de la plementería en las bóvedas de este periodo es complejo ya que en muchas de ellas el material queda oculto detrás de una capa de yeso, en algunos casos totalmente policromada. Así sucede en la capilla del Hospital de la Piedad de Benavente, en la capilla de San Pablo de la catedral de Zamora, en la cabecera de la iglesia del convento de Santa Clara de Toro o en las capillas que conforman la cabecera de la iglesia de San Juan de Puerta Nueva de Zamora, entre otras. En los casos en los que es visible se utilizó un aparejo bastante regular con sillares alargados generalmente dispuestos perpendiculares a la clave central. Por ejemplo en la cabecera de San Antolín de Zamora, en la capilla de la Virgen de Fátima de la iglesia de San Vicente de Zamora y en la cabecera de la parroquial de Benegiles (Fig. 354).

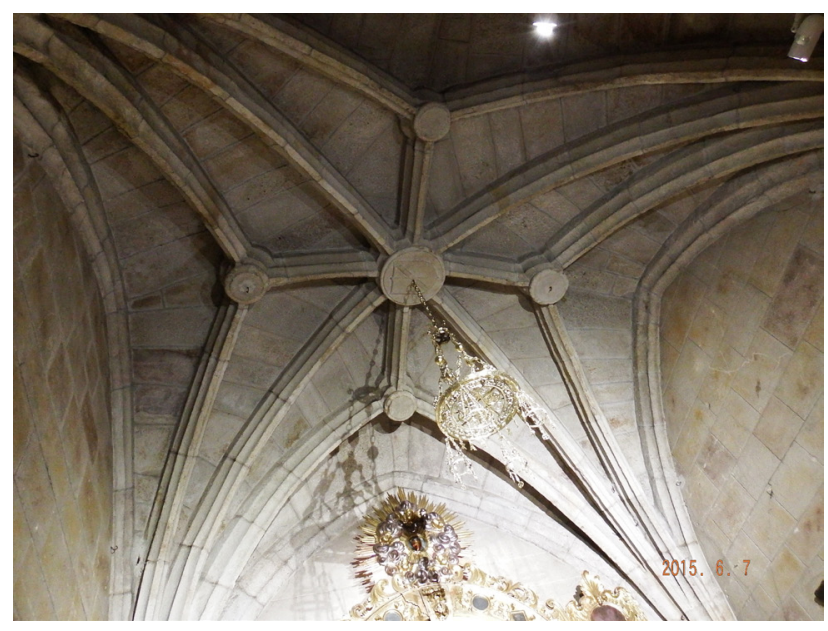

El uso del ladrillo para las plementerías fue menos frecuente. La utilización de este material en Castilla se venía dando desde tiempo atrás. Así, por ejemplo, Juan Guas lo había utilizado en las bóvedas del claustro de la cartuja de Santa María de El Paular cuyas obras comenzaron hacia 1484 y se desarrollaron, en lo fundamental, durante el último cuarto del siglo $X^{381}$. No obstante, Juan Guas utilizó la piedra de sillería para las nervaduras 
a las que dotó de un importante desarrollo. No es probable, que en este caso de El Paular, se utilizase el ladrillo para ahorrar costes. Si podría ser una explicación, sin embargo, para el uso de este material en la provincia de Zamora.
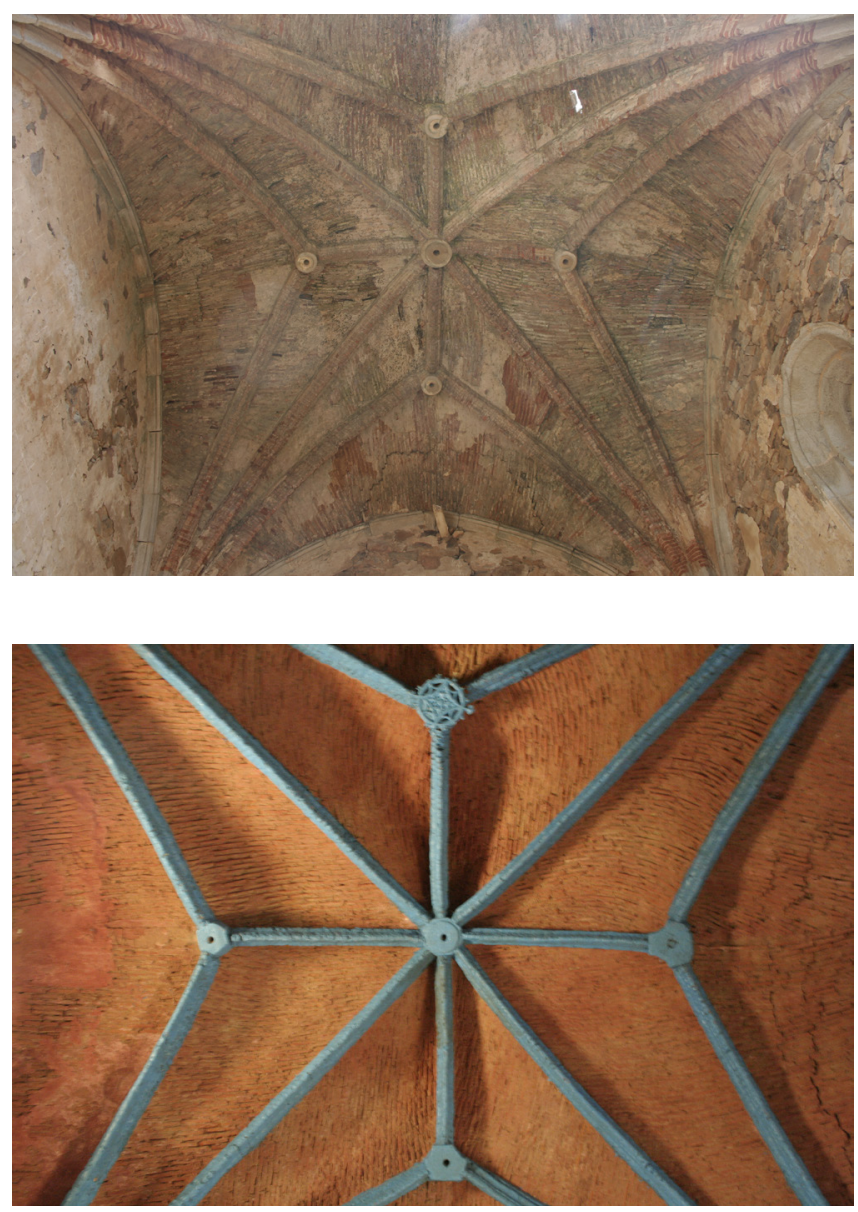

Fig. 355. Bóveda de la capilla mayor de la iglesia de Santa Marina. Tardemézar
Fig. 356. Bóveda de la capilla mayor de la iglesia parroquial de Cunquilla de Vidriales

En la comarca de Benavente y los Valles es el lugar de nuestra provincia en el que más ejemplos se han conservado, de tal forma que fue relativamente común el uso de plementería en ladrillo como puede verse en las bóvedas de las cabeceras de la ruinosa iglesia de Santa Marina de Tardemézar y en la iglesia de San Miguel parroquial de Cunquilla de Vidriales (Figs. 355 y 356). Probablemente ocurre lo mismo en otros templos de la zona aunque el ocultamiento de la bóveda por una capa de yeso nos impide aseverarlo con total certeza.

En la iglesia de Santa María de Villafáfila, es probable que se utilizara el ladrillo para la plementería de todo su sistema abovedado pese a encontrarse en la actualidad cubierto por una capa de yeso que probablemente indujo a Gómez-Moreno 
a apuntar la posibilidad de que estuviesen realizadas con piedra menuda ${ }^{382}$.

También se empleó en las bóvedas de la antigua iglesia parroquial de Quintanilla del Monte, hoy ruinosa, de las que se ha conservado una en pie y pequeñas partes de otras.

Otro ejemplo es la iglesia de Nuestra Señora de la Asunción de Villamor de los Escuderos, cuyos tres tramos de la nave están cubiertos por bóvedas de crucería con combados. Al analizar el sistema constructivo de estas bóvedas, algunas de las cuales muestran evidencia de haber sido comenzadas en piedra y completada su plementería en ladrillo, se podría deducir que ha existido un cambio hacia materiales más económicos y fáciles de trabajar; y ello a pesar de que está documentado el uso del ladrillo en los plementos de las bóvedas de crucería por parte de los Hontañón. De hecho, la existencia de plementos de piedra en las partes fundamentales del edificio (capilla mayor y crucero), así como parcialmente en una de las bóvedas de la nave, abunda en la idea de que plan inicial preveía cubiertas de piedra, pero la falta de recursos las sustituyó por otras de ladrillo en el cuerpo del templo.

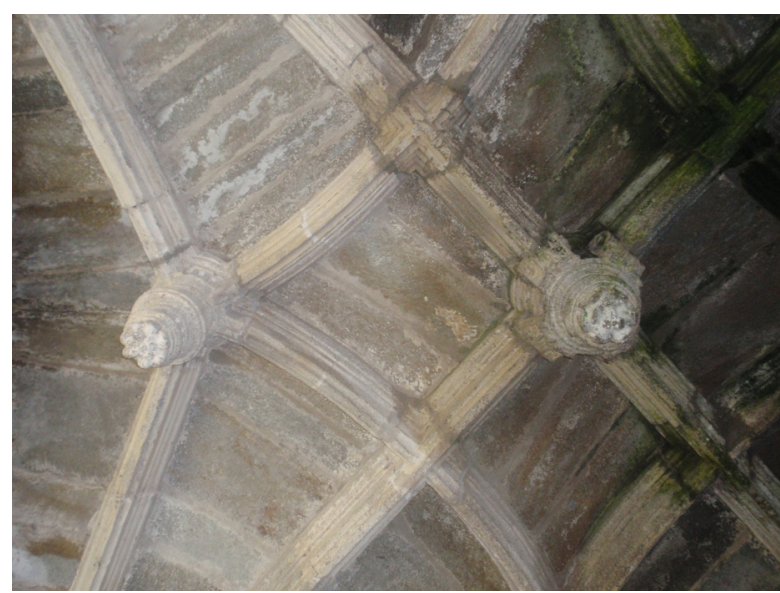

Por último hay que reseñar una particularidad que puede interpretarse nuevamente como otra recurrencia al pasado. Consiste en la utilización de lajas alargadas de piedra que van de nervio a nervio asentando por encima de ellos y cuyo uso fue habitual, por ejemplo, a principios del XIII en monasterios cistercienses ${ }^{383}$. En pleno siglo XVI encontramos este tipo de 382 GÓMEZ-MORENO, M., op. cit., I, 1927 (1980), p. 315.

383 De esta forma se encuentra configurada la plementería de las salas anexas a la iglesia del monasterio de San Martín de Castañeda que se conservan de época medieval. 
plementería y forma de disponerla en la iglesia de Santa María del Azogue de Puebla de Sanabria y en la sacristía del monasterio de San Martín de Castañeda perteneciente también a la comarca sanabresa (Fig. 357).

\section{Nervios}

Ya hemos visto la importancia que adquirieron los nervios combados a partir del primer tercio del siglo XVI aunque se mantuvo el uso de bóvedas únicamente compuestas por nervaduras rectas. También a partir de este mismo momento se generalizó el trazado en medio punto de los formeros, que solamente en algún caso puntual como sucedió en la bóveda del espacio superior de los pies de la iglesia de San Juan Bautista de Casaseca de las Chanas mantuvieron el tradicional trazado en arco apuntado.

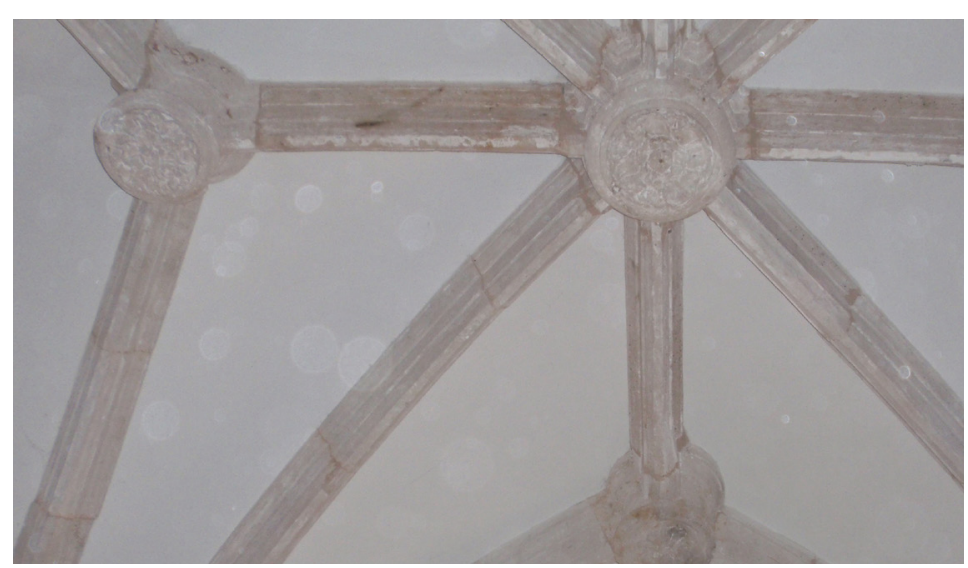

Todas estas nervaduras siguen desarrollando un sencillo perfil triangular que poco a poco se fue apartando de la composición a base de molduras cóncavas que mueren en chaflán y que habían sido utilizadas durante el gótico tardío e incluso algo más allá. A partir de estos momentos los perfiles de las nervaduras van a estar compuestos por lo general de una fina molduración fileteada que mantiene el remate en chaflán, aunque éste por lo general suele ser más estrecho que el utilizado anteriormente. Puede observarse esto en prácticamente cualquiera de las bóvedas de la provincia construida a partir del primer tercio del siglo XVI. Véase, entre otras, las bóvedas de la sacristía del

También lo vemos en la girola y en la sala capitular del monasterio de Santa María de Moreruela y por influencia directa suya en las bóvedas de las iglesias benaventanas de San Juan y en las más antiguas de la iglesia de Santa María del Azogue.
Fig. 358. Detalle de las nervaduras del espacio abovedado de la iglesia de Santa María del Castillo. Fermoselle 
monasterio de San Martín de Castañeda, la bóveda de la sacristía del lado de la epístola de la iglesia de Santa María del Castillo de Fuentesaúco, la correspondiente al pórtico de la iglesia de la Asunción de Nuestra Señora de Fermoselle y las bóvedas de las capillas laterales de la iglesia de la Asunción de Nuestra Señora de Villamayor de Campos (Fig. 358).

\section{Decoración}

El uso de las medias bolas que venía siendo habitual desde finales del siglo XV se prolongó durante buena parte del siglo XVI para decorar la chambrana, el alfiz y, en menor medida, la línea de imposta y las arquivoltas de algunas portadas. Puede verse en las portadas de las parroquiales de Cunquilla de Vidriales, de Moratones de Vidriales, de la Inmaculada Concepción de Pozuelos de Vidriales, de Sitrama de Tera y de Cubo de Benavente.

A excepción de este uso de las medias bolas y el alfiz, se optó por modelos totalmente renacentistas como sucede en las claves, ménsulas, etc., generalmente muy sencillas. El elemento de mayor empaque donde se concentró el despliegue decorativo más amplio fue en las portadas monumentales de algunos templos que igualmente obedecen ya a un concepto plenamente renaciente.

Talleres locales durante los dos últimos tercios del siglo XVI

Durante esta etapa de pervivencias del gótico, y como vimos que sucedía durante el periodo gótico tardío, hemos encontrado relaciones evidentes, en este caso, en un grupo de templos pertenecientes a una comarca zamorana. Estas iglesias poseen unas características comunes en cuanto a estructura y elementos ornamentales, y parece por tanto posible que fuera un mismo taller el que se encargara de la ejecución de, al menos, algunas de ellas. Eclesiásticamente dependen de la diócesis de Astorga y están ubicadas en la comarca de Benavente y los Valles y dentro de ella, más concretamente, en los denominados valles de Vidriales y Tera. 
Se trata, salvo excepciones, de edificios modestos levantados en mampostería y en los que se ha empleado la sillería para lugares concretos como los vanos, contrafuertes y algún otro lugar puntual. Constan generalmente de una sola nave cubierta por techumbre de madera y cabecera cuadrangular de tradición gótica con contrafuertes en diagonal en las esquinas orientales y paralelos al muro en los extremos occidentales. El empleo de la bóveda de crucería se reduce fundamentalmente a la cabecera. Solamente en casos muy concretos la encontramos cubriendo la sacristía o alguna capilla. El tipo de bóveda más común es la de crucería con terceletes a la que en diversas ocasiones se le añaden nervios de ligadura hasta las claves de los formeros. También se empleó la bóveda de crucería simple y, en alguna ocasión, la bóveda de crucería simple con ligaduras a las claves de los formeros. A su vez existe algún diseño novedoso como es el caso del que cubre la sacristía de la iglesia de San Miguel en Carracedo de Vidriales, espacio rectangular cuya bóveda carece de nervios cruceros acaso por influencia de la catedral de Astorga como ya se ha apuntado. Curiosamente en ninguno de los edificios de esta zona se sirvieron de los nervios combados pese a haberse levantado la mayoría avanzado el siglo XVI y, por tanto, en un momento en el que su uso fue muy habitual en Castilla.

Otra particularidad de este grupo de iglesias es el uso del ladrillo para la plementería de algunas de sus bóvedas, como sucede en las correspondientes a las cabeceras de las iglesias de Santa Marina de Tardemézar y San Miguel de Cunquilla de Vidriales ${ }^{384}$.

Además en estos templos se aprecia un curioso retorno a modelos románicos en portadas y canecillos. Se vuelve a un esquema de portada en el que predomina el arco de medio punto adornado con besantes y molduraciones en forma de medias cañas y bocel. No obstante, como ya se ha dicho, por su encuadramiento en alfiz, remiten igualmente a la época de los Reyes Católicos, en la que también la decoración de medias bolas era un motivo común. El uso repetido de las medias 
bolas se extiende también a otras partes del templo como las ménsulas o los capitelitos de los arcos de acceso a la cabecera. La referencia al estilo románico en estos templos se ve reforzada por la presencia de canecillos que sustentan la cornisa exterior, en unos casos distribuidos por la cabecera, en otros alrededor de la nave o, incluso, en otros, por todo el perímetro del edificio. La mayor parte de las veces son muy simples y se componen de una amplia moldura cóncava. Excepcionalmente tienen forma de cabeza humana y, en este caso, podrían interpretarse como restos reutilizados de una edificación anterior.

La pervivencia del gótico en la arquitectura civil de los dos últimos tercios del siglo XVI

Como hemos señalado a la hora de abordar la arquitectura religiosa de estos momentos la gran actividad constructora de principios del siglo XVI desarrollada fundamentalmente en la ciudad de Zamora, aunque también de manera muy significativa en otras localidades como Toro y Benavente, decayó ligeramente durante los dos últimos tercios de este siglo. No obstante, las necesidades de los núcleos de población más importantes favorecieron la edificación de una serie de equipamientos a los que habría que sumar las obras patrocinadas por la iglesia, que ya han sido comentadas, y por la nobleza. La mayoría de las construcciones de esta época, que prácticamente se limitan a edificios con carácter residencial, en el mejor de los casos, han llegado muy trasformadas y, en otros, solamente contamos con testimonios documentales.

Algunos de los elementos que caracterizaron la arquitectura civil del gótico final siguieron utilizándose durante décadas e, incluso en siglos posteriores, en la arquitectura de nuestra provincia. En lo que a los palacios se refiere la planimetría generalizada durante el gótico tardío se mantuvo en líneas generales. En cuanto al tipo de fachada fue muy común la utilización de portadas enmarcadas por alfiz y con arcos compuestos de grandes dovelas y en su mayoría con trazado en medio punto. Ya señalamos en el capítulo dedicado al gótico civil de época tardía cómo el palacio de los condes de Alba de 
Aliste, edificio en su mayor parte de estilo renacentista, es el conjunto arquitectónico del siglo XVI en nuestra provincia en el que mejor se observa la pervivencia de elementos estructurales y decorativos góticos. Desgraciadamente del castillo de Benavente, que fue transformado en residencia urbana integrada en la ciudad durante el siglo XVI, solamente se ha conservado la torre del Caracol, de principios del siglo XVI, pero nada de las edificaciones y reformas que se hicieron durante las siguientes décadas.

No obstante, hay testimonios menos significativos pero que reafirman la presencia de formas góticas muy avanzado el siglo XVI. Indudablemente en los nuevos edificios levantados a partir del primer cuarto este siglo comenzó a mostrarse una clara predilección por modelos y decoraciones de tipo renacentista, pero en ellos, de un modo u otro, se mantuvieron ciertos diseños, formas $y$ ornamentos que se habían generalizado durante los últimos años del siglo XV y los primeros del siglo XVI y que formaban parte del corpus característico del gótico final.

Así sucede en la portada principal del palacio de la Inquisición de Toro que, a pesar de haber sido construida en fecha avanzada del siglo XVI, mantiene el esquema general de portada utilizada durante el gótico tardío, resuelta en este caso en arco de medio punto y enmarcada con alfiz y escudos en las enjutas. Un esquema parecido tiene la conocida como antigua casa de los Aguilar de Mella en Zamora. Esta antigua residencia se encuentra situada inmediata a la iglesia de San Ildefonso y su portada mantiene como encuadre el alfiz y el amplio dovelaje de grandes sillares. Cabe suponer que el esquema general de la portada, más avanzado estilísticamente que la mencionada del palacio de la Inquisición de Toro, sea indicativo de una construcción llevada a efecto en torno a mediados del siglo XVI. Poco tiempo después se levantaron las portadas correspondientes al palacio de Amavízcar y a la casa de la Nunciatura, ambas en Toro ${ }^{385}$. En las dos se utiliza el arco de medio punto con grandes dovelas. El recuerdo del alfiz se mantiene reinterpretado mediante columnas adosadas que sostienen un entablamento. 
También corresponden a estos momentos la portada sur de la antigua Alhóndiga del Pan de Zamora y la portada conservada de la antigua Cárcel Real también de Zamora, ambas pertenecientes a edificios civiles construidos en la segunda mitad del siglo XVI que reproducen nuevamente, y en cierta medida, las características propias de la arquitectura palaciega del gótico tardío. Nuevamente volvemos a constatar cómo la portada habitual de las residencias urbanas, tanto del periodo gótico tardío como ya del pleno siglo XVI, se utilizó indistintamente en todo tipo de edificios no solamente del ámbito civil sino también y aunque de forma menos frecuente en la arquitectura de carácter religioso.

En algún edificio renacentista como el actual monasterio de Santa María la Real de las Dueñas de Zamora la presencia de arcos carpaneles en las galerías del claustro es un indicio de que el recuerdo del gótico no se ha desvanecido por completo. La razón de su mención en este apartado se debe al origen civil de su construcción, ya que el edificio que habitan en la actualidad la comunidad de monjas dominicas, fue levantado en origen como hospital aunque parece que nunca llegó a funcionar como tal ya que recién acabado fue ocupado por las religiosas.

También fue utilizado el arco carpanel, en este caso enmarcado por alfiz, en la galería superior que recorre la fachada principal del palacio de los marqueses de Alcañices de Toro comenzado a edificar a finales del primer tercio del siglo $\mathrm{XV|}{ }^{386}$.

Por último habría que aludir a la bóveda de crucería que fue el elemento fundamental que caracterizó a la arquitectura gótica, si bien su uso se redujo en gran medida al ámbito religioso. No obstante, tenemos algún ejemplo aislado como es el caso del cuerpo superior de la torre oriental del Ayuntamiento de Zamora donde se han conservado restos indicativos de la presencia de este tipo de bóvedas. A pesar de la parcialidad de estos restos, podría afirmarse que probablemente pertenecen a un momento avanzado del siglo XVI.

Junto a los testimonios conservados y que acabamos de mencionar en este apartado relativo a la arquitectura civil no podemos olvidar los edificios desaparecidos totalmente y de los que se tiene constancia de su existencia a partir de 386 VASALLO TORANZO, L., op. cit., 1994, p. 206. 
la documentación. Las fechas en las que se encuadran estas edificaciones y los testimonios documentales e, incluso, fotográficos, que poseemos de alguna de ellas, unido a la relación con la arquitectura que se desarrollaba en el momento y que sí se ha conservado, motivan su mención en este apartado. Por ejemplo existen noticias de residencias urbanas edificadas en los dos primeros tercios del siglo XVI en las que a tenor de lo visto en los edificios de estas características que se han conservado cabría suponer la presencia en ellas de formas góticas. En la ciudad de Zamora, por ejemplo, han desaparecido el palacio de los condes de Castronuevo, que probablemente se edificó en la primera mitad del siglo XVI y en la que intervino el cantero Juan de Castañeda en 1569 levantando una torre con abovedamiento en la parte baja ${ }^{387}$. En la ciudad de Toro es probable que alguno de los palacios de esta época que no han llegado a nuestros días poseyera alguna estructura o elemento gótico ${ }^{388}$.

Igualmente el Hospital de la Piedad de Benavente que había comenzado a edificarse a principios del siglo XVI debió acusar alguna intervención importante avanzada esta centuria o al menos eso parece desprenderse del análisis de la bóveda que cubre su capilla en la que se emplearon los nervios combados y cuyo estudio ha sido incorporado en el apartado correspondiente de la arquitectura religiosa. 
CONCLUSIONES 



\section{CONCLUSIONES}

Como resultado de esta tesis de investigación titulada Arquitectura gótica en Zamora y su provincia podemos concluir que, en comparación con otras zonas geográficas, la actividad constructiva desarrollada en lo que se corresponde con la actual provincia de Zamora no alcanza una presencia especialmente significativa, lo que no excluye el interés tanto histórico como artístico de sus manifestaciones que, por otra parte, son muy numerosas y de no haber sido por las pérdidas irreparables de muchos edificios, su incidencia visual en el panorama artístico hubiera sido muy relevante.

Seguidamente, y teniendo en cuenta que en un estudio tan variado y extenso como este no puede haber una única conclusión, realizo una serie de valoraciones globales de la arquitectura gótica en la provincia de Zamora una vez concluido el estudio y el análisis sistemático de todos sus elementos.

10 El primer aspecto que me ha interesado en este trabajo tiene que ver con la aparición de las formas góticas en un contexto arquitectónico románico. Dada la gran importancia y el enorme desarrollo que había tenido la arquitectura románica en este espacio geográfico, y conscientes de la dificultad de establecer una línea de delimitación entre los estilos artísticos, hemos comenzado por significar los elementos arquitectónicos precursores del gótico en las estructuras de las iglesias románicas, especialmente el arco apuntado y la bóveda de crucería. Puesto que muchas de estas iglesias románicas empezaron a construirse durante la segunda mitad del siglo XII, lo que en buena medida hizo que sus obras se prolongaran durante los primeros años o incluso décadas del siglo XIII, es comprensible que en ellas se incorporaran, en las fases más tardías, estas formas, que en edificios europeos y castellanos más innovadores formaban ya parte del repertorio gótico pleno. El arco apuntado sustituye tímidamente al arco de medio punto en las estructuras y de forma más frecuente en puertas, ventanas y, sobre todo, en multitud de arcosolios. Si bien en principio en ocasiones este arco apuntado 
mantiene todavía el característico doblamiento románico pronto esta disposición fue sustituida por un repertorio de molduras en la rosca que paulatinamente da lugar a un perfil apuntado. La bóveda de crucería, mucho más significativa del cambio de estilo, comienza a utilizarse desde fecha relativamente temprana aunque siempre sobre una base constructiva románica y, en estos primeros momentos dichas bóvedas carecen de arcos formeros que alivien a los muros de su carga. La incorporación del arco apuntado y de la bóveda de crucería en este momento, afecta principalmente a la arquitectura religiosa.

En la arquitectura civil únicamente se constata la presencia de arcos apuntados, pero en este caso habría que tener en cuenta que las razones de su utilización podrían estar justificadas no sólo por los cambios estéticos sino por la misma funcionalidad de estas estructuras. No obstante, estas construcciones civiles se han conservado de forma muy parcial, por lo que las conclusiones se ajustan a lo que actualmente podemos ponderar. Las primeras incorporaciones de elementos formales que preludian la arquitectura gótica en los edificios civiles se van a encontrar principalmente en todas aquellas estructuras que componen la fortificación de la ciudad de Zamora. Esto es, en el castillo, en las murallas y en el puente que, en gran parte, fueron edificados en el tránsito del románico al gótico, de tal modo que en ellas se va a introducir el arco apuntado. En menor medida también lo vemos en los restos de las fortificaciones de otras ciudades como Toro o Fermoselle.

2 Durante el gótico pleno, siglos XIII y XIV, la actividad arquitectónica en la provincia de Zamora se redujo considerablemente respecto a las décadas anteriores. No obstante, y dentro del ámbito religioso, todo parece indicar que, sobre todo, en los núcleos de población más significativos, pudieron haberse construido algunos edificios, en su mayoría de órdenes mendicantes. Pero las escasas noticias de la fundación de dichas casas no permiten concluir sobre la importancia arquitectónica de estos primitivos asentamientos. Aunque existen referencias históricas de su existencia cabe pensar que fueron poco significativas y se han perdido todos salvo 
excepciones como el convento de San Francisco de Zamora o el convento de San Ildefonso de Toro que, aún en estos casos, han llegado al momento presente en estado muy ruinoso. Por el contrario, han llegado a nuestros días en forma más completa las importantísimas reformas emprendidas en dos edificios emblemáticos de nuestra provincia como son la colegiata de Toro y la iglesia de Santa María la Real de la Hiniesta. En la prolongación de la colegiata de Toro hacia el oeste, a mediados del siglo XIII, se edificó una capilla cuya parte más sobresaliente es el denominado pórtico de la Majestad. En la Hiniesta se acometió en el siglo XIV una importantísima intervención que afectó a gran parte del conjunto, fruto de la cual fue su portada sur que constituye junto con la mencionada de la Majestad las obras más relevantes en su género de toda la provincia. También fue notable durante este periodo la transformación sufrida por la iglesia de San Cipriano que pasó de estar configurada mediante tres naves a una sola a la vez que se edificó una capilla.

Del gótico civil pleno apenas se ha conservado nada, solamente algunas partes de la muralla de la ciudad de Zamora podrían encuadrarse en este momento aunque no tienen ninguna relevancia estilística; sin embargo son de gran interés las antiguas casas que poseyó en la ciudad de Toro el obispo de Coria y que más tarde pertenecieron a María de Molina porque, aunque en estado muy fragmentario, constituyen uno de los escasos ejemplos conservados de vivienda urbana de su época en Castilla.

3 l periodo correspondiente al estilo gótico tardío es el que ha aportado un número de obras más abundante. Con excepción de los restos del palacio de las Leyes conservado en la ciudad de Toro y que es un ejemplo destacadísimo de arquitectura civil de mediados del siglo $\mathrm{XV}$, hay que esperar hasta la segunda mitad del siglo XV para que comience a desarrollarse en la provincia de Zamora y más concretamente en su capital una importante actividad constructiva debida en su mayoría a la iniciativa eclesiástica, nobiliaria e, incluso, de los poderes públicos. Así vemos, por tanto, enriquecerse considerablemente el repertorio de formas góticas tanto en lo estructural como en lo decorativo, 
con la abundancia de repertorios ornamentales que afectaron fundamentalmente a los capiteles, a las líneas de imposta y al enmarque de los vanos.

En el ámbito religioso las obras más significativas fueron las que afectaron a la catedral de Zamora y que se llevaron a cabo fundamentalmente bajo el mandato del obispo Meléndez Valdés. Se construyó una gran cabecera gótica, la denominada sacristía vieja con una serie de pequeñas dependencias anejas y el coro, además de enriquecer el templo con ornamentos tales como las espléndidas rejas de la capilla mayor y del coro o los púlpitos. También destacables son las obras realizadas en este mismo templo por encargo del cardenal Mella y del doctor Juan de Grado. Hay que añadir, en estos primeros años del siglo XVI, la proliferación de capillas funerarias en muchos templos de la ciudad y de la provincia así como la transformación de algunas cabeceras de época románica por nuevas cabeceras de estilo gótico como sucedió, aparte de en la ya mencionada catedral, en la iglesia de San Leonardo, también en la ciudad y, por ejemplo, en la iglesia parroquial de Venialbo, en la provincia. También, aunque de manera excepcional, se edificaron o comenzaron a edificarse algunos templos de nueva planta. Ejemplo de ello es la iglesia de San Sebastián de los Caballeros. De especial interés es todo lo conservado de la parroquial de Villar de Fallaves y más concretamente su notoria fachada sur.

La nobleza por su parte mandó construir nuevas residencias urbanas, alguna de ellas de gran empaque como fue el caso de la Casa de los Rodríguez de Ledesma, también conocida como palacio de los Momos, del palacio del regidor don Francisco Ramírez de Noreña también conocido como palacio del Cordón y del palacio de los condes de Alba de Aliste todos ellos en la ciudad de Zamora, del castillo-palacio de los conde de Benavente, de los palacios de Requena y de Villalonso en Toro y del palacio del Chantre en el Perdigón.

Este esplendor que vivió la ciudad de Zamora y algunos pueblos y ciudades de la provincia a finales del siglo $X V$ y principios del siglo XVI se vio también plasmado en edificios públicos patrocinados por los Reyes Católicos como fue el caso del Ayuntamiento de la ciudad de Zamora. 
4ㅇ Por último, así como el gótico se abrió paso muy lentamente en nuestra arquitectura, el renacimiento tardó también en hacer acto de presencia y en comenzar a desplazar al gótico que, con el transcurrir de los siglos, había echado raíces profundas. Así hay que entender que, incluso durante la segunda mitad del siglo $\mathrm{XVI}$, como ocurre, entre otros muchos templos, en la iglesia de San Andrés de Zamora, determinados elementos arquitectónicos góticos, como son en este caso los sistemas abovedados utilizados en la cabecera y en algunas capillas, mantuvieran todavía una clara presencia. En los edificios civiles edificados durante los dos últimos tercios del siglo XVI la presencia de elementos góticos es meramente testimonial y se circunscriben como sucede en la Alhóndiga del Pan y en la Cárcel Real, ambas en la ciudad de Zamora, a algunos pequeños aspectos de sus portadas como es la permanencia del alfiz.

5o Por lo que se refiere a la valoración de la arquitectura desarrollada en la provincia de Zamora desde el siglo XIII hasta el siglo XVI cabe concluir que su línea evolutiva no es regular sino que, salvo obras puntuales del máximo interés durante el gótico pleno, el momento de mayor intensidad constructiva, tanto en el campo religioso como en el civil, es el comprendido entre finales del siglo XV y principios del XVI.

60 En este trabajo se ha concedido mucha importancia al estudio de los elementos arquitectónicos y al análisis de las partes integrantes de su morfología, como fundamento para la determinación de la cronología y para el establecimiento de la evolución estilística, ya que, en la mayoría de los edificios, carecemos de datos concretos que nos faciliten una fecha, aunque sea aproximada. Es por ello que cuando las noticias documentales son prácticamente inexistentes hayamos tenido que recurrir a comparaciones en función de las formas que aportan los estudios de dichos elementos, tanto en arcos, bóvedas como en los repertorios de molduras y ornamentos. 
7ํ He prestado mucha atención al contexto en el que se han realizado todas y cada una de las obras que se incluyen en este estudio puesto que la arquitectura no está desconectada de la sociedad, sino al contrario, es una consecuencia de ella. De este modo he incidido, en los casos en los que tenemos constancia de ello, en aquellos que promovieron determinadas obras o determinados arreglos. Así hemos visto cómo dependiendo de la época, en función de la vida de la ciudad, varían los promotores. Indudablemente la participación del clero y de la nobleza fue fundamental y a ellos se debe la mayor parte de las obras realizadas durante este periodo. A ellos habría que añadir el patrocinio real, el patrocinio público y el aporte del pueblo en la construcción de sus iglesias parroquiales.

En resumen la aportación global de este trabajo es, por un lado, la catalogación completa de las manifestaciones de la arquitectura gótica en la provincia de Zamora, como base e infraestructura de lo que, por otro lado, constituye la verdadera razón de este estudio, que es la de articular la evolución de las formas góticas a lo largo de todo el desarrollo de la arquitectura gótica zamorana, con la puntualización específica de los rasgos que caracterizan cada momento como expresión de los cambios de una sociedad con condicionantes específicos y con momentos de declive y de esplendor. 
BIBLIOGRAFÍA 



\section{BIBLIOGRAFÍA}

AA. VV., Casas y palacios de Castilla y León, Jesús Urrea (Dir.), Junta de Castilla y León, Valladolid, 2002.

AA. VV., IX Centenario de la Fundación de la Diócesis de Zamora (901-2001). 5 octubre 2001-26 mayo 2002. Ciclo de Conferencias. Enero 2002, Zamora, 2002.

AA. VV., Colección Diplomática del Imperial Monasterio de Nuestra Señora de Valparaíso (1143-1499), Instituto de Estudios Zamoranos «Florián de Ocampo» (C.S.I.C.), Diputación de Zamora, 1998.

AA. VV., Fotografías antiguas de Zamora, Centro de Iniciativas y Turismo. Zamora, Valladolid, 1979.

AA. VV., De los plutones a los monumentos: Un recorrido temático por la piedra del este de Sayago (Zamora), (Cuadernos de investigación, 36), Instituto de Estudios Zamoranos «Florián de Ocampo» (C.S.I.C.), Diputación de Zamora, 2012.

AA. VV., El Castillo de Benavente, Centro de Estudios Benaventanos «Ledo del Pozo», Benavente, 1998.

AA.VV., El Convento de San Francisco: memoria histórica, intervención arqueológica y rehabilitación arquitectónica, Fundación “Rei Alfonso Henriques”, Zamora, 1998.

AA.VV., "El Palacio del Cordón de Zamora, excavación de un edificio civil de los siglos XV-XVI", Anuario del Instituto de Estudios Zamoranos «Florián de Ocampo», Zamora, 1993, pp. 165-177.

AA. VV., Historia de Zamora, III tomos, Diputación de ZamoraInstituto de Estudios Zamoranos «Florián de Ocampo»-Caja España, Zamora, 1995.

AA.VV., Historia del Arte de Castilla y León, Arte gótico, tomo III, Ámbito, Valladolid, 1994.

AA.VV., Historia hospitalaria de la Vía de la Plata (José Luis Perona Larraz. Dir.), Salamanca, 2009. 
AA.VV., "Intervención arqueológica en el Castillo de Zamora", Anuario del Instituto de Estudios Zamoranos «Florián de Ocampo», Zamora, 1992, pp. 135-147.

AA.VV., Itinerarios arquitectónicos zamoranos, Ayuntamiento de Zamora, Zamora, 1996.

AA.VV., Jornadas sobre Zamora, su entorno y América, Instituto de Estudios Zamoranos "Florián de Ocampo», Diputación de Zamora, 1992.

AA.VV., La catedral de Burgos, Ediciones Encuentro, Madrid, 2001.

AA.VV., Las catedrales de Castilla y león, León, 1992.

AA. VV., Las catedrales de Castilla y León. Un proyecto eterno, Valladolid, 1995.

AA.VV., La obra en yeso de los Corral de Villalpando, Ministerio de Cultura, Madrid, 1994.

AA. VV., Los instrumentos musicales de los pórticos de la Colegiata de Toro (Isabel Cidón Madrigal Coord.), Zamora, 2002.

AA. VV., Los últimos arquitectos del Gótico (Begoña Alonso Ruiz Coord.), Madrid, 2010.

AA.VV., Memoria gráfica de Zamora, La Opinión-El Correo de Zamora, Zamora, 2000.

A.A.V.V., Moreruela. Un monasterio en la historia del Císter, Hortensia Larrén Izquierdo (Coord.), Junta de Castilla y León, Salamanca, 2008.

A.A.V.V., Patrimonio arqueológico y monumental en el embalse del Esla (Zamora). Tramo. Bretó de la Ribera-Ricobayo, Instituto de Estudios Zamoranos «Florián de Ocampo», Zamora, 2001.

AA.VV., Portada de la Majestad. Colegiata de Toro, 1996.

AA. VV., Primer Congreso de Historia de Zamora, IV tomos, Instituto de Estudios Zamoranos «Florián de Ocampo»Diputación de Zamora, Zamora, 1989.

AA.VV., Privilegios reales de la villa de Benavente (siglos XII$X I V)$, Centro de Estudios Benaventanos "Ledo del Pozo», Círculo de Benavente, 1996. 
AA. VV., Segundo Congreso de Historia de Zamora, IV tomos, Instituto de Estudios Zamoranos «Florián de Ocampo»Diputación de Zamora-Uned, Zamora, 2008.

AA. VV., Sumas y restas de las tablas de Arcenillas. Fernando Gallego y el retablo de la catedral de Zamora, Junta de Castilla y Léon, 2007.

AA.VV., "Trabajos arqueológicos anexos a la restauración de la antigua Alhóndiga del Pan, en Zamora", Anuario del Instituto de Estudios Zamoranos "Florián de Ocampo», Zamora, 2000, pp. 121-139.

AA.VV., Zamora en imágenes. 1925-1950. Fotografía y Sociedad, La Opinión-El Correro de Zamora, Zamora, 2005.

AA. VV., IX Centenario de la Fundación de la Diócesis de Zamora (901-2001). Ciclo de Conferencias. Enero 2002, Obispado de Zamora, Zamora, 2002.

AA. VV., 1984-1995. Catálogo de la exposición Castilla y León restaura, Junta de Castilla y León, Monasterio de Nuestra Señora de Prado, Valladolid, mayo-julio 1995.

ALFONSO ANTÓN, Isabel, La colonización cisterciense en la meseta del Duero. El dominio de Moreruela (siglos XII-XIV), Zamora, 1986.

ALMOÍNA MATEOS, José, Monumentos históricos y artísticos de Benavente, Benavente, 1935 (reedición, Centro de Estudios Benaventanos, Salamanca, 2000).

ALONSO RUIZ, Begoña, "Juan Gil de Hontañón en Segovia. Sus comienzos profesionales" en Boletín del Seminario de Estudios de Arte y Arqueología, LXVI, Valladolid, 2000, pp. 153-162.

ALONSO RUIZ, Begoña, Arquitectura tardogótica en Castilla: los Rasines, Universidad de Cantabria, 2003.

ALONSO RUIZ, Begoña, "De la capilla gótica a la renacentista: Juan Gil de Hontañón y Diego de Siloé en La Vid", Anuario del Departamento de Historia y Teoría del Arte, (U.A.M.), vol. XV, 2003, pp. 45-57. 
ALONSO RUIZ, Begoña, "El cimborrio de la «magna hispalense» y Juan Gil de Hontañón" en Actas del Cuarto Congreso Nacional de Historia de la construcción, Cádiz, 27-29 enero 2005, I, Madrid, 2005, pp. 21-33.

ALONSO RUIZ, Begoña y VILLASEÑOR SEBASTIÁN, Fernando, Arquitectura tardogótica en la Corona de Castilla: trayectorias e intercambios, Santander, 2014.

ÁlVAREZ MARTíNEZ, Ursicino, Zamora Ilustrada (revista literaria semanal), IV tomos, (1882), Diputación de Zamora, Zamora, 1988.

ÁlVAREZ ORTIZ, Pilar, Historia de la Villa y Castillo de Castrotorafe, Salamanca, 2002.

ÁlVAREZ PALENZUELA, Vicente-Ángel, Monasterios cistercienses en Castilla (Siglos XII-XIII), Universidad de Valladolid, 1978.

ÁlVAREZ PALENZUELA, Vicente-Ángel y RECUERO ASTRAY, M., La Fundación de monasterios cistercienses en Castilla. Cuestiones cronológicas e ideológicas, Instituto Enrique Flórez, Madrid, 1984, pp. 429-455.

ÁLVAREZ VÁZQUEZ, José Antonio, "La agricultura de Zamora en la época moderna" en AA.VV., Historia de Zamora. La Edad Moderna, tomo II, Diputación de Zamora, Zamora, 1995.

ANTA LORENZO, Lauro, "El monasterio de San Martín de Castañeda en el siglo X. En torno a los orígenes y la formación de la propiedad dominical", Stvdia Zamorensia, Segunda Etapa, col. III, UNED, Zamora, 1996, pp. 31-52.

ANTÓN Y CASASECA, Francisco, “De arte románico. Los relieves de San Cipriano de Zamora" en Boletín de la Sociedad Española de Excursiones, XXXIV, Madrid, 1926, pp. 167-175.

ANTONIO, Nicolás, Bibliotheca Hispana Vetus, tomo II, libro 10, capítulo X, Reprod. facs. De la ed. De: Matriti: apud viduam et heredes d. loachimi Ibarrae, 1788, Madrid, Visor, 1996, 2 vol.

APCZR., Memoria del PBYE Fase 3: Intervención en torre, solado y entorno de la iglesia de Santa María la Nueva, Zamora, 2011. 
ARBÓS, Fernando, "Informe sobre declaración de monumento nacional de la Iglesia de Santiago del Burgo, de Zamora" en Boletín de la Real Academia de Bellas Artes de San Fernando, Madrid, 1908, pp. 169-171.

AVRIAL Y FLORES, José María, “Catedral de Zamora” en Boletín de la Real Academia de Bellas Artes de San Fernando, Madrid, 1889, pp. 184-192.

AZOFRA, Eduardo, La catedral de Ciudad Rodrigo. Visiones y revisiones, Salamanca, 2006.

BALADO PACHÓN, Arturo y MARTÍNEZ GARCÍA, Ana María, "Excavación arqueológica en el exterior de la iglesia de Santa María del Azogue de Benavente (Zamora)", Anuario del Instituto de Estudios Zamoranos «Florián de Ocampo», Zamora, 2005, pp. 61-73.

BANGO TORVISO, Isidro Gonzalo, "Arte medieval en Zamora. Monasterio de Santa María de Moreruela", Stvdia Zamorensia (Anejos 1), Universidad de Salamanca, Zamora, 1989, pp. 61-116.

BAUDOT, Georges, Utopía e Historia en México, Espasa-Calpe, Madrid, 1983.

BÉCARES BOTAS, Vicente, Los Patronos de Zamora San Ildefonso y San Atilano. Documentación inédita, Zamora, 1990.

BÉCARES BOTAS, Vicente, "Los libros del Cisterciense: fondos localizados de los monasterios zamoranos de Moreruela, Valparaíso y San Martín de Castañeda" en Humanismo y Císter. Actas del I Congreso Nacional sobre humanistas españoles, León, 1996, pp. 509-517.

BÉCARES BOTAS, Vicente, Las Bibliotecas Monásticas y la Desamortización en la Provincia de Zamora, Zamora, 1999.

BECEIRO PITA, Isabel, "Los libros que pertenecieron a los condes de Benavente, entre 1434 y 1530", Hispania: revista española de historia, Madrid, vol. 43, n. 154, 1983.

BECEIRO PITA, Isabel, El condado de Benavente en el siglo XV, Centro de Estudios Benaventanos "Ledo del Pozo» (C.E.C.E.L.C.S.I.C.), Salamanca, 1998. 
BERNHEIMER, Richard, Wild Men in the Middle Ages: A Study in Art, Sentiment and Demonology, Cambridge, Harvard University Press, 1952.

BIALOSTOCKI, Jan, "Le gothique tardif: désaccords sur le concept" in Information d' Histoire de l'Art, no 3, Mai-Juin 1968, pp. 106-128.

BRÍO MATEOS, Asterio-Miguel del y BRÍO CARRETERO, Clara del, El canónigo doctor Juan de Grado. Biografía de un clérigo medieval, Madrid, 1987.

BRío CARRETERO, Clara del, "El doctor Juan de Grado: centenario y revisión", Anuario del Instituto de Estudios Zamoranos «Florián de Ocampo», Zamora, 2005, pp. 315-323.

BUENO DOMÍNGUEZ, Mạ. L., El monasterio de Santa María de Moreruela (1143-1300), Zamora, 1975.

CABAÑAS VÁZQUEZ, Carlos, Las huellas del tiempo en el plano de Zamora, Ayuntamiento de Zamora, Zamora, 2002.

CALDERO FERNÁNDEZ, Jesús, La iglesia arciprestal de San Pedro y San Ildefonso de Zamora, Zamora, 1978.

CALVO ALAGUERO, Gaspar, Historia de la muy leal y antigua ciudad de Toro. Noticias biográficas de sus más ilustres hijos, Valladolid, 1909.

CALVO DE ANDRÉS, José María, Villamor de los Escuderos. Una Historia Rural, Zamora, 2008.

CALVO LORENZO, Luis, Historia de la villa de Villalpando, Zamora, 1981.

CALVO LOZANO, Luis, ROMÁN ALLENDE, Pablo, OSORIO BURÓN, A. Tomás, Parroquias, archivos y cofradías de Villalpando, Centro de Estudios Benaventanos «Ledo del Pozo», Benavente, 2003.

CARNERO FELIPE, Ramón Manuel, Historia de Pereruela de Sayago (Zamora) y su alfarería, Zamora, 1998.

CARNERO FELIPE, Ramón Manuel, Pereruela de Sayago. La parroquia, la desamortización y los Docampo, Salamanca, 1984.

CARNERO FELIPE, Ramón Manuel, La otra historia de Sayago, Zamora, 1988. 
CARRERO SANTAMARÍA, Eduardo, "El claustro medieval de la Catedral de Zamora. Topografía y función", Anuario del Instituto de Estudios Zamoranos «Florián de Ocampo», Zamora, 1996, pp. 107-127.

CARRERO SANTAMARÍA, Eduardo, "Arquitectura y espacio funerario entre los siglos XII y XVI: La Catedral de Zamora", Anuario del Instituto de Estudios Zamoranos "Florián de Ocampo», Zamora, 1998, pp. 201-252.

CASAS, Manuel de las, "En Viva Voz", Ars Sacra, no 19, Madrid, 2001, pp. 54-64.

CASAS Y RUIZ DEL ARBOL, Francisco, Monumentos artísticos de Toro. La Colegiata, San Sebastián, 1950.

CASAS Y RUIZ DEL ÁRBOL, Francisco, Monumentos Nacionales de Toro. Breve guía explicativa, Zamora, 1950 (edición facsímil 1985).

CASAS Y RUIZ DEL ÁRBOL, Francisco, "Geografía histórica de las tierras de Toro", Separata de El Correo de Zamora, 1967.

CASAS Y RUIZ DEL ÁRBOL, Francisco, Motivos de Toro, Zamora, 1970.

CASASECA, Ángel, "Últimas intervenciones en la Catedral de Zamora", Ars Sacra, № 19, Madrid, 2001, pp. 20-29.

CASASECA CASASECA, Antonio, "La iglesia parroquial de Villamor de los Escuderos", Stvdia Zamorensia, tomo I, Salamanca, 1980, pp. 141-155.

CASASECA CASASECA, Antonio, Rodrigo Gil de Hontañón (Rascafría, 1500-Segovia, 1577), Junta de Castilla y León, Salamanca, 1988.

CASASECA CASASECA, Antonio, "Catedral de Zamora" en Las Catedrales de Castilla y León, León, 1992, pp. 205-221.

CASQUERO FERNÁNDEZ, José Andrés, Inventario del Archivo Municipal de Fuentesaúco, Zamora, 2002.

CASQUERO FERNÁNDEZ, José Andrés, "La iglesia de Santiago del Burgo (Zamora): proceso histórico, restauraciones y aislamiento", Stvdia Zamorensia, Segunda Etapa, Volumen XI, Zamora, 2012, pp. 167-204. 
CASTRO, M., O.F.M., "Fray Alfonso de Castro, O.F.M. (14951558), Consejero de Carlos V y de Felipe II", Salmanticensis, № 6, Salamanca, 1958.

CASTRO LORENZO, José de, Retrato de Teresa Gil, Valladolid, 2010.

CASTRO SANTAMARÍA, Ana, "El monasterio de San Jerónimo de Zamora en el siglo XVI", Anuario del Instituto de Estudios Zamoranos «Florián de Ocampo», Zamora, 1993, pp. 247-270.

CASTRO SANTAMARÍA, Ana, Juan de Álava. Arquitecto del renacimiento, Salamanca, 2002.

CASTRO SANTAMARÍA, Ana y VASAllo tORANZO, Luis, "El cantero Juan de Ruesga y los conventos dominicos de Toro y Salamanca" en Separata de Archivo Dominicano, Tomo III, Salamanca, 1992, pp. 175-190.

Catálogo de la exposición Civitas. MC Aniversario de la Ciudad de Zamora, Catálogo de exposición, Zamora, 1993.

Catálogo de la exposición Kyrios. Las Edades del Hombre, Ciudad Rodrigo, 2006.

Catálogo de la exposición "Más vale volando» por el condado de Benavente, Centro de Estudios Benaventanos "Ledo del Pozo", Benavente, 1998.

Catálogo de la exposición Monjes y monasterios: el Císter en el medievo de Castilla y León (Isidro G. Bango Torviso. Dir.), Monasterio de Santa María de Huerta, Soria, julio-octubre de 1998, Junta de Castilla y León, Valladolid, 1998.

Catálogo de la exposición Remembranza. Las Edades del Hombre, Zamora, 2001.

Catálogo de la Exposición Restauración de la portada de la Majestad de la Colegiata de Santa María la Mayor de Toro, Toro, The Samuel H. Kress Foundation, Junta de Castilla y León, El Viso, 1996.

Zamora en la Edad Media. Catálogo de la exposición realizada con motivo del I Congreso de Historia de Zamora, Caja de Zamora, Zamora, 1988. 
CHÍAS NAVARRO, Pilar y ABAD BALBOA, Tomás, Puentes de España, Madrid, 1994.

CHÍAS NAVARRO, Pilar y ABAD BALBOA, Tomás, Los caminos y la construcción del territorio en Zamora. Catálogo de Puentes, Salamanca, 2004.

CHILLÓN, Bartolomé, La portada del Juicio Final de la Colegiata de Toro, Zamora, 1938.

COBOS GUERRA, Fernando y CASTRO FERNÁNDEZ, José Javier de, Castilla y León. Castillos y Fortalezas, Edilesa, León, 1998.

COBOS GUERRA, Fernando, CASTRO FERNÁNDEZ, José Javier de y CANAL ARRIBAS, Rodrigo, Castros y recintos de la frontera de León en los siglos XII y XIII. Fortificaciones de tapial de cal y canto o mampostería encofrada, Edición digital Junta de Castilla y León, Valladolid, 2012.

COTARELO Y VALLEDOR, Armando, Fray Diego de Deza. Ensayo biográfico, Madrid, 1902.

CONTRERAS Y LÓPEZ DE AYALA, Juan de (Marqués de Lozoya), Historia del Arte Hispánico, Barcelona, 1949.

COOPER, Edward, Castillos señoriales de Castilla de los siglos XV y XVI, Fundación Universitaria Española, vols. I y II, Madrid, 1980.

COOPER, Edward, Castillos Señoriales en la Corona de Castilla, vols. I. 1, I. 2, II y III Salamanca, 1991.

COOPER, Edward, La fortificación de España en los siglos XIII y XIV, 2 vols. Madrid, 2015.

CORTÓN DE LAS HERAS, María Teresa, La construcción de la catedral de Segovia (1525-1607), 3 vols., Universidad Complutense, 1990.

CRESPO GONZÁLEZ, José y DE LA MATA GUERRA, Juan Carlos, "Hospitales antiguos de la Vía de la Plata en Castilla y León", capítulo IV, Zamora en (José Luis Perona Larraz (dir.)) Historia hospitalaria de la Vía de la Plata, Salamanca, 2009.

Cristóbal Colón. Textos y documentos completos (Prólogo y notas de Consuelo Varela), Alianza Editorial, Madrid, 1982. 
CUADRADO Y CHAPADO, Antonio, Datos históricos de la ciudad de Toro, Toro (Zamora), 1923.

CUADRADO Y CHAPADO, Antonio, Templo Santa María La Mayor (Colegiata) de Toro, Toro, 1927.

CUESTA SALADO, Jesús, Iglesia de Santa Marina. Prado (Zamora), Valladolid, 2004.

CUESTA SALADO, Jesús, FERNÁNDEZ ALCALÁ, F. Pablo y VILLAR HERRERO, Sarvelio, Castroverde de Campos. Notas de su historia y patrimonio, Centro de Estudios Benaventanos «Ledo del Pozo», C.E.C.E.I. Consejo Superior de Investigaciones Científicas, Benavente, 2011.

DE CASTRO, J., Primera parte del Arbol Cronológico de la Santa Provincia de Santiago, Salamanca, 1722.

DE CASTRO, M., Crónica de la provincia franciscana de Santiago, 1214-1614. Por un franciscano anónimo del siglo XVII, Madrid, 1971.

DIAS, Pedro, A Arquitectura gótica portuguesa, Editorial Estampa, Lisboa, 1994.

DURÁN SANPERE, Agustín y AINAUD DE LASARTE, Juan, Escultura gótica (Ars Hispaniae, vol. VIII), Madrid, 1956.

ENRÍQUEZ DE SALAMANCA, Cayetano, Rutas del románico en la provincia de Zamora, Ediciones Castilla, 1998.

ESCOSURA, Patricio de la y PÉREZ VILLAAMIL, Genaro, España artística y monumental: vistas y descripción de los sitios y monumentos más notables de España, 3 vols, París, 1842-1850.

ESPIAS SÁNCHEZ, Manuel, Monasterios de clausura en Zamora, Zamora, 1980.

FERNÁNDEZ, Jorge Juan, Zamora, Ámbito, Valladolid, 2000.

FERNÁNDEZ, Luis, "El obispo comunero, don Antonio de Acuña, defensor de los bienes de la mitra zamorana (15091518)", Hispania Sacra, vol. XXXVI, Madrid, 1984, pp. 485-506.

FERNÁNDEZ DE PRADA, Miguel, El Real Monasterio de San Martín de Castañeda, Madrid, 1998. 
FERNÁNDEZ DOMÍNGUEZ, José, La guerra civil a la muerte de Enrique IV. Zamora-Toro-Castronuño, Zamora, 1993.

FERNÁNDEZ DURO, Cesáreo, Antigüedades de Zamora: La iglesia de San Cipriano. La ilustración española y americana, $n$ o XXXI, 1879, pp. 111-114.

FERNÁNDEZ DURO, Cesáreo, Memorias históricas de la ciudad de Zamora su provincia y obispado, 4 vols., Madrid, 1882, (edición facsímil, Editorial Maxtor, Valladolid, 2003).

FERNÁNDEZ FERRERO, Alberto, Guía de las ciudades de Zamora y Toro, Imprenta Jambrina, Zamora, 2003.

FERNÁNDEZ FERRERO, Alberto, Guía de Toro, Imprenta Jambrina, Zamora, 2005.

FERNÁNDEZ FERRERO, Alberto e ILLANA GUTIÉRREZ, Laura, Toro, Zamora, 2010.

FERNÁNDEZ, Luis, "El obispo comunero, don Antonio de Acuña, defensor de los bienes de la mitra zamorana (15091518)", Hispania Sacra, vol. XXXVI, Madrid, 1984.

FERNÁNDEZ GONZÁLEZ, Etelvina, Presencia de Oriente y Occidente en la Portada del Obispo de la Catedral de Zamora, Estudios Humanísticos. Geografía, historia, arte 10 [1988].

FERNANDEZ GUERRA, Aureliano, "Puerta y cubo de Santa Clara de Zamora (Informes)" en Boletín de la Real Academia de la Historia, tomo III, noviembre de 1883, pp. 324-332.

FERNÁNDEZ MATEOS, Rubén, “A propósito de varias portadas tardogóticas de los valles del Tera y de Vidriales (Zamora)", CODEX AQVILARENSIS Cuadernos de Investigación del Monasterio de Santa María la Real, 25, Salamanca, 2010, pp. 80-106.

FERNÁNDEZ-PRIETO DOMÍNGUEZY LOSADA, Enrique, Nobleza de Zamora, C.S.I.C., Madrid, 1953.

FERNÁNDEZ-PRIETO DOMINGUEZ Y LOSADA, Enrique, Apuntes históricos del convento de Santa María la Real de las Dueñas de la Orden de Predicadores de la ciudad de Zamora, Zamora, 1954.

FERNÁNDEZ-PRIETO DOMINGUEZ Y LOSADA, Enrique, “EI hospital de Sotelo y el régimen establecido para el mismo en el testamento del fundador en 1530", Anuario del Instituto de 
Estudios Zamoranos "Florián de Ocampo», Zamora, 1993, pp. 487-508.

FERNÁNDEZ-PRIETO DOMÍNGUEZ Y LOSADA, Enrique, "EI sepulcro del Doctor Grado en la Catedral de Zamora", Cúpula, no 4, Asociación “Amigos de la Catedral”, Zamora, 1995, pp. 15-17.

FERNÁNDEZ SALMADOR, Ana Isabel y VASALLO TORANZO, Luis, "La capilla de don Bautista de Monterrey. Juan de Bruselas, Juan de Campos y Diego de Hanequin" en Separata del Boletín del Seminario de Estudios de Arte y Arqueología, tomo LV, Universidad de Valladolid, 1989, pp. 381-385.

FERRERO FERRERO, Florián, Cat. de exp. El Imperial Monasterio de Nuestra Señora de Valparaíso, 23 de diciembre de 1986-11 de enero de 1987, Caja Zamora, Zamora, 1986?

FERRERO FERRERO, Florián, Historia de la Real Cofradía del Santo Entierro, Diputación de Zamora, Zamora, 1987.

FERRERO FERRERO, Florián, La Plaza Mayor de Zamora, Ayuntamiento de Zamora y Archivo Histórico Provincial, Zamora, 1988.

FERRERO FERRERO, Florián, El convento de San Francisco de Zamora (Folleto de la exposición), Zamora, 1988.

FERRERO FERRERO, Florián, VII siglos de romería a La Hiniesta, Ayuntamiento de Zamora, Zamora, 1992.

FERRERO FERRERO, Florián, Leyendas Zamoranas, Zamora, 2001.

FERRERO FERRERO, Florián, La documentación zamorana de la época de Fernando III, Instituto de Estudios Zamoranos «Florián de Ocampo», Zamora, 2002.

FERRERO FERRERO, Florián y VENTURA CRESPO, Concha María, Romances y Leyendas de Zamora, 2 tomos, Editorial Prensa Ibérica, Zamora, 1992.

FERRERO HERNÁNDEZ, Cándida, Juan Gil, Doctor y Maestro del Convento Franciscano de Zamora, (ca. 1241-1318), Zamora, 2006.

FITA REVERT, Ramón, "El "para que" de una restauración" en El Correo de Zamora, Zamora, 1982. 
FITO MANTECA, Francisco Javier, Inventario del Hospital de Sotelo, s/f, inédito, (Archivo de la Diputación Provincial de Zamora).

FLORANES, Rafael, Memorias para la Historia de la ciudad y tierra de Toro, Valladolid, 1994.

Fotografías antiguas de Zamora, Centro de iniciativas y Turismo de Zamora, Valladolid, 1979.

GAIBROIS DE BALLESTEROS, Mercedes, María de Molina. Tres veces reina, Madrid, 1967.

GALLEGO DE MIGUEL, Amelia, Rejería Castellana: Zamora, Valladolid, 1998.

GARCÉS DESMAISON, Marco Antonio, "Rehabilitación de San Martín de Castañeda, Sanabria (Zamora) (1986-1987)", B.A.U. Revista de Arquitectura, no 2/3, Abril, Valladolid, 1990, pp. 121126.

GARCíA ÁlVAREZ, Pedro y LóPEZ ALONSO, Rosa María, Inventario del archivo del vizconde de Garcigrande, Zamora, 1991.

GARCÍA CHICO, Esteban, "El palacio del conde de Benavente" en Boletín de la Real Academia de la Purísima Concepción de Valladolid, 1946, pp. 13-30.

GARCÍA LOZANO, Rafael Ángel, "Rehabilitación de la iglesia parroquial de San Vicente Mártir de Villar de Fallaves (Zamora)", Anuario del Instituto de Estudios Zamoranos «Florián de Ocampo», Zamora, 2006, pp. 151-160.

GARCÍA MARTÍNEZ, Jesús, Historia de la Santa Iglesia Catedral de Zamora, Zamora 1904.

GARCÍA MERCADAL, José, Viajes de extranjeros por España y Portugal: desde los tiempos más remotos hasta fines del siglo XVI, Madrid, 1952.

GARCÍA REDONDO, J. A., Asistencia técnica previa al proyecto de restauración del palacio de los Momos-Zamora. Documento no 2. Propuesta de tratamiento de restauración de los elementos pétreos, Madrid, 1999. 
GARCÍA RUBIO, José Manuel, Recuerdos Zamoranos, Ediciones Monte Casino, Zamora, 1987.

GARCÍA RUBIO, José Manuel, Ayer y Hoy de Zamora, La Opinión-El Correo de Zamora, 2006.

GARCÍA SIMÓN, Agustín, Castilla y León según la visión de los viajeros extranjeros. Siglos XV-XIX, Junta de Castilla y León, Salamanca, 1999.

GARNACHO, Tomás María, Breves noticias sobre algunas antigüedades de Zamora y Provincia, Zamora, 1979.

GAYA NUÑO, Juan Antonio, La arquitectura española en sus monumentos desaparecidos, Madrid, 1961.

GÓMEZ CARABIAS, Faustino, Guía sinóptica, estadísticogeográfica de las poblaciones y parroquias de la Diócesis de Zamora y Vicarías de Alba y Aliste, Zamora, 1884.

GÓMEZ DE LATORRE, Antonio, Corografía de la provincia de Toro, Madrid, 1802 (edición facsímil 2002).

GÓMEZ GARCÍA, Agapito, "Villafáfila: naturaleza e historia", EI Mirador de Castilla y León: cultura y ocio, no 1, Valladolid, 1996.

GÓMEZ MARTíNEZ, Javier, El gótico español de la Edad Moderna. Bóvedas de Crucería, Valladolid, 1998.

GÓMEZ-MORENO, Manuel, Catálogo Monumental de España. Provincia de Zamora, 2 vols., Ministerio de Instrucción Pública y Bellas Artes, Madrid, 1927, (edición facsímil, Editorial Lebrija, León, 1980).

GÓMEZ-MORENO, Manuel, “El primer monasterio español de cistercienses, Moreruela" en Boletín de la Sociedad Española de Excursiones, año XIV, no 159, Madrid, 1906, pp. 97-105.

GÓMEZ RíOS, Manuel, Alba de Aliste (1190-1564) el castillo, el señorío, el condado, Roma, 1997.

GONZÁLEZ ALONSO, Benjamín (Coordinador), "Las Cortes y las Leyes de Toro en 1505" en Actas del Congreso conmemorativo del $\checkmark$ centenario de la celebración de las Cortes y de la publicación de las Leyes de Toro de 1505: Toro, 7 a 19 de marzo de 2005, Cortes de Castilla y León, 2006. 
GONZÁLEZ RODRÍGUEZ, Rafael, “Documentación medieval inédita del monasterio de Moreruela en el Archivo Municipal de Benavente" en Actas II Congreso Internacional sobre el Císter en Galicia y Portugal, Ourense, 1992, pp. 443-459.

GONZÁLEZ RODRÍGUEZ, Rafael, “Escrituras fundacionales del hospital de la Piedad de Benavente", Brigecio, no8, 1998, pp. 169-192.

GRANJA ALONSO, Manuel de la, Estudio histórico, artístico, religioso, agrícola y humano del Real Monasterio de Santa María de Moreruela de la orden cisterciense, Diputación de Zamora, Zamora, 1990.

GRANJA ALONSO, Manuel de la, "Influencia del mudejarismo en el gótico de la iglesia de Santa María del Moral de Villafáfila (Zamora)", Stvudia Zamorensia, no 6, 2002, pp. 219-228.

GRANJA ALONSO, Manuel de la y PEREZ BRAGADO, Camilo, Villafáfila: Historia y actualidad de una villa castellano-leonesa. Villafáfila: sus iglesias parroquiales, Zamora, 1996.

GRAU LOBO, Luis A., "Patrimonio histórico-artístico en torno al lago de Sanabria, I: El monasterio de San Martín de Castañeda", Anuario del Instituto de Estudios Zamoranos "Florián de Ocampo», Zamora, 1991, pp. 405-430.

GRODECKI, Louis, Arquitectura gótica, Madrid, 1989.

GUILARTE, Alfonso María, El obispo Acuña. Historia de un comunero, Valladolid, 1983.

GUTIÉRREZ BAÑOS, Fernando, Las empresas artísticas de Sancho IV el Bravo, Junta de Castilla y León, Burgos, 1997.

GUTIÉRREZ BAÑOS, Fernando, Aportación al estudio de la pintura de estilo gótico lineal en Castilla y León: Precisiones cronológicas y corpus de pintura mural y sobre tabla, 2 tomos, Fundación Universitaria Española, Madrid, 2005.

GUTIÉRREZ GONZÁLEZ, José Avelino, "Las fortificaciones de la ciudad de Zamora. Estudio arqueológico e histórico", Cuadernos de investigación del Instituto de Estudios Zamoranos "Florián de Ocampo», no 6, Zamora, 1990. 
GUTIÉRREZ GONZÁLEZ, José Avelino, Fortificaciones y feudalismo en el origen y formación del reino leonés (siglos IXXIII), Universidad de Valladolid, Zaragoza, 1995.

GUTIÉRREZ ROBLEDO, José Luis, “Los dibujos de Arquitectura Medieval Española de G.E. Street", Papeles de Arquitectura Española, 9, Ávila, 2006.

HERAS GARCÍA, Felipe, Arquitectura religiosa del siglo XVI en la primitiva diócesis de Valladolid, Diputación Provincial de Valladolid, 1975.

HERAS HERNÁNDEZ, David de las, Catálogo ArtísticoMonumental y Arqueológico de la Diócesis de Zamora, Zamora, 1973.

HERNANDEZ CABALLERO, Miguel, Toro, ciudad de realengo, León, 1993.

HERNÁNDEZ MARTÍN, Joaquín, Guía de Arquitectura de Zamora. Desde los orígenes al siglo XXI, Colegio Oficial de Arquitectos de León, 2004.

HERNÁNDEZ VICENTE, Severiano, El Concejo de Benavente en el siglo XV, Zamora, 1986.

HIDALGO MUÑóZ, Elena, La iglesia de Santa María del Azogue de Benavente, Centro de Estudios Benaventanos «Ledo del Pozo», Salamanca, 1995.

HIDALGO MUÑOZ, Elena, La iglesia de San Juan del Mercado de Benavente, Centro de Estudios Benaventanos «Ledo del Pozo», Salamanca, 1997.

HIDALGO MUÑOZ, Elena, "El Hospital de la Piedad de Benavente" en Los Caminos de Santiago en el norte de Zamora, III Jornadas de Estudios históricos. Benavente, 16, 17, 18 y 19 de noviembre de 2004 y Santa Marta de Tera, 20 de noviembre de 2004, Centro de Estudios Benaventanos «Ledo del Pozo», Zamora, 2006, pp. 27-67.

HOAG, John D., Rodrigo Gil de Hontañón. Gótico y renacimiento en la arquitectura española del siglo XVI, Madrid, 1985.

HOYOS Julio, "Santa María de la Horta, Iglesia de los Caballeros Templarios en Zamora", La Ilustración Española y Americana, 1916, no 7, pp. 106-107. 
ISIDRO GARCÍA, César Amador, La construcción y destrucción del monasterio de San Jerónimo de Zamora 1535-1835, Trabajo de Grado, Facultad de Geografía e Historia, Universidad de Salamanca, 2008, inédito.

JARAMILLO GUERREIRA, Miguel Ángel, "Iglesia de San Juan, nueva imagen: al descubierto las fachadas sur y oeste", La Gobierna, № 2, Zamora, 1984.

KAGAN, RICHARD L., (Dir): Ciudades del Siglo de Oro. Las vistas españolas de Antón Van den Wyngaerde, Ediciones EI Viso, 1986.

KARGE, Henrik, La Catedral de Burgos y la Arquitectura del siglo XIII en Francia y España, Junta de Castilla y León, 1995.

LADERO QUESADA, Manuel Fernando, La ciudad de Zamora en la época de los Reyes Católicos. Economía y Gobierno, Instituto de Estudios Zamoranos «Florian de Ocampo» (C.S.I.C), Diputación de Zamora, 1991.

LAMBERT, Elie, El arte gótico en España. Siglos XII y XIII, Cátedra, Madrid, 1977.

LAMPÉREZ Y ROMEA, Vicente, "Santa María del Azogue en Benavente" en Diario Universal, Madrid, 10 de enero de 1904.

LAMPÉREZ Y ROMEA, Vicente, Historia de la arquitectura cristiana española en la Edad Media, Junta de Castilla y León, Consejería de Educación y Cultura, Ámbito, Valladolid, 1999.

LARRÉN IZQUIERDO, HORTENSIA, "Excavaciones de dos sepulcros: el d ela iglesia de San Salvador de Ayoó de Vidriales y el de los Castilla-Fonseca en San Lorenzo el Real de Toro", Anuario del Instituto de Estudios Zamoranos "Florián de Ocampo», Zamora, 1996, pp. 55-66.

LARRÉN IZQUIERDO, Hortensia, Moreruela: un monasterio en la historia del Cister, Junta de Castilla y León, Valladolid, 2008.

LARRÉN IZQUIERDO, Hortensia y PICHEL RAMOS, Luis, Bienes culturales de la provincia de Zamora, Zamora, 2010. 
LEDO DEL POZO, José, Historia de la nobilísima villa de Benavente con la antigüedad de su ducado, principio de su condado, sucesión y hazañas heroicas de sus condes, (Reedición hecha de la impresa en Zamora en el año 1853, por el Dr. Eugenio Llamas Valbuena), Salamanca, 1970.

LEISTIKOW, Dankwart, Edificios hospitalarios en Europa durante diez siglos. Historia de la arquitectura hospitalaria, C.H. Boehringer Sohn, Ingelheim am Rhein, Alemania, 1967.

LERA MAÍlLO, José Carlos de, Catálogo de los Documentos Medievales de la Catedral de Zamora, Instituto de Estudios Zamoranos «Florián de Ocampo» (C.S.I.C.), Diputación de Zamora, 1999.

LERA MAÍlLO, José Carlos de, Bamba y su Santuario de Santa María del Viso. Historia y leyenda, Editorial Semuret, Zamora, 2012.

LERA MAílLO, José Carlos de y TURIÑO MíNGUEZ, Ángel, La Orden militar de Santiago en la provincia de Zamora, Zamora, 2000.

LINEHAN, Peter, Las dueñas de Zamora. Secretos, estupro y poderes en la Iglesia española del siglo XIII, Ediciones Península, Barcelona, 1999.

LOBATO VIDAL, José Carlos, Castillos y murallas de la provincia de Zamora, Editorial Semuret, Zamora, 1997.

LÓPEZ DE GUEREÑO SANZ, María Teresa, Monasterios medievales premostratenses. Reinos de Castilla y León, tomo II, Junta de Castilla y León, Salamanca, 1997.

LÓPEZ DÍEZ, María, Los Trastámara en Segovia. Juan Guas, maestro de obras reales, Caja Segovia, Segovia, 2006.

LÓPEZ ULLOA, Fabián, “George Edmund Street (18241881) y su contribución al estudio de la construcción gótica en España" en Huerta, S. (ed.), Actas del VI Congreso de Historia de la Construcción, Madrid, 2009, pp. 789-801.

LORENZO PINAR, Francisco Javier, "El ejército y la ciudad de Zamora en el siglo XVI" en Actas de las II Jornadas Nacionales de Historia Militar. La organización militar en los siglos XV y XVI, Málaga, 1993. 
LORENZO PINAR, Francisco Javier, Conventos femeninos y vida religiosa en la ciudad de Zamora (1600-1650), Zamora, 2004.

Los castillos y las murallas de Zamora: breve recorridos por las provincias, n 10, Diputación de Zamora, febrero de 1984, pp. 27-30

LUELMO ALONSO, Ramón, La Catedral de Zamora, El Correo de Zamora, Zamora, 1956.

LUELMO ALONSO, Ramón, Una visita al templo zamorano de Santa María de la Horta, Zamora, 1957.

LLAGUNO, Eugenio, y CEÁN BERMÚDEZ, Juan Agustín, Noticias de los arquitectos y arquitectura de España desde su restauración, 4 tomos, Madrid, 1829.

MADOZ, Pascual, Diccionario Geográfico-Estadístico-Histórico de España y sus posesiones de Ultramar, Madrid, 1845, (edición facsímil, Almendralejo, 1989).

MARÍAS, Fernando, El largo siglo XVI. Los usos artísticos del renacimiento español, Madrid, 1989.

MADRAZO, Pedro de, "La Colegiata de Toro", BRAH, XX, 1892.

MARTÍ Y MONSÓ, José, Pleitos de artistas basados en documentos existentes en el archivo de la Real Chancillería de Valladolid. La capilla del Deán don Diego Vázquez de Cepeda en el monasterio de San Francisco de Zamora. B.S.C.E., II (1905-6).

MARTíN GONZÁLEZ, Juan José y URREA FERNÁNDEZ, Jesús, Monumentos Religiosos de la ciudad de Valladolid (Catedral, parroquias, cofradías y santuarios). Catálogo Monumental de la Provincia de Valladolid, Tomo IV, parte primera, Institución Cultural Simancas, Valladolid, 1985.

MARTÍN ARIJA, Ana M., IGLESIAS DEL CASTILLO, Luis E., SALVADOR VELASCO, Mónica y VIÑE ESCARTíN, Ana I., "Nuevos datos arqueológicos en el entorno de la Catedral de Zamora", Anuario del Instituto de Estudios Zamoranos «Florián de Ocampo», Zamora, 1994, pp. 109-122.

MARTín AVEDILLO, Fabriciano, La Catedral de Zamora, Ediciones Fama, Zamora, 1988. 
MARTÍN GONZÁLEZ, Juan José, La arquitectura doméstica del Renacimiento en Valladolid, Valladolid, 1948.

MARTÍN MONTES, Miguel, El Alcázar Real de Valladolid, Fundación Municipal de Cultura del Excmo. Ayuntamiento de Valladolid, Valladolid, 1995.

MARTínEZ, Rafael, “Gómez Díaz de Burgos, (1430-1466), maestro mayor de la obra de la catedral de Palencia", Publicaciones de la "Institución Tello Téllez de Meneses", no 58, 1988.

MARTÍNEZ FRÍAS, José María, El gótico en Soria. Arquitectura y escultura monumental, Universidad de Salamanca, 1980.

MARTÍNEZ FRÍAS, José María, “La configuración arquitectónica de la catedral de Ciudad Rodrigo a lo largo del medievo" en La Catedral de Ciudad Rodrigo. Visiones y revisiones, Salamanca, 2006.

MARTíNEZ RUIZ, María José, La enajenación del patrimonio en Castilla y León (1900-1936), 2 vols., Junta de Castilla y León, 2008.

MARTíNEZ FRÍAS, José María, PÉREZ HERNÁNDEZ, Manuel y LAHOZ, Lucía, El arte gótico en Salamanca, Salamanca, 2005.

MARTínEZ SOPENA, Pascual, La Tierra de Campos Occidental. Poblamiento, poder y comunidad del siglo X al XIII, Institución Cultural Simancas, Diputación Provincial de Valladolid, Valladolid, 1985.

MATEO GÓMEZ, Isabel, Temas profanos en la escultura gótica española. Las sillerías de coro, Consejo Superior de Investigaciones Científicas «Instituto Diego Velázquez», Madrid, 1979.

MATILLA TASCÓN, Antonio, Guía-inventario de los Archivos de Zamora y su provincia, Madrid, 1964.

MENÉNDEZ PIDAL, Luis, Restauración del cimborrio y de las cubiertas pétreas en la Catedral de Zamora, A.E.A. XXXIV (1961).

MENÉNDEZ PIDAL, Luis, "El palacio de los condes de Alba de Aliste, en Zamora" en Boletín de la Real Academia Española de Bellas Artes, no 24, Madrid, 1967. 
MENENDEZ PIDAL, Luis, "El Palacio de las Leyes de Toro (Zamora)" en Boletín de la Real Academia de Bellas Artes de San Fernando, 33, Madrid, 1971.

MERINO DE CÁCERES, José Miguel, "Algunos datos sobre el traslado a los Estados Unidos de determinadas piezas arquitectónicas del castillo de Benavente", Brigecio (Revista de Estudios de Benavente y sus tierras), núm. 3, Centro de Estudios Benaventanos «Ledo del Pozo», 1993, pp. 211-228.

MIGUEL HERNÁNDEZ, Fernando, "Informe preliminar de la excavación arqueológica del Convento de San Francisco (Zamora)", Anuario del Instituto de Estudios Zamoranos "Florián de Ocampo», Zamora, 1993, pp. 211-225.

MIGUEL HERNÁNDEZ, Fernando, El monasterio de San Martín de Castañeda. Zamora. Análisis de su pasado para el futuro, Zamora, 2010.

MIGUEL HERNÁNDEZ, Fernando, Los monasterios cistercienses en la provincia de Zamora, Valladolid, 2010.

MOLINER, María, Diccionario de uso del español, Madrid, 1998.

MÜNZER, Jerónimo, Viaje por España y Portugal 1494-1495 (Prólogo de Manuel Gómez Moreno y traducción de José López Toro), Colección Almenara, Madrid, 1951.

MUÑOZ MIÑAMBRES, José, Nueva historia de Benavente, Ediciones Monte Casino, Zamora, 1982.

MUÑOZ MIÑAMBRES, José, Benavente y tierra de campos, Zamora, 1983.

NAVARRO TALEGÓN, José, "El monasterio premostratense de Santa Sofía" en El Correo de Zamora, Zamora, 18-VII-1975.

NAVARRO TALEGÓN, José, "Aportación al estudio de los Tomé" en El Correo de Zamora, Zamora, 15-4-1977.

NAVARRO TALEGón, José, Catálogo Monumental de Toro y su alfoz, Caja de Ahorros Provincial de Zamora, Zamora, 1980. 
NAVARRO TALEGÓN, José, “Aportaciones al estudio de la carpintería mudéjar en la ciudad de Zamora", Studia Zamorensia, no 3, Universidad de Salamanca, Colegio Universitario de Zamora, 1982, pp. 111-147.

NAVARRO TALEGÓN, José, El legado artístico de Toro: visión panorámica, Fundación González Allende, Toro, 1996 (conferencia pronunciada en el Teatro Latorre de Toro el 30 de septiembre de 1995).

NAVARRO TALEGÓN, José, "La Catedral de Zamora" en Aquellas blancas Catedrales, Valladolid, 1996.

NAVARRO TALEGÓN, José, “Aproximaciones a la arquitectura medieval de Benavente" en AA. VV., Regnum: Corona y Cortes en Benavente (1202-2002), Benavente, 2002, pp. 177-199.

NAVARRO TALEGÓN, José, La Colegiata de Toro, 2005a.

NAVARRO TALEGÓN, José, "Sobre la iglesia de Venialbo y su retablo Mayor", Studia Zamorensia, no 7, 2005b, pp. 187-228.

NIETO, V., MORALES, A. J. y CHECA, F., Arquitectura del Renacimiento en España, 1488-1599, Madrid, 1989.

NIETO GONZÁLEZ, José Ramón, "El sepulcro de don Pedro López en El Perdigón" en Actas do Simpósio Internacional de A Introducào da Arte da Renascença na Península Ibérica, Coimbra, 1981, pp. 105-124.

NIETO GONZÁLEZ, José Ramón, Catálogo Monumental del Partido Judicial de Zamora, Zamora, 1982.

NIETO GONZÁLEZ, José Ramón, "Zamora” en J. Rivera Blanco (coord.), en Catálogo monumental de Castilla y León. Bienes inmuebles declarados, vol.II, Salamanca, 1995.

NIETO GONZÁLEZ, José Ramón, SERRANO PIEDECASAS FERNÁNDEZ, L. y HERRERO PRIETO L. C., El patrimonio histórico en el río Duero, Fundación "Rei Alfonso Henriques", Salamanca, 2001.

OLIVARES MARTÍNEZ, Diana, "El salvaje en la Edad Media", Revista digital de iconografía medieval, vol. 5, no 10, 2013, pp. 41-55. 
OLMEDO RODRÍGUEZ, Felipe, La provincia de Zamora. Guía geográfica, histórica y estadística de la misma, Valladolid, 1905.

ORDÓÑEZ DE VILLAQUIRÁN, Valeriano, La translación de San Ildefonso (1496). Con dedicatorias al Cardenal Cisneros y a la ciudad de Zamora (Edición facsímil, transcripción y traducción de Vicente Bécares Botas), Zamora, 1991.

ORTí BELMONTE, Miguel Ángel, Episcopologio cauriense, Diputación Provincial de Cáceres, Cáceres, 1958.

PANIAGUA, José Ramón, Vocabulario básico de arquitectura, Cátedra, Madrid, 1990.

PEDRERO ENCABO, Claudio Ignacio, "Rehabilitación de la alhóndiga como centro cultural municipal" en Arqscoal, Arquitecturas del COAL, 2004, pp. 21-24.

PEÑAS SERRANO, Pablo y GALÁN VERA, María Jesús, O. P., Noticias sobre la construcción del Monasterio de Santo Domingo el Real de Toledo, s/f, http://www.dominicos.org/monias/estudios/ construccion.htm.

PÉREZ, Joseph, La revolución de las Comunidades de Castilla 1520-1521, Madrid, 1977.

PEREDA DE LA REGUERA, Manuel, Rodrigo Gil de Hontañón, Santander, 1951.

PÉREZ DE CASTRO, Ramón y DUQUE HERRERO, Carlos, "Las fachadas de Santa María de Medina de Rioseco (Valladolid) y su influencia: Villar de Fallaves (Zamora)", Brigecio (Revista de Estudios de Benavente y sus tierras), núm. 16, Centro de Estudios Benaventanos «Ledo del Pozo», 2006, pp. 315-326.

PÉREZ LOPEZ, María Isabel, "La muerte del Conde-Duque de Olivares en Toro", Revista Proculto, n 2, 2006, edición digital.

PÉREZ MARTín, Sergio, MARTín BAILÓN, Marco Antonio y MACEDO COELHO, Luciana, "Recomponiendo un puzle. Disquisiciones acerca de la restauración e interpretación de unas pinturas de estilo gótico lineal en la iglesia de Santa María la Nueva de Zamora" en Ge-Conservación, 2011, no 2, pp. 129-145. 
PÉREZ MONZÓN, Olga, Arte Sanjuanista en Castilla y León. Las encomiendas de la Guareña y su entorno geo-histórico, Junta de Castilla y León, 1999.

PINILLA GONZÁLEZ, Jaime, Castillos de Zamora y Salamanca, Ediciones Lancia, Madrid, 1989.

PINILLA GONZÁLEZ, Jaime, "Dos castillos zamoranos", Stvdia Zamorensia, I, Universidad de Salamanca, Salamanca, 1980, pp. 57-65.

PIÑUELA XIMÉNEZ, Antonio, Descripción histórica de la ciudad de Zamora, su provincia y obispado, Zamora, 1987.

PÍRIZ PÉREZ, Emilio, La arquitectura gótica en la diócesis de Ciudad Rodrigo, Centro de Estudios Salmantinos, Salamanca, 1974.

PITA ANDRADE, José Manuel, "El arte de Mateo en las tierras de Zamora y Salamanca", Cuadernos de Estudios Gallegos, XXV, C.S.I.C., 1953, pp. 207-226.

PORRAS ARBOLEDAS, Pedro A., Juan II: 1406-1454, Diputación Provincial de Palencia, 1995.

PRIETO MORILLO, S., "Síntesis gliptográfica de la iglesia abacial de San Martín de Castañeda", Brigecio, 3, Benavente, 1993, pp. 115-128.

PUENTE, Ricardo, Portadas medievales. La portada de la Majestad de Toro, Editorial Albanega, León, 2008.

QUADRADO, José María y PARCERISA, Francisco Javier, España, sus monumentos y artes, su naturaleza e Historia. Valladolid, Palencia y Zamora, Barcelona, 1861, (edición facsímil, Valladolid, 1990).

QUINTANA PRIETO, Augusto, "La documentación de San Martín de Castañeda (Correcciones y ampliación)" en Archivos Leoneses, no 51, León, pp. 151-230.

RABASA DÍAZ, Enrique, Forma y construcción en piedra. De la cantería medieval a la estereotomía del siglo XIX, Madrid, 2000. 
RÁBANOS GONZÁLEZ, M., "Estudio artístico de Santa María del Azogue", Brigecio (Revista de Estudios de Benavente y sus tierras), Núm. 2, Centro de Estudios Benaventanos «Ledo del Pozo», Consejo Superior de Investigaciones Científicas, 1992, pp. 115-136.

RAMOS DE CASTRO, Guadalupe, "Las pinturas góticas de La Hiniesta" en B.S.A.A., Valladolid, 1972.

RAMOS DE CASTRO, Guadalupe, El arte románico en la provincia de Zamora, Diputación Provincial de Zamora, Zamora, 1977.

RAMOS DE CASTRO, Guadalupe, Las Murallas de Zamora, Colección Arte e Historia 1, Servicio de Publicaciones de la Delegación Provincial del Ministerio de Cultura, Zamora, 1978a.

RAMOS DE CASTRO, Guadalupe, "El Ayuntamiento Viejo de Zamora" en Boletín del Seminario de Estudios de Arte y Arqueología, tomo XLIV, Universidad de Valladolid, 1978b.

RAMOS DE CASTRO, Guadalupe, La Catedral de Zamora, Zamora, 1982.

RAMOS DE CASTRO, Guadalupe, Juderías de Castilla y León, Fundación «Ramos de Castro» Para el Estudio y Promoción del Hombre, Zamora, 1988.

RAMOS MONREAL, Amelia y NAVARRO TALEGÓN, José, "El convento de San Pablo: ambiente y contratiempos de una fundación monástica", Studia Zamorensia, no 3, Colegio Universitario de Zamora, Ediciones Universidad de Salamanca, 1982, pp. 81-110.

RÉAU, Louis., Iconografía del Arte Cristiano. Iconografía de la Biblia. Nuevo Testamento, t. 1, vol. 2, Barcelona, 1996.

REGUERAS GRANDE, Fernando, Pimentel. Fragmentos de una iconografía, Centro de Estudios Benaventanos «Ledo del Pozo», Benavente, 1998. 
REGUERAS GRANDE, Fernando, "Veinticinco años después: el Hospital de la Piedad de Benavente declarado Bien de Interés Cultural", Brigecio (Revista de Estudios de Benavente y sus tierras), Núm. 13, Centro de Estudios Benaventanos «Ledo del Pozo», Consejo Superior de Investigaciones Científicas, Benavente, 2003, pp. 245-252.

REGUERAS GRANDE, Fernando, Iconografía del castillo de Benavente (Cinco siglos de imágenes), Centro de Estudios Benaventanos «Ledo del Pozo», Benavente, 2007.

REGUERAS GRANDE, Fernando y GONZÁLEZ RODRÍGUEZ, Rafael, Álbum de Benavente. Grabados, dibujos y fotografías históricas, Centro de estudios benaventanos "Ledo del Pozo», Zamora, 2013.

REPRESA, Amando, "Génesis y evolución de la Zamora medieval" en Revista Hispania, no 122, 1972, pp. 525-545.

REVILLA, Federico, Diccionario de iconografía, Cátedra, Madrid, 1990.

RICOSANTAMARÍA, Marcos, La catedral de Burgos: Patrimonio del Mundo, Vitoria, 1985, p. 316.

RIESTRA, Pablo de la, La catedral de Astorga y la arquitectura del gótico alemán, Oviedo, 1992.

RIVERA DE LAS HERAS, José Ángel, San Frontis, Extra Pontem, Instituto de Estudios Zamoranos "Florián de Ocampo", Zamora, 1984.

RIVERA DE LAS HERAS, José Ángel, La iglesia zamorana de San Isidoro, Instituto de Estudios Zamoranos "Florián de Ocampo", Zamora, 1985.

RIVERA DE LAS HERAS, José Ángel, Fe y Arte en la Catedral de Zamora, Zamora, 1990.

RIVERA DE LAS HERAS, José Ángel, La iglesia de San Andrés, Zamora, 1995.

RIVERA DE LAS HERAS, José Ángel, “Los instrumentos musicales de los ancianos del apocalipsis en la portada de la iglesia de La Hiniesta (Zamora)", Anuario del Instituto de Estudios Zamoranos «Florián de Ocampo», Zamora, 1997, pp. 183-205. 
RIVERA DE LAS HERAS, José Ángel, En torno al escultor Gil de Ronza, Diputación de Zamora, Zamora, 1998.

RIVERA DE LAS HERAS, José Ángel, La Catedral de Zamora, Durius Cultural, Zamora, 2001a.

RIVERA DE LAS HERAS, José Ángel, Por la Catedral, Iglesias y Ermitas de la Ciudad de Zamora, León, Edilesa, 2001b.

RIVERA DE LAS HERAS, José Ángel, Zamora: Iglesias de Santa Isidoro, La Magdalena, y San Pedro y San IIdefonso, Col. Arte Románico en Zamora, no 2, Ediciones Nobel, Oviedo, 2006.

RIVERA DE LAS HERAS, José Ángel, Zamora: Iglesias de San Cipriano y Santa María la Nueva, Col. Arte Románico en Zamora, no 3, Ediciones Nobel, Oviedo, 2006.

RIVERA DE LAS HERAS, José Ángel, Zamora: Iglesias de San Juan Bautista, San Vicente y Santiago del Burgo, Col. Arte Románico en Zamora, № 4, Ediciones Nobel, Oviedo, 2006.

RIVERA DE LAS HERAS, José Ángel, Zamora: Iglesias del Espíritu Santo, Nuestra Señora de los Remedios y Nuestra Señora de la Vega, Col. Arte Románico en Zamora, no 5, Ediciones Nobel, Oviedo, 2006.

RIVERA DE LAS HERAS, José Ángel, Zamora: Iglesias de Santa María de la Horta y Santo Tomé, Col. Arte Románico en Zamora, no 7, Ediciones Nobel, Oviedo, 2006.

RIVERA DE LAS HERAS, José Ángel, Zamora: Iglesias de San Frontis y Santo Sepulcro, Col. Arte Románico en Zamora, no 8, Ediciones Nobel, Oviedo, 2006.

RIVERA DE LAS HERAS, José Ángel, Zamora: Iglesias de Santa Lucía, San Leonardo, San Esteban, San Andrés y Carmen del Camino, Col. Arte Románico en Zamora, no 9, Ediciones Nobel, Oviedo, 2006.

RIVERA DE LAS HERAS, José Ángel, Benavente: Iglesias de Santa María la Mayor y San Juan del Mercado, Col. Arte Románico en Zamora, no 11, Ediciones Nobel, Oviedo, 2006.

RIVERA DE LAS HERAS, José Ángel, Moreruela, Santa Marta de Tera, Tábara, Col. Arte Románico en Zamora, no 12, Ediciones Nobel, Oviedo, 2006. 
RIVERA DE LAS HERAS, José Ángel, Mombuey. Puebla de Sanabria. San Martín de Castañeda, Col. Arte Románico en Zamora, no 13, Ediciones Nobel, Oviedo, 2006.

RODRIGUEZ GUTIÉRREZ DE CEBALLOS, Alfonso, Las catedrales de Salamanca, Everest, Madrid, 1978.

RUIZ MALDONADO, Margarita, "Dos obras maestras del Románico de transición: la portada del Obispo y el sepulcro de la Magdalena", Stvdia Zamorensia, Anejos 1, Universidad de Salamanca-Colegio Universitario de Zamora, 1988, pp. 33-59.

RUIZ MALDONADO, Margarita, "Reflexiones en torno a la portada de la Majestad. Colegiata de Toro (Zamora)", Goya, no 283, 1998, pp. 75-87.

S-A., Síntesis de la historia de la Cofradía, Ermita del Carmen del Camino y Correa de San Agustín, Prólogo de David de las Heras, Zamora, 1993.

SAINZ SAIZ, Javier, El gótico rural en Castilla y León, León, 1997.

SAINZ SAIZ, Javier, Zamora Pueblo a Pueblo, La Opinión-EI Correo de Zamora, 2001.

SÁINZ SAIZ, Javier, El románico en Zamora, Ediciones Lancia, León, 2002.

SAINZ SAIZ, Javier, Ermitas y romerías de Zamora, Zamora, 2002.

SAINZ SAIZ, Javier, Rutas por la provincia de Zamora, Zamora, 2007.

SAMANIEGO HIDALGO, Santiago, Arquitectura de Santa María del Castillo. Fuentesaúco, Salamanca, 1979.

SAMANIEGO HIDALGO, Santiago, "Portada y claustro de la Catedral" en El Correo de Zamora, 27.06.1979.

SAN JOSÉ ALONSO, Jesús Ignacio, Arquitectura religiosa en Sanabria. Sus espacios, organizaciones y tipologías, Instituto de Estudios Zamoranos «Florián de Ocampo», Zamora, 1994.

SAN MARCELO Y VASALLO, Sergio Jesús, Heráldica y edificios de Zamora, Zamora, 1998. 
SÁNCHEZ LAGO, Pedro, Historia completa de Benavente desde su fundación hasta 1903, Centro de Estudios Benaventanos «Ledo del Pozo», Benavente, 2003.

SANCHEZ-MONGE LLUSA, Macarena, y VIÑE ESCARTíN, Ana Isabel, "Excavaciones arqueológicas en la iglesia de San Ildefonso (Zamora)", en Anuario del Instituto de Estudios Zamoranos «Florián de Ocampo», Zamora, 1989, pp. 133-144.

SANZ GARCÍA, Francisco Javier, (et al.), "Intervención arqueológica en el área claustral del monasterio de San Martín de Castañeda", Anuario del Instituto de Estudios Zamoranos «Florián de Ocampo», Zamora, 2001, pp. 51-65.

SANZ GARCÍA, Francisco Javier, (et al.), "Sondeos arqueológicos en el entorno de la iglesia de San Martín de Castañeda (Galende, Zamora)", Anuario del Instituto de Estudios Zamoranos "Florián de Ocampo», Zamora, 1991, pp. 315-324.

SANZ FUENTES, Mạ Josefa, "El señorío de Villalonso. Aproximación diplomático-histórica" en El pasado histórico de Castilla y León. I Congreso de historia de Castilla y León, volumen I, Edad Media, Burgos 1993, pp. 221-232.

SARTHOU CARRERES, Carlos, Castillos de España, Madrid, 1984.

SENDIN CALABUIG, Manuel, Arquitectura y Heráldica de Ciudad Rodrigo (Siglos XV y XVI), Centro de Estudios Salmantinos, Salamanca, 1972.

SIMAL LÓPEZ, Mercedes, Los condes-duques de Benavente en el siglo XVII. Patronos y coleccionistas en su villa solariega, Centro de Estudios Benaventanos «Ledo del Pozo» (C. E. C. E. L. C. S. I. C.), Benavente, 2002.

SOMOZA, Francisco, "Iglesia de Santa María del Azogue. Puebla de Sanabria (Zamora)", Restauración y rehabilitación (Revista Internacional del Patrimonio Histórico), no 31, Madrid, agosto de 1999.

STREET, George Edmund, La arquitectura gótica en España, Madrid, 1926. 
TEJEDOR MICÓ, Gregorio J., "El sepulcro de don Antonio de Sotelo en la iglesia de San Andrés de Zamora", en Separata del Boletín del Museo e Instituto "Camón Aznar" XXIX (109-121), 1987.

TEJEDOR MICÓ, Gregorio J., “Escultura funeraria: el sepulcro del doctor Grado en la Catedral de Zamora" en Boletín del Museo e Instituto "Camón Aznar", LIII, 1993, pp. 29-70.

TORRES BALBÁS, Leopoldo, "Rincones inéditos de antigua arquitectura española: Patio del convento de Mercedarias descalzas ó de San Juan. Toro (Zamora)" en Arquitectura, tomo II, 1919, pp. 249-251.

TORRES BALBÁS, Leopoldo, "Los cimborrios de Zamora, Salamanca y Toro", Arquitectura IV (1922), pp. 97-117.

TORRES BALBÁS, Leopoldo, Arquitectura gótica (Ars Hispaniae, vol. VII), Madrid, 1952.

URREA, Jesús, Arquitectura y Nobleza. Casas y palacios de Valladolid, Valladolid, 1996.

VACA LORENZO, Ángel, Documentación medieval del archivo parroquial de Villalpando (Zamora), Salamanca, 1988.

VASALLO TORANZO, Luis, "Una nueva obra de Rodrigo Gil de Hontañón en Zamora: La reforma de la iglesia de San Juan de Puerta Nueva" en Boletín del Seminario de Estudios de Arte y Arqueología, Universidad de Valladolid, 1993, pp. 313-318.

VASALLO TORANZO, Luis, Arquitectura en Toro (1500-1650) Instituto de Estudios Zamoranos “Florián de Ocampo", Diputación de Zamora, 1994.

VASALLO TORANZO, Luis, "Casas y palacios en Zamora. Manifestaciones del poder de la nobleza", Anuario del Instituto de Estudios Zamoranos "Florián de Ocampo», Zamora, 2003, pp. 343-357.

VASALLO TORANZO, Luis, "Pedro Berruguete y Juan de Borgoña en el retablo de San Ildefonso de Toro", Boletín del Museo Nacional de Escultura, no 7, 2003, pp. 15-23. 
VASALLO TORANZO, Luis, "Juan de Álava y Pedro de Ibarra al servicio de los condes de Alba de Aliste" en Boletín del Seminario de Estudios de Arte y Arqueología, tomo 69-70, 2003-2004, pp. 279-302.

VASALLO TORANZO, Luis, "La casa del Cordón de Zamora", en Actas del segundo Congreso de Historia de Zamora, Instituto de Estudios Zamoranos “Florián de Ocampo", Zamora, 2007, pp. 277-286.

VASALLO TORANZO, Luis, "La alhóndiga mayor de Zamora. Estudio documental de su construcción", Stvdia Zamorensia, Segunda Etapa, Volumen XI, UNED, Zamora, 2012, pp. 205-234.

VASALLO TORANZO, Luis, "La casa del conde de Benavente en Valladolid, un frustrado palacio al servicio de Carlos V", en MíNGUEZ CORNELLES, V.M., Las artes y la arquitectura del poder, 2013, pp. 829-842.

VASALLO TORANZO, Luis. "Origen y desarrollo de la Plaza Mayor de Zamora. Siglos XV y XVI". En HERNÁNDEZ LUIS, José Luis (ed.). Sic vos non vobis. Colección de estudios en honor de Florián Ferrero. Zamora: Ministerio de Educación, Cultura y Deporte-Junta de Castilla y LeónUNED-ACAL-IEZ Florián de Ocampo, 2015 (publicación electrónica en preparación), pp. 385-406.

VECILLA DOMínGUEZ, Jesús, "El Convento de San Francisco de Zamora" en Anuario del Instituto de Estudios Zamoranos «Florián de Ocampo», Zamora, 1995, pp. 579-603.

VENTURA CRESPO, Concha, y FERRERO FERRERO, Florián, Leyendas Zamoranas, Zamora, 2001.

VELASCO RODRÍGUEZ, Victoriano, Guía turística de la Provincia de Zamora, Zamora, 1960.

VELLÉS, J., Sor Ana de la Cruz. Imagen de la clarisa fundadora del Convento del Corpus Christi en Zamora, y cuatro digresiones acerca de la pintura, Madrid, 1997.

VIDAURRE JOFRE, J., "Memoria, pliego de condiciones, mediciones y presupuesto" en Proyecto de restauración. Casa del Cordón. Zamora. I Fase, Madrid, 1980. 
VIDAURRE JOFRE, Julio, "Memoria, pliego de condiciones, mediciones y presupuesto" en Terminación de la Primera Fase del Proyecto de Restauración de la Casa del Cordón de Zamora. Memoria Justificativa, Dirección General de Bellas Artes, Archivos y Bibliotecas, Ministerio de Cultura, Madrid, 1981.

VIÑÉ ESCARTín, Ana I. y SALVADOR VELASCO, Mónica, “El convento de San Ildefonso de Toro. Documentación de su claustro a través de la intervención arqueológica" en Anuario del Instituto de Estudios Zamoranos "Florián de Ocampo», Zamora, 2002, pp. 61-79.

VILLAR HERRERO, Servelio, Castroverde de Campos. Apuntes en torno a una villa, Zamora, 2001 (redición 2003).

VOCES JOLÍAS, José María, Arte religioso en El Bierzo en el siglo XVI, Ponferrada, 1987.

VORÁGINE, Santiago de la: La leyenda dorada, (2 tomos), Alianza Forma, Madrid, 1995.

WADDINGO, Lucas, Annales Minorum, t. II, Lugduni, 1928.

YARZA LUACES, Joaquín, "La portada occidental de la colegiata de Toro y el sepulcro del doctor Grado, dos obras significativas del gótico zamorano", Stvdia Zamorensia (Anejos 1), Arte Medieval en Zamora, 1988, pp. 117-152.

ZALAMA RODRÍGUEZ, Miguel Ángel, La arquitectura del siglo XVI en la provincia de Palencia, Diputación Provincial de Palencia, 1990.

Zamora Año de 1850. Cuaderno de vistas de Zamora tomadas del natural y ejecutadas por Don José María Avrial y Flores (Coord. Pérez Martín, Sergio y Martín Bailón, Marco Antonio), Zamora, 2013.

ZARAGOZA PASCUAL, Ernesto, Los monasterios benedictinos de la ciudad de Zamora, Nova et Vetera, no 10.

ZURDO, Francisco, Zamora dominicana, Zamora 1994. 
